Death at the opposite ends

of the Eurasian continent

Mortality trends in Taiwan

and the Netherlands

$1850-1945^{\prime \prime}$ e edited by

Theo Engelen, John R.

s

$-$

Shepherd a Yang Wen-shan

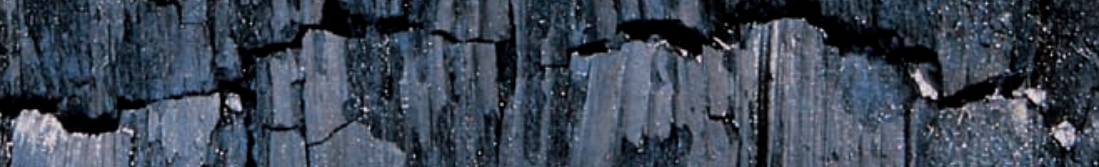

Life at the Extremes Volume IV

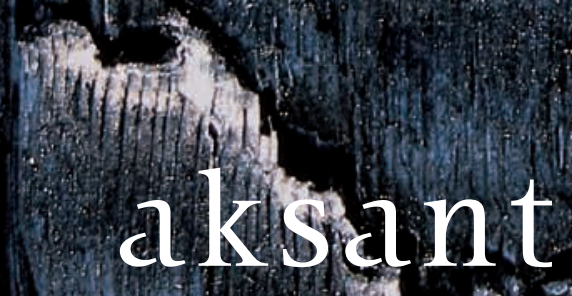




\section{Death at the opposite ends of the Eurasian continent}

Mortality trends in Taiwan and

the Netherlands

I850-1945 
This publication has been made possible with the financial support of the Netherlands Organization for Scientific Research (Nwo)

This volume is the fourth in the series Life at the extremes. The demography of Europe and China (LatE) edited by Chuang Ying-chang (College of Hakka Studies, National Chiao Tung University, Taiwan), Theo Engelen (Radboud University Nijmegen, the Netherlands) and Arthur P. Wolf (Stanford University, U.S.A.)

Previously published:

LatE I: Theo Engelen \& Arthur P. Wolf (eds.), Marriage and the family in Eurasia. Perspectives on the Hajnal hypothesis (Amsterdam: Aksant, 2005) LatE 2: Chuang Ying-chang, Theo Engelen \& Arthur P. Wolf (eds.), Positive or preventive? Reproduction in Taiwan and the Netherlands, 1850-1940 (Amsterdam: Aksant, 2006)

LatE 3: Theo Engelen \& Hsieh Ying-hui, Two cities, one life. Marriage and fertility in Lugang and Nijmegen (Amsterdam: Aksant, 2007)

ISBN 978-90-5260-379-7

(C) 20II, the authors/Aksant Academic Publishers/Amsterdam University Press

All rights reserved including those of translation into foreign languages. No part of this publication may be reproduced or transmitted in any form or by any means, electronic or mechanical, including photocopy, recording, or any information storage and retrieval system, without prioir permission from the copyright owner.

Book Design: MulderVanMeurs, Amsterdam

Printed in the Netherlands by A-D Druk BV, Zeist

Aksant Academic Publishers

Herengracht 22I

IOI6 BG Amsterdam

www.aup.nl 


\section{Death at the opposite}

ends of the Eurasian

continent

Mortality trends in

Taiwan and the

Netherlands I850-I945

edited by

Theo Engelen

John R. Shepherd

Yang Wen-shan

Aksant Amsterdam, 20II 


\section{Contents}

7 Introduction: Death at the opposite ends of the Eurasian continent Mortality trends in Taiwan and the Netherlands, I850-I945

Theo Engelen \& John R. Shepherd

I7 I Trends in mortality and the evolution of the cause-of-death pattern in the Netherlands: $1850-2000$

Frans van Poppel

452 Trends in mortality and causes of death in Japanese colonial period Taiwan John R. Shepherd

8I 3 Mortality in the Netherlands: general development and regional differences Theo Engelen Q Marloes Schoonheim

994 Regional and ethnic variation in mortality in Japanese colonial period Taiwan

John R. Shepherd

I53 5 An outline of socio-medical care in the Netherlands, I9th and early 2 oth centuries

Willibrord Rutten

I65 6 An overview of public health development in Japan-ruled Taiwan Liu Shi-yung

I83 7 The demographic history of smallpox in the Netherlands, I8th -I 9 th centuries

Willibrord Rutten

2038 Anti-malaria policy in colonial Taiwan

Ku Ya-wen

2299 Maternal mortality in Taiwan and the Netherlands, I850-I945 John R. Shepherd, Marloes Schoonheim, Chang Tian-yun Q Jan Kok 
275 Io Maternal depletion and infant mortality

Theo Engelen \& Arthur P. Wolf

289 II The massacre of the innocents

Infant mortality in Lugang (Taiwan) and Nijmegen (the Netherlands)

Theo Engelen \& Hsieh Ying-hui

3I7 I2 Illegitimacy, adoption, and mortality among girls in Penghu, I906-I945

Yu Guang-hong, Huang Yu-lin Q Chuu Ling-in

349 I3 How reliable is Taiwan's colonial period demographic data?

An empirical study using demographic indirect estimation techniques Li Chun-hao, Yang Wen-shan \& Chuang Ying-chang

\section{References}





\section{Introduction:}

Death at the opposite ends of

the Eurasian continent

Mortality trends in Taiwan and

the Netherlands, I850-I945

Theo Engelen \&

John R. Shepherd 
Death is often referred to as the great equalizer. In the end, it is said, it makes up for differences in life chances among social classes, political entities and historical periods. The sad truth is that although every human being inevitably dies, there is a vast range in the causes and timing of mortality, largely determined by location in space and time and social position. This volume looks into the similarities and the differences in mortality at the two ends of the Eurasian continent by taking the Netherlands and Taiwan as case studies representing the WestEuropean and Chinese mortality regimes. This choice is no coincidence. Two centuries ago Thomas Malthus distinguished between a low pressure population system in Western Europe and a high pressure system in Asia, specifically China. In his analysis of the forces determining rates of population growth, Malthus and many of his followers, identified mortality as the major variable in Asia ("positive checks"), and limits on fertility and nuptiality as the major variables in Europe ("preventive checks") (see among many others: Malthus I798; Hajnal I965 and I98I; Wrigley and Schofield I98I; Engelen and Wolf 2005; but also Lee and Wang I999). Malthus argued that in China universal marriage and uncontrolled fertility led to growth that was only constrained by high mortality (thus, 'high pressure'), while in Western Europe, growth was limited by constraints on fertility stemming from late marriage and high rates of celibacy, with mortality playing a smaller role ('low pressure').

The group of Taiwanese, Dutch and US scholars contributing to this book participates in a research project called Population and Society in Taiwan and the Netherlands, dedicated to the comparative study of demographic, social and economic conditions in China and Europe in pre-modern times. The project has already produced three volumes, respectively, on differences in marriage and family systems (Engelen and Wolf 2005), on differences in fertility (Chuang, Engelen and Wolf 2006), and a case-study comparing marriage and fertility in Nijmegen and Lugang, a Dutch and a Taiwanese town (Engelen and Hsieh 2007). The project takes Taiwan and the Netherlands as representatives of the extremes of Eurasia and of Malthus's ideal types. Of course, within territories as vast as China and Europe one finds many differences. Still, the program is guided by the idea that the differences within the two societies are minor compared to the differences between the societies. We controlled our comparison of Taiwan and the Netherlands by choosing two periods in which their economies reached approximately the same level of modernization. As a result, the Taiwanese studies focus on the Japanese colonial period (I895-I945), whereas the Dutch contributions cover roughly the years between I850 and I920. In these two periods the societies resembled each other economically as well as demographically, at least in terms of crude rates. It goes without saying that the social and cultural differences remain.

This volume contains four clusters of chapters. The first cluster deals with long term trends in mortality and the accompanying changes in causes of death 
(Chapters I through 4). The first pair of chapters deals with changes in national

levels and patterns of mortality in each of the two societies. Van Poppel warns that overemphasis on national aggregates can obscure the importance of variation within each society. Therefore, in Chapters 3 and 4 we study the surprisingly large impact on mortality due to regional, ethnic and religious differences.

Both Taiwan and the Netherlands witnessed steady improvements in public health, disease prevention, and socio-medical care in the periods described; these trends are discussed in the second cluster of essays. In Chapters 5 and 6 the authors analyze the histories of public health in the two societies. In each case public officials directed special attention to selected leading causes of death. The Dutch struggle against small-pox is analyzed in Chapter 7. Malaria was an important life threatening disease in Taiwan. Chapter 8 deals with the way the Japanese colonial government tackled this problem.

The third cluster of chapters is geared at understanding mortality patterns in combination with fertility. Our papers deal first with maternal mortality (Chapter 9) and then address a variety of factors affecting infant mortality (Chapters Io-I2). In Chapter ıo the authors link maternal and infant health by focusing on maternal depletion and its relationship to infant mortality. In Chapter II, the authors compare patterns of infant mortality in two cities, one from each society. In the household registers from Taiwan's Penghu islands the Program for Historical Demography (Academia Sinica, Taiwan) discovered a surprisingly large number of illegitimate births and a high incidence of female infant mortality. Whether there is a causal connection, possibly via adoption, is the subject of Chapter i2.

Both the igth century Dutch demographic sources and the Japanese colonial sources on Taiwan have been found to be highly reliable (see Knotter and Meijer I995; Barclay I954). Using a new technique, three Taiwanese authors verify the accuracy of Taiwan's censuses and death reporting in Chapter I3.

In both societies we find a revolutionary decline in mortality and rise in life expectancy for the periods studied. The general decline in mortality was shared unevenly within Taiwan, among groups and between periods. Both disease environments and factors of social position (age, sex) played a role in determining variation around all-island average rates. Cause of death analysis makes clear that malaria played an especially important role in the mortality decline. Malaria was a very significant leading cause of death in I906-08, and its decline represents perhaps the greatest achievement of the Japanese public health effort in colonial Taiwan. Reducing the toll of this leading cause of death had an important secondary effect too, since comorbidity associated with malaria was also reduced. In the Netherlands the structural mortality decline started in the I87os. The improvement shows clearly when we look at the number of years of life the Dutch had at their disposal. In I870 life expectancy in the Netherlands was rela- 
tively low in comparison to other countries in the region, but by I9I0 only the Scandinavian countries did better. The biggest contribution to increased Dutch life expectancy came from the decline in infant mortality. Here, as in Taiwan, we have to stress that one finds great interindividual differences. Until the first decades of the twentieth century the 'disease environment' and economic circumstances varied enormously from place to place, from social class to social class, from men to women and from household to household. This was reflected both in life expectancy and in causes of death.

Regional differences in Dutch mortality can partly be explained by the characteristics of the epidemiologic transition. This transition is characterized by a decline of infectious diseases on the one hand and, due to the postponement of death, the increased significance of old age diseases and external causes of death on the other hand. In the Netherlands deaths attributed to infections caused by polluted water, contaminated food and bad hygienic conditions decreased significantly between 1875 and 1925 . Before the decline, the west of the country suffered from the highest death rates as a result of salination and low-quality drinking water that kept infant mortality high. During the last decades of the Igth century, however, a 'modern culture pattern' emerged, bringing knowledge of sanitary practices and improving hygienic conditions as it spread from the northwest of the country to the southeast. Following these improvements, the southeastern part of the country emerged as the area having the highest (infant) mortality rates. According to some, the Roman Catholic religion was partly responsible for impeding the influence of the new culture in the southeast.

In Taiwan we found the persistence of strong regional differences in the levels of mortality and the underlying causes of death throughout the Japanese period. Unlike the Netherlands, regions in Taiwan did not leapfrog one another as improvements advanced further in some areas. The areas enjoying the highest life expectancies continued to do so from the beginning until the end of the period despite public health interventions and overall declines in mortality. The author also has documented striking ethnic differences. The best explanation for the Hakka advantage over the Hoklo is the Hakka population's good fortune to be heavily concentrated in the area of lowest mortality. Still, the possibility of a 'real' Hakka cultural advantage remains since the author found that in Hsinchu small differences emerged even when the ethnic groups lived in close proximity.

In both societies political changes resulted in governments that adopted vigorous new approaches to public health. Until the Netherlands was unified under a new king in I8I3, the government of the Dutch confederation had lacked the power to take charge and initiate a nationwide campaign to contain epidemics. In I8I8, the new kingdom issued a Medical Regulations Act governing medical education and the practice of medicine. As a result it was possible to make vaccination against smallpox quasi-compulsory in the I820s. In I85I, the 
Municipal Act made local governments more responsible for the health of their citizens and gave them new powers to make improvements. Most importantly this act provided the legal and administrative structures needed to build expensive public works such as piped drinking water and sewer systems, which were prerequisite for the take-off of the public health revolution in the Netherlands.

In Taiwan, the Japanese colonial government adopted public health measures and medical reforms to control epidemic diseases, mainly to improve the living environment for Japanese colonialists. After I9I0, the expansion of clinical medicine and the new structure of colonial medicine benefited the Taiwanese population too. Despite the shortage of medical resources both in Japan and Taiwan, the colonial government succeeded, as the declining mortality rates show. Because the police were put in charge, the public health reporting system served an important surveillance and enforcement role in Taiwan. The degree of control was much stronger than in the Netherlands, where state health inspectors and members of the health councils could only pressure municipal and provincial administrations to improve public hygiene in their areas. The Dutch officials lacked the enforcement powers of the Japanese colonial police.

We find an example of the modernization of public health and disease prevention in the anti-malaria policy in colonial Taiwan. In the I920s, following new scientific insights the Japanese adopted the so-called mosquito approach, seeking to eradicate the disease by eliminating the habitat of the mosquito vectors . This approach, however, because it required constant vigilance and unremunerated labor service by local Taiwanese was difficult to implement. The policy met with so much passive resistance that in the I930s the emphasis on the mosquito approach weakened, and greater emphasis was given to the 'human approach' of blood testing and quinine treatment. The author analyzes how changes in anti-malaria policy reflected not simply changes in scientific knowledge, but changes in Japanese strategies of colonial governance. At the other end of Eurasia smallpox was as dangerous to the population as malaria in Taiwan. Smallpox mortality too shows large variations between urban and rural areas, and between social classes. The history of vaccination shows that socio-medical engineering could be successful even in the setting of a pre-industrial society that suffered from a low standard of living. Infant mortality was curtailed and the urban-graveyard phenomenon disappeared.

Giving birth was a risky event in pre-industrial societies. Still, both in the Netherlands and in Taiwan maternal mortality declined significantly in the periods studied, although initial levels and the rates of decline differ. The decline has to be attributed to the growing number of well-trained midwives though general improvements in health status contributed as well. The two societies resembled each other in other ways too. When mothers were older and at higher parities maternal mortality increased. The loss of a mother also had major implica- 
tions for the survival chances of the child. Although the effect is stronger in Taiwan than in the Netherlands in the first months of life, the probability of surviving the first year drastically declined when the mother died.

With regard to infant mortality proper our authors reach the conclusion that the differences in average level were not as big as Malthusian theory would suggest. What is more, by the end of the two periods, more Taiwanese than Dutch infants reached their first birthday. In the periods compared, conditions in Taiwan improved while industrialization in the Netherlands raised infant mortality rates. There is a major difference in the composition of infant mortality in the two societies. In Taiwan neonatal mortality remained relatively high, possibly due to low birth weights, whereas in Nijmegen post-neonatal mortality was more important, likely due to breastfeeding practices by many mothers that weaned infants prematurely. Another surprising finding about the background of infant mortality in our two cities is the dominance of biologically proximate factors over socio-cultural factors (apart from breastfeeding patterns). The chances of survival were dictated by birth-interval, parity and twinship rather than by father's occupation or, in Nijmegen, religion.

Women have to pay a price for a quick succession of births, especially when resources are scarce. Mothers depleted of energy reserves may produce low birth weight infants who are at high risk. Birth intervals smaller than one and a half year indeed boosted the chances of infant death in both Nijmegen and Lukang. The results also show that maternal depletion was a more active phenomenon in Taiwan. Children born within I8 months after the previous child had a 37 per cent higher chance of dying in Lugang than they had in Nijmegen. Since age of the mother also is positively correlated with infant mortality (and parity), the case for depletion as an important cumulative factor is also strong. The comparison of the two societies also reveals other interesting differences. The average birth interval in the Netherlands was markedly smaller and Nijmegen mothers were on average older than their Taiwanese counterparts. Theoretically this would imply that maternal depletion and neonatal mortality would be more severe in Nijmegen. Since the authors find the opposite result, they take this as an argument that Taiwanese mothers were relatively malnourished and suffered more from maternal depletion. Shorter birth intervals were not an option voluntarily foregone by Taiwanese mothers to limit fertility because fertility levels were already pushing the limits women's bodies and infant mortality rates could bear. Thus the authors' preference for the Malthsian explanation of the differences between Chinese and European populations.

The high mortality among girls in Penghu appears to be difficult to explain. Analysis of the carefully kept household registers controverts the explanations given by local informants in interviews. The high level of illegitimacy, for instance, turns out not to be the result of not-yet-registered minor marriages. 
Instead many illegitimate births were the result of informal marriages among the poorer part of the population. The findings also show that high female infant mortality could not be explained by female infanticide. Instead it is high rates of female adoption and the higher mortality of adopted daughters compared to daughters that raises rates of female infant mortality. Also, illegitimate children were at greater risk than legitimate children, be it only in the first month of life.

All the findings in this book are only convincing when we can trust the data underlying them. Numerous studies have confirmed the accuracy of the Dutch registers. Except for minor problems with the registration of migration, the population registers are of high quality, and the civil registers are nearly error-free. In Taiwan, the registers and the aggregate data compiled from them are also of the highest quality (Barclay I954). Our authors examined the quality and consistency of the censuses and vital statistics from years not examined by Barclay and estimated the completeness of death registration in five intercensal periods. Using an indirect estimation technique they confirmed the high degree of accuracy achieved in Taiwan's census and death reporting.

What do these findings tell us about the mortality patterns Malthus discerned? We compare Taiwan and the Netherlands in periods when they are roughly similar to one another with respect to both level of economic development and crude measures of mortality and fertility. Thus we focus more on differences in patterns than in levels of mortality (cf. Lavely and Wong I998). There are striking differences in the links between social structure and demographic processes in the two societies.

Despite impressive spatial variation in mortality, nuptiality and fertility varied only slightly across Taiwan (Chuang et al. 2006, Barclay I954: 234, 25I). An analogous pattern appears in analyses of Chinese genealogical records spanning several centuries; despite substantial temporal variation in mortality levels, female nuptiality and age-specific marital fertility remained nearly constant (Harrell I995: 7, I5). This invariance testifies to a strong and persistent Chinese culture of early and universal marriage, especially for females, and pronatal family norms, relatively unaffected by exogenous social conditions whose impact was buffered by joint family organization. In the Netherlands, by contrast, we find spatial and temporal variation not only in mortality, but also in rates of marriage and levels of fertility (Chuang et al. 2006, Engelen 2009). In the Nether lands, where marriage is selective and families nuclear, religious and economic differences affected both marriage rates and norms affecting fertility and breastfeeding practices.

In the periods we study, neither Taiwan or the Netherlands was facing the kind of subsistence crisis that worried Malthus. Both populations were growing, Taiwan's at rates that doubled its population from I895 to I945. The Dutch pop- 
ulation more than doubled between I850 and I920 (Barclay I954: I2, Engelen 2009). In both societies economic growth and public health benefitted from technologies unanticipated in Malthus' day. Yet we find hints of Malthusian pressures in the patterns of neonatal and infant mortality. In Taiwan we discovered birth intervals that though longer than Dutch ones could be shortened only at the cost of a steep rise in infant mortality, and high rates of neonatal compared to post-neonatal mortality; both patterns could be linked to maternal depletion and low birth weights. In the Netherlands infant mortality was elevated postneonatally by early weaning, a pattern worsened by industrialization and pressure on mothers to work outside the home. Late marriage created its own pressure to bear children in short intervals, reducing time for infant breastfeeding, and neolocality put the full costs of family life on the shoulders of the married couple alone. Thus we find pressures originating from the West European marriage pattern that link to positive checks as well as preventive ones. After all, it was uncontrolled fertility within marriage that caused Malthus to celebrate limits on marriage itself. For our authors, Malthus' most valuable insights relate to differences in marriage and family systems, which leads to our studies of the connections between marital fertility and infant mortality, rather than his predictions of subsistence crises related to overpopulation. 


Trends in mortality and the evolution of the cause-of-death pattern in the Netherlands: I850-2000

Frans van Poppel Netherlands Interdisciplinary Demographic Institute,

The Hague, the Netherlands 


\section{Abstract}

In this paper we describe the contours of the mortality transition taking place in the Netherlands between the mid-nineteenth century and the end of the twentieth century. We first of all give an overview of the published statistical data that can be used to describe the mortality evolution. Next we present information on the development of our main mortality parameter, the expectation of life at birth, for males and females. We describe the changes in the age and sex patterns of mortality, making use of contour maps, and decomposition techniques. Then we describe the long-term trends in mortality by cause of death, focusing on the most relevant cause-of-death categories.

\section{Introduction}

The commonalities in the pattern of mortality decline in western industrialized countries has led to the formulation of the theory of the epidemiological transition (Omran I97I), a specification of the demographic transition theory. Omran described three stages in the mortality decline, each characterized by a differing cause-of-death pattern: the period in which pestilence and famine dominated the mortality regime, the age of receding pandemics and the age of degenerative and man-made diseases. The epidemiological transition theory gives a description of the basic characteristics of the mortality development in Europe between the middle of the nineteenth and the end of the twentieth centuries mostly based on French, English, Scandinavian and German studies. A key characteristic of the mortality pattern in traditional Europe was the wide regional differences that existed there until the end of the nineteenth century. Although mortality declined in all western industrialized countries, extreme diversity is visible in the dates at which the mortality decline began, the trend of the decline, the age-sex patterns of mortality and other characteristics of the mortality regime (Perrenoud I999; Perrenoud \& Bourdelais 1999). The Netherlands was among the forerunners in the epidemiological transition. Although compared to England and the Nordic countries death rates started to decline rather late, from the last quarter part of the nineteenth century on the Netherlands underwent such a fast decline in mortality that on the eve of the First World War the expectation of life was at the same level as that of the Scandinavian countries, England and Wales, Ireland, Belgium and Switzerland (Reher 2004; Riley 200I; Vallin I99I). The demographic characteristics of this secular mortality decline in the Netherlands will be described

\footnotetext{
I. The statistical data used here were published by the Central Bureau of Statistics and its predecessors. In the past decade a large part of this material has been entered in a database by researchers from NIDI. See Ewa Tabeau, Frans Willekens and Frans van Poppel, Mortality in the Netherlands: The data base (Den Haag I994). Cause-of-death data for the period I875-1992 were collected in a database by Judith Wolleswinkel- van den Bosch, at the Department of Public Health of the Erasmus University Rotterdam.
} 
with a series of mortality parameters, all based on the standard sources of demographic information.

\section{Death registration and mortality statistics}

It comes as no surprise that the countries which were forerunners in the mortality transition were also the ones with the most advanced statistical systems of the time.

Death statistics are based on individual death certificates, which in their turn are based on the reporting of deaths to the Registrar of the municipality in which they occurred. Nation-wide complete death (and birth) registration was introduced in the Netherlands in I8II, at the time of the incorporation of the Netherlands into the French Empire. Although the registration started in most municipalities soon after, the quality of the data collected in the first years was poor: lack of experience of the registration officers, ignorance among the public and among registration officers of the official regulations, war, and other complications were responsible for this. Comparisons of the civil and the parish registers of births and baptisms and of deaths and burials have shown that during these first years a small proportion of births and deaths escaped registration (Kok I991, 34; Noordam 1986, 219-220).

Statistical publications based on this death registration were until the I840 almost absent and have many weaknesses. For example, information on the age and sex of the deceased was only published for the years I 827 and I 828 (Commisie voor de Statistiek I828; I829). Data for the Netherlands as a whole for the years before 1840 did not include data for the Dutch province of Limburg or referred to the Dutch and Belgium provinces of that name together. Death registration up to 1837 did not distinguish between children registered as still-born and children registered as live-born and deceased in their first year of life, leading to biased estimates of the level of infant mortality (Oomens I989, 20-26). Calculating refined mortality parameters was also hindered by the absence of information on the population at risk, classified by sex and age; the first census containing this information was published only in I830.

A continuous annual series of numbers of deaths by age and sex only became available from $\mathrm{I} 840 \mathrm{on}$. By combining this information with population data by age and sex from the decennial censuses and with annual data on live born children, the calculation of annual values of the most important mortality indicators becomes possible. Life tables were published on the basis of these data for the period I840-5I and later. These published life tables however are not very well suited for more refined mortality analysis. The methods used for the construction of the life tables diverged considerably during the last century and a half: changes in the definition of live births and deaths in the first year of life cause serious problems when comparing life tables before and after I9I7 
(Tabeau I994); life tables for the period I94I-I946 were never constructed; and in some periods, deaths due to accidental circumstances like floods and military activities were not included. The published life tables also stretch over intervals of varying length; especially before World War II, when they relate to ten-year periods (Van Poppel, Tabeau and Willekens I996).

Information on differences in the level of mortality - for example by social class, region, marital status etc. - is even more scarce. Provincial level data on mortality started to become available at the same time as national data. On the municipal level data were for the first time published for the period I84I-I860 as a whole. More detailed data, for example on mortality of children in the first year of life according to the number of weeks lived or according to the marital status of the deceased, became available from the middle of the nineteenth century.

An essential element for our knowledge of the mortality transition is information on medical causes of death. The collection of this kind of information started already in the eighteenth century but for a long time this information is practically useless for the study of national trends. The registration of deaths by cause of death had developed from the second half of the eighteenth century on at a strictly local level. Physicians and local councils became to realize that prevention and control of diseases could only be based on detailed data on the causes of disease and death. The municipal council of The Hague was the first to establish a system of disease and death registration in 1755 on the basis of causes of death reported to the town clerk's office, by the person reporting the death. Other cities like Alkmaar, Rotterdam and Amsterdam followed this example and began to compile cause-of-death statistics in the I770s. These kinds of local, lay and non-compulsory registration of causes of death remained the rule until the I86os when after several decades of struggle a national, compulsory system of medical certification of causes of death was established (for the history of causedeath registration in the Netherlands see, Van Poppel and van Dijk I997; Van Poppel and van Dijk 2002).

This nation-wide medically certified cause of death registration was introduced on I June I 865 by the Public Health Inspectorate Act and the Medical Practitioners Act. Upon the death of one of their patients, doctors were required to submit to the registrar a medical certificate, in which they were to state as accurately as possible, what was the cause of death but "with due regard to their oath of confidentiality." The Burial Act of Io April 1869 finally made medical certification of cause of death a national, statutory requirement. Local registrars could not legally issue a burial permit without a reported cause of death. Municipal councils were required to send monthly reports to the Public Health Inspector, detailing the number of local deaths. This inventory was then to be processed by the Public Health Inspectorate. Between 1869 and I899, 94-95\% of all deaths in the Netherlands was reported by doctors. 
The first statistical compilation of data on causes of death of the deceased related to I866, and focused on just six diseases: smallpox, scarlet fever, measles, typhus, angina diphtheria, and cholera. Other diseases, including unknown causes, were grouped together. During the period I867-I874, a more sophisticated system of classification grouped causes of death into eleven main headings, which in turn included 55 causes of death. Data were published by sex and age of the deceased and for provinces and larger cities. From I875 on, a classification system was in use which included 35 causes of death and to subcategories. By 1900 the nomenclature was adjusted to meet internationally developed standards. Municipal data on cause of death by age and sex have been published continuously since I 875 but the publication has been interrupted several times due to budget cuts and for other reasons. In particular from I93I on, only very restricted information on cause of death at the local level is available.

\section{Trends and fluctuations in the expectation of life}

Of all demographic indices of mortality, life expectancy at birth is by far the most widely used. The average number of years of life an individual of a given age is expected to live if current mortality rates continue to apply is a statistical abstraction based on a summary of age-specific death rates as given in a life table. It equals the arithmetic mean of the ages at death of individuals as given in the life table. As was mentioned above, published Dutch life tables with their values of the expectation of life at birth are not very well suited for a comparison of mortality over time. For that purpose, a cross-referenced, comparative series of life tables for each year of the period I850-199I was established, based on a precise inventory of the basic data compiled at the national level, on estimates of the population by sex and single years for each year and on standard methods for the construction of uniform life tables (Tabeau, Van Poppel \& Willekens I994). ${ }^{2}$

The first period for which data on death by age and sex at the national level were available are the years 1827 and 1828 (Commissie voor de Statistiek, I828; I829; Oomens, I989, 2I). By combining this information with data on population numbers by age and sex from the census of 1829 , rather refined mortality parameters can be estimated for this period. For the period I840-5I as a whole estimates are available but they cannot be distinguished by year. Only from I 850 on, annual values for the expectation of life at birth can be computed. They are given in figure $\mathrm{I}$.

2. Population numbers were estimated on the basis of the outcomes of the ten-year censuses, the annual numbers of live births and annual numbers of deaths classified by age, sex and year of birth. Numbers of migrants by sex and age were obtained as the difference between the populations recorded in the census and the population resulting from natural growth only and the migration balances were distributed equally between the years in the intercensal period. 
In I827-28 expectation of life at birth was equal to 36.6 years for males and 39.5 years for women; in I840-185I these values were respectively 36.1 and 38.5. From figure I it is clear that the pre-I 850 values did not deviate much from those after I850. Therefore, we can argue that the increase in life expectancy only started around the middle of the nineteen seventies.

Turning points characterizing significant changes in the global movement of this indicator through time can be located in the 1870 s when the annual fluctuations came to an end and the increase in life expectancy started, in the middle of the I920s when the growth of life expectancy decreased, and after the mid I950s when the increase slowed down further. Notwithstanding the reversal of the declining mortality trend in the I950s, the expectation of life of men and women has doubled since I850.

Fixed features of the old demographic regime - in the Netherlands and elsewhere in Europe- were mortality crises such as epidemics, subsistence crises and wars. They played an important role in the Netherlands as well. The largest fluctuations occurred in I855, I859, I866, I87I, I9I8 and I945 (Ballot I87I). The outbreak of cholera observed in 1855 was combined with attacks of measles and typhus, and as a result the expectation of life fell to values of 33.2 (men) and 35.0 (women) respectively, compared with values in I850 and I85I of 38.5 for men and 40.5 for women. The situation became worse again in 1859 when smallpox and cholera took a heavy toll, leading to a fall in the expectation of life to 29.2 (males) and 31.4 years (females). After a few years, a new violent outbreak of cholera caused the expectation of life to plunge again in I866 to $32 . \mathrm{I}$ and 34.4 years. In I87I expectation of life only reached 31.3 for males and 33.4 for females, due to an epidemic of smallpox. From then on fluctuations were very modest and overall a clear increase was visible. It was only the outbreak of the influenza epidemic in I9I8 that for the first time since I87I sent life expectancy down to much lower levels. While the expectation of life in I9I3-19I5 was circa 56.0 for males and 58.2 for females, in I9I 8 values of 46.5 and 48.5 were observed. This decrease brought the level of mortality back to levels which were found in the last decade of the nineteenth century. 3

The worst crisis of the twentieth century came with the outbreak of World War II. Whereas for women the real crisis in mortality started only in I944, men were already hit in I940. Both sexes suffered most in I945 but the decrease in

\footnotetext{
3. Mortality rates for the years I9I5-I9 are slightly overestimated due to an underestimation of the population at risk in these years. The refugees from Belgium who arrived in the period I9I4-I918 were not yet included in the census of I9Io and had already returned to their country at the moment the census of I920 took place. They thus were not included in the censuses which formed the basis for the calculation of the population at risk but were included among the deaths during that period.
} 


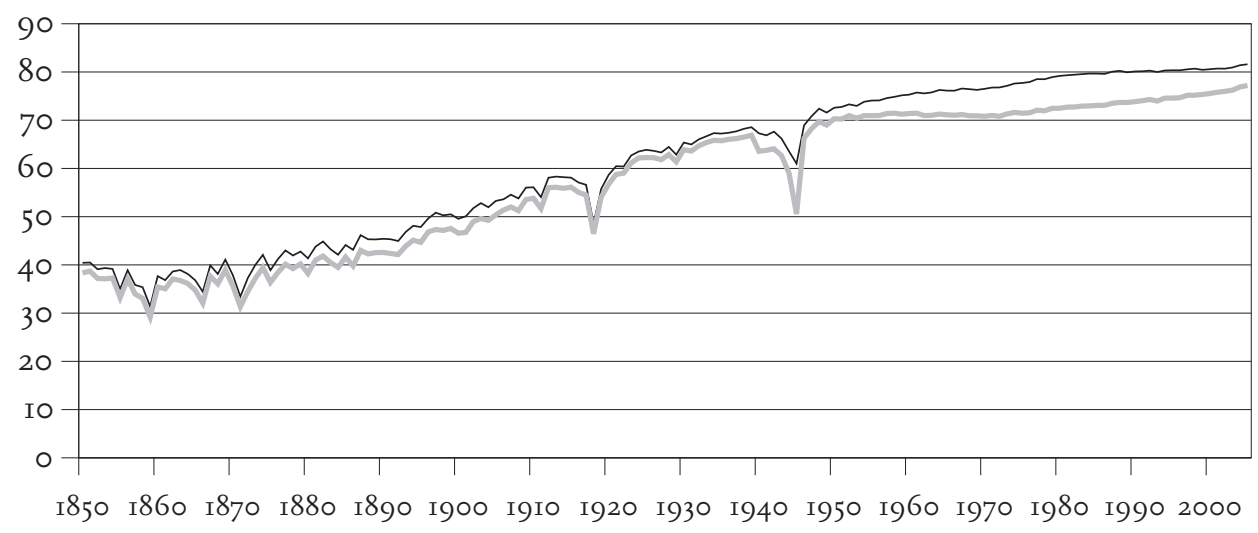

Men - Women

mean length of life was much larger for men than for women. Compared to I939, male length of life in I945 had decreased by i6.3 years to 50.6; among females, the decrease was 7.6 years. 4

\section{Decreasing interindividual variation in mortality}

Averages such as the life expectancy at birth are useful indexes when looking for a single figure to summarize a set of age-specific mortality rates (Wilson and Oeppen 2003). But often some indication of the variations about the average is relevant as even today variation in age at death still dominates. The average length of life does not do justice to this variation between individuals. Various authors have proposed measures for the heterogeneity of the length of life, making it possible to find out whether the increase in the expectation of life at birth has become equally accessible to the whole population. One of these measures is the Gini-coefficient, a measure which is widely used in econometrics as a standard measure of inter-individual inequality in income.

4. The figures for I94I-I945 seriously underestimate the mortality level. Of the estimated 210,000 direct civilian and military casualties of the war only 67,000 were recorded in the Dutch death statistics, either as military or civilian casualties or as deaths from executions, hunger and hardship in camps in the Netherlands. Not included in the national statistics are subjects formally removed from the local population registers on deportation to Germany. Because neither the year of death, nor the birth cohort of the deceased among the deported were known to the NCBS, these war victims were not included in the death records, leading to an underestimation of circa $27 \%$ of the mortality rates during I94I-45. (Those deported included I04,000 Jewish citizens, some I8,000 political prisoners and some 27,000 people who were forced to work in Germany). 


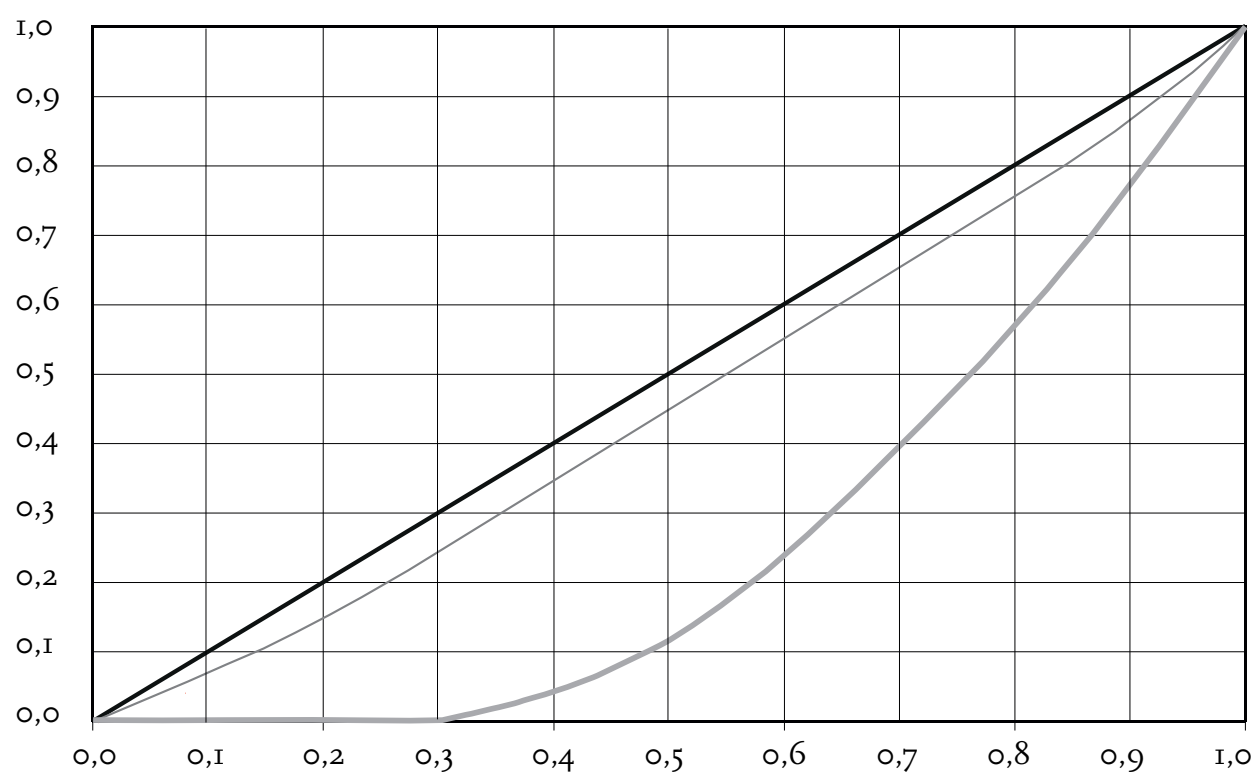

Netherlands 2003 Diagonal line —— Netherlands I850

The Gini-coefficient is based on the Lorenz-curve. The Lorenz curve usually represents the cumulative income share (on the vertical axis) as a function of the cumulative population share (on the horizontal axis): if a population share is always exactly equal to the share in overall income then there is a situation of perfect equality. Applying this to the life table, that is to a schedule of survival by age, one can imagine the sum of person years lived from birth to death to be income and cumulative death numbers to be population. The number of years lived by all individuals (the life table function) is represented cumulatively on the vertical axis, starting with age 0 . On the horizontal axis the cumulative number of deaths from age $o$ to the highest age is represented.

The Lorenz-curve can be compared with the diagonal line which represents perfect equality between both quantities. In the example, the diagonal line indicates that the first io percent of all deaths has lived exactly io percent of the total number of years lived, the first 20 percent of all deaths 20 percent of the number of years lived, etc. The further away the Lorenz-curve is from the diagonal line, the higher the inequality in the numbers of years lived. The Ginicoëfficient is defined as the area between the diagonal and this curve, divided by the whole area below the diagonal. The coefficient varies between $O$ and I. It is equal to zero if all people in a population (or in our case in the life table 


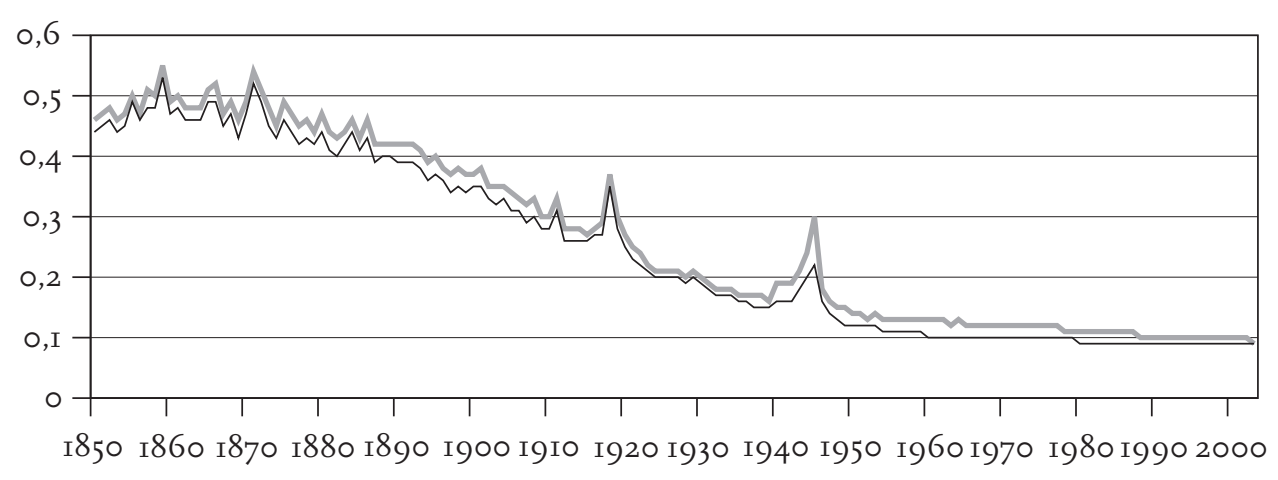

Men — Women

decribing the mortality of the population in a given year) die at the same age and equal to one if all people die at age $o$ and one individual dies at an infinitely old age. Higher values of the Gini-coefficient thus show a greater magnitude of interindividual differences. In a number of studies Gini-coefficients have been applied to mortality schedules to analyse the time trends in the degree of people's inequality in the face of death (Shkolnikov, Andreev and Begun 2003).

Figure 2 shows the Lorenz-curve for Dutch males in in I850 and 2003, and the diagonal line. The figure makes clear that in 1850 there was no question of equality in the average length of life whereas in 2003 the interindividual variation in the length of life had decreased strongly. In I 850 the first 20 percent of all deaths lived less than 0.3 percent of the total number of years lived and the first 50 percent of all deaths only i2 percent. The corresponding Gini-coefficient was 0.46 . In 2003 the first 20 percent of all deaths lived I5 percent of the total number of years lived and the first 50 percent 44 percent. The corresponding Gini-coefficient was 0.09 . To a much stronger degree the average length of life has therefore become within reach of the average man and woman.

Figure 3 depicts for men and women the historical changes in the interindividual variability in the expectation of life. Since the middle of the nineteenth century the increase in the expectation of life has run parallel with the reduction of inequality in length of life. For men, after I894 the values of the Gini-coefficient were never above 0.40 whereas for women this threshold was crossed in 1887 . In the most recent period the Gini-coefficient reached values of around 0.IO. As mortality now is more and more concentrated in higher ages and the mortality risks at low ages could not decline any further, the inequality in ages at death could not decrease any more. The strong reduction in the length 
Figure 4. Percentage of deaths within a ten-years-range of the expectation of life at birth, by sex, $1850-2003$

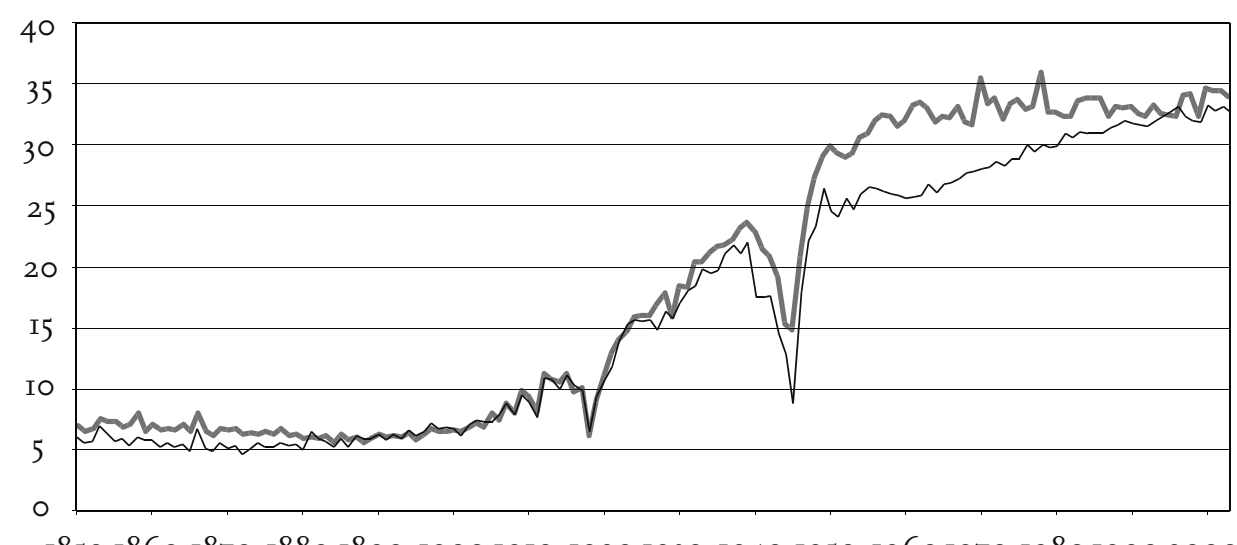

I850 I860 I870 I880 I890 I900 I9I0 I920 I930 I940 I950 I960I970 I980 I990 2000

Men Women

of life inequality can be compared with a process of income redistribution: just as poor people as a consequence of redistribution acquire a higher additional income than rich people do, in the process of the mortality decline infants acquired more additional years of life than adults and the elderly. In the last decades this process of redistribution has however been rather restricted.

The Gini-coefficient is not really a user-friendly measure of the variation in the length of life and cannot provide answers to questions about length of life which individuals ask themselves. A better measure of the interindividual variation in the length of life is possible by calculating which proportion of all life table deaths reached more or less the average age at death, (that is the expectation of life at birth) or by calculating which proportion of all births in the life table was still alive at the average age at death (Smith, 1996; Craig, I998). Figure 4 presents information on the percentage of the life table deaths that died within a ten-year range of the expectation of life, that is died between five years below and five years above the average age at death.

Figure 4 shows that in the period till I900 the expectation of life really is a statistical artifact; among men and women a poor 5 percent of births live till approximately the same age as the average length of life. Only after I900 this percentage starts to increase but even after 2000 only about one third died at around the same age as the expectation of life at birth. 


\section{Changing age-profiles of mortality}

The pattern of mortality change during the period I850-2000 showed large variations from one age group to another. There exists a variety of methods to analyse and present this change in mortality by age. For example, methods have been developed to estimate the contribution of a change in mortality in a given age range to the change in life expectancy at birth. Finally, graphic methods have been used to depict the changing patterns of mortality over a wide age range.

We first of all make use of a method proposed by Arriaga (1984) in which the total change in life expectancy between year $\mathrm{x}$ and a reference year is decomposed into the fraction of that change brought about by a change in the mortality in a specific age group. The age intervals that we distinguish here are those between birth and age I, between ages I and 5, between ages 5 and 20, 20 and 50,50 and 65,65 and 80 and 80 and over. The expectation of life in I850 was used as a reference.

Figures 5 and 6 show that a large part (I 6.2 years for males and $\mathrm{I} 4.7$ for females) of the total increase in life expectancy since I850 (37.6 for men, 40.3 years for women) was caused by the decrease in mortality between birth and age I. Whereas infant mortality decrease alone could explain 43.I percent of the change in life expectancy among males, among females only 36.5 percent of the increase could be ascribed to this age group. From the figures it is clear that mortality decrease in this age group only started to contribute to the increase in life expectancy from I 887 onwards. After I896, infant mortality decrease was always responsible for more than I.5 years increase in life expectancy at birth. From I909 on, interrupted only by the temperature-related temporary increase in infant mortality of I9II, this contribution was 5 years or more. Infant mortality continued to decline after 1930 but at a smaller pace. Over the whole period 1850-2002, mortality decrease among I-5 year old children contributed 7.4 years to the total increase in life expectancy at birth among men and 7.7 years among women. In relative terms, the age group was responsible for around is percent of the change in life expectancy among both men and women. For both sexes this age group started to contribute positively to the increase in life expectancy already in the beginning of the I870s. Age groups 5-20 and 20-50 contributed respectively 3.8 (males) and 4.6 (females) and 6.9 (males) and 8.4 (females) years to the increase in life expectancy. In relative terms, these age groups were responsible for some io and 18 (for males) and II and 2I percent (females) of the change in life expectancy. In age group 20-50, the mortality decline started around 1867 and although this decline was temporarily interrupted in the early I870s, it continued afterwards. Among men and women aged 50-65, mortality started to decline in the years I867-I 872 but mortality decline in this age group contributed only 2.0 years and 2.3 years to the increase in life expectancy among men and women respectively. Contributions for age groups 65 80 and 80 and over were negligible among males and females. 
Figure 5 . The contribution of various age groups to the total difference in expectation of life between 1850 and 2002, The Netherlands, men

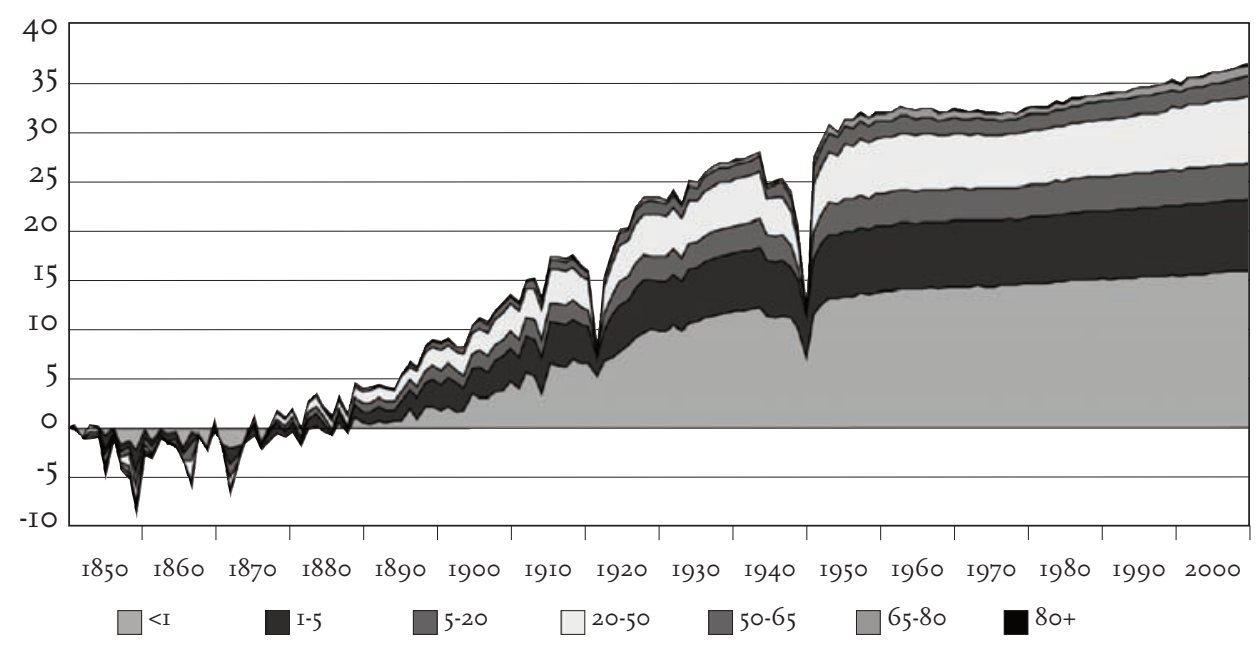

Figure 6 . The contribution of various age groups to the total difference in expectation of life between 1850 and 2002, The Netherlands, women

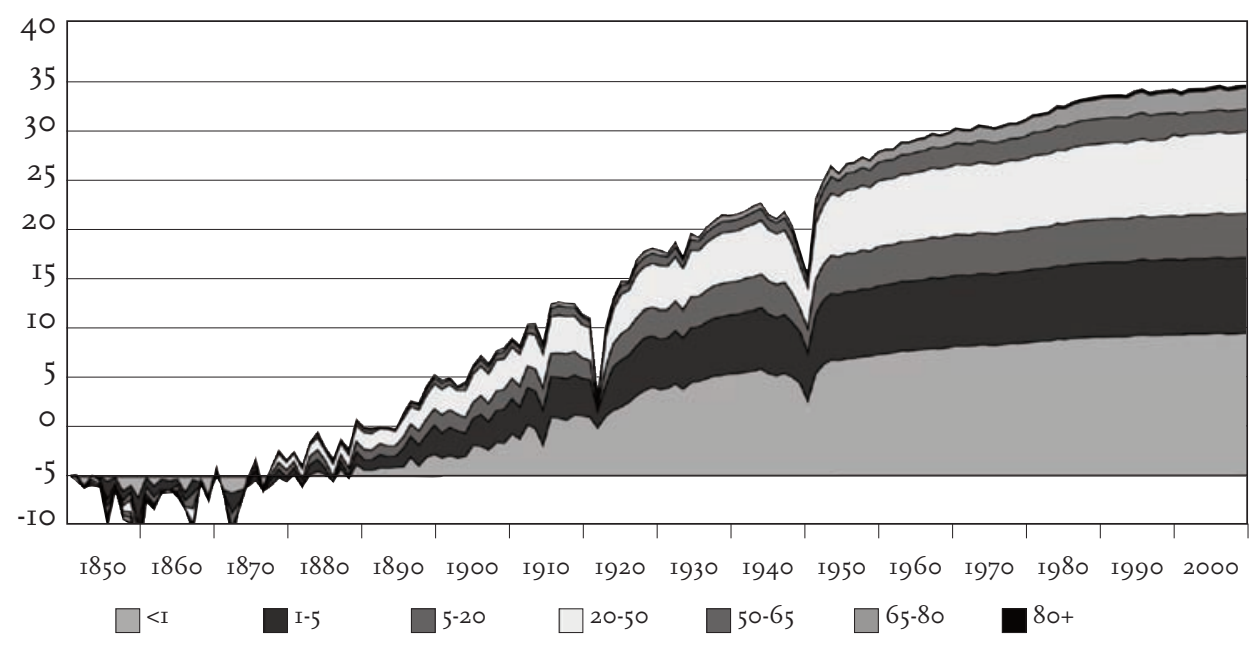


Measures such as the contribution to the increase in the expectation of life

by the mortality decline in a given age group give a distorted picture of the changes in the age-sex pattern of mortality; by definition, mortality changes at younger ages contribute disproportionally to changes in expectation of life. Death rates for single years of age over a long period of time are however difficult to visualize. One option is to use so-called shaded contour maps. These maps, originally developed at the International Institute for Applied Systems Analysis (IIASA), permit a clear representation of a large number of two-dimensional data points (Vaupel, Zhenglian, Andreev, \& Yashin I997). In these maps, surfaces are shaded according to the height of the surface (the level of mortality). We use this method to show the evolution of age-specific mortality for the years I850-2000. The level of mortality is represented by age-specific probabilities of death, that is the proportion of persons of a given age alive at January ist who die before January ist of the next year. The data set consists of probabilities of death for single years of age (ages o to 95) and time (years I850-1998) by sex and contains some I4,000 death probabilities (I49 years times 95 ages).

Figure 7 displays the evolution of death probabilities for Dutch males, and figure 8 does the same for females. The shading varies from light to dark as the surface rises from low to high levels of mortality, equalling an increase in probabilities of death from less than I per Iooo via 25 per Ioo० to more than 200 per Iooo.

The contour map shows the structural changes in mortality as well as the more temporary disturbances of the mortality pattern. Examples of periodeffects are the epidemics of cholera in I853, I854 and I855, in I859, and in I866 and 1867 , the smallpox epidemics of 1858 and I87ı, the Spanish influenza epidemic of I9I8, and the devastation of the Hunger Winter in I944-I945.

The general pattern over time is characterised by high mortality in infancy and among the elderly. As progress is made in the fight against mortality, surfaces with mortality risks of more than 200 per Iooo disappear, first among infants, later among the elderly. The age range characterised by death risks below I per Io०० becomes wider and wider, covering in the I990s almost all ages below 40. Death risks between I and 5 per Ioo०, already visible around I870 at ages around Io years, extend and become common at all ages between I and 30 years. Relatively high death risks shift to the highest ages. Backlashes are visible for example among young male adults between the middle of the I950s and the middle of the I970 as a consequence of the rise in traffic accident mortality and from the early I950s on, among elderly men. Starting with men aged between 55 and 65 and later extending to higher ages as well mortality rates increased as a consequence of increased tobacco consumption and changing diets, trends that both had their origin in changing consumption patterns in the middle of the I920s, but showed an effect with a time lag of several decades. We come back to this issue later on. 


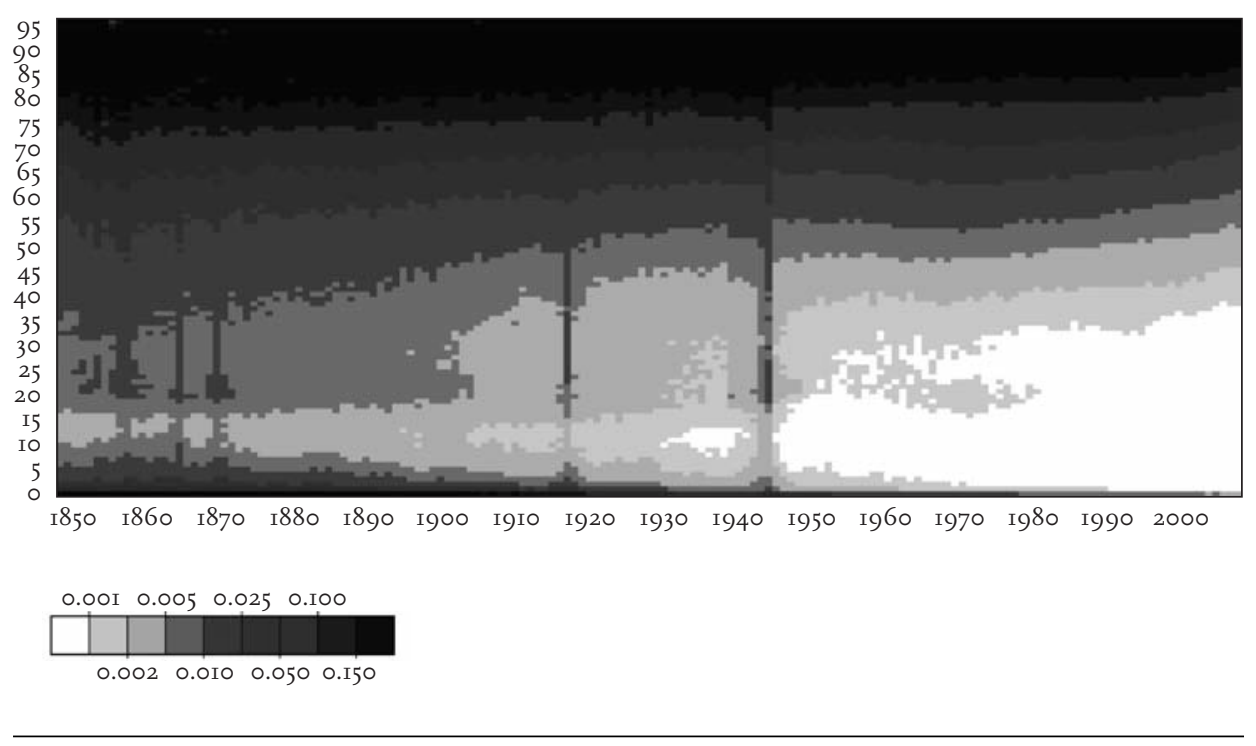

\section{The growth and decline of male excess mortality}

It is clear from the above that from the moment that national data became available, the average length of life of women was some two to three years higher than that for men. Yet there were clear differences over time in the level of that difference.

The period 1850-1898 can be characterized as one of increasing differences. Life expectancy at birth for males in the I850 and early I860 was between I.6 and 2.3 years lower than that for females. Especially around I865, male excess mortality started to increase, reaching values between 2.8 and 3.5 in the years I893-I903. After I903 this trend was reversed and female life expectancy was in the I920s only I.3-I.5 years higher than the value for males. A period characterized by a strong increase in excess mortality started in 1927 and lasted till I975; on average the male/ female differences in life expectancy increased by $3.25 \%$ per year. The increase of male excess mortality was in fact rather modest till the beginning of the I950s; whereas around I950 women lived on average 2.4-2.6 years longer than men, in the middle of the I970s the difference had increased to 6.7 years. From 1975 on, a decrease in excess mortality started.

Decomposition of the male-female difference in life expectancy at birth according to the method devised by Arriaga reveals some interesting findings (see figure 9a).

Male excess mortality was very low or did not even exist at higher ages till the end of the I930s. Between ages 5 and 20, males had lower mortality than 


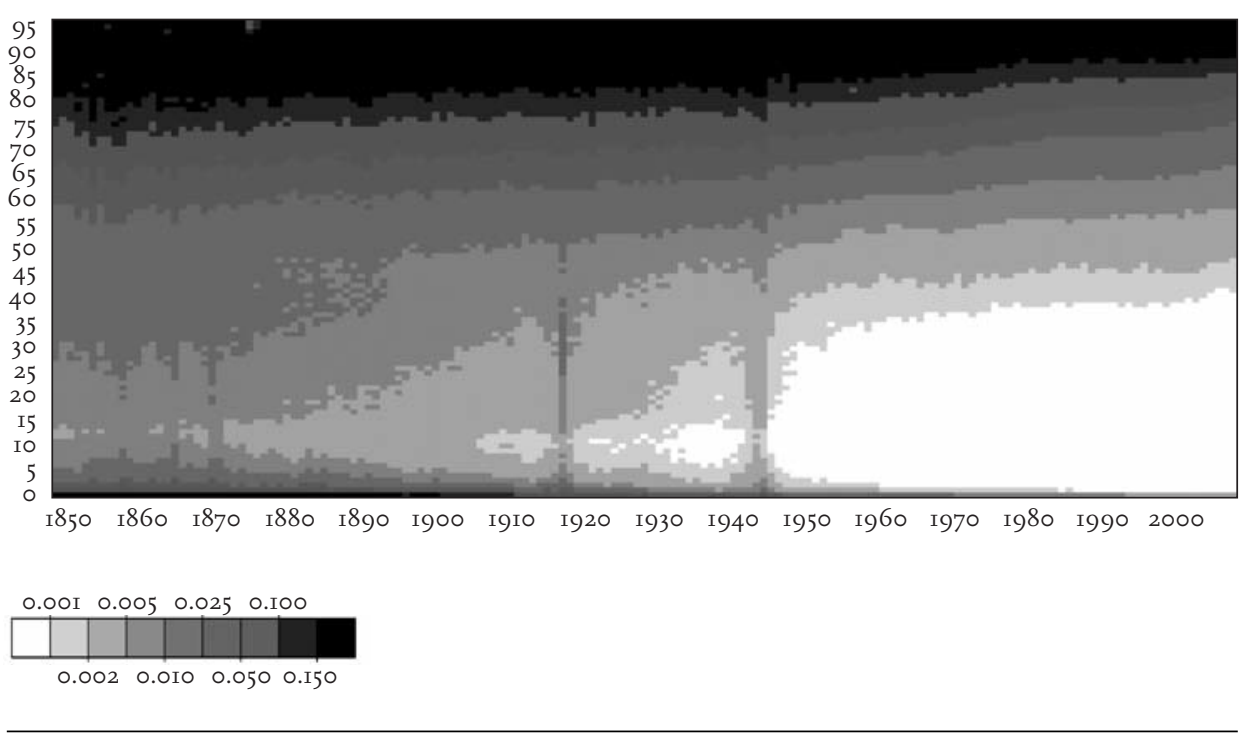

females till the beginning of the I920 B. Between ages 20 and 50, female excess mortality was characteristic till the mid-I88os. From that time on, males aged 20-50 had higher mortality than females.

As figure $9 \mathrm{~b}$ shows, until the I940s, the female advantage was almost completely due to much lower mortality in the first year of life. The difference between the infant mortality rates of males and females increased especially from the end of the I86os. In I880, male excess mortality in the first year of life had the highest impact on the difference between male and female life expectancy at birth, contributing 2.42 years to the total difference of 3.I2 years. The relative contribution of this age group decreased somewhat from the same period on; that had to do with the fact that in other age intervals female mortality decreased somewhat faster. From I880 on, the importance of the difference in mortality in the first year of life decreased nearly continuously; it was less than 0.20 years from 1985 on.

Between ages I and 5, male excess mortality was negligible till the i870s; even after that time, mortality differences contributed only very marginally (maximally 0.40 years) to the difference in expectation of life at birth. Between age 50 and 65, male excess mortality started to increase from 1930 on, reaching a maximum in the I970s. During the period 1962-1987, the contribution of this age group to the total difference in expectation of life was never below I.o years. Very remarkable was the development in age group 65-80. Whereas excess male mortality contributed less than 0.5 year to the total difference before I940, a 
Figure 9a. The contribution of various age groups in years to the total difference in expectation of life between men and women, Netherlands I850-2002

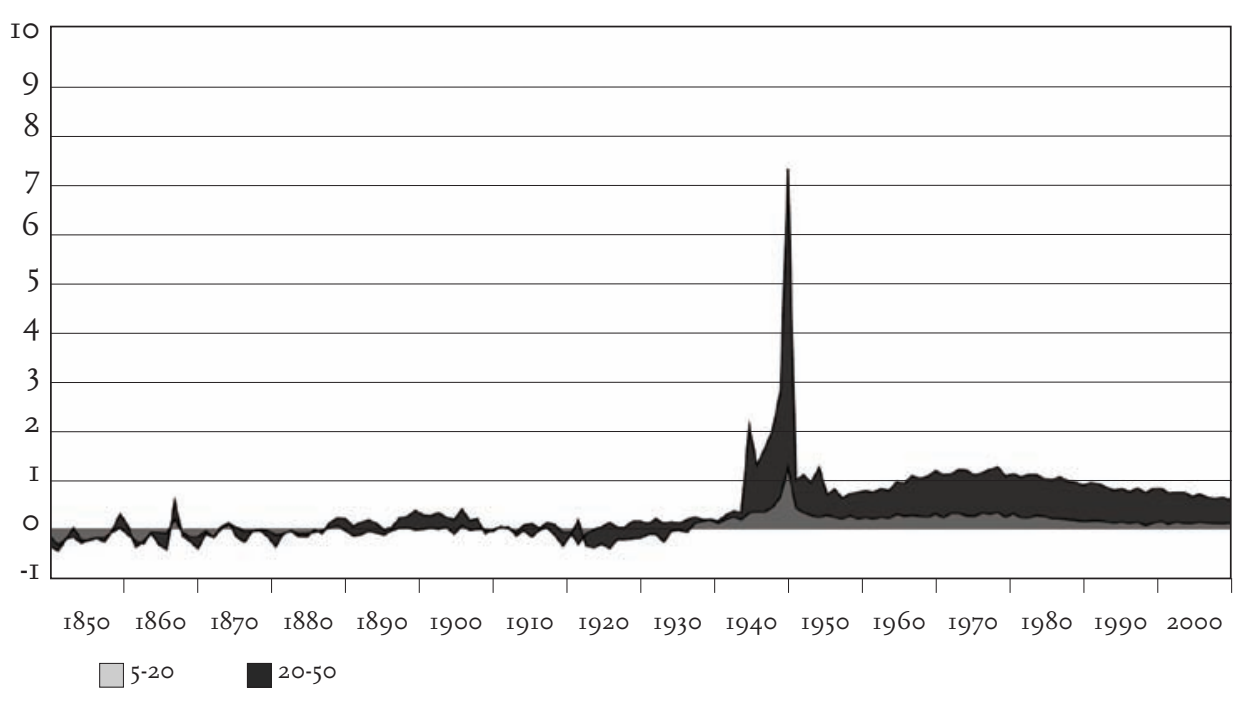

Figure $9 \mathrm{~b}$. The contribution of various age groups in years to the total difference in expectation of life between men and women, Netherlands I850-2002

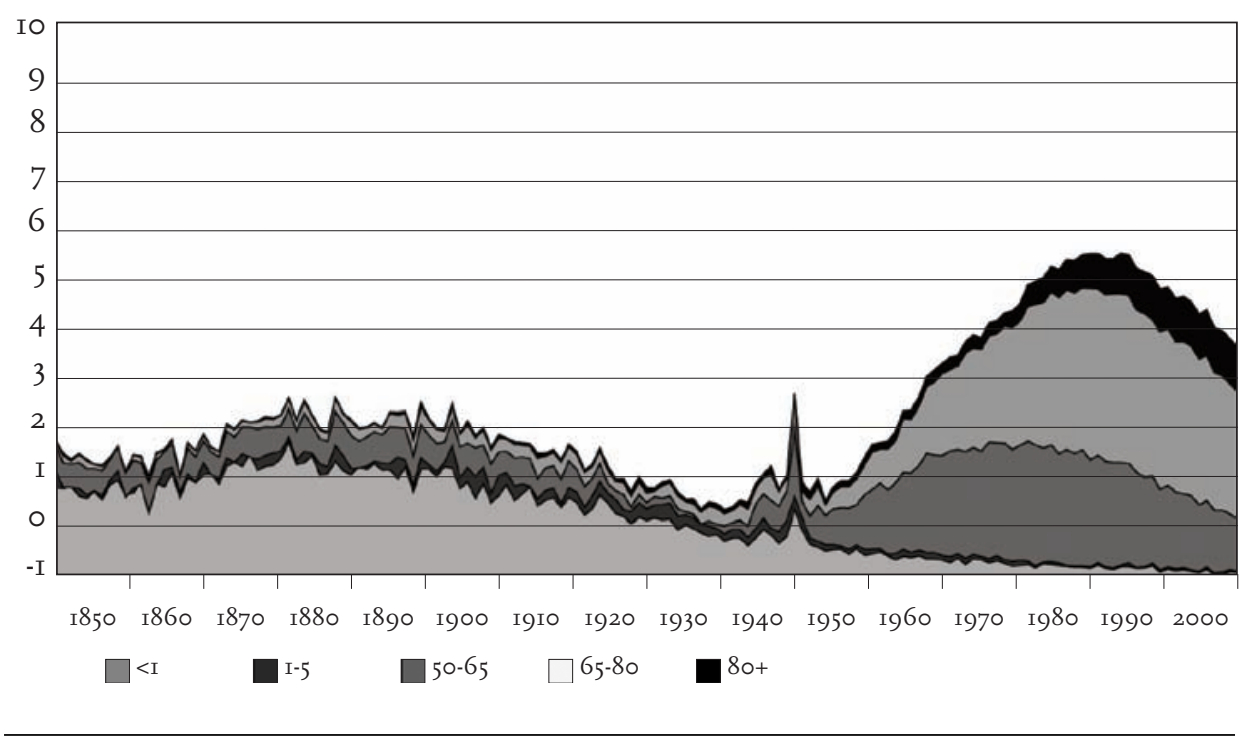


steep increase in male mortality set in from the end of the I940s on. As a con-

sequence, this age group contributed in the beginning of the I980s almost 4 years to the total difference in life expectancy, that is between 55 and $60 \%$. Here too a decrease started in the mid-I980s. Finally, the mortality pattern above age 80, which hardly contributed to the total difference in life expectancy till I900, showed a continous increase in male excess mortality from the I930s on, which accelerated from the mid-I970s on. During the most recent years, it almost contributed one year to the total difference in expectation of life at birth between males and females.

A more nuanced picture might be given by measuring for each separate age the level of male excess mortality. Figure io shows for each age and time combination the ratio of female to male death probabilities. Ratios above I.O (in light greys) indicate that males at the age concerned had a higher death risk than females, ratios below I.O (in dark grey) point to higher mortality of females.

In the past 150 years men had at most ages higher death risks than women. In the nineteenth century, for example, men in the age range between 45 and 70 years had death risks which were 10-30 percent higher than those of women. In the range between 70 and 90 years death risks varied in the same direction.

Four structural changes might be observed in the relation between male and female death risks (for a discussion of the causes see Van Poppel, 2000).

Of a relatively recent date is the strong increase in excess mortality among men aged between 16 and 26 years. This development started in the early i950s, and showed itself as a peninsula of high excess mortality during a period of some thirty years. It was caused by a strong increase in mortality due to motor vehicle accidents, to other accidents and to suicide among men. As a consequence, male death risks in this age range in the I960s and I970s were two to three times higher than those of women.

The increase in male excess mortality at ages above 55 years also dates from the early I950s. This increase started among men aged between 55 and 65 years and in the 1960 s it had already resulted in male death risks which were at least two times higher than those of women. After 1960, this high level of male excess mortality shifted upwards until finally only at ages between 65 and 75 years large discrepancies between male and female mortality probabilities were observed. The very large diagonal blotch of light grey strongly suggests that male excess mortality followed a cohort pattern. It is the long-term effect of the increased consumption of cigarettes which is visible here. Among women cigarette smoking for a long time remained stigmatised and was considered quite definitely a male affair. As a consequence of the late adoption of smoking among women, the cohorts of women with the highest smoking prevalence 


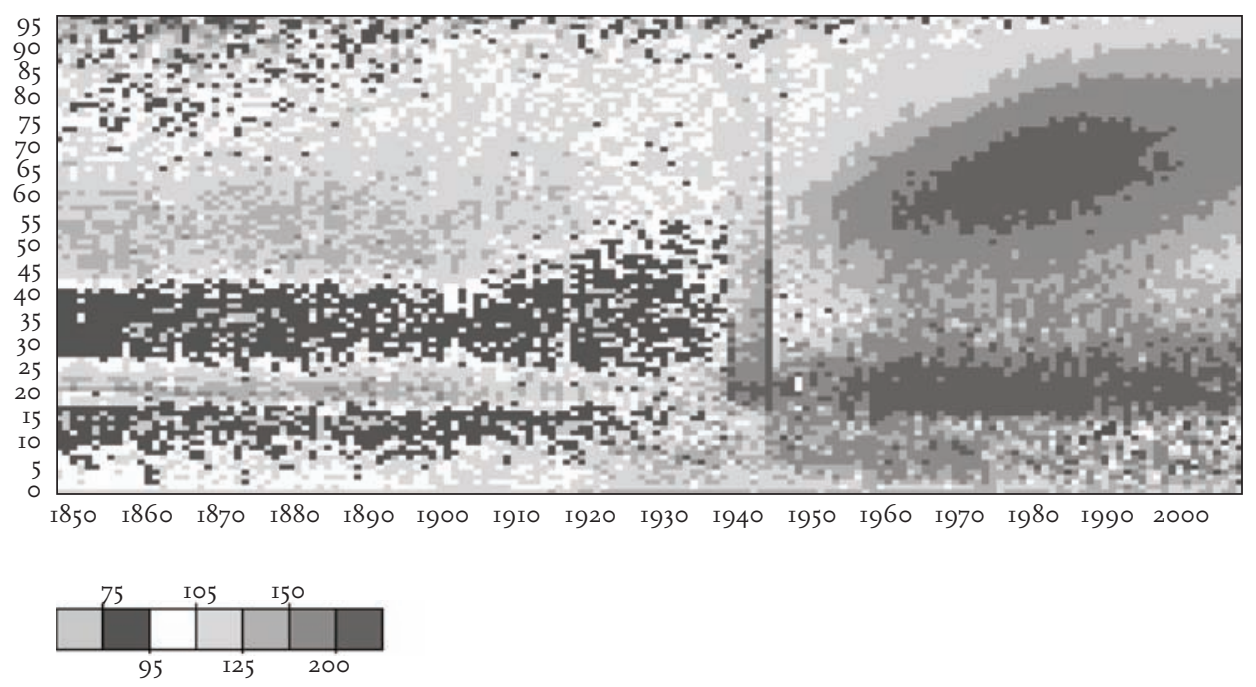

entered only from the I980s on the age range of highest smoking-related mortality. Death rates for lung cancer among women therefore lagged decades behind those of men.

Two other structural changes had their origin before the middle of the nineteenth century. In both cases it involved a situation in which women, in contrast to the usual pattern, had higher death risks than their male age peers. During a long period women aged between 25 and 45 years had higher death risks than men. This excess mortality still was at a level of between 5 and 30 per cent at the beginning of W.W. II and disappeared only after the war.

Higher female death risks were also observed at younger ages. Till around I920 girls aged between eight and I6 years had higher death risks than boys. This excess mortality of girls gradually decreased and finally disappeared towards I930.

\section{Causes of death: From infectious to chronic diseases}

Changes in the pattern of mortality by cause of death over time provide a first insight into the factors responsible for the mortality transition. They allow us to find at least indications regarding the factors behind the mortality decline: standards of living, public health, and medicine in a more narrow sense, behavioral changes, changing virulence etc.

During the period I875-2003 eleven different cause-of-death classifications were in use. To study the trends in cause-specific mortality, use has to be made 
of a nosologically continuous time series of cause of death. During the construction of this time-series the correspondence between the cause-of-death classifications of the various periods had to be determined, making it possible to link the codes of the successive classifications. In addition to that, causes had to be regrouped into meaningful categories, thereby avoiding the grouping together of diseases that were too different from each other anatomically or etiologically (Wolleswinkel-van den Bosch, van Poppel and Mackenbach 1996). The reclassification of the various cause of death categories in use since 1875 resulted in a system consisting of 27 causes of death for the whole period. For more recent periods in which more detailed classifications were in use more refined systems were constructed. We focus here only on the most rudimentary classification and present information on the most important causes of death. For these causes of death we present deaths rates by sex, standardized by age, per I००,००० personyears (for a sketch of the European context, see Caselli I99I).

The most important group of diseases in the nineteenth century were infectious diseases. Following McKeown (1976: 33-35), infectious diseases can be distinguished according to the modes of spread of the infection into the following groups: airborne-diseases, water-and food-borne diseases and other communicable diseases. This distinction is important since it determines in part the possibility in a given situation of preventing contagion and thus mortality. Airborne diseases are transmitted from one individual to another directly via saliva, or indirectly via dust in bed linen, clothing or carpets. To this group of infectious diseases belong bronchitis, pneumonia, and the typical childhood diseases such as whooping cough, croup, measles, scarlet fever, diphtheria, and smallpox. Lung-tuberculosis and puerperal fever also belong to this group but we will treat them separately, the last one together with other puerperal diseases. Water-and food-borne diseases such as cholera, diarrhea, dysentery, typhoid and typhus are spread by drinking or washing with water contaminated with infected human feces or urine, or with micro-organisms carried by animals. Bacterial and some viral and parasitic diseases can also be conveyed via food from contaminated livestock or from animals living in contaminated water or contaminated by infected individuals. Other diseases due to micro-organisms refer to conditions of infective origin which are not spread mainly by air, water or food for which certification of cause of death was unsatisfactory (as in the case of convulsions or teething). 5 Among this group are malaria, anthrax, syphilis, appendicitis, and convulsions.

5. Death through convulsions was usually only the final and fatal effect of infection or some other condition, often (though not widely acknowledged at the time) including dehydration resulting from gastrointestinal disturbances. Contemporary experts considered convulsions and teething as causes of death following digestive sickness which could consequently be subsumed under the digestive disease category (Rombouts, I902, I02). 


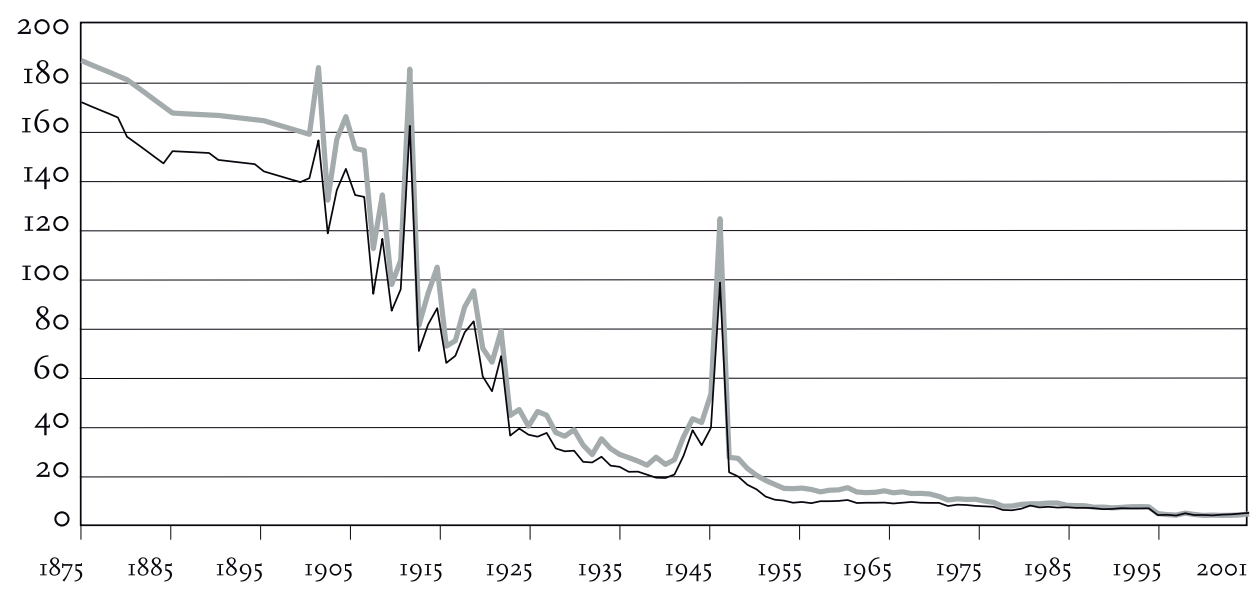

Men — Women

Figure II gives age-standardized mortality rates for water-and food-borne diseases for males and females. The figure shows the enormous decrease of diseases related to hygiene and food and thus make clear what tremendous effect improved public health facilities (sewage systems, water supply), improved personal hygiene, higher food quality, changes in breastfeeding and many other factors had. A very large proportion of all deaths amongst infants during the late nineteenth and early twentieth century were related to this cause of death. It is hard to see whether already before 1875 a decrease in this cause of death had taken place but it is clear that such a decrease was present in the last quarter of the nineteenth century and continued at much higher speed from I9oo on.

Mortality rates for diseases transmitted mainly by air and direct human contact were more or less stable during the last quarter of the nineteenth century. A clear decrease only took place after I900. Mortality from the classic infectious diseases of childhood (scarlet fever, measles, diphtheria and croup, and in particular whooping cough) played only a minor role during the first year of life of the child. Yet there were years in which some of these diseases were epidemic and the number of deaths was relatively high. These causes of death gradually lost their importance only after 1900 .

Other infectious diseases followed the same declining trend but at a much faster rate. The decline here was in full swing from the i870s on.

Mortality due to lung tuberculosis followed more or less the same pattern, characterized by a decrease from the start of the observation period on. Thus, all 
four categories of infectious diseases started at around the same level of between I80 and 250 deaths annually per I00,000 population, decreased very strongly from the beginning or from I890-I900 on and had almost completely disappeared as causes of death of any importance after World War II. Whereas in I875 969 males and 870 females per 100,000 person-years died as a consequence of one of these four groups of infectious diseases, those rates had decreased to 40 and 30 per 100,000 in 2003.

Puerperal fever and other diseases of pregnancy were responsible for only a small number of deaths compared to the aforementioned groups of infectious diseases. The decrease of this cause of death took place in two stages: till I900 and after the middle of the i93os.

External causes of death also played only a minor role. There was a decline until W.W. II, an increase after W.W. II till the middle of the Ig6os, mainly caused by traffic accident mortality and a very strong decrease afterwards. Suicide mortality contributed only to a very small degree to the mortality transition. It showed a decreasing trend, from the I970s followed again by a slight increase.

The present-day mortality pattern is characterized by the dominant role played by cardiovascular diseases and the various forms of cancer. Given the small degree of differentiation in the nineteenth- and early twentieth-century cause-ofdeath statistics it is not possible to distinguish within these groups between the various forms of cancer and between the various cardiovascular diseases. These various forms have all known their own dynamics and differences to which we cannot pay attention when we want to follow the mortality pattern from I875 on.

Mortality due to cancer and due to cardiovascular diseases showed some parallel in their level at the start and in the trend it followed. Both causes of death showed a continuous increase from the start of the registration period onward. Cancer reached a peak in the I980s, cardiovascular diseases in the I970s. The most remarkable aspect however is the tremendous difference between men and women that became visible from the 1950 s on. Whereas among men mortality rates kept on increasing, among women a stabilization or even decrease is visible. This is the main reason for the gender gap in mortality that was so characteristic for the i960-1980 period. 
$38 \quad$ Figure I2. Age-standardized death rates per I00,000 person-years by sex, I8752003, airborne infectious diseases

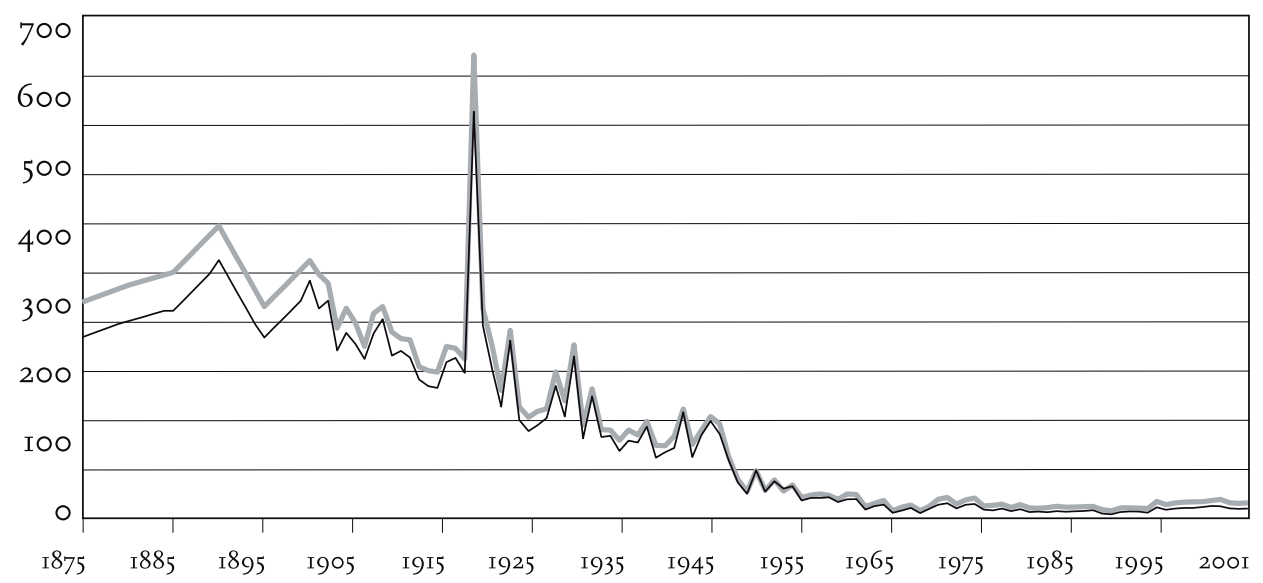

Men — Women —

Figure I3. Age-standardized death rates per 100,000 person-years by sex, 18752003, other infectious diseases

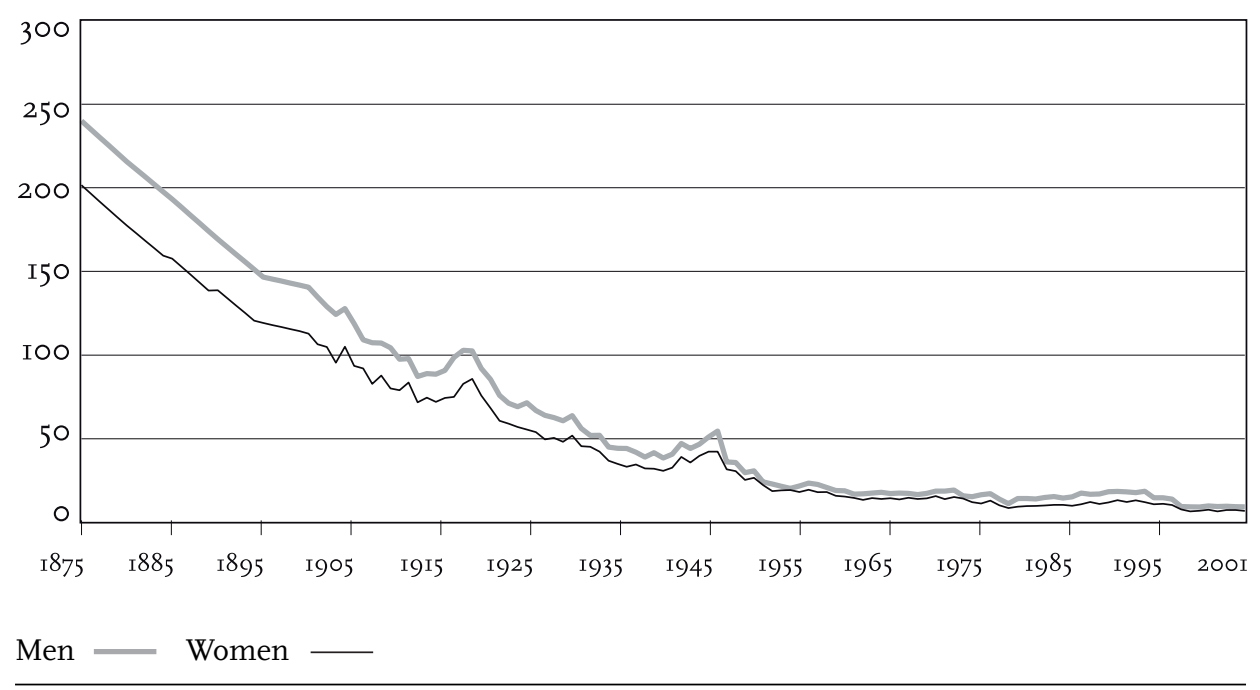


Figure I4. Age-standardized death rates per I00,000 person-years by sex, I8752003, respiratory tuberculosis

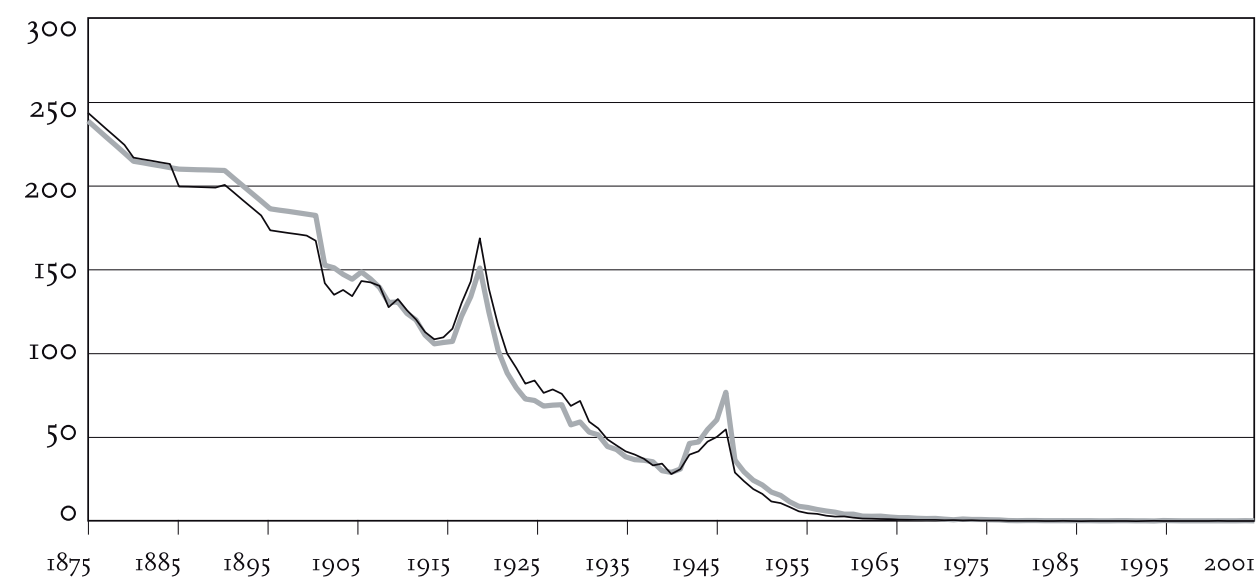

Men — Women -

Figure I5. Age-standardized death rates per 100,000 person-years, 1875-2003, maternal mortality

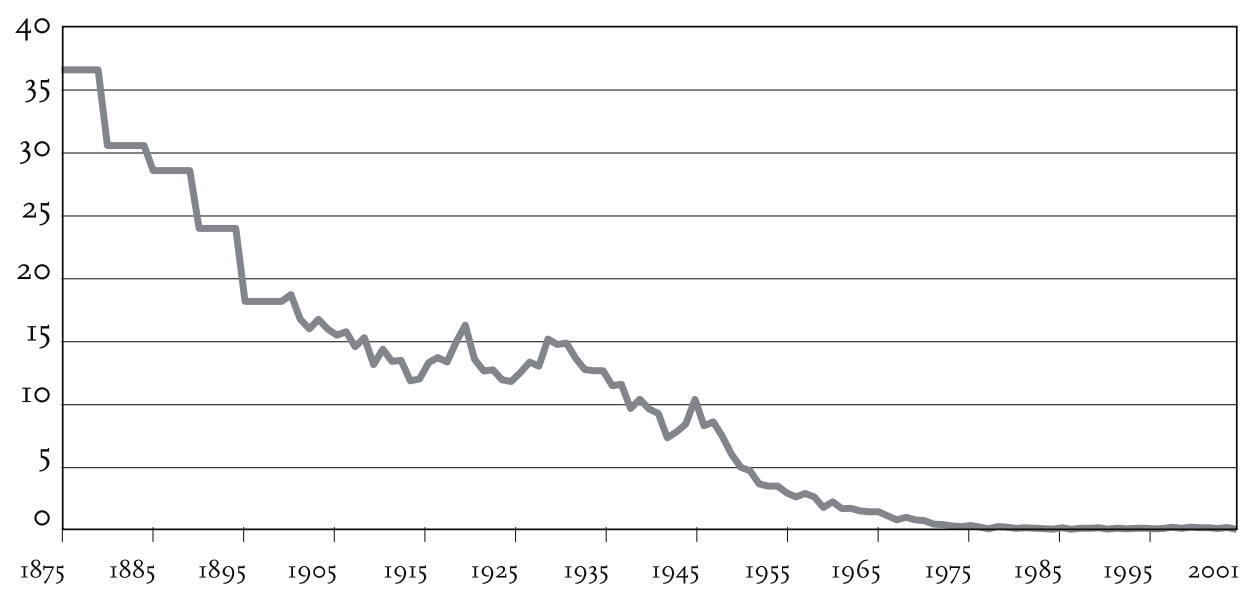


Figure i6. Age-standardized death rates per I00,000 person-years by sex, I8752003, external causes of death

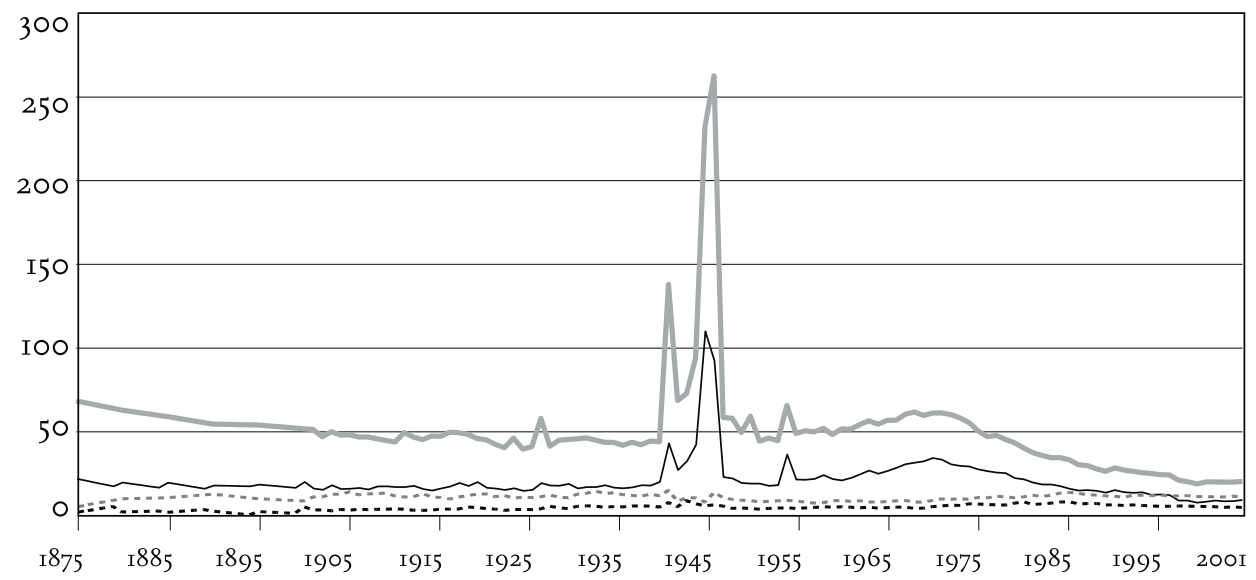

Men, violence and accidents

Women, violence and accidents

Men, suicide -... $\quad$ Women, suicide ....

Figure I7. Age-standardized death rates per 100,000 person-years by sex, I8752003, all forms of cancer

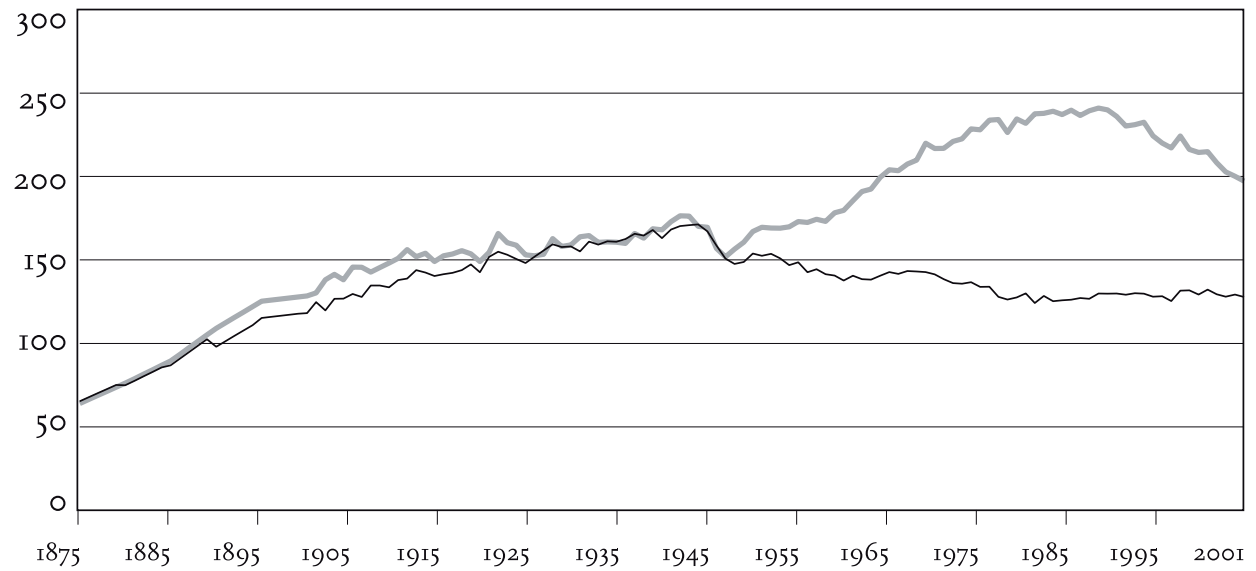

Men — Women 
Figure I8. Age-standardized death rates per I00,000 person-years by sex, I8752003, cardiovascular diseases

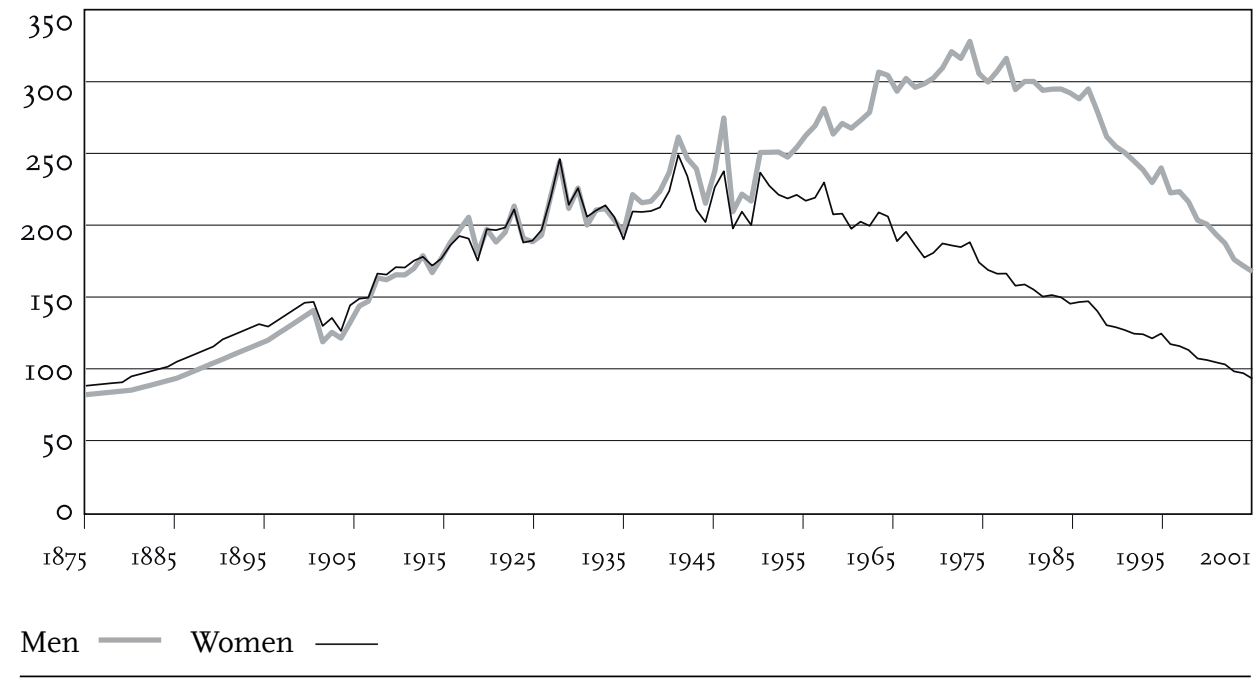

Figure I9. Age-standardized death rates per 100,000 person-years by sex, 18752003, chronic respiratory diseases

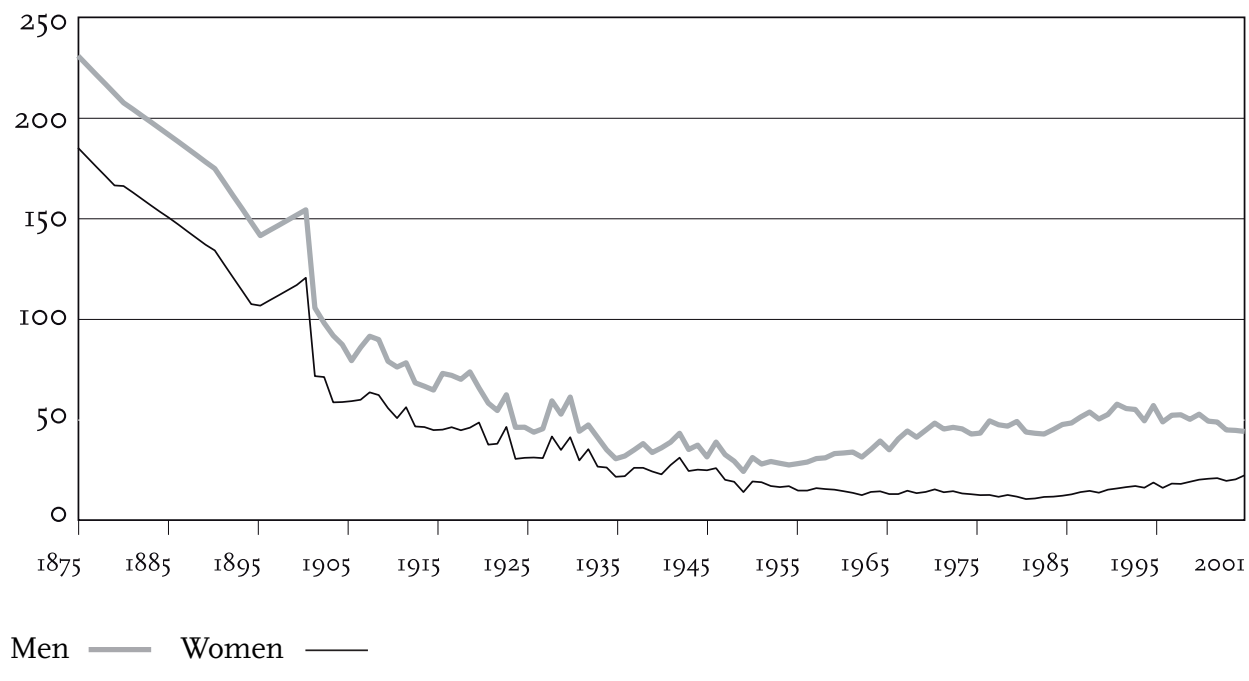




\section{Conclusion}

The real start of the mortality decline in the Netherlands can be localized in the middle of the I870s. Mortality had already been declining from the beginning of the nineteenth century on, as becomes clear from the development of the crude death rates, but the large swings in mortality masked this slow decline. What happened after I880 was of a different order and meant the onset of a new mortality regime in which crisis mortality did not have an effect on the trend anymore (for a discussion of the causes behind the decline see for example Wolleswinkelvan den Bosch, I998; Mackenbach 1992). The pace at which the expectation of life in the Netherlands increased was extraordinary: whereas around I870, the average length of life in the Netherlands lagged some io-I2 years behind the Nordic countries, and some five years behind France and the United Kingdom, in I9I0 the Netherlands were in a better position than most of these countries and only 2-3 years behind Sweden and Norway. After I9Io the Netherlands even reached levels comparable with those of the Scandinavian countries. Compared to I850, the average length of life had doubled in 2003.

The by far largest part of the total increase in life expectancy (between 36 and 43 percent) was caused by the decrease in mortality between birth and age I that took place from 1887 onwards. Mortality among I-5 year old children also contributed heavily to the increase in life expectancy at birth but the mortality decline in this age range started already in the beginning of the I87os. In age groups $20-50$ and 50-65, the mortality decline started around the middle of the I86os.

We have to stress that until I900 there was an enormous interindividual variation in the length of life and the average length of life was reached by only a very small part of the population.

This general overview of the historical mortality decline in the Netherlands might serve as a background to more refined and more local studies. Historians of mortality have increasingly begun to question the value of national-level mortality data for explanatory purposes. Various authors such as Johansson and Kasakoff (2000), Garrett et al. (200I), Imhoff (I990) and others have stressed that until the first decades of the twentieth century the 'disease environment' and economic circumstances varied enormously from place to place, from social class to social class, from men to women and from household to household. That could lead to large differences in the expectation of life at birth between regions, between the sexes, between social class and household categories, sometimes of the order of IO-I5 years. A national value of the expectation of life is in such a situation not a measure that describes the experiences of the majority of the population but a statistical artifact. It also implies that it would be a mistake to assume that one factor (be it improved nutrition or better water supply or public health measures) was equally relevant to the mortality transition in all these groups and 
categories, which each had their own specific type of disease environment. With Johannson (2000) we think that it is necessary to start identifying the different stories of the mortality transition. This has implications for the historical study of mortality and for the study of social history in general. It is urgently needed to identify forerunners and backwaters in the mortality transition and to look for the factors responsible for the mortality decline in various categories of the population. More detailed knowledge of the health situation of various groups, defined according to a variety of criteria will make it possible to reconstruct the living environment and the daily life of historical populations. After all, sickness, physical handicaps and death were essential and integral elements of life that had enormous consequences, not only for the person who became ill, injured or died, but also to persons in the household and the larger community. It brought about large changes in income and consumption; it reallocated labor within and outside the household, and caused the dissolution of households etc (Over, Ellis, Huber and Solon 1992). The region in which one lived, the class to which one belonged, the family situation in which one was in had a great bearing on when and how one died. By introducing this variation in mortality, our knowledge of the historical variation in living conditions can be increased considerably. 

2

Trends in mortality and causes of death in Japanese colonial period Taiwan

John R. Shepherd Department of Anthropology University of Virginia 


\section{Introduction}

This paper explores trends in mortality and causes of death in colonial Taiwan primarily through the study of patterns of mortality by age and sex for selected leading causes of death. The discussion concentrates on the following causes of death in the period I905-1942: malaria, respiratory tuberculosis, respiratory diseases, diarrhea and enteritis, and infant causes. Note that due to an early Japanese period vaccination campaign, smallpox was no longer a leading cause by 1905 when our data series begins (Shepherd 200I). There is not space to treat other causes, many of them the source of important epidemics (e.g., plague, influenza, cholera), but less important to the patterns of mortality overall.

Important early studies of causes of death in Taiwan come from Li T'engyueh (1938), George W. Barclay (I954), and Chen Shao-hsing (I955). Ensuring the consistent definition of cause categories, and a minimum quality of diagnostic skill by those making the determinations of cause is a prerequisite to the use of cause of death reports. Issues of reporting quality in the Taiwan cause of death reports are discussed in detail in the Appendix. The data series for several causes appear to be inconsistently reported between the early years when reporting quality was low and the later years. Such inconsistencies arise from improving diagnostics and training on the part of personnel filling out death certificates, and also changes in the definitions of disease categories (and also rules for deciding between two or more contributing causes). Previous studies of trends in causes of death in Japanese period Taiwan have failed to take into account these inconsistencies (e.g., Chen 1955). In the discussion below of specific causes, those reported inconsistently in the early years will be reported only for the years I924-4I, when the third and fourth international cause of death lists were used to compile the cause of death reports, and reporting quality was highest.

There are two causes, however, malaria and respiratory tuberculosis, that appear to provide relatively consistently reported series for more extended periods. These causes of death present symptoms relatively easy for certifiers to identify, periodic chills and fevers and swollen spleens in the case of malaria, and bloody sputum in the case of respiratory tuberculosis. The international lists for compiling death statistics in use by the colonial authorities also consistently reserved separate categories specific to these causes, which immunized them from inconsistencies arising from changing category definitions.

\section{Reports of Deaths by Cause, Age and Sex in the Taiwan Population Record}

The information necessary to compute age, cause, and sex specific rates of death comes from two sources: the annual volumes of vital statistics reports of cause of death by age and sex, and the census tables reporting the population at risk in each age and sex category. The Japanese colonial government conducted the first 
census of Taiwan in 1905, and subsequent censuses every five years from I9I5 to

I940. Age-specific death rates are based on the notion of deaths during a period, per person-years lived at the specified age. The person years lived are approximated by the number of persons of the specified age present at the middle of the base period (Barclay I958: 45). The censuses reported population age groups by calendar (not lunar) year of birth from I905 to I925 but shifted to western style reporting of age at last birthday on the date of the census 1930-40. To calculate cause specific death rates by age we must convert the census reports of age I905I925 to age in western years; this has been done by estimating the midyear population by western age from life tables constructed for 1906-1926.

For the periods presented in our tables the base period is the date of the census (October I) or a midyear population in the case of 1906-08 and I909-13 rates. The rates presented here are computed from the averages of deaths occurring in the three years centered on the base period (five years in the case of the I909-I3 rates).

All the tables of cause, age and sex specific death rates presented below report an infant death rate at ages o-I. The infant death rates are computed following Barclay (I958:I4I,I43, 287) by dividing the three year average of infant deaths by the average number of births for the corresponding period, rather than by using a midyear estimate of the infant population (five years in the case of the I909-I3 rates)(cf. Barclay I958: 47). This ensures a continuity of presentation when infant mortality is analyzed separately by using the infant death rates. Infant death rates for 'all causes' are corrected for unregistered nonsurvivors for the years 1906-19I5 following Barclay (I954: 159-60, see Shepherd I998 for a fuller discussion of the method used to estimate the extent of underregistration). I have assigned deaths attributed to unregistered nonsurvivors to the 'ill-defined and unknown' cause category.

The use of rates based on averages for multiple years is intended to moderate the effect of yearly variation and give a better picture of long-term trends. Thus the effects of epidemics, such as the malaria outbreak in I9I5, and the influenza epidemics in late I9I8 and early I920, and the cholera outbreak in I9I9, have been somewhat disguised in this presentation. The tables below present multiple year averages for eight periods, four periods covering all years i906I92I, and four three-year periods centered on each five year census I925-1940. The tables thus present the mortality experience of 28 of the 36 years in the period I906-4I.

\section{Introduction to the Tables Presented for Each Cause Group}

For each cause group discussed below I present a series of three tables. The first table for each cause group presents the deaths per I0,000 person years for each age and sex category, I906-194I. Male rates are presented in the upper panel and 
female rates in the lower. It is very easy to see the degree of variation in death rates across the age groups in this table.

To facilitate the identification of historic trends, a second table presents rates for each period that have been indexed on the rate for the first period, igo6o8. These indexed rates make it easy to perceive patterns of decline in terms of percentages of the I906-08 rates. Do the I906-08 rates fairly represent the "normal' level of mortality at the starting point of the Japanese period? Death rates fluctuated greatly in response to periodic epidemics in the early years, and the reduction of epidemic disease was a priority of Japanese policy. The I906-08 rates, for example reflect the impact of plague deaths in I906-7 (over a thousand in each sex each year), and may be somewhat elevated above the 'normal', just as the rates for the succeeding period, I909-I3, are unusually low. The underreporting of deaths prior to I906 means that we lack reliable death rates that could establish pre-I906 levels of mortality. However, stable population analysis using the I906-08 rates suggests close agreement with the age structure of the I905 census, indicating that the I906-08 rates are close to the average rates in the preI906 period (Shepherd I998b: 64ff.).

The indexed tables make it easier to compare the degrees of decline (or increase) across the age and sex categories. A third table presents the sex ratios (male age specific death rate / female age specific death rate) of mortality in each age and sex group. These rates make it easy to see the extent of divergence in the experience of males and females at various ages (values above I. oo show male excess mortality and values below show female excess mortality). Looking at the change in these ratios over time also shows whether the divergence in male and female mortality increased or decreased over the period.

\section{All Causes}

We begin our discussion by considering the overall trends in age and sex specific mortality for all causes. Because it includes all deaths regardless of cause this series is unaffected by changes in quality of cause of death reporting.

It is easy to see in the first table reporting death rates per 10,0०0 person years, that the impact of mortality varied greatly across the age groups. The highest death rates are regularly found at the extremes, among infants and those aged 70 and over. Death rates decline rapidly from infancy to age 9, reach their lowest levels in ages IO-I4, and then begin an accelerating rise to age 70. The rates by age form a typical $j-$ shaped mortality curve, found in most populations. We will see below the degree to which specific groups of causes vary in their contribution to mortality levels at different ages.

The unevenness of the decline in the death rates is immediately observable in the first and second tables. Rates of death in many age groups fell dramatically in I909-13, resurged again in I9I4-I6, remained above the I909-I3 rates in 
a. Cause, Age and Sex specific death rates of Taiwanese, All Causes, 1906-1941. Deaths per Io, 000 person years. The infant death rate is used for age o-I.

\section{All causes}

Years Age at beginning of interval:

\begin{tabular}{|c|c|c|c|c|c|c|c|c|c|c|c|c|c|c|c|c|}
\hline Males & o* & $\mathbf{I}$ & 5 & IO & 15 & 20 & 25 & 30 & 35 & 40 & 45 & 50 & 55 & 60 & 65 & 70 \\
\hline I9०6-08 & I940 & $49 I$ & I39 & 79 & I03 & I54 & 204 & 263 & 333 & $4 \mathrm{I} 8$ & 503 & 602 & 705 & 885 & II54 & 1673 \\
\hline I9०9-I3 & I794 & 385 & 90 & 54 & 74 & I25 & I68 & $2 \mathrm{I} 3$ & 264 & 335 & $4 \mathrm{I} 5$ & 503 & 626 & $76 \mathrm{I}$ & 988 & I499 \\
\hline I9I4-I6 & I933 & 419 & 96 & 58 & 79 & I3O & 182 & 228 & 287 & 350 & 427 & 518 & 649 & $8 \mathrm{I} 2$ & 1033 & $16_{5 I}$ \\
\hline $9 \mathrm{I9}-2 \mathrm{I}$ & I825 & 432 & 98 & 53 & 82 & I29 & I73 & 210 & $25 \mathrm{I}$ & 305 & 357 & 452 & 569 & 722 & 985 & 1500 \\
\hline I924-26 & I8I7 & 356 & 67 & 39 & 60 & 89 & II7 & I54 & I97 & 243 & 302 & 372 & 485 & 674 & $88 \mathrm{I}$ & I443 \\
\hline $9^{29-3 I}$ & I703 & 299 & 46 & 29 & 46 & 69 & 86 & 107 & I33 & I79 & 230 & 296 & 384 & 534 & 749 & I 266 \\
\hline I934-36 & 1620 & 296 & 47 & 30 & 46 & 67 & 86 & IO3 & I 28 & I73 & 222 & 29I & 388 & 509 & 7Io & 1267 \\
\hline $939-4 \mathrm{I}$ & I440 & 289 & 46 & 27 & 45 & 66 & 77 & 96 & II6 & 156 & 210 & 293 & $38 \mathrm{I}$ & 527 & 712 & $29 \mathrm{I}$ \\
\hline
\end{tabular}

Females

\begin{tabular}{|c|c|c|c|c|c|c|c|c|c|c|c|c|c|c|c|c|}
\hline I906-08 & 1930 & $6 \mathrm{I7}$ & 166 & 9I & II6 & I54 & $\mathrm{I} 78$ & 202 & 226 & 258 & 297 & 370 & 462 & 624 & 847 & 1352 \\
\hline I9०9-I3 & I524 & 485 & IO2 & 50 & 82 & I23 & 136 & I59 & I8I & 190 & 227 & 286 & 370 & 470 & 672 & II87 \\
\hline I9I4-I6 & 1676 & 524 & II 5 & 54 & 83 & $\mathrm{I} 2 \mathrm{O}$ & I38 & IGI & I9I & $20 I$ & 223 & 297 & 397 & 537 & $7 \mathrm{I} 2$ & I370 \\
\hline I9I9-2I & I547 & $5^{\mathrm{I} 2}$ & II5 & 56 & 86 & I29 & I48 & I73 & 185 & I94 & $2 \mathrm{I} 3$ & 259 & 348 & 457 & 625 & II95 \\
\hline I924-26 & I5I5 & $4 \mathrm{I} 7$ & $7 \mathrm{I}$ & 36 & 56 & 84 & IOI & I 24 & I44 & I 48 & I68 & $2 \mathrm{I} 7$ & 284 & 4I 4 & 578 & II 20 \\
\hline I929-3I & I4I 8 & 335 & 46 & 26 & 48 & 64 & 73 & 89 & 106 & $\mathrm{I} 20$ & I35 & I7I & $24 \mathrm{I}$ & 327 & 486 & 1020 \\
\hline $1934-36$ & 1356 & 324 & 48 & 28 & 46 & 62 & 70 & 84 & IOI & II4 & I3I & I73 & 237 & 323 & 493 & 1056 \\
\hline I939-4I & I2O 8 & $3 \mathrm{I} 7$ & 45 & 24 & 38 & 53 & 6I & 76 & 9I & I07 & 126 & 165 & 229 & 316 & $45^{I}$ & IO7I \\
\hline
\end{tabular}

* Infant death rate, calculated as a ratio of infant deaths to registered live births for corresponding periods.

Estimates of unregistered nonsurvivors have been added in the years I906-I9I5.

I9I9-2I, and then began a more consistent decline. These bumps in the decline are commonly attributed to the impact of epidemic malaria in I9I5, the influenza epidemics of late I9I8 and early I920, and the cholera epidemic in I9I9.

The degree of decline in the death rates over time also varied by age group. The indexed rates show that the biggest declines occurred in ages 5-I4, followed by ages 15-54; the next largest declines occur in ages 55-69 and I-4. The smallest declines in death rates occurred among infants and those over age 70 . That age groups in the middle of the age range benefited most from the decline in mortality overall is a pattern commonly found in studies of the mortality transition.

Infants and the elderly remain the most vulnerable segments of the population; public health measures only gradually succeed in reducing their expo- 
b. Indices of Cause, Age and Sex specific death rates of Taiwanese, All Causes, I906-194I. Death rates of $1906-8=100$

\section{All causes}

Years Age at beginning of interval:

\begin{tabular}{|c|c|c|c|c|c|c|c|c|c|c|c|c|c|c|c|c|}
\hline Males & $0 *$ & $\mathbf{I}$ & 5 & 10 & I5 & 20 & 25 & 30 & 35 & 40 & 45 & 50 & 55 & 60 & 65 & 70 \\
\hline I9०6-08 & 100 & 100 & 100 & 100 & 100 & 100 & 100 & 100 & 100 & 100 & 100 & 100 & 100 & 100 & 100 & 100 \\
\hline I9०9-I3 & 92.5 & 78.4 & 64.7 & 68.4 & 71.8 & 81.2 & 82.4 & 81.0 & $79 \cdot 3$ & 80.1 & 82.5 & 83.6 & 88.8 & 86.0 & 85.6 & 89.6 \\
\hline I9I4-I6 & $99 \cdot 6$ & 85.3 & 69.1 & 73.4 & 76.7 & 84.4 & 89.2 & 86.7 & 86.2 & 83.7 & 84.9 & 86.0 & 92.1 & 91.8 & 89.5 & 98.7 \\
\hline I9I9-2I & 94.1 & 88.0 & 70.5 & 67.1 & 79.6 & 83.8 & 84.8 & 79.8 & 75.4 & 73.0 & 71.0 & 75.1 & 80.7 & 81.6 & 85.4 & 89.7 \\
\hline I924-26 & 93.7 & 72.5 & 48.2 & $49 \cdot 4$ & $58 \cdot 3$ & 57.8 & $57 \cdot 4$ & 58.6 & 59.2 & 58.1 & 60.0 & 61.8 & 68.8 & 76.2 & 76.3 & 86.3 \\
\hline I929-3I & 87.8 & 60.9 & 33.1 & 36.7 & $44 \cdot 7$ & 44.8 & 42.2 & 40.7 & $39 \cdot 9$ & 42.8 & $45 \cdot 7$ & 49.2 & 54.5 & 60.3 & 64.9 & 75.7 \\
\hline I934-36 & 83.5 & 60.3 & 33.8 & 38.0 & $44 \cdot 7$ & 43.5 & 42.2 & 39.2 & 38.4 & 41.4 & 44.1 & 48.3 & 55.0 & $57 \cdot 5$ & 61.5 & $75 \cdot 7$ \\
\hline I939-4I & 74.2 & $5^{8.9}$ & 33.1 & 34.2 & $43 \cdot 7$ & 42.9 & $37 \cdot 7$ & 36.5 & 34.8 & $37 \cdot 3$ & 41.7 & 48.7 & 54.0 & $59 \cdot 5$ & 61.7 & 77.2 \\
\hline \multicolumn{17}{|l|}{ Females } \\
\hline I906-08 & 100 & 100 & 100 & 100 & 100 & 100 & 100 & 100 & 100 & 100 & 100 & 100 & 100 & 100 & 100 & 100 \\
\hline I9०9-I3 & 79.0 & 78.6 & 61.4 & 54.9 & 70.7 & $79 \cdot 9$ & 76.4 & 78.7 & 80.1 & 73.6 & 76.4 & $77 \cdot 3$ & 80.1 & $75 \cdot 3$ & $79 \cdot 3$ & 87.8 \\
\hline I9I4-I6 & 86.8 & 84.9 & 69.3 & $59 \cdot 3$ & 71.6 & $77 \cdot 9$ & $77 \cdot 5$ & $79 \cdot 7$ & 84.5 & $77 \cdot 9$ & 75.1 & 80.3 & 85.9 & 86.1 & 84.1 & 101.3 \\
\hline I9I9-2I & 80.2 & 83.0 & $69 \cdot 3$ & 61.5 & 74.1 & 83.8 & 83.1 & 85.6 & 81.9 & 75.2 & 71.7 & 70.0 & $75 \cdot 3$ & 73.2 & 73.8 & 88.4 \\
\hline $1924-26$ & 78.5 & 67.6 & 42.8 & $39 \cdot 6$ & 48.3 & 54.5 & 56.7 & 61.4 & 63.7 & $57 \cdot 4$ & 56.6 & 58.6 & 61.5 & 66.3 & 68.2 & 82.8 \\
\hline I929-3I & $73 \cdot 5$ & $54 \cdot 3$ & 27.7 & 28.6 & 41.4 & 41.6 & 41.0 & 44.1 & 46.9 & 46.5 & $45 \cdot 5$ & 46.2 & 52.2 & 52.4 & $57 \cdot 4$ & $75 \cdot 4$ \\
\hline I934-36 & 70.3 & $5^{2} .5$ & 28.9 & 30.8 & $39 \cdot 7$ & 40.3 & $39 \cdot 3$ & 41.6 & $44 \cdot 7$ & 44.2 & 44.1 & 46.8 & $51 \cdot 3$ & 51.8 & 58.2 & 78.1 \\
\hline I939-4I & 62.6 & 51.4 & 27.1 & 26.4 & 32.8 & 34.4 & 34.3 & 37.6 & 40.3 & 41.5 & 42.4 & 44.6 & 49.6 & 50.6 & 53.2 & 79.2 \\
\hline
\end{tabular}

* Infant death rate, calculated as a ratio of infant deaths to registered live births for corresponding periods.

Estimates of unregistered nonsurvivors have been added in the years I906-I9I5.

sure to disease and susceptibility to infection and degenerative conditions. We will see below the degree to which specific groups of causes contribute to decline or increase in the various age groups.

The degree of decline in the death rates is impressive. Death rates in the earliest two periods are as much as 2 to 3 times the rates at the end of the period for age groups 5-I4, and girls at this age benefited somewhat more than boys. Death rates that have fallen to $40-50 \%$ of the rates at the beginning of the period are common in ages $15-54$, and death rates that have fallen to $50-60 \%$ are common in ages $55-69$ and I-4. Infant death rates fell to a range of $65-75 \%$ (the female rate fell more) and rates over 70 fell to $70-80 \%$ of the rates in the earliest periods.

We next turn to discuss the pattern of the sex ratios of mortality, shown in 
c. Sex Ratios of Cause, Age and Sex specific death rates of Taiwanese, All Causes, 1906-194I. Male Death Rate / Female Death Rate.

\section{All causes}

Years Age at beginning of interval:

\begin{tabular}{|c|c|c|c|c|c|c|c|c|c|c|c|c|c|c|c|c|}
\hline & $0 *$ & $\mathbf{I}$ & 5 & IO & I5 & 20 & 25 & 30 & 35 & 40 & 45 & 50 & 55 & 60 & 65 & 70 \\
\hline I906-08 & I.OI & 0.80 & 0.84 & 0.87 & 0.89 & I.OO & I.I5 & I. 30 & I. 47 & I. 62 & I. 69 & I. 63 & I. 53 & I. 42 & I. 36 & I. 24 \\
\hline I9०9-I3 & I.I8 & 0.79 & 0.88 & I.०8 & 0.90 & 1.02 & I. 24 & I. 34 & 1.46 & I. 76 & I. 83 & I. 76 & I. 69 & I. 62 & I. 47 & I. 26 \\
\hline I9I4-I6 & I.I5 & 0.80 & 0.83 & I.O7 & 0.95 & I.०8 & I. 32 & I. 42 & 1.50 & I. 74 & I.9I & I. 74 & I. 63 & I. $5 \mathrm{I}$ & I. 45 & $\mathrm{I} .2 \mathrm{I}$ \\
\hline I9-2I & I.I8 & 0.84 & 0.85 & 0.95 & 0.95 & I.O० & I.I7 & $\mathrm{I} .2 \mathrm{I}$ & 1.36 & I. 57 & I. 68 & I. .75 & I. 64 & I. 58 & I. $5^{8}$ & I. 26 \\
\hline $924-26$ & I. 20 & 0.85 & 0.94 & I.O8 & I.O7 & 1.06 & I.I6 & I. 24 & I. 37 & I. 64 & I. 80 & I.7I & I.7I & I. 63 & I. 52 & $\mathrm{I} .29$ \\
\hline I929-3I & I. 20 & 0.89 & I.OO & I.I2 & 0.96 & I.०8 & I.I 8 & I. 20 & I. 25 & I.49 & I.7O & I. 73 & I. 59 & I. 63 & I. 54 & I. 24 \\
\hline I934-36 & I.I9 & $0.9 \mathrm{I}$ & 0.98 & I.O7 & 1.00 & I.O8 & I. 23 & I. 23 & I.27 & I. 52 & 1.69 & I. 68 & I. 64 & I. 58 & I. 44 & $\mathrm{I} .20$ \\
\hline $39-4 \mathrm{I}$ & I.I9 & $0.9 \mathrm{I}$ & I.O2 & I.I3 & I.I8 & I. 25 & I. 26 & I. 26 & I. 27 & I. 46 & I. 67 & I. 78 & I. 66 & I. 67 & I. 58 & $\mathrm{I} .2 \mathrm{I}$ \\
\hline
\end{tabular}

* Infant death rate, calculated as a ratio of infant deaths to registered live births for corresponding periods.

Estimates of unregistered nonsurvivors have been added in the years I906-I9I5.

the table above. First, note the pattern across the age groups in the early years. There is an expected male excess in infancy, followed by female excess in ages I9 and I5-I9. Sex ratios of mortality are most balanced at ages IO-I4 (with some fluctuation) and consistently at ages 20-24. A male excess beginning at age 25 steadily increases to a peak at 45-54, declines somewhat up to 69 and remains high in the terminal age group. These patterns remain largely intact into the later, lower mortality periods, with the exception of the following. Most notable are the declines in the female excess at ages 5-9 and I5-19 which shift to balanced sex ratios of mortality, and a smaller but certain decline at ages I- 4 where the female excess persists. The pattern of female excess mortality in early childhood is commonly attributed to the son preference of the Chinese family system, resulting in comparative neglect of daughters' health and diet (Barclay 1954: 157). In areas practicing minor marriage, high rates of female adoption which subject girls to additional mortality risks (Wolf I995: 302-07) also contributed to the female excess at young ages. The decline in young female excess mortality is not to be attributed to declines in the degree of son preference (declining rates of adoption for minor marriage in selected areas may have contributed to decline), but rather to the improvement in the disease environment that reduced the risks to which young girls were subjected. Under these circumstances, both boys and girls benefited substantially from the mortality decline, but young girls relative- 
ly more. The other often noted feature of the Taiwanese pattern of sex differential mortality is the large male excess at adult ages 25 and above, despite the added female risk from childbearing in these ages. Many populations show a female excess in the childbearing years (Japan, India and The Netherlands among them)(Barclay 1954: 155-56). The large male excess in the childbearing years is to be attributed to mortality that is much higher among males, not unusually low among females (see further discussion in the maternal mortality paper, this volume). Adult male excess mortality is commonly observed among premodern Chinese populations, though an excess in the childbearing years is unusual (see Chiao et al. 1938:52-54, Liu Ts'ui-jung I985: 49-55, Goldman I980, Campbell I995: 55ff.).

Analysis of cause specific mortality rates for the leading causes will reveal which causes contribute most to these patterns of male and female excess.

\section{Malaria}

As mentioned above, it appears that the reports of malaria deaths provide a relatively consistently reported series for the entire period, I906-I94I. Malaria presents identifiable symptoms, periodic chills and fevers and swollen spleens, which would be known to family members of the deceased and easily reported to the personnel certifying the cause of death (who may or may not have attended the deceased before death). Special training was not needed to correctly identify the bulk of deaths caused by malaria. In addition, the international lists for compiling death statistics in use by the colonial authorities consistently reserved a separate title for malaria, so these reports are free of inconsistencies arising from changing category definitions.

We turn first to the varying impact of malaria deaths across the age groups, focusing on the pattern in the early years when malaria death rates were highest. Rates of death attributed to malaria are at their highest in infancy, decline at ages I-9 to reach their lowest point at ages IO-I4, then begin a steady rise to high rates at ages 55 plus. Male rates at ages 55 plus exceed those at ages I-4, but female rates generally remain below. Malaria age specific death rates thus display a typical j-shaped mortality curve, with the highest rates at the extremes in infancy and old age and the lowest rates IO-I4.

Malaria was consistently a leading cause of death in nineteenth and early twentieth century Taiwan and as such early became a target of Japanese colonial public health efforts (see discussion by Ku Ya-wen, this volume). Decline in malaria death rates was interrupted in I9I5 by epidemic rates of malaria (which did not reach the I906-08 rates for most age groups), but regained momentum thereafter. Over the entire period the degree of the decline in malaria death rates is dramatic and the greatest of the major cause groups. Malaria death rates for most age groups have fallen to half of the 1906-08 levels by 1924-26 and to less 
a. Cause, Age and Sex specific death rates of Taiwanese, Malaria, 1906-1941. Deaths per Io,००० person years. The infant death rate is used for age o-I.

\section{Malaria}

Years Age at beginning of interval:

\begin{tabular}{|c|c|c|c|c|c|c|c|c|c|c|c|c|c|c|c|c|}
\hline Males & ०* & $\mathbf{I}$ & 5 & IO & I5 & 20 & 25 & 30 & 35 & 40 & 45 & 50 & 55 & 60 & 65 & 70 \\
\hline I906-08 & 9I & 54 & 24 & I5 & I9 & 25 & 28 & 33 & 39 & 43 & 48 & 53 & 58 & 56 & 60 & 78 \\
\hline I9०9-I3 & 66 & 37 & I4 & IO & I5 & 20 & 24 & 26 & 27 & 33 & 35 & 36 & 40 & 44 & 42 & 49 \\
\hline I9I4-I6 & 87 & 54 & 22 & I2 & I8 & 24 & 28 & 30 & 33 & 37 & 39 & $4 \mathrm{I}$ & $4 \mathrm{I}$ & 48 & 47 & 65 \\
\hline I9I9-2I & 58 & 35 & I4 & 9 & I3 & I8 & I9 & 22 & 22 & 24 & 24 & 25 & 27 & 30 & 39 & 47 \\
\hline $1924-26$ & 52 & 27 & $\mathrm{I} 2$ & 9 & $\mathrm{I} 2$ & I3 & I4 & I5 & I8 & I9 & I9 & 20 & $2 \mathrm{I}$ & 24 & $3 \mathrm{I}$ & 35 \\
\hline I929-3I & I9 & II & 5 & 4 & 5 & 5 & 6 & 7 & 8 & 8 & 9 & 9 & IO & II & II & I7 \\
\hline I934-36 & I5 & IO & 5 & 4 & 5 & 6 & 6 & 6 & 7 & 8 & 9 & 8 & IO & II & I4 & 22 \\
\hline I939-4I & I3 & 9 & 5 & 4 & 6 & 7 & 6 & 6 & 7 & 7 & 8 & 9 & 9 & I2 & I3 & I8 \\
\hline \multicolumn{17}{|l|}{ Females } \\
\hline I906-08 & 99 & 77 & $3 \mathrm{I}$ & I8 & I9 & 22 & 24 & 27 & 30 & 32 & 36 & $4 \mathrm{I}$ & 45 & $5^{\mathrm{I}}$ & 66 & 80 \\
\hline I9०9-I3 & 69 & $5^{\mathrm{I}}$ & I7 & IO & I3 & I6 & I7 & I9 & 20 & $2 \mathrm{I}$ & 25 & 26 & 28 & $3 \mathrm{I}$ & $4 \mathrm{I}$ & 47 \\
\hline I9I4-I6 & 98 & 72 & 27 & I3 & I6 & 20 & $2 \mathrm{I}$ & 22 & 25 & 26 & 26 & 29 & 38 & 43 & 49 & 69 \\
\hline I9I9-2I & 65 & 44 & I7 & IO & IO & I3 & I4 & I4 & I5 & I8 & I8 & 22 & 24 & 30 & 33 & 43 \\
\hline I924-26 & 53 & 34 & I4 & 8 & 8 & 9 & II & I3 & I4 & I2 & I4 & I7 & I7 & 22 & 30 & 42 \\
\hline I929-3I & 20 & I3 & 6 & 4 & 4 & 4 & 5 & 6 & 6 & 6 & 6 & 7 & IO & IO & II & I6 \\
\hline I934-36 & I6 & II & 5 & 3 & 4 & 4 & 4 & 5 & 5 & 5 & 6 & 7 & 9 & 9 & I4 & 22 \\
\hline I939-4I & I2 & IO & 5 & 3 & 4 & 4 & 5 & 5 & 5 & 5 & 5 & 7 & 7 & 9 & IO & I8 \\
\hline
\end{tabular}

* Infant death rate, calculated as a ratio of infant deaths to registered live births for corresponding periods.

than $20 \%$ by 1939-4I. Somewhat smaller degrees of decline occur in age groups that began the period with the lowest (I0-24 for males, $15-29$ for females) and the highest rates (age 70 plus and infants in I924-26), but overall the gains were widely shared across all age and sex groups.

We turn next to discuss the pattern of the sex ratios of mortality for malaria, shown in table 2.c below. First, note the pattern across the age groups in the early years when malaria mortality was highest. Instead of the usual male excess in infancy we find a female excess, followed by female excesses in ages I-I4 that are deeper than reported for All Causes. At ages 15-19, instead of female excess mortality we find for malaria moderate male excesses, which continue to age 64 but at lower levels than for All Causes. From ages $6_{5}$ on, we find a mix of female excess and nearly balanced sex ratios of mortality, again in contrast to the large 
b. Indices of Cause, Age and Sex specific death rates of Taiwanese, Malaria, I906-194I. Death rates of $1906-8=100.0$

\begin{tabular}{|c|c|c|c|c|c|c|c|c|c|c|c|c|c|c|c|c|}
\hline \multirow{3}{*}{$\begin{array}{l}\text { Years } \\
\text { Males }\end{array}$} & \multicolumn{16}{|c|}{ Malaria } \\
\hline & \multicolumn{16}{|c|}{ Age at beginning of interval: } \\
\hline & $0 *$ & $\mathbf{I}$ & 5 & IO & 15 & 20 & 25 & 30 & 35 & 40 & 45 & 50 & 55 & 60 & 65 & 70 \\
\hline I906-08 & 100.0 & 100.0 & 100.0 & 100.0 & 100.0 & 100.0 & 100.0 & 100.0 & 100.0 & 100.0 & 100.0 & 100.0 & 100.0 & 100.0 & 100.0 & 100.0 \\
\hline I9०9-I3 & 72.5 & 68.5 & 58.3 & 66.7 & 78.9 & 80.0 & 85.7 & 78.8 & 69.2 & 76.7 & 72.9 & 67.9 & 69.0 & 78.6 & 70.0 & 62.8 \\
\hline I9I4-I6 & 95.6 & 100.0 & 91.7 & 80.0 & 94.7 & 96.0 & 100.0 & 90.9 & 84.6 & 86.0 & 81.3 & $77 \cdot 4$ & 70.7 & 85.7 & 78.3 & 83.3 \\
\hline I9I9-2I & $63 \cdot 7$ & 64.8 & $5^{8.3}$ & 60.0 & 68.4 & 72.0 & 67.9 & 66.7 & 56.4 & 55.8 & 50.0 & 47.2 & 46.6 & 53.6 & 65.0 & 60.3 \\
\hline I9 $24-26$ & 57.1 & 50.0 & 50.0 & 60.0 & 63.2 & 52.0 & 50.0 & $45 \cdot 5$ & 46.2 & 44.2 & $39 \cdot 6$ & $37 \cdot 7$ & 36.2 & 42.9 & 51.7 & $44 \cdot 9$ \\
\hline I929-3I & 20.9 & 20.4 & 20.8 & 26.7 & 26.3 & 20.0 & 21.4 & 21.2 & 20.5 & 18.6 & 18.8 & 17.0 & 17.2 & 19.6 & 18.3 & 21.8 \\
\hline $1934-36$ & 16.5 & 18.5 & 20.8 & 26.7 & 26.3 & 24.0 & 21.4 & 18.2 & $17 \cdot 9$ & 18.6 & 18.8 & 15.1 & 17.2 & 19.6 & $23 \cdot 3$ & 28.2 \\
\hline I939-4I & 14.3 & 16.7 & 20.8 & 26.7 & 31.6 & 28.0 & 21.4 & 18.2 & 17.9 & 16.3 & 16.7 & 17.0 & $15 \cdot 5$ & 21.4 & 21.7 & 23.1 \\
\hline \multicolumn{17}{|l|}{ Females } \\
\hline I906-08 & 100.0 & 100.0 & 100.0 & 100.0 & 100.0 & 100.0 & 100.0 & 100.0 & 100.0 & 100.0 & 100.0 & 100.0 & 100.0 & 100.0 & 100.0 & 100.0 \\
\hline I9०9-I3 & $69 \cdot 7$ & 66.2 & 54.8 & $55 \cdot 6$ & 68.4 & 72.7 & 70.8 & 70.4 & 66.7 & 65.6 & $69 \cdot 4$ & 63.4 & 62.2 & 60.8 & 62.1 & 58.8 \\
\hline I9I4-I6 & 99.0 & 93.5 & 87.1 & 72.2 & 84.2 & 90.9 & 87.5 & 81.5 & $83 \cdot 3$ & 81.3 & 72.2 & 70.7 & $84 \cdot 4$ & $84 \cdot 3$ & 74.2 & 86.3 \\
\hline I9I9-2I & 65.7 & 57.1 & 54.8 & 55.6 & 52.6 & 59.1 & $58 \cdot 3$ & 51.9 & 50.0 & 56.3 & 50.0 & $53 \cdot 7$ & $53 \cdot 3$ & $5^{8.8}$ & 50.0 & 53.8 \\
\hline I9 $24-26$ & $53 \cdot 5$ & 44.2 & 45.2 & 44.4 & 42.1 & 40.9 & 45.8 & 48.1 & 46.7 & $37 \cdot 5$ & 38.9 & 41.5 & 37.8 & 43.1 & $45 \cdot 5$ & 52.5 \\
\hline I929-3I & 20.2 & 16.9 & 19.4 & 22.2 & 21.1 & 18.2 & 20.8 & 22.2 & 20.0 & 18.8 & 16.7 & 17.1 & 22.2 & 19.6 & 16.7 & 20.0 \\
\hline $1934-36$ & 16.2 & $14 \cdot 3$ & 16.1 & 16.7 & 21.1 & 18.2 & 16.7 & 18.5 & 16.7 & 15.6 & 16.7 & 17.1 & 20.0 & 17.6 & 21.2 & $27 \cdot 5$ \\
\hline I939-4I & 12.1 & 13.0 & 16.1 & 16.7 & 21.1 & 18.2 & 20.8 & 18.5 & 16.7 & 15.6 & 13.9 & 17.1 & 15.6 & 17.6 & 15.2 & 22.5 \\
\hline
\end{tabular}

* Infant death rate, calculated as a ratio of infant deaths to registered live births for corresponding periods.

male excesses found at these ages for All Causes. At the end of the period in I9394I when malaria death rates have fallen dramatically, the female excesses have disappeared in all but ages I-4 where they have moderated significantly.

Overall, when malaria death rates were high and making an important contribution to the All Causes pattern, malarial deaths rates show a smaller male excess than for All Causes in adulthood, but a significantly greater female excess at ages 0-9. What makes females susceptible to higher death rates from malaria especially at ages 0-9? I have only speculations at this point. Greater exposure seems unlikely, but perhaps females were more exposed to house dwelling anophelines than brothers moving about out of doors (but this would not explain the male excess at higher ages). Differences in resistance seem more likely, if young girls had diets poorer in proteins needed for immune functioning, and 
c. Sex Ratios of Age specific death rates of Taiwanese, Malaria, I906-I94I. Male ASDR/ Fem ASDR.

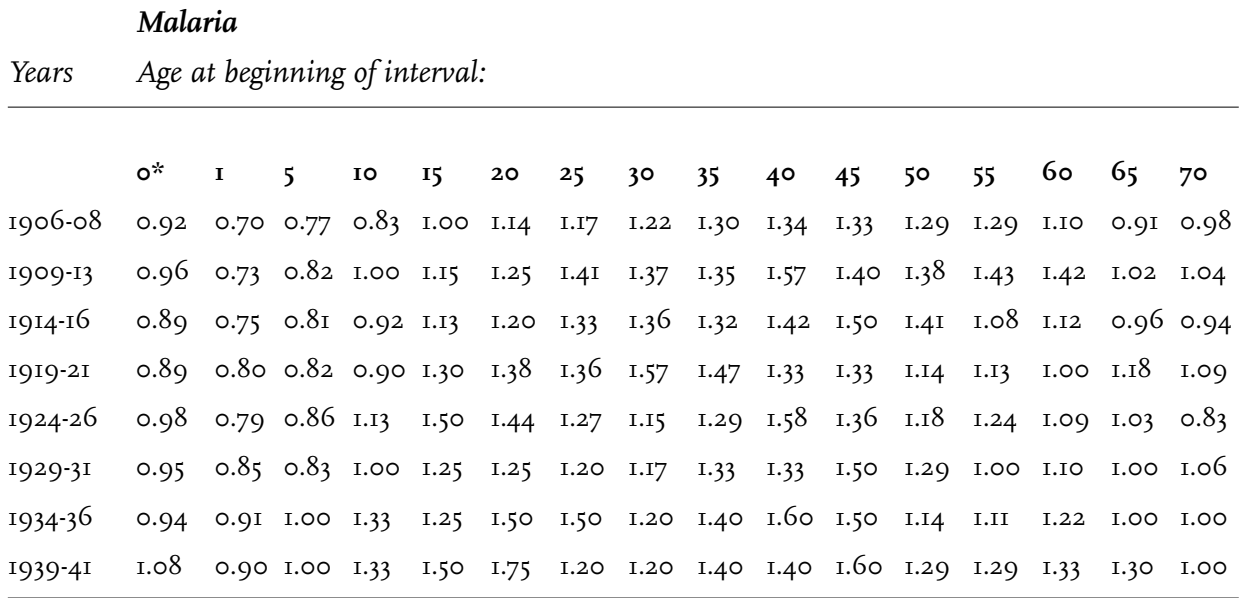

* Infant death rate, calculated as a ratio of infant deaths to registered live births for corresponding periods.

received less care when stricken with fevers. At higher ages pregnant women whose immune system is weakened (to tolerate the fetus) become more susceptible to infectious diseases, malaria among them. This might contribute to higher malaria deaths in fertile age women that would reduce the degree of male excess mortality (Weinberg 1984, Gilles, et al. I969, Shepherd 2002). The pattern of male excess mortality in adult ages may be due to a combination of greater exposure (e.g., work in foothill areas infested with anophelines), and lowered resistance from concurrent diseases, and overwork combined with inadequate nutrition.

The decline in malaria death rates is to be attributed to reduced exposure, the result of public health efforts suppressing anopheline mosquitoes and using quinine to stop the transmission of the plasmodium. We must remember that malaria in the early years is an important contributor to large differences in death rates among the prefectures; malaria death rates were much higher in Tainan and Ahou/Kaohsiung than in the north (see Shepherd "Regional" infra). Malarial death rates are highest in climates most favorable to the propagation of anopheline mosquitoes and the malaria plasmodium. Malaria is most deadly in warmer areas where the falciparum variety can survive, such as south Taiwan. The Taiwan cause, age and sex specific death reports are only available for the island as a whole and not for individual prefectures. We do well to remember that a majority of the malaria deaths reported in our table come from the south- 
ern prefectures. This suggests conditions peculiar to the south, including comorbidity with other diseases having higher rates in the south, may be important factors contributing to the pattern of malaria mortality we see in our tables.

\section{Respiratory Tuberculosis}

The reports of deaths from respiratory tuberculosis appear to provide a relatively consistently reported series for the period, I906-I937. Respiratory tuberculosis presents identifiable symptoms, bloody sputum, coughing, lethargy, which would be known to family members of the deceased and easily reported to the personnel certifying the cause of death. Special training was not needed to correctly identify the bulk of deaths caused by respiratory tuberculosis. In addition, the international lists for compiling death statistics in use by the colonial authorities consistently reserved a separate title for respiratory тв, so these reports are free of inconsistencies arising from changing category definitions.

The sudden and dramatic decline in respiratory tuberculosis death rates in I939-4I reflects underreporting to avoid tuberculosis prevention measures put into force in 1938 that required registration of тв cases, and threatened quarantine and even cremation (Kekkaku yoboho I938, Chen et al. I96r:I6, Lee 2001:67; cf. Wm. Johnston I995: 248, 268, 274-75). There is an obvious and sudden discontinuity in the respiratory тв death reporting series between I937 and I938 when the new regulations came into effect. From I937 to I938, reported deaths attributed to respiratory tuberculosis declined among Taiwanese from 698I to 4770, but increased among Japanese in Taiwan from 313 to 374. Pulmonary tuberculosis cases reported by the public doctors also declined suddenly from 5696 in 1937 to 3462 in I938 (Taiwan Sōtokufu Tökeisho 1937: 468, 1938: 470). Because of the threat of intrusive interference, many Taiwanese families implored doctors to report deaths as due to causes other than tuberculosis; it appears the Japanese population and/or its doctors were less concerned about the consequences of reporting. The obvious underreporting frustrates attempts to measure any effect of increasing public health attention to tuberculosis in the years beyond 1938 .

We turn first to the varying impact of respiratory тв deaths across the age groups. A glance at the table below immediately reveals a very different pattern compared to the All Causes averages. Respiratory тв has its mortality impact almost exclusively in adulthood. From very low levels in infancy and childhood respiratory тв death rates rise rapidly from age 20 to 39 , and continue to increase to peaks most often occurring in the 6o's. This pattern of adult mortality reflects the nature of respiratory тв as a progressive and wasting disease, often following a long incubation period. The absence of a sudden spike in respiratory тв mortality in adolescence and early adulthood, found in many populations in Europe, U.S., and Japan, perhaps due to stresses from adolescent maturation, or increasing 
a. Cause, Age and Sex specific death rates of Taiwanese, Respiratory Tuberculosis, 1906-1936 (and I939-4I affected by underreporting). Deaths per I0,000 person years. The infant death rate is used for age o-I.

\begin{tabular}{lllllllllllllllll}
\multicolumn{10}{c}{ Respiratory Tuberculosis } \\
Years & Age at beginning of interval: \\
Males & O* & I & 5 & I0 & I5 & 20 & 25 & 30 & 35 & 40 & 45 & 50 & 55 & 60 & 65 & 70 \\
I906-08 & 6 & 4 & I & I & 3 & 9 & I7 & 25 & 36 & 45 & 52 & 62 & 57 & 56 & 53 & 53 \\
I909-I3 & 4 & 2 & I & I & 3 & 9 & I6 & 23 & 3 I & 4 I & 5 I & 55 & 57 & 54 & 52 & 38 \\
I9I4-I6 & 2 & 2 & I & I & 4 & 9 & I7 & 24 & 35 & 43 & 53 & 64 & 72 & 70 & 6 I & 44 \\
I9I9-2I & 2 & 2 & I & I & 4 & I2 & I9 & 28 & 40 & $5 \mathrm{I}$ & 65 & 78 & 88 & 98 & I09 & 80 \\
I924-26 & 3 & 2 & I & I & 5 & II & I7 & 27 & 36 & 50 & 65 & 77 & 87 & 97 & 95 & 80 \\
I929-3I & 3 & 2 & I & I & 4 & II & I7 & 22 & 27 & 38 & 52 & 65 & 74 & 80 & 88 & 80 \\
I934-36 & 9 & 5 & I & I & 5 & I2 & I8 & 22 & 26 & 36 & 45 & 58 & 68 & 80 & 90 & 77 \\
1939-41 & 5 & 3 & 1 & 1 & 4 & 9 & 12 & 14 & 17 & 19 & 23 & 29 & 35 & 35 & 34 & 26
\end{tabular}

Females

$\begin{array}{lllllllllllllllll}\text { I9O6-O8 } & 6 & 4 & 2 & \text { I } & 3 & 7 & \text { IO } & \text { I2 } & \text { I4 } & \text { I8 } & 2 \text { I } & 2 \mathrm{I} & 24 & 27 & 25 & 30 \\ \text { I9०9-I3 } & 3 & 2 & \text { I } & \text { I } & 3 & 7 & \text { IO } & \text { I2 } & \text { I6 } & \text { I7 } & 20 & 20 & 23 & 2 \mathrm{I} & 24 & 26 \\ \text { I9I4-I6 } & 3 & 2 & \text { I } & \text { I } & 4 & 7 & \text { II } & \text { I3 } & \text { I7 } & 20 & 22 & 26 & 3 \mathrm{I} & 28 & 3 \mathrm{I} & 30 \\ \text { I9I9-2I } & 2 & 2 & \text { I } & \text { I } & 5 & \text { IO } & \text { I2 } & \text { I7 } & 22 & 25 & 32 & 33 & 40 & 45 & 5 \mathrm{I} & 5 \mathrm{I} \\ \text { I924-26 } & 3 & 2 & \text { I } & \text { I } & 4 & 9 & \text { I3 } & \text { I5 } & 20 & 23 & 28 & 37 & 38 & 4 \mathrm{I} & 5 \mathrm{I} & 47 \\ \text { I929-3I } & 3 & 3 & \text { I } & \text { I } & 4 & 8 & \text { II } & \text { I3 } & \text { I6 } & 2 \mathrm{I} & 25 & 30 & 38 & 43 & 40 & 47 \\ \text { I934-36 } & 6 & 5 & \text { I } & \text { I } & 5 & 8 & \text { I2 } & \text { I2 } & \text { I5 } & \text { I } 8 & 23 & 28 & 34 & 39 & 48 & 49 \\ 1939-41 & 5 & 3 & 1 & 1 & 3 & 5 & 7 & 7 & 7 & 8 & 10 & 13 & 14 & 15 & 17 & 16\end{array}$

* Infant death rate, calculated as a ratio of infant deaths to registered live births for corresponding periods. The I939-4I rates shown in italics are affected by false reporting.

workloads, and exposure in factory worksites, also deserves further consideration.

Respiratory тв also presents a distinctive temporal pattern in our record. Instead of declining through most of the period, respiratory тв death rates rise to peaks in the 1919-1926 period, then decline slightly but remain above the I906-08 rates, except for males 30-54. It should also be noted that respiratory тв in Taiwan was never as significant a cause of death as in some European populations, such as mid-nineteenth century Britain where it was the leading single cause of death (Szreter i988:II).

The sex ratios of respiratory тв mortality present a distinctive pattern of extremely high sex ratios. The degree of excess male mortality, especially above 
b. Indices of Cause, Age and Sex specific death rates of Taiwanese, Respiratory Tuberculosis, 1906-1936. Death rates of $1906-8=100.0$

\section{Respiratory Tuberculosis}

Years Age at beginning of interval:

\begin{tabular}{|c|c|c|c|c|c|c|c|c|c|c|c|c|c|c|c|c|}
\hline Males & $0 *$ & I & 5 & IO & 15 & 20 & 25 & 30 & 35 & 40 & 45 & 50 & 55 & 60 & $6_{5}$ & 70 \\
\hline I906-08 & 100.0 & 100.0 & 100.0 & 100.0 & 100.0 & 100.0 & 100.0 & 100.0 & 100.0 & 100.0 & 100.0 & 100.0 & 100.0 & 100.0 & 100.0 & 100.0 \\
\hline $1909-13$ & 66.7 & 50.0 & 100.0 & 100.0 & 100.0 & 100.0 & 94.1 & 92.0 & 86.1 & 91.1 & $9^{8.1}$ & 88.7 & 100.0 & 96.4 & 98.1 & 71.7 \\
\hline I9I4-I6 & $33 \cdot 3$ & 50.0 & 100.0 & 100.0 & $133 \cdot 3$ & 100.0 & 100.0 & 96.0 & 97.2 & 95.6 & 101.9 & 103.2 & 126.3 & 125.0 & 115.1 & 83.0 \\
\hline I9I9-2I & $33 \cdot 3$ & 50.0 & 100.0 & 100.0 & $133 \cdot 3$ & $133 \cdot 3$ & 111.8 & 112.0 & 111.1 & 113.3 & 125.0 & 125.8 & 154.4 & 175.0 & 205.7 & 150.9 \\
\hline $1924-26$ & 50.0 & 50.0 & 100.0 & 100.0 & 166.7 & 122.2 & 100.0 & 108.0 & 100.0 & 111.1 & 125.0 & 124.2 & 152.6 & 173.2 & 179.2 & 150.9 \\
\hline $929-3 I$ & 50.0 & 50.0 & 100.0 & 100.0 & $133 \cdot 3$ & 122.2 & 100.0 & 88.0 & 75.0 & 84.4 & 100.0 & 104.8 & 129.8 & 142.9 & 166.0 & 150.9 \\
\hline $1934-36$ & 0.0 & 5.0 & 100.0 & 100.0 & 166.7 & $133 \cdot 3$ & 05.9 & 88.0 & 72.2 & 80.0 & 86.5 & $93 \cdot 5$ & $119 \cdot 3$ & 142.9 & 169.8 & $145 \cdot 3$ \\
\hline \multicolumn{17}{|l|}{ Females } \\
\hline $1906-08$ & 100.0 & 100.0 & 100.0 & 100.0 & 100.0 & 100.0 & 100.0 & 100.0 & 100.0 & 100.0 & 100.0 & 100.0 & 100.0 & 100.0 & 100.0 & 100.0 \\
\hline $909-13$ & 50.0 & 50.0 & 50.0 & 100.0 & 100.0 & 100.0 & 100.0 & 100.0 & $114 \cdot 3$ & 94.4 & 95.2 & 95.2 & 95.8 & 77.8 & 96.0 & 86.7 \\
\hline I9I4-I6 & 50.0 & 50.0 & 50.0 & 100.0 & $133 \cdot 3$ & 100.0 & 110.0 & 108.3 & 121.4 & 111.1 & 104.8 & 123.8 & 129.2 & 103.7 & 124.0 & 100.0 \\
\hline I9I9-2I & $33 \cdot 3$ & 50.0 & 50.0 & 100.0 & 166.7 & 142.9 & 120.0 & 141.7 & 157.1 & 138.9 & 152.4 & 157.1 & 166.7 & 166.7 & 204.0 & 170.0 \\
\hline I924-26 & 50.0 & 50.0 & 50.0 & 100.0 & $133 \cdot 3$ & 128.6 & 130.0 & 125.0 & 142.9 & 127.8 & 133.3 & 176.2 & 158.3 & 151.9 & 204.0 & 156.7 \\
\hline I929-3I & 50.0 & 75.0 & 50.0 & 100.0 & $133 \cdot 3$ & $114 \cdot 3$ & 110.0 & 108.3 & $114 \cdot 3$ & 116.7 & 119.0 & 142.9 & 158.3 & $159 \cdot 3$ & 160.0 & 156.7 \\
\hline $1934-36$ & 100.0 & 125.0 & 50.0 & 100.0 & 166.7 & 114.3 & 120.0 & 100.0 & 107.1 & 100.0 & $109 \cdot 5$ & $133 \cdot 3$ & 141.7 & 144.4 & 192.0 & 163.3 \\
\hline
\end{tabular}

*Infant death rate, calculated as a ratio of infant deaths to registered live births for corresponding periods.

age 30 is much greater than the All Causes average. The divergence between the sexes accelerates with age and reaches a peak usually at 50-54 after which there are moderate declines. The male excess remains high throughout the period I906-1936. Also distinctive, though the rates are very low, are the balanced sex ratios throughout infancy and childhood, o-I9. Why Taiwanese men were much more vulnerable to respiratory tuberculosis than women demands explanation; such a large male excess contrasts with known patterns of female excess in Japan at ages 15-20, followed by much more moderate male excesses up to age 40 . Szreter cites Cronje's finding that adult male rates of respiratory тв mortality exceeded female rates in urban counties but fell below female rates in rural counties in Britain (Szreter I988: I3-I4, Cronje I984).

The Taiwanese sex ratios of respiratory tuberculosis mortality diverge from common American ones. Rich cites evidence showing that childbearing in women acts to depress resistance and aggravate symptoms of the active disease 
c. Sex Ratios of Cause, Age and Sex specific death rates of Taiwanese, Respiratory Tuberculosis, I906-I936. Male ASDR/ Fem ASDR.

\section{Respiratory Tuberculosis}

Years Age at beginning of interval:

\begin{tabular}{|c|c|c|c|c|c|c|c|c|c|c|c|c|c|c|c|c|}
\hline & o* & I & 5 & IO & 15 & 20 & 25 & 30 & 35 & 40 & 45 & 50 & 55 & 60 & 65 & 70 \\
\hline I9०6-08 & I.O० & I.OO & 0.50 & I.OO & I.O० & I. 29 & I. 70 & 2.08 & 2.57 & 2.50 & 2.48 & 2.95 & 2.38 & 2.07 & 2.12 & I. 77 \\
\hline I9०9-I3 & I. 33 & I.OO & I.OO & I.OO & I.OO & $\mathrm{I} .29$ & I. 60 & I.92 & I.94 & $2.4 \mathrm{I}$ & 2.55 & 2.75 & 2.48 & 2.57 & $2 . I 7$ & I. 46 \\
\hline I9I4-I6 & 0.67 & I.OO & I.०O & I.०O & I.०O & I. 29 & I. 55 & I. 85 & 2.06 & 2.15 & $2.4 \mathrm{I}$ & 2.46 & 2.32 & 2.50 & I.97 & I. 47 \\
\hline I9I9-2I & I.OO & I.OO & I.OO & 1.00 & 0.80 & I. 20 & I. 58 & I. 65 & I. 82 & 2.04 & 2.03 & 2.36 & 2.20 & 2.I8 & 2.14 & I. 57 \\
\hline I924-26 & I.OO & I.OO & 1.00 & I.०O & I. 25 & I. 22 & I.3I & I. 8 o & I. 80 & 2.I7 & 2.32 & 2.08 & 2.29 & 2.37 & I. 86 & I.70 \\
\hline $29-31$ & I.OO & 0.67 & I.OO & I.OO & I.OO & I. 38 & I. 55 & 1.69 & I.69 & I. $8 \mathrm{I}$ & 2.08 & 2.I7 & I.95 & I. 86 & 2.20 & I.70 \\
\hline I934-36 & I. 50 & I.OO & I.०O & 1.00 & I.OO & I. 50 & I. 50 & I. 83 & I. 73 & 2.00 & I.96 & 2.07 & 2.00 & 2.05 & I. 88 & I. 57 \\
\hline
\end{tabular}

*Infant death rate, calculated as a ratio of infant deaths to registered live births for corresponding periods.

leading to an increasing mortality rate in the fertile ages (Rich I951:I87-9). At later ages as female childbearing declines, this source of aggravation to female health diminishes and, in the American population, the female tuberculosis mortality rate also declines (Rich I951:204). Rich uses this evidence to explain the common observation in the American population of an excess of female over male tuberculosis mortality in the childbearing years, that then gives way to an excess male mortality at older ages (1951:183, 20Iff.). Rates do increase for women in the childbearing years in Taiwan, but not to the degree found among young adult men, nor do they decline following the end of the fertile years.

To explain higher male mortality after the childbearing years in the American population, Rich emphasizes the occupational hazards of males not shared by females: "occupations that involve exposure to the elements, over-exertion and insufficient rest may reasonably be expected to contribute to the tuberculosis mortality of those living in heavily tubercularized communities; for latent infections may be reanimated by such circumstances, and active infections markedly influenced for the worse," (Rich I951:205). Rich discounts the effect of differential exposure between the sexes to sources of infection, as men bring the infection into households where women are present, and the key to mortality remains the individual's ability to resist progression of the disease (I951:205).

Nutritional status is a key determinant of an individual's ability to resist the progress of tuberculosis infection. Rich reviews the great variety of evidence (studies of economic status, body weight, food supply crises, and animal experi- 
ments) that demonstrates that nutritional deficiencies lower resistance to tuberculosis infection (I951:6r8 ff., Comstock I975:377-8). Nutrition must be evaluated against the demands put on the body by activity level as well as sickness ("nutritional stress" when demand exceeds supply). Nevertheless, it would be unexpected to discover that adult males were malnourished compared to adult females in the Taiwanese population and thus to appeal to differentials in nutrition to explain the excess adult male tuberculosis mortality. This factor cannot be ruled out, however, if we appeal to a concept of nutritional stress.

Nutritional stress arising from a higher load of concurrent disease could leave the victim susceptible to respiratory tuberculosis. The disease can reactivate and begin to spread when the immune resistance of the host is weakened, e.g. by another disease or stressful condition. Szreter (I988:I4-I7) suggests that co-morbidity is an especially important factor in $\mathrm{TB}$, and that reductions in smallpox, whooping cough, and the enterics (gastrointestinal diseases like typhoid, cholera, diarrheas) are especially important to enabling people to resist the spread of тв, and to keep it in remission in those who already have nascent cases. Some diseases are very debilitating, and leave those who have survived their onslaught with poor health and weakened immune systems. These people are then more vulnerable to attacks from other diseases that prey on them 'opportunistically' or as 'secondary infections'. This effect is called 'co-morbidity'. One disease may 'set up' a patient to be the victim of a second disease, by weakening, preoccupying and diverting the patient's immune system resistance. Comorbidity is certainly a possible explanation for excess male respiratory tuberculosis death rates in Taiwan, but we should note that death rates due to many other diseases began to decrease much earlier than тв, which seems to have lagged in its decline.

There remains the suggestion that high male rates are the product of a genetically determined weakness in male lungs (Waldron I983). But genetic weakness does not produce male excess mortality in all populations. In other populations where males enjoy more favorable circumstances female rates in the fertile ages eclipse those of males, and male rates overtake female rates only thereafter. In the Taiwanese population however, it appears adverse circumstances for males result in higher death rates even in the fertile years.

Hypotheses accounting for differentials in the incidence of respiratory tuberculosis variously emphasize diet (тв is considered to be a nutritionally sensitive disease, The Conferees I985), exposure to active cases (e.g. within the family), environmental conditions such as crowded living spaces, poor ventilation, and polluted cities, and reduced immune response due to co-morbidity. These factors are often the targets of public health efforts aiming to reduce тв, and their amelioration plays an important role in reducing mortality from respiratory тв. 


\section{Other}

The remaining disease groups to be discussed, respiratory diseases, diarrhea and enteritis, and diseases of infancy are most consistently reported and defined in the period I924-4I.

"Respiratory diseases" is a broad category including pneumonia, bronchitis, influenza ("рвг"), and other respiratory diseases, that weighed heavily on the health of Taiwanese in this period. When combined they are the leading cause of death in all periods, and all prefectures suffered from high rates of these diseases.

We turn first to the varying impact of respiratory disease deaths across the age groups in the 1924-4I period. Respiratory diseases exhibit a j-shaped age curve of mortality, with especially high levels at the extremes in infancy and old age. Levels remain high in early childhood, then reach a low point at ages 5-I9, after which they begin a slow rise that only after age 55 reaches levels as high as those experienced at ages I-4.

Our data series for respiratory diseases covers a smaller range of years, but the degree of decline is nevertheless substantial. The decline in respiratory disease death rates is greatest for both sexes in the 25-39 age groups, but is fairly evenly spread among all the age groups beyond infancy and early childhood. Rates in infancy especially were slow to show improvement, even increasing slightly when rates in other ages were decreasing in I929-3I and 1934-36, but falling by 1939-4I below the initial period. It is not unusual to find rates in infancy responding less to improvements enjoyed more readily at older ages.

The sex ratios of mortality from respiratory diseases exhibit a pattern generally similar to that for All Causes. The sex ratios of mortality for respiratory diseases show a similar male excess in infancy, a small female excess at ages I-4, approach balance in most years at ages 5-I4, then rapidly increase to peaks at ages 40-54 that are much higher than those for all causes. The sex ratio of mortality then declines somewhat but remains higher than that for All Causes from age 55 to the terminal age group. The high excess male mortality in respiratory diseases reaches levels as high as do those for respiratory tuberculosis at ages 40-54, but falls below the тв ratios from ages 55 to the terminal age group. Clearly both groups of respiratory disease, tubercular and the larger nontubercular PBI group, contribute greatly to the male excess mortality at adult ages seen in the All Causes averages.

Pneumonia death rates were the highest of the three Рв pneumonia often bring on death after a person has been stricken by some other disease. Many of the same factors discussed under respiratory tuberculosis may account for the higher male rates - nutritional stress due to diet inadequate to need (pneumonia is nutritionally sensitive, meaning that victims of the disease who are malnourished will suffer more serious cases), work outdoors that increases exposure to the elements, and lowered resistance due to a heavier inci- 
a. Cause, Age and Sex specific death rates of Taiwanese, Respiratory Diseases (РвI), 1924I94I. Deaths per I0,000 person years. The infant death rate is used for age o-I.

\section{Respiratory: Pneumonia, Bronchitis, Influenza, Other}

Years Age at beginning of interval:

$\begin{array}{lllllllllllllllll}\text { Males } & \text { O* } & \text { I } & 5 & \text { I0 } & \text { I5 } & 20 & 25 & 30 & 35 & 40 & 45 & 50 & 55 & 60 & 65 & 70 \\ \text { I924-26 } & 496 & \text { I40 } & 20 & \text { IO } & \text { I6 } & 26 & 37 & 49 & 63 & 77 & 96 & \text { II7 } & \text { I53 } & 2 \text { I4 } & 278 & 406 \\ \text { I929-3I } & 5 \text { I3 } & \text { I22 } & \text { I5 } & 8 & \text { I2 } & \text { I9 } & 24 & 29 & 39 & 52 & 66 & 86 & \text { II2 } & \text { I55 } & 205 & 335 \\ \text { I934-36 } & 520 & \text { I20 } & \text { I5 } & 8 & \text { I2 } & \text { I8 } & 24 & 29 & 38 & 52 & 69 & 89 & \text { II6 } & \text { I52 } & \text { I97 } & 3 \text { I } 8 \\ \text { I939-4I } & 468 & \text { II6 } & \text { I5 } & 7 & \text { I2 } & \text { I9 } & 23 & 30 & 37 & 52 & 70 & \text { IOO } & \text { I24 } & \text { I70 } & 2 \text { I3 } & 3 \text { I5 } \\ \text { Females } & & & & & & & & & & & & & & & & \\ \text { I924-26 } & 425 & \text { I52 } & 22 & 9 & \text { I3 } & \text { I8 } & 24 & 29 & 32 & 35 & 44 & 56 & 82 & \text { I20 } & \text { I54 } & 273 \\ \text { I929-3I } & 432 & \text { I29 } & \text { I5 } & 8 & \text { II } & \text { I3 } & \text { I5 } & \text { I8 } & 22 & 25 & 33 & 42 & 60 & 83 & \text { I26 } & \text { 22I } \\ \text { I934-36 } & 438 & \text { I25 } & \text { I5 } & 8 & \text { II } & \text { I4 } & \text { I5 } & \text { I7 } & 20 & 24 & 29 & 4 \mathrm{I} & 60 & 84 & \text { II9 } & 22 \mathrm{I} \\ \text { I939-4I } & 387 & \text { I20 } & \text { I5 } & 8 & 9 & \text { I3 } & \text { I5 } & \text { I8 } & 2 \text { I } & 26 & 33 & 44 & 64 & 83 & \text { II6 } & 207\end{array}$

* Infant death rate, calculated as a ratio of infant deaths to registered live births for corresponding periods.

b. Indices of Cause, Age and Sex specific death rates of Taiwanese, Respiratory Diseases (PBI), I924-194I. Death rates of 1924-1926 = 100.

Respiratory: Pneumonia, Bronchitis, Influenza, Other

Years Age at beginning of interval:

$\begin{array}{lllllllllllllllll}\text { Males } & \text { O* } & \text { I } & 5 & \text { I0 } & \text { I5 } & 20 & 25 & 30 & 35 & 40 & 45 & 50 & 55 & 60 & 65 & 70 \\ \text { I924-26 } & 100.0 & 100.0 & 100.0 & 100.0 & 100.0 & 100.0 & 100.0 & 100.0 & 100.0 & 100.0 & 100.0 & 100.0 & 100.0 & 100.0 & 100.0 & 100.0 \\ \text { I929-3I } & 103.4 & 87.1 & 75.0 & 80.0 & 75.0 & 73.1 & 64.9 & 59.2 & 61.9 & 67.5 & 68.8 & 73.5 & 73.2 & 72.4 & 73.7 & 82.5 \\ \text { I934-36 } & 104.8 & 85.7 & 75.0 & 80.0 & 75.0 & 69.2 & 64.9 & 59.2 & 60.3 & 67.5 & 71.9 & 76.1 & 75.8 & 71.0 & 70.9 & 78.3 \\ \text { I939-4I } & 94.4 & 82.9 & 75.0 & 70.0 & 75.0 & 73.1 & 62.2 & 61.2 & 58.7 & 67.5 & 72.9 & 85.5 & 81.0 & 79.4 & 76.6 & 77.6 \\ \text { Females } & & & & & & & & & & & & & & & & \end{array}$

* Infant death rate, calculated as a ratio of infant deaths to registered live births for corresponding periods. 

(PBI), I924-I94I. Male ASDR/ Fem ASDR.

\section{Respiratory: Pneumonia, Bronchitis, Influenza, Other}

Years Age at beginning of interval:

\begin{tabular}{lllllllllllllllll} 
& O* & I & 5 & I0 & I5 & 20 & 25 & 30 & 35 & 40 & 45 & 50 & 55 & 60 & 65 & 70 \\
I924-26 & I.I7 & 0.92 & 0.9I & I.II & I.23 & I.44 & I.54 & I.69 & I.97 & 2.20 & 2.18 & 2.09 & I. 87 & I.78 & I.8I & I.49 \\
I929-3I & I.I9 & 0.95 & I.00 & I.00 & I.09 & I.46 & I.60 & I.6I & I.77 & 2.08 & 2.00 & 2.05 & I.87 & I.87 & I.63 & I.52 \\
I934-36 & I.I9 & 0.96 & I.00 & I.00 & I.09 & I.29 & I.60 & I.7I & I.90 & 2.17 & 2.38 & 2.17 & I.93 & I.8I & I.66 & I.44 \\
I939-4I & I.2I & 0.97 & I.00 & 0.88 & I.33 & I.46 & I.53 & I.67 & I.76 & 2.00 & 2.12 & 2.27 & I.94 & 2.05 & I.84 & I.52 \\
\hline
\end{tabular}

* Infant death rate, calculated as a ratio of infant deaths to registered live births for corresponding periods.

dence of concurrent diseases. Pneumonia is often a secondary infection setting in after the victim is weakened by a concurrent disease, which underlines the probable importance of comorbidity in elevating respiratory disease death rates. In this connection it is interesting to note (Shepherd "Regional" infra) that the same north-south gradient in death rates (despite the north's having colder, wetter winters) appears in the case of respiratory diseases as in the case of malaria. Dusty conditions during the southern winter drought period may have aggravated respiratory conditions, though why men should be more affected than women remains a puzzle (Chen Cheng-siang I995: 9-II).

\section{Diarrhea and Enteritis}

Deaths due to diarrhea and enteritis are most consistently reported and defined in the period I924-4I. In this disease group we turn to important water and food borne sources of infection and disease, in contrast to the airborne sources important in respiratory tuberculosis and the $\mathrm{PBI}$ diseases, and the mosquito vector in malaria.

We turn first to the varying impact of these enteric diseases across the age groups in the 1924-4I period. Diarrhea and enteritis exhibit a j-shaped age curve of mortality, but one that has especially high levels in infancy and early childhood ages I-4. Death rates remain very low from 5 to 34 then begin a slow rise that continues to the end of the age range. The second peak at ages 70 and above, which is generally only a third of the rates in infancy, reaches the levels of mortality at ages I- 4 in the case of males but not females.

The data series presented for diarrhea and enteritis covers only the period I924-I94I, but the degree of decline is nevertheless substantial. Diarrhea and enteritis death rates decline most in the middle age ranges 5-54 where rates were already low. Lower degrees of decline that are nevertheless substantial are record- 
a. Cause, Age and Sex specific death rates of Taiwanese, Diarrhea and Enteritis, 1924-194I. Deaths per Io,000 person years. The infant death rate is used for age o-I.

\section{Diarrhea and Enteritis}

Years Age at beginning of interval:

\begin{tabular}{lllllllllllllllll} 
Males & O* & I & 5 & IO & I5 & 20 & 25 & 30 & 35 & 40 & 45 & 50 & 55 & 60 & 65 & 70 \\
I924-26 & 297 & 89 & 7 & 3 & 3 & 4 & 6 & 9 & I3 & I6 & 20 & 27 & 32 & 52 & 6 I & 94 \\
I929-3I & 322 & 9 I & 6 & 2 & 3 & 3 & 5 & 6 & 7 & I2 & I5 & I8 & 27 & 37 & 57 & 93 \\
I934-36 & 274 & 70 & 4 & I & 2 & 2 & 3 & 4 & 5 & 8 & IO & I3 & 21 & 26 & 40 & 7 I \\
I939-4I & 227 & 64 & 4 & 2 & 2 & 2 & 3 & 4 & 4 & 7 & II & I6 & 22 & 32 & 42 & 77 \\
Females & & & & & & & & & & & & & & & & \\
I924-26 & 275 & IIO & 8 & 2 & 2 & 3 & 5 & 6 & 8 & 9 & IO & I3 & 20 & 28 & 43 & 77 \\
I929-3I & 306 & III & 6 & 2 & 2 & 3 & 4 & 5 & 6 & 7 & 9 & IO & I7 & 2 I & 37 & 73 \\
I934-36 & 255 & 83 & 4 & I & I & 2 & 2 & 3 & 4 & 6 & 6 & 9 & I4 & I9 & 3 I & 66 \\
I939-4I & 209 & 77 & 5 & I & I & 2 & 3 & 3 & 4 & 5 & 6 & 8 & I3 & 2 2I & 29 & 70 \\
\hline
\end{tabular}

*Infant death rate, calculated as a ratio of infant deaths to registered live births for corresponding periods.

b. Indices of Cause, Age and Sex specific death rates of Taiwanese, Diarrhea and Enteritis, 1924-194I. Death rates of $1924-1926=100$.

\section{Diarrhea and Enteritis}

Years Age at beginning of interval:

$\begin{array}{lllllllllllllllll}\text { Males } & \text { 0* } & \text { I } & 5 & \text { I0 } & \text { I5 } & 20 & 25 & 30 & 35 & 40 & 45 & 50 & 55 & 60 & 65 & 70 \\ \text { I924-26 } & 100.0 & 100.0 & 100.0 & 100.0 & 100.0 & 100.0 & 100.0 & 100.0 & 100.0 & 100.0 & 100.0 & 100.0 & 100.0 & 100.0 & 100.0 & 100.0 \\ \text { I929-3I } & 108.4 & 102.2 & 85.7 & 66.7 & 100.0 & 75.0 & 83.3 & 66.7 & 53.8 & 75.0 & 75.0 & 66.7 & 84.4 & 71.2 & 93.4 & 98.9 \\ \text { I934-36 } & 92.3 & 78.7 & 57.1 & 33.3 & 66.7 & 50.0 & 50.0 & 44.4 & 38.5 & 50.0 & 50.0 & 48.1 & 65.6 & 50.0 & 65.6 & 75.5 \\ \text { I939-4I } & 76.4 & 71.9 & 57.1 & 66.7 & 66.7 & 50.0 & 50.0 & 44.4 & 30.8 & 43.8 & 55.0 & 59.3 & 68.8 & 61.5 & 68.9 & 81.9 \\ \text { Females } & & & & & & & & & & & & & & & & \end{array}$

* Infant death rate, calculated as a ratio of infant deaths to registered live births for corresponding periods. 

1924-194I. Male ASDR/ Fem ASDR.

\section{Diarrhea and Enteritis}

Years Age at beginning of interval:

\begin{tabular}{|c|c|c|c|c|c|c|c|c|c|c|c|c|c|c|c|c|}
\hline & $0 *$ & I & 5 & IO & 15 & 20 & 25 & 30 & 35 & 40 & 45 & 50 & 55 & 60 & $6_{5}$ & 70 \\
\hline I924-26 & I.०8 & $0.8 \mathrm{I}$ & 0.88 & I. 50 & I. 50 & I. 33 & I. 20 & I. 50 & I. 63 & I. 78 & 2.00 & 2.08 & I. 60 & I. 86 & I. 42 & I. 22 \\
\hline I929-3I & 1.05 & 0.82 & I.०O & I.OO & I. 50 & I.OO & I. 25 & I. 20 & I.I7 & I.7I & I. 67 & I. 80 & I. 59 & I.76 & I. 54 & I. 27 \\
\hline I934-36 & I.O7 & 0.84 & I.OO & 1.00 & 2.00 & I.OO & I. 50 & I. 33 & I. 25 & I. 33 & I. 67 & I. 44 & I. 50 & I. 37 & I.29 & I.08 \\
\hline I939-4I & I.09 & 0.83 & 0.80 & 2.00 & 2.00 & I.०O & 1.00 & I. 33 & 1.00 & I. 40 & I. 83 & 2.00 & 1.69 & I. 52 & I. 45 & I.IO \\
\hline
\end{tabular}

* Infant death rate, calculated as a ratio of infant deaths to registered live births for corresponding periods.

ed at ages 0-4 and 55-69. The rates in the terminal age group declined the least. It is impressive that the very high rates in infancy, despite a surge in I929-3I, declined to the degree they did.

The sex ratios of mortality from diarrheal diseases exhibit a somewhat distinctive pattern. The diarrheal diseases show a smaller male excess in infancy, and a deeper female excess at ages I-4 than for is the case for All Causes. Ratios at ages 5-34 generally show a male excess, but the rates at these ages are so low for both males and females that they cause the sex ratios to be less meaningful (i.e., very small absolute differences (e.g., 2 to I) produce very large ratios (2.00)). When the rates begin to rise significantly from age 35 there is a consistent and substantial male excess that then declines somewhat at ages above 65 . The sex ratios of mortality for diarrheal diseases at ages 35 and above generally resemble the ratios for All Causes.

The low sex ratios of diarrheal disease mortality at ages $0-4$ reveal these diseases to be important contributors to the mortality of female infants and young girls, and to the pattern of female excess mortality at ages I-4 in the All Causes average. The female excess mortality at ages I-4 for diarrheal diseases I924-I94I is greater than that found in any of the other disease groups we have discussed, including malaria (excepting I924-26). The diarrheal death rates are also greater in absolute terms than malaria death rates in the 1924-I94I period.

Why should the excess female mortality at ages I-4 be greater from diarrheas than from respiratory tuberculosis and respiratory diseases, when all are considered nutritionally sensitive? Diarrheal diseases stem from water and food borne sources of infection, so food and drink sanitation practices play an important role in their spread. Were boys and girls differentially exposed to contaminated food and drink? Did son preference mean that boys ate fresher foods and daughters left-overs? Or were differences in resistance related to nutrition more 
important, perhaps because boys' resistance to disease benefited from eating more and more nutritious (meat) foods? Or did the difference lie in the degrees of care and rest allowed boys vs. girls suffering from diarrheas? And what about the male excess at ages above 35? Is this the result of greater exposure or lower resistance?

It is important to note that diarrheas, because they interfere with the absorption of nutrients when the immune system is most in need of them, can be important causes of the worsening of concurrent diseases. Diarrheas thus are linked to nutritional distress on the immune system, and are debilitating infections that can leave the victim vulnerable to opportunistic infections, especially respiratory diseases that are nutritionally sensitive, including respiratory tuberculosis and other bacterial infections such as whooping cough, and pneumonia (Lunn I99I). Omran (I97I) refers to the 'pneumonia-diarrhea- malnutrition' complex in children. Higher rates of diarrhea and enteritis thus could play an important role in raising the rates of death from other diseases.

Separate work on regional variation in causes of death (Shepherd "Regional" infra) shows a divide between the northern and the southern prefectures (including Taichung) in diarrhea and enteritis death rates similar to that found for malaria and respiratory tuberculosis, though not as extreme as in the case of malaria. Higher rates in the south for all three disease groups suggest that comorbidity may have further elevated mortality in those prefectures. The cooler northern climate likely reduces the amount of food and drink contaminated by bacteria in that region.

The importance of food and drink sanitation practices to the spread of diarrheal diseases points to the importance of reducing exposures to contaminated water and food to the historic decline of these diseases. Public water works and sewer systems were not important outside the major cities in colonial Taiwan (where only a small proportion of the population lived). I hypothesize that the spread of more sanitation-conscious food and drink preparation and preservation practices were more important to reducing the sources of diarrheal diseases. These practices would include publicly supervised slaughter houses and markets, as well as changes in domestic kitchens.

\section{Causes of Death in Infancy}

We turn next to examine together the many important causes leading to death in infancy. Newborns in colonial Taiwan suffered from rates of mortality higher than those in any other age group, as the All Causes table reveals. Deaths in infancy are most consistently reported and defined in the period i924-4I.

The table below reports the infant death rates attributed to ten leading causes of death in infancy, as well as the All Causes average. Of the four disease groups discussed above, three are represented here: malaria, respiratory diseases (PBI) and diarrhea and enteritis. Rates of death in infancy from Respiratory тв are too 
low to be considered. Two cause groups, 'certain diseases of infancy' and tetanus, not previously discussed, are of very great significance to infant mortality.

Certain diseases of infancy includes causes occurring overwhelmingly in the first month of life, such as congenital malformation and debility (the two largest subgroups), prematurity, and birth trauma. Certain diseases of infancy reports primarily endogenous and neonatal deaths, rather than exogenous causes related to environmental exposures.

Infantile tetanus is also a cause of death that occurs overwhelmingly in the first month of life. It is likely that infantile tetanus was 'overreported' in our data sources, as neonatal deaths from other causes were carelessly reported as infantile tetanus. This is the conclusion of Li T'eng-yue based on a review of the cause of death reports for the year I934 (I938d: I6I6). Li discovered that slightly more than half of all infant deaths classified as tetanus were reported to have occurred within five days of birth, too soon for most tetanus infections to have incubated and caused death (infantile tetanus on average shows symptoms within seven days with death following in a few days). Thus half of tetanus deaths should be reclassified as due to other neonatal causes, including jaundice/icterus. The overwhelming balance of deaths classified as tetanus took place within ten days of birth. This leaves a very significant number of deaths attributed to tetanus proper. Medical authorities in colonial Taiwan regularly criticized midwives and other birth attendants for unsanitary practices in cutting the umbilical cord that led to tetanus (see Wu Chialing 2006). Reclassification of a portion of these deaths does not affect our assessment that the infantile tetanus category reports overwhelmingly neonatal deaths.

Five diseases that also contributed significantly to infant death rates will be discussed briefly. Most of these causes arise from infections contracted from the environment. Congenital syphilis is a partial exception as it is transmitted to the infant from an infected mother. Convulsions is a symptomological category rather than an identifiable disease, but is usually associated with the dehydration brought on by infantile diarrheas (Szreter I988: I7). Stomach complaints is a category that captures a variety of gastrointestinal problems Meningitis, measles, and whooping cough are infectious diseases which easily overwhelm immature infant immune systems.

The All Causes average of infant mortality declined consistently over the period I924-4I for both sexes, despite increases in measles I934-4I, and temporary surges in respiratory diseases 1929-36, diarrheas 1929-31, certain diseases of infancy in 1934-36, and syphilis I939-4I. Major contributors to the overall decline were diarrhea and enteritis, and tetanus. Convulsions also declined dramatically, but many of these deaths may have been reclassified to other causes (perhaps diarrhea) in the later years as this was a disfavored symptomological category. All the remaining diseases contributed significant but smaller absolute amounts to the decline with the exception noted of measles. 
a. Infant Death Rates by Cause and Sex, Taiwanese, I924-4I. Deaths per I0,000 births.

\begin{tabular}{lllllll}
\hline Infant & All & Respir- & Diarrhea, Certain & Tetanus & Malaria & Measles, Convul- \\
Death & Causes & atory & Enteritis Dis.Inf. & Whoop- sions & genital & gitis \\
Rate* & & (PвI) & & ing cough & Syphilis \\
\hline
\end{tabular}

Males

\begin{tabular}{|c|c|c|c|c|c|c|c|c|c|c|c|}
\hline I924-26 & I8I7 & 496 & 297 & 324 & 293 & 52 & 27 & 88 & 30 & 35 & I8 \\
\hline I929-3I & I703 & $5^{\mathrm{I} 3}$ & 322 & 284 & 289 & I9 & 22 & 44 & I9 & 28 & I4 \\
\hline I934-36 & 1620 & 520 & 274 & 310 & 256 & I5 & 43 & I5 & I7 & 27 & 5 \\
\hline I939-4I & I 440 & 468 & 227 & 284 & $23 \mathrm{I}$ & I3 & $5^{2}$ & 3 & II & 28 & 3 \\
\hline \multicolumn{12}{|l|}{ Females } \\
\hline I924-26 & I5I 5 & 425 & 275 & $25 \mathrm{I}$ & 203 & 53 & 24 & 74 & 30 & $3 \mathrm{I}$ & I4 \\
\hline I929-3I & I4I 8 & 432 & 306 & 219 & $20 \mathrm{I}$ & 20 & 22 & 36 & I8 & 24 & IO \\
\hline $1934-36$ & 1356 & 438 & 255 & 243 & I87 & 16 & 45 & I2 & 16 & 22 & 4 \\
\hline I939-4I & I2O8 & 387 & 209 & 235 & I72 & $\mathrm{I} 2$ & 50 & 3 & 9 & 24 & 2 \\
\hline
\end{tabular}

* Infant death rate, calculated as a ratio of infant deaths to registered live births for corresponding periods.

b. Indices of Infant Death Rates by Cause and Sex, Taiwanese, I924-4I. Death rates of I924$1926=100$

\begin{tabular}{lllllll} 
Infant & All & Respir- & Diarrhea, Certain & Tetanus & Malaria & Measles, Convul- \\
Death & Causes & atory & Enteritis Dis.Inf. & Whoop- sions & genital gitis \\
Rate* & & (рвI) & & ing cough & Syphilis \\
\hline
\end{tabular}

Males

\begin{tabular}{|c|c|c|c|c|c|c|c|c|c|c|c|}
\hline $1924-26$ & 100.0 & 100.0 & 100.0 & 100.0 & 100.0 & 100.0 & 100.0 & 100.0 & 100.0 & 100.0 & 100.0 \\
\hline I929-3I & $93 \cdot 7$ & 103.4 & 108.4 & $87 \cdot 7$ & 98.6 & 36.5 & 81.5 & 50.0 & 63.3 & 80.0 & 77.8 \\
\hline I934-36 & 89.2 & 104.8 & 92.3 & $95 \cdot 7$ & $87 \cdot 4$ & 28.8 & $159 \cdot 3$ & 17.0 & 56.7 & 77.1 & 27.8 \\
\hline I939-4I & $79 \cdot 3$ & $94 \cdot 4$ & 76.4 & $87 \cdot 7$ & 78.8 & 25.0 & 192.6 & $3 \cdot 4$ & 36.7 & 80.0 & 16.7 \\
\hline \multicolumn{12}{|l|}{ Females } \\
\hline I924-26 & 100.0 & 100.0 & 100.0 & 100.0 & 100.0 & 100.0 & 100.0 & 100.0 & 100.0 & 100.0 & 100.0 \\
\hline I929-3I & 93.6 & 101.6 & 111.3 & $87 \cdot 3$ & 99.0 & $37 \cdot 7$ & 91.7 & 48.6 & 60.0 & $77 \cdot 4$ & 71.4 \\
\hline $1934-36$ & 89.5 & 103.1 & 92.7 & 96.8 & 92.1 & 30.2 & $187 \cdot 5$ & 16.2 & $53 \cdot 3$ & 71.0 & 28.6 \\
\hline I939-4I & $79 \cdot 7$ & 91.1 & 76.0 & 93.6 & 84.7 & 22.6 & 208.3 & 4.1 & 26.7 & 77.4 & $14 \cdot 3$ \\
\hline
\end{tabular}

* Infant death rate, calculated as a ratio of infant deaths to registered live births for corresponding periods. 


\begin{tabular}{|c|c|c|c|c|c|c|c|c|c|c|c|}
\hline $\begin{array}{l}\text { Infant } \\
\text { Death } \\
\text { Rate* }\end{array}$ & $\begin{array}{l}\text { All } \\
\text { Causes }\end{array}$ & $\begin{array}{l}\text { Respir- } \\
\text { atory } \\
(\mathrm{PBI})\end{array}$ & $\begin{array}{l}\text { Diarrhea, } \\
\text { Enteritis }\end{array}$ & $\begin{array}{l}\text { Certain } \\
\text { Dis.Inf. }\end{array}$ & Tetanus & Malaria & $\begin{array}{l}\text { Measles, } \\
\text { Whoop- } \\
\text { ing cough }\end{array}$ & $\begin{array}{l}\text { Convul- } \\
\text { sions } \\
\text { h }\end{array}$ & Stomach & $\begin{array}{l}\text { Con- } \\
\text { genital } \\
\text { Syphilis }\end{array}$ & $\begin{array}{l}\text { Menin- } \\
\text { gitis }\end{array}$ \\
\hline I9 $24-26$ & I. 20 & I.I7 & I.०8 & 1.29 & I. 44 & 0.98 & I.I3 & I.I9 & I.OO & I.I3 & I. 29 \\
\hline I929-3I & I. 20 & I.I9 & 1.05 & I. 30 & I. 44 & 0.95 & I.०O & I. 22 & 1.06 & I.I7 & I. 40 \\
\hline I934-36 & I.I9 & I.I9 & 1.07 & I. 28 & I. 37 & 0.94 & 0.96 & I. 25 & I.०6 & I. 23 & I. 25 \\
\hline I939-4I & I.I9 & $\mathrm{I} .2 \mathrm{I}$ & I.O9 & $\mathrm{I} .2 \mathrm{I}$ & I. 34 & I.०8 & I.O4 & 1.00 & I. 38 & I.I7 & I. 50 \\
\hline
\end{tabular}

* Infant death rate, calculated as a ratio of infant deaths to registered live births for corresponding periods.

Maternal and infant health are linked in many ways, and poor maternal health through pregnancy is thought to increase the chance of neonatal deaths, particularly those in the 'certain diseases of infancy' category (malformation, debility, prematurity, birth trauma)(cf. Loudon I992). Low birth weight neonates and those whose mothers are unable to produce adequate breastmilk are also at added risk of death. The decline in mortality in infancy cannot be attributed to improved maternal and infant health arising from lower fertility and lengthened birth intervals, however. Birth rates increased over the period and remained higher in 1930-40 than in any previous decade (Barclay 1954: 24I, 243, 246). This suggests that explanations relying on excess fertility and crowded spacing to explain high neonatal death rates are less important than factors related to the disease environment. The sharp declines in deaths among women in the fertile ages over the period so obvious in the All Causes and other tables above suggest that improved maternal health made it possible to achieve both higher fertility and lower rates of infant mortality.

The sex ratio of infant death for the All Causes average shows a consistent male excess; this is as expected in most populations. Male infants generally report larger numbers in the malformation and debility categories, have lungs that are less mature than those of female infants (Waldron I983), and are generally more vulnerable to infection. The sex ratios of infant mortality reflect these patterns: male excess mortality is substantial in certain diseases of infancy, respiratory diseases, and tetanus. Significant male excesses are also reported in convulsions, meningitis, and syphilis. The lowest sex ratios are reported for diarrheas and stomach, malaria, and measles, all primarily post-neonatal causes of death. We have already discussed possible sources of excess female mortality in diarrheas at ages I-4, and these considerations likely apply to deaths due to diarrheas and stomach complaints in infancy, which are largely postneonatal. Poorer quality nutrition and earlier weaning that exposes the grastrointestinal tract to infected food and drink undoubtedly contribute to elevate female rates in the postneona- 
Deaths per thousand.

Indexed Infant Death Rates,

I924-26 = I00.

\begin{tabular}{lllllllll}
\hline & $\begin{array}{l}\text { Infant } \\
\text { Death } \\
\text { Rate }\end{array}$ & $\begin{array}{l}\text { Neonatal } \\
\text { Death } \\
\text { Rate }\end{array}$ & $\begin{array}{l}\text { Post- } \\
\text { neonatal } \\
\text { Death } \\
\text { Rate* }\end{array}$ & $\begin{array}{l}\text { Neonatal } \\
\% \text { of IDR }\end{array}$ & $\begin{array}{l}\text { Infant } \\
\text { Death } \\
\text { Rate }\end{array}$ & $\begin{array}{l}\text { Neonatal } \\
\text { Death } \\
\text { Rate }\end{array}$ & $\begin{array}{l}\text { Post- } \\
\text { neonatal } \\
\text { Death } \\
\text { Rate* }\end{array}$ & $\begin{array}{l}\text { Neo- } \\
\text { natal \% }\end{array}$ \\
& & & & & & & & \\
Males & & & & & & & 100 & 100 \\
I924-26 & I8I.7 & 90.9 & 99.9 & 50.0 & 100 & 100 & 100 \\
I929-3I & I70.3 & 8 I.9 & 96.3 & 48.1 & 94 & 90 & 96 & 96 \\
I934-36 & I62.0 & 74.8 & 94.3 & 46.1 & 89 & 82 & 94 & 92 \\
I939-4I & I44.0 & 67.7 & 8 I. 8 & 47.0 & 79 & 74 & 82 & 94 \\
Females & & & & & & & 100 & 100 \\
I924-26 & I5I.5 & 67.3 & 90.3 & 44.4 & 100 & 100 & 100 \\
I929-3I & I4I.8 & 60.1 & 86.9 & 42.4 & 94 & 89 & 96 & 95 \\
I934-36 & I35.6 & 55.4 & 84.9 & 40.9 & 90 & 82 & 94 & 92 \\
I939-4I & I20.8 & 52.0 & 72.6 & 43.1 & 80 & 77 & 80 & 97 \\
\hline
\end{tabular}

* PNN death rate calculated as deaths per survivors of the first month of life.

Source: Taiwan jinkō dōtai tōkei.

Table 8. Sex Ratios of Infant, Neonatal and Post-neonatal Death Rates, Taiwanese, 1924-4I. Male ASDR/ Fem ASDR.

$\begin{array}{llll}\text { Infant } & \text { Neonatal } & \text { Postneonatal Neonatal \% of } \\ \text { Death Rate } & \text { Death Rate } & \text { Death Rate* } & \text { IDR }\end{array}$

$\begin{array}{lllll}\text { I924-26 } & \text { I.20 } & \text { I.35 } & \text { I.II } & \text { I.I3 } \\ \text { I929-3I } & \text { I.20 } & \text { I.36 } & \text { I.II } & \text { I.I3 } \\ \text { I934-36 } & \text { I.I9 } & \text { I.35 } & \text { I.II } & \text { I.I3 } \\ \text { I939-4I } & \text { I.I9 } & \text { I.30 } & \text { I.I3 } & \text { I.09 }\end{array}$

tal period (and lower the sex ratio). Measles and whooping cough are nutritionally sensitive and the lower sex ratio for these diseases may reflect poor nutrition and earlier weaning in females. More curious is the low sex ratio for malaria. 
The tables above confirm that the male disadvantage in infancy is greatest in the neonatal period, where certain diseases of infancy and tetanus are concentrated. The male disadvantage relative to females declines in the postneonatal period when exogenous causes and environmental exposures increase. Over the period I924-I94I, the decline in the neonatal period is slightly greater than the decline in the postneonatal period.

Our knowledge of the distribution of the infant causes between the neonatal and postneonatal periods is much indebted to Li T'eng-yue's analysis of the cause of death reports for I934 (I938d). Li was a medical doctor and member of staff at Taipei Imperial University Medical College. He obtained the original cause of death tickets from the Government-general's statistical office for the year 1934 in order to conduct a detailed statistical analysis of the timing of death in infancy by cause (1938d: I45I). The results of Li's analysis are summarized in Table 9 below (as precisely as his tables allow; supplemented by the reports of infant deaths by month in the I934 Taiwan jinkō dōtai tōkei). A second table calculates neonatal and postneonatal death rates for the leading causes in I934.

Li's analysis shows that certain diseases of infancy and tetanus combined accounted for 7I\% of neonatal deaths in I934. More than $90 \%$ of deaths attributed to certain diseases of infancy occur in the first month of life, and more than $96 \%$ of deaths attributed to tetanus occur in the first month of life, confirming that these two causes are overwhelmingly neonatal. Respiratory diseases and diarrheas and enteritis accounted for $75 \%$ of post-neonatal deaths. Deaths attributed to diarrhea and enteritis increase especially in the last six months of the first year of life, a pattern which is likely related to weaning from breastfeeding and increasing amounts of supplements to breastmilk that are susceptible to contamination. Measles also noticeably increases in the last six months; weaning could also play a role here by reducing the transfer of passive immunities passed from mother to infant in breastmilk. Overall, $82 \%$ of all infant deaths are accounted for by four causes: certain diseases of infancy, tetanus, respiratory diseases and diarrhea and enteritis.

\section{The Causes Combined}

The tables below combine the rates for All Causes, and the four individual cause groups discussed here, respiratory diseases, diarrhea and enteritis, malaria and respiratory tuberculosis for the initial and terminal years for which we have consistent series for all these causes, I924-26 and 1939-4I. The proportion of total deaths that these four causes account for is shown in the accompanying tables. The four selected causes account for half or more of all deaths in most age groups in the 1924-26 period, and somewhat lower proportions in 1939-4I. The proportion of total female deaths accounted for is generally lower than for males. Much work remains to be done. 
Table 9. Causes of infant death in neonatal and post-neonatal periods, Taiwanese, 1934.

\begin{tabular}{|c|c|c|c|c|}
\hline \multirow{2}{*}{$\begin{array}{l}1934 \\
\text { Cause of death }\end{array}$} & \multicolumn{2}{|c|}{ Neonatal } & \multicolumn{2}{|c|}{ Postneonatal } \\
\hline & Male & Female & Male & Female \\
\hline Certain Dis. Inf. & $38.0 \%$ & $38.9 \%$ & $2.5 \%$ & $2.5 \%$ \\
\hline Tetanus & 33.0 & 32.7 & 0.7 & 0.8 \\
\hline Respiratory (РВI) & II. 8 & II. 5 & 46.3 & 44.6 \\
\hline Diarrhea and enteritis & 6.5 & 5.6 & 28.6 & $29 \cdot 4$ \\
\hline Stomach & 0.5 & 0.6 & I.O & 0.9 \\
\hline Measles & 0.2 & 0.2 & 4.0 & 5.0 \\
\hline Beriberi & 0.2 & 0.2 & 0.7 & 0.6 \\
\hline Syphilis & I. 3 & I. 5 & I. .7 & I.6 \\
\hline Septicemia & I. 5 & I. 5 & I. 5 & I. 5 \\
\hline Mening. \& Inf.Convul. & I. 5 & I.3 & $2 . \mathrm{I}$ & I.9 \\
\hline Malaria & 0.2 & 0.2 & I.4 & I.7 \\
\hline Erysipelis & 0.9 & I.O & I.2 & I.3 \\
\hline Other \& unknown & $4 \cdot 4$ & 4.6 & 8.3 & 8.0 \\
\hline Total \% & $100.0 \%$ & I00.०\% & $100.0 \%$ & $100.0 \%$ \\
\hline Total deaths & 8520 & 6084 & 10303 & 9147 \\
\hline$N N \%$ of IDR & $45.3 \%$ & $39.9 \%$ & & \\
\hline
\end{tabular}

Source: Li T’eng-yue I938d: I609-16I5, Taiwan jinkō dōtai tōkei, I934.

Many more cause groups await individual analysis. The age group with the lowest proportions is the elderly. Adding degenerative causes, such as stroke, heart diseases, and nephritis will increase the proportion of total deaths accounted for among the elderly. Adding maternal causes will increase the proportion among women in fertile ages. And for both sexes at adult ages, adding stomach related causes including ulcers, and accidents will account for significant increases. Rates in infancy and childhood can also be raised by adding a few significant causes. We saw above that adding certain infant causes and tetanus increases the proportion of infant deaths accounted for to $82 \%$ in I934. The proportion of deaths accounted for by the four causes is highest in early childhood, ages I-4, despite the very low contribution of respiratory тв and the declining significance of malaria to rates at this age. Clearly respiratory causes and diarrheas play a dominant role in mortality in early childhood. Adding infectious diseases (e.g., measles and whooping cough) will also raise the rates in childhood significantly. 
Taiwanese, 1934** Deaths per Iooo.

\begin{tabular}{|c|c|c|c|c|}
\hline 1934 & Neonat & & Postneor & Rates \\
\hline Cause of death & Male & Female & Male & Female \\
\hline Certain Dis. Inf. & 29.05 & 22.44 & 2.52 & 2.34 \\
\hline Tetanus & 25.25 & I 8.88 & 0.65 & 0.74 \\
\hline Respiratory (РВI) & 9.02 & 6.63 & 46.32 & $4 \mathrm{I} .02$ \\
\hline Diarrhea and enteritis & $4 \cdot 94$ & 3.24 & 28.6I & 27.07 \\
\hline Stomach & 0.40 & 0.37 & 0.98 & 0.86 \\
\hline Measles & 0.19 & 0.13 & 4.05 & $4.6 \mathrm{I}$ \\
\hline Beriberi & O.I4 & O.II & 0.67 & 0.58 \\
\hline Syphilis & 0.98 & 0.87 & I.70 & I. 48 \\
\hline Septicemia & I.I2 & 0.87 & I. 48 & I.42 \\
\hline Mening. \& Inf.Convul. & I.I2 & 0.77 & 2.13 & I. 78 \\
\hline Malaria & 0.16 & 0.12 & I. 39 & I. 54 \\
\hline Erysipelis & 0.65 & 0.60 & I. 24 & I. 24 \\
\hline Other \& unknown & 3.40 & 2.65 & 8.34 & $7 \cdot 34$ \\
\hline All Causes & 76.43 & 57.68 & 100.07 & 92.03 \\
\hline Total deaths & 8520 & 6084 & 10303 & 9147 \\
\hline Births* & 111474 & 105480 & & \\
\hline
\end{tabular}

* Calculated using the births of I933 and I934, and a separation factor of 0.3 (Barclay I958: I40-I4I).

$* *$ PNN death rate calculated as deaths per survivors of the first month of life. Based on Li T'eng-yueh I938d:

I609-I6I5 and the table above.

\section{Conclusion}

The All Causes table presented at the beginning of this discussion summarizes our main story: there was a significant decline in mortality through the period I906-I94I that was shared broadly by all age and sex groups. We have investigated the contribution to that decline made by four separate cause groups, malaria, respiratory тв, respiratory causes ( $\mathrm{PBI})$, and diarrhea and enteritis. And in the case of infant deaths we have also assessed the contribution of several additional causes, in particular certain diseases of infancy and tetanus.

For each cause group we have been concerned to detect patterns of differential incidence and decline among the age groups and sexes that would provide insight into the epidemiological factors elevating or decreasing death rates. Both disease environment and factors of social position played a role in whether a particular age and sex group exhibited death rates higher or lower than the period 
Table II. Cause, Age and Sex specific death rates of Taiwanese, All Causes and Selected Leading Causes, 1924-26. Deaths per I0,000 person years. The infant death rate is used for age o-I.

1924-26 All Causes and Selected Leading Causes, 1924-26

Years Age at beginning of interval:

\begin{tabular}{|c|c|c|c|c|c|c|c|c|c|c|c|c|c|c|c|c|}
\hline Males & o* & $\mathbf{I}$ & 5 & IO & 15 & 20 & 25 & 30 & 35 & 40 & 45 & 50 & 55 & 60 & $6_{5}$ & 70 \\
\hline AllCaus & I8I7 & 356 & 67 & 39 & 60 & 89 & II7 & I54 & I97 & 243 & 302 & 372 & 485 & 674 & 88I & I443 \\
\hline Resp & 496 & I4O & 20 & IO & I6 & 26 & 37 & 49 & $6_{3}$ & 77 & 96 & II7 & I53 & $2 \mathrm{I} 4$ & 278 & 406 \\
\hline Diarr. & 297 & 89 & 7 & 3 & 3 & 4 & 6 & 9 & I3 & I6 & 20 & 27 & 32 & 52 & 6I & 94 \\
\hline Malar. & $5^{2}$ & 27 & I2 & 9 & I2 & I3 & I4 & I5 & I 8 & I9 & I9 & 20 & $2 \mathrm{I}$ & 24 & $3 \mathrm{I}$ & 35 \\
\hline Respтв & 3 & 2 & I & I & 5 & II & I7 & 27 & 36 & 50 & $6_{5}$ & 77 & 87 & 97 & 95 & 80 \\
\hline \multicolumn{17}{|l|}{ Females } \\
\hline AllCaus & I5I5 & $4 \mathrm{I} 7$ & $7 \mathrm{I}$ & 36 & 56 & 84 & IOI & $\mathrm{I} 24$ & I44 & $\mathrm{I} 48$ & I68 & $2 \mathrm{I} 7$ & 284 & $4 \mathrm{I} 4$ & 578 & II 20 \\
\hline Resp & 425 & I52 & 22 & 9 & I3 & I8 & 24 & 29 & 32 & 35 & 44 & 56 & 82 & $\mathrm{I} 20$ & I54 & 273 \\
\hline Diarr. & 275 & IIO & 8 & 2 & 2 & 3 & 5 & 6 & 8 & 9 & IO & I3 & 20 & 28 & 43 & 77 \\
\hline Malar. & 53 & 34 & $\mathrm{I} 4$ & 8 & 8 & 9 & II & I3 & I4 & I2 & I4 & I7 & I7 & 22 & 30 & $4^{2}$ \\
\hline Respтв & 3 & 2 & I & I & 4 & 9 & I3 & I5 & 20 & 23 & 28 & 37 & 38 & $4 \mathrm{I}$ & $5 \mathrm{I}$ & 47 \\
\hline
\end{tabular}

* Infant death rate, calculated as a ratio of infant deaths to registered live births for corresponding periods.

Table I2 Proportion of All Causes accounted for by selected leading causes, 1924-26.

1924-26 Proportion of All Causes accounted for by Selected Leading Causes, 1924-26

Years Age at beginning of interval:

\begin{tabular}{lllllllllllllllll} 
Age & 0 & I & 5 & I0 & I5 & 20 & 25 & 30 & 35 & 40 & 45 & 50 & 55 & 60 & 65 & 70 \\
Males & 46.7 & 72.5 & 59.7 & 59.0 & 60.0 & 60.7 & 63.2 & 64.9 & 66.0 & 66.7 & 66.2 & 64.8 & 60.4 & 57.4 & 52.8 & 42.6 \\
Females & 49.9 & 71.5 & 63.4 & 55.6 & 48.2 & 46.4 & 52.5 & 50.8 & 51.4 & 53.4 & 57.1 & 56.7 & 55.3 & 5 I.0 & 48.1 & 39.2 \\
\hline
\end{tabular}


Table 13. Sex Ratios of Age and Sex specific death rates of Taiwanese, All Causes and Selected Leading Causes, 1924-26. Male ASDR/ Female ASDR.

924-26 All Causes and Selected Leading Causes, 1924-26

Years Age at beginning of interval:

\begin{tabular}{lllllllllllllllll} 
& 0 & I & 5 & I0 & I5 & 20 & 25 & 30 & 35 & 40 & 45 & 50 & 55 & 60 & 65 & 70 \\
AllCaus & I20 & 85 & 94 & I08 & I07 & I06 & II6 & I24 & I37 & I64 & I80 & I7I & I7I & I63 & I52 & I29 \\
Resp & II7 & 92 & $9 \mathrm{I}$ & III & I23 & I44 & I54 & I69 & I97 & 220 & 218 & 209 & I87 & I78 & I8I & I49 \\
Diarr. & I08 & $8 \mathrm{I}$ & 88 & I50 & I50 & I33 & I20 & I50 & I63 & I78 & 200 & 208 & I60 & I86 & I42 & I22 \\
Malar. & 98 & 79 & 86 & II3 & I50 & I44 & I27 & II5 & I29 & I58 & I36 & II8 & I24 & I09 & I03 & 83 \\
Respтв & I00 & I00 & I00 & I00 & I25 & I22 & I3I & I80 & I80 & 217 & 232 & 208 & 229 & 237 & I86 & I70 \\
\hline
\end{tabular}

Table I4. Cause, Age and Sex specific death rates of Taiwanese, All Causes and Selected Leading Causes, I939-4I. Deaths per I0,000 person years. The infant death rate is used for age o-I.

1939-41 All Causes and Selected Leading Causes, 1939-41

Years Age at beginning of interval:

\begin{tabular}{|c|c|c|c|c|c|c|c|c|c|c|c|c|c|c|c|c|}
\hline Males & $\circ$ & I & 5 & IO & I5 & 20 & 25 & 30 & 35 & 40 & 45 & 50 & 55 & 60 & $6_{5}$ & 70 \\
\hline AllCaus & I440 & 289 & 46 & 27 & 45 & 66 & 77 & 96 & II6 & 156 & 210 & 293 & $38 \mathrm{I}$ & 527 & $7 \mathrm{I} 2$ & I29I \\
\hline Resp & 468 & II6 & I5 & 7 & I2 & I9 & 23 & 30 & 37 & 52 & 70 & IOO & I24 & I70 & $2 \mathrm{I} 3$ & 315 \\
\hline Diarr. & 227 & 64 & 4 & 2 & 2 & 2 & 3 & 4 & 4 & 7 & II & I6 & 22 & 32 & 42 & 77 \\
\hline Malar. & I3 & 9 & 5 & 4 & 6 & 7 & 6 & 6 & 7 & 7 & 8 & 9 & 9 & I2 & I3 & I8 \\
\hline Respтв* & 5 & 3 & I & I & 4 & 9 & $\mathrm{I} 2$ & I4 & I7 & I9 & 23 & 29 & 35 & 35 & 34 & 26 \\
\hline \multicolumn{17}{|l|}{ Females } \\
\hline AllCaus & I2O 8 & $3 \mathrm{I} 7$ & 45 & 24 & 38 & 53 & 6I & 76 & $9^{\mathrm{I}}$ & 107 & $\mathrm{I} 26$ & 165 & 229 & 316 & $45 \mathrm{I}$ & IO7I \\
\hline Resp & 387 & 120 & I5 & 8 & 9 & I3 & I5 & I8 & $2 \mathrm{I}$ & 26 & 33 & 44 & 64 & 83 & II6 & 207 \\
\hline Diarr. & 209 & 77 & 5 & I & I & 2 & 3 & 3 & 4 & 5 & 6 & 8 & I3 & $2 \mathrm{I}$ & 29 & 70 \\
\hline Malar. & I2 & IO & 5 & 3 & 4 & 4 & 5 & 5 & 5 & 5 & 5 & 7 & 7 & 9 & IO & I8 \\
\hline Respтв* & 5 & 3 & I & I & 3 & 5 & 7 & 7 & 7 & 8 & IO & I3 & I4 & I5 & I7 & I6 \\
\hline
\end{tabular}

Respiratory тв rates are seriously underreported in I939-4I, as noted in the text. 
1939-41 Proportion of All Causes accounted for by Selected Leading Causes, 1939-41

Years Age at beginning of interval:

\begin{tabular}{lllllllllllllllll} 
Age & 0 & I & 5 & I0 & I5 & 20 & 25 & 30 & 35 & 40 & 45 & 50 & 55 & 60 & 65 & 70 \\
Males & 49.5 & 66.4 & 54.3 & 5 I.9 & 53.3 & $56 . I$ & 57.1 & 56.3 & 56.0 & 54.5 & 53.3 & 52.6 & 49.9 & 47.2 & 42.4 & 33.8 \\
Females & 50.7 & 66.2 & 57.8 & 54.2 & 44.7 & 45.3 & 49.2 & 43.4 & 40.7 & 4 I.I & 42.9 & 43.6 & 42.8 & 40.5 & 38.1 & 29.0 \\
\hline
\end{tabular}

Table i6. Sex Ratios of Age and Sex specific death rates of Taiwanese, All Causes and Selected Leading Causes, I939-4I. Male ASDR/Female ASDR.

1939-41 All Causes and Selected Leading Causes, 1924-26

Years Age at beginning of interval:

\begin{tabular}{lllllllllllllllll} 
& O & I & 5 & I0 & I5 & 20 & 25 & 30 & 35 & 40 & 45 & 50 & 55 & 60 & 65 & 70 \\
AllCaus & II9 & 9 I & I02 & II3 & II8 & I25 & I26 & I26 & I27 & I46 & I67 & I78 & I66 & I67 & I58 & I2I \\
Resp & I2I & 97 & I00 & 88 & I33 & I46 & I53 & I67 & I76 & 200 & 212 & 227 & I94 & 205 & I84 & I52 \\
Diarr. & I09 & 83 & 80 & 200 & 200 & I00 & I00 & I33 & I00 & I40 & I83 & 200 & I69 & I52 & I45 & II0 \\
Malar. & I08 & 90 & I00 & I33 & I50 & I75 & I20 & I20 & I40 & I40 & I60 & I29 & I29 & I33 & I30 & I00 \\
Resptв & I00 & 100 & I00 & I00 & I33 & I80 & I7I & 200 & 243 & 238 & 230 & 223 & 250 & 233 & 200 & I63 \\
\hline
\end{tabular}

average. Each cause of death leaves a distinctive imprint on the population that creates different patterns and levels of mortality across the age and sex groups.

While all causes decreased significantly, the most dramatic decline is in the malaria death rates. Malaria was a very significant leading cause in 1906-08, and its decline represents perhaps the greatest achievement of the Japanese public health effort in colonial Taiwan. As the substantial declines in the other cause groups demonstrate, the reduction in deaths rates was not by any means confined to malaria. Yet part of the decline in these other causes may be traced to the benefits of reduced comorbidity associated with malaria (and smallpox, whose near elimination preceded our data series). In general the pattern of decline occurring broadly across many causes simultaneously suggests that the benefits of reduced comorbidity from many diseases compounded the effects of limited public health efforts. Future study of temporal patterns of fluctuation to detect cause rates that increased and decreased together may shed light on which dis- 
eases were more tightly linked by comorbid relationships. That the same pattern

of broad decline was replicated in the separate prefectures (Shepherd "Regional" infra) underlines the likelihood that reduced comorbidity played an important role in the Taiwanese colonial mortality decline.

\section{Appendix: Issues of Reporting Quality in the Reports of Deaths by Cause in the Taiwan Population Record.}

Reports of cause of death by age and sex for the Taiwanese population are included in the annual volumes of vital statistics available from I905 to I942 (Taiwan jinkō dōtai tōkei). These volumes classify deaths according to a succession of four different cause of death lists. Because some previous studies ignored the issues of consistency introduced by changes between lists (drawing erroneous conclusions from inconsistent data), it is important to clarify the nature and significance of these changes for studies of long term trends in causes of death.

The Japanese devised an abridged version of the first revision of the international classification of causes of death in 1899 for use in Japan. This list provided for forty-six primary categories of disease and it was this list that was adopted for use in Taiwan in 1905 when the new household registration and vital statistics system was implemented following the first census (the following discussion of quality of cause of death reporting is drawn from the fuller discussion in Shepherd 2003).

Decennial revisions adopted by the International Commission regularly updated the international lists of causes of death. The second revision was adopted in 1909 , the third in 1920 , and the fourth in I929. While Japan had only adopted the abridged version of the first revision, it adopted both the much longer detailed lists and the intermediate or abridged lists when implementing the subsequent revisions. In Taiwan the detailed lists were used in tables reporting cause of death by age and sex, while the abridged or intermediate lists were most often used for statistics on cause of death by prefecture, season, ethnicity, and occupation. The periods during which Taiwan used the various revisions for vital statistics reporting and the numbers of causes in each list are presented in the table on the next page.

The successive revisions added categories by subdividing causes and creating new titles, as well as reclassifying causes according to updated medical understandings. Thus as time progressed, inconsistencies were introduced as the detailed list expanded and subcategories were reclassified. In many cases these inconsistencies can be minimized by broad groupings of subcategories that achieve continuity across the revisions. Thus we are not prevented by revisions in the international lists from following trends for causes consistently defined and reported. However, inconsistent implementation of the classifications by statistical personnel sometimes frustrates this task.

Another important source of inconsistency arises from misreporting due 
International

No. of Titles:

Years in use:

Classification:

$\begin{array}{lll}\text { Ist revision, I900 } & \text { Abridged: } 46+ & \text { I905-I9I5 } \\ \text { 2nd revision, I909 } & \begin{array}{l}\text { Intermediate: 6I } \\ \text { Detailed: } 2 \text { I7 }\end{array} & \text { I9I6-I922 } \\ \text { 3rd revision, I920 } & \begin{array}{l}\text { Abridged: } 38 \\ \text { Detailed: } 205\end{array} & \text { I923-I93I } \\ \text { 4th revision, I929 } & \text { Intermediate: } 85 & \text { I932-I942 } \\ & \text { Detailed: } 206 & \end{array}$

Source: Taiwan jinkō dōtai tōkei, various years.

to poor quality of diagnosis, the use of popular and imprecise terms in certificates, and inadequate training and education of the personnel authorized to certify causes of death. The Taiwan cause of death statistics were compiled at the central statistical office from tickets reporting the cause of death set forth in the death certificate which had to be completed before a burial permit would be issued to the family of the deceased (Appendix, Taiwan jinkō dōtai tōkei, I9०6, supp.I, p. 4, supp. 2, p. I). The Vital Statistics volume for 1906 explains that causes of death were to be certified by either of two classes of licensed medical practitioner. The 'first class doctors' (J: ishi, C: $y i$-shi, 醫師) were those who had received training in modern medical science (J: konnichi no igaku; C: jinri yixue, 近日醫學) (i.e. Western biomedicine) and the second class were Chinese-style traditional practitioners who had been licensed by the government-general (J: isei, C: yisheng, 醫生). Policemen also certified causes where no medical man was available.

The I906 Vital Statistics volume explains that the assignment of cause in many cases had to depend on Chinese-style doctors who were not well versed in modern medicine or modern systems of disease classification. These doctors often certified causes using popular or imprecise terms. It was up to statistical coders to classify terms used in the death certificates according to the title categories of the official nomenclature. In the first years of the reporting system, there were many cases where cause was assigned to the "ill-defined and unknown condition" titles. Often these were cases where the certifying practitioner was unfamiliar with the case and the circumstances leading up to death and uncertain as to cause of death. Cases also had to be assigned to the "ill-defined" title due to the use of an ambiguous name by a Chinese-style doctor.

Over time the increase in the number of trained modern doctors (and the 
\% of Total Causes certified by \% of Total Causes assigned to

first class doctors Senility and Ill-defined titles

\begin{tabular}{lllll} 
Year & Male & Female & Male & Female \\
I906 & $8.8 \%$ & $8.3 \%$ & $46.2 \%$ & $49.6 \%$ \\
I915 & 36.2 & 33.0 & I6.4 & I9.7 \\
I920 & 58.2 & 56.8 & 8.1 & 10.0 \\
I925 & 73.3 & 71.2 & 5.7 & 7.8 \\
I930 & 81.4 & 79.7 & 4.2 & 6.2 \\
I935 & 89.2 & 88.5 & 3.0 & 4.9 \\
\hline
\end{tabular}

Source: Taiwan jinkō dōtai tōkei. Taiwanese only.

decline in the number of licensed traditional practitioners) led to increases in the proportion of all causes certified by first class doctors, as shown in the table above. In 1906 only $8 \%$ of all causes were certified by modern doctors, but the proportion increased rapidly, to more than $56 \%$ by 1920 , and $89 \%$ by 1935 , the final year for which cause statistics were reported by class of doctor. Similar rapid improvement was made in reducing the numbers of deaths reported in the vague and imprecise categories "ill-defined and unknown" and "senility."

The rapid improvement in diagnosis quality documented in the table above was experienced broadly in all age and sex groups. As the quality of cause of death reporting increased, more and more causes became reliably and consistently reported. This increased comparability in the annual reports and enables us to assess historic trends in death rates by cause, age and sex. 

3

Mortality in the Netherlands: general development and regional differences

Theo Engelen \&

Marloes Schoonheim

Radboud University

Nijmegen, The Netherlands 
The decline of mortality in Europe throughout the nineteenth and twentieth centuries is generally referred to as the epidemiological transition. The first phase of the transition was a decline of mortality from a period of wars, pestilence and "famine" (Meuvret 1946; Flinn 198I) that had been characterized by both structurally high levels of mortality and incidental outbursts of very high mortality peaks, mainly following bad harvest years. In the second phase, declines in deaths due to infectious diseases brought a broad mortality decline. This lasted until well into the twentieth century, when mortality decreased to a low and stable level. During the third phase it was not the level of mortality that changed, but rather the character. Malnutrition and infectious diseases ceased to be the main causes of death. Instead, cardio-vascular diseases and cancer took their place as well as external causes like murder, suicide and accidents (Omran I97I and I983).

By the end of the eighteenth century, death was still in the first phase of this transition and thus at a high level, between 30 and 40 deaths per year per 1000 of the population. Population levels nevertheless remained approximately even due to high fertility rates. During epidemics of the plague, smallpox, typhoid, dysentery, malaria and tuberculosis, aggravated by subsistence crises, mortality exceeded fertility. Infants and the elderly were particularly vulnerable and during these epidemics the population in parts of Europe could be decimated. In the Netherlands, though, the effects of the epidemics were not as disastrous as they could be elsewhere in Europe. Dutch agriculture had long been highly commercialized and the various parts of the country were as well connected with each other as with other countries, resulting in a steady supply of food.

It has proven impossible to point out a single reason for the decline of mortality that marked the second phase of the epidemiological transition. The mortality decline started at the time of industrialization, which entailed unhealthy working conditions and unsanitary, crowded living conditions in the cities, which could hardly have improved the health of the population. On the other hand we know that the agrarian revolution that preceded industrialization, as well as the economic growth that resulted from it, improved the standard of living considerably. Thomas McKeown has argued that the improvement in the availability of food was the most important reason for the decrease of mortality (McKeown 1976). Other scholars have pointed at improvements in living conditions, access to clean drinking water and medical care (Preston 1975). According to Simon Szreter it was mostly the new organization of health care that curtailed death rates, including vaccination against smallpox. More and more local governments implemented ideas concerning public health by developing sanitary systems and safe water supplies (Szreter 1988). Both McKeown and Szreter, however, argue that increased welfare was the decisive factor in declining mortality rates. More recently social-cultural influences on the transition have received 

(in five-yearly periods)

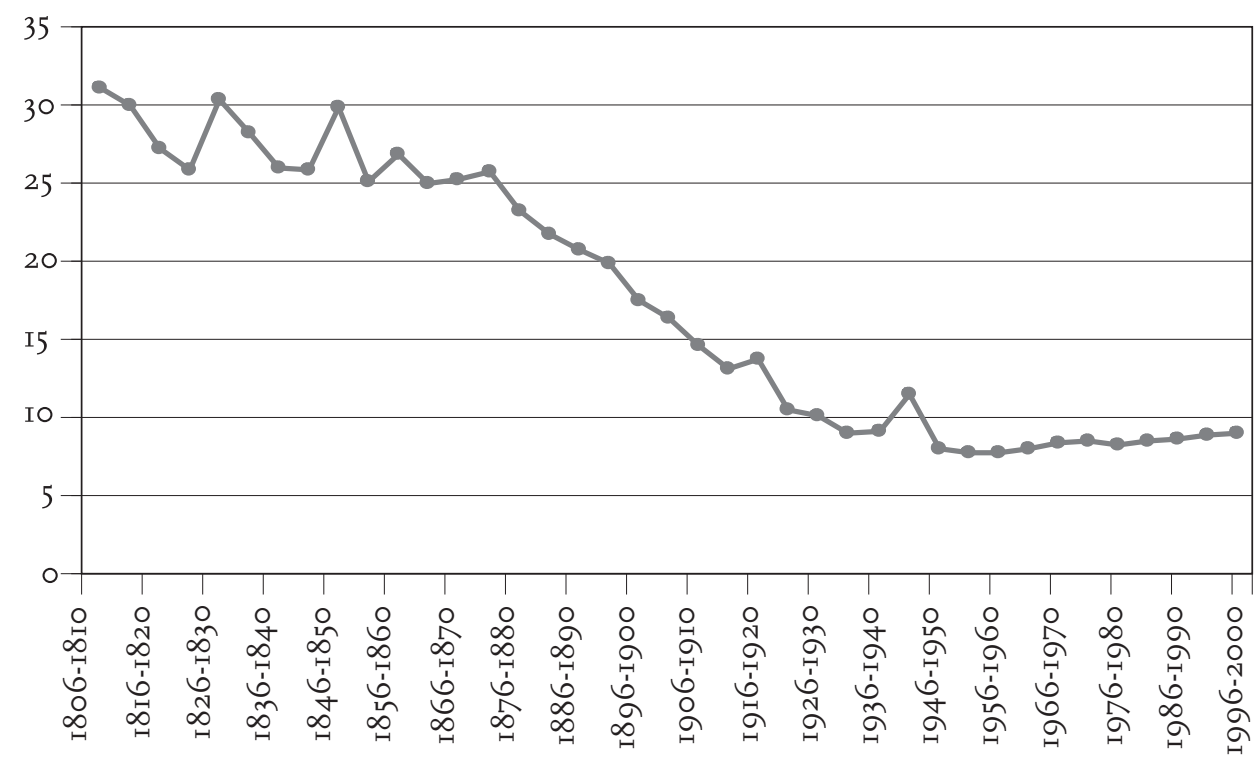

Source: until I975: Hofstee, Korte demografische geschiedenis, I22-I23; I975-I990: Historische Databank Nederlandse Gemeenten; I990-2000: Свs, Statline.

scholarly attention. It has been suggested that new ideas regarding hygiene were taken on faster because of secularization and rationalization of the society at large, as well as the increasing literacy of the population (Preston and Haines I99I; Corsini and Viazzo I997).

Graph I shows the development of Dutch mortality in the nineteenth and twentieth centuries. Until approximately 1850 , mortality in the Netherlands matched the characteristics of the first part of the epidemiological transition. The death rate was lower than in the 18 th century, but it remained at a relatively high level and showed strong fluctuations. Structural decline started around I875 and the lowest level of mortality was reached in I950 with 7.6 deaths per Iooo of the population. Only the First and Second World Wars disturbed the development and caused small increases in death rates. Due to ageing of the population, mortality has increased moderately since the ig6os. The changing cause-of-death pattern behind this development is dealt with by Frans van Poppel (this volume). Here we concentrate on the regional differences. Map I shows the Netherlands and the eleven provinces within the country.

Regional differences in mortality have played an important role in the demographic history of the Netherlands. Looking at the municipal mortality levels of 1850 


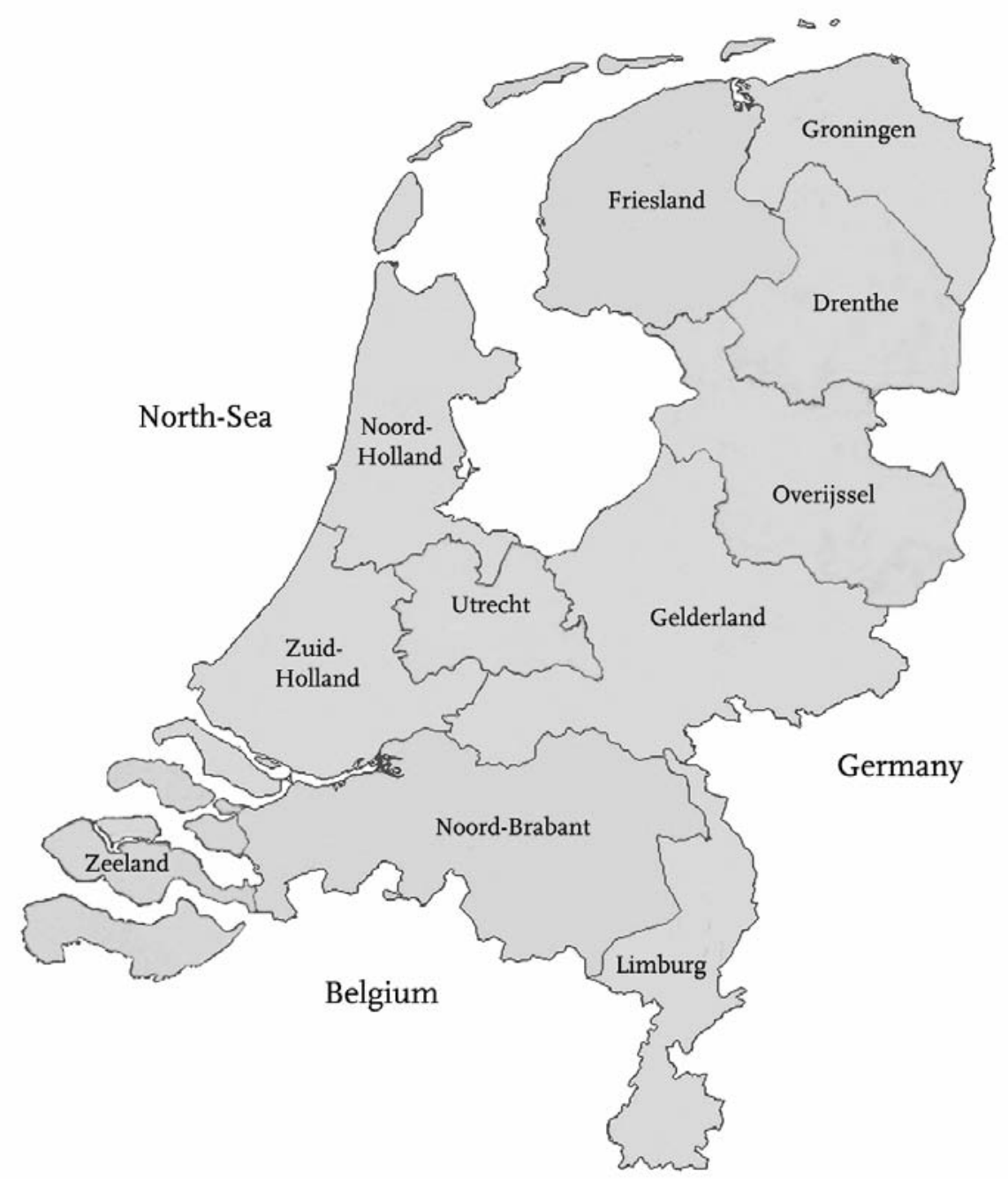

(see map 2), E.W. Hofstee noticed a concentration of high levels of mortality in the alluvial areas of Noord- and Zuid-Holland, Zeeland, the western part of Utrecht, Groningen and Friesland. Hofstee suggested three factors to explain the regional differences. For one, the soil in these areas suffered from salination. This provided an excellent habitat for the malaria mosquito and in addition it led to a shortage of high quality drinking water. The third cause for the high mortality, according to Hofstee, was urbanization that resulted in high concentrations of people.

Though epidemics of malaria no longer occurred after I830, mortality in the west of the country remained high until I875 because of high levels of infant and 
child mortality. After I875 mortality declined rapidly, particularly in these western

provinces. By 1900 the mortality rates of Zuid-Holland and Zeeland already were the lowest in the country. Still, salination, bad quality surface water and urbanization had not disappeared and the large-scale construction of the water supply system had not yet started. Again it appears to be changes in mortality among the youngest age groups (I to 5 years) that caused the difference: enteritis and other kinds of diarrhea declined fastest in the west. According to Hofstee, an improvement in hygienic conditions had caused this development. A 'modern pattern of culture' that included eagerness to change traditional ideas and life styles emerged in the northwest and only later spread to the southeast of the country.

Between I845 and I885 regional variation in mortality thus changed dramatically. Maps 2 and 3 show that the concentration of high mortality rates in the west and north of the country declined while the province of Gelderland (especially the regions Veluwe and Achterhoek), the eastern part of Noord- Brabant (de Peel, de Meijerij, Maaskant) and the province of Limburg (Noord-Limburg and the Mijnstreken) emerged as high-mortality areas. Map 4, showing the situation in I935, indicates that the populations of Zeeland, Zuid-Holland and the southern part of Noord-Holland, formerly high-risk areas, were now relatively well off. The provinces of Noord-Brabant, Limburg, Gelderland, Overijssel, and Friesland all showed relatively high mortality rates in I935. The development of regional variation in Dutch mortality, therefore, seems to have two characteristics. First, there has been a switch of provincial rankings, and, secondly, a convergence. This convergence is reflected in graph 2, which shows that the differences between the provinces were most pronounced in the first half of the nineteenth century. From I875 onwards the regional differences declined and almost disappeared in the twentieth century. Graph 3 shows the provincial variation in mortality compared to the Dutch average (o) and shows even more clearly the convergence in provincial mortality levels. Moreover, the graph shows a remarkable development in the south of the country: in the years leading up to I89o mortality levels in Limburg and Noord-Brabant moved from below average to a level above the national average. The difference disappeared in the I930s when mortality in the southern provinces declined to a level of mortality just as low as the national average.

\section{Infant and child mortality}

The contribution of infant mortality to the development of the total Dutch mortality has been of considerable importance, particularly in the nineteenth century. The trend in levels of infant mortality differed from that of total mortality. While the latter stabilized and declined slightly until I875, the survival chances of children below the age of I deteriorated in the third quarter of the century. Research indicates that between 1840 and 1870 infant mortality increased in 


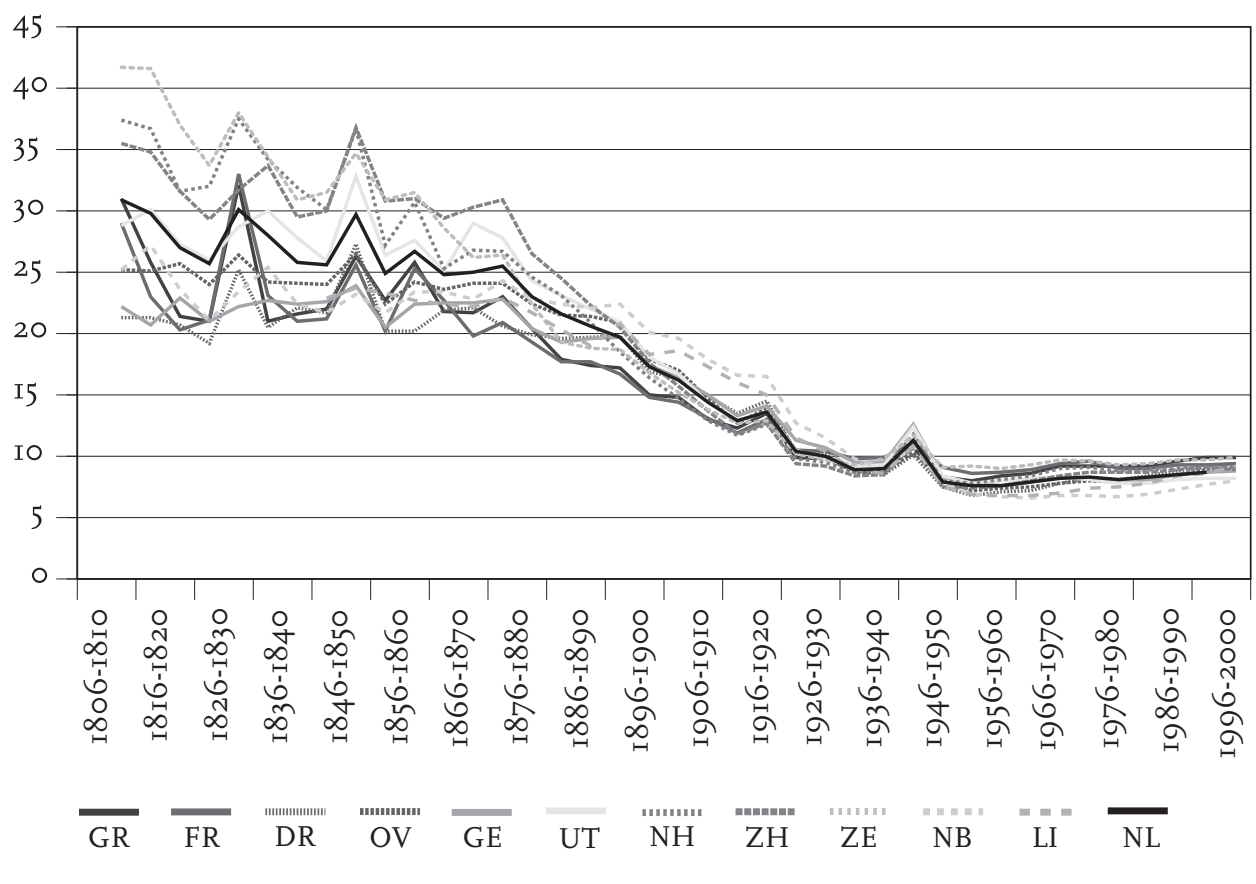

many European countries, Germany (Knodel I988), France (Vallin I99I) and Spain (Reher et al. 1997). The Netherlands was no exception: Van Poppel and Mandemakers found that between I840 and I876 Dutch infant mortality increased tremendously (Van Poppel and Mandemakers 1997).

Graph 4 shows the trend of the infant mortality rate. On a national level infant mortality increased to more than 200 in the middle of the I870s, after which it declined rapidly. Although this development showed considerable regional variations, the pattern of increase followed by decline remained basically the same. The question remains why infant mortality increased in the third quarter of the nineteenth century, and why this increase switched into a decrease after I875.

Those who witnessed the increased infant mortality with their own eyes formed opinions as to its underlying causes. As early as I809, king Louis Napoleon had issued a decree encouraging mothers to breastfeed their babies. Medical men at the start of the twentieth century came to the same conclusion. Infant mortality was at its highest level during the summer months, which nineteenth and twentieth century scholars attributed to digestive problems (Hoogerhuis 2003: 4-I2). Recent research in the city of Tilburg indicated that infant mortality was usually caused by diseases like diarrhea, particularly during warm summer months (Van der Heijden I995: I72 and I88-189). These causes 


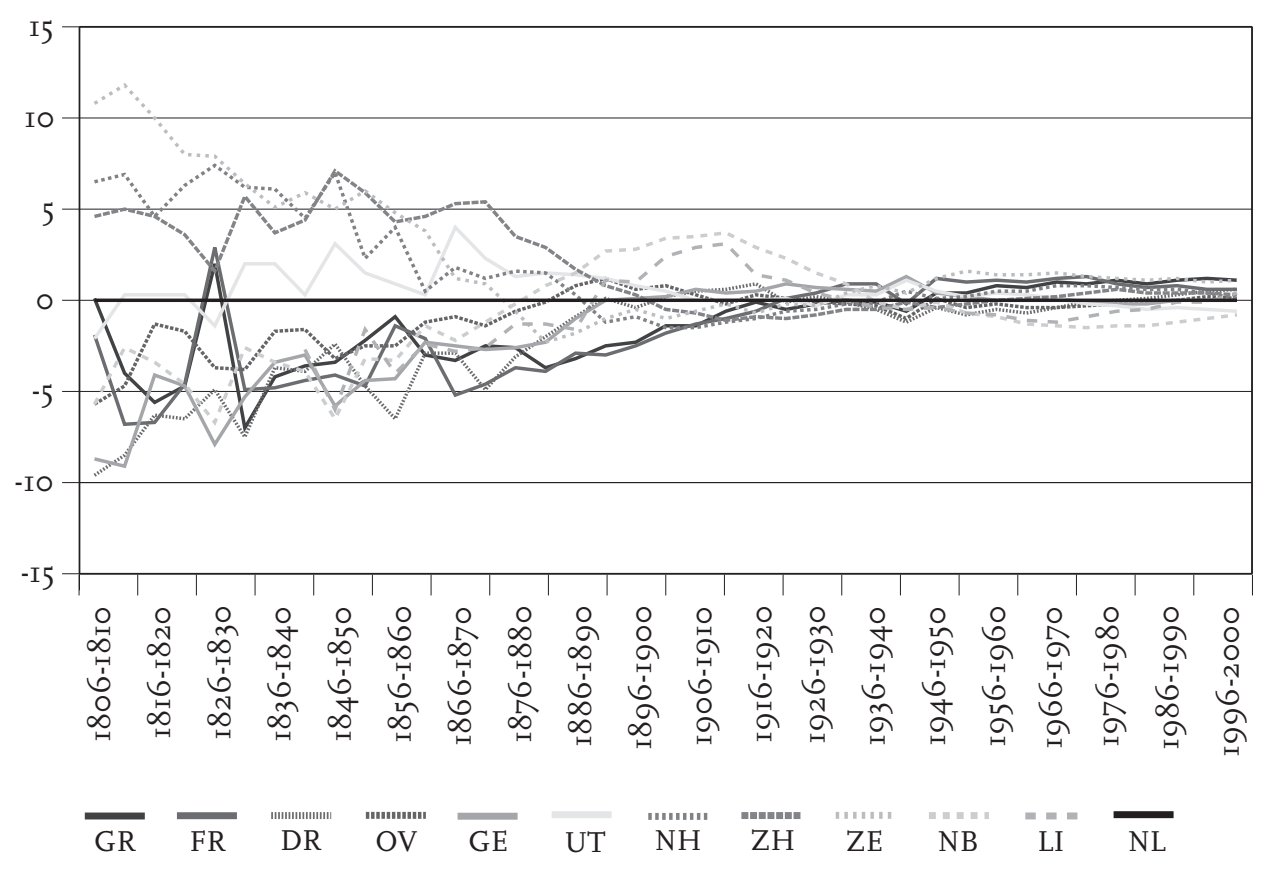

of death are also mentioned in a national qualitative analysis for the period I903I907, when nearly $33 \%$ of all infant deaths in the Netherlands were ascribed to intestinal problems, against almost $15 \%$ that died of respiratory diseases (Methorst 1909). Research on infant mortality in Paris in I898 also showed an increased risk for infants that were given bottled milk as opposed to those given breast milk (Pollet I997: 224). Similar research was done in the Netherlands (Jonkers I903:38; Hoogerhuis 2003:I2I-I26).

Does the research on the importance of breastfeeding provide a clue to the regional differences in Dutch mortality? When infant mortality declined between I875 and 1900, we once more notice a strong difference between the southwest and northeast of the country. The provinces of Zeeland, Noord-Holland and particularly Zuid-Holland were high-risk areas for infants. A quarter of a century later the regional difference had shifted to a north-south dichotomy. At the start of the twentieth century, infant mortality was highest in Noord-Brabant, followed by Limburg, Zeeland and Zuid-Holland (Wolleswinkel-van den Bosch et al. 2000: I034). Utrecht was the only province that showed a high infant mortality rate throughout both periods. The absolute number of infant deaths per tooo live births in the period I875-I879 was: Zuid-Holland 259, Utrecht 234, Zeeland 224, Noord-Holland 209 and Noord-Brabant 206. The national average was I98. 


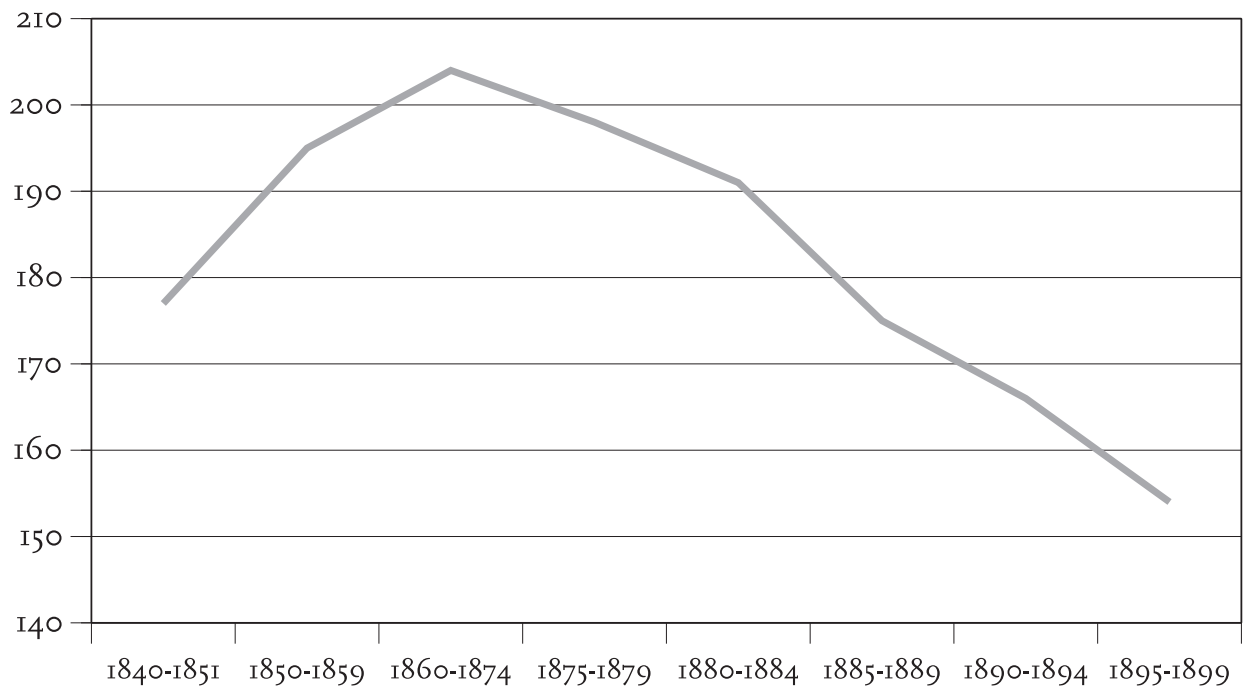

Source: Hofstee, Korte demografische geschiedenis, I34-I35.

During the years $1890-99$, the overall rates declined but the ranking changed into Noord-Brabant 204, Zuid-Holland I80, Utrecht I77, Zeeland I74 and Limburg I7I, with a national average of I60 (Hofstee I98I: I34-I35).

Graph 5 shows the provincial levels for the crucial period in the development of infant mortality, and focuses on their relative deviation from the national average. The level of infant mortality in the northern and northeastern provinces of Groningen, Friesland, Drenthe, Overijssel and Gelderland was always below the national average. Infants in Zeeland, Zuid-Holland, NoordHolland and Utrecht on the other hand had a lower survival chance - though the values for Zeeland, Zuid-Holland and Noord-Holland decreased during this period. The most striking development is in Noord-Brabant and Limburg. Initially, infant mortality rates were lower than in other provinces, but when rates in other provinces started to decline, infant mortality in Noord-Brabant and Limburg increased both relatively and absolutely (see Appendix Table 2). According to Hofstee, the high infant mortality in the west of the country was caused by polluted water used for food that replaced breast milk. Chr. Vandenbroeke, F. van Poppel and A. van der Woude took up this point and argued that in various parts of the Low Countries (Noord-Brabant, Belgian and Dutch Limburg, Luik and Antwerpen) the period of breast feeding was shorter because of female labor participation (Vandenbroeke et al. I98r: 484-489).

Another possibility concerns the differences in pace and intensity of the 

(relative numbers; Nederland $=100$ )

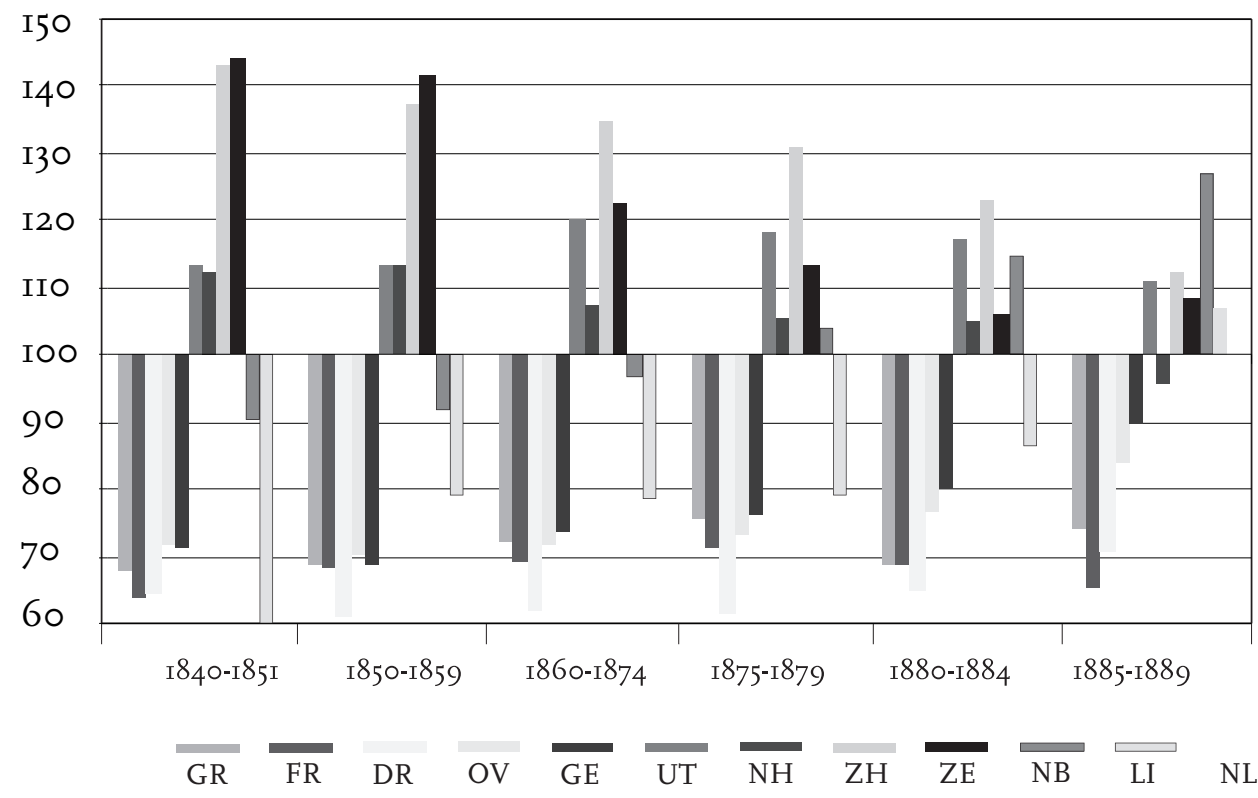

Source: Hofstee, Korte demografische geschiedenis, I34-I35.

economic modernization of the Netherlands. Van Poppel and Mandemakers argued that although infant mortality had been high among all nineteenth century social groups, there were considerable differences. Families of the middle and upper class had more money to increase the life chances of their children, by changing hygienic conditions, better quality drinking water, and an improved sewer system (van Poppel and Mandemakers I997: 298-299). Research on a town in the province of Zeeland also showed social differences in infant mortality (Hoogerhuis 2003: I43-I46). A more recent research differentiates these results, and showed that in all provinces infant mortality among the lower class was higher than in other classes. Infants of farmers as well as the petty bourgeoisie had the best chances of survival. Regional factors, however, have a stronger effect than social variations: in Friesland even the lowest social groups had lower infant mortality rates than the highest social groups in Utrecht and Zeeland. The general well-being of the population (the quality of the drinking water, hygienic conditions) and the length of the breastfeeding period probably caused regional differences in infant mortality (Van Poppel et al. 2005: 303-306).

Some authors are convinced that religious denomination of the population also affected the levels of infant mortality, as was shown in a study on 
Holland between I855 and I9ı2 by Van Poppel, Schellekens and Liefbroer (2002: 277). As mentioned before, infant mortality increased in the two Catholic provinces of the country during the last quarter of the nineteenth century. It has been suggested that the adverse development in Noord-Brabant and Limburg, contrary to the national declining trend, was caused by small birth intervals and consequently care that had to be shared with more siblings (De Sweemer i984; Conde-Agudelo et al. 2006; Ellison 200I). Catholics, these authors argue, were also less prone to accept new insights on hygiene and medical care, which were already accepted by socialists, liberals and even Protestants. Finally, breastfeeding was less accepted among Catholics than other groups, because of matters of sexuality, shame and the taboo on baring the female body (Wolleswinkel et al.20or: I037-1038).

\section{Summary}

The decline of mortality marked a demographic revolution in the Netherlands, as elsewhere in Europe. We noticed, however, that this revolution was clearly regionally differentiated. When we look at the development for the country as a whole we find similar processes as elsewhere in Europe. Improvements in food production and new insights into the causes of diseases date back to the eighteenth century. Mortality declined from I875 onwards, but until I9I7 declines in infant mortality most affected the general rates. Cultural causes for this development were gradually replaced by economic variables. From the First World War onwards the character of the mortality decline changed: the decrease sped up until I955 and mostly adults profited. Between I955 and I970 mortality declined more gradually. Along with mortality rates, life expectancy improved in the Netherlands. During the first half of the nineteenth century life expectancy at birth was around 40 years; which increased to 80 years in the second half of the 2oth century for both men and women. Putting infant mortality aside, life expectancy at age I increased by Io years between I800 and I850.

The concept of the epidemiologic transition emphasizes the decline of infectious diseases and the relative increase in old age diseases and external causes of death. Indeed, deaths attributed to infections caused by polluted water, lowquality food and bad hygienic conditions decreased between I875 and i925. The prevalence of respiratory diseases, however, declined at a much slower rate. Deaths due to infectious diseases like bronchitis and pneumonia only declined after the introduction of antibiotics, after the Second World War. Of course, the degree of the decline of mortality and the causes of death differed for men and women but in particular among social groups, caused by differences in behavior, life style and availability of health care (Mackenbach i994).

An important determinant of the mortality decline was the trend in infant mortality, which increased between 1840 and 1876 and then fell rapidly in the fol- 
lowing fifty years. The development of infant mortality was similar to that in the

rest of Western Europe and was affected by changing breastfeeding patterns, which proved decisive in the survival chances of infants. In addition, deteriorating hygienic circumstances (partly as a result of urbanization) affected the levels of infant mortality. Large regional differences characterized the development of infant mortality in the Netherlands. Before 1875 infant mortality rates in the southwest of the country (Zeeland, Zuid-Holland and parts of Noord-Holland and Utrecht) were higher than the national average. Infants were better off in the north and east of the country. This changed, however, and until Igoo infant morality increased in the southern provinces of Noord-Brabant and Limburg, where rates exceeded the national average. The regional divergence in the development of infant mortality is partly explained by salination and low-quality drinking water that kept infant mortality high in the west of the country before I875. During the last decades of the I9th century, however, a 'modern culture pattern' emerged, spreading medical care and improved hygienic conditions from the northwest of the country to the southeast. That Catholics inhabited the two southern provinces of the country is related to their level of infant mortality, according to some authors. The slow acceptance of the modern culture that had so many non-Catholic elements, as well as the taboo on breastfeeding affected the life chances of infants in that part of the Netherlands. 


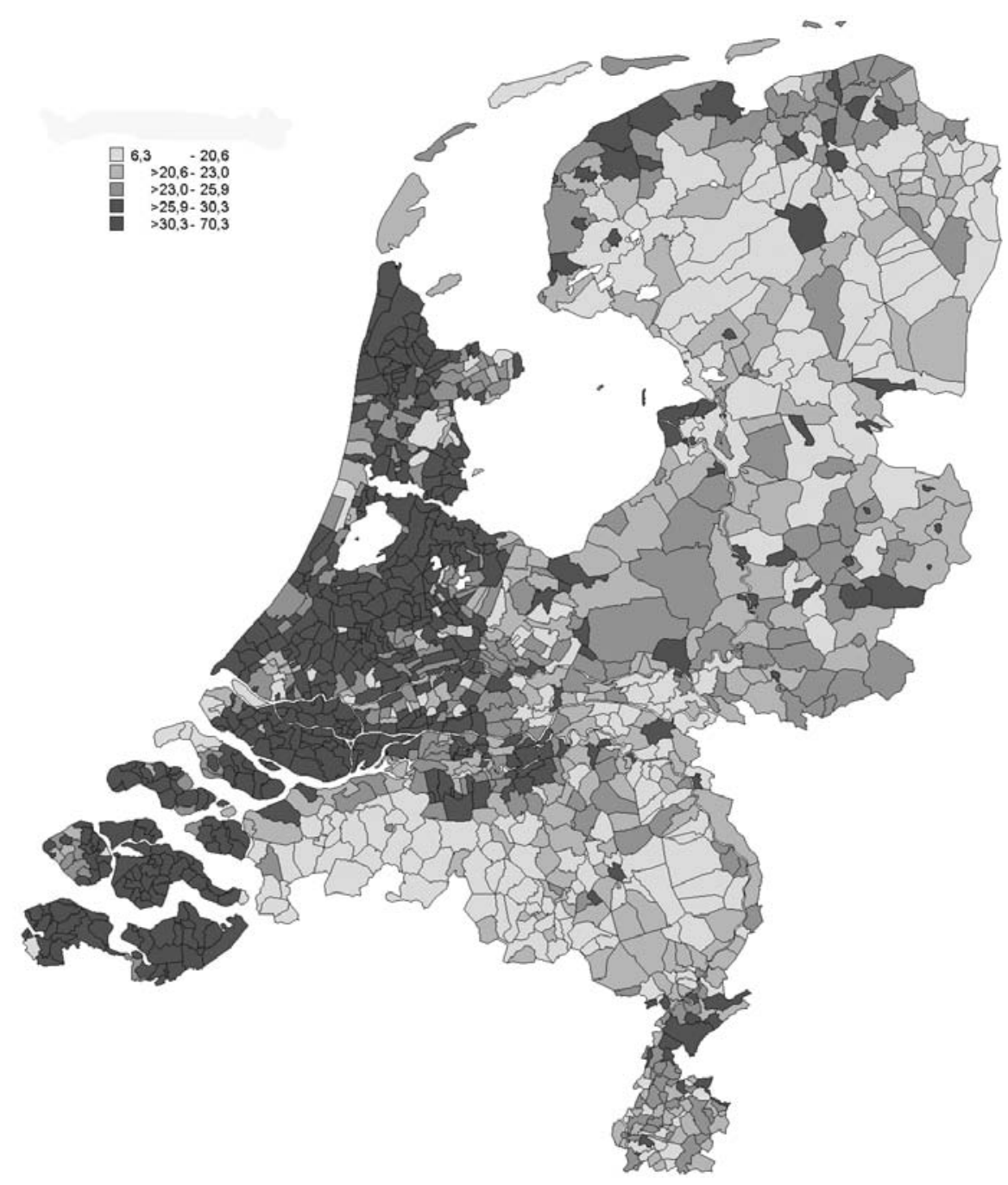




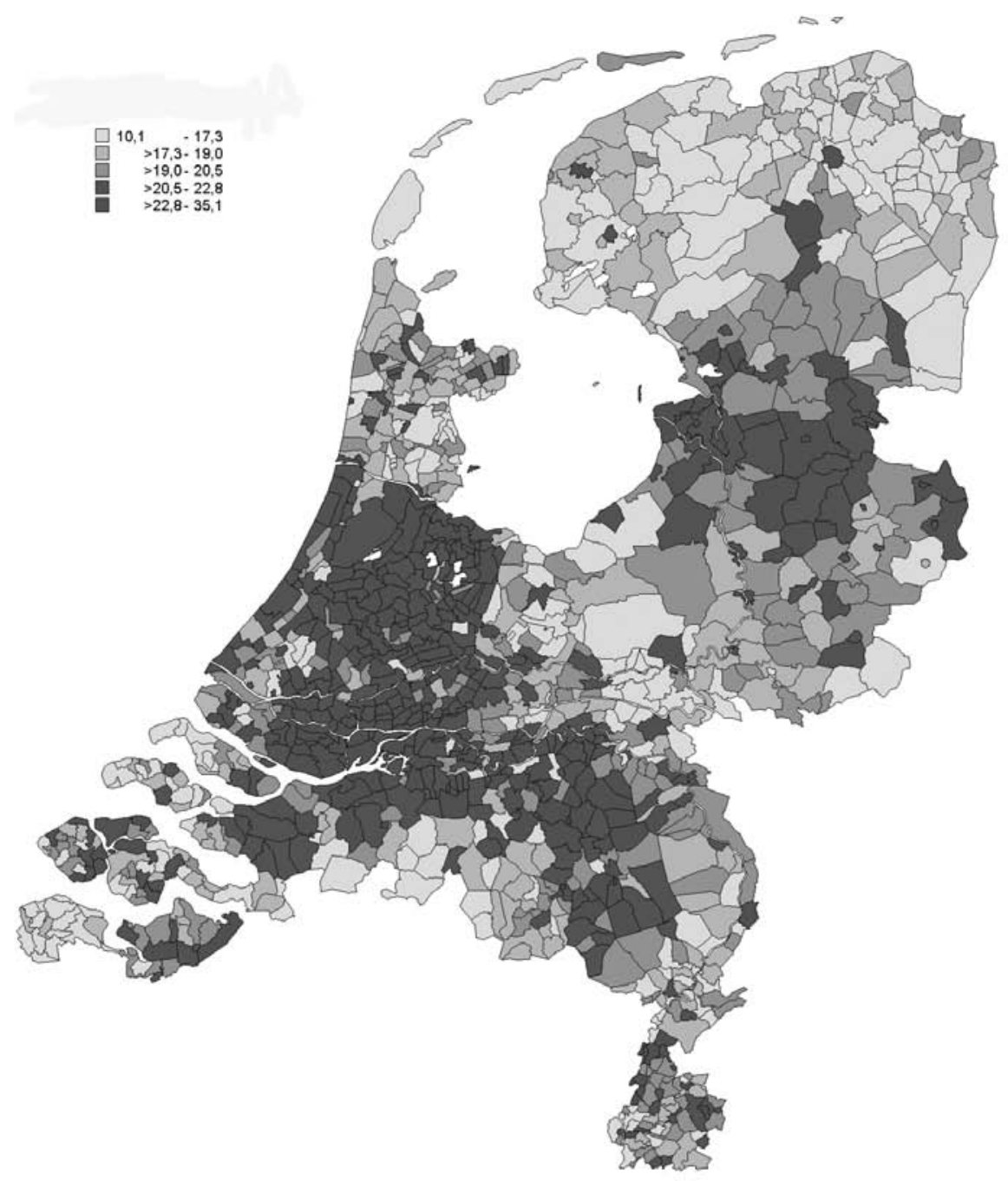




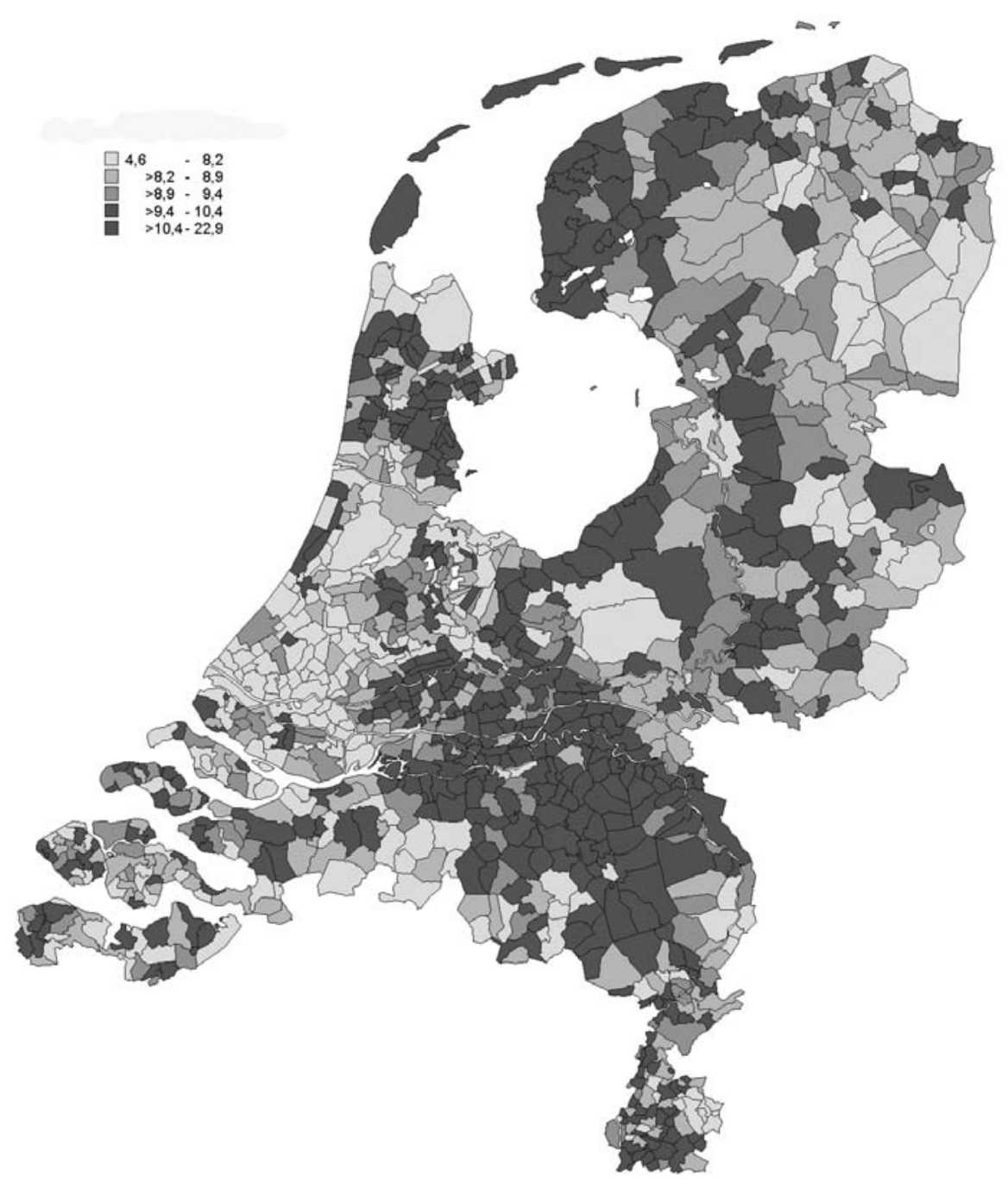




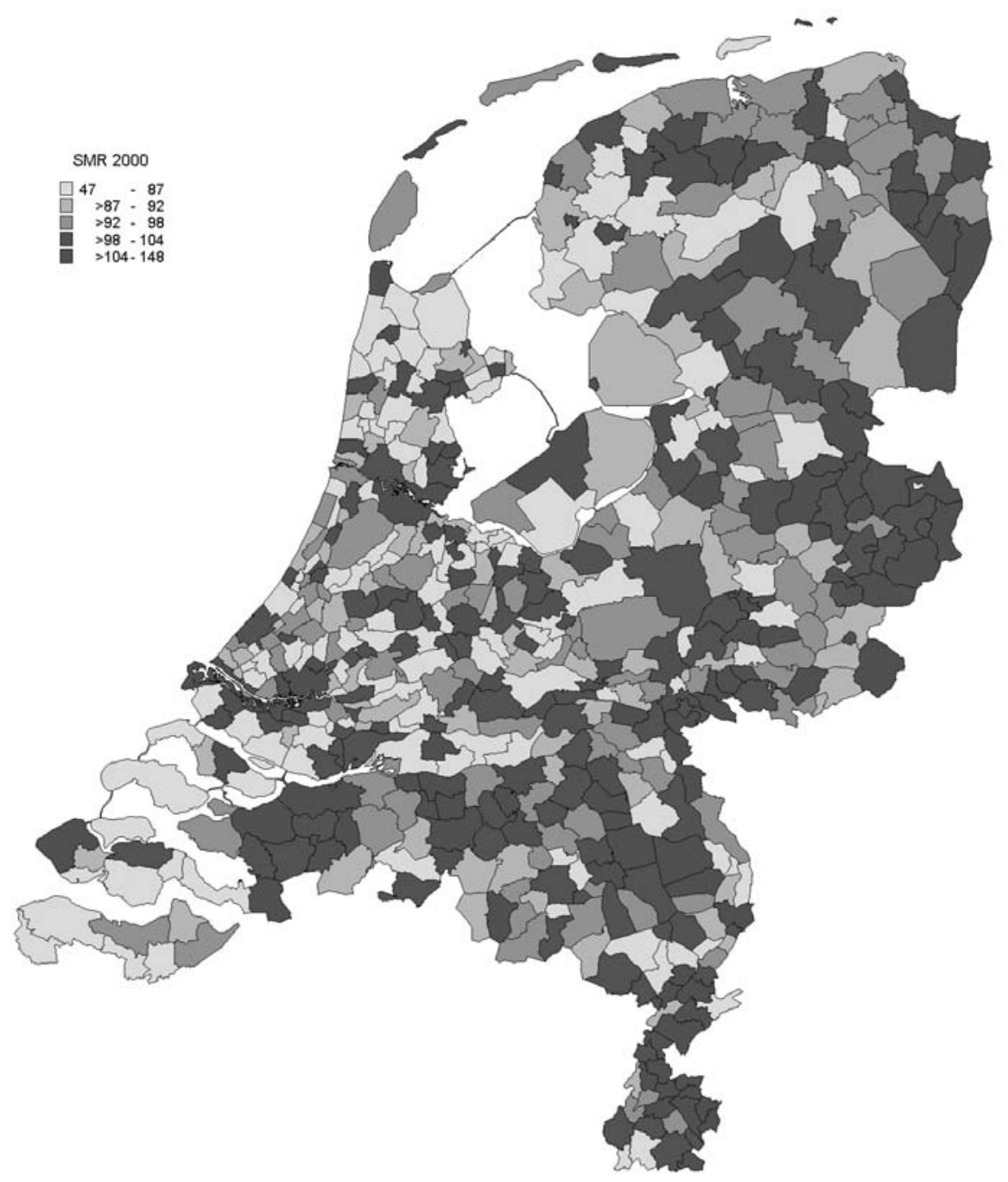




\begin{tabular}{|c|c|c|c|c|c|c|c|c|c|c|c|c|}
\hline & GR & $\mathbf{F R}$ & DR & OV & GE & UT & NH & ZH & $\mathbf{Z E}$ & NB & LI & NL \\
\hline I8০6-I8Iо & 31.0 & 29.0 & $2 \mathrm{I} .3$ & 25.2 & 22.2 & 28.8 & 37.4 & 35.5 & 4I.7 & 25.2 & & 30.9 \\
\hline I8II-I8I5 & 25.8 & 23.0 & $2 \mathrm{I} .3$ & $25 . \mathrm{I}$ & 20.7 & 30.1 & 36.7 & 34.8 & 4I.6 & 27.2 & & 29.8 \\
\hline I8I6-I820 & $2 \mathrm{I} .4$ & 20.3 & 20.7 & 25.7 & 22.9 & $27 \cdot 3$ & 3г.6 & 31. 6 & 37.0 & 23.6 & & 27.0 \\
\hline I82I-I825 & 21.0 & 2I.I & 19.2 & 24.0 & $2 \mathrm{I} .0$ & 26.0 & 32.0 & $29 \cdot 3$ & 33.7 & 2I.I & & 25.7 \\
\hline I826-I830 & 32.1 & 33.0 & 25.2 & 26.4 & 22.2 & 28.7 & 37.5 & 3I.7 & 38.0 & 23.4 & & 30.I \\
\hline I83I-I835 & $2 \mathrm{I} .0$ & 23.I & 20.5 & 24.2 & 22.7 & 30.0 & 34.2 & $33 \cdot 7$ & $34 \cdot 4$ & 25.4 & & 28.0 \\
\hline I836-I840 & 2I. 6 & 21.0 & $22 . \mathrm{I}$ & $24 . I$ & 22.4 & 27.8 & 31.9 & 29.5 & 30.9 & 22.4 & & 25.8 \\
\hline I84I-I845 & 22.0 & $2 \mathrm{I} .2$ & 21.7 & 24.0 & 22.6 & 25.9 & 30.I & 30.0 & 3I. 5 & $2 \mathrm{I} .7$ & 22.9 & 25.6 \\
\hline I846-I850 & 26.3 & 25.6 & $27 \cdot 3$ & 26.5 & 23.9 & 32.8 & 36.7 & 36.8 & 34.7 & 23.2 & 23.7 & 29.7 \\
\hline I85I-I 855 & 22.7 & 20.2 & 20.2 & 22.4 & 20.5 & 26.4 & 27.2 & 30.8 & 30.9 & $2 \mathrm{I} .7$ & 23.3 & $24 \cdot 9$ \\
\hline I856-I860 & 25.8 & 25.3 & 20.2 & 24.2 & 22.4 & 27.6 & 30.7 & 31.0 & 31.5 & 23.4 & 22.7 & 26.7 \\
\hline I86I-I865 & 21. 8 & 22.7 & 2I.9 & 23.6 & 22.5 & $25 \cdot \mathrm{I}$ & $25 \cdot 3$ & 29.4 & 28.6 & 23.4 & 22.4 & 24.8 \\
\hline I866-I870 & $2 \mathrm{I} .7$ & I9.8 & $22 . \mathrm{I}$ & $24 . I$ & 22.5 & 29.0 & 26.8 & 30.3 & 26.2 & 22.8 & 22.2 & 25.0 \\
\hline I87I-I875 & 23.0 & 20.9 & 20.6 & $24 . I$ & 22.8 & 27.8 & 26.7 & 30.9 & 26.4 & $24 \cdot 3$ & 22.9 & 25.5 \\
\hline I876-I880 & 20.4 & I9.3 & 19.9 & 22.4 & 20.4 & $24 \cdot 3$ & 24.6 & 26.5 & 22.4 & 22.8 & $2 \mathrm{I} .7$ & 23.0 \\
\hline I88I-I885 & 17.9 & I7.7 & 19.6 & $2 \mathrm{I} .5$ & 19.3 & 23.1 & $23 . I$ & 24.5 & 19.3 & 22.4 & 20.3 & 2I.6 \\
\hline I886-I890 & $I 7 \cdot 4$ & $\mathrm{I} 7.7$ & I9.7 & $2 \mathrm{I} .4$ & I9. 6 & 22.0 & 20.9 & 22.3 & І 8.8 & $22 . \mathrm{I}$ & 19.0 & 20.6 \\
\hline I89I-I895 & I7. 2 & 16.7 & I9. 8 & 20.9 & I9.7 & 20.9 & $\mathrm{I} 8.5$ & 20.5 & I8.7 & 22.4 & 20.8 & 19.7 \\
\hline I896-I9०o & I5.0 & $\mathrm{I} 4.8$ & 16.9 & 17.9 & $\mathrm{I} 7.4$ & I8.I & I6.4 & I7.6 & I6.8 & 20.I & I 8.3 & $\mathrm{I} 7 \cdot 3$ \\
\hline I9OI-I9O5 & I 4.8 & $\mathrm{I} 4.4$ & I6.4 & I7.0 & I6.4 & 16.7 & $\mathrm{I} 4.7$ & I5.7 & $\mathrm{I} 5.2$ & 19.6 & I8.6 & 16.2 \\
\hline I9०6-I9ıо & 13.0 & I3.I & I 4.9 & $\mathrm{I} 4.7$ & I5.0 & $\mathrm{I} 4.4$ & I2.9 & $\mathrm{I} 3.7$ & $\mathrm{I} 3.8$ & $17 \cdot 9$ & $\mathrm{I} 7 \cdot 3$ & $\mathrm{I} 4.4$ \\
\hline I9II-I9I5 & I 2.3 & II.9 & $\mathrm{I} 3.5$ & I2.7 & I3. 3 & I2.9 & II.7 & II. 8 & I 2.7 & I6.6 & 16.0 & 12.9 \\
\hline I916-I920 & I3. 5 & I3.O & $\mathrm{I} 4.5$ & 13.9 & I4.I & I3.6 & $\mathrm{I} 2.6$ & $\mathrm{I} 2.7$ & I2.9 & I6.5 & I5.0 & 13.6 \\
\hline I92I-I925 & $9 \cdot 9$ & IO. 5 & IO. 3 & IO. 5 & II. 3 & 10.5 & 9.8 & 9.4 & 10.2 & $\mathrm{I} 2.7$ & II. 5 & I0.4 \\
\hline 1926-1930 & 9.8 & IO. 4 & 10.2 & $9 \cdot 9$ & IO.7 & 9.7 & 9.5 & 9.2 & 9.7 & II. 5 & 10.4 & IO.O \\
\hline I93I-I935 & 8.9 & 9.8 & 8.8 & 8.7 & $9 \cdot 5$ & 9.2 & 8.7 & 8.4 & $9 \cdot 3$ & 9.8 & 8.9 & 8.9 \\
\hline I936-I940 & 8.9 & $9 \cdot 9$ & 8.5 & 8.7 & 9.5 & $9 \cdot 3$ & 8.9 & 8.5 & 9.8 & 8.9 & 8.6 & 9.0 \\
\hline I94I-I945 & IO.7 & II.I & IO.I & IO. 3 & I2. 6 & $\mathrm{I} 2.4$ & II. 8 & II. 2 & II.7 & Io. 8 & Io. 8 & II. 3 \\
\hline I946-I950 & 8.3 & 9.1 & $7 \cdot 5$ & 8.0 & 8.3 & 8.4 & 8.0 & 7.5 & 9.I & 7.8 & $7 \cdot 5$ & $7 \cdot 9$ \\
\hline I95I-I955 & 8.0 & 8.6 & 6.8 & 7.2 & 7.8 & 7.8 & 7.8 & 7.4 & 9.2 & 6.9 & 6.9 & 7.6 \\
\hline 1956-1960 & 8.4 & 8.7 & 7.I & $7 \cdot 4$ & 7.6 & 8.0 & 8.I & $7 \cdot 6$ & 9.0 & 6.7 & 6.8 & 7.6 \\
\hline I96I-I965 & 8.6 & 8.9 & 7.2 & $7 \cdot 5$ & $7 \cdot 9$ & 8.2 & 8.4 & 8.0 & $9 \cdot 3$ & 6.6 & 6.8 & $7 \cdot 9$ \\
\hline I966-I970 & 9.2 & 9.4 & 7.8 & 7.8 & 8.3 & 8.3 & 9.0 & 8.4 & 9.7 & 6.8 & 7.0 & 8.2 \\
\hline I97I-I975 & 9.2 & 9.6 & 8.2 & 8.0 & 8.2 & 8.I & 9.I & 8.7 & 9.6 & 6.8 & $7 \cdot 4$ & 8.3 \\
\hline I976-I980 & 9.2 & 9.0 & 8.I & $7 \cdot 9$ & $7 \cdot 9$ & 7.8 & 8.8 & 8.7 & $9 \cdot 3$ & 6.7 & $7 \cdot 5$ & 8.I \\
\hline I98I-I985 & 9.2 & 9.0 & 8.4 & 8.2 & 8.I & 7.8 & 8.9 & 8.7 & 9.4 & 6.9 & 7.8 & 8.3 \\
\hline I986-I990 & 9.6 & $9 \cdot 3$ & 8.8 & 8.5 & 8.5 & 8.I & 9.I & 8.9 & 9.7 & $7 \cdot 3$ & 8.4 & 8.5 \\
\hline I99I-I995 & $9 \cdot 9$ & $9 \cdot 3$ & 9.2 & 8.9 & 8.7 & 8.2 & 9.I & $9 . \mathrm{I}$ & 9.7 & $7 \cdot 7$ & 8.6 & 8.7 \\
\hline $1996-2000$ & 9.9 & 9.4 & 9.4 & 8.9 & 8.8 & 8.2 & 8.9 & $9 . \mathrm{I}$ & 9.9 & 8.0 & 9.2 & 8.8 \\
\hline
\end{tabular}

Source: until I975: Hofstee, Korte demografische geschiedenis, p. I22-I23; I975-I990: HDNG; I990-2000: CBS, Statline

GR=Groningen. FR=Friesland. DR=Drenthe. ov=Overijssel. $\mathrm{GE}=$ Gelderland. $\mathrm{UT}=$ Utrecht. NH=Noord-Holland. $\mathrm{ZH}=$ Zuid-Holland. $\mathrm{ZE}=$ Zeeland. $\mathrm{NB}=$ Noord-Brabant. LI=Limburg. $\mathrm{NL}=$ The Netherlands. 


\begin{tabular}{lcccccccccccc} 
& GR & FR & DR & OV & GE & UT & NH & ZH & ZE & NB & LI & NL \\
I840-I85I & I20 & I13 & II4 & I27 & I26 & 20I & I99 & 253 & 255 & I60 & I06 & I77 \\
I850-I859 & I34 & I33 & II9 & I37 & I34 & 22I & 22I & 268 & 276 & I79 & I54 & I95 \\
I860-I874 & I47 & I4I & I26 & I46 & I50 & 245 & 2 I9 & 275 & 250 & I97 & I60 & 204 \\
I875-I879 & I50 & I4I & I22 & I45 & I5I & 234 & 209 & 259 & 224 & 206 & I57 & I98 \\
I880-I889 & I26 & I25.5 & II8.5 & I40.5 & I46.5 & 2 I4 4.5 & I92 & 225.5 & I93.5 & 2 I0 & I58.5 & I83 \\
I890-I899 & II9 & I04.5 & II3.5 & I34.5 & I44 & I77.5 & I53.5 & I79.5 & I73.5 & 203.5 & I7I & I60 \\
\hline
\end{tabular}



4

Regional and ethnic variation in mortality in Japanese colonial

period Taiwan

John R. Shepherd

Department of Anthropology

University of Virginia 
"For a land so small, and a population of so few, sectional differences of this magnitude are indeed surprising."

George W. Barclay, Colonial Development and Population in Taiwan, 1954: 168 .

\section{Introduction}

This paper explores the degree to which mortality in colonial Taiwan followed regional and/or ethnic lines of differentiation. The impact of mortality varies across many axes of human society, differentially affecting groups defined by age, sex, marital status, legitimacy status, wealth and class, educational level, and many other determinants of position in the social structure. Several of these factors are the focus of other papers in this collection. The current paper explores whether regional and ethnic differences should also be included in the list of significant determinants of mortality levels. The paper begins by exploring regional differences in mortality, and then moves to a discussion of ethnic variation. The paper provides a basis for comparison with Dutch society in the nineteenth and early twentieth centuries where regional and religious (rather than 'ethnic') differences in mortality are well known (see Engelen and Schoonheim, this volume).

High quality reporting of demographic information on the Taiwanese population in the Japanese period begins in October 1905, when the first census was conducted and a vital statistics reporting system based on household registration was inaugurated. Annual volumes of vital statistics were published through I942 and these, along with frequent censuses provide the data for this analysis. The discussion here treats only the population of 'islanders' (J; hontōjin, C: bendaoren 本島人) in the terminology of the census and vital statistics, which I will refer to as 'Taiwanese,' and excludes the Japanese resident in the island (J: naichijin, C: neidiren 內地人).

Demographic studies of regional variation in mortality in Japanese period Taiwan are of course constrained by the kinds of data reported by regional subunits in the censuses and vital statistics (J: Taiwan jinkō dōtai tōkei 台灣人口動態 統計) which are available from I905-I942. In general, the degree of detail reported in the vital statistics varies by administrative level, with less detail at the lower levels. Vital statistics data is reported in the greatest detail at the all-island level. Data on cause of death by age and sex, cause of death by sex and season, cause of death by provenance and sex, and cause of death by occupation and sex are only reported at the all-Taiwan level, and thus are not available for use in the study of regional variation. But many more tables also report data by prefectural units. Thus the vital statistics tables report deaths by age, sex, and prefecture, deaths by cause, sex and prefecture, deaths by season, sex and prefecture, deaths by provenance, sex and prefecture (up to I935), deaths in infancy by age, sex, legitimacy status, and prefecture, and stillbirths by gestational age, sex, legitimacy status, 
and prefecture. After I920, deaths by cause and sex and deaths by provenance (up to I93I) and sex are also reported at the district and city level (J: gun, shi, C: jun shi, 郡市). At the lowest level of detail, the vital statistics reported total deaths by sex at the subprefectural level (J: shichō, C: zhiting 支廳) up torgI9, and from I920 at the district level. An additional annual series, statistics of the defacto population (J: Genju jinko tokei, 現住人口統計), reported deaths by sex down to the lowest township level (J: gai shō, C: jie zhuang 街庄) for the entire period, I905I942. We shall make use of many of these tables for the analysis presented in this paper, while focusing on variation at the prefectural level.

\section{Changing Boundaries and the Regional Distribution of the Population}

Not only does the nature of the information on mortality vary by administrative level, the number and boundaries of the reporting units themselves change over time. To document this we must describe the changing nature of prefectural boundaries in the Japanese period.

From I90I to I909 Taiwan was divided administratively into twenty prefectural units (J: chō, C: ting 廳). In I909 nineteen of these units were consolidated into ten and Taitung was divided in two. In 1920 another consolidation reduced these twelve units to seven prefectures (I refer in English to all the post I920 units as prefectures and ignore the different administrative nomenclature for the five large (J: shü, C: zhou 州) vs. the smaller two or three units, as this difference had little bearing on reporting in the vital statistics and censuses). In I926 an eighth prefecture was added when the Penghu islands were divided from Kaohsiung prefecture and made once again an independent prefectural unit. These eight prefectures remained in place until the end of the Japanese period in I945. The table below gives a rough approximation of the territorial changes. Prefectures are listed counterclockwise from the northeast to southwest, followed by Penghu, and the east coast prefectures of Taitung and Hualien (which brings us back to Ilan on the northeast coast).

The consolidation of the prefectures into larger and larger units created five prefectures which from 1920 contained in excess of $96 \%$ of the total population. For reasons of space and time, this presentation will focus on mortality trends in these five units, and their namesake predecessors before I920. In the pre-I920 period four of these prefectures occupy the cores of the large consolidated prefectures created in 1920 that bore the same name. The spatial discontinuity is greatest in the case of Ahou - Kaohsiung, as Ahou did not include the Fengshan area that would become the core of Kaohsiung prefecture. Before I920 the five namesake prefectures accounted for a much smaller proportion of the total population, $33 \%$ in 1905 and 65\% in I9I5 (see table below). Mortality levels in the namesake prefectures in 1905 and 1915 are close to those in the neigh- 


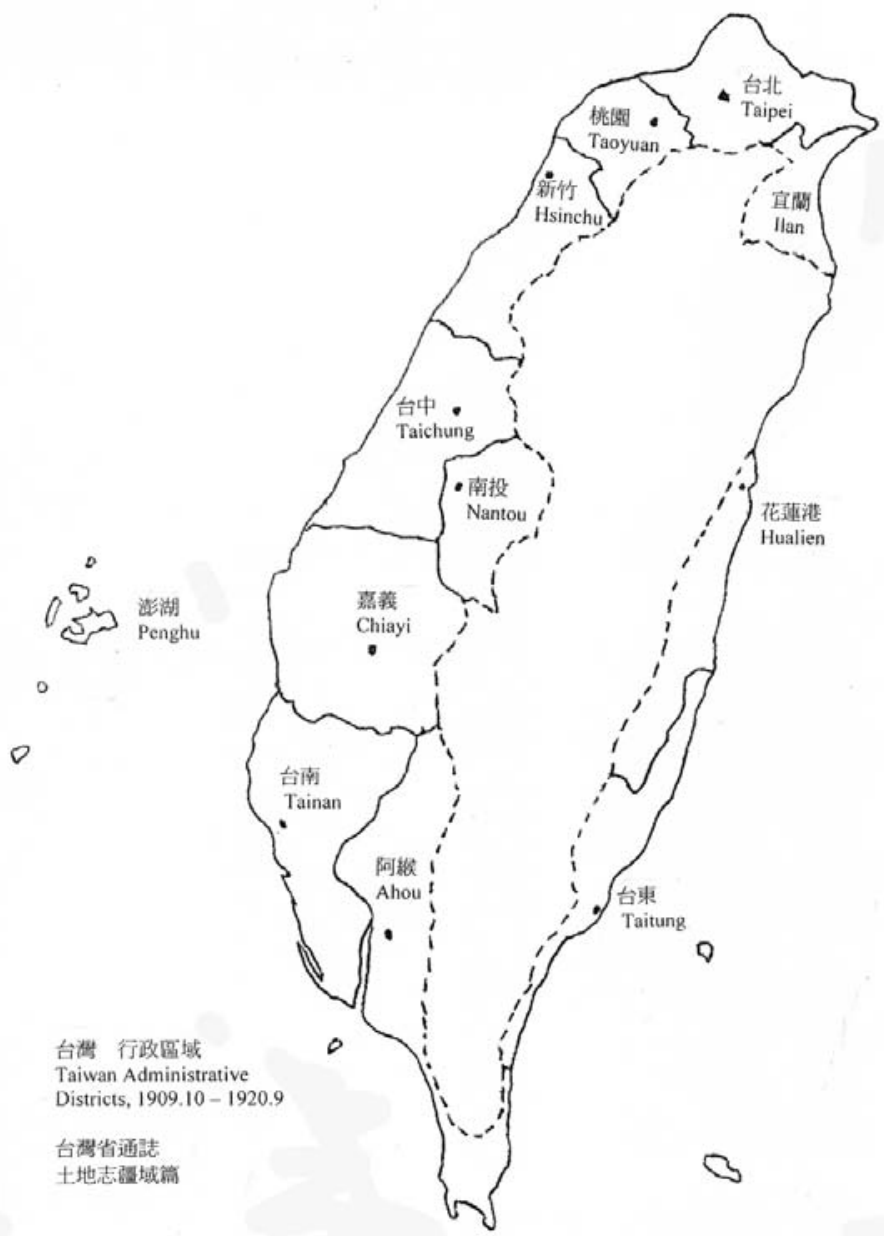

boring prefectures they would incorporate by I920, and are representative of the regional variation in mortality that characterized the island pre-I920.

\section{Regional Differences in Mortality}

In his I954 classic on the demography of Taiwan George W. Barclay made note of extreme regional differences in mortality rates in colonial Taiwan. "Whatever the causes, there were wide disparities in age-specific mortality among the various Prefectures as late as 1925... For some unknown reason Hsinchu was the most favored part of the island, followed by Taipei. The range from highest to lowest at this date was almost as great as between the beginning and the end of the Japanese period." (Barclay I954: I66, cf. Li T’eng-yueh I938b:II44, II52). While puzzled by Hsinchu's low mortality rates, Barclay seems to have assumed that low mortality in Taipei was due largely to Japanese colonial public health 


\begin{tabular}{|c|c|c|c|}
\hline 1901-1909: 20 units & 1909-1920:12 units & 1920-1926: 7 units & 1926-1945: 8 units \\
\hline Ilan & Ilan & \multirow[b]{2}{*}{ Taipei } & \multirow[b]{2}{*}{ Taipei } \\
\hline $\begin{array}{l}\text { Taipei } \\
\text { Keelung } \\
\text { Shenkeng }\end{array}$ & Taipei & & \\
\hline Taoyuan & Taoyuan* & \multirow[b]{2}{*}{ Hsinchu } & \multirow[b]{2}{*}{ Hsinchu } \\
\hline $\begin{array}{l}\text { Hsinchu } \\
\text { Miaoli* }\end{array}$ & Hsinchu & & \\
\hline $\begin{array}{l}\text { Taichung } \\
\text { Changhua }\end{array}$ & Taichung & \multirow[t]{2}{*}{ Taichung } & \multirow[t]{2}{*}{ Taichung } \\
\hline Nantou & Nantou & & \\
\hline $\begin{array}{l}\text { Touliu* } \\
\text { Chiayi }\end{array}$ & Chiayi & \multirow[b]{2}{*}{ Tainan } & \multirow[b]{2}{*}{ Tainan } \\
\hline $\begin{array}{l}\text { Yenshuikang* } \\
\text { Tainan }\end{array}$ & Tainan & & \\
\hline Fengshan & Tainan & \multirow[b]{2}{*}{ Kaohsiung } & \multirow[b]{2}{*}{ Kaohsiung } \\
\hline $\begin{array}{l}\text { Fanshuliao } \\
\text { Ahou } \\
\text { Hengchun }\end{array}$ & Ahou & & \\
\hline Penghu & Penghu & Kaohsiung & Penghu \\
\hline \multirow[t]{2}{*}{ Taitung } & Taitung & Taitung & Taitung \\
\hline & Hualien & Hualien & Hualien \\
\hline
\end{tabular}

Boundary changes are documented in Taiwan Sheng Tongzhi, Vol.I, Tudizhi, Jiangyupian, book I (台灣省通志, 卷

一, 土地志, 疆域篇, 第一冊) I970: 54b-74b.

* indicates that in the subsequent consolidation a subportion of this unit was allocated to a neighboring unit other than the one indicated in the chart.

measures: "As the site of the most modern cities and the favorite residence of Japanese, Taipei Prefecture was one of the safest places in which to live. It was also more liberally supplied with medical facilities than any other Prefecture... It was relatively free from malaria, and contained the most elaborate sanitary facilities in the island." (Barclay 1954: I66). We follow Barclay's lead by extending to all periods the analysis of regional variation in mortality Barclay conducted only for the I924-25 period, and by adding the cause of death reports by prefecture to the analysis. The results will underline the exceptionalism of Hsinchu and call into question Barclay's notion that colonial public health efforts can explain the low rates of mortality in Taipei and Hsinchu. 
Distribution of the Taiwanese population among the Prefectures, 1905-1920.

\begin{tabular}{|c|c|c|c|c|c|c|}
\hline \multirow{2}{*}{$\begin{array}{l}1920 \\
\text { Prefecture }\end{array}$} & \multicolumn{3}{|c|}{ Taiwanese Population } & \multicolumn{3}{|c|}{ \% of Total Taiwanese Population } \\
\hline & 1905 & 1915 & 1920 & 1905 & 1915 & 1920 \\
\hline Taipei & 265832 & 459353 & 658184 & $8.94 \%$ & $\mathrm{I} 3.8 \mathrm{I} \%$ & 18.99\% \\
\hline Hsinchu & I68684 & 321020 & 549401 & 5.67 & 9.65 & 15.85 \\
\hline Taichung & 203802 & 579726 & 754466 & 6.85 & $\mathrm{I} 7.43$ & 21.76 \\
\hline Tainan & I84396 & 545609 & 922337 & 6.20 & I6.4I & 26.6I \\
\hline Kaohsiung & $162196 *$ & $252067 *$ & 509270 & 5.46 & 7.58 & 14.69 \\
\hline Taitung & 48480 & 34824 & 35260 & 1.63 & I.O5 & $\mathrm{I} .02$ \\
\hline Hualien & - & 33 II4 & 37589 & - & I.०O & I.०8 \\
\hline Taiwan & 2973280 & 3325755 & 3466507 & I00.00 & I00.00 & 100.00 \\
\hline Five Prefectures & 9849 го & 2157775 & 3393658 & $33 \cdot 13$ & 64.88 & $97 \cdot 90$ \\
\hline
\end{tabular}

*Ahou prefecture.

Source: Census of 1905, kekka hyō p.8-9, Census of 1915, kekka hyō p. 8-9, Census of 1920, Daiikkai Taiwan kokusei chosa yoran hyō, table I, pp. 2-7.

We begin our analysis of prefectural variation with tables showing life expectancies by sex for all Taiwan and the five major prefectures. Economy of presentation prevents showing the small east coast prefectures of Taitung and Hualien, and the Penghu islands; they contribute to the all Taiwan average, but they will not be discussed individually here. [Several additional factors complicate the analysis of mortality in these prefectures: small numbers, substantial migration, and in the east coast prefectures, administrative expansion to include new populations of aborigines, and low levels of reporting quality. Migration is an important factor affecting the age composition of the three smaller prefectures, which has to be taken into account in assessing the mortality indicators.] The five major prefectures following the 1920 administrative reorganization occupied the entire western coast of Taiwan and all major population centers, and contained $96 \%$ of the Taiwanese population in 1930. For the periods 1906-1919 the rates reported in the tables are for the smaller prefectures that formed the core of the prefectures (of the same name, but Ahou in the case of Kaohsiung) consolidated in 1909 and then again in 1920 ; please refer to the table documenting the prefectural consolidations I9OI-I945 above. Continuity across the I920 divide is least in the case of Ahou-Kaohsiung, which in 1920 acquired the coastal area (old Fengshan) that contained what would become the port of Kaohsiung city. 
One of the most detailed tables in the annual vital statistics volumes reports deaths by single years of age and by sex at the prefectural level. When combined with the census tables of population by age and sex, these tables enable us to compute life tables for all Taiwan and for each prefecture. From life tables based on data for a given set of years, we can compute the expectation of life at birth, a figure which summarizes the impact of mortality across all ages for the given period. Because life table measures are based on age-specific measures, they are not subject to bias due to differences in age structures among the prefectures (as is the case of crude death rates). Thus life expectancy provides an ideal measure for comparing prefectural units.

The table below presents measures of life expectancy for all Taiwan and for the five prefectures across the entire period. Each figure is centered on a census year, with the exception of 1906-08, the first reporting years following the I905 census, and 1920-22, which follows the administrative reorganization of the prefectures in I920. The right hand side of the table presents indexed figures based on the all Taiwan life expectancy for the given year.

The most striking pattern the table reveals is that Hsinchu has the highest life expectancies for both men and women from the first period to the last. Hsinchu's life expectancies are considerably higher than the all Taiwan average, and are also substantially higher than Taipei's, which generally rank second, except for 1934-36 when Taipei's are the lowest! The lowest life expectancies are consistently reported in Tainan and Kaohsiung. Life expectancy in Taichung is regularly the closest to the all-Taiwan average. The general pattern is thus of a north-south gradient in mortality, with low mortality and high life expectancy in the north, and high mortality and low life expectancy in the south. But it is Hsinchu rather than Taipei that has the most favorable conditions. The life expectancies of women are consistently higher than those of men in every period and prefecture; the female advantage averages approximately ı०\% over the period.

Over time, the average life expectancy increases in all prefectures (the largest gains are in the southern prefectures) and the gap between the highest and the lowest expectancies narrows. Thus the degrees of Hsinchu's advantage and the southern prefectures' disadvantage gradually diminish. As we shall see below, the factors that likely were most important in raising the all Taiwan average life expectancy and lowering the very high death rates in Kaohsiung and Tainan were malaria suppression and other public health efforts that had their greatest impact in the south.

Regional divergences in life expectancy of similar magnitude were found by William Farr in nineteenth century Britain: he estimated life expectancy at birth in I84I at 45.I in rural Surrey, 36.7 in London, and only 25.7 in Liverpool (Szreter I988: 20). The British pattern of large urban - rural differences reflects the much 

Years, ı906-194I.

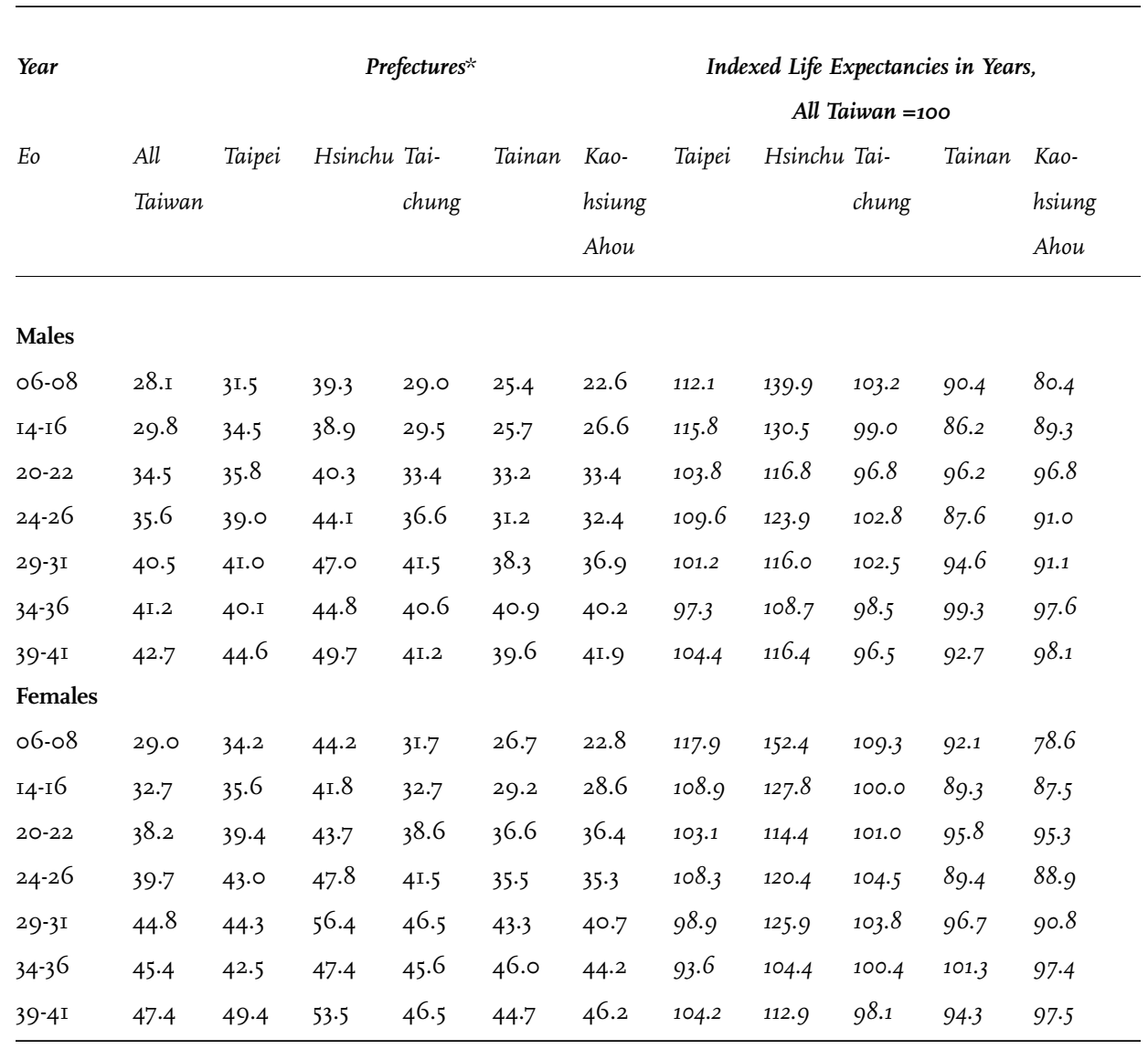

* Pre-I920 boundaries enclosed only parts of the areas defined by the boundaries set in I920. Figures for Kaohsiung in I920-26 include Penghu.

greater role of crowded and unsanitary urban environments in raising death rates in England during industrialization. Taiwan's level of urbanization remained quite low in comparison throughout the Japanese period, and divergences in life expectancy in Taiwan reflect large regional rather than urban - rural differences. Regional differences in life expectancy in Japan were also great. In I920-25 expectation of life at birth in Japan's prefectures ranged from 35.9 to 47.9 for males and 36.6 to 50.5 for females. In I930-35 the range had narrowed to 39.2 to 49.2 for males and 40.7 to 5 1.8 for females (Taeuber 1958: 94). Regional divergences in Taiwan were extreme in 1906, when life expectancy ranged from 22.6 to 39.3 for males and 22.8 to 44.2 for females. Differences among Taiwan's prefectures narrowed in later years, but remain impressive, especially given the much smaller geographic expanse of Taiwan compared to Britain and Japan. 


\section{Crude Death Rates and Cause Specific Death Rates among the Prefectures}

Life expectancies are a powerful measure and tell the story of regional variation in mortality very succinctly. However, to assess which factors gave rise to the large regional differences in life expectancies within Taiwan we need to look further. Most important for the analysis here are the tables in the vital statistics that report deaths by cause, sex and prefecture. These tables enable us to see the contributions different causes of death make to variation in mortality among the prefectures. We use these tables in conjunction with the total population by sex of each prefecture to compute crude death rates for all causes and cause specific death rates for major causes for each prefecture and period.

The table below presents the crude death rates for all causes for all Taiwan and the five larger prefectures by sex for the years I906-I94I. To facilitate comparison, rates for each year have been indexed on the all Taiwan rate to show where each prefecture stands in relation to the average death rate for the island as whole. The table reveals the same pattern documented by the life expectancies table above. That Hsinchu had the lowest crude death rates for males and females for all years, I906-I94I, is immediately clear. Taipei had the second lowest rates for years 1906-26, and I939-4I, but not for years 1929-36. Surprisingly, in 1934-36 when we would expect public health efforts to have been at their most effective, Taipei had the highest death rates of the five prefectures. In most other years the highest rates are consistently found in the southern prefectures of Tainan and Kaohsiung. Hsinchu's advantage over the other prefectures is substantial. From I906-1926 Hsinchu enjoyed death rates ranging from 20-30\% below the all island average, and from 1929-194I from 10-20\%. Moreover, Hsinchu's advantage predates all important public health interventions by the Japanese colonial government, and persists despite heavy public health investments in Taipei and across the island. Hsinchu also benefited from public health interventions and death rates in Hsinchu declined significantly from I906 to I94I, but Hsinchu's mortality advantage throughout the colonial period stems from factors beyond these interventions.

The life expectancies and the crude death rates both confirm the wide differences in mortality among Taiwan's prefectures, the low mortality in Hsinchu and the north generally, and the much higher mortality in the south of Taiwan. Crude rates, however, because they combine age groups whose death rates vary widely, are less reliable indicators of difference when the populations being compared also vary widely in age structure (Barclay 1958: I35). In Japanese period Taiwan differences in age composition among the prefectures are not great enough to affect the agreement of the crude death rates with the life expectancies measure when comparing the prefectures. Differences in age composition among the five larger prefectures are small in Japanese period Taiwan, as shown 
Table 2. Cause Specific Crude Death Rates by Sex and Prefecture, All Causes, I906-194I. Deaths per 100,000.

\begin{tabular}{|c|c|c|c|c|c|c|c|c|c|c|c|}
\hline \multirow{2}{*}{$\begin{array}{l}\text { Year } \\
\text { All Causes }\end{array}$} & \multirow{2}{*}{ All } & \multirow[b]{2}{*}{ Taipei } & \multicolumn{3}{|c|}{ Prefectures $^{* * *}$} & \multicolumn{6}{|c|}{$\begin{array}{c}\text { Indexed Crude Death Rates by Cause, } \\
\text { All Taiwan }=100\end{array}$} \\
\hline & & & Hsinchu & $\begin{array}{l}\text { Tai- } \\
\text { chung }\end{array}$ & Tainan & $\begin{array}{l}\text { Kao- } \\
\text { hsiung } \\
\text { Ahou }\end{array}$ & Taipei & Hsinchu & $\begin{array}{l}\text { Tai- } \\
\text { chung }\end{array}$ & Tainan & $\begin{array}{l}\text { Kao- } \\
\text { hsiung } \\
\text { Ahou }\end{array}$ \\
\hline \multicolumn{12}{|l|}{ Males } \\
\hline $06-08 *$ & 3582 & 3087 & $244 \mathrm{I}$ & 3520 & 3880 & 4368 & 86.2 & 68.1 & 98.3 & 108.3 & 121.9 \\
\hline O9-I3* & 2990 & 2597 & 2227 & 3 IIO & 3283 & 3384 & 86.9 & $74 \cdot 5$ & 104.0 & 109.8 & 113.2 \\
\hline $\mathrm{I} 4-\mathrm{I} 6 *$ & 3192 & 2653 & 2272 & $324 \mathrm{I}$ & $384 \mathrm{I}$ & 3689 & 83.1 & 71.2 & 101.5 & 120.3 & 115.6 \\
\hline I7-I9 & $3 \mathrm{I} 78$ & 2753 & 2324 & 3086 & 3742 & 3766 & 86.6 & 73.1 & 97.1 & $117 \cdot 7$ & 118.5 \\
\hline $20-22$ & 2918 & 2652 & 2403 & 3036 & 3290 & 3080 & 90.9 & 82.4 & 104.0 & 112.7 & 105.6 \\
\hline $24-26$ & $26 I I$ & 2343 & I968 & 2509 & 3029 & $27 \mathrm{I} 3$ & $89 \cdot 7$ & $75 \cdot 4$ & 96.1 & 116.0 & $103 \cdot 9$ \\
\hline $29-31$ & 2242 & $22 \mathrm{I} 2$ & I799 & $2 \mathrm{I} 8 \mathrm{I}$ & 2455 & 2463 & 98.7 & 80.2 & $97 \cdot 3$ & $109 \cdot 5$ & $109 \cdot 9$ \\
\hline $34-36$ & 2198 & 2283 & I96I & 2265 & $223 \mathrm{I}$ & 2201 & 103.9 & 89.2 & 103.0 & 101.5 & 100.1 \\
\hline $39-4 \mathrm{I}$ & 2060 & I9O5 & I6I5 & 2209 & 2330 & 2006 & 92.5 & 78.4 & 107.2 & 113.1 & $97 \cdot 4$ \\
\hline \multicolumn{12}{|l|}{ Females } \\
\hline $06-08 *$ & 3583 & 2876 & 2209 & 3387 & 3762 & 4303 & 80.3 & 61.7 & 94.5 & 105.0 & 120.1 \\
\hline og-I3* & 2789 & 2524 & I975 & $284 \mathrm{I}$ & 3046 & 3233 & 90.5 & 70.8 & 101.9 & 109.2 & $115 \cdot 9$ \\
\hline $\mathrm{I} 4-\mathrm{I} 6 *$ & 2970 & 2628 & 2088 & 2993 & 3402 & 3542 & 88.5 & 70.3 & 100.8 & $114 \cdot 5$ & $119 \cdot 3$ \\
\hline I7-I9 & 2933 & 2640 & 2087 & 2675 & 3507 & 3564 & 90.0 & 71.2 & 91.2 & 119.6 & 121.5 \\
\hline $20-22$ & 2703 & 2474 & 2222 & 2702 & $298 \mathrm{I}$ & 2909 & 91.5 & 82.2 & 100.0 & 110.3 & 107.6 \\
\hline $24-26$ & 2354 & 2173 & I8I4 & 2185 & 2680 & 2467 & 92.3 & 77.1 & 92.8 & 113.8 & 104.8 \\
\hline 29-3I & 2032 & 2102 & I66I & 1929 & 2165 & 2265 & 103.4 & 81.7 & 94.9 & 106.5 & 111.5 \\
\hline $34-36$ & I98I & 2128 & I857 & 1963 & I967 & 2002 & 107.4 & 93.7 & 99.1 & $99 \cdot 3$ & 101.1 \\
\hline $39-4 \mathrm{I}$ & I8II & 1696 & I449 & I886 & 2020 & I82I & 93.6 & 80.0 & 104.1 & 111.5 & 100.6 \\
\hline
\end{tabular}

* Rates for I906-I5 have been corrected for infant unregistered nonsurvivors.

** Pre-I920 boundaries enclosed only parts of the areas defined by the boundaries set in I920. Figures for Kaohsiung in I920-26 have been adjusted to exclude Penghu.

in the table below. Thus we are able to read differences in prefectural cause specific death rates as indicators of differences in the incidence and severity of disease rather than differences in age structure. 


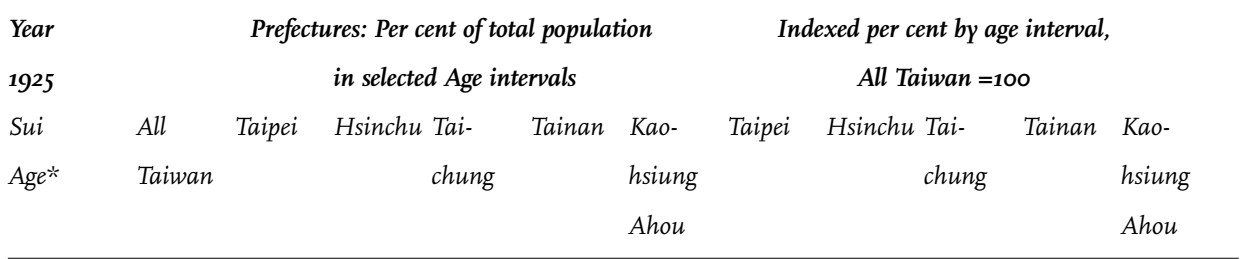

Males

\begin{tabular}{|c|c|c|c|c|c|c|c|c|c|c|c|}
\hline I-5 & I4.98 & I3.83 & 15.39 & I5.57 & 14.90 & I5.54 & 0.92 & 1.03 & 1.04 & 0.99 & 1.04 \\
\hline 6-I5 & 24.83 & 23.20 & 25.48 & 25.13 & 25.40 & $25 \cdot 5 \mathrm{I}$ & 0.93 & 1.03 & 1.01 & 1.02 & 1.03 \\
\hline I6-30 & 28.27 & 28.86 & $27 \cdot 35$ & 28.35 & 28.6I & 27.49 & 1.02 & 0.97 & 1.00 & 1.01 & 0.97 \\
\hline $3 \mathrm{I}-45$ & 18.56 & I8.52 & I6.80 & 17.89 & 19.20 & I9.6I & 1.00 & 0.91 & 0.96 & 1.03 & 1.06 \\
\hline $45-60$ & I0.22 & II. 63 & I0.57 & 10.36 & 9.32 & 9.27 & 1.14 & 1.03 & 1.01 & 0.91 & 0.91 \\
\hline $60+$ & 3.15 & 3.96 & 4.42 & 2.70 & 2.57 & 2.58 & 1.26 & 1.40 & 0.86 & 0.81 & 0.82 \\
\hline Total & 100.00 & I00.০0 & IO०.०0 & I00.০0 & I00.00 & I00.00 & & & & & \\
\hline \multicolumn{12}{|c|}{ Females } \\
\hline$I-5$ & I5.28 & 14.63 & I5.24 & I5.86 & I5.I8 & 15.50 & 0.96 & 1.00 & 1.04 & 0.99 & 1.01 \\
\hline 6-I5 & 24.42 & 23.12 & 24.25 & 24.87 & 25.09 & 24.75 & 0.95 & 0.99 & 1.02 & 1.03 & 1.01 \\
\hline I6-30 & 26.52 & 26.33 & 26.46 & 27.II & 26.52 & 25.79 & 0.99 & 1.00 & 1.02 & 1.00 & 0.97 \\
\hline $3 \mathrm{I}-45$ & I6.79 & 16.62 & I6.53 & 16.02 & 16.90 & $\mathrm{I} 7.8 \mathrm{I}$ & 0.99 & 0.98 & 0.95 & 1.01 & 1.06 \\
\hline $45-60$ & II. 44 & 12.69 & II. 37 & II.I9 & I0.97 & II.O4 & 1.11 & 0.99 & 0.98 & 0.96 & 0.97 \\
\hline 6o+ & $5 \cdot 55$ & 6.60 & 6.15 & 4.95 & $5 \cdot 33$ & 5.10 & 1.19 & 1.11 & 0.89 & 0.96 & $0.9^{2}$ \\
\hline Total & I00.00 & I00.00 & I00.00 & I00.00 & I00.00 & I00.00 & & & & & \\
\hline
\end{tabular}

* 'Sui Age by cohort': the censuses from 1905 to I925 report 'age' by year of birth, beginning with those born in the year of the census, who are listed as sui age I. Thus there is no age 'o' by this reckoning. Note that this reckoning is by birth year cohort and does not correspond either to traditional Chinese lunar year 'sui' or to Western measures of age at last birthday.

\section{Regional Differences in Mortality: Cause Specific Death Rates among the Prefectures}

We turn now to an exploration of the leading causes of death among the different prefectures to understand what causes make Hsinchu death rates so much lower and the southern prefectures' death rates so much higher than the all Taiwan average. Cause of death data is reported in the Vital Statistics by prefecture and by sex but not by age so we can report only 'crude' cause specific rates for each prefecture. I should also note that the quality of cause of death reporting in the early periods was not as high as it would be in later years. The challenges of assessing the quality of cause of death reports is discussed in a separate paper on 'Trends in Mortality' elsewhere in this volume. I conclude that the general impressions these 
data convey are reliable, and increasingly so as reporting quality improves. The data series for several causes appear to be inconsistently reported across the periods. Such inconsistencies arise from improving diagnostics and training on the part of personnel filling out death certificates, and changes in the definitions of disease categories (and also rules for deciding between two or more contributing causes). These causes will be reported only for the years I924-4I, during which the third and fourth international cause of death lists were used to compile the cause of death reports. There are two causes, however, malaria and respiratory tuberculosis, that appear to provide relatively consistently reported series both before and after I924. These causes of death present symptoms relatively easy for certifiers to identify, periodic chills and fevers and swollen spleens in the case of malaria, and bloody sputum in the case of respiratory tuberculosis. The international lists for compiling death statistics in use by the colonial authorities also consistently reserved separate categories specific to these causes, which immunized them from inconsistencies arising from changing category definitions.

The tables below report the death rates by cause for the leading causes of death. Death rates by cause are computed as a ratio of the deaths assigned to a specific cause to a mid-year population; demographers refer to these crude rates by cause as cause-specific death rates (Barclay 1958: I5I-55). To facilitate comparison among the prefectures the prefectural death rates are indexed on the all Taiwan average cause-specific death rates by sex in each year.

Malaria. We look first at the death rates by prefecture and sex attributed to malaria. Malarial death rates in Taiwan are extremely high in the early years of the century, and remain high until a decline set in around I920-22 that would continue to I94I. Through most of this period Hsinchu enjoyed the lowest malaria rates. The exceptions are 1909-13 and I9I7-I9I9 when Taipei rates were lower, and I934-36 when both Hsinchu and Taipei suffered a resurgence in malaria deaths. Otherwise Taipei regularly ranked second lowest, confirming the generalization that the northern prefectures suffered much less from malaria than did the southern prefectures of Kaohsiung and Tainan. Malaria death rates in Kaohsiung-Ahou are the highest in every year except 1920-26 when they rank second highest behind Tainan. Ahou's rates are extremely high I906-I919; Kaohsiung's rates fall below those of Tainan in 1920-1926 (after Ahou was consolidated with less malarial areas in Fengshan to form Kaohsiung) but they surpass Tainan again in 1929-4I. Tainan generally ranks second highest in years other than 1920-26 and the anomalous years $1934-36$. The degree of prefectural difference is especially great in the early years when Hsinchu and Taipei malarial death rates were regularly less than half and Ahou/Kaohsiung's twice as high as the all Taiwan average. Even after declining rates brought down Kaohsiung's extreme rates, Hsinchu and Taipei regularly (excepting $1934-36$ ) had only $50 \%$ to $60 \%$ of the all Taiwan rate. 

I94I. Deaths per 100,000.

\begin{tabular}{|c|c|c|c|c|c|c|c|c|c|c|c|}
\hline \multirow{2}{*}{$\begin{array}{l}\text { Year } \\
\text { Malaria }\end{array}$} & \multirow[b]{2}{*}{$\begin{array}{l}\text { All } \\
\text { Taiwan }\end{array}$} & \multirow[b]{2}{*}{ Taipei } & \multicolumn{3}{|c|}{ Prefectures* } & \multirow[b]{2}{*}{$\begin{array}{l}\text { Kao- } \\
\text { hsiung } \\
\text { Ahou }\end{array}$} & \multicolumn{5}{|c|}{$\begin{array}{c}\text { Indexed Crude Death Rates by Cause, } \\
\text { All Taiwan }=100\end{array}$} \\
\hline & & & Hsinchu & $\begin{array}{l}\text { Tai- } \\
\text { chung }\end{array}$ & Tainan & & Taipei & Hsinchu & $\begin{array}{l}\text { Tai- } \\
\text { chung }\end{array}$ & Tainan & $\begin{array}{l}\text { Kao- } \\
\text { hsiung } \\
\text { Ahou }\end{array}$ \\
\hline \multicolumn{12}{|l|}{ Males } \\
\hline ०6-०8 & 356 & I96 & 89 & 200 & 329 & $83 \mathrm{I}$ & 55.1 & 25.0 & 56.2 & 92.4 & 233.4 \\
\hline O9-I3 & 257 & II6 & II6 & 218 & 263 & 664 & 45.1 & 45.1 & 84.8 & 102.3 & 258.4 \\
\hline I4-I6 & 324 & $\mathrm{I} 34$ & I2I & 272 & 375 & 726 & $41 \cdot 4$ & $37 \cdot 3$ & 84.0 & $115 \cdot 7$ & 224.1 \\
\hline I7-I9 & 250 & $\mathrm{IO} 4$ & II 5 & 169 & $3 \mathrm{I} 4$ & 556 & 41.6 & 46.0 & 67.6 & $125 \cdot 6$ & 222.4 \\
\hline $20-22$ & 222 & I33 & IIO & 205 & 325 & 255 & $59 \cdot 9$ & $49 \cdot 5$ & 92.3 & 146.4 & 114.9 \\
\hline $24-26$ & I77 & 83 & 56 & I33 & 296 & $25 \mathrm{I}$ & 46.9 & 31.6 & 75.1 & 167.2 & 141.8 \\
\hline $29-3 I$ & 76 & 45 & 34 & 59 & 90 & I3I & $59 \cdot 2$ & $44 \cdot 7$ & 77.6 & 118.4 & 172.4 \\
\hline $34-36$ & $7 \mathrm{I}$ & $8 \mathrm{I}$ & 55 & 6I & 57 & 95 & 114.1 & $77 \cdot 5$ & 85.9 & 80.3 & 133.8 \\
\hline $39-4 \mathrm{I}$ & 70 & 40 & 34 & 72 & 80 & 99 & $57 \cdot 1$ & 48.6 & 102.9 & $114 \cdot 3$ & 141.4 \\
\hline \multicolumn{12}{|l|}{ Females } \\
\hline ०6-०8 & $38 \mathrm{I}$ & I35 & 90 & I87 & 377 & 896 & $35 \cdot 4$ & 23.6 & 49.1 & 99.0 & 235.2 \\
\hline ०9-I3 & $25 \mathrm{I}$ & 98 & II 8 & 202 & 264 & 722 & 39.0 & 47.0 & 80.5 & 105.2 & 287.6 \\
\hline I4-I 6 & 333 & III & IO8 & 276 & 378 & 795 & $33 \cdot 3$ & 32.4 & 82.9 & $113 \cdot 5$ & 238.7 \\
\hline I7-I9 & 250 & 78 & IO8 & 152 & 343 & 597 & 31.2 & 43.2 & 60.8 & 137.2 & 238.8 \\
\hline $20-22$ & 216 & IOO & $9^{\mathrm{I}}$ & I77 & 349 & 266 & 46.3 & 42.1 & 81.9 & 161.6 & 123.1 \\
\hline $24-26$ & I73 & 64 & $5^{\mathrm{I}}$ & I26 6 & 298 & 264 & 37.0 & $29 \cdot 5$ & 72.8 & 172.3 & 152.6 \\
\hline 29-3I & 73 & 35 & 30 & 56 & 90 & I4O & $47 \cdot 9$ & 41.1 & 76.7 & 123.3 & 191.8 \\
\hline $34-36$ & 66 & 7I & 6I & 54 & 57 & 93 & 107.6 & 92.4 & 81.8 & 86.4 & 140.9 \\
\hline $39-4 \mathrm{I}$ & 62 & 32 & $2 \mathrm{I}$ & 54 & 73 & 98 & 51.6 & 33.9 & 87.1 & 117.7 & 158.1 \\
\hline
\end{tabular}

* Pre-1920 boundaries enclosed only parts of the areas defined by the boundaries set in I920. Figures for Kaohsiung in I920-26 have been adjusted to exclude Penghu.

Malaria was consistently a leading cause of death in nineteenth and early twentieth century Taiwan and as such early became a target of Japanese colonial public health efforts. Malaria is clearly an important contributor to large differences among the prefectures in overall death rates especially in the early years before decline set in. Malarial death rates are highest in climates most favorable to the propagation of anopheline mosquitoes and the malaria plasmodium. Malaria is most deadly in warmer areas where the virulent falciparum variety can survive, as in southern Taiwan. As control efforts strengthened, malarial death 
rates declined most dramatically in the southern prefectures where they had been highest. The result is that malaria contributes less overall to prefectural differences in the last half of the period. Note that the sex differential in malarial deaths rates is small and often shows a slight female excess in the southern prefectures.

Respiratory Tuberculosis. Deaths attributed to respiratory tuberculosis are consistently reported up to I938. In I938 the adoption of the tuberculosis prevention law requiring mandatory reporting and invasive measures of prevention caused a sudden drop in the reported number of respiratory тв deaths, which doctors (at the urging of families) assigned to other causes (Kekkaku yobōhō I938; Chen et al. I96r:I6, Lee 2001:67; cf. Wm. Johnston 1995: 248, 268, 274-75). Death rates attributed to respiratory tuberculosis were regularly at their lowest in Hsinchu excepting only 1906-08 when Taichung rates were lower. The highest rates occurred in Tainan 1906-26; in 1929-3I the highest male rates were in Tainan and Kaohsiung but the highest female rates in Taipei. In 1934-I936 Taipei had the highest rates, followed by Tainan. Respiratory tuberculosis death rates declined from 1920 island wide, but the decline was interrupted in Taipei and Hsinchu in $1934-36$. The 1934-36 upsurge in respiratory tuberculosis in Taipei and Hsinchu paralleled an upsurge in malaria in those prefectures. Male rates of death from respiratory tuberculosis were much higher than female rates in all prefectures and periods (sex ratios of mortality for respiratory tuberculosis generally range from $\mathrm{I} 60$ to $\mathrm{I} 80$ ).

Hypotheses accounting for differentials in the incidence of respiratory tuberculosis variously emphasize diet (тв is considered to be a nutritionally sensitive disease, The Conferees 1985), exposure to active cases (e.g. within the family), environmental conditions such as crowded living spaces, poor ventilation, and polluted cities, and reduced immune response due to co-morbidity. One or many of these factors may underlie the high rates in Tainan and Taipei. Why men were much more vulnerable to respiratory tuberculosis in Taiwan than women demands explanation; such a large male excess contrasts with more balanced rates between the sexes in Japan.

High respiratory tuberculosis death rates in Taipei and Tainan prefectures suggest the possibility that especially high rates in Taiwan's two largest cities, Taipei city and Tainan city, may account for the high prefectural rates. Tuberculosis is often associated with crowded living conditions among the urban poor. Is there evidence to support this hypothesis? We have reports of deaths by cause and sex broken down to subprefectural districts and cities for Taiwanese from 1929-194I. We can compute rates for each city and for the prefectures less the city to see if the nonurban prefectural rates remain high. In the case of Taipei prefecture, we include both Taipei and the port city of Keelung in the urban category, and the remainder of Taipei prefecture in the rural category. 


\begin{tabular}{|c|c|c|c|c|c|c|c|c|c|c|c|}
\hline \multirow{2}{*}{$\begin{array}{l}\text { Year } \\
\text { Resp. } \\
\text { TB }\end{array}$} & \multirow[b]{2}{*}{$\begin{array}{l}\text { All } \\
\text { Taiwan }\end{array}$} & \multirow[b]{2}{*}{ Taipei } & \multicolumn{3}{|c|}{ Prefectures* } & \multicolumn{6}{|c|}{$\begin{array}{l}\text { Indexed Crude Death Rates by Cause, } \\
\qquad \text { All Taiwan }=100\end{array}$} \\
\hline & & & Hsinchu & $\begin{array}{l}\text { Tai- } \\
\text { chung }\end{array}$ & Tainan & $\begin{array}{l}\text { Kao- } \\
\text { hsiung } \\
\text { Ahou }\end{array}$ & Taipei & \multicolumn{2}{|c|}{$\begin{array}{l}\text { Hsinchu Tai- } \\
\text { chung }\end{array}$} & Tainan & $\begin{array}{l}\text { Kao- } \\
\text { hsiung } \\
\text { Ahou }\end{array}$ \\
\hline \multicolumn{12}{|l|}{ Males } \\
\hline 06-08 & $\mathrm{I} 72$ & 228 & I57 & 152 & 325 & 202 & 132.6 & 91.3 & 88.4 & 189.0 & 117.4 \\
\hline O9-I3 & I53 & I64 & 82 & I48 & $2 \mathrm{I} 4$ & I 57 & 107.2 & 53.6 & 96.7 & $139 \cdot 9$ & 102.6 \\
\hline I4-I6 & 169 & $\mathrm{I} 72$ & 83 & I6I & 237 & 165 & 101.8 & $49 \cdot 1$ & $95 \cdot 3$ & 140.2 & 97.6 \\
\hline I7-I9 & $2 \mathrm{II}$ & $2 \mathrm{I} 4$ & II3 & $2 \mathrm{I} 8$ & 292 & $2 \mathrm{I} 3$ & 101.4 & 53.6 & 103.3 & 138.4 & 100.9 \\
\hline $20-22$ & $2 \mathrm{II}$ & 204 & 94 & 232 & 29I & 206 & 96.7 & 44.5 & 110.0 & $137 \cdot 9$ & 97.6 \\
\hline $24-26$ & 205 & 180 & 90 & 229 & 273 & 223 & 87.8 & $43 \cdot 9$ & 111.7 & 133.2 & 108.8 \\
\hline $29-3 \mathrm{I}$ & I74 & I77 & 80 & I86 & $2 \mathrm{I} 4$ & 190 & 101.7 & 46.0 & 106.9 & 123.0 & 109.2 \\
\hline $34-36$ & I74 & I94 & 109 & 183 & I87 & 183 & 111.5 & 62.6 & 105.2 & $107 \cdot 5$ & 105.2 \\
\hline \multicolumn{12}{|c|}{ Females } \\
\hline $06-08$ & 94 & $\mathrm{I} 42$ & 97 & 83 & 189 & 129 & 151.1 & 103.2 & 88.3 & 201.1 & 137.2 \\
\hline O9-I3 & 85 & III & 47 & 77 & II7 & 84 & 130.6 & $55 \cdot 3$ & 90.6 & 137.6 & 98.8 \\
\hline I4-I6 & 97 & II6 & 48 & 89 & I39 & 92 & 119.6 & $49 \cdot 5$ & 91.8 & $143 \cdot 3$ & 94.8 \\
\hline I7-I9 & $\mathrm{I} 26$ & I37 & 56 & II9 & I87 & I23 & 108.7 & 44.4 & 94.4 & 148.4 & 97.6 \\
\hline $20-22$ & I3I & I3I & 47 & I 45 & I74 & I39 & 100.0 & 35.9 & 110.7 & 132.8 & 106.1 \\
\hline $24-26$ & $\mathrm{I} 22$ & $\mathrm{I} 24$ & 46 & I28 & I57 & I44 & 101.6 & $37 \cdot 7$ & 104.9 & 128.7 & 118.0 \\
\hline $29-3 \mathrm{I}$ & IIO & I3I & $4 \mathrm{I}$ & IIO & I30 & I3O & 119.1 & $37 \cdot 3$ & 100.0 & 118.2 & 118.2 \\
\hline $34-36$ & IO9 & I29 & 6I & IOI & I23 & $\mathrm{I} 2 \mathrm{O}$ & 118.3 & 56.0 & 92.7 & 112.8 & 110.1 \\
\hline
\end{tabular}

* Pre-I920 boundaries enclosed only parts of the areas defined by the boundaries set in I920. Figures for Kaohsiung in I920-26 have been adjusted to exclude Penghu.

The table below reveals that Taipei-Keelung and Tainan cities had rates of respiratory tuberculosis mortality considerably above the surrounding countryside, and higher than any prefecture. Taipei-Keelung has the highest rates I92936. The urban population of Taipei-Keelung is a substantial proportion of the population of Taipei prefecture $(26 \%$ in 1935$)$ and the urban rates have a strong impact on the prefectural rates. Rural Taipei's respiratory tuberculosis death rates are thus much lower than that of the prefecture as a whole, and fall below the all-Taiwan average but above the Hsinchu rates. Tainan city is a much smaller proportion of Tainan prefecture's total population (7\% in 1935), and the urban rates have a smaller impact on the prefectural rates. Thus the respiratory тв 

Tuberculosis, 1929-1936. Deaths per 100,000.

\begin{tabular}{|c|c|c|c|c|c|c|c|c|c|c|c|c|}
\hline \multirow[t]{2}{*}{ Year } & \multicolumn{6}{|c|}{ Prefecture, Urban and Rural Districts } & \multicolumn{6}{|c|}{$\begin{array}{l}\text { Indexed Crude Death Rates by Cause, } \\
\qquad \text { All Taiwan }=100\end{array}$} \\
\hline & $\begin{array}{l}\text { Taipei } \\
\text { Pref }\end{array}$ & $\begin{array}{l}\text { Urban } \\
\text { Taipei } \\
\text { Q Kee- } \\
\text { lung }\end{array}$ & $\begin{array}{l}\text { Rural } \\
\text { Taipei } \\
\text { Pref. }\end{array}$ & $\begin{array}{l}\text { Tainan } \\
\text { Pref. }\end{array}$ & $\begin{array}{l}\text { Urban } \\
\text { Tainan }\end{array}$ & $\begin{array}{l}\text { Rural } \\
\text { Tainan } \\
\text { Pref. }\end{array}$ & $\begin{array}{l}\text { Taipei } \\
\text { Pref. }\end{array}$ & $\begin{array}{l}\text { Urban } \\
\text { Taipei } \\
\text { Q Kee- } \\
\text { lung }\end{array}$ & $\begin{array}{l}\text { Rural } \\
\text { Taipei } \\
\text { Pref. }\end{array}$ & $\begin{array}{l}\text { Tainan } \\
\text { Pref. }\end{array}$ & $\begin{array}{l}\text { Urban } \\
\text { Tainan }\end{array}$ & $\begin{array}{l}\text { Rural } \\
\text { Tainan } \\
\text { Pref. }\end{array}$ \\
\hline ales & & & & & & & & & & & & \\
\hline $29-31$ & I77 & 282 & I43 & $2 \mathrm{I} 4$ & 264 & 210 & 101.7 & 162.1 & 82.2 & 123.0 & 151.7 & 120.7 \\
\hline $34-36$ & I94 & 306 & I54 & I87 & I95 & І86 & 111.5 & $175 \cdot 9$ & 88.5 & $107 \cdot 5$ & 112.1 & 106.9 \\
\hline Female & & & & & & & & & & & & \\
\hline $29-31$ & I3I & $22 \mathrm{I}$ & 99 & I3O & 202 & I 24 & 119.1 & 200.9 & 90.0 & 118.2 & 183.6 & 112.7 \\
\hline $34-36$ & 129 & 202 & IOI & I23 & I79 & II9 & 118.3 & $185 \cdot 3$ & 92.7 & 112.8 & 164.2 & 109.2 \\
\hline
\end{tabular}

death rates of rural Tainan continue to rank high among the prefectures, and above the all-Taiwan average. So we find in Taipei high rates of respiratory tuberculosis are an urban phenomenon not shared by the surrounding countryside, but in Tainan and the south generally high rates of respiratory tuberculosis are also important in rural areas.

The remaining disease groups to be discussed, respiratory diseases, diarrhea and enteritis, and certain diseases of infancy are most consistently reported and defined in the period i924-4I.

Respiratory Diseases. "Respiratory diseases" is a broad category including pneumonia, bronchitis, influenza ("PBI"), and other respiratory diseases, that weighed heavily on the health of Taiwanese in this period. From I924-I94I respiratory diseases accounted for 3I and 29 per cent of total deaths for males and females respectively. When combined they are the leading cause of death in all periods, and all prefectures suffered from high rates of these diseases. Death rates attributed to respiratory diseases were regularly at their lowest in Hsinchu, and second lowest in Taipei, excepting females I929-3I when Taichung rates were lower. Tainan and Kaohsiung had the highest rates except I934-36 when Taichung males had the highest rate, and I939-4I when Taichung's rates exceeded those of Kaohsiung but not Tainan's. The degree of prefectural difference in respiratory disease death rates, while substantial, is much less extreme compared to malaria, and even respiratory tuberculosis. Hsinchu's advantage is nevertheless considerable as its respiratory disease death rates range between $70 \%$ and $80 \%$ of the all-Taiwan average 

Diseases (PBI), I924-I94I. Deaths per 100,000.

\begin{tabular}{|c|c|c|c|c|c|c|c|c|c|c|c|}
\hline \multirow{2}{*}{$\begin{array}{l}\text { Year } \\
\text { Resp. } \\
\text { PBI }\end{array}$} & \multirow[b]{2}{*}{$\begin{array}{l}\text { All } \\
\text { Taiwan }\end{array}$} & \multirow[b]{2}{*}{ Taipei } & \multicolumn{3}{|c|}{ Prefectures* } & \multirow[b]{2}{*}{$\begin{array}{l}\text { Kao- } \\
\text { hsiung }\end{array}$} & \multicolumn{5}{|c|}{$\begin{array}{c}\text { Indexed Crude Death Rates by Cause, } \\
\text { All Taiwan }=100\end{array}$} \\
\hline & & & $H \operatorname{sinchu}$ & $\begin{array}{l}\text { Tai- } \\
\text { chung }\end{array}$ & Tainan & & Taipei & Hsinchu & $\begin{array}{l}\text { Tai- } \\
\text { chung }\end{array}$ & Tainan & $\begin{array}{l}\text { Kao- } \\
\text { hsiung }\end{array}$ \\
\hline \multicolumn{12}{|l|}{ Males } \\
\hline $24-26$ & 809 & 687 & 575 & 870 & 957 & 874 & 84.9 & 71.1 & 107.5 & 118.3 & 108.0 \\
\hline $29-3 I$ & 697 & 673 & 562 & 743 & 766 & 804 & 96.6 & 80.6 & 106.6 & 109.9 & $115 \cdot 4$ \\
\hline $34-36$ & 704 & 648 & $6 \mathrm{I} 8$ & 759 & 749 & 730 & 92.0 & 87.8 & 107.8 & 106.4 & 103.7 \\
\hline $39-4 \mathrm{I}$ & 683 & 530 & 509 & 760 & 838 & $67 \mathrm{I}$ & 77.6 & $74 \cdot 5$ & 111.3 & 122.7 & 98.2 \\
\hline \multicolumn{12}{|c|}{ Females } \\
\hline $24-26$ & 671 & 606 & 469 & 685 & 788 & 735 & 90.3 & 69.9 & 102.1 & $117 \cdot 4$ & $109 \cdot 5$ \\
\hline $29-31$ & 586 & 600 & 465 & 563 & 633 & 688 & 102.4 & $79 \cdot 4$ & 96.1 & 108.0 & $117 \cdot 4$ \\
\hline $34-36$ & 579 & 567 & 534 & 590 & 6oI & 621 & $97 \cdot 9$ & 92.2 & 101.9 & 103.8 & $107 \cdot 3$ \\
\hline $39-4 \mathrm{I}$ & 542 & 422 & $4 \mathrm{I} 7$ & 580 & 653 & $5^{6 I}$ & $77 \cdot 9$ & 76.9 & 107.0 & 120.5 & 103.5 \\
\hline
\end{tabular}

* Figures for Kaohsiung in I924-26 have been adjusted to exclude Penghu.

(excepting I934-36). But the rates in the high ranking prefectures exceed the allTaiwan average by only I0-20\%. Still it is interesting to discover that the same north-south gradient in death rates (despite the north's having colder, wetter winters) appears in the case of respiratory diseases as in the case of malaria.

Pneumonia death rates were the highest of the three named diseases; cases of pneumonia often bring on death after a person has been stricken by some other disease. What accounts for the higher rates - diet (pneumonia is nutritionally sensitive, meaning that victims of the disease who are malnourished will suffer more serious cases), environmental and climatic conditions, lowered resistance due to a heavier incidence of concurrent diseases, or higher exposure rates? Tainan and Kaohsiung have already figured prominently in our discussion of malaria and respiratory tuberculosis, increasing the probability that comorbidity plays an important role in higher respiratory disease rates.

Diarrhea and Enteritis. Diarrhea and enteritis were consistently among the leading causes of death, accounting for approximately I2-15\% of total deaths for both sexes, I924-I94I. Death rates attributed to diarrhea and enteritis were regularly at their lowest in Hsinchu followed by Taipei, and at their highest in Tainan, I924-4I. Hsinchu (47-57\% of the all island average) and Taipei (63-80\%) rates are substantially lower than the all Taiwan average, which is pushed up by very 

Enteritis, 1924-I94I. Deaths per 100,000.

\begin{tabular}{|c|c|c|c|c|c|c|c|c|c|c|c|}
\hline Year & \multirow[b]{2}{*}{ All } & \multirow[b]{2}{*}{ Taipei } & \multicolumn{3}{|c|}{ Prefectures* } & \multirow[b]{2}{*}{$\begin{array}{l}\text { Kao- } \\
\text { hsiung }\end{array}$} & \multicolumn{5}{|c|}{$\begin{array}{l}\text { Indexed Crude Death Rates by Cause, } \\
\text { All Taiwan }=100\end{array}$} \\
\hline $\begin{array}{l}\text { Diarrhea } \\
\text { Enteritis }\end{array}$ & & & Hsinchu & $\begin{array}{l}\text { Tai- } \\
\text { chung }\end{array}$ & Tainan & & Taipei & Hsinchu & $\begin{array}{l}\text { Tai- } \\
\text { chung }\end{array}$ & Tainan & $\begin{array}{l}\text { Kao- } \\
\text { hsiung }\end{array}$ \\
\hline \multicolumn{12}{|l|}{ Males } \\
\hline $24-26$ & 330 & 207 & $\mathrm{I} 72$ & 334 & 457 & 344 & 62.7 & 52.1 & 101.2 & 138.5 & 104.2 \\
\hline $29-3 \mathrm{I}$ & 340 & 215 & I6I & 352 & $46 I$ & 420 & 63.2 & $47 \cdot 4$ & 103.5 & 135.6 & 123.5 \\
\hline $34-36$ & $27 \mathrm{I}$ & 198 & I54 & 282 & $34 \mathrm{I}$ & 320 & 73.1 & 56.8 & 104.1 & 125.8 & 118.1 \\
\hline $39-4 \mathrm{I}$ & 244 & 152 & $\mathrm{I} 25$ & 283 & 322 & 272 & 62.3 & 51.2 & 116.0 & 132.0 & 111.5 \\
\hline \multicolumn{12}{|l|}{ Females } \\
\hline $24-26$ & 330 & 223 & I73 & 342 & 432 & 345 & 67.6 & 52.4 & 103.6 & 130.9 & 104.5 \\
\hline $29-3 \mathrm{I}$ & $35 \mathrm{I}$ & 246 & 165 & 366 & 469 & $42 \mathrm{I}$ & 70.1 & 47.0 & 104.3 & 133.6 & 119.9 \\
\hline $34-36$ & 277 & $22 \mathrm{I}$ & I54 & 282 & 346 & 322 & 79.8 & 55.6 & 101.8 & 124.9 & 116.2 \\
\hline $39-4 \mathrm{I}$ & 244 & IGI & I30 & 275 & 312 & 277 & 66.0 & $53 \cdot 3$ & 112.7 & 127.9 & 113.5 \\
\hline
\end{tabular}

* Figures for Kaohsiung in 1924-26 have been adjusted to exclude Penghu.

high rates in the south. Tainan's rates (25-39\% higher than the average) are more than twice as high as Hsinchu's. The diarrhea rates thus show a sharp divide between the northern and the southern prefectures (including Taichung), similar to that we found for malaria and respiratory tuberculosis, though not as extreme as in the case of malaria. Diarrheal disease rates by sex show a slight female excess in all prefectures and periods; sex ratios of mortality for these diseases generally range from 95 to Ioo. It is interesting that the sex ratio of mortality remains largely constant across sharp regional variations. Why should women, who have such a large advantage over men in respiratory tuberculosis and respiratory diseases, have a slight disadvantage in the diarrheas, when all three categories of disease are considered nutritionally sensitive?

What can explain such a sharp regional difference? Differential exposure (perhaps resulting from climatic factors favoring bacterial growth) and resistance are likely possibilities. The cooler northern climate likely benefits Hsinchu and Taipei in reducing the amount of food and drink contaminated by bacteria. Could differences in food and drink sanitation practices between north and south also play a role in the regional contrasts? It is important to note that diarrheas, because they interfere with the absorption of nutrients can be important causes of the worsening of concurrent diseases. Higher rates of diarrhea and enteritis thus likely play an important role in raising the rates of death from other diseases. 
Diarrhea and Enteritis, 1934-194I. Deaths per 100,000.

\begin{tabular}{|c|c|c|c|c|c|c|c|c|c|c|c|}
\hline \multirow{2}{*}{$\begin{array}{l}\text { Year } \\
\text { Diarrhea }\end{array}$} & & \multirow[b]{2}{*}{ Taipei } & \multicolumn{3}{|c|}{ Prefectures* } & \multirow[b]{2}{*}{$\begin{array}{l}\text { Kao- } \\
\text { hsiung }\end{array}$} & \multicolumn{5}{|c|}{$\begin{array}{l}\text { Indexed Crude Death Rates by Cause, } \\
\qquad \text { All Taiwan }=100\end{array}$} \\
\hline & $\begin{array}{l}\text { All } \\
\text { Taiwan }\end{array}$ & & Hsinchu & $\begin{array}{l}\text { Tai- } \\
\text { chung }\end{array}$ & Tainan & & Taipei & Hsinchu & $\begin{array}{l}\text { Tai- } \\
\text { chung }\end{array}$ & Tainan & $\begin{array}{l}\text { Kao- } \\
\text { hsiung }\end{array}$ \\
\hline \multicolumn{12}{|l|}{ Males<2 } \\
\hline $34-36$ & 2470 & $2 \mathrm{I} 42$ & 1633 & 2573 & 2758 & 2882 & 86.7 & 66.I & IO4.2 & III.7 & II 6.7 \\
\hline $39-4 \mathrm{I}$ & 2055 & 1526 & II94 & 2288 & $25 \mathrm{I} 7$ & 2234 & $74 \cdot 3$ & $58 . \mathrm{I}$ & III.3 & I22. 5 & I08.7 \\
\hline \multicolumn{12}{|c|}{ Females $<2$} \\
\hline $34-36$ & 2478 & 2276 & I577 & $26 I 6$ & $277 \mathrm{I}$ & 2799 & 91.8 & 63.6 & 105.6 & III. 8 & II 3.0 \\
\hline $39-4 \mathrm{I}$ & 2047 & I599 & I257 & 2298 & 2396 & 2207 & 78.I & 6r.4 & II 2.3 & II7.0 & 107.8 \\
\hline \multicolumn{12}{|l|}{ Males>2 } \\
\hline $34-36$ & 83 & 49 & 32 & $8 \mathrm{I}$ & II9 & 94 & $59 \cdot 0$ & 38.6 & $97 \cdot 6$ & $\mathrm{I} 43.4$ & II 3.3 \\
\hline $39-4 \mathrm{I}$ & 90 & 47 & 33 & IOO & I32 & IO3 & 52.2 & 36.7 & III.I & 146.7 & II 4.4 \\
\hline \multicolumn{12}{|c|}{ Females $>2$} \\
\hline $34-36$ & 88 & 62 & 37 & 78 & I24 & IO4 & 70.0 & $4^{2.0}$ & 88.6 & 140.9 & II 8.2 \\
\hline $39-4 \mathrm{I}$ & 92 & 47 & 37 & 96 & I35 & IIO & 5I.I & 40.2 & IO4.3 & 146.7 & II9. 6 \\
\hline
\end{tabular}

Table io. Sex Ratios of Cause, Age and Sex Specific Death Rates of Taiwanese, Diarrhea and Enteritis, 1934-I94I. Male Death Rate/Female Death Rate.

\begin{tabular}{|c|c|c|c|c|c|c|}
\hline Year & & Prefectures & & & & \\
\hline Diarrhea & All Taiwan & Taipei & Hsinchu & Taichung & Tainan & Kaohsiung \\
\hline \multicolumn{7}{|l|}{ Enteritis } \\
\hline \multicolumn{7}{|l|}{ Age $<2$} \\
\hline I934-36 & I.OO & 0.94 & I.O4 & $0.9^{8}$ & I.OO & 1.03 \\
\hline I939-4I & I.OO & 0.95 & 0.95 & I.OO & I.O5 & I.OI \\
\hline \multicolumn{7}{|l|}{ Age $>2$} \\
\hline I934-36 & 0.94 & 0.79 & 0.86 & I.O4 & 0.96 & 0.90 \\
\hline I939-4I & 0.98 & I.OO & 0.89 & I.O4 & $0.9^{8}$ & 0.94 \\
\hline
\end{tabular}

Diarrheal diseases are an important cause of infant mortality and a large proportion of deaths due to diarrhea occur in infancy $(42 \%$ and $37 \%$ for males and females in 1939-4I), early childhood (35\% and $42 \%$ for males and females ages I-4, I939-4I), and in the older age groups age 55 and above (I0\% I939-4I). 
The fourth international classification of causes of death separates deaths due to diarrhea below age 2 from deaths above age 2. Thus for the years $1934-36$ and I939-4I we are able to report age and cause specific death rates for diarrhea across the prefectures. The very high diarrhea death rates below age 2 reflect the concentration of diarrhea deaths in infancy and early childhood. In I939-4I 65\% and $66 \%$ of all male and female diarrhea deaths occurred below age 2 . Both age groupings show sharp regional difference between low northern and high southern diarrhea death rates; the regional contrast is even greater above age two. The high diarrhea death rates below age 2 provide insight into a leading cause of infant mortality and a major contributor to regional differences in infant death rates. In I939-4I diarrhea and enteritis deaths accounted for $19 \%$ and $21 \%$ of all male and female deaths below age 2 and $16 \%$ and I7\% below age I.

These findings have relevance for our understanding of the impact of adoption on infant and early childhood death rates, especially for females. We have strong evidence that adoption at early ages is associated with elevated rates of female mortality (Wolf I995: 302ff., Yu Kuang-hong et al. this volume). A likely causal pathway raising the death rates of adopted girls is one that links early weaning and consumption of contaminated food and drink to diarrheal diseases. If our assumption that rates of adoption of girls at young ages are much higher in Taipei and Hsinchu than in the south is correct, and that adoption is an important determinant of infant and early childhood mortality patterns overall, we would expect to find higher rates of diarrheal mortality among girls compared to boys in the northern prefectures, and among girls in the north compared to girls in the south. Diarrheal causes of death are concentrated in the postneonatal period (see Shepherd "Trends", infra), so the strong disadvantage of boys in the neonatal period compared to girls should not affect our comparison. We find that girls below age 2 suffer from higher rates than boys in Taipei in both years and Hsinchu in one year, while in the other prefectures there is little difference between the sexes. This gives some support to the hypothesis that female adoption elevates diarrheal death rates in the north, rather than a general son preference - daughter neglect pattern that would raise female rates (both adopted and non-adopted) in all prefectures. However, the regional comparison casts doubt on the overall significance of the adoption hypothesis. Southern rates of female diarrheal mortality below age 2 are much higher than northern rates, despite the presumed low rates of female adoption. That diarrheal death rates are much higher in the south for both sexes both below age 2 and above shows that environmental and epidemiological factors are much more important than adoption patterns as determinants of levels of diarrheal disease mortality in all the prefectures.

Certain Diseases of Infancy. 'Certain diseases of infancy' is a cause category restricted to deaths occurring in infancy, and which includes causes occurring 

Diseases of Infancy, I924-I94I. Deaths per 100,000.

\begin{tabular}{|c|c|c|c|c|c|c|c|c|c|c|c|}
\hline \multirow{2}{*}{$\begin{array}{l}\text { Year } \\
\text { Dis. of } \\
\text { Infancy }\end{array}$} & \multirow[b]{2}{*}{$\begin{array}{l}\text { All } \\
\text { Taiwan }\end{array}$} & \multirow[b]{2}{*}{ Taipei } & \multicolumn{3}{|c|}{ Prefectures* } & \multirow[b]{2}{*}{$\begin{array}{l}\text { Kao- } \\
\text { hsiung }\end{array}$} & \multicolumn{5}{|c|}{$\begin{array}{l}\text { Indexed Crude Death Rates by Cause, } \\
\qquad \text { All Taiwan }=100\end{array}$} \\
\hline & & & Hsinchu & $\begin{array}{l}\text { Tai- } \\
\text { chung }\end{array}$ & Tainan & & Taipei & Hsinchu & $\begin{array}{l}\text { Tai- } \\
\text { chung }\end{array}$ & Tainan & $\begin{array}{l}\text { Kao- } \\
\text { hsiung }\end{array}$ \\
\hline \multicolumn{12}{|l|}{ Males } \\
\hline $24-26$ & I42 & I35 & 136 & I43 & I59 & I 22 & 95.1 & 95.8 & 100.7 & 112.0 & 85.9 \\
\hline 29-3I & I32 & I32 & II4 & I27 & I47 & I33 & 100.0 & 86.4 & 96.2 & 111.4 & 100.8 \\
\hline $34-36$ & I44 & I59 & I35 & 130 & I52 & I35 & 110.4 & 93.8 & 90.3 & 105.6 & 93.8 \\
\hline $39-4 \mathrm{I}$ & I29 & I35 & 96 & I23 & I57 & II9 & 104.7 & 74.4 & $95 \cdot 3$ & 121.7 & 92.2 \\
\hline \multicolumn{12}{|l|}{ Females } \\
\hline $24-26$ & IO9 & II 2 & IO2 & I09 & II9 & 88 & 102.8 & 93.6 & 100.0 & 109.2 & 80.7 \\
\hline $29-31$ & IOO & I07 & 82 & 96 & IO7 & 99 & 107.0 & 82.0 & 96.0 & 107.0 & 99.0 \\
\hline $34-36$ & 109 & I24 & $9^{6}$ & 97 & II6 & IO7 & 113.8 & 88.1 & 89.0 & 106.4 & 98.2 \\
\hline $39-4 \mathrm{I}$ & IO2 & IO8 & 77 & 98 & $\mathrm{I} 22$ & 95 & 105.9 & $75 \cdot 5$ & 96.1 & 119.6 & 93.1 \\
\hline
\end{tabular}

* Figures for Kaohsiung in I924-26 have been adjusted to exclude Penghu.

overwhelmingly in the first month of life, such as congenital malformation, debility, prematurity, and birth trauma. Hsinchu regularly reports the lowest or next lowest rates (excepting males 1924-26 when Hsinchu ranks third), and Tainan regularly reports the highest or next highest rates. Both the Hsinchu advantage over the all Taiwan average and the Tainan excess are the smallest of the disease groups discussed. Because the certain diseases of infancy category reports primarily endogenous and neonatal deaths, rather than exogenous causes related to environmental exposures, a smaller degree of variation among the prefectures is to be expected.

Note that while the death rates reported in this category are the smallest of the disease groups reported so far, they exceed the rates reported for malaria in I93I-4I for all prefectures (excepting Kaohsiung females) and for the northern prefectures from 1924. Thus certain diseases of infancy though restricted to the first year of life nevertheless ranks high as a leading cause of death for all prefectures. But note also that these rates are reported as a crude death rate where the entire population forms the denominator when in fact the population at risk is restricted to newborns.

To get a more precise picture of variation across the prefectures with respect to infant causes of death we can refine these measures by limiting the denominator to the exposed population of live births. The 'certain diseases of 
Table I2 Infant Death Rates and certain neonatal causes of death by prefecture, I924-4I. Deaths per thousand.

\begin{tabular}{|c|c|c|c|c|c|c|c|c|}
\hline \multirow{2}{*}{$\begin{array}{l}\text { Year } \\
\text { IDR }\end{array}$} & & \multirow{2}{*}{$\begin{array}{l}\text { Prefectures } \\
\text { Hsinchu Tai- } \\
\text { chung }\end{array}$} & \multirow[b]{2}{*}{ Tainan } & \multicolumn{5}{|c|}{$\begin{array}{l}\text { Indexed Crude Death Rates by Cause, } \\
\text { All Taiwan }=100\end{array}$} \\
\hline & $\begin{array}{l}\text { All Taipei } \\
\text { Taiwan }\end{array}$ & & & $\begin{array}{l}\text { Kao- } \\
\text { hsiung }\end{array}$ & Taipei & $\begin{array}{l}\text { Hsinchu Tai- } \\
\text { chung }\end{array}$ & Tainan & $\begin{array}{l}\text { Kao- } \\
\text { hsiung }\end{array}$ \\
\hline
\end{tabular}

Males

InfDeathRate

$\begin{array}{llllllllllll}\text { I924-26** } & \text { I8I.7 } & \text { I70.2 } & \text { I54.6 } & \text { I79.7 } & \text { I94.8 } & 207.6 & 93.7 & 85.1 & 98.9 & 107.2 & 114.3 \\ \text { I929-3I } & \text { I70.3 } & \text { I68.I } & \text { I43.9 } & \text { I69.5 } & \text { I76.6 } & \text { I90.6 } & 98.7 & 84.5 & 99.5 & 103.7 & 111.9 \\ \text { I934-36 } & \text { I62.0 } & \text { I63.9 } & \text { I53.9 } & \text { I6I.0 } & \text { I64.4 } & \text { I65.5 } & 101.2 & 95.0 & 99.4 & 101.5 & 102.2 \\ \text { I939-4I } & \text { I44.0 } & \text { I33.0 } & \text { I23.8 } & \text { I43.9 } & \text { I59.5 } & \text { I45.5 } & 92.4 & 86.0 & 99.9 & 110.8 & 101.0 \\ \text { NN death rate } & & & & & & & & & & & \\ \text { I924-26 } & \text { 90.9 } & 80.6 & 73.6 & 9 \text { I.0 } & \text { IOI.3 } & \text { III.5 } & 88.7 & 81.0 & 100.1 & 111.4 & 122.7 \\ \text { I929-3I } & \text { 8I.9 } & \text { 8I.3 } & 69.8 & 84.3 & 84.0 & 9 \text { I.2 } & 99.3 & 85.2 & 102.9 & 102.6 & 111.4 \\ \text { I934-36 } & 74.8 & 74 . I & 74.2 & 74 . I & 76.4 & 76.3 & 99.1 & 99.2 & 99.1 & 102.1 & 102.0 \\ \text { I939-4I } & 67.7 & - & - & - & - & - & & & & & \end{array}$

PNN death rate*

$\begin{array}{llllllllllll}\text { I924-26 } & 99.9 & 97.5 & 87.5 & 97.6 & \text { I04.0 } & \text { I08.I } & 97.6 & 87.6 & 97.7 & 104.1 & 108.2 \\ \text { I929-3I } & 96.3 & 94.6 & 79.7 & 93.0 & \text { I0I.0 } & \text { I09.4 } & 98.2 & 82.8 & 96.6 & 104.9 & 113.6 \\ \text { I934-36 } & 94.3 & 97.0 & 86.0 & 93.9 & 95.2 & 96.6 & 102.9 & 91.2 & 99.6 & 101.0 & 102.4 \\ \text { I939-4I } & 8 \text { I.8 } & - & - & - & - & - & & & & & \\ \text { NN\% } & & & & & & & & & & & \\ \text { I924-26 } & 50.0 & 47.4 & 47.6 & 50.6 & 52.0 & 53.7 & 94.8 & 95.2 & 101.2 & 104.0 & 107.4 \\ \text { I929-3I } & 48.1 & 48.3 & 48.5 & 49.8 & 47.6 & 47.8 & 100.4 & 100.8 & 103.5 & 99.0 & 99.4 \\ \text { I934-36 } & 46.1 & 45.2 & 48.2 & 46.0 & 46.5 & 46.1 & 98.0 & 104.6 & 99.8 & 100.9 & 100.0 \\ \text { I939-4I } & 47.0 & - & - & - & - & - & & & & & \end{array}$

Cert.Dis.Infancy

$\begin{array}{llllllllllll}\text { I924-26 } & 32.4 & 33.9 & 3 \text { I.3 } & \text { 3I.3 } & 35.9 & 29.2 & 104.6 & 96.6 & 96.6 & 110.8 & 90.1 \\ \text { I929-3I } & 28.4 & 3 \text { I.6 } & 25.7 & 26 . \text { I } & 29 . \text { I } & 28.7 & 111.3 & 90.5 & 91.9 & 102.5 & 101.1 \\ \text { I934-36 } & 3 \text { I.0 } & 38.3 & 30.6 & 26.8 & 30.5 & 28.9 & 123.5 & 98.7 & 86.5 & 98.4 & 93.2 \\ \text { I939-4I } & 28.4 & 32.8 & 2 \text { I.3 } & 25.6 & 32.3 & 27.5 & 115.5 & 75.0 & 90.1 & 113.7 & 96.8 \\ \text { Tetanus*** } & & & & & & & & & & & \\ \text { I934-36 } & \text { 25.6 } & 20.5 & 28.4 & 26.4 & 25.9 & 27.7 & 80.1 & 110.9 & 103.1 & 101.2 & 108.2 \\ \text { I939-4I } & \text { 23.I } & \text { I8.6 } & 27.6 & 22.2 & 24 . \text { I } & 23.9 & 80.5 & 119.5 & 96.1 & 104.3 & 103.5 \\ \text { Females } & & & & & & & & & & & \\ \text { InfDeathRate } & & & & & & & & & & & \\ \text { I924-26** } & \text { I5I.5 } & \text { I43.4 } & \text { I23.7 } & \text { I46.7 } & \text { I63.8 } & \text { I73.2 } & 94.7 & 81.7 & 96.8 & 108.1 & 114.3 \\ \text { I929-3I } & \text { I4I.8 } & \text { I44.8 } & \text { II5.0 } & \text { I36.5 } & \text { I44.0 } & \text { I66.9 } & 102.1 & 81.1 & 96.3 & 101.6 & 117.7\end{array}$




$\begin{array}{llllllllllll}\text { I934-36 } & \text { I35.6 } & \text { I43.6 } & \text { I23.5 } & \text { I29.2 } & \text { I37.2 } & \text { I43.7 } & 105.9 & 91.1 & 95.3 & 101.2 & 106.0 \\ \text { I939-4I } & \text { I20.8 } & \text { III.3 } & \text { I0I.4 } & \text { II7.8 } & \text { I34.6 } & \text { I27.I } & 92.1 & 83.9 & 97.5 & 111.4 & 105.2 \\ \text { NN death rate } & & & & & & & & & & & \\ \text { I924-26 } & 67.3 & \text { 60.I } & 52.8 & 66.5 & 75.5 & 8 \text { I.I } & 89.3 & 78.5 & 98.8 & 112.2 & 120.5 \\ \text { I929-3I } & \text { 60.I } & \text { 6I.6 } & 48.5 & 60.4 & 59.7 & 7 \text { I.I } & 102.5 & 80.7 & 100.5 & 99.3 & 118.3 \\ \text { I934-36 } & 55.4 & 57.0 & 5 \text { I.8 } & 53.5 & 56.4 & 59.8 & 102.9 & 93.5 & 96.6 & 101.8 & 107.9 \\ \text { I939-4I } & 52.0 & - & - & - & - & - & & & & & \end{array}$

PNN death rate*

$\begin{array}{llllllllllll}\text { I924-26 } & 90.3 & 88.7 & 74.8 & 85.9 & 95.5 & \text { I00.3 } & 98.2 & 82.8 & 95.1 & 105.8 & 111.1 \\ \text { I929-3I } & 86.9 & 88.7 & 69.9 & 8 \text { I.0 } & 89.7 & \text { I03.I } & 102.1 & 80.4 & 93.2 & 103.2 & 118.6 \\ \text { I934-36 } & 84.9 & 9 \text { I.8 } & 75.6 & 80.0 & 85.6 & 89 . \text { I } & 108.1 & 89.0 & 94.2 & 100.8 & 104.9 \\ \text { I939-4I } & 72.6 & - & - & - & - & - & & & & & \end{array}$

\section{NN\%}

$\begin{array}{llllllllllll}\text { I924-26 } & 44.4 & 4 \text { I.9 } & 42.7 & 45.3 & 4 \text { 6.I } & 46.8 & 94.4 & 96.2 & 102.0 & 103.8 & 105.4 \\ \text { I929-3I } & 42.4 & 42.6 & 42 . \mathrm{I} & 44.3 & 4 \text { I.4 } & 42.6 & 100.5 & 99.3 & 104.5 & 97.6 & 100.5 \\ \text { I934-36 } & 40.9 & 39.7 & 4 \text { I.9 } & 4 \text { I.4 } & 4 \text { I.I } & 4 \text { I.7 } & 97.1 & 102.4 & 101.2 & 100.5 & 102.0 \\ \text { I939-4I } & \text { 43.I } & - & - & - & - & - & & & & & \end{array}$

Cert.Dis.Infancy

\begin{tabular}{|c|c|c|c|c|c|c|c|c|c|c|c|}
\hline I924-26 & $25 . \mathrm{I}$ & 27.5 & $24 \cdot \mathrm{I}$ & 24.2 & $27 . I$ & 2І. 8 & 109.6 & 96.0 & 96.4 & 108.0 & 86.9 \\
\hline I929-3I & 21.9 & $25 \cdot 5$ & I9.I & 20.1 & 21.8 & $2 \mathrm{I} .7$ & 116.4 & 87.2 & 91.8 & $99 \cdot 5$ & 99.1 \\
\hline I934-36 & $24 \cdot 3$ & 29.9 & 22.6 & 20.6 & $24 \cdot 3$ & 23.4 & 123.0 & 93.0 & 84.8 & 100.0 & 96.3 \\
\hline I939-4I & 23.5 & 26.3 & I8.I & $2 \mathrm{I} .4$ & 26.7 & 22.5 & 111.9 & 77.0 & 91.1 & 113.6 & $95 \cdot 7$ \\
\hline \multicolumn{12}{|l|}{ Tetanus**** } \\
\hline I934-36 & I8.7 & I5.7 & 19.3 & I8.6 & I9.8 & 2I.I & 84.0 & 103.2 & $99 \cdot 5$ & 105.9 & 112.8 \\
\hline I939-4I & I7.3 & I3. 8 & I8.9 & I5.8 & I9.2 & I9.6 & 79.8 & 109.2 & $91 \cdot 3$ & 111.0 & $113 \cdot 3$ \\
\hline Total Fertility & 6.24 & 5.77 & 6.43 & 6.5 & 6.66 & 5.96 & 92.5 & 103.0 & 104.2 & 106.7 & $95 \cdot 5$ \\
\hline \multicolumn{12}{|c|}{ Rate, I94I $I^{*} * * * *$} \\
\hline Total Marital & 7.62 & 6.85 & 7.8 & 8.01 & 8.13 & $7 \cdot 34$ & 89.9 & 102.4 & 105.1 & 106.7 & 96.3 \\
\hline \multicolumn{12}{|l|}{ Fertility Rate, } \\
\hline $1941^{* * * * * *}$ & & & & & & & & & & & \\
\hline
\end{tabular}

* PNN death rate calculated as deaths per survivors of the first month of life.

**infant death rate reported here diverges from the life table infant mortality rate in $1924-26$ where the life table is based on birth cohorts and uses only two full years of infant deaths and births spread across the I92426 period.

$* * *$ Infantile Tetanus for prefectures is estimated as $82 \%$ of reported deaths due to "other infectious and parasitic" causes, except in $1934-36$ when it is $83 \%$ for males.

**** Fertility rates calculated from Fubo no nenreibetsu shussei oyobi shisan tōkei, I94I (Statistics of live births and stillbirths by age of parents). Taiwan Sōtokufu Sōmukyoku. Taihoku i943. 
infancy' category reports only deaths in the first year of life, which enables us to report such deaths per thousand live births. The table above presents several additional measures of infant mortality. First is a direct computation of the infant death rate, the neonatal and postneonatal death rates, and the percentage of infant deaths neonatal by prefecture and sex. Second is the rate of infantile tetanus, I934-4I (estimated for the prefectures as $82 \%$ of reported deaths due to "other infectious and parasitic" causes, based on the detailed list used in the reports of deaths by age for all Taiwan in those years). Infantile tetanus is a cause of death occurring overwhelmingly in the first month of life. However, there is some reason to believe that infantile tetanus was 'overreported', as neonatal deaths from other causes were carelessly reported as infantile tetanus; this does not however affect our assessment that this category reports overwhelmingly neonatal deaths (see Shepherd "Trends", infra). Third are reports of the total and marital fertility rates by prefecture for I94I.

Despite having lower than average infant death rates and lower than average neonatal death rates, Hsinchu has higher than average rates of deaths due to 'tetanus', and Taipei higher than average rates of deaths due to certain diseases of infancy.

Hsinchu's neonatal death rate is low despite having above average fertility rates while Kaohsiung's neonatal death rate is high despite having below average fertility rates. This suggests that explanations relying on excess fertility and crowded spacing to explain high neonatal death rates are less important than factors related to the disease environment in the various prefectures. This contradicts the usual assumption that neonatal deaths are relatively immune to environmental influences. Perhaps environmental influences on neonatal death rates are operating via effects on maternal health, independent of fertility, which in turn result in higher proportions of low birth weight babies?

Certain diseases of infancy and tetanus combined account for at least $70 \%$ of total neonatal deaths in 1934 (see Shepherd "Trends", infra). From I924 to I94I, the PBI category accounts for $27-32 \%$ of total infant deaths, the diarrhea category accounts for $16-21 \%$, certain diseases of infancy accounts for $16-20 \%$, the tetanus category accounts for $\mathrm{I} 3-\mathrm{I} 7 \%$, and malaria accounts for I-3\%. While certain diseases of infancy and tetanus account for the bulk of neonatal deaths, respiratory diseases and diarrheas account for the bulk of postneonatal diseases (Shepherd "Trends", infra). Of the causes of death reviewed here, malaria and respiratory tuberculosis are of little significance in infant mortality.

The patterns of difference between the prefectures with regard to the infant death rates and neonatal and postneonatal death rates confirm our impression that Hsinchu is the healthiest prefecture and Tainan and Kaohsiung are the least healthy. Overall the degree of variation among the prefectures in infant death rates is more moderate than for many of the causes we have reviewed; 


\begin{tabular}{|c|c|c|c|c|c|c|c|c|c|c|c|}
\hline \multirow{2}{*}{$\begin{array}{l}\text { Year } \\
I D R\end{array}$} & \multicolumn{5}{|c|}{ Prefectures* } & \multicolumn{6}{|c|}{$\begin{array}{c}\text { Indexed Infant Death Rate, } \\
\text { All Taiwan }=100\end{array}$} \\
\hline & $\begin{array}{l}\text { All } \\
\text { Taiwan }\end{array}$ & Taipei & Hsinchu & $\begin{array}{l}\text { Tai- } \\
\text { chung }\end{array}$ & Tainan & $\begin{array}{l}\text { Kao- } \\
\text { hsiung }\end{array}$ & Taipei & Hsinchu & $\begin{array}{l}\text { Tai- } \\
\text { chung }\end{array}$ & Tainan & $\begin{array}{l}\text { Kao- } \\
\text { hsiung }\end{array}$ \\
\hline \multicolumn{12}{|l|}{ Males } \\
\hline $06-08 *$ & I94.0 & I 84.5 & I59.4 & 200.I & 201.6 & I99.3 & 95.1 & 82.2 & 103.1 & 103.9 & 102.7 \\
\hline I4-I6* & I96.6 & 192.0 & 178.2 & 2O2.I & 207.9 & 205.7 & $97 \cdot 7$ & 90.6 & 102.8 & 105.7 & 104.6 \\
\hline $20-22$ & I76.5 & I74.० & I56.3 & I86.2 & I73.0 & 190.7 & $9^{8.6}$ & 88.6 & $105 \cdot 5$ & $9^{8.0}$ & 108.0 \\
\hline $24-26$ & I8I.7 & I70.2 & I54.6 & I79.7 & I94.8 & 207.6 & 93.7 & 85.1 & $9^{8.9}$ & 107.2 & $114 \cdot 3$ \\
\hline $29-31$ & I70.3 & I68.I & I 43.9 & 169.5 & I76.6 & I90.6 & $9^{8.7}$ & 84.5 & $99 \cdot 5$ & 103.7 & 111.9 \\
\hline $34-36$ & 162.0 & 163.9 & 153.9 & I6I.o & I 64.4 & 165.5 & 101.2 & 95.0 & $99 \cdot 4$ & 101.5 & 102.2 \\
\hline $39-4 \mathrm{I}$ & I 44.0 & I33.0 & I23.8 & 143.9 & I59.5 & I $45 \cdot 5$ & 92.4 & 86.0 & $99 \cdot 9$ & 110.8 & 101.0 \\
\hline \multicolumn{12}{|l|}{ Females } \\
\hline $06-08 *$ & 193.0 & I57.I & I22.3 & 2II. 3 & I9I.I & 200.8 & 81.4 & 63.4 & $109 \cdot 5$ & 99.0 & 104.0 \\
\hline I4-I6* & I72.2 & I80.0 & I37.0 & I8I. 8 & I80.9 & I8I. 3 & 104.5 & 79.6 & 105.6 & 105.1 & $105 \cdot 3$ \\
\hline $20-22$ & $\mathrm{I} 48.3$ & I5I. 8 & I30.7 & I 49.5 & I 45.6 & I 62.5 & 102.4 & 88.1 & 100.8 & 98.2 & 109.6 \\
\hline $24-26$ & I5I. 5 & I 43.4 & I23.7 & 146.7 & I63.8 & 173.2 & 94.7 & 81.7 & 96.8 & 108.1 & 114.3 \\
\hline $29-31$ & I4I. 8 & I 44.8 & II 5.0 & I3 6.5 & I 44.0 & 166.9 & 102.1 & 81.1 & 96.3 & 101.6 & $117 \cdot 7$ \\
\hline $34-36$ & I35.6 & 143.6 & I23.5 & $\mathrm{I} 29.2$ & $\mathrm{I} 37.2$ & I 43.7 & 105.9 & 91.1 & $95 \cdot 3$ & 101.2 & 106.0 \\
\hline $39-4 \mathrm{I}$ & I2O.8 & III. 3 & IOI.4 & II7. 8 & 134.6 & I27.I & 92.1 & 83.9 & 97.5 & 111.4 & 105.2 \\
\hline
\end{tabular}

* Pre-I920 boundaries enclosed only parts of the areas defined by the boundaries set in I920. Figures for Kaohsiung in 1920-26 include Penghu.

Hsinchu's advantage and Kaohsiung and Tainan's excess above the all Taiwan average are relatively small. It is interesting that Kaohsiung's infant death rates in these periods are regularly higher than those in Tainan, which modifies our impression from the other causes of death that Tainan was more often the worse off. There is little variation among the prefectures in the percentage of infant deaths neonatal, which is higher for males than females. The sex ratio of mortality is highest for the neonatal death rates (generally ranging I30-I40) and falls in the postneonatal period (generally ranging IO7-II7), as is expected.

\section{Conclusion to Regional Differences}

One of the most striking features of these tables taken as a whole is that the advantage enjoyed by Hsinchu and the disadvantages suffered by Tainan and Kaohsiung are consistent across all causes, rather than concentrated in one or two. Moreover the advantages and disadvantages are constant across all periods 
Table I4. Crude Death Rates by Sex, Urban vs. Rural, All Causes, I929-I94I. Deaths per 100,000.

\begin{tabular}{|c|c|c|c|c|c|c|}
\hline \multirow{3}{*}{ Year } & \multirow{3}{*}{$\begin{array}{l}\text { Urban Taipei a } \\
\text { Keelung }\end{array}$} & \multicolumn{3}{|c|}{ Death Rates Inside and Outside Cities } & \multicolumn{2}{|c|}{ Ratio of Urban to Rural } \\
\hline & & Rural Taipei & Urban & Rural Tainan & Taipei & Tainan \\
\hline & & Pref. & Tainan & Pref. & & \\
\hline \multicolumn{7}{|l|}{ Males } \\
\hline $29-3 \mathrm{I}$ & 2483 & $2 \mathrm{I} 24$ & $236 \mathrm{I}$ & 2462 & 1.17 & 0.96 \\
\hline $34-36$ & 2405 & $224 \mathrm{I}$ & 1933 & 2254 & 1.07 & 0.86 \\
\hline $39-4 \mathrm{I}$ & $202 \mathrm{I}$ & 1857 & I8oI & 2380 & 1.09 & 0.76 \\
\hline \multicolumn{7}{|c|}{ Females } \\
\hline $29-3 \mathrm{I}$ & 2254 & 2048 & 2109 & 2169 & 1.10 & 0.97 \\
\hline $34-36$ & 2107 & 2136 & $\mathrm{I} 778$ & I98I & 0.99 & 0.90 \\
\hline $39-4 \mathrm{I}$ & I779 & 1660 & I684 & 2050 & 1.07 & 0.82 \\
\hline
\end{tabular}

despite fluctuations in rates. This pattern of division between "healthy districts" and "unhealthy districts" suggests that disease comorbidity is an important contributor to overall death rates. High rates of diseases like malaria and diarrheas in the warmer southern districts lower the population's immune resistance and increase rates of secondary and opportunistic diseases like respiratory tuberculosis and pneumonias. But when a district like Hsinchu is relatively free of malaria and the diarrheas, the local population's immune responses remain relatively unimpaired, the population is better able to resist opportunistic infections, and the result is lower death rates overall.

A separate comparison of the large cities of Taipei-Keelung and Tainan for each of the cause categories (not shown here) shows that in comparison to the rural areas of their respective prefectures both cities have lower death rates for malaria, diarrheas, and respiratory diseases. But this urban advantage is offset by communicable diseases such as respiratory tuberculosis, measles and whooping cough, which spread easily in dense populations and whose severity is greatest among the poorly nourished. The table above showing the urban-rural comparison for all causes summarizes the results.

The overall balance of factors finds urban Tainan enjoying a growing advantage over its countryside. But the disadvantage in respiratory tuberculosis and infectious diseases leaves urban Taipei-Keelung with net death rates higher than its countryside. Thus we find regional climatic and epidemiological factors, rather than urban-centered public health measures (contra Barclay) to be the most important determinants of northern Taiwan's regional advantage in mortality in colonial period Taiwan. 
In the balance of this paper we turn to discuss variation in mortality levels among the major ethnic groups in Taiwan (not considered here are the resident Japanese nationals). Among the questions we address are: Is there evidence that mortality varied by ethnicity in colonial Taiwan? Is such variation a consequence of regional variation in mortality or is it itself a determinant of regional variation? We begin with a brief introduction to Taiwan's ethnic groups.

A substantial majority of the colonial Taiwanese population were descendants of Han Chinese migrants from China's southern Fujian province and were speakers of the southern Min ("Minnan") language. These Minnan speakers are known as "Hoklo" (also "Hokkien") and their provenance/nationality was classified as "Fujianese" in the household registers and the censuses and vital statistics based on them. [Readers interested in a more detailed introduction to the definition of ethnic groups in Taiwan may refer to a previous essay by Shepherd et al., 2006 "Group identity and fertility." ] An important minority of Taiwanese descended from Han migrants from the province of Guangdong who spoke a Chinese language known as Kejia. These Kejia speakers are known as "Hakka" and were entered into the household registers as "Guangdongese."

The household registers assigned individuals to provenance groupings (Fujianese and Guangdongese) based on ancestral origin and descent (through the presumed biological father or mother if father was unknown) rather than ethnicity or language. For the great majority provenance and ethnolinguistic affiliation coincided unproblematically. The I9I5 census reports that more than 99\% of those registered as Fujianese were also Min speakers. However, approximately $15 \%$ of Guangdongese (from Chaochou prefecture) were speakers of a language more closely related to Minnan than Kejia. This is the most important exception to our practice of equating the provenance categories of Fujianese and Guangdongese to Hoklo and Hakka, respectively. Additional exceptions may result from marriages and adoptions across these categories.

A third ethnolinguistic grouping considered here is the Plains Aborigines, descendants of the indigenous Austronesian inhabitants of the island. The provenance/ nationality category used to enter the Plains Aborigines (also known as pingpuzu or "Pepo") into the household registers was "shu," meaning "shufan" or "civilized aborigine." Taiwan's Plains Aborigines descend from as many as ten separate ethnolinguistic groups dispersed across the lowland areas of the island, where they were early brought under Chinese influence and domination. A small minority in numbers, most Plains Aborigines by I9I5 were speakers of the southern Min language, and had adopted many Han customs.

During the I8th and igth centuries Taiwan was a frontier of Chinese agricultural settlement. The often times turbulent process of frontier settlement resulted in the creation of mutually antagonistic residentially segregated com- 
munities based on provenance and speech group. Conflicts between Hoklo and Hakka, and Hoklo or Hakka and Plains Aborigines were frequent, and reinforced the cultural identity of separate ethnic communities.

The two Han groups, Hoklo and Hakka, shared many Han customs, including patrilineal ancestor worship, strong parental authority, equal property inheritance among brothers, and folk religious practices. Hoklo and Hakka practiced similar forms of marriage and adoption, including little daughter in law marriage ('minor' marriage), and had similar levels of marital fertility (Shepherd et al. 2006). But there were also differences, most notably mutually unintelligible languages, different patron deities, and the Hakka refusal to bind the feet of daughters. This latter distinction meant that female Hakka were able to perform field labor and contribute economically to their families in ways denied to adult Hoklo women, over ninety percent of whom were bound-footed (up to I9I5 when the Japanese banned the practice, Shepherd 200I ms).

By the beginning of the twentieth century, Plains Aborigines had adopted many Hoklo customs and the great majority were native speakers of the southern Min language. Most Plains Aborigines practiced forms of family organization, property inheritance, marriage (excepting minor marriage), and folk religion similar to those of neighboring Han. Important markers of ethnic difference were the lack of footbinding among the Plains Aborigines, worship of distinctive deities on special festival days, and in some cases membership in Presbyterian and Catholic churches.

Despite the many similar customs shared among all three groups, the remaining differences, whether in language, footbinding or historical experience became the focus of separate ethnic identities that perdured into the twentieth century. Whether these cultural distinctions had important consequences for differential mortality among these groups is explored below.

\section{Changing Boundaries and the Regional Distribution of the Population by Ethnic Group}

In our discussion of demographic differences we need to keep in mind that the three groups, and especially the two minority ethnic groups (Hakka and Plains Aborigine), were not evenly distributed among all the localities of the island, but rather showed marked regional concentrations in certain prefectures. [Changes in prefectural boundaries in the Japanese period have been reviewed above.]

We look at the regional distribution of the ethnic groups in two ways; first we examine the ethnic composition of each prefecture's population. Among Taiwanese overall in I9I5, the Hoklo population clearly dominated demographically ( $82.8 \%$ of Taiwanese were Hoklo), and was spread widely throughout the island. The Hoklo were the majority ethnic group in every prefecture except Hsinchu, Taichung, and Hualien (in the latter two prefectures, mountain aborig- 
Taiwanese, 1915

\begin{tabular}{|c|c|c|c|c|c|}
\hline Prefecture & Fukien & Kwangtung & $\begin{array}{l}\text { Plains } \\
\text { Aborigine }\end{array}$ & $\begin{array}{l}\text { Total \% of } \\
\text { Taiwanese }^{*}\end{array}$ & $\begin{array}{l}\text { Number of } \\
\text { Taiwanese }\end{array}$ \\
\hline Taipei & $99.5 \%$ & $0.3 \%$ & $0.2 \%$ & $100.0 \%$ & 459353 \\
\hline Ilan & 96.8 & І.6 & І. 6 & 100.0 & I40IO3 \\
\hline Taoyuan & $54 \cdot 3$ & 45.5 & 0.2 & 100.0 & 228688 \\
\hline Hsinchu & 30.8 & 68.5 & 0.6 & 100.0 & 321020 \\
\hline Taichung & 89.7 & I0.2 & O.I & 100.0 & 579726 \\
\hline Nantou & 87.3 & 8.2 & 4.3 & 99.9 & I228IO \\
\hline Chiayi & 99.0 & 0.6 & 0.3 & 100.0 & 552605 \\
\hline Tainan & 98.8 & O.I & I.I & 100.0 & 545609 \\
\hline Ahou & 62.3 & 29.0 & 8.6 & 99.9 & 252067 \\
\hline Taitung & I0.6 & 3.4 & 6.7 & 20.7 & 34824 \\
\hline Hualien & 21.0 & 10.2 & $\mathrm{I} 3.8$ & 45.I & 33114 \\
\hline Penghu & 100.0 & $\circ$ & $\circ$ & I00.0 & 55836 \\
\hline Taiwan & $82.8 \%$ & $\mathrm{I} 4.4 \%$ & I. $4 \%$ & $98.6 \%$ & 3325755 \\
\hline
\end{tabular}

Census of 1915, kekka hyō. P. 8-9.

* Not included here are the additional Taiwanese subcategories 'other Han' and 'raw aborigines'.

Table i6. Ethnic composition of prefectural populations, by percent of Taiwanese, 1920

\begin{tabular}{llllll}
\hline Prefecture & Fukien & Kwangtung & $\begin{array}{l}\text { Plains } \\
\text { Aborigine }\end{array}$ & $\begin{array}{l}\text { Total \% of } \\
\text { Taiwanese* }\end{array}$ & $\begin{array}{l}\text { Number of } \\
\text { Taiwanese }\end{array}$ \\
\hline Taipei & $98.7 \%$ & $0.8 \%$ & $0.5 \%$ & 100.0\% & 658184 \\
Hsinchu & 37.4 & 62.I & 0.5 & 100.0 & 54940 I \\
Taichung & 88.3 & I0.9 & 0.8 & 100.0 & 754466 \\
Tainan & 98.5 & 0.7 & 0.8 & 100.0 & 922337 \\
Kaohsiung & 80.3 & I5.3 & 4.4 & 99.9 & 509270 \\
Taitung & II.8 & 3.9 & 7.4 & 23.1 & 35260 \\
Hualien & 23.7 & I4.I & I2.I & 49.9 & 37589 \\
Taiwan & $82.3 \%$ & I5.0\% & I.4\% & $98.7 \%$ & 3466507 \\
\hline
\end{tabular}

Census of 1920, daiikkai Taiwan kokusei chōsa yōran hyō, table I, pp. 2-7.

* Not included here are the additional Taiwanese subcategories 'other Han' and 'raw aborigines'. 
ines dominated). The Hakka (I4.4\% of the Taiwanese population) were the majority population in Hsinchu, and constituted large pluralities in Taoyuan and Ahou. Plains Aborigines (only I.4\% of the Taiwanese population) were always small minorities in the prefectures, but had significant presences in Hualien, Ahou, Taitung and Nantou. In the consolidation of prefectures in 1920 Hsinchu maintained its sizeable Hakka majority when it absorbed most of Taoyuan, and concentrations of Hakka in Kaohsiung, Hualien, and Taichung remained significant pluralities. The I920 consolidation meant that the Plains Aborigine concentrations in Nantou and Ahou were absorbed into Taichung and Kaohsiung, diluting their percentages of these larger units.

A slightly different perspective emerges when we examine the distribution among the prefectures of the three ethnic groupings. In I9I5 the bulk of the large Hoklo population was concentrated in two adjacent southern prefectures of Chiayi and Tainan, the mid-island prefecture of Taichung, and the northern prefecture of Taipei. In all, these four prefectures account for $75 \%$ of the total Hoklo population. The same pattern continued after 1920 when Tainan absorbed Chiayi. In I9I5 the Hakka population was concentrated in the northern prefectures of Hsinchu and Taoyuan, followed by Ahou in the south, and Taichung. These four prefectures account for $95 \%$ of the total Hakka population. After 1920 more than $65 \%$ of the Hakka population was concentrated in the single prefecture of Hsinchu, and smaller concentrations remained in Taichung ( $16 \%$ ) and Kaohsiung (I5\%). In I9I5 more than half the plains aborigine population was concentrated in Ahou and Tainan in the south, and smaller concentrations were located in Nantou in the mid-island foothills, and Hualien on the east coast. These four prefectures account for $79 \%$ of the total plains aborigine population. The same pattern continued after 1920 when Kaohsiung absorbed Ahou and Taichung absorbed Nantou; leaving Kaohsiung and Tainan with more than half the Plains Aborigine population and Taichung and Hualien with significant concentrations.

It is also worth pointing out that Taiwan's small urban population was overwhelmingly Hoklo. Five cities (Taipei, Keelung, Taichung, Tainan, and Kaohsiung) were recognized in the 1925 census and the 1926 ethnic survey, and they accounted for approximately eight percent of the total Taiwanese population (cf. Barclay I954: II6). Living in these five cities in 1926 were $9.8 \%$ of the Hoklo population and only $0.9 \%$ of the Hakka population. The Hakka and plains aborigine populations were thus overwhelmingly rural, while a small percent of the Hoklo population lived in the small major cities. It is also likely that the larger and more urban Hoklo population was stratified internally to a greater degree than the other populations.

Because of the marked regional concentrations, especially of the minority Hakka and plains aborigine populations, generalizations based on all-island data about the separate ethnic groups must raise an immediate question: is the select- 


\begin{tabular}{|c|c|c|c|}
\hline Prefecture & Fukien & Kwangtung & Plains Aborigine \\
\hline Taipei & I6.6\% & $0.3 \%$ & I.9\% \\
\hline Ilan & $4 \cdot 9$ & 0.5 & $4 \cdot 7$ \\
\hline Taoyuan & $4 \cdot 5$ & $2 \mathrm{I} .7$ & 0.9 \\
\hline Hsinchu & 3.6 & 46.0 & $4 \cdot \mathrm{I}$ \\
\hline Taichung & I8.9 & $\mathrm{I} 2.3$ & I. 2 \\
\hline Nantou & 3.9 & $2 . \mathrm{I}$ & II. 2 \\
\hline Chiayi & I9.9 & 0.7 & 3.6 \\
\hline Tainan & I9. 6 & O.I & I 2.4 \\
\hline Ahou & $5 \cdot 7$ & 15.3 & $45 \cdot 5$ \\
\hline Taitung & O.I & 0.2 & $4 \cdot 9$ \\
\hline Hualien & 0.2 & 0.7 & 9.6 \\
\hline Penghu & 2.0 & $\circ$ & $\circ$ \\
\hline Taiwan & $100.0 \%$ & $100.0 \%$ & I00.०\% \\
\hline Total Number & $2,753,2 \mathrm{I} 2$ & 478,557 & 47,676 \\
\hline
\end{tabular}

Census of 1915, kekka hyō.p. 8-9

Table I8. Distribution of the ethnic groups among the prefectures, 1920.

\begin{tabular}{|c|c|c|c|}
\hline Prefecture & Fukien & Kwangtung & Plains Aborigine \\
\hline Taipei & $22.8 \%$ & I.I\% & $6.2 \%$ \\
\hline Hsinchu & 7.2 & 65.7 & 5.2 \\
\hline Taichung & 23.4 & I5. 8 & I2.9 \\
\hline Tainan & $3 \mathrm{I} .9$ & $\mathrm{I} .2$ & $\mathrm{I} 5 \cdot 3$ \\
\hline Kaohsiung & I 4.3 & I5.0 & $45 \cdot 7$ \\
\hline Taitung & O.I & 0.3 & $5 \cdot 4$ \\
\hline Hualien & 0.3 & I. 3 & $9 \cdot 3$ \\
\hline Taiwan & Iо०\% & $100 \%$ & I0०\% \\
\hline Total Number & $2,85 \mathrm{I}, 353$ & 519,770 & 48,894 \\
\hline
\end{tabular}

Census of 1920, daiikkai Taiwan kokusei chōsa yōran hyō, table I, pp. 2-7. 


\begin{tabular}{lllllll} 
Sui Age & \multicolumn{2}{c}{ Fukien } & \multicolumn{2}{c}{ Kwangtung } & \multicolumn{2}{c}{ Plains Aborigines } \\
by cohort* & Male \% & Female \% & Male \% & Female \% & Male \% & Female \% \\
\hline & & & & & & \\
I-5 & I4.I & I4.4 & I4.7 & I5.0 & I3.5 & I3.0 \\
6-I5 & 25.9 & 25.4 & 25.8 & 25.4 & 25.2 & 23.8 \\
I6-30 & 27.5 & $25 . \mathrm{I}$ & 27.5 & 25.9 & 26.0 & 24.8 \\
3I-45 & 20.I & I8.4 & I8.4 & I7.6 & 21.2 & 20.7 \\
46-60 & 9.4 & I0.9 & 9.5 & I0.3 & I0.7 & I2.2 \\
6I \& over & 3.0 & 5.8 & 4.0 & 5.8 & 3.4 & 5.6 \\
\hline
\end{tabular}

Census of 1920, Dai-ikkai Taiwan kokusei chōsa shukei gempyō zentō no bu, table 2, pp. 2-43.

* 'Sui Age by cohort': the census reports 'age' by year of birth, beginning with those born in the year of the census, I9I5, who are listed as sui age I. Thus there is no age 'o' by this reckoning. Note that this reckoning is by birth year cohort and does not correspond either to traditional Chinese lunar year 'sui' or to Western measures of age at last birth.

ed characteristic the result of cultural differences or the result of differences linked to regional ecology, such as climate, epidemiology, agrarian economy, wealth, access to ports, administrative influence, etc.? Throughout the following discussion of differences and similarities among the three ethnic groups, we must not lose sight of the possibility that these regional concentrations are likely to have an important influence on the patterns we observe.

\section{Age Structure among the Ethnic Groups}

The Taiwan vital statistics (J: Taiwan jinkō dōtai tōkei) annual volumes contain reports of stillbirths, births, and deaths by ethnic group and sex for each year from I906 to I935, and deaths by cause, sex, and ethnic group for each year from I906 to I93I. When combined with reports of the population by ethnic group from the censuses, these tables provide the information needed to compute crude rates of death and death by cause for each ethnic group by sex over more than twenty years. As crude rates, these measures give us a convenient summary measure of the impact of mortality on each group. Crude rates, however, because they combine age groups whose death rates vary widely, are less reliable when comparing groups whose age structures also vary widely (unfortunately the absence of death data by age and ethnicity makes it impossible to calculate age specific death rates by ethnic group from the vital statistics)(Barclay 1958: 135). Fortunately, the censuses for I9I5 and I920 (but not I925 and I930) published tables that enable us to check for divergent age structures among our groups.

Examination of the age composition of the ethnic groups (shown here only for 
Deaths per I00,000.

Cause Specific Crude Death Rates by Ethnicity, Deaths per 100,000

Year

All

Causes
Indexed Crude Death Rates,

$$
\text { Hoklo }=100
$$

Hakka Plains Aborigine

Plains Aborigine Hakka Plains Aborigine

Male Female Male Female Male Female Male Female Male Female

\begin{tabular}{lllllllllll}
\hline $06-8 *$ & 3617 & 3548 & 2454 & 2365 & 3163 & 2956 & 68 & 67 & 87 & 83 \\
I4-6* & 3305 & 3075 & 2289 & 2165 & 3272 & 2919 & 69 & 70 & 99 & 95 \\
I9-2I & 3038 & 2823 & 2586 & 2384 & 2909 & 2987 & 85 & 84 & 96 & 106 \\
$24-26$ & $268 \mathrm{I}$ & 2406 & $215 \mathrm{I}$ & 1968 & 2760 & 2664 & 80 & 82 & 103 & 111 \\
$29-3 \mathrm{I}$ & 2356 & 2123 & I856 & I7I9 & 2453 & 2396 & 79 & 81 & 104 & 113 \\
\hline
\end{tabular}

* No correction for unregistered nonsurvivors has been possible for the deaths by ethnic groups.

Vital statistics from the Taiwan jinkō dōtai tōkei, and populations at risk from the Taiwan censuses for the relevant years.

I920) reveals no major differences in age structure among our groups that would affect our ability to interpret differences in death rates as reflecting differences in the incidence and severity of disease rather than differences in age composition.

\section{Crude Death Rates by Ethnic Group}

Given their similar age distributions, we can discount the danger that any differences we observe in crude death rates among the ethnic groups are merely the products of differences in age structure. What differences do we observe? We begin with the table above which is drawn from the reports of deaths by cause by ethnic group and sex for the years I906-I93I. Three year averages have been computed and related to the population totals by ethnic group reported in the censuses of I905 (adjusted to a midyear population I907), I915, I920, I925 and I930. The table reports the crude death rates for all causes, and to facilitate comparison among the groups, the right most columns index the death rates by sex in each period on the Hoklo rates, which represent more than $80 \%$ of Taiwanese.

The crude death rates by sex for each cultural group presented in the table above reveal strikingly lower death rates among the Hakka compared to the Hoklo and plains aborigine groups. The Hakka and Plains Aborigines (in the early years) regularly report death rates which are only a fraction of the Hoklo rates. The large divergence in the death rates of the Hakka in contrast to the other groups is consistently maintained from I906 to I93I. Compared to the Hoklo the 
Table 2I. Cause Specific Crude Death Rates by Leading Causes and by Ethnicity and Sex, I906-I93I. Deaths per I00,000. (IDR as deaths per thousand live births).

Cause Specific Crude Death Rates by Ethnicity,

Deaths per 100,000
Indexed Crude Death Rates,

Hoklo $=100$

Year Hoklo Hakka Plains Aborigine Hakka Plains Aborigine

$\begin{array}{lllllllllll}\text { Malaria } & \text { Male } & \text { Female } & \text { Male } & \text { Female } & \text { Male } & \text { Female } & \text { Male } & \text { Female } & \text { Male } & \text { Female } \\ \text { I906-8 } & 365 & 392 & 290 & 308 & 754 & 806 & 79.5 & 78.6 & 206.6 & 205.6 \\ \text { I9I4-I6 } & 340 & \text { 35I } & \text { 22I } & \text { 22I } & 492 & 8 \mathrm{I} 4 & 65.0 & 63.0 & 144.7 & 231.9 \\ \text { I919-2I } & 2 \text { I4 } & \text { 2I2 } & \text { I98 } & \text { I79 } & 306 & 325 & 92.5 & 84.4 & 143.0 & 153.3 \\ \text { I924-26 } & \text { I77 } & \text { I72 } & \text { I45 } & \text { I46 } & 34 \mathrm{I} & 345 & 81.9 & 84.9 & 192.7 & 200.6 \\ \text { I929-3I } & 7 \mathrm{I} & 68 & 75 & 73 & \text { I65 } & 224 & 105.6 & 107.4 & 232.4 & 329.4\end{array}$

Resp. TB

$\begin{array}{lllllllllll}\text { I906-8 } & \text { I9I } & \text { I04 } & 84 & 5 \text { I } & \text { III } & 64 & 44.0 & 49.0 & 58.1 & 61.5 \\ \text { I9I4-I6 } & \text { I89 } & \text { I09 } & 75 & 38 & \text { I34 } & 6 \text { I } & 39.7 & 34.9 & 70.9 & 56.0 \\ \text { I9I9-2I } & 237 & \text { I50 } & 96 & 44 & \text { II3 } & 82 & 40.5 & 29.3 & 47.7 & 54.7 \\ \text { I924-26 } & 227 & \text { I37 } & \text { I08 } & 53 & \text { I29 } & 85 & 47.6 & 38.7 & 56.8 & 62.0 \\ \text { I929-3I } & \text { I95 } & \text { I24 } & 95 & 48 & \text { I20 } & \text { I20 } & 48.7 & 38.7 & 61.5 & 96.8\end{array}$

Resp. Dis.

$\begin{array}{lllllllllll}\text { I924-26 } & 848 & 700 & 639 & 535 & 894 & 878 & 75.4 & 76.4 & 105.4 & 125.4\end{array}$

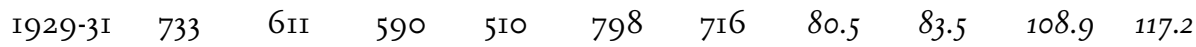

Diarrhea,E

$\begin{array}{lllllllllll}\text { I924-26 } & 352 & 353 & \text { I90 } & \text { I92 } & 342 & 349 & 54.0 & 54.4 & 97.2 & 98.9\end{array}$

$\begin{array}{lllllllllll}1929-31 & 369 & 384 & \text { I95 } & 202 & 367 & 343 & 52.8 & 52.6 & 99.5 & 89.3\end{array}$

Cert.Dis.Inf.

$\begin{array}{lllllllllll}\text { I924-26 I45 II2 } & \text { I39 } & \text { I06 } & \text { I25 } & 76 & 95.9 & 94.6 & 86.2 & 67.9\end{array}$

$\begin{array}{lllllllllll}\text { I929-3I } & \text { I38 } & \text { I06 } & \text { II5 } & 79 & \text { I86 } & \text { I30 } & 83.3 & 74.5 & 134.8 & 122.6\end{array}$

Cert.Dis.Inf as IDR*

$\begin{array}{lllllllllll}\text { 1924-26 } & 32.9 & 25.5 & 32.3 & 24.7 & \text { 3I.I } & \text { I9.8 } & 98.2 & 96.9 & 94.5 & 77.6\end{array}$

$\begin{array}{lllllllllll}\text { I929-3I } & 28.7 & 22.4 & 25.9 & \text { I8.0 } & 45 . \text { I } & 3 \text { I.4 } & 90.2 & 80.4 & 157.1 & 140.2\end{array}$

* IDR as deaths per thousand live births. Vital statistics from the Taiwan jinko dotai tokei, and populations at risk from the Taiwan censuses for the relevant years.

Plains Aborigines reported lower rates when Hoklo rates were highest in the first two periods, but higher rates in the final two periods when Hoklo rates dropped.

We turn now to an exploration of the causes of death among the different cultural groupings to see which causes account for most of the ethnic variation in death rates. Cause of death data is reported in the Vital Statistics by subcultural 
grouping by sex but not by age, so we can report only 'crude' cause specific rates

for each group (which are vulnerable to differences in age structure, as discussed above). Also as noted above the quality of cause of death reporting in the early periods was not as high as it would be in later years.

The table above reports the death rates by cause for the leading causes of death. The right most panel indexes the death rates by sex in each period on the Hoklo rates.

Malaria was consistently a leading cause of death in nineteenth and early twentieth century Taiwan and as such early became a target of Japanese colonial public health efforts. Although declines in malaria death rates are noticeable in all the groups from I9I9 to I93I, differences among the subcultural groups remain substantial in all periods. The Plains Aborigines show much higher rates for both sexes, and the Hakka show much lower rates, compared to the Hoklo, for all years except 1929-3I when rates were at their lowest. Within each group the sex differential in malarial death rates is small, qualified somewhat by the excess for plains aborigine females. The sharp differences among the cultural groups in malarial death rates is surely accounted for by their regional distribution. Malarial death rates are highest in climates most favorable to the propagation of anopheline mosquitoes and the malaria plasmodium. It appears that the plains aborigine population is concentrated in areas with such an unfavorable climate: the subtropical foothills. The Hakka population, on the other hand, appears to have had the good fortune to be concentrated in areas least favorable to malaria-bearing mosquitoes (especially Hsinchu and Taoyuan). The key factor in malaria death rates is most likely to have been differential rates of exposure, as differences in other factors, disease resistance or methods of prevention, are unlikely to have been significant.

Respiratory tuberculosis shows strikingly higher rates among the Hoklo than the Hakka and the Plains Aborigines. Hypotheses accounting for differentials in the incidence of respiratory tuberculosis variously emphasize diet, exposure to active cases, crowded living spaces, poor ventilation, and polluted cities, and reduced immune response due to co-morbidity. One or many of these factors may underlie the high Hoklo rates. The Hoklo dominance in urban areas, where respiratory tuberculosis rates were highest (see above), contributes to these high rates for Hoklo.

"Respiratory diseases" is a broad category including pneumonia, bronchitis, influenza, and other respiratory diseases, that weighed heavily on the health of Taiwanese in this period. When combined they are the leading cause of death in all periods, and all three groups suffered from high rates of these diseases. In all three groups, pneumonia death rates were the highest of the three named diseases; cases of pneumonia often bring on death after a person has been stricken by some other disease. The same Hakka advantage appears in the respiratory 
death rates, as the Plains Aborigine and Hoklo groups suffered from significantly higher respiratory death rates. The Hoklo disadvantage, however, is lower than in the case of respiratory tuberculosis. What can account for the higher Plains Aborigine and Hoklo rates - diet (pneumonia is nutritionally sensitive), environmental conditions, lowered resistance due to a heavier incidence of concurrent diseases, or higher exposure rates?

Diarrhea and enteritis is our next disease category. The disdvantage of the Hoklo and the Plains Aborigines when compared to the Hakka in diarrhea and enteritis death rates is the second greatest, after respiratory tuberculosis, of the leading causes. What can explain such a sharp difference? Differential exposure (perhaps resulting from climatic factors favoring bacterial growth?) and resistance are possibilities, but differences in food and drink sanitation practices may also play an important role. Do we have evidence here supporting the reputation of the Hakka for better sanitation? It is important to note that diarrheas, because they interfere with the absorption of nutrients when the immune system is most in need of them, can be important causes of the worsening of concurrent diseases. Higher rates of diarrhea and enteritis could play an important role in raising the rates of death from other diseases among the Hoklo and Plains Aborigines.

Certain diseases of infancy is a cause category restricted to deaths occurring overwhelmingly in the first month of life. The Hakka advantage in this category over the Hoklo is small compared to the other leading causes. The Plains Aborigine rate in this category fluctuates greatly between I924-26 and I929-3I for some unknown reason, and may reflect inconsistent cause reporting. To get a more precise picture, we can measure this category of deaths as a proportion of live births. Reporting certain diseases of infancy as an infant death rate does not change our impression of the relative rates of death among the ethnic groups.

The most striking feature of these tables is that the Hakka advantage is consistent across all causes, rather than concentrated in one or two, and that the advantage is continuous across all periods despite fluctuations in rates. This could suggest that some factor related to Hakkaness is beneficial to health and longevity? But before we leap to conclusions, astute readers will remember that the Hakka, and the Plains Aborigines are not dispersed as widely as the Hoklo, but are heavily concentrated in certain localities. Is the Hakka advantage a product of Hakkaness, or of the environments in which Hakka are fortunate to live?

\section{Crude Death Rates by Ethnicity and Prefecture}

The vital statistics reports births and deaths by both prefecture and ethnicity; this enables us to test whether the Hakka advantage so visible in the data aggregated by ethnic group is enjoyed by Hakka regardless of where they live. The same data enable us to see whether some Hoklo and Plains Aborigines also benefit from living in healthy districts dominated by Hakka. 
The tables below present the crude death rates by prefecture and ethnic group in I906-08, I914-16, I920-22, I924-26, and 1929-31. Rates for Hakka and Plains Aborigines are only shown for prefectures where each sex of each group numbered greater than Iо००. We will focus our discussion on the highlighted prefectures which have the more significant concentrations of Hakka and Plains Aborigine populations.

Do Hakka uniformly have the lowest rates of death regardless of prefecture? Or if regionally specific factors are more important than ethnicity, do Hoklo living in prefectures where Hakka have low rates of death also enjoy lower rates than Hoklo elsewhere? Let us begin our discussion with the Taoyuan- Hsinchu -Miaoli prefectures where $65 \%$ of Taiwan's Hakka population is concentrated. The Hakka in these prefectures ('Hsinchu' after 1920) have a clear advantage over their Hoklo neighbors in all periods shown in the tables, although for all periods after I9I4 it is interesting that the advantage is smaller than the average Hakka advantage for all Taiwan. This is because Hoklo have their lowest death rates in Taoyuan I906-I9I6, and in Hsinchu I920-I93I (shown in bold in the tables). Thus Hoklo also benefited from living in these prefectures and the healthier environment they provided, even if they did not benefit from any possible health benefits of Hakkaness?

Any assumption that Hakkaness everywhere confers health advantages is contradicted when we look beyond Hsinchu. The advantage of being Hakka disappears when we move to the southern prefectures. In Fanshuliao and Ahou in I906-I6, and in Kaohsiung I920-193I (where I5\% of Hakka reside), the Hakka death rate is very close to that of the Hoklo and sometimes worse (as in Fanshuliao in 1906-08, and Kaohsiung 1924-26). So it appears that if some aspect of Hakkaness confers a health benefit in the northern climate of Hsinchu, this factor is not effective when confronted with the southern environment of Kaohsiung. And when we compare the death rates of Hakka in Kaohsiung to those of Hoklo in northern districts, and for Taiwan as a whole (which because Hoklo are $80 \%$ of the total population their rates are very close to the average for all Taiwanese), the southern Hakka death rates exceed these averages. Clearly the southern Hakka, concentrated in the eastern parts of Kaohsiung (today's Pingtung) lack the health advantage enjoyed by their northern cousins.

The hypothesis that some aspect of Hakkaness confers a health advantage is considerably weakened by the high death rates of the southern Hakka. Nevertheless, it is still the case that the Hsinchu Hakka appear to do better than their Hoklo neighbors, suggesting that environment alone is not the full explanation (we explore this further below).

Hoklo death rates also varied significantly by prefecture. The highest rates regularly occurred in the southern districts of Chiayi, Tainan, and Ahou (I906I6), and Tainan and Kaohsiung (I920-3I) (putting aside the very high rates occur- 
Crude Death Rates by Ethnicity,

\begin{tabular}{|c|c|c|c|c|c|c|c|c|c|c|}
\hline \multirow{3}{*}{$\begin{array}{l}\text { Year } \\
\text { Prefecture }\end{array}$} & \multicolumn{6}{|c|}{ Deaths per 1000} & \multicolumn{4}{|c|}{ Hoklo $=100$} \\
\hline & \multicolumn{2}{|c|}{ Hoklo } & \multicolumn{2}{|c|}{ Hakka } & \multicolumn{2}{|c|}{ Plains Aborigine } & \multicolumn{2}{|c|}{ Hakka } & \multicolumn{2}{|c|}{ Plains Aborigine } \\
\hline & Male & Female & Male & Female & Male & Female & Male & Female & Male & Female \\
\hline Taipei & 29.7 & 27.5 & & & & & & & & \\
\hline Keelung & $27 \cdot 9$ & 26.1 & & & & & & & & \\
\hline Ilan & 28.4 & 26.9 & & & 22.6 & I9.7 & & & 79.8 & 73.2 \\
\hline Shenkeng & $27 . \mathrm{I}$ & 25.2 & & & & & & & & \\
\hline Taoyuan & 25.0 & 23.5 & I9.I & 19.4 & & & 76.7 & 82.3 & & \\
\hline Hsinchu & 30.8 & 28.6 & I9.9 & $\mathrm{I} 8.2$ & & & $64 \cdot 4$ & 63.5 & & \\
\hline Miaoli & 34.5 & $3 \mathrm{I} .7$ & 2I. 6 & 20.9 & 23.4 & I8.9 & 62.6 & 65.8 & 67.9 & $59 \cdot 5$ \\
\hline Taichung & $35 \cdot \mathrm{I}$ & $3 \mathrm{I} .2$ & 24.4 & 22.4 & & & 69.4 & 71.6 & & \\
\hline Changhua & 38.2 & 36.8 & $25 \cdot 3$ & $25 \cdot 5$ & & & 66.2 & 69.3 & & \\
\hline Nantou & 34.8 & 33.9 & 33.2 & 37.1 & $3 \mathrm{I} .2$ & 27.0 & $95 \cdot 5$ & $109 \cdot 5$ & 89.8 & $79 \cdot 5$ \\
\hline Douliu & $37 \cdot 7$ & 38.1 & & & & & & & & \\
\hline Chiayi & 46.7 & 49.1 & & & & & & & & \\
\hline Yanshuigang & 38.4 & 40.6 & & & $3 \mathrm{I} .2$ & $33 \cdot 9$ & & & 81.1 & 83.5 \\
\hline Tainan & $37 \cdot 7$ & 36.3 & & & 24.8 & $24 \cdot 3$ & & & 65.7 & 66.9 \\
\hline Fanshuliao & 38.4 & $34 . \mathrm{I}$ & 40.3 & $37 \cdot 6$ & 42.4 & 39.1 & 104.9 & 110.3 & 110.3 & $114 \cdot 7$ \\
\hline Fengshan & $4 \mathrm{I} \cdot 4$ & 40.7 & & & & & & & & \\
\hline Ahou & $44 \cdot 5$ & $43 \cdot 3$ & 4I.O & 38.3 & 32.1 & $3 \mathrm{I} .2$ & 92.1 & 88.5 & 72.1 & 72.0 \\
\hline Hengchun & 3I. 8 & 31.9 & $27 \cdot 7$ & 25.4 & 29.0 & 24.5 & 87.0 & 79.8 & $91 \cdot 3$ & 76.8 \\
\hline Taitung & $54 \cdot 4$ & $44 \cdot 4$ & & & 37.0 & 34.3 & & & 68.0 & 77.2 \\
\hline Penghu & 32.1 & 36.3 & & & & & & & & \\
\hline All Taiwan & 36.0 & 35.2 & 23.9 & 22.8 & $3 \mathrm{I} .4$ & 29.3 & 66.4 & 64.8 & 87.2 & 83.2 \\
\hline
\end{tabular}

ring in the east coast prefectures of Taitung and Hualien I906-1922 suffered by small populations of Hoklo [most likely malaria related]). And the lowest Hoklo rates regularly occurred in the northern prefectures that would form Taipei and Hsinchu after 1920. The strong regional differentiation that persists throughout the period represented in the tables is particularly marked in the early years but declines somewhat as rates overall moderate in the later years.

Death rates for the Plains Aborigine minority also demonstrate a strong north- south regional differentiation. We noted above that Plains Aborigines overall did better than Hoklo I906-I6 and worse I924-31, but the regional data enable us to qualify that generalization. Plains Aborigines did worse than Hoklo in southern Fanshuliao I906-08 and better than Hoklo in Taichung and Tainan 
Crude Death Rates by Ethnicity,

Deaths per 1000
Indexed Crude Death Rates,

Hoklo $=100$

\begin{tabular}{|c|c|c|c|c|c|c|c|c|c|c|}
\hline \multirow{2}{*}{$\begin{array}{l}\text { Year } \\
\text { Prefecture }\end{array}$} & \multicolumn{2}{|c|}{ Hoklo } & \multicolumn{2}{|c|}{ Hakka } & \multicolumn{2}{|c|}{ Plains Aborigine } & \multicolumn{2}{|c|}{ Hakka } & \multicolumn{2}{|c|}{ Plains Aborigine } \\
\hline & Male & Female & Male & Female & Male & Female & Male & Female & Male & Female \\
\hline Taipei & 26.2 & 25.8 & & & & & & & & \\
\hline Ilan & 23.9 & 23.2 & & & $25 . \mathrm{I}$ & I6.9 & & & 105.1 & 72.6 \\
\hline Taoyuan & 21.5 & $2 I .4$ & I8. 3 & I8. 3 & & & 85.1 & 85.4 & & \\
\hline Hsinchu & 26.7 & $23 \cdot 9$ & $20 . \mathrm{I}$ & I9.I & & & $75 \cdot 4$ & $79 \cdot 9$ & & \\
\hline Taichung & 33.2 & 30.2 & $24 \cdot 4$ & 20.7 & & & 73.5 & 68.3 & & \\
\hline Nantou & 32.8 & 28.7 & 22.5 & 23.5 & 30.3 & 26.2 & 68.7 & 82.1 & 92.2 & 91.5 \\
\hline Chiayi & 38.7 & 36.5 & I9.5 & 23.5 & & & 50.3 & 64.4 & & \\
\hline Tainan & 38.0 & 33.9 & & & 38.9 & 27.6 & & & 102.4 & 81.5 \\
\hline Ahou & 36.8 & 35.8 & $37 \cdot 3$ & $34 \cdot 9$ & 35.8 & $33 \cdot 3$ & 101.2 & $97 \cdot 3$ & 97.2 & 92.9 \\
\hline Taitung & $25 \cdot 4$ & $2 \mathrm{I} .4$ & & & 36.9 & 26.6 & & & $145 \cdot 4$ & 124.2 \\
\hline Hualien & 43.0 & 30.2 & 26.4 & $2 \mathrm{I} .7$ & $3 \mathrm{I} .2$ & 29.6 & 61.3 & 71.8 & 72.4 & 98.0 \\
\hline Penghu & 32.0 & $3 \mathrm{I} \cdot 7$ & & & & & & & & \\
\hline All Taiwan & 33.0 & 30.8 & 22.9 & $2 \mathrm{I} .7$ & 32.7 & 29.2 & 69.2 & 70.4 & 99.0 & 94.9 \\
\hline
\end{tabular}

Table 24. Crude Death Rates by Ethnicity and Prefecture, 1920-22.

Crude Death Rates by Ethnicity,

Deaths per 1000
Indexed Crude Death Rates,

Hoklo $=100$

\begin{tabular}{lcccccccccc} 
Year & \multicolumn{2}{c}{ Hoklo } & \multicolumn{2}{c}{ Hakka } & \multicolumn{2}{c}{ Plains Aborigine } & Hakka & \multicolumn{2}{c}{ Plains Aborigine } \\
\hline & & & & & & & & & & \\
Prefecture & Male & Female & Male & Female & Male & Female & Male & Female & Male & Female \\
Taipei & 26.7 & 24.9 & I7.6 & I8.7 & 22.7 & I5.7 & 65.8 & 75.1 & 85.2 & 63.2 \\
Hsinchu & $\mathbf{2 5 . I}$ & $\mathbf{2 2 . 5}$ & 23.4 & 22.0 & 20.5 & 22.7 & 93.4 & 97.8 & 81.7 & 100.6 \\
Taichung & 30.8 & 27.5 & 28.6 & 23.6 & 25.6 & 26.9 & 92.9 & 85.8 & 83.3 & 97.6 \\
Tainan & 31.7 & 29.9 & 25.4 & 27.7 & 25.1 & 24.1 & 80.0 & 92.7 & 79.1 & 80.5 \\
Kaohsiung & 30.8 & 29.2 & 31.3 & 28.8 & 30.1 & 31.1 & 101.4 & 98.6 & 97.7 & 106.8 \\
Taitung & 31.0 & 26.2 & & & 34.3 & 34.8 & & & 110.9 & 133.0 \\
Hualien & 42.4 & 35.2 & 31.0 & 28.8 & 33.6 & 29.1 & 73.1 & 82.0 & 79.2 & 82.6 \\
All Taiwan & 29.8 & 27.6 & 25.5 & 23.4 & 28.3 & 28.2 & 85.7 & 84.9 & 95.1 & 102.1 \\
\hline
\end{tabular}


Crude Death Rates by Ethnicity,

Deaths per 1000
Indexed Crude Death Rates,

Hoklo $=100$

\begin{tabular}{lcccccccccc} 
Year & \multicolumn{2}{c}{ Hoklo } & \multicolumn{2}{c}{ Hakka } & \multicolumn{2}{c}{ Plains Aborigine } & \multicolumn{2}{c}{ Hakka } & \multicolumn{2}{c}{ Plains Aborigine } \\
\hline & & & & & & & & & & \\
Prefecture & Male & Female & Male & Female & Male & Female & Male & Female & Male & Female \\
Taipei & 23.6 & 2 I.8 & II.9 & I6.I & I7.0 & I7.4 & 50.3 & 73.9 & 71.8 & 79.6 \\
Hsinchu & 2I.I & I9.2 & I8.8 & I7.5 & 24.3 & 23.3 & 88.8 & 91.4 & 115.0 & 121.8 \\
Taichung & 25.8 & 22.4 & 20.0 & I7.9 & 22.I & 21.0 & 77.4 & 80.2 & 85.6 & 93.8 \\
Tainan & 30.5 & 26.9 & I9.6 & I9.8 & 23.1 & 22.4 & 64.4 & 73.6 & 76.0 & 83.4 \\
Kaohsiung & 28.3 & 26.5 & 36.1 & 30.8 & 32.3 & 30.5 & $\mathbf{1 2 7 . 6}$ & $\mathbf{1 1 6 . 3}$ & 114.0 & 115.3 \\
Taitung & 25.9 & 26.1 & 24.6 & 25.8 & 30.2 & 35.0 & 95.3 & 99.2 & 116.6 & 134.3 \\
Hualien & 26.7 & 25.9 & 25.0 & 23.2 & 26.6 & 24.1 & 93.6 & 89.4 & 99.9 & 93.1 \\
All Taiwan & 26.8 & 24.1 & 2 2I.5 & I9.7 & 27.6 & 26.6 & 80.2 & 81.8 & 103.0 & 110.7
\end{tabular}

Table 26. Crude Death Rates by Ethnicity and Prefecture, 1929-3I.

Crude Death Rates by Ethnicity

Deaths per 1000

Year

Hoklo
Indexed Crude Death Rates,

Hoklo $=100$

Plains Aborigine
Hakka

Plains Aborigine

$\begin{array}{lcccccccccc}\text { Prefecture } & \text { Male } & \text { Female } & \text { Male } & \text { Female } & \text { Male } & \text { Female } & \text { Male } & \text { Female } & \text { Male } & \text { Female } \\ \text { Taipei } & 22.5 & \text { 2I.3 } & \text { II.0 } & \text { I2.0 } & \text { I2.0 } & \text { I2.6 } & 48.9 & 56.1 & 53.6 & 59.0 \\ \text { Hsinchu } & \text { I9.9 } & \text { I8.I } & \text { I7.3 } & \text { I6.2 } & 23.2 & 23.1 & 86.9 & 89.3 & 116.5 & 127.4 \\ \text { Taichung } & 22.8 & \text { 20.I } & \text { I7.8 } & \text { I5.9 } & 20.7 & \text { I7.7 } & 78.0 & 79.1 & 90.6 & 87.9 \\ \text { Tainan } & 24.8 & \text { 21.8 } & \text { I4.7 } & \text { I4.5 } & 20.9 & 20.2 & 59.3 & 66.5 & 84.5 & 92.9 \\ \text { Kaohsiung } & 25.8 & 23.8 & 26.0 & 23.3 & 27.2 & 26.8 & 100.6 & 98.2 & 105.2 & 112.8 \\ \text { Taitung } & \text { 24.I } & \text { 20.I } & 27.0 & 20.0 & 32.3 & 29.6 & 112.0 & 99.5 & 134.0 & 147.3 \\ \text { Hualien } & 22.4 & \text { 21.0 } & \text { I9.0 } & 20.0 & 25.5 & 26.9 & 84.9 & 95.4 & 114.0 & - \\ \text { 128.3Penghu 24.5 } & \text { I9.9 } & - & - & - & - & - & - & - & - \\ \text { All Taiwan } & 23.6 & \text { 21.2 } & \text { I8.6 } & \text { I7.2 } & 24.5 & 24.0 & 78.8 & 81.0 & 104.1 & 112.9\end{array}$

I920-3I. The $45 \%$ of Plains Aborigines living in Kaohsiung (I920-3I) regularly suffered from higher death rates than those living outside the southern prefectures. It is particularly interesting to note in Kaohsiung that while Plains Aborigine men sometimes did slightly better than their Hakka neighbors (though worse than Hoklo), Plains Aborigine women fared much worse than both Hakka and Hoklo. 


\section{Refining the Test of Ethnicity vs. Locality: District Level and Household Register Data}

District Level Data. The crude death rates by prefecture and ethnicity have enabled us to refine generalizations about the health advantages and disadvantages of ethnic group membership based on data by cause aggregated by ethnic group alone. We have identified several localities where the apparent health consequences of ethnicity contradict the pattern found for all Taiwan, and found that strong regional differences affect all the ethnic groups. But so far our tests of the role of ethnicity vs. locality have been applied only at the level of the prefecture, leaving open the possibility that health disadvantages and advantages (such as that of the Hakka in Hsinchu) are the product not of ethnicity within a regional context but of environmental differences among much smaller districts. Because ethnic groups are segregated by residence within prefectures, it is conceivable that the environments of subdistricts occupied by particular ethnic groups have an important effect on their death rates which is hidden when data are aggregated at the prefectural level. Is the impression that ethnicity plays a significant role within prefectural units an effect of over-aggregation of data?

We can refine our assessment of the role of ethnicity vs. locality somewhat by focusing on subprefectural districts (J: gun, C: jun, 郡) that contain substantial populations of both ethnic groups. In Hsinchu, five of eight districts contain large populations of both Hoklo and Hakka: Hsinchu, Chungli, Tachi, Chunan, and Miaoli. In Taichung prefecture, two districts containing large populations of both Hoklo and Hakka are Fengyuan and Nenggao (Puli); the latter also contains a large Plains Aborigine population. In Kaohsiung prefecture, three districts contain large populations of Hoklo, Hakka and Plains Aborigines: Chishan, Pingdong, and Chaochou. Do the districts simply replicate the prefectural level patterns of ethnic differences in mortality, or do they reveal local influences that complicate the prefectural ethnic patterns?

In four of the five districts in Hsinchu, Hakka consistently have death rates for both males and females lower than Hoklo (the single exception is females in Hsinchu jun in I920-22) in agreement with the prefectural pattern. But in the fifth district of Chungli, where both the Hoklo minority and the Hakka consistently have death rates below the Hakka prefectural average, Hakka death rates are nevertheless consistently higher than Hoklo. Thus within Hsinchu, the Hakka advantage does not hold in every case. Whether Hakka crude death rates are higher or lower than Hoklo, it is interesting that the Hakka males always did better (index is lower) compared to their Hoklo counterparts than the Hakka females, with the single exception of Miaoli in I929-3I.

In Taichung, Hakka death rates are consistently lower than Hoklo rates in Fengyuan, but more often higher in Nenggao. In Kaohsiung's Chishan and Pingdong death rates for both Hoklo and Hakka are lower than or very close to the 


\begin{tabular}{|c|c|c|c|c|c|c|c|c|c|c|}
\hline \multirow{3}{*}{$\begin{array}{l}\text { Year } \\
\text { District }\end{array}$} & \multicolumn{6}{|c|}{$\begin{array}{c}\text { Crude Death Rates by Ethnicity, } \\
\text { Deaths per } 1000\end{array}$} & \multicolumn{4}{|c|}{$\begin{array}{l}\text { Indexed Crude Death Rates, } \\
\qquad \text { Hoklo }=100\end{array}$} \\
\hline & \multicolumn{2}{|c|}{ Hoklo } & \multicolumn{2}{|c|}{ Hakka } & \multicolumn{2}{|c|}{ Plains Aborigine } & \multicolumn{2}{|c|}{ Hakka } & \multicolumn{2}{|c|}{ Plains Aborigine } \\
\hline & Male & Female & Male & Female & Male & Female & Male & Female & Male & Female \\
\hline Hsinchu & 25.1 & 22.5 & $23 \cdot 4$ & 22.0 & 20.5 & 22.7 & 93.4 & 97.8 & 81.7 & 100.6 \\
\hline \multicolumn{11}{|l|}{ Pref. } \\
\hline Hsinchu Jun & 26.2 & 22.3 & $23 \cdot 9$ & $23 \cdot 4$ & & & 91.2 & $104 \cdot 9$ & & \\
\hline Chungli & $22 . \mathrm{I}$ & $20 . \mathrm{I}$ & 23.0 & 22.5 & & & 104.1 & 111.9 & & \\
\hline Tachi & 28.2 & 27.2 & 24.2 & 25.2 & & & 85.8 & 92.6 & & \\
\hline Chunan & 23.5 & 20.0 & 23.0 & 20.1 & & & $97 \cdot 9$ & 100.5 & & \\
\hline Miaoli & $25 \cdot 3$ & 21.0 & 23.4 & 20.4 & & & 92.5 & 97.1 & & \\
\hline Taichung & 30.8 & $27 \cdot 5$ & 28.6 & 23.6 & 25.6 & 26.9 & 92.9 & 85.8 & $83 \cdot 3$ & $97 \cdot 6$ \\
\hline \multicolumn{11}{|l|}{ Pref. } \\
\hline Fengyuan & 25.8 & $24 \cdot 7$ & 23.5 & I8.9 & & & 91.1 & 76.5 & & \\
\hline Nenggao & 34.I & 27.2 & 38.0 & 29.0 & 24.7 & 25.7 & 111.4 & 106.6 & 72.4 & 94.5 \\
\hline Kaohsiung & 30.8 & 29.2 & $3 \mathrm{I} \cdot 3$ & 28.8 & 30.1 & 3I.I & 101.4 & $9^{8.6}$ & $97 \cdot 7$ & 106.8 \\
\hline \multicolumn{11}{|l|}{ Pref. } \\
\hline Chishan & 29.5 & 28.3 & $32 . I$ & $29 . I$ & 36.5 & 36.5 & 108.8 & 102.8 & 123.7 & 129.0 \\
\hline Pingdong & 30.7 & $28 . \mathrm{I}$ & 26.9 & 25.8 & $24 \cdot 4$ & 26.4 & 87.6 & 91.8 & $79 \cdot 5$ & 94.0 \\
\hline Chaochou & 37.6 & $34 \cdot \mathrm{I}$ & 33.5 & 30.3 & 30.1 & 30.3 & 89.1 & 88.9 & 80.1 & 88.9 \\
\hline
\end{tabular}

prefectural averages; Hakka death rates are consistently higher than Hoklo in Chishan (single exception of females in I924-26), but are more often lower (especially for females) in Pingdong. In Chaochou death rates for both Hoklo and Hakka are substantially higher than the prefectural averages for both groups, but Hakka death rates are lower than Hoklo in two out of the three periods. In the Kaohsiung districts Hakka females consistently did better than males compared to their Hoklo counterparts (single exception of Pingdong in I920-22), the opposite of the Hsinchu pattern. These multiple differences among districts within prefectures reveal internal variations which suggest that local environmental conditions were more important than ethnicity in determining levels of mortality between Hoklo and Hakka.

Plains aborigine death rates also show the important influence of local environments. Plains aborigine death rates in Kaohsiung compared to Hoklo are consistently higher in Chishan and Pingdong (with the exception of I920-22) but lower in Chaochou, and often lower than Hakka. Plains aborigine death rates in Taichung's Nenggao are more often lower than Hoklo rates.

The sex ratio of mortality among the selected districts in Hsinchu is con- 
Crude Death Rates by Ethnicity,

Deaths per 1000

Year

\begin{tabular}{|c|c|c|c|c|c|c|c|c|c|c|}
\hline \multirow{3}{*}{$\begin{array}{l}\text { Year } \\
\text { District }\end{array}$} & \multicolumn{6}{|c|}{ Deaths per 1000} & \multicolumn{4}{|c|}{ Hoklo $=100$} \\
\hline & \multicolumn{2}{|c|}{ Hoklo } & \multicolumn{2}{|c|}{ Hakka } & \multicolumn{2}{|c|}{ Plains Aborigine } & \multicolumn{2}{|c|}{ Hakka } & \multicolumn{2}{|c|}{ Plains Aborigine } \\
\hline & Male & Female & Male & Female & Male & Female & Male & Female & Male & Female \\
\hline Hsinchu & 2I.I & 19.2 & 18.8 & 17.5 & $24 \cdot 3$ & 23.3 & 88.8 & 91.4 & 115.0 & 121.8 \\
\hline \multicolumn{11}{|l|}{ Pref. } \\
\hline Hsinchu Jun & 22.4 & 20.2 & I8.7 & $\mathrm{I} 7.3$ & & & 83.4 & 85.3 & & \\
\hline Chungli & I6.9 & I4.7 & 17.0 & $\mathrm{I} 6.4$ & & & 100.9 & 111.1 & & \\
\hline Tachi & 20.I & I7.9 & 16.9 & $\mathrm{I} 7.2$ & & & 83.7 & 96.3 & & \\
\hline Chunan & 22.I & 20.8 & 19.7 & 19.2 & & & 89.1 & 92.2 & & \\
\hline Miaoli & 24.3 & 19.2 & 20.5 & 18.9 & & & 84.5 & 98.4 & & \\
\hline Taichung & 25.8 & 22.4 & 20.0 & 17.9 & 22.I & 21.0 & $77 \cdot 4$ & 80.2 & 85.6 & 93.8 \\
\hline \multicolumn{11}{|l|}{ Pref. } \\
\hline Fengyuan & 23.0 & I8.5 & 2I.I & I8.4 & & & 92.0 & $99 \cdot 2$ & & \\
\hline Nenggao & $25 \cdot 4$ & 19.3 & 2I.I & 20.5 & 23.6 & 20.4 & 83.1 & 106.1 & 92.8 & 105.8 \\
\hline Kaohsiung & 28.3 & 26.5 & 36.I & 30.8 & 32.3 & 30.5 & 127.6 & 116.3 & 114.0 & $115 \cdot 3$ \\
\hline \multicolumn{11}{|l|}{ Pref. } \\
\hline Chishan & 26.3 & 26.7 & 33.6 & 25.6 & $3^{\text {т. }} .8$ & 30.6 & 128.0 & 95.7 & 121.1 & 114.3 \\
\hline Pingdong & 30.7 & 30.5 & 32.3 & 30.1 & $35 \cdot 3$ & 32.9 & 105.2 & 98.6 & 115.1 & 108.0 \\
\hline Chaochou & 34.I & 34.0 & 43.3 & 36.5 & 32.2 & 28.I & 126.8 & 107.2 & 94.2 & 82.5 \\
\hline
\end{tabular}

Indexed Crude Death Rates,

Hoklo $=100$

sistently lower among the Hakka than among the Hoklo (even in Chungli), with the single exception of Miaoli in 1929-3I. But even this aspect of Hakka population cannot be generalized beyond Hsinchu; the sex ratio of mortality among Hakka in the Taichung districts is as often higher as it is lower than Hoklo, and in the Kaohsiung districts is consistently higher compared to Hoklo with the single exception of Pingdong in I920-22. There is a slight tendency for the lower mortality group to have a lower sex ratio of mortality; high mortality appears to accentuate the differences between the sexes regardless of ethnicity.

The sex ratio of mortality among the Plains Aborigines in Taichung's Nenggao is lower than that of the Hoklo in two out of three periods, and lower than the Hakka in only one period. Among the Plains Aborigines in Kaohsiung the sex ratio of mortality is lower in all three districts than the Hakka sex ratio in all three periods, and lower than the Hoklo in two periods out of three. This points to plains aborigine female death rates which are frequently higher than among Hoklo and Hakka. District level differences also point to the important effect of environmental conditions on mortality among the plains aborigines. 
Crude Death Rates by Ethnicity,

Deaths per 1000
Indexed Crude Death Rates,

\begin{tabular}{|c|c|c|c|c|c|c|c|c|c|c|}
\hline \multirow[b]{2}{*}{ Year } & \multicolumn{6}{|c|}{ Deaths per 1000} & \multicolumn{4}{|c|}{ Hoklo $=100$} \\
\hline & \multicolumn{2}{|c|}{ Hoklo } & \multicolumn{2}{|c|}{ Hakka } & \multicolumn{2}{|c|}{ Plains Aborigine } & \multicolumn{2}{|c|}{ Hakka } & \multicolumn{2}{|c|}{ Plains Aborigine } \\
\hline District & Male & Female & Male & Female & Male & Female & Male & Female & Male & Female \\
\hline Hsinchu & 19.9 & I8.I & $17 \cdot 3$ & $\mathrm{I} 6.2$ & 23.2 & 23.1 & 86.9 & $89 \cdot 3$ & 116.5 & $127 \cdot 4$ \\
\hline \multicolumn{11}{|l|}{ Pref. } \\
\hline Hsinchu Jun & 20.8 & I9.I & I8.0 & I6.7 & & & 86.4 & 87.8 & & \\
\hline Chungli & I5. 5 & $\mathrm{I} 4.7$ & I6.2 & $15 \cdot 9$ & & & $104 \cdot 4$ & 108.5 & & \\
\hline Tachi & 19.9 & I9. 6 & 17.9 & I8.7 & & & 89.7 & 95.2 & & \\
\hline Chunan & $2 \mathrm{I} \cdot 3$ & I7.9 & $\mathrm{I} 7 \cdot 7$ & I6.4 & & & 83.0 & 91.5 & & \\
\hline Miaoli & 20.9 & I8.4 & $\mathrm{I} 7 \cdot 7$ & I5.3 & & & 84.7 & 82.9 & & \\
\hline Taichung & 22.8 & 20.1 & I7.8 & 15.9 & 20.7 & 17.7 & 78.0 & 79.1 & 90.6 & 87.9 \\
\hline \multicolumn{11}{|l|}{ Pref. } \\
\hline Fengyuan & 20.4 & I7.I & І8.8 & I5.5 & & & 92.5 & 90.8 & & \\
\hline Nenggao & 2I.I & I8.0 & 20.5 & I8.7 & $2 \mathrm{I} .2$ & I7.6 & 97.2 & 103.8 & 100.4 & $97 \cdot 4$ \\
\hline Kaohsiung & 25.8 & 23.8 & 26.0 & 23.3 & 27.2 & 26.8 & 100.6 & 98.2 & 105.2 & 112.8 \\
\hline \multicolumn{11}{|l|}{ Pref. } \\
\hline Chishan & 22.8 & $2 \mathrm{I} . \mathrm{I}$ & 25.2 & 22.2 & 24.8 & 25.9 & 110.5 & $105 \cdot 3$ & 108.8 & 122.9 \\
\hline Pingdong & 23.7 & $2 \mathrm{I} .9$ & 23.8 & $2 \mathrm{I} .2$ & 30.5 & 28.6 & 100.4 & 96.9 & 128.7 & 130.3 \\
\hline Chaochou & 30.7 & 28.4 & 28.9 & 26.2 & 28.6 & 27.5 & $94 \cdot 3$ & 92.4 & 93.2 & 97.0 \\
\hline
\end{tabular}

Household Register Data. We can refine our tests of ethnicity vs. locality even further by using the household register databases for two localities, thanks to the Program for Historical Demography at the Academia Sinica. The first site is that of Chupei, located in the northwestern county of Hsinchu, whose population is divided between a Hoklo area (Jiugang) and a Hakka area (Liujia)(the registers come from the villages of Maoerding in Jiugang and the village of Liujia in Liujia). The second site is that of Tanei, located in the southwestern county of Tainan, and having a majority Hoklo population but also a significant Plains Aborigine minority. The two sites, because they combine two ethnic groups within a small area, give us the opportunity to see if ethnic differences in mortality persist even when two groups occupy much the same environment.

To create samples as ethnically homogeneous as possible, I have excluded from the sample individuals who had a birth mother or adopted mother whose registered provenance/ethnicity differed from their own (which almost always followed the registered provenance of the father) because they came from the comparison group. However, women adopted by a plains aborigine 

CDR/Female CDR.

\begin{tabular}{|c|c|c|c|c|c|c|c|c|c|}
\hline & $1920-22$ & & & $1924-26$ & & & $1929-31$ & & \\
\hline District & Hoklo & Hakka & P.A. & Hoklo & Hakka & P.A. & Hoklo & Hakka & P.A. \\
\hline Hsinchu Pref. & III.6 & 106.4 & 90.3 & 109.9 & 107.4 & IO $4 \cdot 3$ & IIO.O & 107.0 & 100.4 \\
\hline Hsinchu Jun & II7.5 & IO2.I & & IIo.6 & I08.2 & & $109 \cdot 3$ & 107.6 & \\
\hline Chungli & IIO.O & 102.2 & & II 4.3 & I03.7 & & 106.0 & IO2.0 & \\
\hline Tachi & I03.7 & 96.0 & & II 2.5 & 97.8 & & IOI.6 & $95 \cdot 7$ & \\
\hline Chunan & II7. 5 & II 4.4 & & 106.2 & I02.7 & & II8.9 & 107.9 & \\
\hline Miaoli & 120.5 & II 4.7 & & I26.6 & I08.7 & & $\mathrm{II} 3.2$ & II 5.7 & \\
\hline Taichung Pref. & II2.O & $\mathrm{I} 2 \mathrm{I} .2$ & 95.2 & $\mathrm{II} 5.2$ & III.7 & 105.2 & $\mathrm{II} 3.4$ & III.9 & II6.9 \\
\hline Fengyuan & IO4. 5 & $124 \cdot 3$ & & I 24.0 & II5.0 & & II9. 2 & I2I. 4 & \\
\hline Nenggao & I25.4 & I3I.० & 96.I & І3г.6 & IO3.I & II5.5 & II7.I & 109.7 & I20.6 \\
\hline Kaohsiung Pref. & 105.5 & I08.7 & 96.8 & 106.8 & II7.2 & 105.9 & I08.4 & III.6 & IOI. 5 \\
\hline Chishan & IO4.2 & IIO.3 & I00.0 & 98.2 & I3I.4 & IO4.I & I08.3 & II3.6 & $95 \cdot 9$ \\
\hline Pingdong & $\operatorname{IOg} \cdot 3$ & IO4.3 & 92.4 & I0०.8 & 107.5 & 107.4 & I08.I & II 2.0 & 106.8 \\
\hline Chaochou & IIO. 3 & IIO.6 & $99 \cdot 3$ & 100.3 & II 8.7 & II 4.6 & Io8.I & IIO.4 & 103.9 \\
\hline
\end{tabular}

foster parent were included in the Plains Aborigine group. Comparing samples of people raised by fathers and mothers having the same ethnicity provides the clearest test of the effect of ethnic group membership.

Chupei: Hakka and Hoklo. The next three tables below present various measures of mortality comparing the Hakka and Hoklo of Hsinchu's Chupei. Despite living in villages in close proximity to one another, these data show that the Chupei Hakka enjoyed lower levels of mortality and higher levels of life expectancy than their Hoklo neighbors. The table below presents childhood mortality rates. In infancy (1qo) and early childhood (4q1) both the Hakka males and females fared better than the Hoklo. A higher percentage of infant deaths occurring in the first month of life (neonatal percentage), combined with a lower infant morality rate over all, suggests that Hakka infants suffered less from post-neonatal causes of death, primarily exogenous factors related to environmental conditions and exposure to communicable diseases. This advantage grew even greater in the next four years of life. Differences in breastfeeding patterns might be invoked to explain such differences in European populations, but we have no evidence that Hakka and Hoklo differed in this regard in Taiwan. Wolf has shown that adoption at young ages had an adverse mortality consequence (perhaps connected to premature weaning) particularly 

Hoklo, Chupei., 1906-1945.

\begin{tabular}{|c|c|c|c|c|c|c|c|c|}
\hline & \multicolumn{4}{|c|}{ Probability of death, per thousand person prs. } & \multicolumn{2}{|c|}{$\begin{array}{c}\text { Indexed Probability of } \\
\text { Death, Hoklo }=100 \\
\text { Hakka }\end{array}$} & \multicolumn{2}{|c|}{$\begin{array}{c}\text { Sex Ratio } \\
\text { of Mortality } \\
\text { Male/Female }\end{array}$} \\
\hline & Male & Female & Male & Female & Male & Female & Hoklo & Hakka \\
\hline 190 & I73. 5 & I4I.O & I 49.6 & I23.2 & 86.2 & 87.4 & I23.0 & I2I. 4 \\
\hline $4 q 1$ & II 4.7 & $\mathrm{I} 64.8$ & 72.1 & 95.5 & 62.9 & 57.9 & 69.6 & 75.5 \\
\hline 590 & 268.3 & 282.6 & 210.9 & 206.9 & 78.6 & 73.2 & 94.9 & IOI.9 \\
\hline 595 & 31.0 & 24.6 & 26.5 & 29.I & 85.5 & 118.3 & 126.0 & 9I.I \\
\hline 1090 & 291.0 & 300.3 & $23 \mathrm{I} .9$ & 230.0 & $79 \cdot 7$ & 76.6 & 96.9 & 100.8 \\
\hline NN\% & 4I.०\% & $24.2 \%$ & $57.4 \%$ & $54.7 \%$ & 140.0 & 227.9 & I70.8 & 104.9 \\
\hline $\begin{array}{l}\text { Total } \\
\text { person yrs. }\end{array}$ & 52264 & 46438 & 59902 & 54472 & & & & \\
\hline
\end{tabular}

on young girls (1995: 303). Lower rates of adoption (affecting primarily females) compared to Hoklo might also be invoked to explain the Hakka female advantage in ages I-4, but in Chupei, both Hakka and Hoklo adopted females and practiced little daughter in law marriage at high rates (Wolf I995: 50-5I, 54, I77 (mean age at adoption of 4 , slightly lower for Hoklo)). The Hakka male death probability (4qI) shows almost the same advantage over Hoklo as the female in these years, which suggests factors other than female adoption create the Hakka advantage in early childhood. It is worth noting that the sex ratio of mortality is quite low among both groups at ages I-4 and especially among the Hoklo; this indicates high excess female mortality that could be the result of high rates of adoptions in both groups. There is a big divergence in the sex ratios of mortality at ages 5-Io (595); the Hakka ratio shows a female excess when the Hoklo sex ratio shows a substantial male excess.

The Hakka advantage in life expectancy persists for males throughout the life cycle, but diminishes rapidly for Hakka females to levels much closer to those of the Hoklo and even falls below the Hoklo life expectancy at age 30; this is related to the higher probabilities of death at ages 30-45 for Hakka females. Differences in fertility might be suspected to contribute to higher death rates at these ages among a higher fertility group, but previous work shows no significant differences in fertility levels and patterns between the Chupei Hakka and Hoklo (Shepherd et al. 2006:I43). Note that the sex ratios for probabilities of death after age 20 almost always show much higher male disadvantages among the Hoklo than among the Hakka. Similarly, the sex ratios of life expectancies are much closer for the Hakka 
Life Expectancy at Dfferent Ages, in Years

$$
\text { Hoklo }=100
$$

Hakka

Hoklo

Hakka

Male Female Hoklo Hakka

\section{Chupei}

Male Female Male

Female
Sex Ratio of Life

Expectancy

Male/Female

I906-I945

\begin{tabular}{lllllllll}
\hline & 38.0 & $4 \mathrm{I} .8$ & 44.7 & 46.3 & 117.6 & 110.8 & 90.9 & 96.5 \\
I & 44.9 & 47.6 & $5 \mathrm{I} .5$ & $5 \mathrm{I} .8$ & 114.7 & 108.8 & 94.3 & 99.4 \\
5 & 46.6 & 52.8 & $5 \mathrm{I} .4$ & $53 . \mathrm{I}$ & 110.3 & 100.6 & 88.3 & 96.8 \\
I0 & 43.0 & 49.0 & 47.8 & 49.6 & 111.2 & 101.2 & 87.8 & 96.4 \\
30 & 27.8 & 33.5 & $3 \mathrm{II} .8$ & $33 . \mathrm{I}$ & 114.4 & 98.8 & 83.0 & $96 . \mathrm{I}$ \\
50 & I5.9 & I7.9 & I8.0 & I8.5 & 113.2 & 103.4 & 88.8 & 97.3 \\
\hline
\end{tabular}

Table 33. Age Specific Death Rates, Hakka and Hoklo, Chupei. Deaths per Io०o person years.

Age Specific Death Rates, per thousand

\begin{tabular}{|c|c|c|c|c|c|c|c|c|}
\hline \multirow{2}{*}{$\begin{array}{l}\text { Chupei } \\
\text { Age at begin. } \\
\text { of interval }\end{array}$} & \multicolumn{4}{|c|}{ Age Specific Death Rates, per thousand } & \multicolumn{2}{|c|}{$\begin{array}{c}\text { Indexed Probability of } \\
\text { Death, Hoklo }=100 \\
\text { Hakka }\end{array}$} & \multicolumn{2}{|c|}{$\begin{array}{c}\text { Sex Ratio } \\
\text { of Mortality } \\
\text { Male/Female }\end{array}$} \\
\hline & Male & Female & Male & Female & Male & Female & Hoklo & Hakka \\
\hline$\circ$ & 197.4 & ${ }_{15} 6.4$ & 167.1 & $\mathrm{I} 34.8$ & $84 \cdot 7$ & 86.2 & $\mathrm{I} 26.2$ & I 24.0 \\
\hline I & 30.8 & 46.0 & I 8.8 & $25 \cdot 4$ & 61.0 & 55.2 & 67.0 & 74.0 \\
\hline 5 & 6.3 & 5.0 & $5 \cdot 4$ & $5 \cdot 9$ & $85 \cdot 7$ & 118.0 & $\mathrm{I} 26.0$ & 91.5 \\
\hline IO & 3.9 & $3 \cdot 3$ & 3.5 & 2.3 & $89 \cdot 7$ & $69 \cdot 7$ & II 8.2 & 152.2 \\
\hline I5 & 4.2 & 5.0 & $4 \cdot 3$ & 3.8 & 102.4 & 76.0 & 84.0 & $\mathrm{II} 3.2$ \\
\hline 20 & 9.I & 6.7 & 5.9 & 4.6 & 64.8 & 68.7 & $\mathrm{I} 35.8$ & $\mathrm{I} 28.3$ \\
\hline 25 & II.9 & 7.I & 7.2 & 6.7 & 60.5 & 94.4 & I67.6 & 107.5 \\
\hline 30 & I6.4 & 5.8 & 8.6 & 6.9 & 52.4 & 119.0 & 282.8 & $\mathrm{I} 24.6$ \\
\hline 35 & I 4.0 & IO. 4 & II. 4 & $\mathrm{I} 3.2$ & 81.4 & 126.9 & I34. 6 & 86.4 \\
\hline 40 & 22.2 & 7.1 & I3. 8 & IO.O & 62.2 & 140.8 & $3 \mathrm{I} 2.7$ & I38.0 \\
\hline 45 & 23.3 & I 2.7 & I8.6 & I 2.7 & 79.8 & 100.0 & I83.5 & $\mathrm{I} 46.5$ \\
\hline 50 & 3I.I & I8.0 & 21.9 & I5.2 & 70.4 & 84.4 & I72.8 & I44.I \\
\hline 55 & 40.0 & 37.0 & 28.0 & 29.3 & 70.0 & 79.2 & I08.I & 95.6 \\
\hline 60 & 53.6 & 42.8 & 48.2 & $49 \cdot 7$ & $89 \cdot 9$ & 116.1 & $\mathrm{I} 25.2$ & 97.0 \\
\hline 65 & $79 \cdot 9$ & 60.2 & 49.0 & 6I.4 & 61.3 & 102.0 & I32.7 & 79.8 \\
\hline 70 & II $4 \cdot 5$ & 93.9 & I02.9 & 77.6 & $89 \cdot 9$ & 82.6 & I2I.9 & I32.6 \\
\hline
\end{tabular}


than the Hoklo indicating a much larger gap in the life expectancies of Hoklo males compared to Hoklo females, a factor to be discussed below.

Comparison with rates for other parts of the island show that both the Hoklo and the Hakka benefited from the healthier environment of Hsinchu, but as these data show even in the circumscribed area of Chupei, a Hakka advantage persists. Both the Hakka advantage and the advantage conferred by the Hsinchu environment demand explanation. The regional differences in causes of death discussed above provides clues to the general Hsinchu advantage. Within the township of Chupei, microecological differences between Jiugang's Maoerding and Liujia likely made a difference. Jiugang is a coastal area of large nucleated villages with some full-time fishermen among a majority of farmers, while Liujia is an agricultural area with a dispersed settlement pattern (Chuang Ying-chang I994: 15, I9, 23). It may have been easier for communicable diseases to spread among the concentrated population in Maoerding compared to the more dispersed farmsteads of Liujia. Because fish waste attracts flies, which can transport bacteria to human food, it may also have been easier for gastrointestinal diseases to spread in Maoerding compared to Liujia. Both areas are reputed to rely on relatively clean well water and not surface sources of water, but well water near the coast may have been salty and less pure. Windiness in coastal areas may cause greater respiratory illness, and also eye problems ( I am indebted to Shih Tianfu for these comments).

There remains the possibility that cultural differences mattered, but which aspects of Hakkaness contributed to higher survival in the Hsinchu environment remain a mystery. Is it greater resistance to disease or less exposure that explains the Hakka advantage? There are many popular notions about Hakka - Hoklo differences that could provide clues. Could the reputation for the greater orderliness and cleanliness of Hakka villages (Kleinman I980: $338 \mathrm{n}$, Chuang Ying-chang personal communication) reflect a generally higher level of sanitation that had a positive impact on their health? Could the reputation of Hakka for strong group solidarity (Pasternak I972: 128, Kleinman I980: 338 n) imply a community that provided support for the sick and disadvantaged in ways that reduced death rates? Are there dietary and food preparation practices among Hakka that led to lower levels of diarrhea and enteritis? Or did lower levels of malaria in Hsinchu somehow differentially benefit the Hakka and lead to lower disease levels overall due to reduced negative impacts of comorbidity? Did the Hakka reputation for bodily cleanliness associated with regular afternoon bathing (Myron Cohen, personal communication), have positive health consequences, or reflect sanitary practices that carried over into food and drink preparation? Why are respiratory tuberculosis rates so low among the Hakka? What does this reflect about the situation of Hakka in Hsinchu - is it an advantage of having so little of its population living in urban 
centers (note such an argument could not explain the Chupei differences)?

Were there more scholars and medical professionals per capita among the Hakka than among the Hoklo (Kleinman I980: 338n)? Was the Hakka population (or the Hsinchu population generally compared to all Taiwan) better educated (higher rates of school attendance?) and thus more familiar with germ theory and sanitary principles based on it?

Did Hakka women benefit compared to their bound-footed Hoklo counterparts from having natural feet and freedom of movement, or suffer from heavy labor as Hoklo critics alleged? A health benefit from natural feet fails to explain why Plains Aborigine women, similarly free of binding, benefited so much less, and why Hakka men shared the same health advantages as Hakka women over Hoklo counterparts. But perhaps the health of both male and female Hakka benefited from women's natural feet? Note that adult men are much more vulnerable than adult women to respiratory diseases; perhaps the increased share of farm field labor borne by Hakka women reduced the exposure of vulnerable Hakka men to the elements and to the risk of death due to respiratory diseases, without jeapordizing the similar advantage of Hakka women over Hoklo in respiratory diseases? If Hakka men and women more freely switched off in otherwise gendered tasks when an opposite sex family member was sick, the sick person could be left to recover and over the long run both sexes would enjoy a health advantage. (Note that even after the demise of the footbinding practice from I9I5, the Hoklo gender division of labor likely continued to contrast with that of the Hakka.) This implies a lower sex ratio of mortality at adult ages for Hakka compared to Hoklo, which is supported by our data for Chupei and Hsinchu (but not for the south). This gives a different meaning to the Hoklo critique of lazy Hakka men benefiting from the heavy labor of Hakka women and suggests that it was Hoklo men as much as Hoklo women who paid the price of footbinding in poorer health.

Overall it is striking how many potentially viable hypotheses there are that could explain a Hakka mortality advantage. Yet we must remember that the actual advantage of Hakka over Hoklo within Hsinchu is moderate, and that the advantage disappears in the context of Kaohsiung. If a Hakkaness hypothesis survives further testing, it will be in a conditional form that acknowledges the importance of environmental factors. Unfortunately we have no reports of causes of death by both ethnic group and prefecture with which to pursue these questions. The reports of causes of death by prefecture reviewed above showed a pattern of low rates for all leading causes for Hsinchu that are consistent with those shown for the Hakka when compared to the Hoklo at the all-Taiwan level. But because of the extensive presence of both Hakka and Hoklo, the prefectural cause of death data can shed no light on ethnic differences within Hsinchu. 
148 Tanei: Hoklo and Plains Aborigines. The next three tables compare the various measures of mortality for the Plains Aborigines and Hoklo of Tanei. Not surprisingly, given Tanei's southern location within Tainan prefecture, the life expectancies of both Tanei groups are considerably lower than those in Hsinchu's Chupei. The first table below presents childhood mortality rates. There is little difference in the probabilities of death between Plains Aborigine and Hoklo men and women in the first five years of life (590) but Plains Aborigine women have a surprisingly higher probability of death at ages 5-IO (595) than Hoklo women. This contradicts our notion that a higher value placed on female children would result in a survival benefit for Plains Aborigine daughters compared to the Hoklo. The much lower sex ratio of mortality among Plains Aborigines than Hoklo at ages I-4 (491) and 59, indicating high rates of excess female mortality compared to male, is further evidence of adverse conditions for Plains Aborigine girls. Rates of little daughter in law marriage and female adoption are low in Tanei among the Hoklo, so the adverse consequences of adoption are not operating to raise the Hoklo rates of deaths. The Plains Aborigine pattern of adopting Hoklo girls (though not for little daughter in law marriages) probably raises the Plains Aborigine rates. Overall the probabilities of death 0-9 (10q0) for Plains Aborigine and Hoklo children in Tanei show only minor differences, but the degree of excess female mortality shown by the Plains Aborigine sex ratio of mortality for ages 0-9 is surprising.

The differences between the two Tanei groups in life expectancy are generally less than between the Hakka and Hoklo of Chupei, with an interesting discrepancy between the sexes that changes with age. The life expectancy of Plains Aborigine women is lower than that of Hoklo women up to age 30 but is essentially the same thereafter, while Plains Aborigine men do somewhat better than Hoklo men up to age 50 when they fall slightly behind. Plains Aborigine women have higher probabilities of death at ages 20-40, which coincides with the childbearing years. Differences in fertility might be suspected to contribute to higher death rates at these ages among a higher fertility group, but previous work shows no significant differences in fertility patterns between the Tanei Plains Aborigines and Hoklo (Shepherd et al. 2006: I43). The sex ratios of life expectancies show a greater sexual difference among the Hoklo than the Plains Aborigines up to age 50. The sex ratio of mortality for Hoklo consistently shows a male excess from age 20, while the Plains Aborigines show a female excess ages 20-35, and a male excess thereafter up to age 70.

The Tanei Plains Aborigines are reputed to be poorer than their Hoklo neighbors, but this does not seem to have translated into a significant difference in probabilities of survival. Both Tanei groups suffered from levels of mortality much higher than the Hsinchu groups, reflecting the adverse consequences of their southern environment. But neither Tanei group demonstrates a peculiar ethnic advantage or disadvantage via a vis one another in their mortality patterns. 


\begin{tabular}{|c|c|c|c|c|c|c|c|c|}
\hline & \multicolumn{4}{|c|}{$\begin{array}{l}\text { Probability of death, } \\
\text { per thousand person } \text { Yrs. }^{2}\end{array}$} & \multirow{2}{*}{\multicolumn{2}{|c|}{$\begin{array}{c}\text { Indexed Probability } \\
\text { of Death, Hoklo }=100 \\
\text { Plains Aborigine }\end{array}$}} & \multirow{2}{*}{\multicolumn{2}{|c|}{$\begin{array}{c}\text { Sex Ratio of } \\
\text { Mortality } \\
\text { Male/Female }\end{array}$}} \\
\hline & \multicolumn{2}{|c|}{ Hoklo } & \multicolumn{2}{|c|}{ Plains Aborigine } & & & & \\
\hline & Male & Female & Male & Female & Male & Female & Hoklo & P.A. \\
\hline $1 q 0$ & 160.3 & I47.I & I77.6 & $\mathrm{I} 43 \cdot 3$ & 110.8 & $97 \cdot 4$ & IO9.0 & I23.9 \\
\hline 491 & $\mathrm{I} 39.2$ & $\mathrm{I} 53.2$ & II 8.4 & I56.I & 85.1 & 101.9 & 90.9 & 75.8 \\
\hline 590 & 277.2 & $277 \cdot 7$ & 275.0 & 277.0 & 99.2 & $99 \cdot 7$ & 99.8 & $99 \cdot 3$ \\
\hline 595 & $40 . \mathrm{I}$ & 46.5 & $25 \cdot 3$ & 67.0 & 63.1 & 144.1 & 86.2 & 37.8 \\
\hline $10 q 0$ & 306.2 & 3 III.3 & $293 \cdot 3$ & $325 \cdot 5$ & 95.8 & 104.6 & 98.4 & $90 . \mathrm{I}$ \\
\hline NN\% & $47 \cdot 9 \%$ & 4I.7\% & $54.8 \%$ & $4 \mathrm{I} .7 \%$ & 114.4 & 100.0 & II 4.9 & I3I. 4 \\
\hline $\begin{array}{l}\text { Total } \\
\text { person yrs. }\end{array}$ & I24880 & II 6215 & I6944 & I9395 & & & & \\
\hline
\end{tabular}

Table 35. Life Expectancy at Different Ages, Plains Aborigines and Hoklo, Tanei, I906-1945.

Life Expectancy at

Different Ages, in Years.

Hoklo

Plains Aborigine

Male

Female

Male

36.0

Female

Male

106.5

109.2

107.0

106.3

102.1

97.8

$17 \cdot 7$
Indexed Life Expectancy, Sex Ratio of Life

Hoklo $=100$

Expectancy

Male/Female

\begin{tabular}{lllllll} 
I3.6 & I 7.7 & I3.3 & 100.0 & 76.8 & 75.1 \\
\hline
\end{tabular}

Overall, the mortality of the Hoklo groups, whether located in Tanei or in Hsinchu, more resemble those of their close neighbors than they do those of other Hoklo.

\section{Conclusion}

We have documented in this paper the persistence of strong regional differences in the levels of mortality and the underlying causes of death throughout the 

per 1000 person years.

\begin{tabular}{|c|c|c|c|c|c|c|c|c|}
\hline \multirow[b]{2}{*}{$\begin{array}{l}\text { Age at begin. } \\
\text { of interval }\end{array}$} & \multicolumn{4}{|c|}{ Age Specific Death Rates, per thousand } & \multicolumn{2}{|c|}{$\begin{array}{l}\text { Indexed Probability of } \\
\text { Death, Hoklo }=100 \\
\text { Plains Aborgine }\end{array}$} & \multicolumn{2}{|c|}{$\begin{array}{c}\text { Sex Ratio } \\
\text { of Mortality } \\
\text { Male/Female }\end{array}$} \\
\hline & Male & Female & Male & Female & Male & Female & Hoklo & P.A. \\
\hline$\circ$ & I80.6 & 164.0 & 202.9 & I59.3 & 112.3 & 97.1 & IIO.I & I27.4 \\
\hline I & 38.0 & 42.4 & $3 \mathrm{I} \cdot 7$ & 43.0 & 83.4 & 101.4 & 89.6 & $73 \cdot 7$ \\
\hline 5 & 8.2 & 9.6 & 5.2 & I3.9 & 63.4 & 144.8 & 85.4 & 37.4 \\
\hline IO & 6.I & 5.0 & 2.0 & 5.5 & 32.8 & 110.0 & I22.0 & 36.4 \\
\hline 15 & 7.I & $7 \cdot 7$ & $7 \cdot 7$ & $7 \cdot 3$ & 108.5 & 94.8 & 92.2 & 105.5 \\
\hline 20 & $\mathrm{I} 3.3$ & I2.5 & 8.5 & I5.I & 63.9 & 120.8 & 106.4 & 56.3 \\
\hline 25 & I4.4 & I2.7 & 8.4 & I8.I & 58.3 & 142.5 & II 3.4 & 46.4 \\
\hline 30 & I9.0 & I3.9 & IO.० & I7.9 & 52.6 & 128.8 & I36.7 & 55.9 \\
\hline 35 & 25.0 & I 4.2 & 19.9 & I8.I & 79.6 & 127.5 & I76.I & I09.9 \\
\hline 40 & 28.4 & 22.4 & 33.I & I7.5 & 116.5 & 78.1 & $\mathrm{I} 26.8$ & I89.I \\
\hline 45 & 34.I & $2 \mathrm{I} .2$ & 41.6 & II.9 & 122.0 & $5^{6.1}$ & I60.8 & 349.6 \\
\hline 50 & 43.I & 22.8 & 39.4 & 24.2 & 91.4 & 106.1 & I89.0 & $\mathrm{I} 62.8$ \\
\hline 55 & 50.7 & 31. 8 & 64.0 & $27 . I$ & 126.2 & 85.2 & I59.4 & 236.2 \\
\hline 60 & 73.2 & 42.3 & 68.7 & 37.9 & 93.9 & 89.6 & I73.O & I8I.3 \\
\hline 65 & II9.9 & 68.9 & I52.7 & 52.3 & 127.4 & 75.9 & I74.O & 292.0 \\
\hline 70 & II6.9 & 88.4 & III. 8 & I 48.7 & 95.6 & 168.2 & $\mathrm{I} 32.2$ & 75.2 \\
\hline
\end{tabular}

Japanese period in Taiwan. These differences show up strongly from the earliest date and persist to the end of the period despite public health interventions and overall declines in mortality. It is likely that the environmental and epidemiological factors giving rise to these patterns long predated the accession of Japanese rule.

We have also documented striking ethnic differences, especially in the case of the Hakka minority. The best explanation for the Hakka advantage overall is the Hakka population's good fortune to be heavily concentrated in the area of lowest mortality. But within Hsinchu we also find a moderate Hakka advantage over Hoklo persists even within small districts that keeps alive the possibility of a cultural advantage for Hsinchu Hakka. But this advantage disappears in the southern context of Kaohisung. 


5

\section{An outline of socio-medical care in the Netherlands, I9th and early 2oth centuries}

Willibrord Rutten Sociaal Historisch

Centrum Limburg / Maastricht University

The Netherlands 
Except for precautions against plague, disease prevention policies on a national scale were non-existent in the Netherlands until the turn of the I8th/I9th century. The political constellation of the Republic of the United Provinces was a serious obstacle for the development of an active health policy. The government of the Dutch confederation lacked the power to take charge and initiate a campaign to contain epidemics.

\section{Medical Police}

Then the Batavian Revolution (1795) put an end to the old Republic and paved the way for the formation of a national state after the Napoleonic model. The Republic of the Free Bataves (1796-1806) came into being. In quick succession it was followed by the Kingdom of Holland (I806-18I0) as a French puppet state, then annexation by the French empire (I8IO-I8I3), and finally in I8I3 the restoration of the House of Orange and the establishment (I8I4) of an independent, constitutional Kingdom, which still exists today. The new form of government, in accordance with the French administration, was highly centralized. Health now became a political issue (Batavian Constitution I798, art. 62). Bearing the primary responsibility for protecting the public health, the state had the right to regulate hygiene and sanitation to improve the public good. The concept of medical police as conceived originally by the Prussian medical reformer Johann-Peter Frank (I745-I82I) found a strong advocate in doctor Jan van Heekeren (I773I803), Secretary of State for Public Health in the Batavian Republic.

As in most European countries this strategy was not fully implemented in the Netherlands until the late igth century. The budgetary allocations for Medical Police formed only a very small part of the budget of the Ministry of Home Affairs. Nonetheless, establishing the medical police and instituting civil registration to be administered by civilian officials were major achievements matching other reforms of the Batavian-French era (monetary unification, unification of weights and measures, military conscription). Van Heekeren saw the value the registration of births, marriages, and deaths, combined with regular censuses, would have for understanding patterns of disease and assisting the medical police in carrying out their duties (Heederik I973: 54-75; 247-249).

In 1804 the first government medical regulation (Geneeskundige Staatsregeling I804) came into being, soon (I806) to be completed by a set of Additional Articles. After the liberation of the country in $18 \mathrm{I} 3$ these regulations were adopted without any modifications by the first health provisions of the Kingdom of the Netherlands, the Act of March 12, I8I8 (Geneeskundige Staatsregeling I8I8). This Act provided regulated medical practice and medical education. Local Committees on Medical Supervision (Stedelijke Geneeskundige Commissies) were to be established in those cities where at least four physicians were practising; they were charged with supervision of all medical and paramed- 
ical practice and the teaching of medical subjects outside the universities. They

were to adopt local ordinances on health matters and take preventive and relief measures in case of epidemics (Van der Korst I988: I79-20I).

Each of the eighteen provinces (eleven after the Belgian separation in I830) was to have a similar committee to carry out the same tasks in the vast majority of rural and small town municipalities lacking a local committee. ${ }^{\mathrm{I}}$ These provincial committees (Provinciale Commissies van Geneeskundig Onder zoek en Toevoorzicht) also had the task of examining practitioners without university training and of judging their qualifications. However, these committees of unpaid practitioners were heavily dependent on the backing of an active and vigorous local or provincial government. In some parts of the country (not necessarily less developed regions), these authorities showed hardly any intelligent interest in health problems, leaving the Local or Provincial Committees on Medical Supervision almost powerless.

\section{The spearhead of medical police: vaccination}

Nonetheless, real progress was made in health matters. Since the Batavian Revolution an enlightened civil society became conceivable (Kloek and Mijnhardt 200I: 578-580). The gloomy picture of public health care in the early I9th century as sketched in some textbooks (Van Zon 1993: 55) requires some modification. The fight against smallpox for example gained momentum. In April I80I, the Executive Committee of the Batavian Republic named smallpox the number one public enemy. This was confirmed in a decree promulgated in I 808 by Louis Napoleon, King of Holland, and again in I8I4 and I8I8 by William I, Sovereign of the Kingdom of the Netherlands. By making clear that humans were able to improve their lot, disease prevention through vaccination became the showpiece of the enlightened state. The Local and Provincial Committees on Medical Supervision were actively engaged in the fight against smallpox by providing cowpox lymph, monitoring the campaign for vaccination, training vaccinators, reporting outbreaks of smallpox, and educating the public.

Vaccination was made quasi-compulsory in the 1820 s and since that time national vaccination rates regularly averaged 50-60\%. Children lacking a vaccination certificate were supposed to be turned away from primary school. The recording of the names of vaccinated individuals, in conjunction with civil registration, made it possible to track down those who were not yet vaccinated. The poor and destitute who failed to have their children vaccinated risked losing their relief allowances. However, because the central government failed to get these

I. To be complete: populous provinces like North- and South Holland were divided into medical districts (Amsterdam, Haarlem, The Hague, Dordrecht). Each district was fitted out with a provincial medical committee. 
provisions codified into a national vaccination act, these instructions remained embedded in a range of provincial and local regulations or by-laws that were quite easy to evade (Rutten I997: 270-279).

\section{Medical aid: quality and availability}

Apart from vaccination, medical aid was of uncertain quality. In the first half of the igth century no less than twelve different kinds of medical practitioners, all with different levels of competence, ranging from the fully qualified doctor of medicine, surgery and obstetrics to the rural surgeon whose competence was limited to the application of salves, bandages, blood-letting and cupping. It was hardly possible to distinguish between the various qualifications and to determine exactly who was entitled to do what. Parts of the field were left to practitioners without adequate training. Probably an exception should be made for midwives in the Netherlands. These women, coming mostly from lower social classes, in general were well-trained (Van Lieburg and Kloosterman I984: 59; 66; 74-78).

The medical sector operated like a market, where all sorts of medical practitioners offered their services to sick people in exchange for financial rewards. Theoretically grounded doctors as well as pragmatically grounded surgeons, healers, and midwives were active in this market. Practitioners competed to serve consumers trying to improve and prolong their lives with the help of money. Health was one of the aspects of society which began to demonstrate commercial characteristics. People began to see their bodies as earthly properties. When this property was threatened by disease, money could buy its owner a cure (Cappers I993: 93-94).

Medical care was not just reserved for the well-to-do. Medical aid was supplied in a primitive form for a wide range of patients. Early in the Igth century it became customary for physicians to make an arrangement with families of small means. For the periodic payment of a small fixed sum (one or two cents a week) doctors undertook to give free treatment and medicine in the case of illness. However, families of no means, who in some regions were up to half the population, had to rely on municipal medical aid or charity. An enormous burden was laid on the local authority and charitable institutions for the care of the poor in general (Van Leeuwen 1992; Gales I995). As part of poor-aid the local authority provided physicians, surgeons and midwives for the poor as well as hospitalization. Aid came with rigorous means tests, but vaccination was free to all. The linking of public medical care with the care of the poor reduced medical care to the level of poor aid, i.e. the lowest possible minimum.

The demand for medical care in the more prosperous coastal provinces attracted growing numbers of doctors, surgeons, and midwives. By the middle of the century this resulted in a medical overpopulation, and young practitioners were 
urged to move to the less densely populated peripheral provinces in the east and south of the country. The family doctor had made his debut in the majority of Dutch families as early as the I86os-1870s. This is shown from a study dealing with the frequency of medical attention in the Netherlands between c. I870 and 1900. As few as 5 to 6 percent of those who died were not treated by a doctor (Rutten I985). However age differentials among those who benefited from medical care were considerable. On the domestic level, inequality in the frequency of medical attention looked very much like discrimination against the youngest members of the family. In general, medicalisation of the extreme age categories (infants, seniors) was relatively hard to achieve, on the other hand the medical practitioner gained easy access to adults (Rutten I986). Of course, physicians in this era had few effective therapies for the ills of infants and elderly.

Admittedly, the role of medical doctors with respect to curative care was limited until the late igth century. Medical doctors could, however, serve as intermediaries between the upper class and working class. In that way they could convey ideas on hygienic behaviour and child care that had been accepted earlier by the upper class, to the working classes. 'Civilised behaviour' could diffuse to lower classes through the physician (Wolleswinkel I998: 150-I60).

To put it briefly, at this stage of the development of medical care availability was less an issue than quality. In I849 qualified doctors were brought together by the founding of the Dutch Society for the Advancement of Medicine (Nederlandsche Maatschappij tot bevordering der Geneeskunst). The NMG aimed to sponsor and regulate improved medical training and also promulgated a medical code of ethics to govern the nature and quality of communication between practitioners and between practitioner and patient. In this way the practice of medicine became a profession. Meanwhile the new Medical Society in meetings and publications sought to improve the quality of medicine by exposing lacunae in medical training and in health care.

\section{Hygienists}

More importantly, the NMG gave birth to the so-called hygienists, young urban medical practitioners who played a central role in matters of public hygiene and public health such as the introduction of water mains, sewage disposal systems and school hygiene (Houwaart I993-I and I993-2). During the course of the I850s these doctors made the prevention of epidemics and the improvement of public hygiene their full-time profession. The hygienists often started their careers working with a medical service for the poor, run by a municipality or by one of the many church societies operating in the Netherlands. They believed that when medicine was transformed into a positive science, useful to society, there would be an end to doctors' impotence in the face of epidemics. A new science of public health was to be founded upon the topographical method devel- 
158 oped in the I8th century, and upon the new science of social statistics. This would be able to demonstrate the relationships between social and sanitary hazards on one hand and high mortality and epidemics on the other. In order to map out the health conditions of the population, the hygienists established the number of deaths and cases of sickness per month or per year by district, often beginning in their own places of residence. Hygienists like Zeeman, Ali Cohen and De Man were particularly active members of the influential NMG committee on statistics. The basic principle of statistics developed by the hygienists in the I85os was the simple calculation of overall death rates or death rates by cause. This method, called the biometer, was adopted from William Farr, the British epidemiologist. It provided the chance to develop a standard, and to establish deviations from that standard, by means of which healthy and unhealthy districts could be distinguished from each other. Excessive mortality was supposed to be the expression of insufficient civilization and faulty policy making. Diseases were thus signs of poor leadership (Houwaart I993: I07-IIO).

\section{The local government made responsible (I85I)}

In I85I a new Municipal Act was introduced by the then Minister of the Interior (Home Secretary), Johan Rudolf Thorbecke, a statesman who had a great influence on legislation in the Netherlands. In this Act the powers and duties of local government were formulated anew. The Municipal Act stated that matters of public health were 'fit to be regulated' by local ordinance, in as much as these were not dealt with in general by an Act of the central government. As we are facing the period of economic liberalism with its doctrine of non-interference by the state, in practice very few issues of public health had been pre-empted by the central government. The burden of tasks and responsibilities was easily delegated to the municipalities. The Municipal Act indirectly stimulated the institution in a large number of cities and towns of local health committees, consisting of hygienists, other doctors, lawyers and scientists in the fields of physics and chemistry. The most active of these committees lobbied for new local disease control ordinances (Houwaart I993: II5). But in many cases municipalities simply replaced earlier county ordinances by a local version, as in the case of regulations to contain smallpox.

\section{The take-off of the public health revolution in the Netherlands}

More importantly, the Municipal Act provided the legal and administrative structures needed to build expensive works such as piped drinking water and sewers, which were prerequisite for the take-off of the public health revolution in the Netherlands. The first large municipality with piped drinking water was Amsterdam (1854) followed by Rotterdam and The Hague in the I86os, and Leiden, Utrecht and Arnhem in I870s and I880s. By the end of the century 
around $40 \%$ of Dutch people had piped drinking water (Verdoom I965: 2II).

This was followed by the expansion of sewers. A system for draining away human excrement by a vacuum pump developed by Charles Liernur, was introduced in Amsterdam, Leiden and Dordrecht in the I870s. Most cities however preferred a system of sewers flushed by rainwater, for example Rotterdam (since I883). In the early 2oth century sewerage systems served more than half the Dutch population (Van Zon I986). Theories of disease causation (imbalance of corporal humours, miasma, filth) continued to be quite erroneous. The early introduction of piped drinking water in Amsterdam was less for hygienic reasons than for the benefit of foreign investors who supplied the capital needed to start a paying water supply business. Effective intervention does not always need accurate knowledge of disease causation (Mackenbach 2007). In any case, new sewage disposal and water supply systems revolutionised public health in the Netherlands. Mortality rates declined rapidly at an annual pace of $\mathrm{I.2} \%$ in the period running from I880 to I9I7. Infectious diseases like typhoid and respiratory tuberculosis contributed most to this decline (Wolleswinkel I998: 227).

\section{Health legislation (1865)}

Being few in numbers, the hygienists restricted their activities to the major urban centres. The sanitary movement initially failed to reach small towns and rural areas. In these places the local government lacked sufficient insight into the consequences of different kinds of health hazards. This situation led to mounting pressure on the state to intervene for the sake of the health of the nation. The threat posed by cholera epidemics was an additional reason for the Health Acts that came into being. These Acts, again authored by Thorbecke, opened a new era of medical and health care. In I865 the health regulation of I8I8 was replaced with four new laws. Two of the acts laid down as before that only qualified persons would be admitted to medical and pharmaceutical practice. The third Act stipulated the conditions of qualification for physicians, apothecaries and midwives. Qualification could only be gained by passing an examination before a government commission after suitable training received in the Universities (physicians and apothecaries) or at approved training schools (midwives). These regulations standardized the training and competence of practitioners, ending a disgraceful state of affairs from which medical practice had suffered since the establishment of the Kingdom of the Netherlands.

\section{The Health Inspectorate}

The fourth Act regulating public health (Wet regelende het Geneeskundig Staatstoezicht) introduced the State Health Inspectorate (Geneeskundig Staats-toezicht). Virtually every hygienist became a member of the Inspectorate; some hygienists worked as inspectors and were made full government officials, while others were 
unpaid officials on the health councils of the new body. Inspectors and members of the health councils brought unceasing pressure to bear on municipal and provincial administrations to improve public hygiene in their areas (Houwaart I993: II6). The Health Inspectors and assistant inspectors however had to be satisfied with only an advisory and instructive function. The authority to take measures rested exclusively with the local governments. The national government did not want to invade municipal autonomy except in those places where the local authority failed to suppress obstinacy and narrow-mindedness in the cause of general interest (Querido I968: 32).

\section{Epidemic Diseases Act}

From the early days of their service it was evident to the inspectors that nothing would be accomplished without a certain modicum of centralized power arising from specific legislation. Three Acts came into being with this purpose: I) the Burial Act (1869) stipulated that permission to bury a corpse could only be given after reception of the death certificate signed by the doctor who had treated the case, or after an official municipal autopsy. Moreover, the doctor or pathologist carrying out autopsy had to try to establish the cause of death. 2) The Cattle Act (I870) established a Veterinary Inspectorate separate from the Health Inspectorate for Humans. 3) The Epidemic Diseases Act (1872) introduced a system for monitoring and containment of communicable diseases. These Acts implied an encroachment on the sacred autonomy of local authority. The Municipal Council - Board of Aldermen or the Mayor - was charged to regulate specific matters by ordinance and to enforce these regulations. For example the Epidemic Diseases Act required the Mayor to deal with certain infectious diseases like cholera, smallpox, typhoid fever and typhus by isolation, decontamination et cetera. Municipalities, designated by the Crown, were to establish decontamination installations as well as facilities for the isolation and care of all patients, with or without means, suffering from the diseases mentioned in the Act. Furthermore a system of compulsory vaccination against smallpox became effective. The I87I-72 smallpox epidemic claiming 20,575 victims helped to make compulsory vaccination acceptable. Universal vaccination was required by the Epidemic Diseases Act, resulting in the eradication of endemic smallpox by the end of the igth century.

\section{Weaknesses}

The expenditures resulting from isolation, quarantine and vaccination were charged to the municipal treasury since no other source was indicated. Increasing amounts of public money were spent on public health apart from public assistance. The municipalities however did not show much decisiveness in carrying out the obligations of the Epidemic Diseases Act. Local governments 
lacked sufficient insight into the consequences of health hazards and different kinds of contamination. Besides, people in local government did not want to act against private interests, which was often necessary in order to improve sanitary conditions. Practically from the start there were conflicts between municipal governments and the Health Inspectorate as a result of the differences in understanding and perceptions of the urgency of action. Often the inspectors were ignored in cases in which they should have been consulted, or their advice was disregarded. One of the tasks of the State Health Control was to submit an annual report of its activities, the Report to the King on the findings and activities of the State Health Control (Verslag aan de Koning van de Bevindingen en Handelingen van het Geneeskundig Staatstoezicht). The reports contain numerous instances of contagious contamination and environmental pollution the inspectorate had to deal with. Where possible the solutions that had been provided or the measures that had been taken were reported as well. In most cases however, there was nothing to report because no action or insufficient action had been taken (Van Zon I986: 25I-255). This should be taken into account when one tries to evaluate the contribution of sanitation to mortality decline in the Netherlands in the period I875 to I900. In spite of the institution of the Health Inspectorate, infectious diseases, e.g. cholera and tuberculosis, continued to take their toll. The power of persuasion of the inspectors fell short when confronted by ignorance and obstinacy. In my opinion the top down character of the Inspectorate's approach was a major obstacle to success. In 1902 a new Public Health Act became operative which was a serious attempt to remove the organizational weaknesses which had previously hampered development. The number of inspectors was increased, but their jobs remained in the main unchanged. The real solutions were accomplished by others.

\section{Community approach}

Conscious of the urgency of the problem prominent citizens created private societies for assistance in time of epidemics, called cross societies. As the Red Cross acted in time of war, the White Cross Society proposed to meet disasters in time of peace. The first Cross Society was founded in 1875 in the province of NorthHolland, starting with ir local branches counting 600 members. Later on this White Cross Society (Het Witte Kruis) was followed by several others. The Green Cross (Het Groene Kruis, I90I) was a neutral or interconfessional federation that started in the county of Southern-Holland and later fanned out over the country. The Limburg Green Cross (Het Limburgse Groene Kruis) was a confessional federation, established in I9Io to provide sociomedical care for the Roman Catholics in the diocese of Roermond, which coincides with the province of Limburg (Philips I96r). The White-Yellow-Cross (Het Wit-Gele Kruis, I9I6) was meant for Roman Catholics living in the dioceses of Breda and Den Bosch, covering the 
entire province of Northern-Brabant, as well as those belonging to the archbishopric of Utrecht. Finally the Orange-Green Cross (Het Oranje-Groene Kruis, I938) provided care for orthodox Protestants in the Bible Belt or living dispersed all over the country. Together these cross societies provided the organization for much preventive medicine. In I920 they included 860 local branches with 400,000 members contributing one to two guilders per year. These local branches were autonomous and formed federations in provinces or dioceses in the case of the Roman Catholic cross societies. The cross societies are one of the reasons for the curious and complicated structure of health care in the Netherlands.

During the early years of the cross associations the main occupation of the local branches was home nursing, infant care and lending out nursing commodities. Infant care mainly consisted of antenatal classes, and educational meetings at which expectant mothers were taught how to look after their babies. A lot of attention was paid to promoting breast-feeding and infant-hygiene. The diocesan or provincial federations supported the local branches. They employed specific professional workers, as e.g. a poll-taker for tuberculosis and infant welfare. During the early years of its existence the cross organizations reached the people mainly by means of word-of-mouth advertising. The district nurse who visited the families in case of illness or childbirth, promoted the organization and its work. Nurses tried to win over housewives first to modern hygienic practice, such as weekly baths, healthy meals, application of disinfectants and hygienic housekeeping. The district nurse was the key figure in local branches, and did the daily work. The board of directors consisted of dignitaries: mayor, notary, general practitioner and parish priest; their job was to make sure that there was enough money to pay for the necessary expenses. Since the district nurse at least in the southern counties had a religious status, especially before World War II, she did not need wages to provide for herself. Therefore at a local level the financial problems were minimal (Wijnen-Sponselee I997: I94-I97).

The cross societies could flourish because of a feature of Dutch social structure, called pillarization (verzuiling). The entire society was organized on the basis of membership in a religious-ideological pillar. This religious segregation applied to political parties, labour unions, businessmen's organizations, sports clubs, health care organizations et cetera. The atmosphere of pillarization stimulated competition between pillars and cooperation within them. For example, the Limburg Green Cross benefited from financial aid from the powerful Roman Catholic peasant's union and its cooperative banking business.

As compared to the Health Inspectorate the approach of the cross societies was much more bottom up and for that reason more successful. More precisely it was a community approach, adapted to the religious and regional mentality of the people living in the peripheral, more rural counties of the Netherlands. Because these health organizations matched the denomination of their target 
group the message that hygienic measures were necessary could be successfully spread among the people. At the beginning of the zoth century the provinces of Northern Brabant and Limburg (Philips I980) faced a relative disadvantage compared to the rest of the country. Statistics showed higher morbidity and mortality figures, and infant mortality levels were appalling. From the ig2os these counties witnessed a medical-hygienic transformation that can be attributed to the activities of the district nurses. District nurses were usually nuns, who paid regular visits to families and brought into their homes the message of hygiene from the cross societies. Now we are entering the second phase of the epidemiological transition running from I9I7 to the I950s, in which mortality decline accelerated to a level of I.6\% per annum (Wolleswinkel I998: 227). In this stage mortality decline profited both from environmental measures (health technologies) and changes in individual behaviour (health education), and after the second world war from antibiotics like penicillin.

\section{Social legislation}

In addition to the community approach of the cross societies, which focused on the households and families, social legislation tried to combat unhealthy and dangerous situations in the workshops and factories. As compared to its neighbor state Prussia, comprehensive labour laws were relatively late in the Netherlands: the 1874 Child Labour Law was the first, and it was highly ineffective in reducing child labour. More effective public law rules on health and safety emerged by the end of the igth century and the turn of the century (Van der Valk I99I). They were both general enactments, such as the first Labor Act (Arbeidswet, I889), the Safety Act (Veiligheidswet, I895), the Industrial Accidents Act (Ongevallenwet, I90I), and specific statutes such as the Mining Regulation (Mijnreglement, 1906). The Housing Act (Woningwet, I90I) was a major achievement putting an end to the unsanitary, shoddy construction which encouraged demolition of slums (Klep 1987). Municipalities had to draft building regulations imposing quality standards. The act is best known, however, for its housing associations, which were non-profit organizations that provided good, affordable housing for the destitute. Some of the worst offences against personal health, in the field of working and housing conditions, had been substantially eradicated by the eve of World War I (I9I4). 



\section{An overview of public health development in Japan-ruled Taiwan}

Liu Shipung Institute of Taiwan History, Academia Sinica, Taiwan 
"Medicine and civilization" were two of the main themes that the Japanese colonial government repeatedly used to persuade Taiwanese to accept colonization. By accepting governmental statistics from colonial Taiwan at face value, post-war scholars commonly conclude that Japanese colonial medicine improved the survival chances of the Japanese in Taiwan and that the Taiwanese gradually enjoyed the benefits of advanced modern medicine, without understanding the complexities of both the scientific and the social history of medicine, and the policy compromises these involve. The social history of medicine in colonial Taiwan developed after the I990s has never gone beyond the assumptions of modernization theory to inquire into the evolution of state medicine in the colonial period This article therefore analyzes the factors that shaped public health infrastructures in Taiwan, reassesses Japanese colonial policies in the medical field, and explores major changes in public health during the colonial period that illuminate weaknesses in the uncritical portrayal of Japanese colonial medicine's achievements. Generally speaking, the aim of writing this article is not simply to provide an account of the development of modern medicine and public health in colonial Taiwan, but to explore the major features and weaknesses of medical services and public health infrastructures in colonial Taiwan (I895-I945).

\section{The German origin of Japanese colonial medicine in Taiwan}

During Taiwan's colonial era, the Japanese government introduced new medical ideas, methods, education, and devices to amend or improve Taiwan's hygienic environment. The effort dramatically shaped Taiwanese population and society in various ways. Undoubtedly, medicine and health care services in colonial Taiwan benefited from the application of modern medical science and technology as well as the implementation of improved administrative and educational systems. ${ }^{\text {I }}$ The transmission of modern medical knowledge to colonial Taiwan took place through two related processes: the creation of medical resources in Taiwan and the implementation of new policy goals and organizational models for maximizing the development and distribution of new medical techniques and service delivery concepts. Both processes were particularly difficult because Japan's own process of medical Westernization by copying the German concept of Staatsmedizin had begun only in 1870 , less than thirty years before.

The roots of German medicine in Japan had a long history that traces back to the tradition of "Dutch learning" (Rangaku) in the Tokugawa period (I6oo-

\footnotetext{
I. Historians in Taiwan have frequently approached colonial medicine in Taiwan from the perspective of scientific modernization - a concept which, not coincidentally, was emphasized by the Japanese colonial government before I945. Zhuang Yunmin once called this condition a la mode. Guo and Ye, "Yixue yu renwen lishi de jiaohui - fang Zhuang Yunmin tan Taiwan yixueshi (The interaction between medicine and humanity - interview with Zhuang Yunmin on Taiwan's medical history)." Yiwang (Hope) 8 (I995):20.
} 
I868). In the late Tokugawa period, Japanese reactions to Western medicine varied widely. John Bowers portrays Chinese and Western medicine in Tokugawa Japan as "fundamentally divergent" and in conflict with each other (Bowers I980: 157). The first half of the nineteenth century, however, saw an increase in physicians' interest in Western medicine (especially German medical texts written in the Dutch language) (Keene I969: I0; I9-29; IOI-I03).

In early Meiji Japan, Western medicine was seen as an integral part of Western power and culture, not as a politically neutral science or benign welfare program. The restored Meiji government in I868 decided to adopt Western medicine as part of its broader modernization effort. Following the strong recommendation of the Reverend Guido Verbeck (1830-1898), an American missionary of Dutch origin, the Meiji government chose Germany as the model for Japan's medical Westernization (Naimushō I925: 7-8). Only after the Meiji government issued its Medical Regulations (Ise) in I874 did Japanese medical authorities reject the British hospital-based, clinically oriented medicine ${ }^{2}$, and fully turn to the German university-based system which gave greater prominence to scientific training and laboratory work, and which the new science of bacteriology had raised to a position of world leadership. At the same time the emphasis on state-building in German Staatsmedizin was highly attractive to the Meiji reformers in Japan.

German Staatsmedizin was implemented in Japan by Meiji reformers, with the major differences between the Japanese and German forms being not in the administrative structure but in the way it was implemented. 3 The number of German expert advisers in Japan peaked in I887-88. Soon, the German language not only provided the technical terms of medicine, but also served as the lingua franca of the Japanese medical profession (Hirakawa i968). Meanwhile, the Japanese Ministry of Education awarded most of its grants to students studying in major German medical schools such as Berlin University and the

\footnotetext{
2. Dr. William Willis (I847-94) joined the British mission in Japan in I86r. He was later appointed professor and clinical chief of the igakkō (later the faculty of medicine of Tokyo Imperial University). In I87o Willis resigned to become head of the hospital and medical school in Kagoshima. With the outbreak of the Satsuma rebellion in $\mathrm{I} 877$ Willis returned to Tokyo. He returned to England in I88I, and later spent time in Bangkok. Hugh Cortazzi, Dr. Willis in Japan, 1862-1877: British Medical Pioneer.

3. The concept of Staatsmedizin, which arose in the nineteenth century, was based on the idea that the state should bear the primary responsibility for protecting the public health and had the right to regulate hygiene and sanitation in ways that improve the public good. The strategy was initiated by Prussian medical reformers like the layman J. P. Frank, among others, in response to various social and medical problems, and as a result, public health issues were increasingly addressed by state authorities during the late nineteenth and early twentieth centuries. However, due to political upheaval, state medicine was not fully implemented until the establishment of the German Empire after i871. George Rosen, A History of Public Health, 223-235.
} 
Academy of War, which were then ranked highest among all German universities. These schools had a formative influence on the education of the future medical elite of Japan (Ninomi i987: 4; 60). Contact with German physicians in both Germany and Japan meant that Japanese medical students, both at home and abroad, made remarkably rapid progress. By the end of the Meiji period, Japanese medicine enjoyed world renown for its own independent successes in bacteriology. Kitasato Shibasaburo (I852-I93I), for instance, who worked as a pupil of Koch in Berlin from I884 to I89I, developed antitoxins against diphtheria and anthrax, and discovered the bacillus that causes bubonic plague (Odaka I989).

Bacteriology was not the only thing that Japanese doctors learned from their German mentors. One of these Japanese students, Kuwata Kumazo suggested that Japan should remind itself of its social responsibilities and resolve the growing medical problems of its population (Pyle I974). Gotō Shinpei (I857-I929), who spent three years in Berlin where he adopted ideas combining state medicine and social hygiene, was later a "founder of modern medicine in colonial Taiwan" (Miora I980). Early medical elites in Japan, like Gotō, were soon affected by Virchow's theory of social medicine, Bismarck's ideas of social policy, and Herbert Spencer's concept of social Darwinism (Fruhstuck 2003: 22). A key concept among the Meiji medical elite was expressed by Gotō as a "biological principle" (seibutsugakū genri), a term which denoted a medical "social Darwinism," or, more simply, the "survival of the fittest" in medical matters. The Meiji medical elite, and certainly Gotō, usually preferred the term Biologische principien, in part because of the prestige of German, but also because it was "scientific" and implied the application of biological knowledge in order to promote Japanese survival within global competition (Baelz I886), as well as their "civilizing mission" in Taiwan after I895.

However, modifying elements of German Staatsmedizin to meet health needs in colonial Taiwan was a complex and difficult process. Surveys undertaken between I874 and I89o revealed the continued dominance of Chinese medicine in Meiji medical practice (Takenaka I958: 39). Many of the Meiji leaders were in fact physicians who had training in Chinese medicine, but became committed to Western medicine because of their faith in Jennerian vaccination against smallpox (Janetta and Preston I99I). Rapid change was hampered by a shortage of doctors trained in the new biomedical sciences. On the policy front, the colonial government in Taiwan was guided by two approaches, adapted from the Germans, 'public hygiene' (koshū eisei) and 'social hygiene'(shakai eisei). 4 As

\footnotetext{
4. René Sand, the Belgian historian, offers a distinction between public hygiene and social hygiene: public hygiene means the construction of a sanitary urban environment - indeed, it is the science of urbanism itself and essentially includes sanitary engineering and city planning as its tools, while social hygiene incorporates both individual and public hygiene. See Porter and Porter, "What Was Social Medicine?” Journal of Historical Sociology I:I, 9I.
} 
tools of colonial health policy, public hygiene emphasized public works (clean

water supplies, sewer systems, etc.) in primarily urban areas dominated by Japanese populations, while social hygiene pointed to broader policies that reached the Taiwanese masses, and extended to the countryside. Social hygiene was a highly expansive notion, and in continental Europe evolved into 'social medicine,' a view that holds every medical problem is rooted in social problems, and only social order and social discipline can cure a society and prevent medical crises (Porter and Porter I988: 9I; 95-96). Generally speaking, as J. Alfred Ryle suggested, social hygiene unifies preventive and remedial services and encompasses all diseases and the whole spectrum of medical practice. Social hygiene is more concerned with social problems and behavior patterns that cause medical crises (Ryle I985: II-24). While the colonial health planners did not go as far as 'social medicine' would take them, their concept of 'social hygiene' did lead to attempts to reform elements of Taiwanese health behavior and not just the Taiwanese health environment.

Early Japanese medical reformers knew what and why they learned from Germany. It is also reasonable to suppose that the Japanese knew how and why they wanted to apply certain features of Japanese colonial medicine in Taiwan.

\section{Modifying Staatsmedizin for the medical needs of colonial Taiwan}

Initially, Taiwan's difficult and dangerous conditions discouraged the ambitions of the Japanese colonizers. From the first year of the occupation, rebellions and epidemics were the primary killers of transplanted Japanese, sickness even claimed the life of a high-ranking prince serving in the occupation army. 5 Indeed, as Chen Shaoxing found, mortality rates in Taiwan remained very high through the first decades of colonial rule and fell only after modern public health facilities had been established (Chen I985: I9-2I). Medical Westernization had begun in Japan only thirty years before its occupation of Taiwan, and the resources for and experience in Western medical practices in Japan was still insufficient. Given these conditions, the pessimism of the Surgeon-General of the Japanese Army, Mori Ōgai on improving Taiwan's medical conditions was understandable.

However, Gotō Shinpei (I857-1929), a politician with a medical background, seized the opportunity presented by Imperial Japan's newest territory. Takagi Tomoe, a former member of the Kitasato Institute and close associate of Gotō, ${ }^{6}$ followed through on Gotō's ideas but was forced to compromise the Western approach to Taiwan's medical services by including local practitioners.

5. For a brief description about the death of Kitashirakawa nomiya yoshihisa shinnō, see Cai "Beibaichuangong nengjiu qin wang," in Xu, ed., Taiwan lishi cidian, 228. 
Through Gotō and Takagi, the German-Japanese Staatzmedizin model was adapted to satisfy the needs of colonial Taiwan.

\section{Sanitary police force}

One important feature of Japanese Staatsmedizin that Gotō transferred to Taiwan was the sanitary police. Most of Gotō's ideas of sanitary police were taken from Louis Pappenheim's Handbuch der Sanitätspolizei (Handbook of Sanitary Police).7 Accordingly his original plan for establishing a public health administration in colonial Taiwan emphasized two functions of the Japanese system - a sanitary police force and a public medical service (the koi system). The colonial government, by a statute of I9OI, instituted a sanitary police force. The act provided a system for sanitary policing to be carried out by police officers and laid down regulations which set up sanitary measures, listed nuisances, regulated drainage, and outlawed unlicensed practices such as those used by traditional healers (Taiwan Sōtokufu Chūō kenkyūsho I922 and I942).

However, Gotō was unable to implement his ideas until he received Takagi's help in I904. The famous Kitasato's pupil, Takagi moved to Taiwan and by 1904 was formally in charge of the department of sanitary police. As modified by Takagi, the system of sanitary police was designed to integrate with Taiwan's local security administration, the ho-kō (baojia in Chinese) ${ }^{8}$, to promote several of the colony's sanitary measures (Taiwan Sōtokufu keimukyoku i938: 746-749). The colonial government used the ho-kō system to penetrate Taiwanese society at the local level and mobilize residents to address hygienic issues. Generally speaking, in addition to providing a solid social base for colonial rule, the ho-kō system was given a new role of helping the regime carry out its sanitary goals.

To cover the financial costs, Gotō expected that funding for the sanitary

\section{Takagi Tomoe was born in 1858 and graduated from the Medical College of Tokyo Imperial University in} I885. After graduation, he took a position at Fikui Hospital and then worked in the Kitasato Institute between I893 and I897. In I895, after the Sino-Japanese war, Gotō and Takagi were both in charge of the quarantine station in Osaka. In I897, Takagi studied at the Koch Institute in Germany. After he returned in I899, he concentrated on epidemic prevention in Japan and Taiwan and helped the colonial government in Taiwan establish research institutes, a medical school, and an electric power system. For his contribution to medicine, Takagi was awarded a doctoral degree in I9I3. Takagi worked in Taiwan until I929, then retired from the Taiwan Electric Power Company upon Gotō Shinpei's death. For Takagi Tomoe’s career, see Du ed., I957: I-3.

7. Pappenheim was a German medical doctor and sanitary official. His book was published in Berlin in I886. See Shuitsu, "Gotō Shinpei 'kokka eisei genri' shiriron no sengen," Nihon ishigakushi zasshi 34:I, 79-8I.

8. The Japanese adopted the ho-kō system established during the Qing dynasty in Taiwan as a system of collective security among households, adapting it to better address crime and epidemics. The ho-kō system in colonial Taiwan was supported and financed by local police departments who used it to implement governmental orders. Tōen, Taiwan no ho-kō seido, 3-6. 
police system would be raised by revenue generated in Taiwan. In general, for

Gotō and his colleagues, the sanitary police force was a good way of ensuring the cleanliness of the immediate environment for Japanese residents without asking them to pay for it (Tong 2004: 83). Another of the main tasks of the sanitary police was to monitor Taiwanese doctors' practices and to enforce cooperation with the police surveillance and reporting system, with the urban population as the major target. Qin Xianyu has argued that the colonial sanitary police provided an omnipresent surveillance system used to control the Taiwanese population medically and even socially (Qin I998).

\section{Quarantine and Epidemics: invasion from outside}

The colonial government built a variety of medical institutions in accordance with Gotō's design. While the sanitary police looked after problems within the colony, a new quarantine system was established to prevent disease from entering the island. Severe pandemics such as plague and cholera pushed Gotō's public health reform forward faster than expected. In I894, the bustling international seaport of Hong Kong was the point from which the third pandemic of bubonic plague began its spread around the world (Benedict I996). Because Hong Kong was seen as the origin of the epidemic and many cases were found in people sailing from Hong Kong, Taiwanese called plague the "Hong Kong disease" (Iijima 2003). To deal with the crisis, Gotō in I896 transferred his experiences setting up quarantine stations in Japan to Taiwan and issued the Enforcement of Notifiable Diseases Act. Temporary quarantine services in five major ports were quickly established (Taiwan Sōtokufu fupō I899). Three years later, in I899, permanent quarantine stations were established in Keelung and Tanshui (Danshui) harbors, the two northern harbors used for shipments to Japan. In I9I8, the government attempted to enforce additional bylaws concerning health conditions in the colony's harbors. These conditions included epidemic relief, notification of infectious diseases, isolation of infectious cases, and immunization registration. According to the regulations, each port was required to have three to five health inspectors, an isolation hospital, and a quarantine station (Xu 2000: IOI-I03). In order to coordinate the activities of the existing sanitary police force, the colonial government requested that the police carry out surveillance and inspection beyond the harbor while the Bureau of Harbor Affairs officially dealt with incidents within it (Xu 2000: I67-I70). Only in the event of a crisis such as the cholera epidemic of I9I9 in China would the sanitary police enter the harbor area and offer free cholera vaccinations for sailors. 9

9. Probably because the colonial government in Taiwan neglected the serious impact of the Spanish influenza in I9I8, the police force was not then mobilized. However, the police department took extensive action during the I9I9 plague epidemic due to the terrifying experience of the I9I8 flu. See Yoshino and Aida, "Taiwan kaikyōe ken'etsu no kishi)," Kōshū bōeki zasshi no.23, 3 and 5-II. 
Due to the strict quarantine, the number of plague deaths in the years from 1896 to I9I7 was limited. There were two years of peak mortality: there were 4,496 cases of infection and 3,670 deaths in I901, and 4,494 cases of infection and 3,370 deaths in 1904. Beside these two years, the case morbidity and mortality rates were much lower than in other Asian regions and no native case was reported after I9I7 (Zhang 200I: I3-I4). While quarantine services blocked the intrusion of epidemic diseases into the island and the sanitary police monitored domestic conditions to retard transmission, medical care facilities such as hospitals and dispensaries provided ways to cure cases and reduce the impact of illnesses within Taiwan. Gotō believed that firm state control was the only way to effectively offer basic medical protection for the population.

For Gotō and his colleagues, medical facilities such as hospitals and quarantine services were the hallmark of advanced Japanese medicine in the colonial territory (Taiwan Sōtokufu minseibu I9I3: 13-I7). The challenge was to find adequately qualified health workers to staff these institutions. Takagi Tomoe accepted Gotō's invitation to serve as the Chancellor of the Hospital of the GovernmentGeneral in Taipei and principal of the medical school in I902. Takagi also took charge of epidemic prevention affairs including plague prevention and the colony's first anti-malaria campaign. ${ }^{\mathrm{IO}}$ In $\mathrm{I}_{903}$, the Home Ministry approved a plan to establish the Temporary Agency of Prevention (Rinji hōekyoku, 'TAP'). The TAP, a joint institute with the Sanitary Police Department, focused exclusively on anti-epidemic affairs; Takagi served as its first chairman. Takagi also helped the government organize the Temporary Committee on Prevention in his role as

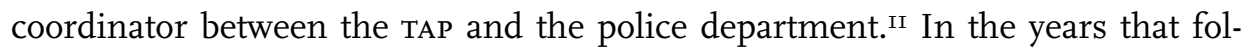
lowed, Takagi designed a plague and cholera control program (I903-I9I8) and pioneered an anti-malaria campaign in I9Io.

As the immediate threat of plague eased, other epidemic problems such as cholera and endemic malaria eventually became the targets of Japanese colonial medicine. The Meiji government had considerable experience enforcing quarantines against cholera in Japan (Chemouilli 2004), and had little difficulty extending quarantines to Taiwan to fight against cholera and plague. Takagi Tomoe played an important role introducing the anti-cholera program to Taiwan. In I895, after the Sino-Japanese war, Gotō Shimpei and Takagi Tomoe were both in charge

Io. Gotō proudly claimed that the successful rule in colonial Taiwan depended heavily on various talented individuals from Kitasato's Private Institute of Infectious Disease, among them Takagi Tomoe, who were expected to totally reform health conditions and medical services. For this reference and Takagi's early activities in Taiwan, see Nagaki I992: 245 .

II. "Daiichi keisatsu kikan no kōsei," in Taiwan Sōtokufu, ed, Taiwan Sōtokufu keisatsu enkakushi, II5 and I22. To learn more about the establishment of the Temporary Committee on Prevention, see "Keisatsu honsho oku rinji hōekika" and "Rinji hōe kiien kaikitai," in Sōtokufu fupō kunrei 188, 10 October Meiji 36 (I9०3). 
of the quarantine station at Ninoshima in Osaka. Within two months, they established three fully-equipped quarantine stations and examined 687 ships and more than 232,000 soldiers (Tsurumi I985: 554-652; 751-868). While under the command of General Kodama Gentaro at Ninoshima, Gotō worked closely with Takagi. To prevent an outbreak of cholera, Takagi produced an anti-cholera serum, thus initiating the first mass immunization against the disease in modern medical history (Ninoshima rinji rikugun kenekijo I886: I-5). Gotō maintained close relationships with Takagi and General Kodama. When General Kodama was appointed governor of colonial Taiwan in I897, Gotō was one of the first invited to serve as Deputy Chief of Civil Affairs (Minsei chōkan). ${ }^{\mathrm{I2}}$ Five years later, Gotō seized the opportunity afforded by the ongoing conflict between the Kitasato Institute and Tokyo Imperial University, to invite Takagi, who had left the Institute for the new medical college at Keio University, to become the Consultant on Sanitary Affairs (Eisei komon) and assist in Taiwan's sanitary reform.

To adapt the program they had devised in Osaka to Taiwan, Gotō and Takagi outlined a new plan to build healthy residential areas for the Japanese in Taiwan. With quarantines as the external defense, they worked to strengthen Taiwan's internal defenses against cholera and other infectious diseases. Accordingly they drew on the experience of the sanitary movements in European cities to build a comprehensive water system, the first of which was established in 1896 to serve Taipei city. In time, the population served by the system increased substantially. Prior to 1905 , the water supply system served less than I.5 percent of the total population but this rose to nearly I6.I percent by 1942 . However, piped water construction was heavily concentrated in cities $165 \%$ of pipes laid were in Taipei city alone), where the clean water supply differentially benefited Japanese residents (Taiwan suidō kenkyūkai I94I). As a result, from I930-I939 the average incidence of summer diarrhea in Taipei was 3.7\% among Japanese but I6.4\% among Taiwanese; compared to the I920s the Japanese rate had been cut in half while the Taiwanese rate remained the same. But there were also risks to relying on modern water and sewage systems when they were not properly managed. Between 1933 and 1936 in Taipei, periodic outbreaks of typhoid occurred in Japanese residential areas when leaking sewers serving flush toilets contaminated the water supply (Taihokushū keisatsu ka I932-I940).

Building water supply systems in colonial Taiwan had multiple purposes. The linkage between sanitary engineering, city planning, and promoting colonial rule is especially clear in light of the heavy investment in Japanese residential areas.

I2. On Gotō's cooperation with General Kodama, see Tsurumi, Goto Shinpei, 657-750. The resistance from the medical school of Tokyo Imperial University to Gotō's reforms is discussed in Tsurumi, Gotō Shinpei, 855-870, and Nagaki, Kitasato Shibasaburu to sono ichimon, 294-297. 


\section{Malaria: the endemic problem}

In part because malaria was not a major health threat in Japan in contrast to cholera and plague, malaria in Taiwan did not receive attention until the threats of plague and cholera were reduced. Although malaria was the major killer in Taiwan and a leading cause of death before the I920s, the anti-malaria program was developed relatively late. The sickness known in Chinese as zhang (a malaria-like symptom) was the most prevalent and virulent medical problem in Qing Taiwan (Liu and Liu 1998). In addition, during the military actions of I895, Japanese troops in Taiwan suffered from several endemic diseases ( $f \bar{u} d o b y \bar{o})$, of which malaria was the major killer. Therefore, phrases like "prevalence of lethal malaria" and "an island of ghosts" dominated Japanese impressions of Taiwan before the igoos (Fan I996: II). The Japanese understood that malaria had been a major obstacle to Western colonization and carefully monitored the Western malariology programs being developed in the Igoos. Success in controlling endemic malaria in Taiwan would be a significant achievement for the Japanese Empire in demonstrating its status as a new colonial medical power.

The colonial government remained preoccupied by the fight against plague and cholera, and other diseases in the major cities and did not carry out a concerted anti-malarial campaign until I906, when a serious malaria outbreak occurred in the camphor production areas of southern Taiwan. Although the I906 outbreak in southern Taiwan put the government on notice that endemic malaria was a serious threat, the response was only a small-scale campaign on an experimental basis to deal with the immediate problem; longer term preventive strategies were confined to academic circles. ${ }^{13}$ Takagi hosted a special meeting to map out an anti-malarial strategy for the whole island in I909, and a year later, comprehensive pilot programs were launched to experiment with Koch's method of requiring compulsory blood tests for residents and treating suspected and confirmed cases with quinine. In I9I3, regulations were promulgated mandating the establishment of malarial control districts of about 2,000 residents each, where anti-malarial stations were responsible for the enforcement of compulsory tests and treatment ( $\mathrm{Xu}$ 2004: 1032).

Reliable population records were a key requirement for the success of the Koch method. Successful eradication in a malarial area had to reach a certain proportion of the population to break the transmission of malaria. The strategy is similar to that underlying smallpox vaccination programs. By 1932, there were 208 malarial control districts, and by the end of the decade, more than three million people were undergoing routine blood examinations every year (Weishengshu I995: 2I6-2I7). It is clear that the objective was the suppression of malaria with modern 
biomedical solutions, utilizing a "vertical" approach to exploit the existing centralized administrative structure in which police and village headmen collaborated to enforce anti-malarial measures. As Barclay explained, the government "avoid[ed] every possible expense in equipment and physical facilities, and [depended] on intensive use of all the administrative resources" at the government's command (Barclay I954: 136). The coercive power of the colonial state and the hegemony of biomedical science reinforced one another to ensure the control of malaria, and the decline in malaria mortality - from 10,562 deaths in 1906 to 3,716 in 1937 - testified to the success of these efforts (Taiwan Sheng Tongzhigao 1953: 183-I84).

\section{Medical Education}

Generally speaking, after Gotō's departure in 1906, Takagi extended the whole framework of medical services and sanitary works to keep them in line with trends in Japan. In 1907, he created the Research Institute of the Colonial Government (Sōtokufu Kenkyūsho, or RICG) as the center for laboratory medicine. To supplement the insufficient medical manpower and replace traditional practitioners, Takagi twice increased enrollments in the government medical school (established in 1905), to provide annually at least sixty-five vocational-level graduates of the medical schools (igaku-senmongakkō) (Taihoku igakkō I930: 4). Because of Takagi's efforts, a miniature Japanese Staatsmedizin system was created in colonial Taiwan, complete with a research institute to satisfy the demands of laboratory medicine plus one medical school to educate practitioners in clinical medicine. Until the I920s, however, the two components of Japanized Staatsmedizin, laboratory medicine and clinical medicine, were both controlled by the sanitary police, rather than independently joined together as in Japan. In I9I9, Takagi appointed the military surgeon Horiuchi Takao as his successor. ${ }^{14}$ Leaving the laboratories solely in the hands of Japanese professionals, Horiuchi' expanded clinical medicine and put it at the center of Japanese colonial medicine. ${ }^{15}$ The infrastructure for colonial medicine in Taiwan was completed in the late I9IOs but was soon expanded by Horiuchi, who was more devoted to train-

I4. With Takagi's full support, Horiuchi studied bacteriology in Germany and returned to Taiwan to succeed Takagi and continue his mission of medical reform. He also held several important positions, including director of the Taihoku (Taipei) Red Cross Hospital and the principal of the Taihoku Medical College (Taihoku igakusenmongakkō) in I9ı6. Horiuchi served at the Medical College until I947.For details about the career of Horiuchi Takao, see Ishigi, ed., Horiuchi Takao boshi zhuidaozhi, Nanmin huazhi no. II.

I5. Born in 1873, Horiuchi, like Gotō, had only a high-school level of medical training before becoming a surgeon during the Sino-Japanese War in 1895 . Following the occupation of Taiwan, Horiuchi traveled extensively through the island with the military. According to an application he submitted to study in Germany, Horiuchi admitted that he lacked training in laboratory medicine and relied instead on clinical observation for diagnosis and treatment. Oda, Taiwan igaku gojunen, 3-5 and I2. 
ing clinicians (many of them Taiwanese) than educating laboratists. ${ }^{16}$ In I9I9 the existing vocational medical school (醫學校), the lowest rank in the three-tiered Japanese medical educational system, was elevated to the rank of a medical college (醫學專門學校) but kept focusing on clinician training (university status would not come until I936). Graduates of university level medical schools (大學 醫學部 or 醫科大學) in Japan served primarily in government hospitals and laboratories (Lin 1997: 93). Thus the majority of medical practitioners in Taiwan were either graduates of vocational medical schools or of medical colleges (Weishengshu 1995: 104-I09). From the I920s private practitioners dominated clinical medicine. The number of public hospitals never exceeded 35, while the number of private dispensaries, usually owned by Taiwanese physicians, grew to 263 by 1940 (Taiwan Sheng Xingzheng Zhangguan Gongshu I946: I249-I250). The large expansion in the number of clinicians made medical care accessible to a growing proportion of the Taiwanese population. Although Takagi and Horiuchi had training in laboratory medicine, their educational policies increased the influence of clinical medicine in Taiwan.

\section{Improvement of the public health surveillance system}

The main purpose of using sanitary police in the public health system in colonial Taiwan was to provide surveillance against potential outbreaks of epidemics in Japanese settlements and military compounds coming from rural Taiwan. While the harsh environment in Taiwan dampened the ambitions of military surgeons like Moriōgai, it also drove others deeper into investigation. Taiwan Chūō eiseikai (the Central Sanitary Committee in Taiwan, or CSCT) was established right after the occupation in I895. Unlike its counterpart in Japan, CsCT was merely a technical institution affiliated to the sanitary police. While the Central Sanitary Bureau in Japan conducted independent research, the CsCT in Taiwan was simply a scientific unit charged with investigating and identifying epidemics for police action. In 1896 , the Committee for the Investigation of Endemic and Epidemic diseases in Taiwan (Taiwan Chihobyō oyobi densenbyō chōsa iinkai) was given the same charge. Rapidly it became clear that the first priority of the colonial administrator was to grapple with epidemic crises first and address long term scientific interests second (Oda I995: 12-23). In the next year, 1897 , the establishment of the Temporary Agency of Prevention (TAP) completely replaced the Investigation

I6. Formal medical education began in colonial Taiwan in I897, when Yamaguchi Hidetaka established the Native Doctor Training Institute (Dojin Ishi Yōseisho). What began as an intensive first-aid program soon expanded into a formal medical school upon Takagi's appointment as principal in I902; it became part of the Japanese imperial university system in I928.The medical school changed the title to "college" after I9I9. However, the education in the college remained vocational training in clinical medicine until it was merged with the Taihoku Imperial University in 1938. 
Committee of Endemic and Epidemic Diseases in Taiwan and, in I903, its successor, the Temporary Committee on Prevention, served mainly as an investigative unit coordinating anti-epidemic campaigns with the police (Oda 1977).

Up to I909, CSCT was the highest institution in the system charged with providing experimental findings for the practical needs of the Department of Sanitary Police. However, because сscr had only limited capabilities in biological research, this work was farmed out to affiliated laboratories at public and military hospitals. But these laboratories lacked the proper equipment and stable budget needed to accomplish their goals (Horiuchi Takao I903). It was in this context that in 1907, Takagi proposed that the colonial government establish the Research Institute of Central Government, or RICG in line with a similar trend in Japan (Oda I995: IOI). The RICG was expanded to a total of twelve laboratories and changed its name to Central Research Institute (Chūō Kenkyūsho, CRI) in I92I (Taiwan Sōtokufu Chūō kenkyūsho I922: IO). Annual reports of the RICG and CRI through 1940 indicated that the researchers in both institutes were primarily concerned with medical experimentation rather than therapeutic skill. This attitude was very similar to the situation in Japan. Japanese were in the majority on the staffs of both the RICG and CRI; only three Chinese names appear on annual reports during the total 30-year history of the two institutes. ${ }^{17}$ In short, RICG and CRI were research centers for Japanese medicine operating in colonial Taiwan and the government's placing them at the top of the medical system in the colonial bureaucracy did not compensate for the shortcomings of CSCT and TAP.

Considering the shortage of manpower and the limited capacity of modern medicine in Taiwan before the I920s, the targets of surveillance and prevention by the sanitary police had to be highly selected. Aside from the urgent strategic need to combat epidemics, the ability of Japanese modern medicine in the I900s to cure or prevent certain diseases was the key determining which major diseases in Taiwan would receive the most attention. Because the Japanese were experienced in controlling plague and cholera in Japan but not malaria, the anti-malaria campaign was postponed. ${ }^{8}$ And for the same reasons, mass vaccination was carried out against smallpox. ${ }^{19}$ However, the success of Jennerian immunization in Taiwan had to rely on more than its reputation for success among Japanese. The need to prevent the spread of infection to Japanese required a new surveillance system and mass vaccination in the wider Taiwanese population. Although

I7. See summaries of annual reports in Taiwan Sōtokufu Chūō kenkүūsho eiseibu gyōseiki. (I922 and I942) I8. An interesting and controversial topic in the history of modern medicine is the race between Alexander Yersin and Kitasato to discover the plague bacillus in 1894 in Hong Kong. For a brief description of their competition, see Stefan Riedel, "Plague: From natural disease to bioterrorism," Baylor University Medical Center Proceedings I2:8, II9. For Kitasato's works on the I9II anti-plague campaign in Manchuria, please refer to Wu, Memories of Wu Lienteh: The Plague Fighter, 4I-45. 
smallpox had been recognized as endemic in Qing Taiwan, the disease was rarely treated in hospitals (Office of Inspector-General of Customs I876-1877: 32; 54). Japanese records later revealed that the disease was in fact prevalent among the Taiwanese population (Liu and Liu I998: 260-265). Only limited numbers had been vaccinated by missionary physicians in late Qing Taiwan (Chen I997: 4364). In I896, the Japanese launched the first systematic campaign of Jennerian vaccination in Taiwan (Takekoshi I907: 283 ff.; Government-General of Taiwan I9I2: 407). However, the vaccination effort was not able to produce the expected results before I905 after it became obvious that the colonial government could not rely on temporary investigation units or intermittent actions to deal with the permanent vaccination needs of an "unhealthy" Taiwanese society. ${ }^{20}$

The establishment of a comprehensive Household Registration System (HRS) was essential to compensate for the insufficiency of CSCT and TAP and to improve the effectiveness of the epidemic prevention and mass vaccination efforts. The household registration system was reformed in I905 in conjunction with the first modern census. Because of this census, the colonial government realized the inaccuracy of the data gathered by the regular police system. ${ }^{2 \mathrm{I}}$ The government thus began to revise its data reporting, especially the death reports, and vaccination records (Taiwan zongdufu I906). The HRs provided a valuable tool for tracking the vaccination of individuals. However, the household registers recording of infant and child (under age 5) mortality remained incomplete until about I9I0 (Zhang I986: I9). An important problem in the vital statistics reporting system was the need to rely on traditional doctors incorporated into the kōi (public doctor) system to issue death certificates. Although $k \bar{o} i$ were originally designated to carry out vaccinations, their number was too small to complete the mission. In addition, as many were Japanese it was difficult for them to win the trust of the Taiwanese. In I902 practitioners of traditional Chinese medicine were allowed to be licensed after passing an examination, and then they assisted in the vaccination program under the supervision of kōi. These practitioners list-

I9. The Jennerian vaccination of cowpox was introduced to Japan in I849. Due to its safety and high effectiveness, the Bakufu government promoted vaccination, which eventually symbolized the superiority of Western medicine to Japanese society. For the introduction of the Jennerian vaccination and Japanese trust in it in the first-quarter of the twentieth century, see Itazawa, Tenrento ni kansuru kenkyu.

20. During the anti-plague campaign in I9O2, a deficit in the reporting system had been discovered. However, the government was still searching for a way to effectively re-organize the system. For one case, see "Wanli weisheng zhuangkuang," Taiwan nichinichishinpō (Chinese version), May, 8, I903.

2I. Until a completed household registration system was introduced to colonial Taiwan, the functions of surveillance and control of certain diseases as well as mass vaccinations could not be enforced. "Yufang shuyi", Taiwan nichinichishinpō (Chinese version), January, 30, I906, and Xu., Taiwan zongdufu gongwen leizuan weisheng shiliao huibian (Mingzhi (Meiji) 29 nian 4 yue zhi Mingzhi 29 nian 12 yue), I26. 
ed questionable causes of death such as douzhe (pox-symptom) and pao (pox) on death certificates. The use of vague causes of death reduced the quality of both case and cause of death reporting. Although the classification of the cause of death in Taiwan was in line with the international list, the quality of diagnosis and certification needed to be improved. ${ }^{22}$

As the HRs became more reliable, the original surveillance function of the police reporting system remained. Improvements in medical services enhanced the reliability of the public health system after the I920s. Because of the expansion of the public education system, and the extension of vaccination to Taiwanese children enrolled in schools after I9I0, the Japanese population in Taiwan became less vulnerable to smallpox than to other diseases which were less controllable. ${ }^{23}$ The cooperation of the growing number of new Japanese-supported and -trained Taiwanese clinicians helped ensure the success of the vaccination effort.

The most important improvement in the identification of diseases and causes of death was the growth of medical facilities including private dispensaries. Beginning in the I920s, private and charity hospitals (public hospitals were included from the beginning ${ }^{24}$ ) were enlisted to aid local police and heads of ho-ko in the identification of diseases. After I923, all hospitals took full responsibility for identifying cases of smallpox and vaccination and left it to the police to fill out the reporting forms correctly.25 Because of cooperation in identification of diseases and the ubiquitous police system, data on causes of death became more accurate than ever before. Moreover, private dispensaries began to flourish after the mid-I920s. All public dispensaries and even some private dispensaries in the countryside were charged with providing disease identification.

After I920, the colonial government decided to appoint well-equipped private dispensaries to serve as reporting agents and permitted all licensed doctors to supervise vaccination by qualified nurses and midwives (Ishii I957: 44). With the rapid growth of private dispensaries in the I930s, a comprehensive public health reporting system evolved from cooperation among the sanitary police, the $h o-k \bar{o}$ system, and various medical facilities. As a result, both certification of causes of death and epidemiological statistics improved. Chen

22. Lu, "Gaoshi diaocha," in Taiwan lishi cidian, 7I9. And Tomita, "I905 nen rinji Taiwan kokō chōsa to naichijin no shisen," Taiwanshi Kenkyubu, ed., Tawain no kindai to Nippon, I03-I05.

23. The role of the public school system was essential to the success of Japanese colonial medicine in Taiwan.The function of cowpox vaccination was included in the school hygiene of the public school system. See Taiwan zongdufu gongwenleizuan di 6 men, weisheng (sanitation), “Taiwan zhong dou fa ji shixing size (March. 29,1929),"I-2.

24. Ibid., p. 6.

25. Taiwansheng wenxian weiyuanhui, ed., Taiwansheng tongzhigao: zhengshizhi, 430. 
Shaoxing says: "in I906, only one-tenth of death certificates were issued by the Western-trained doctors including policemen, while the Chinese traditional physicians were responsible for the rest of them... But by the end of I935, the situation had been reversed: only one-tenth of death certificates were issued by the Chinese traditional physicians, while the Western-trained doctors issued the rest of them" (Chen I985: I25). Such change implies the improvement of accuracy regarding causes of death in governmental statistics and increased the reliability of the surveillance function of the reporting system. After such improvement, as George Barclay claims, we can present “Taiwan's statistical system as a paradigm even among those of the technologically advanced nations in the world" (Barclay I954: I64).

\section{Concluding remarks}

Hygienic intervention and medical reform in Taiwan were aimed to control epidemic diseases mainly to improve the living environment for Japanese settlers and, later for the colonized Taiwanese. Many contemporary Taiwanese historians believe that the rapid health improvement in colonial Taiwan is the best evidence in support of the achievements of Japanese colonial medicine. The process of improvement also reflects Charles Rosenberg's concern about "the way disease definitions and hypothetical etiologies can serve as tools of social control, as labels for deviance, and as a rationale for the legitimization of status relationships" (Rosenberg and Golden 1992: xv). Gotō Shinpei's adoption of German Staatsmedizin and Takagi Tomoe's actions promoting modern medicine in colonial Taiwan fostered a strong governmental role in improving sanitary conditions in colonial Taiwan. In general, while Gotō Shinpei paid particular attention to the health needs of the Japanese colonizers, Takagi Tomoe saw Taiwanese society as a whole and enlarged Gotō's plan into a comprehensive system in which, from a medical vantage point, the line between colonizer and the colonized became blurred.

Despite the emphasis placed by historians on Gotō Shinpei's desire to apply his theory of Biologische Principien to Japanese colonial medicine in Taiwan, more important was Takagi Tomoe's initiating new forms of medical organization and new policy goals. After I9I0, Tagaki's designs accelerated the expansion of clinical medicine and produced a structure of colonial medicine that far surpassed what Gotō ever imagined. In sum, Japanized Staatsmedizin created a colonial medicine in Taiwan that succeeded despite the shortage of medical resources both in Japan and Taiwan, but at some cost in political liberty and human life. The surveillance function of the public health reporting system in colonial Taiwan remained important as long as the police department was in charge. However, as the public school system expanded and a privatized body of clinical medicine grew after the mid-I920s, the effectiveness of the public health system 
as well as governmental statistics greatly improved. Reviewing the development of modern medicine in colonial Taiwan reveals many non-medical factors played essential roles. 



\section{The demographic history of smallpox in the Netherlands, I8th-I9th centuries}

Willibrord Rutten Sociaal Historisch

Centrum Limburg / Maastricht University,

The Netherlands 
This paper looks at the demographic history of smallpox in the Netherlands in the I8th and igth centuries. It examines the claim that smallpox vaccination was a prime-mover in the European mortality decline starting about I800 (Razzell I977; Mercer 1990; Aaby 1991; Sköld 1996). In the Netherlands smallpox mortality dropped in an unprecedented way from the early igth century. Largescale vaccination campaigns, launched by Louis- Napoleon, King of Holland, and continued by the new-founded Kingdom of the Netherlands, are considered responsible for the decline of smallpox. At the same time a significant acceleration in Dutch population growth was observed (Hofstee 1978). A similar coincidence has been observed in many other European countries as well (Mercer 1990). Until recently, the impact of smallpox on Dutch mortality levels has never been established with certitude. Was smallpox really a major check upon Dutch population growth?

\section{Smallpox in the 'Randstad' area}

Since the I7th century the 'Randstad' (the urban agglomeration of the Western Netherlands) was very densely populated, allowing crowd diseases like smallpox easy circulation. In the I8th century smallpox epidemics were very frequent in major Dutch cities like Amsterdam, Rotterdam, the Hague and Utrecht, with recurring outbreaks every three years. Smallpox had a noticeable destabilizing effect on the number of deaths, especially in childhood (Table I).

In epidemic years, urban mortality commonly increased 25 to $30 \%$, and occasionally 40 to $50 \%$. However, few smallpox epidemics generated a mortality crisis as defined by the French demographer Jacques Dupâquier (I979: 248250). Dupâquier's Index equals (D-M)/ $\sigma$, where $D$ is the number of deaths in the calendar year concerned, $\mathrm{M}$ is the mean number of deaths during the ten preceding calendar years, and $\sigma$ the standard deviation of deaths during the same ten years. A scale is used, which goes in geometric progression from a magnitude of $\mathrm{I}$ for a minor crisis (index values $>\mathrm{I} \leq 2$ ) to one of 6 for a catastrophe (index values exceeding 32). During the one hundred years, from i7io to I809, each of the cities Amsterdam, Rotterdam and Utrecht suffered a genuine mortality crisis on fifteen occasions (appendix I). Only five of these were generated by smallpox epidemics, though in others smallpox made an additional contribution to surplus mortality.

Smallpox was mainly a childhood disease, with $90-95 \%$ of deaths occurring among children under the age of ten. The contribution of the disease to child mortality was considerable: up to I $8 \%$ of deaths among those younger than 20 years were caused by smallpox. However, in cities like Amsterdam, Rotterdam and The Hague occasionally adults were also affected by the disease, presumably because of the presence of numerous rural immigrants who had not had it earli- 


\begin{tabular}{lllll}
\hline period & age category & \multicolumn{2}{c}{$\begin{array}{c}\text { coefficient of variation*: } \\
\text { smallpox } \\
\text { included }\end{array}$} & $\begin{array}{l}\text { smallpox } \\
\text { excluded }\end{array}$ \\
\hline Amsterdam $* * *$ & I780-I804 & O-I9 & $23 \%$ & II \% \\
Rotterdam & I770-I804 & O-I6 & 25 & I5 \\
The Hague & I755-I773 & O-I4 & 26 & I5 \\
Utrecht & I777-I80I & O-I6 & 29 & I4 \\
\hline
\end{tabular}

\footnotetext{
* The standard deviation as a proportion of the mean.

$* *$ Amsterdam figures do not include the Jewish population. These data are drawn from i8th century Bills of mortality.

Source: GA Amsterdam, P.A. nr. 27, Archief Collegium Medicum, inv.nr. 66, I7I-I73 (jaarverslagen Plaatslijke Commissie van Geneeskundig Toevoorzigt). Nieuwenhuys, Geneeskundige Plaatsbeschrijving (I820) dl. I, I6I-I63, I83 ,tabel IX tegenover p. 307, dl. II, 56 tafel XIII en dl. III, I82, tafel T.. Naamlijsten van Manheer (I777- ). Mentink en Van der Woude, De demografisch ontwikkeling te Rotterdam en Cool (I965) tabellen 8-II. Dierquens, Verzameling van naauwkeurige lijsten (I774). GA Utrecht, inv.nr. 6o8, Registers van de Momboirkamer. P.D. 't Hart, De stad Utrecht (I983) tabellen 25, 34.
}

er (cf. Landers 1987). In smallpox epidemic years, the number of deaths for ages older than 20 was $5 \%$ above the normal level in Rotterdam, while in Amsterdam surplus mortality for young adults climbed to $7 \%$ above the average (Table 2). Smallpox made a significant contribution to the so-called urban graveyard effect (Van der Woude I982).

\section{One or the other: highly fatal or universal?}

Smallpox is generally believed to be both highly fatal and universal. However, I argue that at least one of these claims is false. For this purpose I constructed a smallpox morbidity table, which combines a classic cohort survival table with elements of an epidemiological trial which has a continuous intake and incomplete follow-up. The full model is explained in appendix 2. Data for this table were taken from the burial registers of the Hague, I755-73, compiled and published in 1774 by Dierquens. The Hague, residence of the confederal government of the United Provinces and the third city in the metropolitan 'Randstad'-complex, had a stable population of about 38,000 inhabitants in the second half of the eighteenth century. Smallpox mortality in The Hague matched the level of the metropolis of Amsterdam. In either city smallpox contributed 8-9\% of all deaths, and I8-i9 \% of deaths in the age group o-I9. Smallpox epidemics recurred every 3 to 4 years. 


\section{Rotterdam}

Amsterdam, 1776-1800

$\begin{array}{ll}\text { Age group } & \text { Inflation factor } \\ 0 & \text { I.I6 } \\ \text { I } & \text { I.90 } \\ 2-9 & \text { I. } 89 \\ \text { I0-19 } & \text { I.I3 } \\ 20-29 & \text { I.O7 } \\ 30-39 & 0.99 \\ 40-49 & \text { I.OI } \\ 50-59 & \text { I.०0 } \\ 60-69 & \text { I.O2 } \\ 70-79 & \text { I.02 } \\ \geq 80 & 0.99 \\ \text { Epidemic years: I777, I780, I784, I788, I79I, I794, I797, I800 }\end{array}$

Rotterdam, 1776-1802

$\begin{array}{ll}\text { Age group } & \text { inflation factor } \\ \text { O } & \text { I.24 } \\ \text { I-4 } & \text { I. } 74 \\ \text { 5-9 } & 2.04 \\ \text { IO-I9 } & \text { I.IO } \\ \geq 20 & \text { I.05 }\end{array}$

Epidemic years: I776, I781, I784, I785, I789, I79I, I793, I794, I797

Source: Nieuwenhuys, Geneeskundige Plaatsbeschrijving (I820) dl. I, tabel IX tegenover p. 307. Naamlijsten van Manheer (I777- ).

The model requires the input of smallpox morbidity data. Morbidity (the number of cases) was calculated by multiplying smallpox deaths, as recorded in the Dierquens collection, by the inverse of the Case Fatality Rate (CFR). The selection of the overall CFR is crucial for the outcome of the model. Minor variations in the CFR appear to generate substantial changes in the proportion that had had smallpox.

An adjustment for age-specific variations in CFR was attempted to account for the U-shaped age curve of smallpox mortality. In practice this refinement hardly affects the proportions at ages io and above. It was omitted in calculating table 3 . 


\begin{tabular}{|c|c|c|c|c|}
\hline $\begin{array}{l}\text { Case Fatality } \\
\text { Rate }\end{array}$ & Multiplier & $\begin{array}{l}\text { Prop } \\
\text { living }\end{array}$ & es per & \\
\hline$\%$ & & 5 & 10 & 15 \\
\hline I2. 5 & 8.0 & 6iо & 955 & 996 \\
\hline $\mathrm{I} 4.3$ & 7.0 & 523 & 8I9 & 854 \\
\hline I6.7 & 6.0 & 436 & 682 & 712 \\
\hline 20.0 & 5.0 & 349 & 546 & 569 \\
\hline
\end{tabular}

Source: calculated from Dierquens, Verzameling van naauwkeurige lijsten (I774). Duvillard, Analyse et tableaux de linfluence de la petite vérole (1806).

The model demonstrates that the proportion of immunes rises as the level of the case fatality rate decreases and vice versa. Equally it shows that on average case fatality must have been $\mathrm{I} 2.5 \%$ at least. Lower case fatality rates are not compatible with the number of reported smallpox deaths as they would require more cases than individuals at risk. Higher case fatality rates produce too few immune survivors; the number left at risk contradicts the reported low level of mortality from smallpox at higher ages.

If the assumption is justified that in urban environments virtually no single individual could escape smallpox infection during childhood, then average case fatality should match I2 to I3 \%. In this scenario those dying from smallpox at ages 20 and higher as in Amsterdam in the late I8th century (table 2) are assumed to be immigrants.

\section{Reported case fatality rates}

What do historical documents report about case fatality rates? Are they compatible with the assumption of the universality of smallpox in urban environments? Before answering the question a few preliminary observations on the quality of fatality data are suitable.

It is a well-known fact that fatality rates calculated from hospitalized cases are suspect. Patients admitted to hospitals were not representative of the total spectrum of cases (Fenner 1989: 50). Morbidity rates assumed to apply to non hospitalized cases tend to exaggerate fatality particularly if the reporting system is poor. Definitely that is the case in historical and actual Third World settings. Mild non-lethal cases receiving no medical attention were easily overlooked and consequently have not been included in the data.

Additionally we should take into account that previously unexposed populations were extremely vulnerable to the disease (Christie I977: 263). Fatality 
rates referring to these virgin soil epidemics were not representative of smallpox in historical European populations and should be discarded. We better confine ourselves to the experience of endemic areas.

The virulence of variola major, the virus at issue, was notoriously variable. Case fatality rates ranged from 5 to $25 \%$ or even more (Fenner I989: 4, 97). J.N. Biraben referring to eighteenth century France points out that lower fatality rates prevailed but two or three times per century fatality exceeded 15,20 or even $30 \%$. (Biraben I973: 28). Variations in the severity of the disease were observed from place to place and from year to year (Benenson 1977: 547). Consequently a set of case fatality rates is required, in order to calculate an average figure, that is more or less representative.

During the first half of the twentieth century all outbreaks of smallpox due to variola major in Asia and most of those in Africa had case fatality rates of at least $20 \%$ in the unvaccinated (Fenner I989: 3, 54). In nineteenth century Europe very high fatality rates exceeding $30 \%$ prevailed (Razzell I977: I26-I27, I33-I34). In the I893-94 outbreak in Rotterdam case fatality was $43 \%$, in the Nijkerk outbreak of I87I-72 it was $37 \%$, during the same epidemic in Utrecht city $56 \%$. In my opinion these extreme rates observed in the I 800 s are related to the impact of the massive vaccination campaigns which left bad risk individuals -for example migrant labourers- in the unvaccinated segment of the population.

In contrast, from the pre-vaccination era much lower case fatality rates have been reported. The median score of fatality in a set of 37 epidemics in eighteenthcentury England was i6.9 \%. (Razzell I977: I3I-I33). Before the large-scale adoption of variolation fatality in early eighteenth century Boston (Massachusetts) ranged from Io to I5 \%. In the I72I- epidemic the CFR was I4.6 \%, in I730 I3.9 $\%$ and in $17529.7 \%$. (Fenner I989: 257). The aggregate rate for these epidemics together covering more than 14,000 cases was I2.6\%. During an epidemic in I797 in Prussia the overall fatality rate for three towns near Breslau covering I,25I cases was $15.9 \%$. Comparable rates were reported from Italy in the early nineteenth century. The aggregate CFR in the unvaccinated was II. $5 \%$ in the province of Verona (I810-38) and $16.2 \%$ in Piemonte and Liguria during a smallpox epidemic in I829 (Del Panta 1980: 70-72). Curiously, I9th-century European communities that rejected vaccination for religious reasons continued to display case fatality rates similar to the level prevailing in the pre-vaccination era. For example the Lippowaner, an ethnic minority of Russian origin living isolated in the mountains of Bukovina (Austro-Hungarian Empire), were visited by smallpox in I898. In 667 cases fatality was $13.5 \%$ (Kramer i9i6: I4I). In the Netherlands, there was an orthodox Calvinist community living on the island of Urk in the former Zuyderzee. The population counted about I,200 inhabitants. Apart from a few vaccinated outsiders, the majority of the islanders had rejected vaccination as being against Providence. The island was visited by smallpox in I844-45. Again 
case fatality was relatively low by nineteenth century standards: I3 \% in 446 unvaccinated cases (Kramer I9I6: 80-8I).

The smallpox morbidity table (Table 3 ) demonstrates that high case fatality rates of $20 \%$ and more are not compatible with the alleged universality of the disease. To do justice to the eighteenth century context, only fatality rates from the pre-vaccination era should be imported into the model. If applied to the case of the Hague only the Boston rate (12.6\%) is compatible with the alleged universality of smallpox. However, at the English rate (I6.9 \%), the model leaves a considerable proportion still susceptible, more than $25 \%$ at age I5. This suggests that a considerable number of urban children had not been infected before adolescence. On the other hand, the English figure may well be biased by underreporting. Probably a substantial number of missed cases inflated the fraction of urban natives presumed susceptible. In sum, recorded levels of mortality indicate that where exposure to smallpox approached the universal, case fatality rates cannot have been high, and where case fatality rates were high, exposure cannot have been universal.

\section{Smallpox in small towns and rural areas}

In spite of its endemic character, the impact of smallpox on medium-sized cities, small towns and the countryside was of minor importance, being the cause of death for no more than 4 to $5 \%$ of total mortality. Even in a medium-sized city like Haarlem, a stone's throw from Amsterdam, probably half the population did not contract the disease, providing the case fatality rate equalled the classical i4 - I5 \% standard. Outside the 'Randstad' intervals between epidemics varied from five to ten years. Accordingly, the age-distribution of smallpox mortality in these settings shows a substantial proportion of older children and adolescents among the victims (about $15-40 \%$ ).

An analysis of the physical descriptions of thousands of conscripts born in the Dutch province of Limburg in the late I8th and early I9th century shows that disfigurement by facial pock-marks was relatively frequent in densely populated southern districts close to urban centres like Liège and Aachen (Aix-la-Chapelle), but was relatively uncommon among conscripts coming from the remote and sparsely populated northern and central districts of Limburg (Table 4). Facial scarring is a suitable indicator of the presence or absence of smallpox in a particular area. It is more difficult to estimate from a scar survey what the incidence of smallpox has been. That many smallpox survivors, especially the young ones, lost their pockmarks within a couple of years must be taken into account (Benenson I982). At best an approximation is possible, in relative terms, of the prevalence of the disease 


\section{Disfigured conscripts Per 10,000 inhabitants in 1795}

(number)

\begin{tabular}{lll}
\hline & & \\
rural areas of Northern Limburg & 52 & I5 \\
rural areas of Central Limburg & 63 & 29 \\
rural areas of Southern Limburg & 324 & 57 \\
cities * & 90 & 35 \\
\hline
\end{tabular}

\begin{tabular}{ll} 
province Limburg & 529 \\
\hline
\end{tabular}

* Maastricht, Roermond, Venlo.

Source: RA Limburg, Alfabetische klappers op de militieregisters (A t/m K).

\section{Social inequality}

It has been suggested by Hopkins (1983) and many others that smallpox did not discriminate between the rich and the poor. However, in smallpox epidemic years, excess mortality was much lower among the wealthiest io \% of Amsterdam citizens than it was among the other $90 \%$ (Table 5). The clear-cut difference was manifest as early as I734-I752. Apparently people of good fortune were able to evade risk long before artificial means of inducing immunity against various infectious diseases developed, such as variolation. Variolation was a method of purposefully infecting a person with smallpox (variola) in a controlled manner that minimised the severity of the infection in order to induce permanent immunity. This rather hazardous technique of variolation was only occasionally employed upon children of the Amsterdam upper-class in the second half of the I8th century. The small-scale practise of variolation did not seem to affect smallpox mortality. On the contrary, surplus mortality even tended to increase in the second and the third period in observation, regardless of social class (see Table 5). Variolation was to be eclipsed within less than a decade as the safer vaccination method, discovered by Edward Jenner in I798, became available.

\section{Smallpox and fertility}

The I87I-explosion of smallpox in the Dutch municipality of Nijkerk was extraordinarily well documented, which made it possible to analyse such issues as the interrelationship between disease, death, conception, and birth. There is no evidence that smallpox infection was responsible for the decline in natural fertility by making male patients sterile (Rutten I993). Of 48 marriages between small- 
Table 5. Smallpox mortality by social class in Amsterdam. Mean surplus mortality in epidemic years as compared to reference years (I734 - I800).

\begin{tabular}{|c|c|c|c|c|c|}
\hline \multirow[t]{2}{*}{ Period } & Class 1* & Class 2 & Class 3 & Class 4 & 'Pro deo' \\
\hline & \multicolumn{5}{|c|}{ Surplus mortality expressed as $\left(\mathrm{d}_{\mathrm{p}} / \mathrm{d}_{\mathrm{r}}\right) \times 100$} \\
\hline I734-I752 & 104 & IO4 & 107 & II8 & I2I \\
\hline I763-I783 & Io8 & II6 & $\mathrm{II} 3$ & $\mathrm{I} 2 \mathrm{O}$ & I29 \\
\hline \multirow[t]{2}{*}{ I784-I80o } & 108 & ІІ8 & II4 & $\mathrm{I} 24$ & 129 \\
\hline & \multicolumn{5}{|c|}{ Surplus mortality expressed as $\left(\mathrm{d}_{\mathrm{p}}-\mathrm{d}_{\mathrm{r}}\right) \times \sigma_{\mathrm{r}}$} \\
\hline I734-I752 & 0.3 & 0.3 & 0.4 & I. 4 & I. 9 \\
\hline I763-I783 & I.I & I. 3 & $\mathrm{I} .2$ & 3.0 & 3.0 \\
\hline I784-I8०० & 0.5 & I. 7 & 0.9 & 3.0 & 3.0 \\
\hline
\end{tabular}

Notes:

$d_{p}=$ mean number of burials in smallpox years.

$\mathrm{d}_{\mathrm{r}}=$ mean number of burials in reference years.

$\sigma_{\mathrm{r}}=$ standard deviation in reference years.

*Classes are arrayed from highest (I) to lowest (pro deo).

Source: GA Amsterdam, Collection dr. S. Hart, voorl. nr. I26.

pox survivors of all ages and women younger than 30 years, two couples $(4.2 \%)$ remained childless. When the age of the bride was up to 35, the proportion of childless couples rises to 5-6\% (3 out of 52). In historical European populations, primary sterility varied between three and seven per cent, when the age of the bride at marriage was below 30. Contrary to expectations the proportion we found for the smallpox cohort fits within that range. The claim put forward by Razzell (I977), McFalls et al. (1984), Anderson (1988) and Sköld (1996) that smallpox was a major cause of male infertility acting upon long-term swings in fertility has to be rejected.

However, non-permanent effects on reproduction rates could be detected (Rutten I993). Pregnant women were highly vulnerable to the disease, and it is argued that many miscarriages have been caused by smallpox. The occurrence of foetal loss due to smallpox has been reported by historical observers as well. Yet, estimates of the impact of pregnancy loss in historical European populations should take into account that smallpox commonly was a childhood disease before vaccination campaigns in the nineteenth century induced a shift in age-incidence. 

54. Per I, 000 live-births (both sexes)

\begin{tabular}{lllll} 
Cohort of birth: & \multicolumn{5}{c}{ Proportion surviving of 1,000 live births by age. } \\
& $5-9$ & $10-15$ & $16-19$ & $20-24$ \\
\hline I805-09 & & & & 638 \\
I810-19 & & 680 & 648 & 632 \\
I820-29 & 705 & 660 & 637 & 608 \\
I830-39 & 688 & 659 & 628 & 610 \\
I840-49 & 681 & 648 & 634 & \\
I850-54 & 670 & & & \\
\hline
\end{tabular}

Source: Volkstellingen I829 t/m I859. Tweede Verzameling van Staten. Jaarboekjes van Lobatto, I826-. Statistisch Jaarboekje, I85I-. Hofstee, De demografische ontwikkeling (1978) p. I90 en I96. More details in Rutten, I997, $379-380$

\section{Smallpox and marriage}

According to Sköld (1996) those who had been infected from smallpox married later in life than those who were susceptible or vaccinated. In Sweden infected men and women were considered less attractive within the marriage market. It would be useful to know how the marriage chances of Dutch smallpox survivors compared with those of the population at large. Unfortunately this information is not readily available. Celibacy rates cannot be calculated, so we will have to be content with figures about mean age at first marriage calculated from the Nijkerk sample of male, married smallpox survivors. Of these 36 men were married before they contracted smallpox in I87I-72 and their mean age at first marriage was 26.4 years. Another 63 married after the epidemic, at some time in the period I872-I902. These pockmarked men had a mean age at marriage as high as 29.2 years (median 27.5), a difference of 2.8 years. Remarkably, age at marriage of their partners remained at 26.8 years for both categories. Apparently these pockmarked bridegrooms had some difficulties finding partners, but was it because of their disfigured faces?

The last quarter of the Igth century witnessed a period of delayed economic growth, the so called Great Depression. Since it was the agricultural sector that was most badly hit by the depression (Bieleman I992: 2I6-2I7), its effect on the economic development of the as yet non-industrialized Nijkerk-region was great. In pre-industrial society postponement of marriage was a suitable reaction of tenant farmers, market gardeners and farm labourers to cope with declining incomes and widespread unemployment. The rise of mean age at marriage might have been a consequence of increasing poverty. The impact of economic 
Figure I. Vaccination coverage in the Netherlands, accounting for infant mortality $<6$ months. Number of cowpox vaccinations per Io० births, Io-years moving average (overlapping)

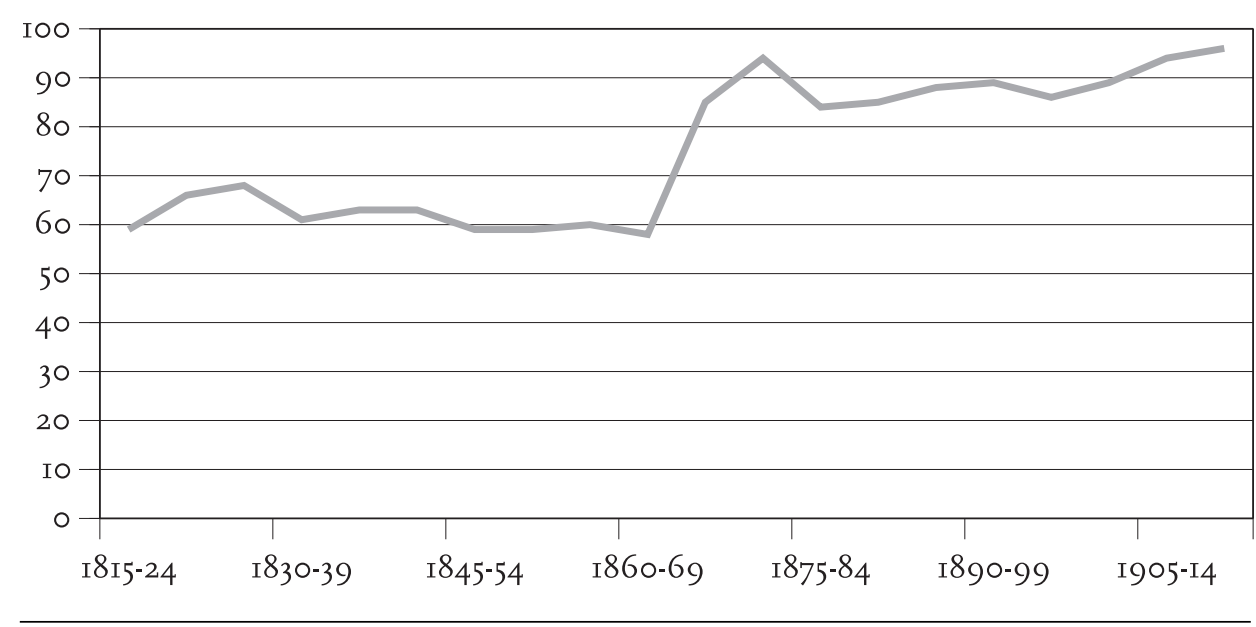

stress should be disentangled from the effect of smallpox. The question is: how does mean age at marriage of pockmarked men compare with those of the population at large? A sample of 280 observations taken from the Nijkerk marriage records in the I870 and I880 shows that in the general population mean age at (first) marriage of bridegrooms was at least as high as that of the pockmarked men: 29.7 years on average (median: 27.5 )

\section{Smallpox in the I9th century}

The first experiment with cowpox vaccination on Dutch soil was performed as early as October 1799 by the dr. Levie Salomon Davids (I77I-I820) from Rotterdam. From the beginning vaccination coverage was rather high in the Netherlands. Adjusted for infant mortality up to six months, on average 60 to 70 $\%$ of children were protected by the cowpox vaccine before the I87os. Vaccination coverage rose to $80-90 \%$ and more after the proclamation of national compulsory vaccination in I872 (Figure I). The incidence of smallpox dropped in an unprecedented way after c. I8Iо. A causal link with the implementation of Jennerian vaccination is plausible. The proportion of smallpox deaths in total urban mortality decreased (Figure 2). The unexpected outbreak observed in I871/72 was part of a worldwide pandemic of the variola virus. It was the last nationwide upsurge of smallpox in the Netherlands (Rutten I997: 380-40I). But long before 1872 urban mortality rates stabilized somewhat as appears from the reduction in the number of years in which deaths exceeded births. In the last three decades of the I8th century Amsterdam and Rotterdam suffered excess 
Figure 2. Smallpox fatalities as a percentage of total mortality in Amsterdam, Rotterdam and The Hague (1755-1902). Annual figures.

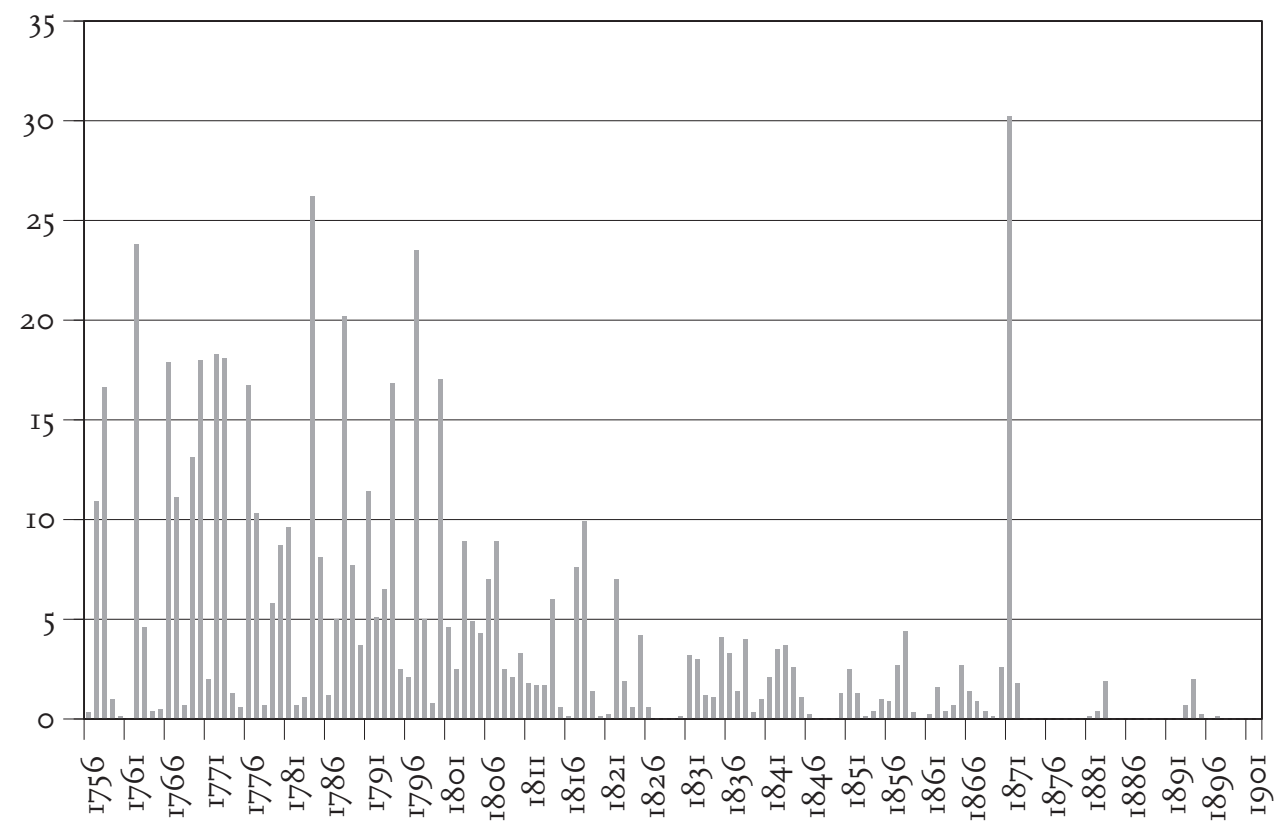

mortality time and again. Deaths exceeded births in $55 \%$ and $48 \%$ of all years, respectively. From I8Io to I850 Amsterdam suffered a death surplus in $42 \%$ and Rotterdam in $37 \%$ of the years in observation (Figures 3 and 4).

It has been suggested by contemporary authors like Thomas Malthus that the eradication of a single cause of death is useless in an environment where poverty and underdevelopment prevail: 'For my own part I feel not the slightest doubt that if the introduction of the cow-pox should extirpate the small-pox, and yet the number of marriages continue the same, we shall find a very perceptible difference in the increased mortality of some other diseases. Nothing could prevent this effect but a sudden start in our agriculture' (Malthus I872: 4I5). Referring to statistics from early Igth-century Berlin, Imhof observes that other killing diseases rapidly took over after the suppression of smallpox (Imhof I983, I984). He is suggesting that smallpox was just a secondary cause of death, easily replaced by other childhood infections. But this happened not to be the case in Holland. As a matter of fact the containment of smallpox epidemics was accompanied by a remarkable reduction in child mortality in Amsterdam and Rotterdam, in spite of deteriorating urban living conditions, especially in boom town Rotterdam (Figures 5 and 6).

However, before jumping to conclusions it should be remembered that smallpox was traditionally of minor importance in smaller cities and rural areas 
Figure 3. Birth/death surplus in Amsterdam, I755-1849. Annual figures.

Smallpox fatalities (scale right)

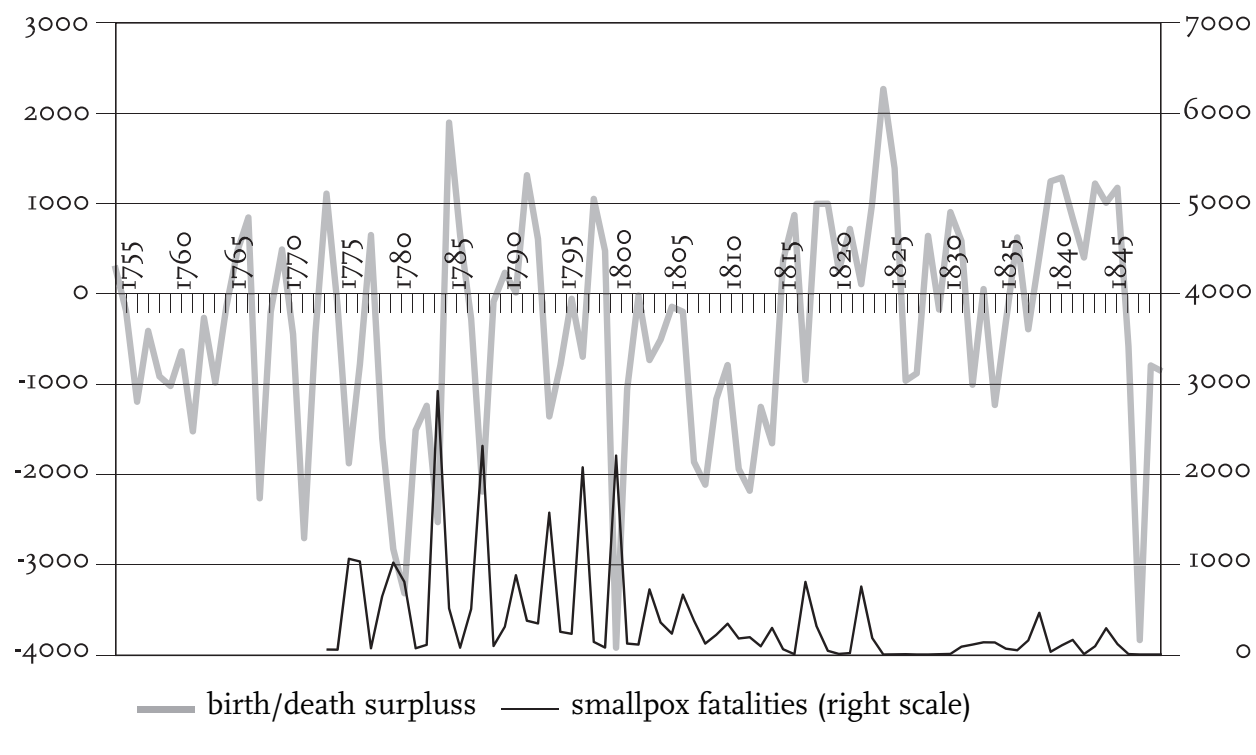

Figure 4. Birth/death surplus in Rotterdam, 1750-I849. Annual figures.

Smallpox fatalities (scale right)

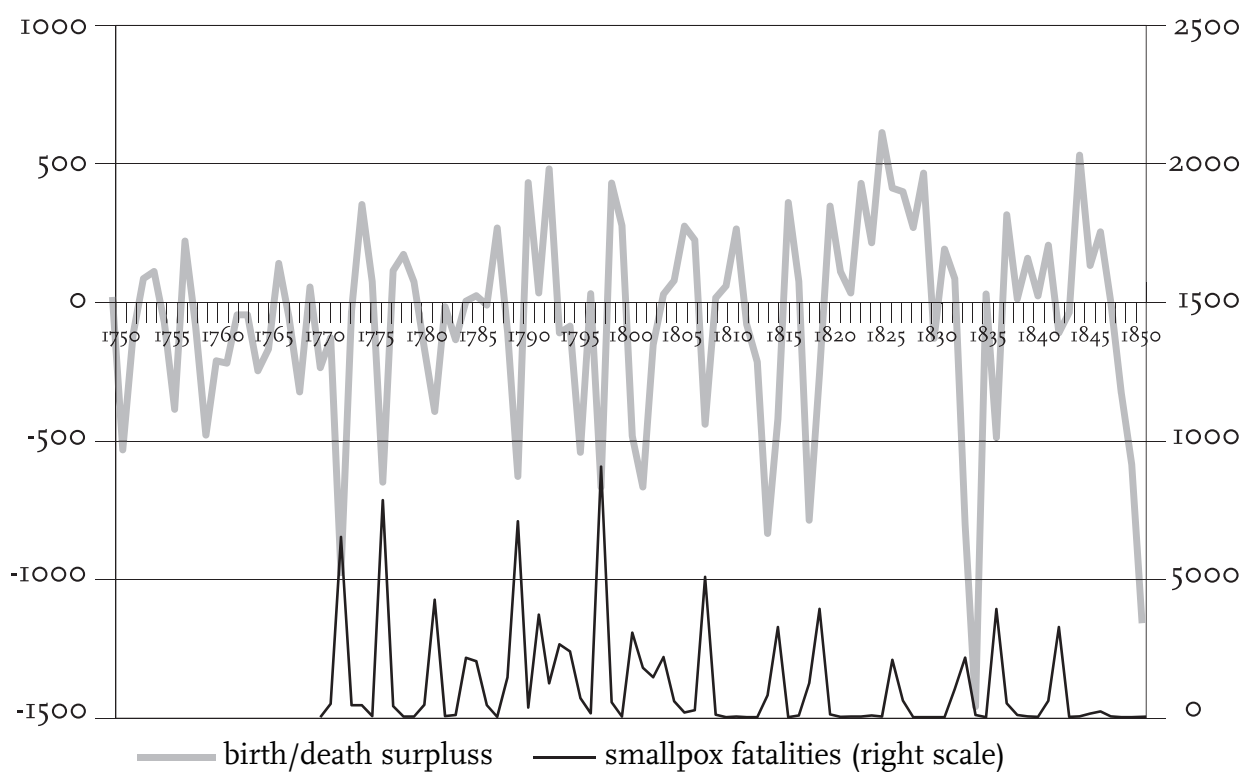



years of age per I.000 live births. Average figures per decade.

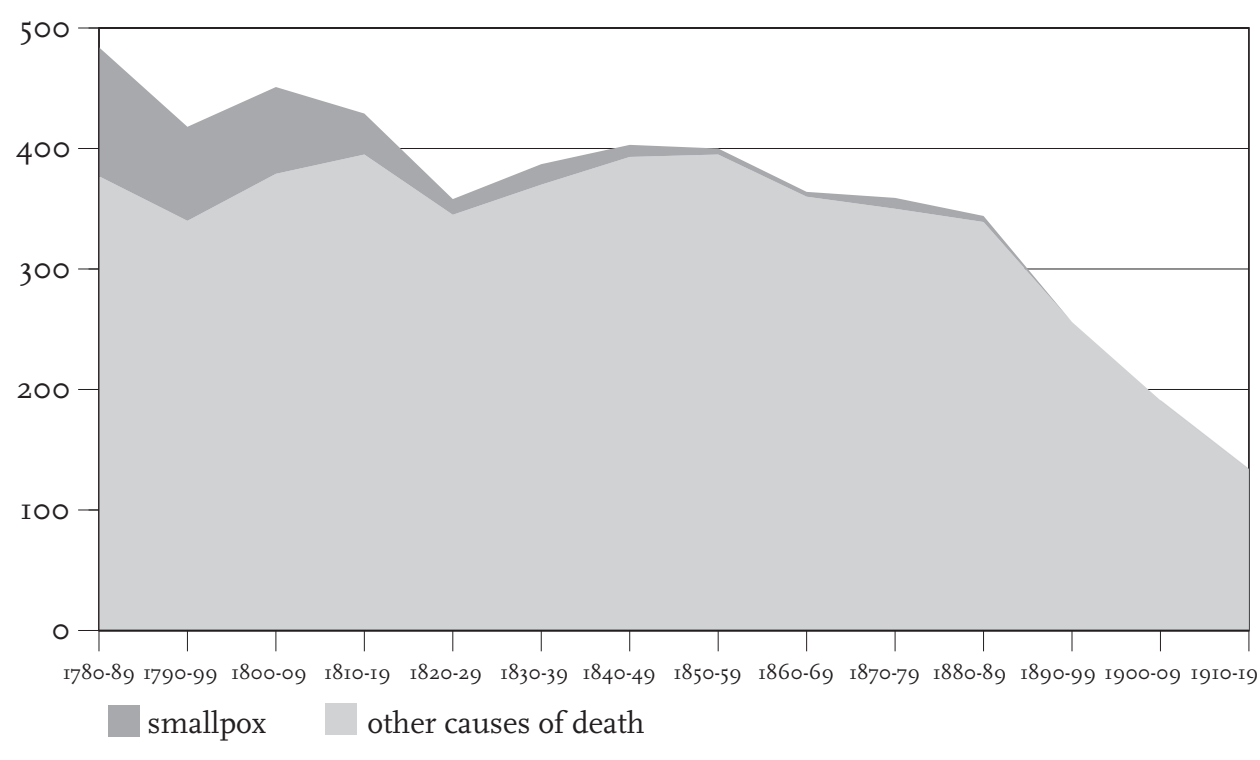

Figure 6. Childhood mortality rates in Rotterdam, I770-I839. Deaths $<20$ years of age per 1.000 live births. Average figures per decade.

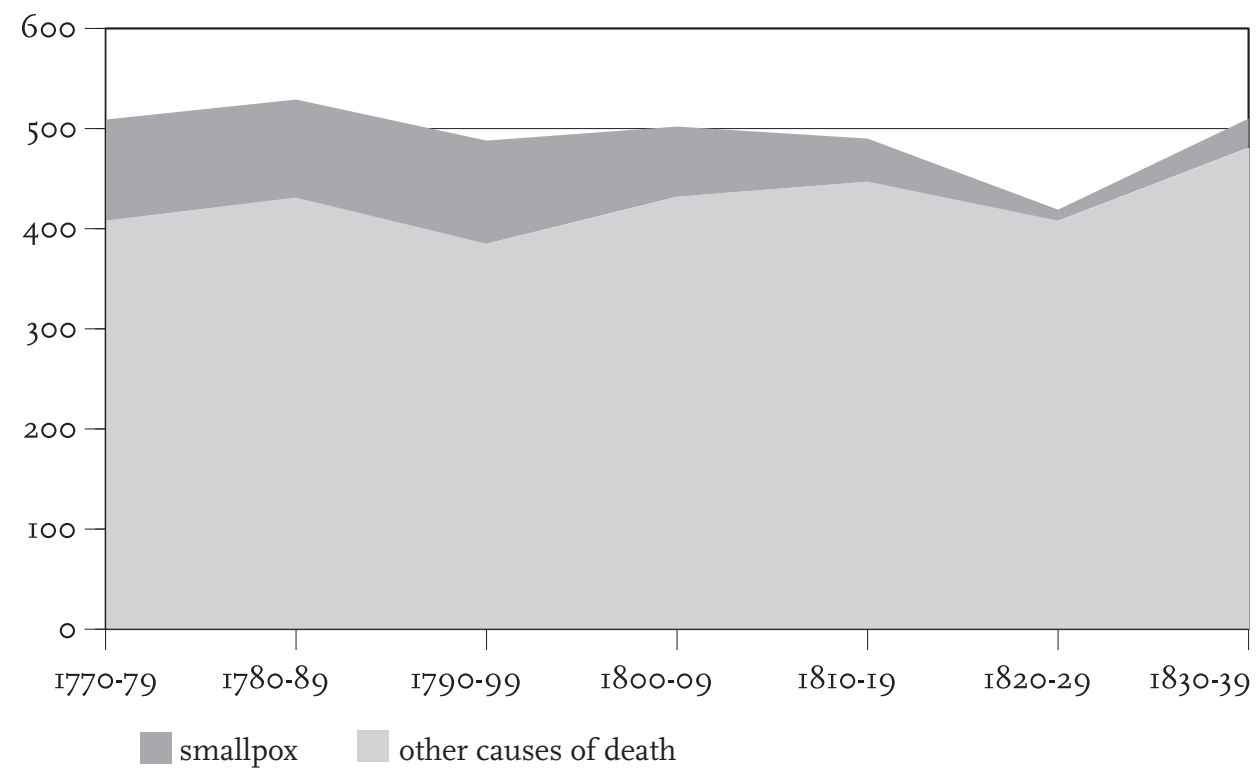


long before preventive measures became effective. Extrapolation of the

Amsterdam and Rotterdam figures to these areas is fundamentally wrong. Needless to say the claim of an overall effect of the decline of smallpox incidence on national survival rates is problematic. The survival rates of the post -I8Io birth cohorts should have improved, while the opposite seems to be the case, as is shown by table 6 .

\section{Conclusion}

The history of vaccination shows that socio-medical engineering was successful even in the setting of a pre-industrial society that suffered from a miserable standard of living. Progress in health matters became conceivable. The containment of smallpox helped to extend life-expectancy at childhood at least in major cities and it helped to reduce the urban graveyard effect. However, it did not initiate Dutch population growth. 
Appendix I. Mortality crisis in major Dutch cities (I7IO-I809). (Severity (I - 4) on the scale of Dupâquier).

\begin{tabular}{|c|c|c|c|}
\hline Year & $A^{\prime} d a m$ & $R^{\prime} d a m$ & Utrecht \\
\hline I7IO & - & - & - \\
\hline I7II & - & - & 3 \\
\hline I7I2 & - & - & - \\
\hline I7I3 & - & - & - \\
\hline I7I4 & - & - & - \\
\hline I7I5 & I & - & - \\
\hline I7I6 & - & - & I \\
\hline I7I7 & - & - & - \\
\hline I7I8 & I & - & I \\
\hline I7I9 & 3 & - & - \\
\hline I720 & - & - & - \\
\hline I72I & - & - & - \\
\hline I722 & - & - & - \\
\hline I723 & - & - & 3 \\
\hline I724 & - & - & - \\
\hline I725 & - & - & - \\
\hline I726 & I & - & - \\
\hline I727 & 3 & - & - \\
\hline I728 & 3 & - & - \\
\hline I729 & 2 & - & 2 \\
\hline I730 & - & - & - \\
\hline I73I & - & - & - \\
\hline I732 & - & - & - \\
\hline I733 & - & - & - \\
\hline I734 & - & - & - \\
\hline I735 & - & - & - \\
\hline 1736 & - & - & - \\
\hline I737 & - & - & - \\
\hline I738 & - & - & - \\
\hline I739 & - & - & - \\
\hline I740 & I & - & 2 \\
\hline I74I & I & 3 & 2 \\
\hline I742 & - & - & - \\
\hline I743 & - & - & - \\
\hline
\end{tabular}




\begin{tabular}{|c|c|c|}
\hline I744 & - & - \\
\hline I745 & - & - \\
\hline $\mathrm{I} 746$ & - & - \\
\hline I747 & - & - \\
\hline I748 & I & I \\
\hline I749 & I & - \\
\hline I750 & - & - \\
\hline I75I & - & - \\
\hline I752 & - & - \\
\hline I753 & - & - \\
\hline I754 & - & - \\
\hline I755 & - & - \\
\hline 1756 & - & - \\
\hline I757 & - & - \\
\hline 1758 & - & - \\
\hline I759 & - & 2 \\
\hline I760 & - & - \\
\hline $\mathrm{I} 76 \mathrm{I}$ & - & - \\
\hline 1762 & I & - \\
\hline $176_{3}$ & - & - \\
\hline I764 & 2 & - \\
\hline 1765 & - & - \\
\hline I766 & - & - \\
\hline I767 & - & - \\
\hline I768 & 3 & I \\
\hline 1769 & - & - \\
\hline I770 & - & - \\
\hline I77I & - & - \\
\hline I772 & 2 & 3 \\
\hline I773 & - & - \\
\hline I774 & - & - \\
\hline I775 & - & - \\
\hline 1776 & - & I \\
\hline I777 & - & - \\
\hline I778 & - & - \\
\hline I779 & - & - \\
\hline I780 & 2 & - \\
\hline I78I & 2 & I \\
\hline I782 & - & - \\
\hline I783 & - & - \\
\hline I784 & I & - \\
\hline
\end{tabular}




\begin{tabular}{|c|c|c|c|}
\hline I785 & - & - & - \\
\hline I786 & - & - & - \\
\hline I787 & - & - & - \\
\hline I788 & I & - & - \\
\hline 1789 & - & 3 & 4 \\
\hline I790 & - & - & - \\
\hline I79I & - & - & - \\
\hline I792 & - & - & - \\
\hline I793 & - & - & - \\
\hline I794 & I & - & - \\
\hline I795 & - & - & I \\
\hline I796 & - & - & - \\
\hline I797 & - & 2 & - \\
\hline I798 & - & - & - \\
\hline I799 & - & - & - \\
\hline I80o & 2 & I & - \\
\hline I8OI & - & - & - \\
\hline I8O2 & - & - & - \\
\hline 1803 & - & - & - \\
\hline I8०4 & - & - & - \\
\hline I805 & - & - & - \\
\hline I806 & - & - & - \\
\hline I807 & - & I & - \\
\hline I8०8 & - & - & - \\
\hline 1809 & - & - & - \\
\hline
\end{tabular}

Note: (I) minor crisis index values $>$ I $\leq 2$; (2) medium index values $>2 \leq 4$; (3) heavy $>4 \leq 8$; (4) extreme $>8 \leq$ I6; (5) supercrisis $>\mathrm{I} 6 \leq 32$; (6) catastrophe $>32$. Magnitudes 5 and more non-existent in this dataset.

Source: Statistiek der bevolking van Amsterdam (I923) p. I79. Mentink en Van der Woude, De demografische ontwikkeling te Rotterdam en Cool (I965) p. I23-I30. GA Utrecht, Retroacta Burgerlijke Stand, register van overledenen, aangebracht bij de Momboirkamer. 
Appendix 2. Age-specific smallpox morbidity table. The Hague I755-I773. Calculation of the number of people surviving smallpox per thousand living at the end of interval. Ages up to 15 years.

\begin{tabular}{|c|c|c|c|c|c|c|c|c|c|c|c|c|}
\hline$a$ & $b$ & $c$ & $d$ & $e$ & $f$ & $g$ & $h$ & $i$ & $j$ & $k$ & $l$ & $m$ \\
\hline ○ & 24554 & - & 280 & 3.33 & 933 & 653 & 653 & 5795 & .236 & I54 & 499 & - \\
\hline I & I8479 & 499 & 276 & 4.00 & IIO4 & 828 & $\mathrm{I} 327$ & 1042 & .056 & 75 & $\mathrm{I} 252$ & 27 \\
\hline 2 & I716I & $\mathrm{I} 252$ & 292 & 5.00 & 1460 & II68 & 2420 & 705 & $.04 \mathrm{I}$ & 99 & $232 \mathrm{I}$ & 73 \\
\hline 3 & I6I64 & $232 \mathrm{I}$ & 362 & 5.00 & I8Iо & I 448 & 3769 & 457 & .028 & 107 & 3662 & I 44 \\
\hline 4 & I5345 & 3662 & 260 & 6.67 & 1733 & I473 & 5135 & $25 \mathrm{I}$ & .016 & 84 & $505 \mathrm{I}$ & 239 \\
\hline 5 & I 4834 & 5051 & 228 & 8.33 & 1520 & I292 & 6343 & 226 & .015 & 97 & 6246 & $34 \mathrm{I}$ \\
\hline 6 & I 4380 & 6246 & $\mathrm{I} 72$ & 8.33 & I 433 & I26I & 7507 & I 40 & . о10 & 73 & 7434 & 434 \\
\hline 7 & I4068 & 7434 & II7 & 8.33 & 975 & 858 & 8292 & 163 & .012 & 96 & 8196 & 528 \\
\hline 8 & I 3788 & 8196 & 85 & I0.०० & 850 & 765 & 8961 & 129 & .009 & 84 & 8877 & 594 \\
\hline 9 & I3574 & 8877 & 30 & 10.00 & 300 & 270 & 9147 & $9^{\text {I }}$ & .007 & 6I & 9086 & 654 \\
\hline Io & I 3453 & 9086 & 69 & I0.০० & 690 & 621 & 9707 & 430 & .032 & 310 & 9397 & 675 \\
\hline I5 & I2954 & 9397 & & & & & & & & & & 725 \\
\hline O-I4 & & & $2 \mathrm{I7I}$ & 5.90 & I2809 & & & 9429 & & I240 & & \\
\hline
\end{tabular}

Legenda
a age
$\mathrm{h}$ accumulated number of smallpox survivors $=\mathrm{c}+\mathrm{g}$
b number at risk (calculated from Dierquens)
i deaths from other causes (as given by Dierquens)
c number of smallpox survivors at begin age interval
j mortality quotient from other causes (calculated)
d smallpox casualties in each age category (as given by Dierquens)
$\mathrm{k}$ deaths from other causes among smallpox survivors $=\mathrm{h} * \mathrm{j}$
e inflator $=$ IOO/CFR (assumption)
1 number of smallpox survivors at end age interval $=\mathrm{h}-\mathrm{k}$
f smallpox cases $=d * e$
$\mathrm{m}$ smallpox survivors per thousand living at beginning interval $=\mathrm{c} / \mathrm{b} * \mathrm{I} 000$
g number recovered from smallpox $=\mathrm{f}-\mathrm{d}$
Source: [Dierquens], Verzameling van naauwkeurige lijsten (I774) 

8

\section{Anti-malaria policy in Colonial Taiwan}

Ku Ya-wen Assistant Professor, Graduate Institute of History,

National Changhua University of Education 


\section{Introduction}

In I965, the World Health Organization registered Taiwan on its list of countries where malaria eradication had been achieved. This remarkable achievement has often been presented as a story of scientific conquest, and modern anti-malaria measures undertaken during the colonial period from I895 to I945 have been hailed simply as a positive legacy of Japan's medical and public health work. ${ }^{\mathrm{I}}$ Recent studies, however, have not been satisfied with viewing these events in abstract scientific terms, but have tried to interpret medical developments within an existing colonial context. They have criticized the heroic narrative of the progress of science (or medicine), and emphasized the close relationship between medicine and colonial power. Medicine as "the tool of empire," is a dominant theme in the historiography of colonial anti-malaria policy and its practice. These studies consider colonial malaria countermeasures and modern malariology as a "tool" used to ensure the wellbeing of the Japanese colonial government and the home country by protecting the health of Japanese elites and settlers, to eliminate obstacles to natural resource development, and to demonstrate the efficacy of colonial rule. In addition, these studies emphasize that the malaria countermeasures were "imposed from above," rather than "evolved from below" through interaction with the colonized Taiwanese people. In this view, the hegemonic and coercive power of the colonial administrative system validated the effectiveness of malaria control (Fann 1994, I996; Yip 2000, 200I).

These studies have sketched the contours of anti-malaria policy in colonial Taiwan. Yet many questions remain. First, they tend to paint a static picture of the development of anti-malaria policy in Taiwan, shaped by concern for short-term effectiveness and economic or political interests of the colonizers at a particular time without examining carefully policy changes that occurred during the entire colonial period. In fact, the making of anti-malaria policy was a dynamic process: whereas the initial objective was suppression of malaria through modern biomedical science, the motive of eradicating malaria appeared in the I920s. This led to a change in the direction of the policy which should be understood in the context of the Japanese cultural perception of the disease as well as the subtle change of relationship that took place between the colonizer and the colonized after the initiation of Japan's assimilation policy in I9I9. In the I920s, the colonial government began to mobilize people to destroy the habitat of mosquitoes.

Second, the response of the colonized to the anti-malaria policy was sel-

I. This has been a popular view, especially in studies of colonial medicine done by Taiwanese medical professionals. During the colonial period, the Japanese doctors regarded colonial medicine as scientific progress and one of the most important Japanese colonial achievements left in Taiwan. Some Taiwanese doctors adopted this scientific paradigm after 1945. For example, see Department of Health, ed., Malaria Eradication in Taiwan, Taipei: Department of Health, I991, pp.8-16. 
dom discussed; or, if it was, the response was portrayed as belonging to a voiceless community which passively received coercive anti-malaria measures, or embraced modern explanations of the disease. In actuality, implementation of the policy resulted in a tense relationship between the colonizer and the colonized during the ig2os. This tension came about from a difference in the cultural understanding of malaria between the Japanese and Taiwanese, and could not be appreciated without recognizing that the change in anti-malaria policy in the I920s was combined with an intention on the part of the Japanese to reform a "pre-modern" people and change the "uncivilized" environment in Taiwan. The resistance of the Taiwanese people showed that the modern anti-malaria knowledge and methods could not penetrate colonial society easily when implementation clashed with the traditional culture. This conflict was one of the obstacles which prevented malaria eradication. By the I930s, any enthusiasm for anti-mosquito mobilization was gradually dying. The establishment of the Malarial Treatment Laboratory in 1929 reflected the government's anxiety about the existing policy and its decision to change direction once again.

The purpose of this chapter is to discuss the dynamics of change in antimalaria policies in colonial Taiwan and their consequences. I shall first examine how the Taiwanese and Japanese formed their respective understanding of the etiology and perception of malaria, and how the Japanese created a discourse of "othering" to define malaria. I shall then discuss the initial process of anti-malaria policymaking in the I9IOs and the real concerns behind malaria as a health issue. In the third section, I shall identify the facts - neglected in studies of colonial Taiwan medicine - associated with the change in direction of anti-malaria policy beginning in 1919, and suggest that the promulgation of assimilative reform is the key to understanding this change. Instead of targeting merely the parasite in the human body or the mosquitoes, the effort to eradicate the colonial disease came to involve an attempt to transform the Taiwanese people and environment. Since direct government social intervention was more complicated than previously thought, we have to examine as well the social response to this policy. Finally, I will show how the Japanese colonizers themselves assessed the results of the anti-malaria policies. The obvious decrease of malaria mortality had always been used to prove their success. However, this does not explain the government's continued anxiety over malaria control as reflected by frequent changes in policy. In fact, the colonial government also kept an eye on the malaria morbidity situation. I will therefore show the statistical data of malaria morbidity, in order to reconsider "effectiveness" and "ineffectiveness" within the historical context. I argue that the adoption of anti-malaria strategies and the consequences of their implementation are not determined by a universal, scientific truth, but should be understood in the context of the interaction between empire and local society. 


\section{The redefinition of malaria: a disease that should be feared}

Malaria is an old disease in Taiwan. Owing to its easily recognizable clinical symptoms, it is believed that most of the descriptions of nue (瘧, a term derived from traditional Chinese medicine for 'tertian chills and fever') and zhang (瘴, 'foul air') in Qing (I644-I895) literature referred to malaria (Liu and Liu I998). Nue, according to the descriptions of symptoms, generally denoted the nonmalignant type of tertian fever which comes from invasion of "evil qi" or a "nue devil". Moral rightness, prayers and herbal medicine were therefore believed to be ways to prevent or drive out nue. Zhang was on the other hand considered to be the poisonous vapor that caused malignant fever. In earlier records, zhang was portrayed as a terrible ailment afflicting migrants to uncultivated areas, and land reclamation was believed by the Taiwanese people to be the only means to eliminate zhang and avoid illness. Nevertheless, since the igth century, a new perception emerged. The growth and prosperity of the island was accompanied by a relative decline in zhang and Taiwan actually became a "promised land" for officials and agricultural immigrants from the Chinese mainland. Historical records reveal that for the Taiwanese people, malaria was not viewed as such a serious threat from the igth century onward, although it is hard to give a satisfactory answer for this apparent change ( $\mathrm{Ku}$ 2005: 34-45).

On the other hand, the Japanese colonizers' understanding of malaria was formulated within a totally different social context and based on their own experience of the disease. In Japan, only a non-malignant type of malaria existed. Since the Meiji Restoration in I868, the Meiji government endeavored to achieve rapid modernization in Japan under the slogan of fukoku kyōhei (富國強兵, rich nation and strong army) and shokusan kōgyo (殖產興業, nurturing and stimulating domestic industrial development). In order to create and maintain a strong military and labor force, health care was no longer considered an individual problem but became a national responsibility. All diseases, including malaria, were viewed as national enemies.

In I879, when the Meiji government abolished the Ryukyu Kingdom and forcibly established the prefecture of Okinawa, Japanese authorities became well aware of the threat to settlers' health posed by the malignant type of malaria, which they had never encountered in inland Japan. Okinawa provided a laboratory for the Japanese to develop their form of malariology. Although researchers dispatched to Okinawa generally accepted the Western "miasma theory" which held that invisible mists and vapors given off by swamps and decaying organic matter produced malaria, they tried to learn more of the disease through investigations and experiments. ${ }^{2}$ Once the association of malaria with its causative parasites was 
made by a French military surgeon Charles A. Laveran in I880, the focus of investigation shifted to finding out how the parasites invaded the human body.

Meanwhile, the Japanese colonial government encountered another serious malaria problem when their occupation of Taiwan commenced in 1895 . Many Japanese officials and soldiers succumbed to this disease. Miura Moriharu (三浦守治), a professor of pathology at the Tokyo Imperial University Medical School and an authority on Okinawa's endemic diseases, was puzzled by the indigenous people's apparent immunity to the disease. He thought that it was related to the local customs avoiding drinking unboiled water and getting wet while crossing rivers, and theorized that the malarial plasmodium was taken into the human body through water. Miura proposed a list of preventive measures, recommending that all water, whether used for drinking, bathing, or washing dishes, should be boiled. This principle became the initial health guideline for the garrison stationed in Taiwan (Miura I896).

After the anopheles transmission of malaria was demonstrated by an English surgeon, Donald Ross in the late 1890 , the mosquito as vector theory was introduced to Japan and soon influenced the Japanese medical community in Taiwan. In I899, the Committee on Local and Infectious Diseases in Taiwan (台 湾地方病及伝染病調查委員会) was established. Extensive epidemiological studies on anopheles and malaria pathology were carried out (Morishita I976: II4-II6). These investigations further solidified the position of imperial modern malariology and the conventional Taiwan conception of the disease came to be viewed as pre-modern. Imperial doctors rejected traditional knowledge of malaria etiology, treatment, and prevention as backward or mere superstition. Adhering to prevailing malariology and microscopy techniques, the imperial medical community redrew the boundary between health and illness based on the authority of the new interpretation of the disease. The Taiwanese people, who had previously been considered healthy, were redefined as "pasty-faced, potbellied because of splenomegaly, and suffering from devastating malaria." (Taiwan Kōikai ı9ıо: 25).

Ironically, while the colonized were depicted as suffering, they were criticized for their “lack of fear toward malaria." For example, Takagi Tomoe (高木友 枝), chief of the Sanitation Section of the Government-general, complained to the Congress of the Taiwan Medical Association (1904/II/13) that a large number of people did not believe in anopheles transmission, and were not afraid of the disease. He emphasized that the people "should realize that malaria is a barrier to production, and an obstacle to industrial development." (Takagi Tomoe I905). This kind of assertion stemmed from an "othering" process that depicted the colonized people as ignorant with low intelligence: in fact the very reason for the prevalence of malaria in Taiwan. Malaria should be feared. Thus, the "othering" process applied to Taiwanese society helped define and bolster the imperial explanation of malaria etiology. 
Furthermore, the development of modern malariology also included the construction of the "otherness" of the colonial environment. It was the lethal combination of heat and humidity that appeared to create the pathogenic environment in which malaria could flourish. To Japanese colonizers from the temperate zone, Taiwan's forest, creeks, and marshes, together with its hot and humid climate, seemed to provide a prototypical example of the savage aspects of a hostile environment. Though the definition of "hostile environment" had changed from "disease-generating miasma" to "plasmodium-carrying water" and "favorable anopheles habitat," malaria was still thought to be a by-product of an intrinsically hostile environment.

For the local population, however, malaria was an accepted way of life. For the Japanese colonizer, malaria was a national enemy that should be feared, for it resulted in huge losses of military strength and economic production. The "othering" of colonial society and environment held that the cause of this disease was an "intrinsic evil" of Taiwan itself. This reasoning affected the development of Japanese colonial anti-malaria policy with significant consequences.

\section{The promulgation of anti-malaria policy and the "human approach" in I9II}

The focus of the Second Congress of the Formosan Medical Association held in I904 was malaria. Contemporary anti-malaria policies in the West and their colonies were the main topics discussed. Since the means of malaria transmission was discovered in the late igth century, malariologists and medical officials in the West were eager to find a solution to this problem either in their home countries or in their colonies. Ronald Ross, the researcher who established the role of the anopheles mosquitoes in malaria transmission, was enthusiastic about destroying the habitat of mosquitoes in British colonies. On the other hand, Robert Koch who conducted experiments in a German colony, claimed that periodic quinine treatment for people carrying plasmodium in their blood would be effective in controlling the disease. He thought it was beyond human power to destroy or reduce a species of insect in large geographical areas. Scholars in Italy offered a different view by stressing that the proposed anti-mosquito measures overlooked the suffering patient. They promoted traditional methods of land reclamation, use of mosquito nets, and the taking of quinine. They considered malaria as a social disease and tried to raise living standards by improving housing conditions and increasing the food supply.

The Japanese medical community finally settled on one of two choices: the first, human-targeted, was based on blood testing and quinine treatment. Borrowing a Japanese official's term, I call it the "human approach." The other was mosquito-targeted, and included all available methods used to kill mosquitoes or reduce their population. I call this the "mosquito approach" in this chapter 
(Tsukiyama I905). ${ }^{3}$ In fact, discussions by Japanese officials about the relative effectiveness of these two approaches continued during the entire colonial period.

In I9II, the Governor-General in Taiwan convened a special meeting to decide the direction of malaria control and a series of laws were promulgated in I9I3. 4 The laws gave the Governor-General and local commissioners the right to create anti-malaria districts. The local police system and a local self-policing system called the hoko (保甲) were used to carry out the human approach of malaria control in these districts. Local policemen and headmen of hoko were to round up residents and visitors and force them to take a compulsory blood test. 5 Anyone found carrying plasmodium in his blood was to take quinine for I 8 days in the presence of a policeman.

Compared to other regions of the contemporary world, Taiwan's antimalaria policy of government-directed quinine treatment was noteworthy. Yet, considering the vigorous research on anopheles since the I90os, the application of the human approach in the I9IOs was regarded "a little abnormal" by Morishita Kaoru, one of the most famous malariologists of the colonial period (Morishita I976: II6). Liu and Liu have pointed out that since the colonial government tended to use the least amount of financial and manpower resources to deal with health problems in Taiwan, the human approach was chosen because the government considered improving environmental conditions to be too expensive and not very effective (Liu and Liu I998: II3). Other studies by Iiijma and Wakimura have compared differences between anti-malaria policies of colonial India and Taiwan, emphasizing the political factor in the formulation of policies. The Indian colonial government, for example, made an effort to segregate colonists and local society in order to protect the former. Moreover, the authors have noted that the policy in Taiwan followed "Koch's way," which had the consequence of enabling the colonial government to intervene in local society and extend its control over the Taiwanese people. By practicing the human approach policy, the colonial authority thoroughly permeated local Taiwan society, even to the point of controlling the body of the individual.

Although these studies have highlighted some important characteristics of the anti-malaria policy in Taiwan, some aspects have been neglected while others need to be elaborated. First, most recent studies tend to present the overly

\footnotetext{
3. Tsukiyama reduced these policies to “hito ni taisuru hōhō 人に対する方法” and “ka ni taisuru hōhō 蚊に対する 方法”.

4. “Mararia bōatsu kisoku," Taiwan Sōtokufu kōbun ruisan No.24-3-8, I9I3/4/I; "Mararia bōatsu kisoku toriatsukai kitei," Taiwan Sōtokufu kōbun ruisan No.24-3-8, I9I3/4/I.

5. The hokō system was at the lowest level of colonial administration. Ten households constituted a unit called “kō (甲)”, headed by a leader called “kōchō (甲長)”, and ten “kō” constituted a “ho (保)”, headed by a “hosei (保

正)". Those headmen were responsible to the local police office.
} 
simplistic picture that the anti-malaria policy in Taiwan focused almost entirely on the use of the human approach and that there was no controversy associated with its implementation. However, the attempt to eradicate malaria in the I920s emphasized the mosquito approach. The initial human-targeted policy was based on several pilot programs launched in the Igoos which were carried out under precise cost-benefit analysis, reflecting the economic considerations underlying the policy.

In I906, Kinoshita Kashichiro (木下嘉七郎), a professor at Taipei Medical School, was commissioned by the Monopoly Bureau to proceed with an antimalaria project for the camphor industry in Jiasian (甲仙). Camphor was one of the most important products of the Japanese empire at that time. There was no official report of the Jiasian experiment probably because Kinoshita died in 1908 shortly after the project ended. Nevertheless, the project was seen as a notable achievement and publicized widely in NichiNichiShinpo (日日新報) - the official newspaper with the widest circulation in colonial Taiwan, and the reports provide us with many details of this project.

Trained in protozoology at the Bernhard Nochi Tropical Diseases Institute in Germany, Kinoshita performed blood tests on the workers, analyzed the morbidity rate, and concluded that over 50,000 working days had been lost because of malaria. He argued that it would be impossible to destroy the anopheles mosquitoes since the rice paddy was their major habitat. Also, the beneficial results of using mosquito netting or window screens would be minimal as a great deal of capital and good discipline would be needed for them to be effective. Considering the factors of cost-benefit and social conditions, he settled on quinine-taking as a treatment for patients and a preventive for the healthy. Since the average incubation period - the time required for plasmodium to reproduce within the human body - was about I4 days, the reproducing plasmodium would be killed completely and transmission interrupted if the patient could take enough quinine during this period and repeat the course of treatment during the entire month (e.g., taking Ig of quinine every 9 th and Ioth day for a month). By the time the Jiasian experiment ended, the number of patients had decreased by half, and the average cost of treatment was only I.4 yen per capita. ${ }^{6}$

Kinoshita's project was evaluated highly even though the morbidity rate increased again after the project ended. Other malariologists conducted experiments in different areas. In I909, Hatori Shigerō (羽鳥重郎) was appointed as a medical official to succeed to Kinoshita's mission. Hatori carried out his antimalaria experiments in a military sanatorium located in a hot spring area, Beitou (北投). In order to use quinine more efficiently, he launched compulsory blood 
tests of residents and treatment with quinine only for plasmodium-carrying cases (Hatori Shigerō I9II, Horiuchi Tsugio I9I3).

Based on the results of these experiments, Takagi Tomoe presented an antimalaria memorial to Governor-General Sakuma Samata (佐久間左馬太, I906-I9I5) in I9I0. Takagi's plan revealed clearly the primacy of economic concerns. He argued that as a result of malaria, a total of $150,4 \mathrm{I} 6$ working days per year for the Japanese living in Taiwan, and 3,365,896 working days per year for the Taiwanese people were lost. Assuming a treatment fee of 0.3 yen per capita per day, the total cost would be $2,254,893$ yen a year. Furthermore, if the estimated value of human lives was included, the loss would be 4,609,267 yen per year. Thus, malaria control was an urgent task since the economic loss caused by malaria would be at least 6,800,000 yen each year (Taiwan Sōtokufu Keimukyoku Eiseika 1932: I8). In fact, the Japanese colonial government faced considerable financial difficulties until the mid-IgIos. Takagi's memoir indicated that Governor-General Ando Teibi (安東真美, I9I5-I9I8), newly appointed in I9I5, planned to allocate a hundred million yen to solve the malaria problem. However, Takagi argued that eradicating malaria over the entire island of Taiwan would yield only half of the benefit expected from the money and effort invested. He suggested suppressing malaria only where public offices were located because the cost would be lower (Takagi I920). Thus, although the anti-malaria program officially began in I9II, malaria eradication was not part of the initial design. Using precise cost estimates, the human approach was adopted to reduce outlay and economic loss.

As Takagi suggested, the human approach was in fact only introduced in assigned areas and treatment was limited to certain "select" people. Figure I shows the anti-malaria districts and malaria mortality rate maps overlaid with GIS (Geographic Information System). The circles represent the distribution of antimalaria districts in the I9IOS, I920s and I93I (the location of anti-malaria districts after 1932 is unavailable), where the human approach was practiced. The shading shows different levels of malaria mortality in each gun (郡, county). Not surprisingly, initial malaria districts in I9II were located in centers where Japanese resided, such as urban areas and natural resources development sites. As the maps show, although the number of districts increased gradually over the years, these districts did not correspond to areas of greatest risk. The increase in the number of districts in the I920s and I930s still did not suggest a general, islandwide program, as new districts remained restricted to specific areas, especially to work sites of natural resource development, such as camphor lands, farms with large-scale irrigation, and waterpower stations. This indicates that the colonial government's interest in the human approach was wedded to the development of natural resources, rather than to considerations of relieving the suffering of victims of the disease, or to attempts to extend its control over the Taiwanese people. 

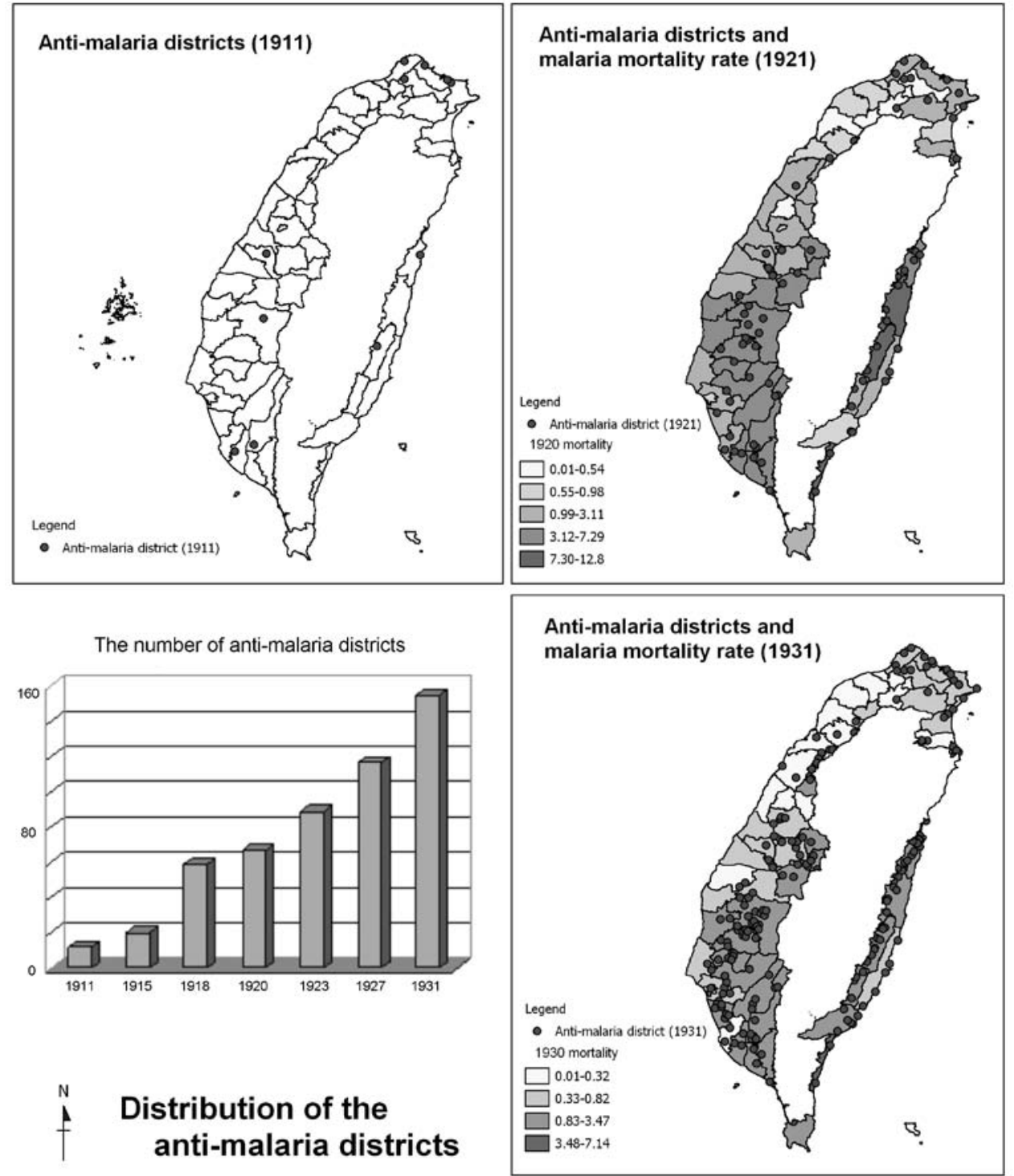

As noted, though the human approach continued until the end of the colonial period, it was never widely employed. In I92I, I93I and I944, the number of districts increased to 77, 153, and then 197. However, the numbers accepting blood tests never exceeded Io\% of the total population in Taiwan. Besides, not all residents or visitors living in the anti-malaria districts accepted the compulsory blood test. People above 50 years old and children less than 2 years old were con- 
sidered as "low malaria risk" and were usually excluded from the blood tests (Morishita 1976: 120).

More importantly, while the colonial government did pay more attention to the human approach initially, there was an important change of policy in I9I9. This change attempted to establish the mosquito approach as the primary line of attack in the anti-malaria effort, and malaria eradication became the goal at this time. To be specific, in those areas designated as anti-malaria districts, anti-mosquito efforts were added to blood testing and quinine treatment. In areas outside the designated districts, local colonial governments also began to mobilize and organize people against mosquitoes. Thus, anti-mosquito work was promoted by the Japanese colonial government much more intensively than quinine prophylaxis during the I920s, although, as I shall discuss later, the mosquito approach would gradually become more nominal in the i93os.

\section{From Man to Mosquito: a Change of Anti-malaria Policy in 1919} Compared to previous studies, this paper probes deeper into the relationship between policy, society, and colonial rule in order to better understand policy change as a dynamic process. We need to know why policy changes occurred, and how the mosquito approach was implemented. An analysis of this process reveals that the application of the mosquito approach was intertwined with the colonial government's political intentions to "reform" the people and the environment of Taiwan.

The year I9I9 was indeed a turning point in the development of antimalaria policies in Taiwan. The Japanese colonial government decided to adopt the mosquito approach as the primary method to eradicate malaria, and legitimized the new approach by enacting anti-mosquito laws. According to the revised laws, residents living in anti-malaria districts had new responsibilities to eliminate anopheles mosquitoes, such as removing weeds from irrigation ditches, draining ponds, trimming bamboo and plantain, filling in puddles and draining swamps. The county chiefs were empowered to impose restrictions on land use for the purpose of mosquito eradication.7 In addition, local governments published detailed regulations for the anti-mosquito effort in the I920s, mandating that such activities should be carried out in both designated anti-malaria districts as well as in other areas. ${ }^{8}$ In other words, while the human approach tar-

7. “Mararia bōatsu kisoku shikō kisoku kaisei no ken (マラリア防遏規則施行規則中改正の件),” Taiwan Sōtokufu kōbun ruisan no. 2927-I4, I9I9/O7/OI; “Mararia bōatsu kisoku shikō kitei (マラリア防遏規則施行規程),”Sōtokufu fuhō no.I831,1919/5/14.

8. For example, the “mararia bōatsu kisoku shikō saisoku (マラリア防遏規則施行細則)” was published in Takao state in I92I, Shinchiku state in I922, Taipei state, Tainan state and Karenkō chō in I923, Taichu state in I927. See Taiwan Sōtokufu Keimukyoku Eiseika, ed., Mararia bōatsu si, pp.91,99,I09,II3, I37, I49. 
geted very limited areas, the mosquito approach marked the beginning of a geographically much broader campaign in the early ig2os.

The ineffectiveness of the existing human approach was the ostensible reason for the change in policy. Medical practitioners such as the president of the medical school of the Government-General, Horiuchi Tsugio (堀内次雄), were aware of the rising total mortality rate since I9I4, and attributed the increases to uncontrollable deaths caused by malaria since I9I2, the second year after the anti-malaria policy was introduced (Horiuchi I926). These criticisms seem to have contributed to the eventual policy change later.

In the meantime, the clamor for malaria eradication and scientific optimism about the mosquito approach steadily increased during the late igros. Some medical officials began to assert that the human approach was merely a means to meet an urgent need, and only the mosquito approach could solve the malaria problem in Taiwan.9 Scientific thinking in Taiwan during this time should be put in the broad historical perspective of global malariology. One of the important characteristics of contemporary tropical medicine was the combination of biology and medical science. Based on Ronald Ross's work on mosquito transmission, a majority of malariologists, especially in the British Empire and later in America, believed that by simply eliminating the species that transmits malaria, the disease could be eradicated as well. The British colonial government consulted Ross and his proponents on how and where to attack malarial mosquitoes in the Caribbean Islands, Central America, and Africa. First, they conducted a survey under the guidance of an entomologist in order to accurately locate breeding places of anopheles. Then, paid workers were recruited into "Mosquito Brigades", "Drains Brigades", or "Petroleum Brigades" to clear standing water, drain basins, and put oil on larger bodies of water (Boyce I909: 64-75). These mosquito-targeting methods and their positive results were reported frequently in the Journal of the Formosan Medical Association, the most prestigious medical journal in colonial Taiwan. Meanwhile, stories about successful malaria countermeasures from the West were hailed as a demonstration of the integrated mosquito-control program, including using larvicide and adulticide to eradicate mosquito sources. It is reasonable to assume that the success of the U.S. government in controlling malaria during the construction of the Panama Canal contributed to the broad acceptance of the mosquito approach.

For example, Suzuki Shintaro, Chief of the Sanitation Section (鈴木信太郎, I9I7.5-I9I9.3), used an equation designed by Ross to estimate the malaria infection rate in Taiwan. He argued that if the number of anopheles was fewer than 7.4 per person, the infection would eventually cease of its own accord even when there 
were many existing patients. On the contrary, if the number of anopheles was

greater than 7.4, the number of patients would increase rapidly even if there was only one patient initially. He thus concluded that the infection rate was mainly determined by the number of anopheles rather than the number of patients. Suzuki asserted that anti-malaria policy should make more of an effort to kill anopheles rather than treat the disease because it would be impossible to eradicate malaria with the human approach according to the Ross model (Suzuki igI9).

Ross's theory and its applications were highly praised by the imperial medical community in Taiwan in the late igios. However, the practice of the mosquito approach in Taiwan differed from the "Ross version", as revealed in a report written by Shimomura Hachigoro (下村八五郎), a local hygiene technician. Shimomura was an active participant in the anti-malaria effort in Tainan since I923 (Shimomura 1935). He criticized the limitations of existing anti-malaria policy in Tainan which targeted only 60 thousand people living within the antimalaria districts and excluded the other 900 thousand residents. The local government decided to accept his recommendation and published detailed regulations on how to execute the mosquito approach policy across the entire region. After 1924, the state was divided into small regions according to police precincts, and an executive director was assigned to every gun to train the police. Residents in each precinct were required to weed, cut clumps of bamboo, drain ponds, sweep streets, and collect trash under the command and supervision of the police (see Photo I). In addition, influential leaders, such as school principals or hoko headmen were appointed to the anti-malaria committee, and were expected to act as role models for the populace. The region judged to have done its work best would win a medal and be designated as an anti-malaria model area.

Unlike the "Ross version" of mosquito control that relied on a bureaucracy of specialists and trained, paid workers, the local government transformed anti-malaria work into a routine duty of the Taiwanese people. In fact, this strategy combined mosquito control with an altogether different intention to transform the people and environment of Taiwan to meet a "Japanese standard". Shimomura explained: "In the anti-malaria districts, we had published pamphlets, hung posters, held exhibitions and speeches in order to offer hygienic knowledge to (Taiwanese) people, but they paid no attention to these things and forgot them immediately .... People are lacking in knowledge. Some don't believe malaria is transmitted by mosquito ... But we believe that while mobilizing people to carry out anti-malaria work, the knowledge can be infused (emphasis in the original) into ignorant people through their hands, feet, eyes and ears." (op.cit.: 59). Clearly, Japanese medical officials denied the validity of the Taiwanese perception of malaria and tended to view the Taiwanese as ignorant laypeople in need of enlightenment through education provided by the colonizers. A region selected to be a model of anti-malaria work was inevitably considered to be more 


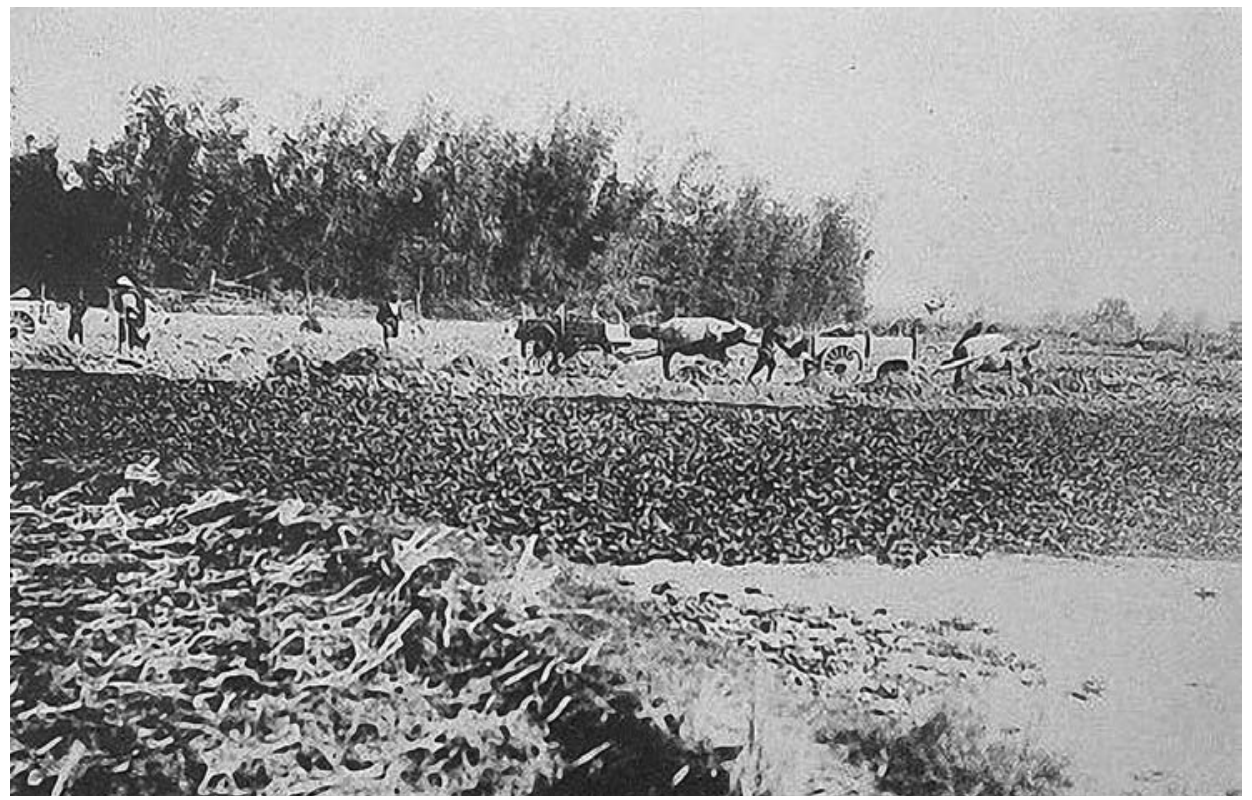

Photo 2. A place where the anti-mosquito work was considered done very well (photos show conditions before and after improvements)
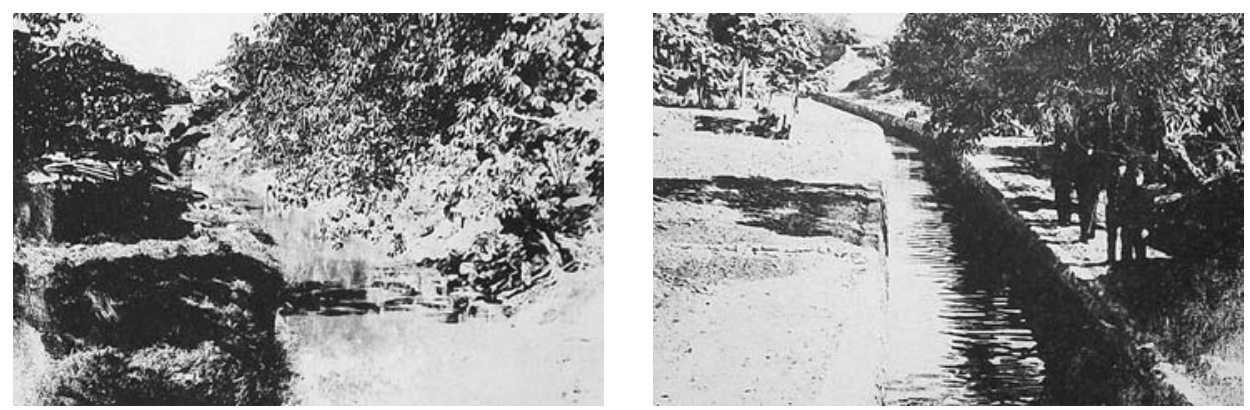

"civilized." Officials insisted that each place should "become neat and beautiful like a grand park" after anti-malaria work had been carried out (see Photo 2). This view corresponded to the colonizers' understanding of malaria etiology: the prevalence of malaria resulted from the "intrinsic evil" of the Taiwanese people and their environment and "civilizing" the people and the environment was the ultimate means to eradicate this disease.

\section{"Interior Extensionism" and Malaria Eradication}

My contention is that the colonial government's intention to eradicate malaria in the late I9Ios reflected not only the controversy over scientific effectiveness, but 
also changes in the political environment. The strong interest in "reform" coin-

cided with the new political objectives of the assimilation policy during the I920s. Since 1919, Den Kenjiro (田健治郎, I919-I923) became the first civilian Governor-General, and the Taiwan colonial government adopted "Interior Extensionism (内地延長主義)" as a principle of colonial rule (“interior” here refers to the home islands of Japan).

To appreciate the significance of the concept, it is necessary to examine more closely the structure of Japanese colonial rule. Taiwan had been governed under so-called "biological principles" established by Civil Affairs Bureau Chief, Gotō Shimpei (後藤新平) since I898. Trusted by the Governor-General, Gotō, who had a background of medical training, operated with a broad latitude of authority in managing the civil affairs of the colonial administration. Well-versed in principles of biology, he argued that grafting all the institutions directly from Japan onto pre-modern Taiwan would be like transplanting the eyes of a bream onto a flatfish. Thus he rejected absolute assimilation and called for an investigation of local customs as the groundwork for colonial governance (Tsay 2002). By the late I9Ios, however, colonial leaders increasingly embraced the idea of "Interior Extensionism" which was considered to be a policy through which Japanese colonialists would be able to cultivate Taiwanese support in light of the rise of global movements of national self-determination after World War I. Prior to Den's departure for Taiwan, he and Prime Minister Hara Takashi (原敬) agreed to pursue an assimilation policy wherein Taiwan would be viewed as an extension of the Home Islands and the Taiwanese would be educated to understand their role and responsibilities as Japanese subjects.

There is a large body of literature on "Interior Extensionism" and its consequences - positive or negative - for Taiwan. My focus here is to examine how the colonizers endeavored to transform the life-style and thinking of the Taiwanese people so that they could conform to Japanese cultural norms. Educational reforms were carried out, and the colonial government promoted "racial co-education" at the post-elementary level and implemented an integrated school system for Japanese and Taiwanese students. Education was intended to cultivate loyalty, morality, and civility, and a Social Education Section was established within central and local governments. Traditional customs were portrayed as undesirable or superstitious. Local elites were urged to form committees, with financial support from local governments, to lead people toward the goals of using Japanese, and reforming native religion, customs, and habits (Wu 2002). Similarly, the anti-malaria policy was framed within the context of premodern Taiwan versus modern Japan. The colonizers' etiology of malaria and the intentions of assimilation reinforced one another. Imperial authorities viewed Taiwan's social traditions and its environment as backward, the root cause of malarial prevalence, and in need of reform. A discourse was framed 
which suggested that malaria could be eradicated through reforming the "bad" environment and people's "pre-modern" life style, and the mosquito approach policy - modified from the "Ross version" to a Taiwan version that relied strongly on the structure of local society for implementation - was construed as the device to achieve this goal.

\section{Resistance and Indifference to the "Mosquito Approach"}

Not everyone, however, agreed with the application of the "mosquito approach." Koizumi Tan (小泉丹), a parasitologist and an entomologist who was appointed to Taiwan in I9I4 and who established the Medical Zoology and Malaria Laboratory in the Central Research Institute of the Government-General, believed that imported anti-mosquito ideas might not necessarily be suitable for the environmental conditions in Taiwan (Koizumi I928). After returning to Tokyo in I923 as Professor of parasitology at Keio University, Koizumi continued his criticism, arguing that official publications had overestimated the achievements of the antimalaria policy (Koizumi I929). Despite the investment in money and manpower, the results of malaria control had fallen short of expectation, and he attributed the unsatisfactory performance to a number of scientific shortcomings. These included the failure to do a good job of locating and surveying the breeding places of anopheles before the start of anti-mosquito work, and the difficulty of sustaining what had been accomplished in the transformation of the environment in a tropical climate subjected to the destructive power of wind, rain, and vegetation. Moreover, he pointed to such human factors as the residents' dwindling financial resources because of misguided anti-malaria work, and the "lack of wariness and fear of malaria" on the part of the Taiwanese people (Koizumi i928: 23).

Koizumi's evaluation revealed that the unsatisfactory results of the mosquito approach was related not only to scientific shortcomings, but also in part to local resistance and apathy toward the policy. As noted earlier, the target of the new policy was to reform people's behavior and the living environment, not the destruction of mosquitoes per se. Thus, we also need to examine the causes of "ineffectiveness" within the social context, and to consider how the policy was received by local society.

Public resistance and apathy toward the anti-mosquito policy was portrayed realistically in a fictional work entitled Getting a Medal (奪錦標) that described how a policeman mobilized residents of a village to win a medal in an anti-malaria competition. Written by a Taiwanese writer and published in I93I, the story showed how the execution of anti-mosquito work created problems for the local people trying to maintain their current life style. ${ }^{\text {Io }}$ In the story, the ambitious policeman urged the residents to work harder to get rid of the mosquitoes under the supervision of the hoko headman. Most of the residents, being farmers, were reluctant to cooperate since the anti-malaria work would mean addi- 
tional chores without payment and interfere with their farming duties. Although they could hire substitute workers for the anti-malaria duties, most of them could not afford to do so after paying their heavy taxes. Thus, they fulfilled their obligations half-heartedly, and even then only when the headman persuaded them to or threatened them with force. The production of rice and sugar cane suffered as anti-mosquito work occupied most of the time and energy of farmers who had to pay their taxes even when harvests were poor. It became clear that the intrusion into their daily lives had led to the farmers' resistance. The policeman blamed the farmers' unwillingness to cooperate on their laziness and tried to coerce them to cooperate. At the end of the story, the village did win the medal and was selected as a model anti-malaria region. Yet once the policeman was promoted and transferred to another locality, no one in the village was willing to continue the anti-malaria work.

A statement made by the policeman in the story summed up the attitude taken by the colonial government in the anti-malaria effort. He complained: "I toiled all day long just to protect your health, to improve the hygiene of you lowly people" (Tsai I990: 185). Imposing anti-mosquito work on the Taiwanese people was justified as a means to emancipate the people from their inescapable suffering from malaria, a disease that the locals had had much experience of. Public health investigations during the I920s provide additional historical material for examining the roots of the Taiwanese people's understanding and perception of the disease. From I92I to I93I, the colonial government conducted comprehensive public health studies of local areas, choosing one or two small "unhealthy" regions in each state every year, and gathering such information as birth rates, death rates, morbidity rates, physical measurements, and customs related to death (Taiwan Sōtokufu Keimukyoku Eiseika I92I: I-8). According to these reports, even leaders of hoko who were considered local intellectuals, regarded malaria just like a common cold, and viewed anti-mosquito activities as sheer nonsense. The colonizers' representation of malaria as a scientific discourse was not embraced by all Taiwanese people, and since the anti-mosquito policy brought no substantial benefits while making life more difficult for them, it was met by passive resistance and even incidents of protest. ${ }^{\text {II }}$

Io. Tsai Chou Tong, “Duō Jin Biao (奪錦標), “Taiwan Shinmin pō no. 374, 375, 376, I931. Republished in Chang Heng Hao, ed., Taiwan tsuo-chia chuan-chi: Yang Yun Ping,Chang Wo Chun, Tsai Chou Tong Chi (台灣作家全集 : 楊雲萍、張我軍、蔡秋桐集), pp.I83-I94. Taipei: Avant-garde Publishing, I990.The author Tsai was a Taiwanese hosei (保正) in Tainan. His works are considered as reconstruction of factual experiences. He also declared himself that the story is based on real events, only the names of the characters are modified. Instead of criticizing openly, he always used a satirical way to express disapproval of colonial policies. II. See "Incident: A man used abusive language against the anti-malarial work," Taiwan NichiNichiShinpō, Jan. 23, 1934 . 
Moreover, the anti-malaria policy's explicit condemnation of the environment of Taiwan conflicted with the traditional beliefs of the local society. For example, medical officials always described villages with such statements as "dense with bamboo and trees which obstruct the sunlight and fresh air," and they "look unclean, dark and make people gloomy." But bamboo was important for the local people both because of its benefits and symbolic meaning. During the Qing dynasty, houses were built with bamboo forming an outside barrier which not only protected the house as a windbreak but also kept thieves away. When there was plague, people would put an incense stick at the entrance to the bamboo forest to pray for blessings. Some believed that cutting down bamboo recklessly would bring bad luck (Tomita I955). Public outcry became quite vocal when the new anti-malaria policy mandated the removal of the bamboo fences. ${ }^{12}$ The mosquito approach remained the colonizer's conviction, rather than the colonized people's necessity.

It is hard to say in which year the mosquito approach was de-emphasized during the i930s. The colonial government did not revise the anti-malaria laws again after the I920s. However, in I929, a "Malaria Therapy Laboratory" was established in the public health section of the Central Research Institute of the Government-general. The founding declaration characterized the results of the existing anti-malaria policy as "in need of improvement," and declared the main purpose of the institute was to "research the diagnosis and therapy of malaria patients, particularly for chronic patients, in order to provide a basis of policy making which gives priority to the treatment of patients and to the eradication of carriers," (Taiwan Sōtokufu Chūōkenkyūjo Eiseikabu I926). The declaration thus revealed the anxiety toward, and concern for, the results of the mosquito approach and endorsed returning to the human approach. At the same time several construction projects carried out in the name of anti-malaria policy built sewers to process polluted water. Ironically, that the larvae of anopheles mosquitoes in Taiwan exist only in clean, unpolluted water was well known. This suggests that the performance of anti-mosquito tasks gradually became merely nominal in the late I930s (Ku: 209).

\section{Statistical assessment of the anti-malaria policy}

In the final section, I will discuss the statistical assessment of the anti-malaria policy by the colonial government, in order to reconsider how the discourse of the effectiveness and ineffectiveness of each approach emerged in its historical context. To policymakers and public health practitioners, statistics were necessary for

I2. For example, "Compelled to Cut Bamboo, Voices of Protest Got Loud," Taiwan Minpō no.243, Jan. 3, I929.

"What a Civilized Village! The Villagers Cursed the New Anti-malaria Method of Cutting Their Fences," Taiwan Minpō no.252, March 17, 1929. 
Figure 2. Malaria mortality of Taiwanese and Japanese in colonial Taiwan (1897I94I) (Deaths per thousand)

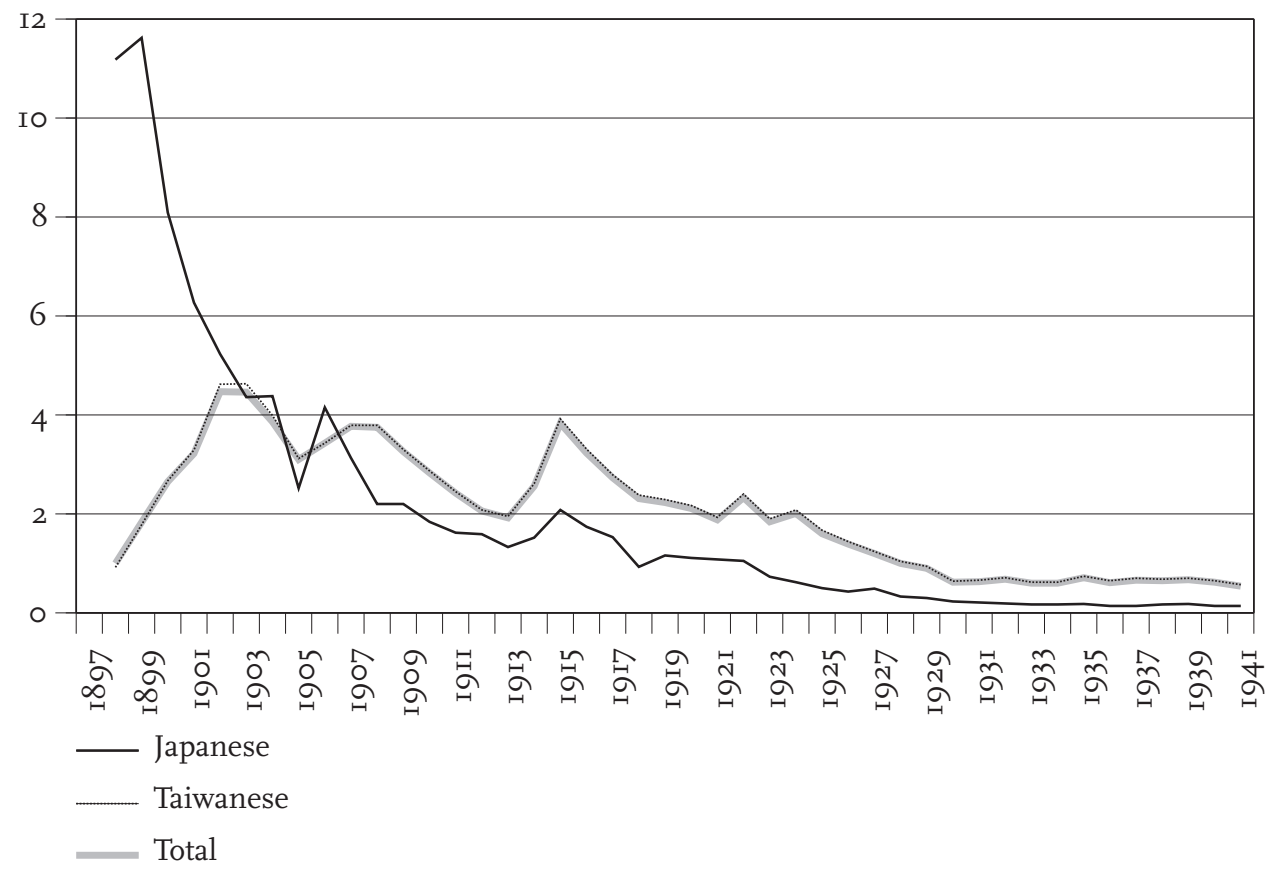

them to assess the effectiveness of the policy. Thus many investigations were conducted and abundant statistical data exist.

Mortality data had always been used by the colonial government to prove the success of malaria control. Malaria mortality declined quite sharply for both the Japanese and Taiwanese from I906 to I942. Moreover, among major causes of death in colonial Taiwan, malaria was the leading cause in I9II, but fluctuated between the first and third places from I9I2 to I92I, competing with pneumonia and diarrhea. After I925, it fell out of the top four leading causes of death, taking the tenth place in I935 (Chen I979: 82-83). Official publications such as Statistics of Malaria in Taiwan (台湾マラリア統計) explained that the mortality rate of Japanese was initially high because of their inadaptability to the Taiwanese environment, but soon it was reduced once the anti-malaria policy began. On the other hand, the slower decline in Taiwanese malaria mortality was due to "the lack of modern hygienic understanding" among the local people (Taiwan Sōtokufu Keimukyoku Eiseika I926: 8-13). Nevertheless, the official accounts claimed that the apparent drop in both rates demonstrated the achievement of anti-malaria efforts.

It is significant that malaria mortality had been sharply reduced by the end 
of the colonial period. However, uncritically accepting the discourse of the colonizer is inadequate. First, the extent to which the anti-malaria policies improved the mortality rate remains to be further discussed. As mentioned above, according to the narrative of zhang in the Qing dynasty, the malaria situation seems to have become stable in the igth century. In the early stage of the colonial era, however, population movement due to migration, revolts and military expeditions was so great that it must have contributed to the outbreak of malaria. Therefore, the very high mortality rate in the early colonial years should not be seen as "normal", and the overall decline of the mortality rate in the later years might indeed represent a return to the "normal" pattern as the population structure and settlements stabilized. This might help explain the overall decline of mortality before the adoption of the human approach in I9II.

Moreover, the contrast between the colonial government's confidence in reducing malaria mortality and its anxiety over the direction of the anti-malaria policy was remarkable. From an epidemiological point of view, the drop in malaria mortality does not necessarily indicate the success of disease control, since low mortality could simply result from a decline in the fatality rate and not from low morbidity. In fact, the colonial government also kept an eye on malaria morbidity. Two regularly reported statistics document morbidity levels. First, from I905, the colonial government began to collect statistical data about the numbers of patients who accepted malaria treatment, based on yearly returns of local public hospitals as well as public dispensaries. Second, in the anti-malaria districts, the "parasite rate" was recorded monthly to show the proportion of the population showing the malaria parasite in their blood.

Figure 3 displays these sets of statistical data. ${ }^{13}$ In Figure 3 the malaria morbidity curve closely parallels the curve of malaria mortality before I920. After the I920s, however, the two trends diverge from one another. In the anti-malaria districts, the parasite rate declines a bit when both the mosquito approach and the human approach were implemented after 1920 , but dramatically increases after I930.14 In the whole island, the malaria morbidity level was reduced slightly when the mosquito approach was carried out enthusiastically during the i920s, but gradually increased in the I930s.

I3. The number of public hospitals and dispensaries increased gradually as well as the number of patients they treated. At the end of colonial period, there were 284 public dispensaries and I2 public hospitals. In order to eliminate bias resulting from the growing number of public hospitals and dispensaries, the total number of patients is taken as a denominator to calculate malaria morbidity, rather than the absolute number of the population. See Taiwan Sōtokufu Keimukyoku Eiseika, ed. 1926. Eisei chōsasho-kihonchōsa no4: Taiwan mararia tōkei, p.I45. I4. The rapid increase of parasite rate after I930 partly resulted from a technically advanced blood test. After I933, the method of examining blood parasites was replaced by a new one, which helped the technicians find parasites in blood more easily. 


\section{Taiwan (1897-1943)}

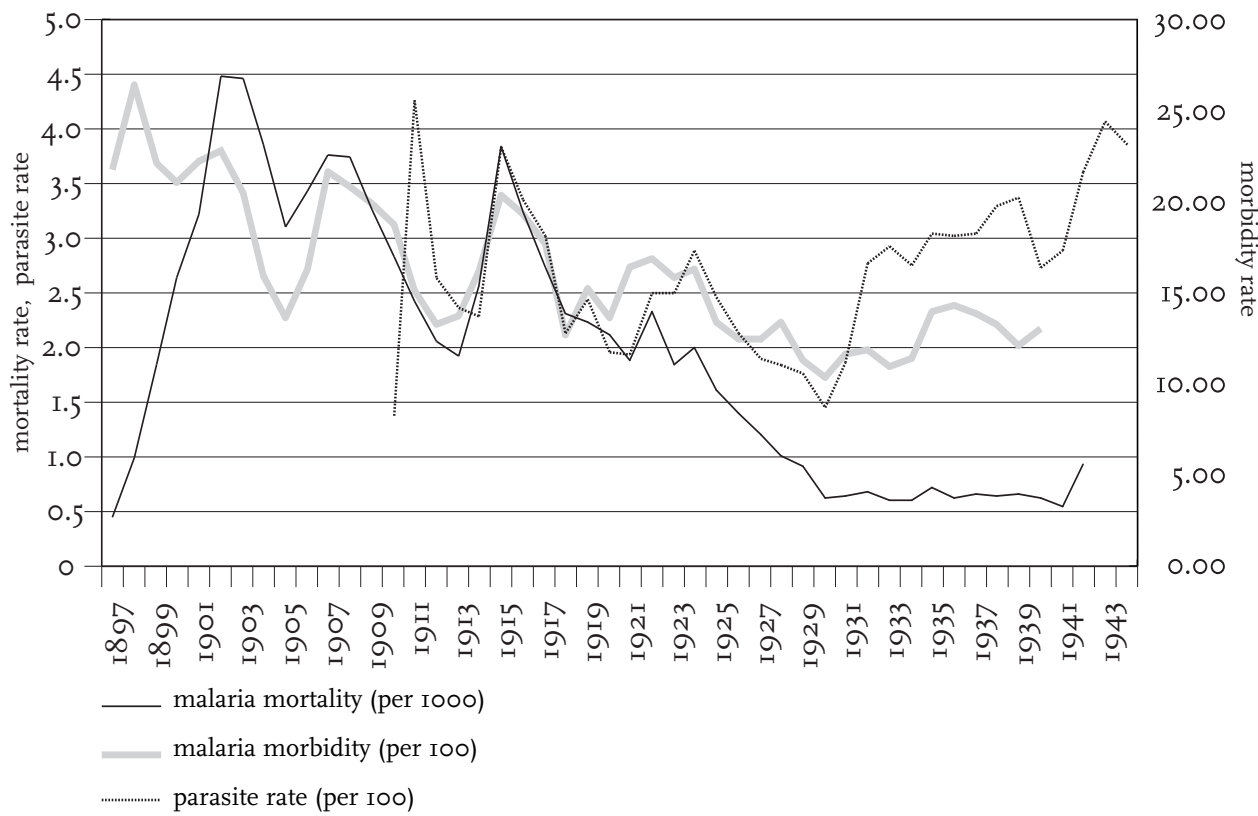

Figure 4. Malaria Morbidity of Taiwanese and Japanese in local public hospitals (I905-194I)

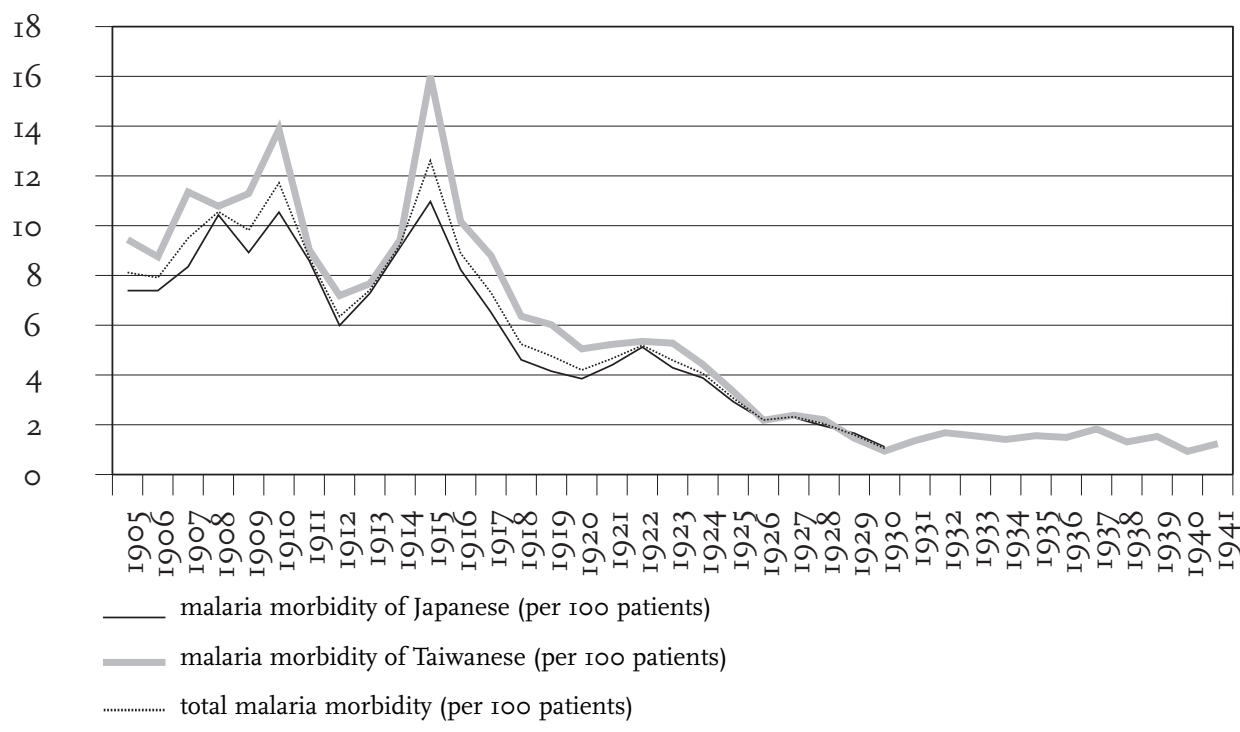




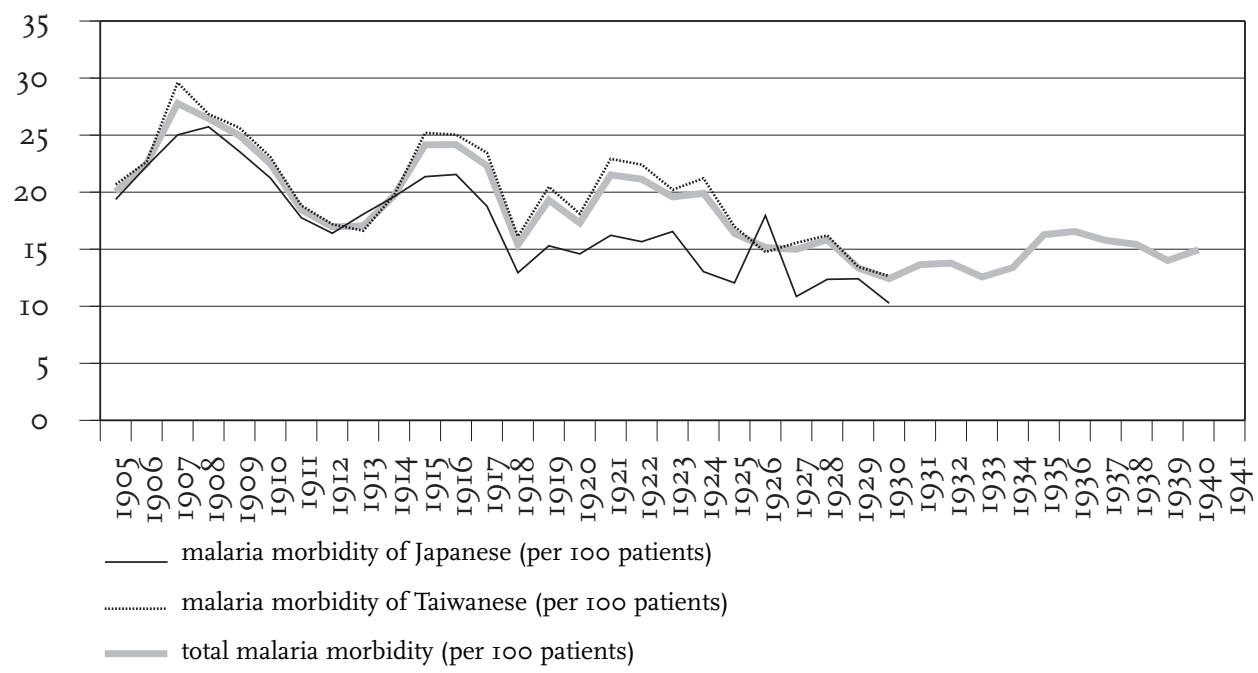

In order to understand the morbidity situation at the local level, the statistics of public hospitals and public dispensaries should be analyzed separately. The former were located in cities whereas the latter were almost always in the countryside; thus these statistics provide a rough comparison of the situation in urban and rural areas. ${ }^{15}$ It is clear that in urban areas (see Figure 4), both Japanese morbidity and Taiwanese morbidity decreased significantly before I920, and continued to decrease after I920. In rural areas on the other hand (see Figure 5), rates were higher and Taiwanese morbidity remained higher than Japanese morbidity, fluctuating between I5-20\%, almost at the same level from I9II-I929.

In fact, statistics in the hospital reports reveal only a partial picture of the situation among the Taiwanese people. According to reports of public health investigations in the Ig20s, most of the Taiwanese people did not go to a hospital until the patient's condition became very serious. However, since the reports include the malaria parasite rate and spleen rate (i.e., the prevalence of splenomegaly), ${ }^{16}$ they too provide another index showing that the prevalence of malaria did not fall in rural areas during the I920s. In most of Tainan state, for example, the rate of parasite infection was over $3 \%$ and the spleen rate over $20 \%$. Moreover, many regions recorded "low malaria mortality but high malaria prevalence."

I5. Taiwan Sōtokufu Keimukyoku Eiseika, ed. 1926. Eisei chōsasho-kihonchōsa no4: Taiwan mararia tōkei, pp.I45-I5O. I6. In regions of endemic malaria, repeated malarial infections and resulting hemolysis lead to splenomegaly. Thus, the prevalence of splenomegaly (spleen rate) reflects the frequency of clinical malaria. 
The reasons why malaria morbidity did not decrease or decreased less

than malaria mortality, remain to be studied further. Here my focus is on how the statistical assessment affected the direction of anti-malaria policy. The colonial government's concern for and anxiety about the policy was caused by the ineffectiveness of attempts to reduce the Taiwanese morbidity level. This ineffectiveness was measured not simply by objective statistical numbers, but was also based on contemporary political and social considerations. In the I9IOs while the human approach was adopted in a limited number of districts, the total morbidity in urban areas and Japanese morbidity in rural areas decreased, but overall morbidity was not improved. After 1920 , and the adoption of the assimilation policies, the human approach was considered ineffective since the prevalence of malaria was believed to have resulted from the "intrinsic evil" of the Taiwanese people and their environment. Thus reforming these pre-modern elements through the mosquito approach was viewed as the ultimate means to eradicate this disease. The mortality rate did decline rapidly in the I920s during the period when the mosquito approach was promoted quite enthusiastically. However, the decrease of morbidity did not occur as expected: it only occurred in the anti-malaria districts and urban areas, and among the Japanese - but not the Taiwanese living in the countryside. The resistance of the Taiwanese showed that their cultural understanding and traditions could not be suppressed or transformed easily through the mosquito approach. Thus the mosquito approach came to be considered ineffective, and eventually support for it collapsed.

\section{Concluding Remarks}

This chapter has examined the dynamics of the development of an anti-malaria policy and its consequences in colonial Taiwan. First, the Japanese colonizers' perception of malaria framed anti-malaria policymaking. Since malaria was considered to be a serious threat to the economic development of Taiwan, the human approach was adopted as an effective way to suppress malaria in selected areas and protect economic interests. Yet it is important to point out the temporary, but important, shift in policy to the mosquito approach in the I920s and this fact has generally not been explored in studies of colonial Taiwan. The Japanese government portrayed the mosquito approach developed by Ross as an authoritative scientific truth in order to justify its adoption, although the approach implemented differed from Ross' version in its application in colonial Taiwan. At the same time, the human approach was considered ineffective as a way to achieve malaria eradication, since the cause of this disease was an "intrinsic evil" of Taiwan itself. After the Japanese government introduced the policy of assimilation, the authority of the mosquito approach was also used by the colonial government to justify its intention of "reforming" the island and its people. The political assimilation propaganda of the I92os portrayed the local people's 
beliefs, traditions, and living environment as "uncivilized," and the undesirable elements had to be removed to fit the "Japanese standard". Thus, I argue that the change of policy and the features of the modified mosquito approach paralleled the change in Japanese colonial policy toward Taiwan.

This chapter also suggests that the anti-malaria policy and its consequences should be reconsidered from the points of view of both the colonizer and the colonized. In previous studies of colonial medicine, the colonized Taiwanese have always been portrayed as a silent community that accepted forced modernization either actively or passively. However, as far as the anti-malaria policy is concerned, coercive measures and scientific authority did not banish the indigenous explanations and treatment of malaria. On the contrary, a different understanding of the disease led to a tense relationship between the two groups when the mosquito approach was put in practice during the I920s. Since the target had expanded beyond the mosquitoes to include local customs and the environment, local resistance emerged. The "reform" of indigenous lifestyle and changes to the environment disrupted people's lives and violated long-held beliefs.

By the late I920s, the mosquito approach was being criticized as ineffective. The founding of the Malaria Therapy Laboratory revealed the plan to give priority back to the human approach again. In the latter half of the I930s, the anti-mosquito efforts were not abandoned in name, but were de-emphasized in reality. Local apathy and resistance were key reasons for the rather weak impact of the anti-mosquito campaign; colonial health policy, imposed from above, met with resistance from below.

To assess the anti-malaria policy many investigations of malaria were carried out and abundant statistical data produced. Statistical analysis shows malaria morbidity, especially for Taiwanese, did not decrease or decreased less than malaria mortality. Around the end of the I9Ios, the human approach was deemed inadequate to achieve the aim of malaria eradication. After the I920s, the discourse of ineffectiveness shifted to the mosquito approach because to a significant extent the Taiwanese morbidity level remained high. The high morbidity rate also suggested that the attempt to reform and assimilate the Taiwanese people through the mosquito approach had not succeeded. Thus, the adoption and efficacy of the anti-malaria policies are not, and should not, be interpreted as being determined solely by a universal scientific truth, but should be understood in the context of the interaction between empire and local society. 


9

\section{Maternal mortality in Taiwan and the Netherlands, I850-1945}

John R. Shepherd Department of Anthropology University of Virginia

Marloes Schoonheim

Radboud University, Nijmegen

Chang Tian-yun

Department of Sociology,

Vanderbilt University

Jan Kok

IISG, Amsterdam 
Maternal mortality is an important measure of the standard of living in societies both in the past and at present. Recent research on maternal mortality has focused on its relation to fertility behavior, infant mortality, and broader trends in death rates and sex differential mortality (Chen et al. I974, Hieu I999, Loudon I992). Difficulties in collecting data and constructing measures to estimate maternal mortality have also received the attention of scholars (Bouvier-Colle et al. I99I; Graham 1989; Rutenberg et al.; Stanton et al. 1996; Stecklov 1995). Results from studies like these have had considerable impact on development policies.

Maternal mortality rates and trends are inextricably intertwined with family and gender systems. Few scholars have compared maternal mortality in two societies like the Taiwanese and the Dutch where these systems are radically different. In this article we compare data drawn from the Taiwanese household registers, vital statistics reports, and censuses from the Japanese colonial period (1906-1945) with comparable data from the Netherlands (I850-I920). During these periods, we examine the demographic characteristics as well as the institutional and cultural contexts relevant to a comparison of maternal death rates in both countries. Register data for colonial Taiwan show that the number of deaths per Iooo women age I5 to 49 averaged 9.4 ; the comparable rate for the Netherlands I850-I920 averaged between 5.6 and 6.3 (see Tables 7A- 7D). In the same periods, the general fertility rate (births per 1000 women I5-49 per year) was 233.6 for Taiwan and 134 for the Netherlands.

Midwives were chiefly responsible for delivering births in both Taiwan and the Netherlands, and thus we begin by discussing maternal care during the research period and the effect midwives may have had on the level of maternal mortality. We also introduce the data sets used as well as the statistical measures employed to measure maternal mortality. The second section of the paper provides for an overview of mortality in the two countries by comparing female and maternal mortality in both countries and contrasting male to female death rates. In the third part of the paper we turn our attention to factors increasing the risk of maternal death, including maternal age, parity and birth interval. Fourthly we discuss the relation between maternal and infant mortality.

\section{Maternal mortality: care, causes of death, registration, and measures}

\section{Maternal care in the Netherlands}

When contrasting maternal deaths of Taiwan and the Netherlands we should take into account that the Dutch rates and patterns are by no means representative of Western Europe. Compared to other European countries, maternal and perinatal mortality in the Netherlands were extremely low during our period of research (Loudon 1992:449). The reason for this difference in mortality rates was that 


\begin{tabular}{llllll}
\hline & I865 & I875 & I885 & I895 & I900 \\
\hline Home deliveries* & 8.1 & 6.6 & 6.7 & 4.0 & 3.I \\
Maternity hospital & 42.2 & 54.3 & I9.2 & I4.I & 7.2 \\
\hline
\end{tabular}

* Home deliveries attended by doctors and midwives. Source: Loudon I992:419

most deliveries in the Netherlands took place at home, under the care of skilled midwives. Even in a large city like Amsterdam only 3 to $5 \%$ of all deliveries took place in a hospital between 1865 and I900 (Loudon I992:449).

The fact that home deliveries were the rule lowered the maternal mortality rate considerably. Across Europe and the United States, hospitals experienced very high rates of maternal mortality. As table I shows, the maternal mortality rate in Amsterdam hospitals was many times higher than in home deliveries. (Loudon I992:440). Despite the many measures taken to fight the high numbers of maternal deaths (like fumigation of beds, cleaning of instruments and isolation of infected patients) hospital rates declined only after the introduction of antisepsis in the I880s.

During the nineteenth century, most deliveries took place at home in the presence of midwives who, compared to colleagues abroad, were highly skilled. The case-book of a licensed Dutch midwife, Vrouw Waltman, who practiced her profession between I84I and I872 in the city of Dordrecht, provides insight into the way midwives practiced their profession (Drogendijk I936). Midwife Waltman first established whether the delivery was early or full term, determined the position of the child and whether or not it was necessary to call in another (man) midwife. Only rarely did Vrouw Waltman call in a colleague for the dozens of deliveries with non-normal head presentation and for births with a transverse position and other difficulties. Midwives like Waltman could recognize which conditions were life-threatening and could employ techniques of version and extraction. In only one out of almost 5000 births she attended, did Waltman need instruments to complete the delivery (Van Lieburg and Marland I989:303-304).

Systems for training, apprenticeship and examination of midwives began as early as I8I8 in the Netherlands. In the I82os schools for midwifery were set up in several large towns (Abraham-Van der Mark I993; Van der Borg 1992). From I85I, new regulations required that midwives be trained by a university professor in obstetrics (Van Lieburg and Marland 1989:307). The shortage of well-trained midwives that followed the new regulations resulted in the founding of a state school for midwives in Amsterdam in I86I; a second one followed 
in I882 in Rotterdam. The training was free, but those who graduated were obliged to practice as midwives to the poor for a few years. Amsterdam admitted 26 candidates per year; Rotterdam 32. Candidates had to be between 25 and 35 years old, preferably unmarried or widowed, and of unblemished reputation. The training, which took two years, included anatomy and physiology, special knowledge of the female reproductive organs, care of infants and sick women, theoretical and practical midwifery (Van Lieburg and Marland 1989:307). As more and more women received training and licensing, these licensed midwives gradually supplanted unlicensed birth attendants and attended an increasing proportion of total deliveries.

Midwives were required to call in obstetric doctors or man-midwives in cases of difficult or dangerous deliveries. Man-midwives were obstetric specialists who lacked qualification as a medical doctor. Towards the end of the nineteenth century, man-midwives faced increasing competition from the growing numbers of academically trained obstetric practitioners (both doctors of obstetrics and general practitioners). In I865 the qualification of man-midwife was abolished and their numbers swiftly declined (Van Lieburg and Marland I989:299, 305).

The competition between midwives and doctors partly motivated the Medical Act of I865 that restricted midwives to attending only normal deliveries 'that were the work of nature, or which could be executed by hand' (Van Lieburg and Marland I989:305). Following the act, examinations on the provincial level were replaced by state licensing. After 1885 , midwives trained in the way stipulated by the Medical Act outnumbered those licensed according to provincial regulations (see table 2). Because of the strict licensing, the numbers of midwives during the late igth and early 20 th century did not keep up with the increase in population. The role of midwives and the damaging effects of the new regulations on their earnings and working conditions led to the so-called 'midwife debate' during the first decades of the 2oth century. Although their right to perform certain obstetric procedures and the division of labor between general practitioners and midwives were questioned, the importance of the midwife and her key position in obstetric practice were never undermined (Van Lieburg and Marland I989:317). Compared to other European countries the maternity service in the Netherlands was still exceptionally efficient in that period (Loudon I992: 419).

The second half of the nineteenth century marked the development of the medical profession in the Netherlands. Only after 1838 were medical doctors allowed combined practice, and this led to many acquiring second degrees in obstetrics. As table 3 shows, the number of obstetric doctors increased rapidly between 1840 and 1855 . It is estimated that by $186659 \%$ of the medical doctors held an obstetric degree (Van Lieburg and Marland I989:30I). These academically trained obstetric practitioners provided serious competition for the man- 
Midwives

Totals

Trained (\%) $\quad$ Trained (\%)

before $1865 \quad$ after 1865

\begin{tabular}{|c|c|c|c|}
\hline I840 & 8II & (100\%) & \\
\hline 1850 & 8II & (100\%) & \\
\hline I860 & 725 & (I००\%) & \\
\hline \multicolumn{4}{|c|}{$186_{5}$ Medical act } \\
\hline I875 & 767 & $596(78 \%)$ & I7I $(22 \%)$ \\
\hline I885 & 764 & $383(50 \%)$ & $38 \mathrm{I}(50 \%)$ \\
\hline I895 & 830 & $238(29 \%)$ & $592(71 \%)$ \\
\hline
\end{tabular}

Source: Van Lieburg and Marland I989:30I

midwives. Rivalry between obstetric practitioners with and without a degree increased with the introduction of general practitioners (artsen) with the Medical Act of 1865 . From that year, those who wanted to practice the medical profession had to pass a state exam. Candidates who succeeded were allowed to practice all branches of medicine. While the numbers of general practitioners increased rapidly (see table 3) the degree of obstetric doctor became insignificant and the qualification of man-midwife was abolished. Towards the end of the nineteenth century, obstetrics and gynecology became important again as specialties (Van Lieburg and Marland I989:304-305).

The expansion of biomedical approaches to obstetrics in the late nineteenth century affected the practice of midwifery. The Netherlands was already unusual in Europe in the degree to which midwives were trained and licensed. The midwife training and licensing system readily incorporated new biomedical learning. For example, after the rise of the germ theory of disease and the introduction of antisepsis in the r88os, antiseptic techniques were included in midwife training. This helped reduce the incidence of puerperal fever which was a leading cause of maternal deaths.

\section{Maternal Care in Taiwan}

As in the Netherlands, almost all births in colonial Taiwan were home births attended by midwives. Early in the research period, midwives qualified by experience, by learning from family members who were midwives, or by receiving training from Chinese medical doctors or Taoist practitioners (Hung \& Chen 2002:7; Yu 1993:50). We refer to these women as "traditional midwives" or "unlicensed midwives." The Japanese government, however, believed that traditional 
Medical practitioners

\begin{tabular}{|c|c|c|c|c|c|c|}
\hline & Totals & $M D *(\%)$ & $O D *(\%)$ & $S^{*}(\%)$ & $G P *(\%)$ & $M M^{*}(\%)$ \\
\hline c.I840 & 1920 & $84 \mathrm{I}(23 \%)$ & $268(7 \%)$ & $\mathrm{I} 453(40 \%)$ & - & IIO2(30\%) \\
\hline \multirow[t]{2}{*}{ I855 } & 2334 & IO22(24\%) & 475(І1\%\%) & $\mathrm{I} 422(34 \%)$ & - & $\mathrm{I} 268(30 \%)$ \\
\hline & \multicolumn{6}{|c|}{1865 Medical act } \\
\hline I866 & 2276 & $990(23 \%)$ & $586(13 \%)$ & $1639(36 \%)$ & $8(0.2 \%)$ & $\mathrm{I} 302(29 \%)$ \\
\hline I875 & $\mathrm{I} 774$ & $875(43 \%)$ & $?$ & IOIO(50\%) & I32(7\%) & $?$ \\
\hline $\mathrm{I} 885$ & $\mathrm{I} 883$ & $563(32 \%)$ & $?$ & $622(36 \%)$ & $556(32 \%)$ & $?$ \\
\hline 1895 & 2223 & $384(21 \%)$ & $?$ & $408(23 \%)$ & $1009(56 \%)$ & $?$ \\
\hline
\end{tabular}

Source: Van Lieburg and Marland I989:302

* MD medical doctor; OD obstetric doctor; S Surgeon; GP general practitioner; MM man-midwife.

midwives were not qualified to attend deliveries and were responsible for the high neonatal death rate. Medical authorities and educators subsequently recognized a need to improve maternal and infant health care, and took steps to improve the qualifications of midwives by educating and training young women to serve as licensed midwives. Therefore, from 1902 the government started to train and license midwives and to forbid traditional midwives to attend deliveries. However, even in the late colonial period, unlicensed midwives still attended most Taiwanese births. During the research period, the term 'midwife' refers to both traditional (unlicensed) and licensed midwives.

Traditionally, Taiwanese found midwives within their families and communities. Only rarely would people ask a total stranger to assist a delivery. Female family members, neighbor women and a traditional midwife might all attend a birth. They would set up a labor room in the home and equip it with a bed, a birth chair (生子/子孫椅), and a birthing tub (生子/子孫桶), and spread dry grass on the ground. As the time drew near the birth attendants would set up a fire pot and burn rice and salt, to produce a smoke believed to clean the room of unlucky influences (Hung \& Chen 2002:8-9). The attendants would also help the expectant woman prepare for the birth. Women about to deliver were anxious to bathe and wash their hair, as the traditional practice of 'sitting the month' mandated that they avoid bathing for a month following delivery (Gould-Martin I976:65).

Traditionally, mothers assumed a crouching position to deliver a baby. When the woman was ready to deliver, she would leave the bed, put one foot on the birth chair and bend her body forward. One of the women assisting her would stand behind the woman in labor to keep her in a standing position by holding her shoulders and back. The midwife or another birth attendant would 
stand in front of the woman to catch the baby, who would be caught in the birth

tub or land on soft grass laid out on the floor. After the birth the midwife would cut the umbilical cord by tying it tightly near the abdominal area with a piece of string and cutting it with cleaned scissors. The midwife then put sesame oil on the umbilical stump and wrapped the baby in the old, unwashed clothes of siblings, a custom that was believed to stimulate the growth of infants (Hung \& Chen 2002:8-9; Yu I993: 51).

If the birth involved a non-normal head presentation, a traditional midwife would try to massage the belly of the pregnant woman to turn the baby into the right position. If that did not work, the woman in labor was helped to sit on a so-called belly bucket (腰桶), which was believed to help the delivery, while a Taoist priest would perform a ritual and pray. If these measures failed, the traditional midwife would cut the woman's perineum to deliver the baby. Pulling the baby out by hand would be the last resort. In addition to fetal malpresentations, traditional midwives sometimes had to deal with retained placentas. They had specific rituals and customs to deal with complications like these, like putting an iron stick immersed in vinegar between the legs of the woman (Hung \& Chen 2002: 9-10)

Japanese period newspaper articles and doctors' observations were highly critical of the practice of traditional midwives and blamed them for endangering infant health (Hung \& Chen 2002:II-I6; Yu I993: 52). When training midwives began in 1902 the colonial government only trained Japanese women. But from the late I9Io's onwards, Taiwanese women were given the opportunity to be trained and licensed as midwives. However, the number of institutions training midwives was limited, and midwives who received a license mostly practiced in cities. To solve these problems, from the end of the I930's to the mid I940's, the government changed its policy of licensing midwives. The government authorized private hospitals to train midwives, and made it possible for traditional midwives to get licenses (Hung \& Chen 2002:32-35; Yu I993:60-63, Wu 2004:3-4). Table 4 shows the results of the gradually expanding midwife training and licensing efforts through the Japanese colonial period.

The training of new midwives included courses on anatomy, hygiene and bacteriology, nursing, first aid, antisepsis, normal and abnormal pregnancy, delivery, post-delivery care, and regulations governing the practice of midwifery. The training also included practical training and clinical experience (Hung \& Chen 2002: 90). Both a short course and a long course were offered; the longer course included greater classroom work. Three-day workshops were also offered to traditional midwives who, if they successfully completed the training, could receive restricted licenses (Yu I993: 54-63, Hung \& Chen 2002: 7I-73). Among those midwives who were licensed, some owned their own clinic and were allowed to practice their profession without any limitations but others were only allowed to 


\begin{tabular}{|c|c|c|c|c|c|}
\hline Year & Number & Year & Number & Year & Number \\
\hline I897 & 9 & I9II & I43 & 1925 & I033 \\
\hline I 898 & I2 & I9I2 & $26 I$ & 1926 & IO94 \\
\hline I899 & 26 & I9I3 & 235 & 1927 & IO7I \\
\hline 1900 & 35 & I9I4 & 264 & 1928 & II66 \\
\hline I9OI & 32 & I9I5 & 297 & 1929 & $\mathrm{I} 2 \mathrm{I} 5$ \\
\hline 1902 & 37 & I9I6 & 308 & 1930 & I29I \\
\hline 1903 & 40 & I9I7 & 345 & I93I & 1406 \\
\hline 1904 & 44 & I9I8 & 370 & 1932 & I524 \\
\hline 1905 & 68 & I9I9 & 385 & I933 & 1524 \\
\hline 1906 & 69 & 1920 & $4 \mathrm{OI}$ & I934 & $16_{3 I}$ \\
\hline 1907 & I03 & I92I & 423 & I935 & I66I \\
\hline I9०8 & 66 & 1922 & $4^{2 I}$ & 1936 & 1665 \\
\hline 1909 & $5^{\mathrm{I}}$ & 1923 & 408 & I937 & I747 \\
\hline I9Io & I26 & 1924 & 932 & 1938 & 1796 \\
\hline
\end{tabular}

Source: Yu I993:68. Table includes both Taiwanese and Japanese midwives.

practice midwifery in restricted areas. Other midwives were employed by the government or by hospitals. However they were employed, these various categories of midwives all practiced their profession in similar ways (Yu I993: 69-7I).

An important part of the duties of licensed Taiwanese midwives concerned health promotion, and the reform of traditional customs deemed unsanitary. Licensed midwives promoted deliveries from a prone position, clean bedclothes and clean clothes for the baby, and antiseptic treatment of the cord. The practice of licensed midwives influenced those of traditional midwives. Some traditional midwives began to bathe infants after delivery rather than wiping them clean by using old clothes or paper; they also learned to apply alum powder to the umbilical stump (Wu 20I0).

Prior to delivery, a licensed midwife was expected to check temperature, pulse, breath, and blood pressure, do a vaginal examination, get the pregnant woman's history, and make records of this information. Licensed midwives were asked to send these records to the local government monthly, where the records were used to study pregnant women's health status and also to supervise licensed midwives' practices. A licensed midwife would also teach pregnant women to use a pregnancy support belt. In some situations the midwife might use a pincette to break the water and bring on the delivery. During the delivery, a licensed midwife would try to prevent tearing of the pregnant woman's perineum. She also mas- 
saged the uterus to stimulate contractions, prevent bleeding and ensure expulsion of the placenta.

After a delivery, licensed midwives were trained to use sterilized scissors to cut the infant's umbilical cord, iodoform ointment to disinfect the umbilical cord and puerperal ulcers, alcohol and boric acid for papillary infections, and silver nitrate for neonatal ophthalmia. They were also trained to handle emergency situations, such as hemorrhage (Gould-Martin 1976: 64-65; Hung \& Chen 2002: 74-75). If there were complications of a sort which midwives were not allowed to treat, the midwife called in a doctor. However, some researchers report that licensed midwives would feel the belly of the woman who was about to give birth and massage it in case of non-normal head presentation. These methods were learned by experience or from traditional midwives, rather than from their training (Yu I999: 72). If the mother was torn during the delivery, the midwife sewed the wounds and would try to prevent infection. Although licensed midwives were aware of the importance of disinfection of their instruments (like scissors and needles) not all midwives had the equipment to do so (Yu I999:72).

Apart from caring for the mother, midwives cut the umbilical cord and gave the baby its first bath. They would make sure the mother knew how to take care of the baby, and would teach her how to breastfeed and wash the baby. In all these matters, health promotion was central. For instance, women who had given birth were traditionally confined to a room with closed windows and doors for fear of drafts. Midwives tried to promote fresh air and would stress the importance of a clean house. Finally, the midwife issued the birth certificate, which was used to register the birth. At first Taiwanese midwives could report stillbirths and complicated births, but in later periods this was done by a doctor (Yu I993:69-75).

Most previous studies focus on the role of licensed midwives in improving infant health, but they also reduced the risks to mothers. Comparing the activities of traditional and licensed midwives, there are four major differences. First, traditional midwives only assisted in delivery, but licensed midwives started their service prior to delivery. Licensed midwives did prenatal physicals, checked vital signs and recorded the readings. This increased the chances that complications would be recognized before delivery. Second, licensed midwives were trained to deal with emergencies that might arise during delivery. However, there is little evidence that licensed midwives had greater ability than traditional midwives to deal with complications, as they were required to refer such cases to doctors. Nevertheless the licensed midwives had greater knowledge and ability of new techniques to deal with emergency situations, such as hemorrhage, which must have saved some lives. Third, licensed midwives had greater knowledge of and made greater use of antisepsis than traditional midwives, which helped reduce the risks for both mothers and infants. Government-employed midwives, for example, were expected to have as basic equipment nail clippers and emery 
238 Table 5 Births per Licensed Midwives and Doctors, Taiwan I935 and the Netherlands I 875

\begin{tabular}{llllll}
\hline & $\begin{array}{l}\text { Licensed } \\
\text { Midwives }\end{array}$ & Doctors ${ }^{\mathrm{I}}$ & $\begin{array}{l}\text { Total live } \\
\text { births }^{2}\end{array}$ & $\begin{array}{l}\text { Total births } \\
\text { per midwife }\end{array}$ & $\begin{array}{l}\text { Total births per } \\
\text { professional }^{2}\end{array}$ \\
\hline Taiwan & I66I & I907 & 225980 & I39 & 65 \\
Netherlands & 767 & 2017 & I40967 & I84 & $5 \mathrm{I}$ \\
\hline
\end{tabular}

I. For Taiwan the number includes all licensed doctors, which includes some trained in traditional Chinese medicine; for the Netherlands the number includes MDs, surgeons and GPs.

2. Taiwan births are the average births I934-1936; Dutch births are the average births I874-1876

3. Professional includes licensed midwives and doctors.

Sources: Taiwan: Medical professionals from Taiwan Sōtokufu Tōkeisho; births from Taiwan jinkō dōtai tōkei; the Netherlands: van Lieburg and Marland I989:301,302 and Human Mortality Database.

boards, hand washing brushes, sterilizers, mercurochrome, iodoform, alcohol, lysol, and silver nitrate, all items for washing and disinfecting (Hung \&Chen 2002: 69). Fourth, although some licensed midwives provided health care for mothers and infants after delivery, traditional midwives customarily provided more assistance to new mothers.

Although the licensed midwives might provide mothers and infants with these benefits, most Taiwanese continued to rely on traditional midwives and called on trained midwives only in difficult cases (Gould-Martin I976: 62). Throughout the colonial period, most deliveries in Taiwan continued to be attended by midwives rather than doctors, and many of the midwives remained traditionally trained. From 1932 to 1940 physicians attended only $2 \%$ of births. In I 932 about $20 \%$ of the births were attended by licensed midwives; in I 940 the proportion had increased to $36 \%$. As late as I940, traditional midwives attended over 60\% of the births (Hung \& Chen, 2002: 136-7). Even after the colonial period midwives remained responsible for attending deliveries: in I957 for example $7.8 \%$ of births were attended by physicians, $\mathrm{I} 4.6 \%$ were attended by health station midwives, $40.8 \%$ were attended by private midwives and $36.8 \%$ by "unqualified personnel" (Weisheng tongji I98I: 230 table 49; 93 table 28).

Table 5 compares the numbers of licensed midwives and doctors and the number of births per professional in Taiwan 1935 and the Netherlands, I875. In colonial Taiwan since unlicensed midwives attended the majority of births, the ratio of total births to licensed midwives given in table 5 overstates the number of births attended per licensed midwife. In the Netherlands midwives shared the burden of attending births with doctors, so the ratio of births to professional is likely to be the better indictor of the availability of professional care for mothers. 


\section{Causes of maternal death}

The three most common causes of maternal mortality in the early twentieth century were puerperal fever, toxaemia and hemorrhage (Loudon I992: 43). Puerperal fever (also referred to as puerperal septicaemia) was perhaps everywhere the leading cause of puerperal deaths in the nineteenth century and early decades of the twentieth century.

Puerperal fever results from a bacterial infection of the uterus introduced in most cases during or after delivery. After a latent period the infection would spread, causing death to occur in the first or second week following delivery. Once the infection entered the uterine cavity it could spread out into the pelvic tissue, the peritoneal cavity, and the bloodstream. The most frequent causes of death were septicemia and the dreaded peritonitis, which caused intolerable pain (Loudon I992: 53-56). Induced abortion carried a high risk of introducing infections that would lead to sepsis. When the contagious nature of the infection was understood, it became recommended practice for birth attendants to adopt antiseptic methods in obstetrics, including disinfecting hands and instruments, shampooing, and using alcohol, carbolic acid and iodine (Loudon I992: 80, 204, 238). These preventive methods helped reduce maternal mortality in Western countries around the turn of the twentieth century, but could not entirely prevent the infection, which was also spread by asymptomatic carriers who might carry the bacteria in their respiratory tracts (Loudon I992: 8I, 238-39). Until the I930's treatment of cases of puerperal fever was limited to methods such as disinfectant douches which were rarely successful. Only when the antibiotic sulphonamides and penicillin were introduced in the late I930's and late I940's, respectively, did medical practitioners have a more effective weapon against the infection (Loudon I992: 254ff, 258).

The second of the three most common causes of maternal mortality in the early twentieth century appears in the international list under the title 'puerperal albuminuria and convulsions'; this title includes such terms as eclampsia, toxaemia, and nephritis of pregnancy. Loudon refers to the disease as puerperal toxaemia and hypertensive disease of pregnancy. The condition usually develops in the later months of pregnancy and is indicated by blurred vision and swelling of the legs (oedema), high blood pressure, and protein in the urine, a sign of damage to the kidneys. The condition may progress to convulsions (eclamptic fits), kidney failure and death. The disease is also associated with prematurity and underweight infants, and is a leading cause of fetal death. Toxaemia occurs more frequently in first pregnancies and in women over 35 . Only delivery can resolve the condition (Loudon I992: 85-86, 506).

There was no sure and effective way to prevent or treat toxaemia in the early twentieth century; only delivery (which might be induced at risk to the mother) would resolve the condition. In the I920's it became common in 
Western countries to recommend prenatal care in the belief that toxaemia could be prevented. Cases were identified through blood pressure and urinalysis, and bed-rest recommended, or labor induced (Loudon I992: 89-92)

The third of the three most common causes of maternal mortality in the early twentieth century appears in the international list under the title 'puerperal hemorrhage'; this title includes such terms as hemorrhage after labor, hemorrhage of uterus, and placenta praevia. In a normal birth, the contraction of the uterus after delivery expels the placenta and stops the flow of blood from the blood vessels lining the uterine wall. In cases where the placenta is retained or uterine contractions are weak, copious bleeding may lead to the death of the mother. Particularly vulnerable to this condition were women who had given birth many times before, and whose uterine contractions were too weak to stop the flow of blood (Loudon I992: 99). Other forms of puerperal hemorrhage arise before delivery. Hemorrhage may be caused when the placenta becomes partially detached during pregnancy, endangering the life of both mother and fetus. This condition is also most common in high parity mothers. Placenta praevia is a complication of childbirth that occurs when the placenta lies so low in the uterus that cervical dilation causes the placenta to detach and hemorrhage. This creates a dilemma: "the hemorrhage cannot be stopped until the baby and placenta are delivered, and the placenta stands in the way of delivering the baby" (Loudon I992: IOI).

In cases of postpartum hemorrhage, skilled birth attendants (midwives or physicians) may be able to induce uterine contractions through external manipulation of the uterus or by a riskier procedure involving manual removal of the placenta (Loudon I992: 97, 99). The chances of successful treatment of pre-partum hemorrhage were much lower in the early twentieth century. Attempts to treat placenta praevia involved turning the baby in the uterus, and pulling down both legs to deliver as a breech. Since the I930's caesarian section has become the preferred treatment for placenta praevia (Loudon I992: IOI-IO2). Blood transfusions, used to replenish blood lost due to hemorrhage, became more widely available during World War II (Loudon I992: 27I, 257).

In addition to the three leading causes, a variety of other conditions lead to maternal deaths. These come under headings such as thrombosis and pulmonary embolus (most commonly postpartum), 'other accidents of labor' and 'accidents of pregnancy.' Accidents of labor included maternal deaths resulting from breech presentation, injuries in delivery, protracted labor, deformed pelvis, and cesarean section. Accidents of pregnancy concerned deaths due to ectopic pregnancies, abortions, and premature delivery.

\section{Cause-of-death registration in the Netherlands}

With the introduction of a national system of death registration in I8II, municipalities were required to keep a register of deaths, including name and surname 
of the deceased as well as age, occupation, municipality of residence and hour and day of death (but not cause). As elsewhere in Europe the call for national registration of cause of death grew louder, particularly among Dutch hygienists, in the middle of the Igth century. The 1865 Medical Act, in addition to regulating midwives, required doctors to report the cause of death of a deceased. With the introduction of the Burial Act of 1869 cause-of-death registration became decisively regulated as from that year onwards, no person could be buried without a cause of death report (Van Sonsbeek 2005:I6).

From I866 to I90I, a medical state commission published cause-of-death data on the Netherlands annually. From I90 onwards the CBs (Statistics Netherlands) published the data. From 1867 to 1874 , the commission reported maternal mortality as one cause of death and did not distinguish between sub-causes. From I875 to I902, maternal deaths were reported under two categories: puerperal fever and 'deaths from other diseases of pregnancy and maternity'. Only from I903 onwards did the CBS publish the deaths from all sub-categories in addition to these two main maternal mortality categories.

The quality of cause of death reporting gradually improved. Initially, the proportion of reports stating an unknown cause of death was high (I3 per cent in I868) as was the proportion of 'death without medical treatment'. Towards the end of the igth century these proportions declined and doctors certified causes for almost 95 per cent of deaths. Of course the system for cause of death registration was far from perfect. "It was in particular the conversion of the diagnosed pathological process into a medical certificate of cause of death which was riddled with imperfections," as Van Poppel and Van Dijk explain (Van Poppel and Van Dijk I997:273). Attempts to improve the system and classification were continuously made. In the I920s more detailed questions on the cause of death - information on the primary, secondary and the concomitant disease - were added to the death certificate, which significantly improved the quality of mortality statistics

\section{Cause of Death Registration in Taiwan}

Statistics of deaths by cause are reported in the Vital Statistics volumes for Taiwan from I905 to I942 (Taiwan jinkō dōtai tōkei). The quality of cause of death certification was initially low due to the scarcity of qualified medical personnel, but gradually improved as Taiwan began to train and license an increasing number of medical doctors. The proportion of deaths related to childbirth certified by trained medical professionals increased to more than $60 \%$ by 1920 and $80 \%$ by 1930 (Shepherd 2002: 4). From I905-I9I5 maternal deaths were reported under only two headings, puerperal fever and other maternal causes, but from I9I6 more detailed lists distinguished maternal deaths among the major headings of puerperal fever, toxemias, hemorrhage, accidents of birth and other causes. 
For both countries, this study is able to complement measures derived from aggregated vital statistics data (such as the cause of death reports discussed above) with measures based on samples of individual register-based data.

The Dutch sample data used in this research are from the Historical Sample of the Netherlands (HSN 2007). The point of departure in this sample is not the household but the so-called 'research person', a historical subject whose birth registration was randomly selected and whose life was then traced through the population registers of the entire country. Data-entry included all household members of this research person. Households and their members were entered, as the research person is a part of the household. The research person as well as household members might be followed from birth to death or only for a portion of their lives, when observation was interrupted, for example due to emigration.

The sample from the HsN data release used for this research concerns two periods: life courses from the birth period I850-I922 from the provinces of Friesland, Zeeland, Utrecht and the city of Rotterdam and life courses from the birth period I883-I922 from the rest of the country. From this sample, 85,057 children born between I850 and I899 were linked to their mothers and information was retrieved on the period of observation of both. Most births are concentrated towards the end of the research period. In addition, births from the province of Friesland are overrepresented in this sample.

The Taiwan sample data used in this paper is drawn from household registers (1906-1945) maintained during the Japanese colonial period. Registers from nineteen sites throughout Taiwan have been entered into a household register database by the Project for Historical Demography, Academia Sinica. The household register (HR) data used here is drawn from a combined sample pooling all births and deaths from ig individual sites. The point of departure for the Taiwan data is the locality, rather than the individual; we only observe those portions of any individual's life that occurred while the individual was present and registered in a household located in one of the sites. Births and maternal deaths (or survival) are included in our sample only if a mother remains under observation (does not move beyond the confines of a village site) from the day of birth until the earlier of her death or the ninetieth day following the birth. Estimates of infant survival in connection with the survival of mothers are made only for infants remaining under observation from birth to the day of death or the end of the first year of life.

In both the Dutch and Taiwan register data, we identify maternal deaths (as cause of death is not reported in the sample data) as those deaths of mothers who die within 90 days of giving birth; thus we use a more liberal criterion than the more stringent 42 days often used in such studies (Knodel I988: I02-5). Undoubtedly this procedure includes deaths that were not related to maternal 
causes, but that number is likely to be small; only small proportions of total maternal deaths fall beyond 30 days (see tables II A and IıB, below). Also small in number are maternal deaths excluded because they occurred beyond the 90day window. However, a larger number of excluded maternal deaths were those related to stillbirths, abortions, and unregistered births, which we have no way of including because these events were not reported in the registers. Relatively low numbers of maternal and infant deaths in the first days following birth in the Dutch sample (Tables IIB and IID below) can be related to the fact that in several communities registration in the population registers (used for the HSN database) did not immediately follow registration in the civil registers (Kok 2006). In such communities, children dying at a very early age were entered only in the civil registers and not in the population registers and we therefore cannot link their mother's death to their birth.

As noted above, both the Dutch and the Taiwan vital statistics reported cause of death data for the relevant periods. We use vital statistics data in conjunction with census counts of population to compute death rates by period and by age for maternal causes. The registration of deaths and births in the whole of the Netherlands has covered the entire nation since I8I5. Census counts of the Dutch population have been available since 1895 . The historical data on the population, deaths and births between I850 and I950 were adjusted by the Netherlands Interdisciplinary Demographic Institute (NIDI) and included in its mortality database (Tabeau, van Poppel and Willekens I994). The NIDI database formed the base of the Dutch data in the online-available Human Mortality Database (HMD). The population count data, death count data and birth count data on the whole of the Dutch population used in this paper are downloaded from that database.

The first modern census of Taiwan was taken in 1905, which also inaugurated the beginning of the household registration system and the publication of annual vital statistics which continued until I942. Censuses were taken in I905, and every five years from I9I5 to I940.

We can check the degree to which our method of identifying maternal deaths results in under- or overcounts by comparing rates based on our registerbased counts to those based on counts of maternal deaths in the cause of death data. As graph IA (see table 6 in the appendix) shows, the sample from the Taiwanese registers seriously underestimates maternal mortality rates for the early period in particular (I906-I9I5). As birth reporting in the case of nonsurviving neonates improved, we are better able to identify maternal deaths in the registers, and the register based maternal mortality rates converge toward the rates based on cause of death reports. (The Taiwan register database appears to underrepresent the highest mortality areas, as a comparison of death rates I5-49 in graphs $2 \mathrm{~A}$ and $2 \mathrm{C}$ reveals.) A comparison between Dutch maternal mortality 

statistics and register samples, deaths per Io,००० live births

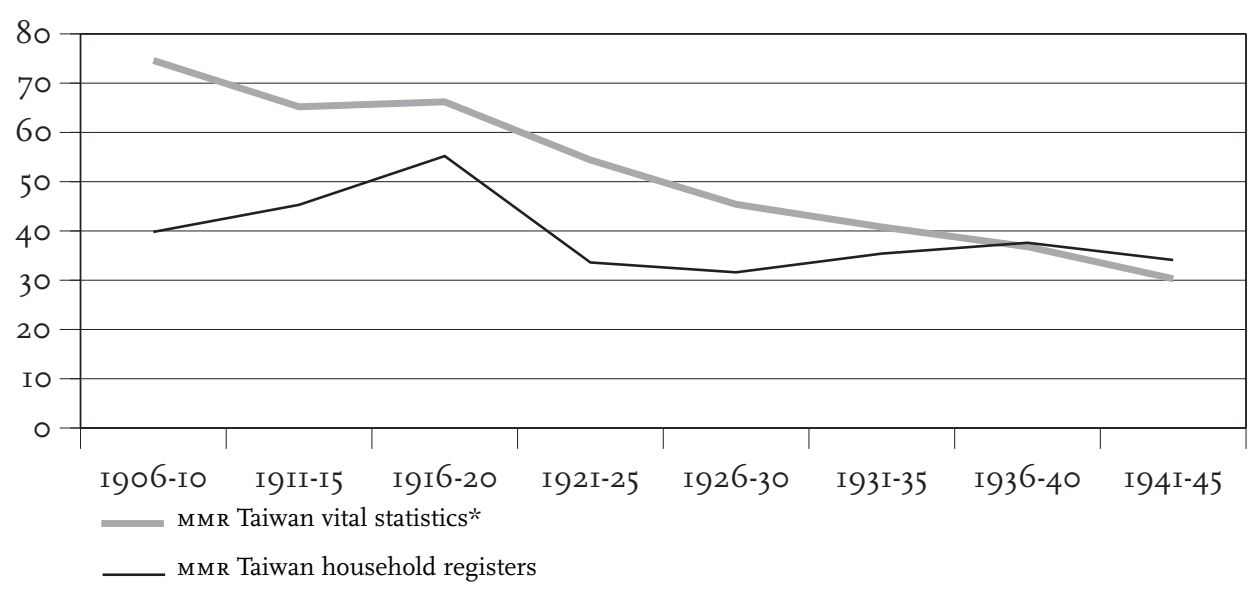

* Source: Shepherd 2002: 31. See Table 6, Appendix.

Graph IB. Maternal mortality rates the Netherlands I85I-I920 based on vital statistics and register samples, deaths per Io, 000 live births

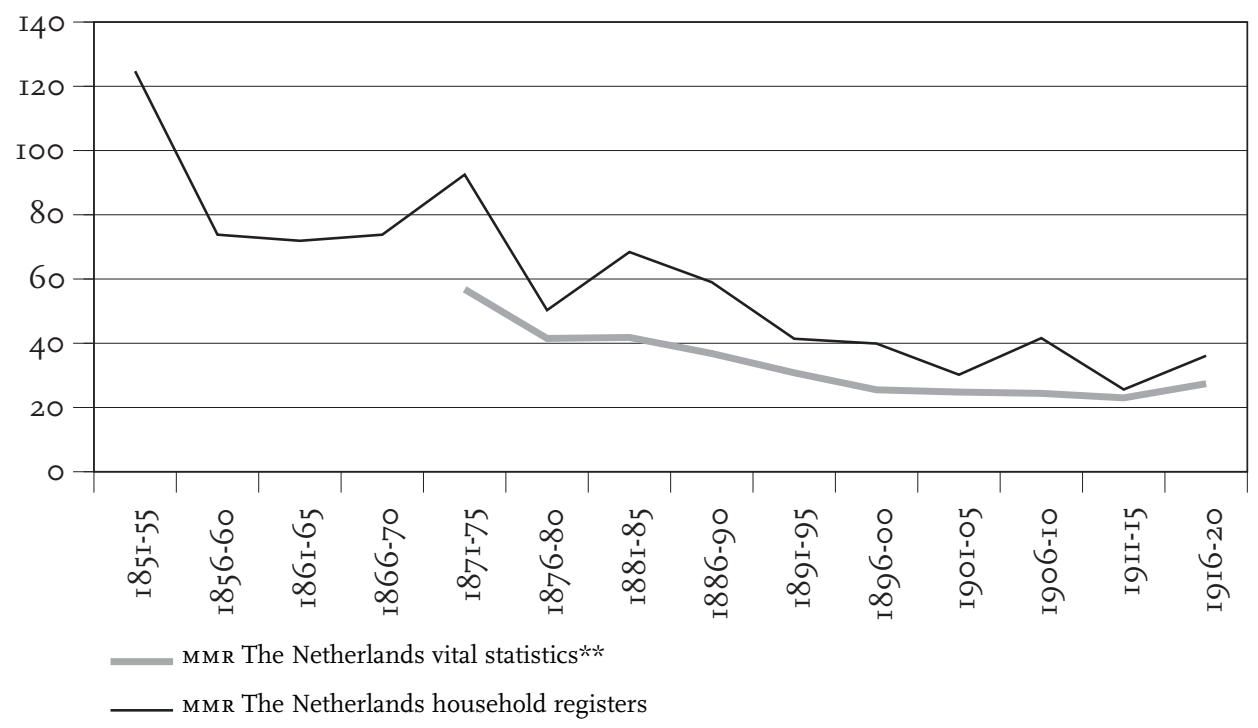

** Source: Geneeskundig Staatstoezicht I87I-I9or. See Table 6, Appendix. 


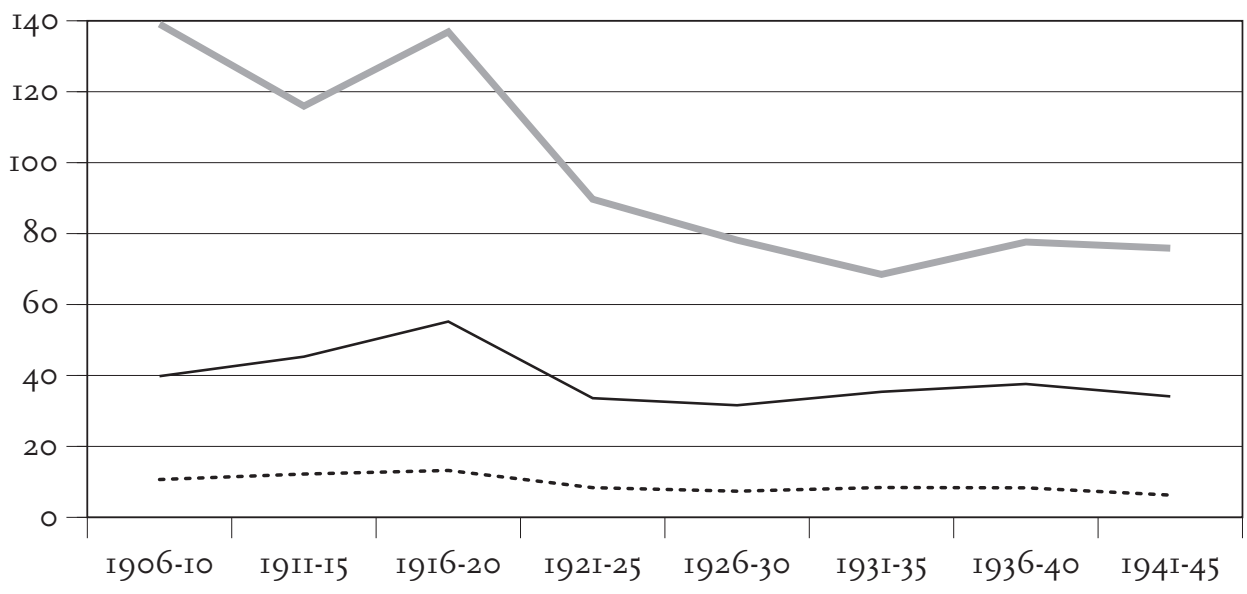

Female deaths per I0,000 women- years I5-49 __ Maternal deaths* per Io,000 live births Maternal deaths per Io,000 women- years I5-49

* Deaths within 90 days of delivery. See Table 7A, Appendix.

\section{Graph 2B. Measures of Female Mortality in the Netherlands (HSN data I850-1920)}

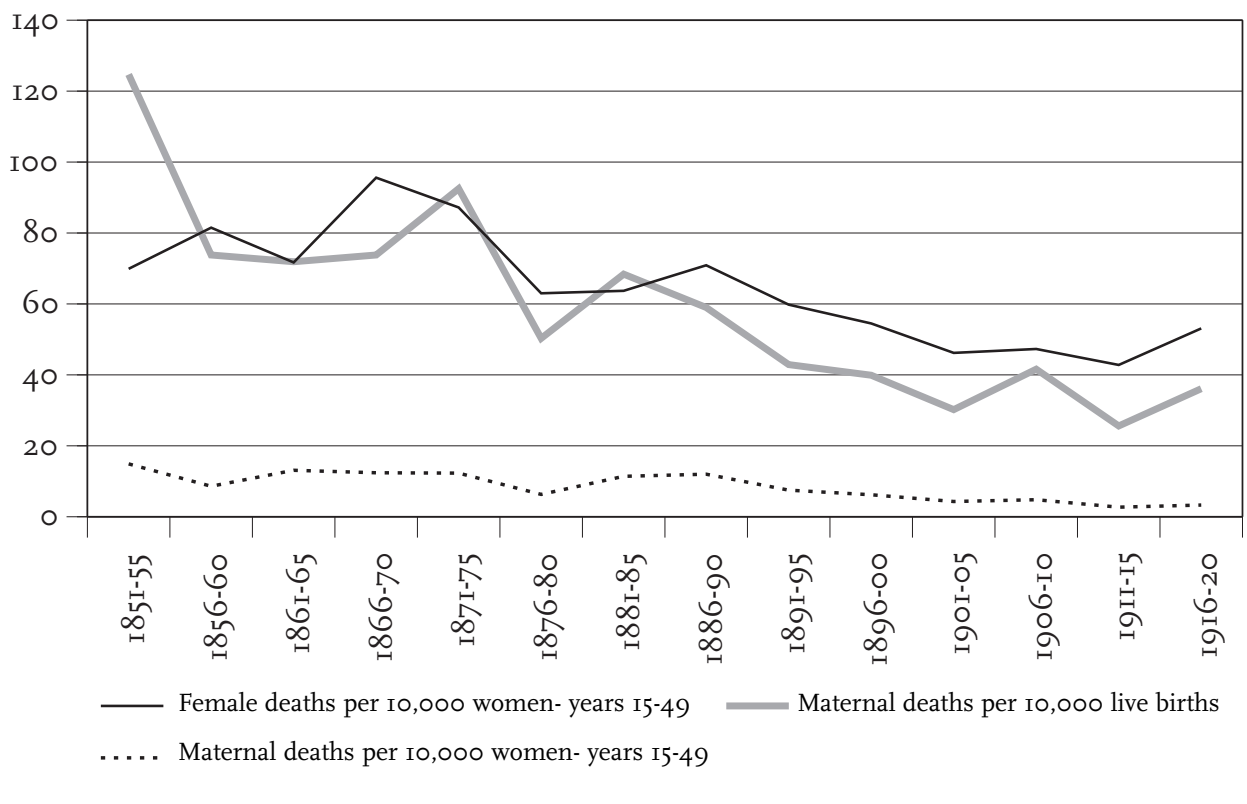

See Table 7B, Appendix. 
rates based on cause-of-death data and sample rates (graph IB, see table 6 in the appendix) also shows discrepancies, but here the register sample reports higher rates than the vital statistics. In this case it appears our method of identifying maternal deaths in the Dutch sample includes deaths that the vital statistics does not consider maternal deaths.

\section{Maternal mortality}

We turn now to a general overview of the levels of maternal mortality in Taiwan and the Netherlands in our research periods. Graphs 2A and B (see tables $7 \mathrm{~A}$ and $\mathrm{B}$ in the appendix) present for the household register samples the five-year average rates of mortality among fertile-age women (I5-49) from all causes and from maternal causes in Taiwan (I906-I945) and in the Netherlands (I85I-I920).

In the register samples, female deaths from all causes per Io000 women I5-49 fell from I39.072 to 75.88 in Taiwan (I906-I945) and from 69.9 to 42.8 in the Netherlands (I85I-I9I5). Maternal deaths per Ioo०o women I5-49 fell from I0.66 to 6.27 in Taiwan and from I4.9 to 2.7 in the Netherlands. Maternal deaths per I0000 births fell from 39.8 to 34. I in Taiwan and from I24.7 to 25.6 in the Netherlands. These overall declines were not as smooth as our summary suggests but were interrupted by several factors that caused temporary increases. In the Netherlands, epidemics, smallpox in I858 and I87I, and cholera in I866-7 (Van Poppel and Beekink 2003:73), caused these rates to rise before they started a gradual decline. In both populations, female mortality increased due to the worldwide Spanish influenza epidemics, I9ı8-1920. The low maternal mortality shown in the register data for Taiwan in I906-I9Io - only 39.8 maternal deaths per Io,0०० births - is caused by our inability to link maternal deaths to unreported births of unregistered non-survivors. Improved registration of births helps explain the increase in maternal deaths per ı०,০০০ live births in the register data to a high of 55.2 in I9I6-I920.

Graphs $2 \mathrm{C}$ and 2D, based on census and vital statistics reports (see tables $7 \mathrm{C}$ and $\mathrm{D}$ in the appendix), present a parallel set of mortality rates for fertile-age women ( 15 -49) from all causes and from maternal causes for the entire populations of Taiwan (I906-I94I) and the Netherlands (I87I-I920). In these tables maternal deaths are identified from the cause of death reports from the annual vital statistics published in each country. These data confirm the trends identified in the household register based samples. Vital statistics for our periods show that female deaths from all causes per I000o women I5-49 fell from I89.7 to 69.5 in Taiwan and from I03.4 to 44.9 in the Netherlands (prior to the influenza epidemic). Maternal deaths per I0000 women I5-49 fell from I3.3 to 6.6 in Taiwan and from 8.4 to 2.6 in the Netherlands. Maternal deaths per Ioooo births fell from 75.5 to 32.6 in Taiwan and from 56.4 to 23 in the Netherlands.

The vital statistics data confirm that deaths from maternal causes rose 

data, 1906-1945)*

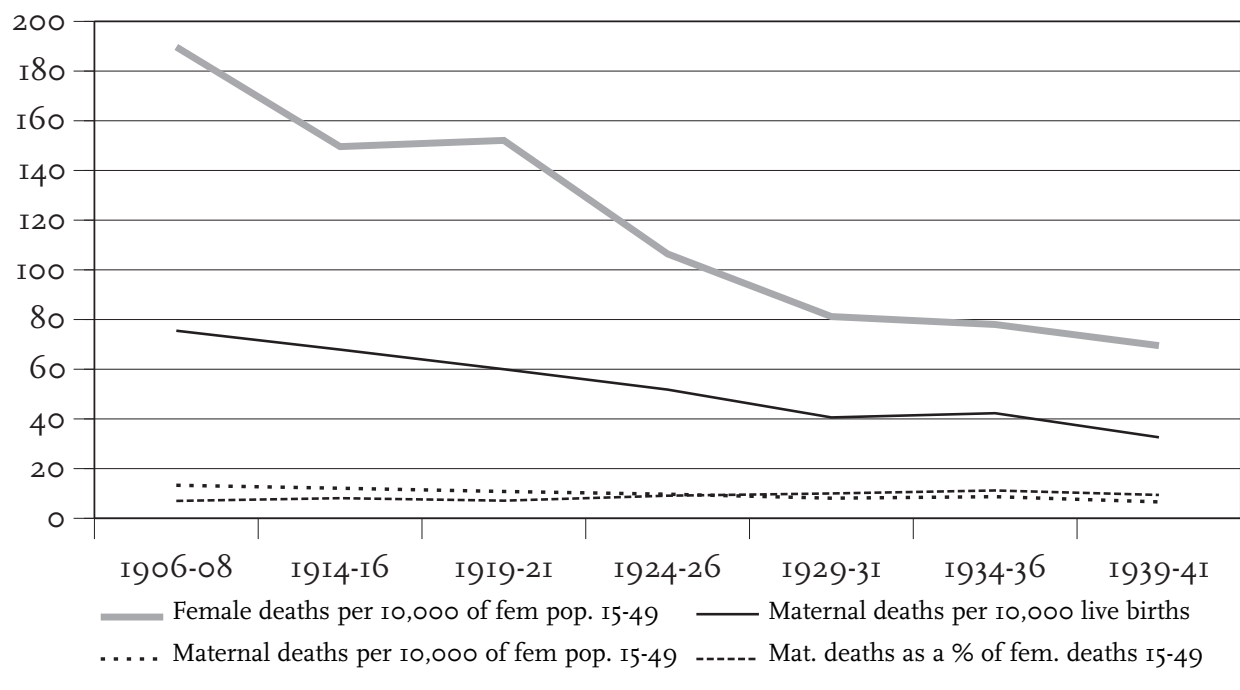

* Figures represent a three-year average around census years, with the exception of I906-8.

Live births have been corrected for unregistered nonsurvivors in the period I906-I9I5. Maternal deaths identified in cause of death reports, corrected I920-29 as detailed in Shepherd 2002: 22. See Table 7C, Appendix.

\section{Graph 2D. Measures of Female Mortality in the Netherlands (vital statistics, I87I-} 1920)

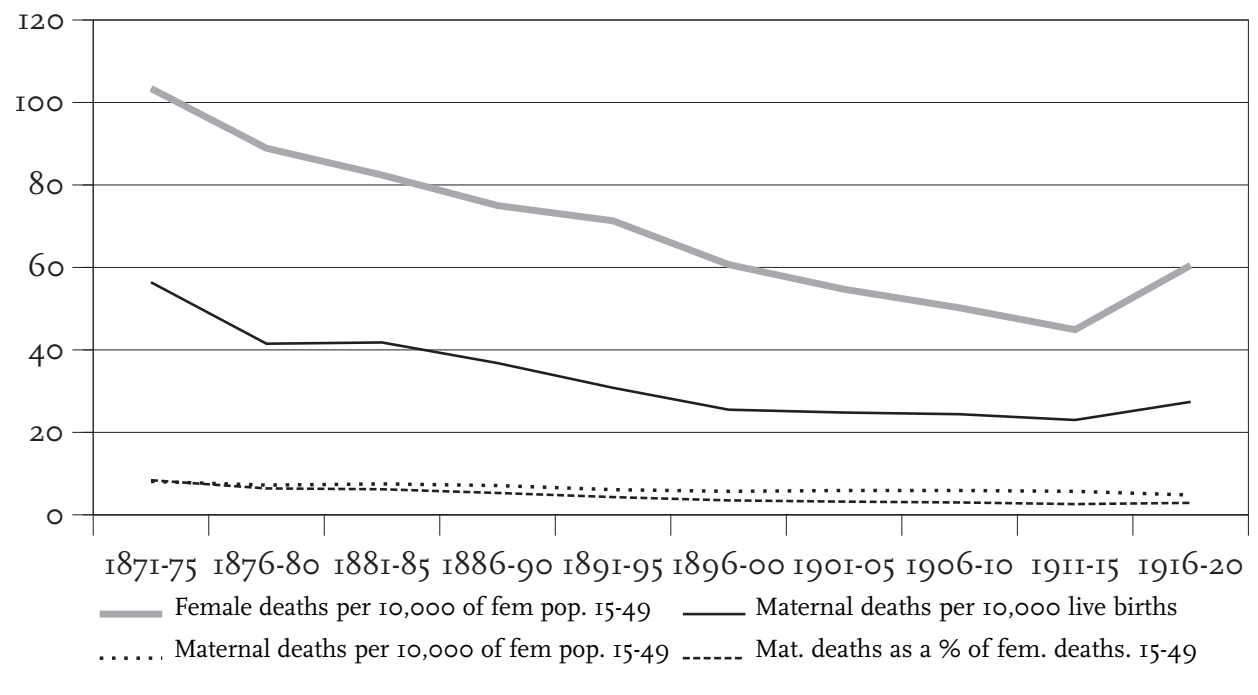




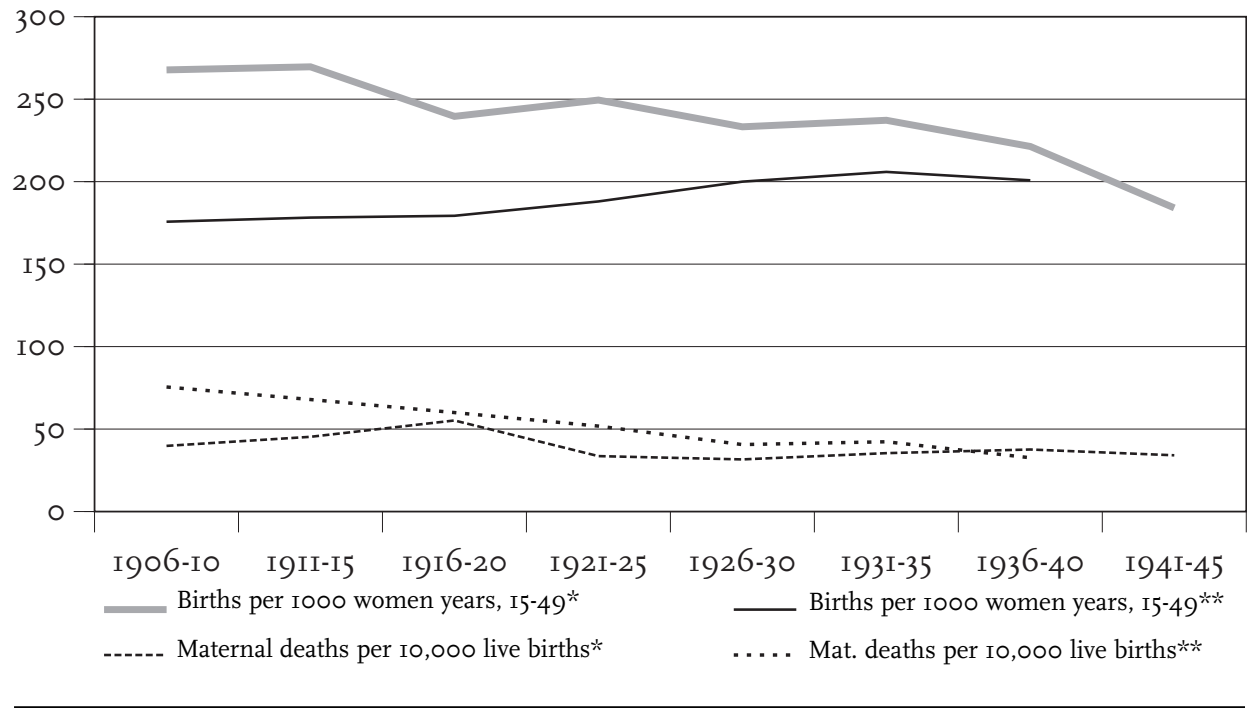

* Register sample ** Census and vital statistics data. See Tables ${ }_{7} \mathrm{~A}$ and $7 \mathrm{C}$, Appendix.

\section{Graph 2F. Trends in Fertility and Maternal Mortality, The Netherlands}

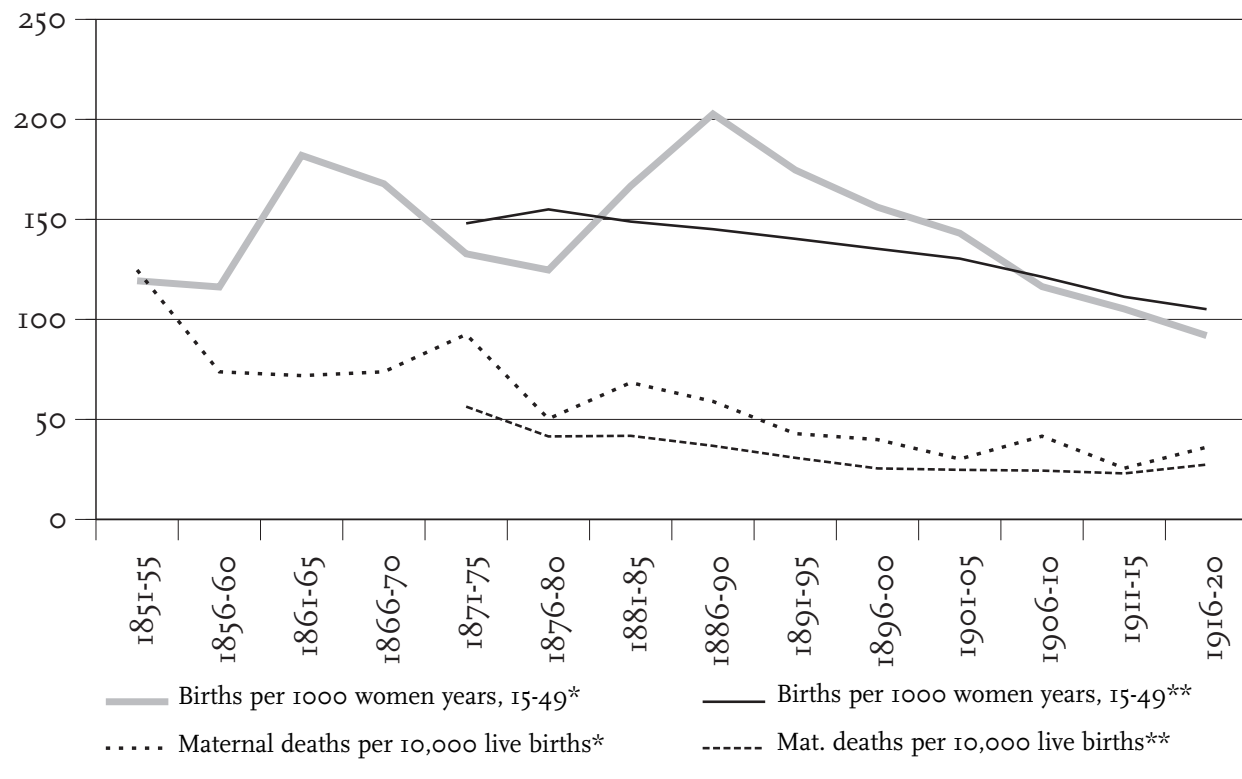

* HSN Register sample ** Census and vital statistics data. See Tables $7 \mathrm{~B}$ and $7 \mathrm{D}$, Appendix. 
Years.

\begin{tabular}{llllll}
\hline Year & $\begin{array}{l}\text { Maternal } \\
\text { Deaths }\end{array}$ & $\begin{array}{l}\text { Puerperal } \\
\text { Fever }\end{array}$ & $\begin{array}{l}\text { Puerperal } \\
\text { Hemorrhage }\end{array}$ & $\begin{array}{l}\text { Puerperal } \\
\text { Toxemia }\end{array}$ & Other \\
\hline I924-34 & 9225 & 3194 (34.6\%) & $3557(38.6 \%)$ & $756(8.2 \%)$ & I7I8 (I8.6\%) \\
$1935-42$ & 6815 & $2253(33.1 \%)$ & $2574(37.8 \%)$ & $1025(15.0 \%)$ & $963(\mathrm{I} 4.1 \%)$ \\
\hline
\end{tabular}

Source: Shepherd 2002:I3.

Table 8B. Maternal Deaths by Leading Causes, the Netherlands, Vital statistics.

\begin{tabular}{|c|c|c|c|c|c|}
\hline \multirow[t]{2}{*}{ Year } & \multirow{2}{*}{$\begin{array}{l}\text { Maternal } \\
\text { Deaths }\end{array}$} & \multirow{2}{*}{$\begin{array}{l}\text { Puerperal } \\
\text { Fever }\end{array}$} & \multicolumn{3}{|c|}{ Other diseases of pregnancy and maternity } \\
\hline & & & Hemorrhage & Toxemia & Other \\
\hline I87I-75 & $38 \mathrm{I} 8$ & n.a. & & n.a. & \\
\hline I876-80 & 3033 & $98 \mathrm{I}(32.3 \%)$ & & $2052(67.7 \%)$ & \\
\hline I88I- 85 & 3099 & 9IO $(29.4 \%)$ & & $2189(70.6 \%)$ & \\
\hline I886-90 & 2809 & $920(32.8 \%)$ & & $1889(67.2 \%)$ & \\
\hline I89I-95 & 2423 & $883(36.4 \%)$ & & $1540(63.6 \%)$ & \\
\hline I896-00 & 2096 & $575(27.4 \%)$ & & I52I (72.6\%) & \\
\hline I9OI-05 & $2 \mathrm{IO} 3$ & $634(30.1 \%)$ & & $1469(69.9 \%)$ & \\
\hline I906-10 & 2083 & $616(29.6 \%)$ & $442(2 \mathrm{I} .2 \%)$ & $312(15.0 \%)$ & $7 \mathrm{I} 3(34.2 \%)$ \\
\hline I9II-I5 & 1964 & $579(29.5 \%)$ & $464(23.6 \%)$ & $407(20.7 \%)$ & $5 \mathrm{I} 4(26.2 \%)$ \\
\hline I9I6-20 & 2398 & $833(34.7 \%)$ & $5 \mathrm{I} 6(2 \mathrm{I} .5 \%)$ & $527(22.0 \%)$ & $522(2 \mathrm{I} .8 \%)$ \\
\hline
\end{tabular}

* includes milk leg. Source: Geneeskundig Staatstoezicht I87I-I90I; cBS I90I-I920

from $7 \%$ to $9 \cdot 5-11 \%$ of total deaths to Taiwanese women, age I5-49, and declined from $8 \%$ to $5 \%$ of total deaths to Dutch women. While the proportion of total female deaths 15-49 attributed to maternal causes increases in Taiwan over the period, it decreases in the Netherlands. This suggests that in Taiwan greater progress was achieved in dealing with non-maternal causes, while in the Netherlands, maternal causes declined at a faster rate than non-maternal causes. These trends in maternal mortality must also be seen against the background of changes in fertility rates over the period. Graph $2 \mathrm{E}$ shows the general fertility rates (births per I,000 woman years 15-49), and the maternal mortality rates (maternal deaths per 10,000 live births) for Taiwan from both the register sample and the vital statistics (tables $7 \mathrm{~A}$ and $7 \mathrm{C}$ ). The vital statistics measures show the decline in maternal mortality was achieved in Taiwan despite the rise in fer- 

Statistics I940-42.

\begin{tabular}{|c|c|c|c|c|c|c|c|}
\hline $\begin{array}{l}\text { Mother's } \\
\text { Age }\end{array}$ & $\begin{array}{l}\text { Live } \\
\text { births }\end{array}$ & $\begin{array}{l}\text { Still- } \\
\text { births }\end{array}$ & $\begin{array}{l}\text { Maternal } \\
\text { Deaths } \\
\text { Total }\end{array}$ & $\begin{array}{l}\text { Deaths } \\
\text { due to } \\
\text { puerperal } \\
\text { fever }\end{array}$ & $\begin{array}{l}\text { Deaths } \\
\text { due to } \\
\text { puerperal } \\
\text { hemorrhage }\end{array}$ & $\begin{array}{l}\text { Deaths } \\
\text { due to } \\
\text { puerperal } \\
\text { toxaemia }\end{array}$ & $\begin{array}{l}\text { Other } \\
\text { Maternal } \\
\text { causes }\end{array}$ \\
\hline I5-I9 & 25017 & 1084 & 82 & $32(39 \%)$ & $24(29 \%)$ & I9 (23\%) & $7(9 \%)$ \\
\hline $20-24$ & 67152 & 2436 & I49 & $45(30 \%)$ & 6I (4I\%) & 24 (I6\%) & I9 I3\%) \\
\hline $25-29$ & 60647 & I900 & I29 & $48(37 \%)$ & $43(33 \%)$ & I9 (I5\%) & I9 (I5\%) \\
\hline $30-34$ & 47129 & I49I & I47 & $45(31 \%)$ & $56(38 \%)$ & $22(\mathrm{I} 5 \%)$ & 24 (I6\%) \\
\hline $35-39$ & 29534 & 1042 & I49 & 42 (28\%) & 65 (44\%) & I8 (I2\%) & 24 (I6\%) \\
\hline $40-44$ & II 248 & 438 & 83 & I9 (23\%) & 47 (57\%) & 9 (II\%) & 8 (го\%) \\
\hline $45-49$ & 913 & $5^{\mathrm{I}}$ & 9 & $2(22 \%)$ & $4(44 \%)$ & I (II\%) & $2(22 \%)$ \\
\hline All ages & 241640 & 8442 & 748 & 233 (31\%) & 300 (40\%) & II2 (15\%) & IO3 (I4\%) \\
\hline
\end{tabular}

Table 9B. Maternal Mortality Rates by Age of Mother, Taiwan, I940-42.

\begin{tabular}{|c|c|c|c|c|c|c|}
\hline Mother's Age & $\begin{array}{l}\text { MMR per } \\
\text { 10,00o total } \\
\text { births all } \\
\text { gestations }\end{array}$ & $\begin{array}{l}\text { MMR per } \\
\text { 10,000 } \\
\text { live births }\end{array}$ & $\begin{array}{l}\text { Deaths due } \\
\text { to puerperal } \\
\text { fever, per } \\
\text { 10,ooo live } \\
\text { births }\end{array}$ & $\begin{array}{l}\text { Deaths due } \\
\text { to puerperal } \\
\text { hemorrhage, } \\
\text { per 10,000 } \\
\text { live births }\end{array}$ & $\begin{array}{l}\text { Deaths } \\
\text { due to } \\
\text { puerperal } \\
\text { toxemia, } \\
\text { per 10,000 } \\
\text { live births }\end{array}$ & $\begin{array}{l}\text { Deaths } \\
\text { due to } \\
\text { other maternal } \\
\text { causes, } \\
\text { per 10,000 } \\
\text { live births }\end{array}$ \\
\hline I5-I9 & $3 \mathrm{I} \cdot 4$ & 32.8 & I 2.8 & 9.6 & 7.6 & 2.8 \\
\hline $20-24$ & $2 \mathrm{I} .4$ & 22.2 & 6.7 & 9.I & 3.6 & 2.8 \\
\hline $25-29$ & 20.6 & 2I.3 & $7 \cdot 9$ & 7.I & $3 . \mathrm{I}$ & $3 . I$ \\
\hline $30-34$ & 30.2 & $3 \mathrm{I} .2$ & $9 \cdot 5$ & II.9 & 4.7 & 5.I \\
\hline $35-39$ & 48.7 & 50.5 & $\mathrm{I} 4.2$ & 22.0 & 6.I & 8.I \\
\hline $40-44$ & 7I.० & 73.8 & 16.9 & 4I. 8 & 8.0 & 7.I \\
\hline $45-49$ & 93.4 & 98.6 & 21.9 & 43.8 & II.O & 21.9 \\
\hline All Ages & 29.9 & 31.0 & 9.6 & I2.4 & 4.6 & $4 \cdot 3$ \\
\hline
\end{tabular}

tility from I906 to 194I. The register data implies a decline in fertility took place over the period in the I9 sample sites, contrary to the usual expectation.

Graph 2F shows the general fertility rates (births per I,000 woman years I5-49), and the maternal mortality rates (maternal deaths per ı०,००० live births) for the 
Vital Statistics 1920

\begin{tabular}{llllll}
\hline Mother's Age & $\begin{array}{l}\text { Maternal } \\
\text { Deaths Total }\end{array}$ & Puerperal Fever & Hemorrhage & Toxemias* & Other Causes \\
\hline I5-19 & 6 & I (I7\%) & $0(0 \%)$ & $3(50 \%)$ & $2(33 \%)$ \\
$20-29$ & I52 & $58(38 \%)$ & $20(13 \%)$ & $46(30 \%)$ & $28(\mathrm{I} 8 \%)$ \\
$30-39$ & 231 & $85(37 \%)$ & $50(22 \%)$ & $49(21 \%)$ & $47(20 \%)$ \\
$40-49$ & 78 & I8 (23\%) & $25(32 \%)$ & $20(26 \%)$ & I5 (19\%) \\
All Ages & 467 & I62 (34\%) & $95(20 \%)$ & II8 (25\%) & $92(20 \%)$ \\
\hline
\end{tabular}

* includes milk leg.

Netherlands from both the register sample and the vital statistics (tables $7 \mathrm{~B}$ and ${ }_{7 D}$ ). Both sets of measures indicate a decline in general fertility by the beginning of the twentieth century, that paralleled the decline in maternal mortality. This suggests that part of the decline in maternal mortality in the Netherlands is to be attributed to fewer high risk births connected to high parity, close spacing, and advanced age associated with high levels of fertility.

Tables 8A and B present numbers of maternal deaths broken down by leading causes of maternal mortality for Taiwan and the Netherlands from vital statistics cause of death reports. These illustrate the relative importance of each of the three leading causes of maternal deaths in our populations, as well as changes over time in the salience of the various causes. As the tables show, deaths due to puerperal fever accounted for about one third of all maternal deaths in both Taiwan and the Netherlands. Puerperal hemorrhage seems to have been lower in the Netherlands than in Taiwan, while toxemias (albuminuria and milk leg) were a higher proportion of total maternal deaths in the Netherlands. Differences in the frequency of the different causes indicate different conditions in the two countries, and perhaps different skill levels in the midwives delivering the infants. The lower proportion of maternal deaths attributed to puerperal hemorrhage in the Netherlands in the twentieth century compared to Taiwan may indicate that Dutch professionals (whether midwives or doctors) were more successful in countering the dangers of hemorrhage. However, lower fertility rates in this period in the Netherlands may also have reduced the number of high-risk births that were prone to hemorrhage. Despite the training in antisepsis for licensed midwives in both countries, the proportion of total maternal deaths attributed to puerperal fever changes very little over the periods. This does not rule out a contribution of antisepsis to the overall decline in maternal mortality rates in the periods, but suggests that progress against puerperal fever did not come at a faster pace than progress against the other maternal causes. 
Tables 9A, B and C and show the frequency of the different causes of maternal deaths by age of mother for Taiwan and the Netherlands from vital statistics cause of death reports. These illustrate the relative importance of each of the three leading causes of maternal deaths according to the age of the mother. [We are unable to compare rates between the two populations, as unfortunately the number of live births and stillbirths by age of mother are not available for the Netherlands for the research period.] In both populations deaths due to puerperal hemorrhage as a proportion of total deaths increase significantly with age. The proportion of maternal deaths due to puerperal fever while significant at all ages, declines somewhat at higher ages. The proportion of deaths due to toxemias is highest among younger aged mothers. In Taiwan where vital statistics data reporting births by age of mother are available for I94I-42, we can compute maternal mortality rates per Io, , o live births. As expected, maternal mortality shows a J-shaped curve of mortality, with a lesser peak in the youngest age group, and a significant increase beginning with the $35-40$ age group rising to a peak in the 45-49 age group. The maternal mortality rates for Taiwan confirm the significant rise in the risk of puerperal hemorrhage with age.

\section{Sex Differential Mortality, Taiwan and the Netherlands}

It is often assumed that maternal mortality leads to an excess of female over male mortality in the childbearing ages, $\mathrm{I5}-49$. How did female mortality compare to male mortality in the two countries? Graph 3 (see tables IoA, B, C and D in the appendix) shows the sex ratio of mortality by age group for Taiwan (I906I945) and the Netherlands (1850-I920), based on household register data and on census and vital statistics data. Although the crude death rates (combining all age groups) for both countries and both sexes are very close in the periods under consideration, the patterns of sex differential mortality are quite different. In Taiwan, male mortality was higher than female mortality in all age groups between 15 and 49. Male survival chances were particularly lower than those of females among the higher age groups, 40-49. The Taiwan male disadvantage persisted in ages $15-49$ despite the added risk of maternal mortality for females, and contrasts sharply with the Dutch pattern. For age groups 2529 to 40-44, the Netherlands shows an excess female mortality, which is not entirely to be ascribed to maternal mortality. A study of excess female mortality among German adults in the late I8th and I9th centuries showed that the addition of a child increased the mother's mortality by more than twice the amount of the father's - even though maternal mortality was excluded (Klasen I998). This difference was caused by heavy labor, restrictions on mobility, maternal depletion, competition for food, care and money, and increased potential household sources of transmission for diseases. Yet in Taiwan, where an even higher proportion of female deaths $15-49$ can be attributed to maternal 
Graph 3. Sex ratio of mortality by age (Taiwan and The Netherlands, assorted years, male death rate/ female death rate)

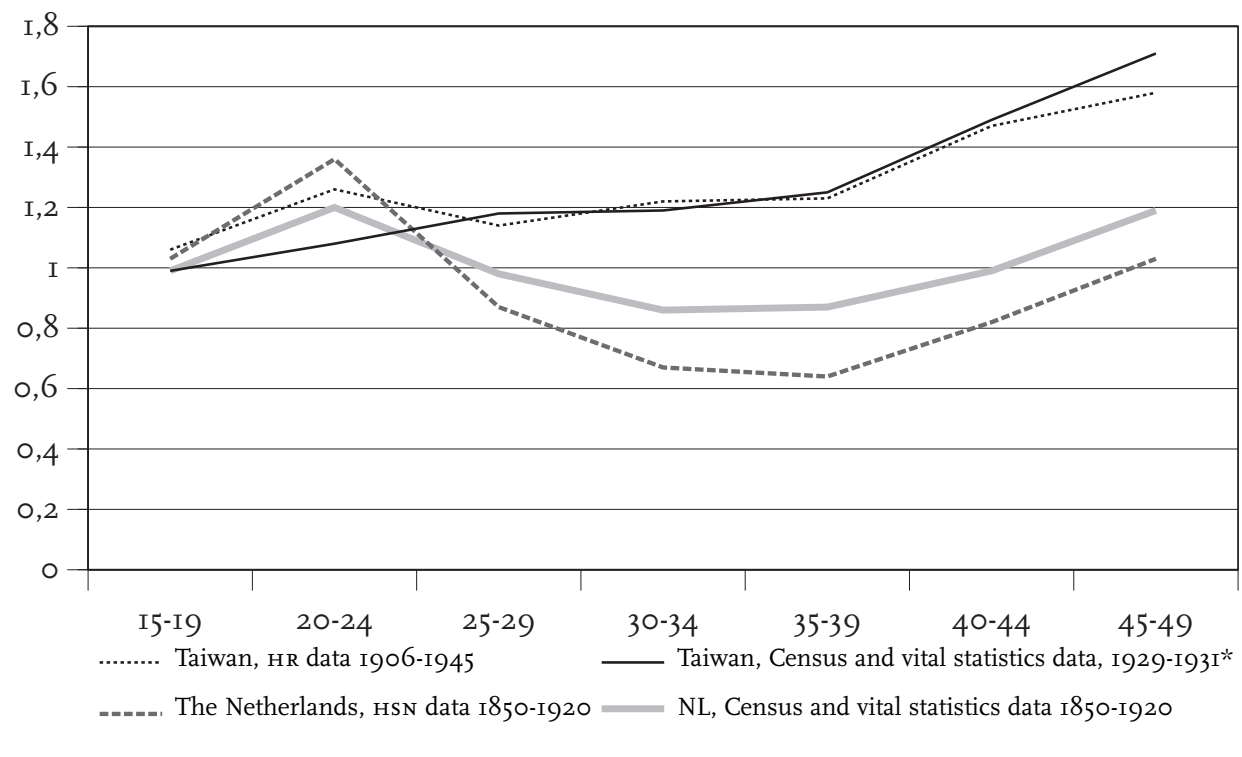

* In I929-3I the overall average death rate is close to the death rate found in the household registers.

Source: Tables IoA, IоB, IоC, IоD, Appendix.

Graph 4. Female mortality by age, deaths per Iooo woman-years (Taiwan and The Netherlands, assorted years)

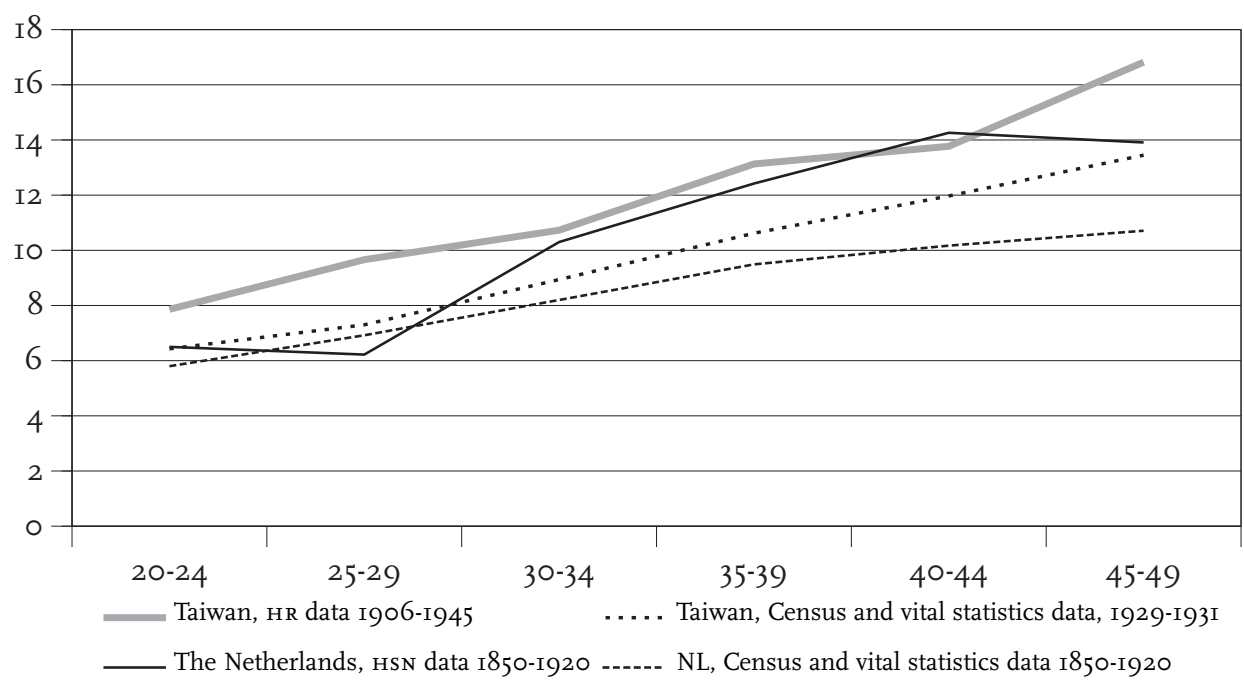

Source: Tables IoA, IoB, IoC, IoD, Appendix 


\begin{tabular}{llll} 
Days following delivery & \multicolumn{2}{l}{ Maternal Deaths } \\
& $N$ & $\%$ & cum\% \\
\hline O days & & 24.2 & 24.2 \\
I-7 days & I3I & 28.0 & 52.2 \\
8-30 days & I52 & 26.8 & 79.0 \\
3I-60 days & I45 & I3.7 & 92.6 \\
6I-90 days & 74 & 7.4 & 100 \\
Total & 40 & I0O & \\
\hline
\end{tabular}

Table inB. Timing of maternal deaths (The Netherlands, HSN data, I850-1920)

\begin{tabular}{|c|c|c|c|}
\hline \multirow[t]{2}{*}{ Days following delivery } & \multicolumn{3}{|c|}{ Maternal Deaths } \\
\hline & $N$ & $\%$ & cum\% \\
\hline o days & $4 \mathrm{I}$ & 10.3 & I0.3 \\
\hline I-7 days & 92 & $23 . \mathrm{I}$ & $33 \cdot 4$ \\
\hline 8-30 days & 167 & 4I.9 & $75 \cdot 3$ \\
\hline 3I-6o days & 57 & $\mathrm{I} 4.3$ & 89.6 \\
\hline 6I-90 days & 42 & I0.5 & I00.0 \\
\hline Total & 399 & IOO & \\
\hline
\end{tabular}

causes, females still had a mortality advantage and males a disadvantage. This points to very high rates of death among adult males compared to females in Taiwan. Graph 4 shows the mortality rates for females by age, which are used in the computation of the sex ratios of mortality in Graph 3. Graph 4 makes clear the importance of increasing age to increases in the overall death rate for females. We take up the connection of maternal mortality to age specific fertility rates and high-risk births below.

For centuries, the health risks involving pregnancies and deliveries resulted in divergent gender-specific mortality rates. In his paper on long-term trends in health differences between the sexes in the Netherlands, Van Poppel finds that excess mortality among women of fertile age groups was between 5 and 30 per cent in I940 - only to disappear after the Second World War when antibiotics and medical advances reduced maternal mortality rates dramatically (Van Poppel 2000:I2I). Van Poppel argues that cause-of-death statistics show that maternal mortality was responsible for a considerable part of this difference 'Between I875 


\begin{tabular}{|c|c|c|c|c|c|c|c|c|c|c|}
\hline \multirow[t]{3}{*}{$\begin{array}{l}\text { Days } \\
\text { following } \\
\text { delivery }\end{array}$} & \multicolumn{3}{|c|}{$\begin{array}{c}\text { Infant deaths } \\
\text { associated with } \\
\text { a maternal death }\end{array}$} & & ming o & afant & $h$ in $r$ & ion to & ternal d & \\
\hline & & & & \multicolumn{2}{|c|}{ Before } & \multicolumn{2}{|c|}{ Same } & \multicolumn{2}{|c|}{ After } & \multirow{2}{*}{$\begin{array}{l}\text { Total } \\
\%\end{array}$} \\
\hline & $\mathrm{N}$ & $\%$ & cum\% & $\mathrm{N}$ & $\%$ & $\mathrm{~N}$ & $\%$ & $\mathrm{~N}$ & $\%$ & \\
\hline o days & 24 & I0.3 & I0.3 & I6 & 66.7 & 8 & 33.3 & $\circ$ & $\circ$ & 100.0 \\
\hline I-7 days & $8 \mathrm{I}$ & 34.9 & 45.3 & 45 & 55.6 & 7 & 8.6 & 29 & 35.8 & 100.0 \\
\hline 8-30 days & 83 & 35.8 & 8т.० & I6 & 19.3 & I & I. 2 & 66 & 79.5 & 100.0 \\
\hline 3I-60 days & 28 & I2.I & 93.I & 4 & I 4.3 & I & 3.6 & 23 & 82.1 & 100.0 \\
\hline 6I-90 days & I6 & 6.9 & 100 & 2 & I2.5 & $\circ$ & 0.0 & $\mathrm{I} 4$ & 87.5 & 100.0 \\
\hline Total & 232 & 100 & & 83 & 35.8 & I7 & 7.3 & $\mathrm{I} 32$ & 56.9 & 100.0 \\
\hline
\end{tabular}

Table IID. Timing of infant deaths associated with maternal deaths (The Netherlands, HSN data, I850-1920)

\begin{tabular}{|c|c|c|c|c|c|c|c|c|c|c|}
\hline \multirow[t]{3}{*}{$\begin{array}{l}\text { Days } \\
\text { following } \\
\text { delivery }\end{array}$} & \multicolumn{3}{|c|}{$\begin{array}{c}\text { Infant deaths } \\
\text { associated with } \\
\text { a maternal death }\end{array}$} & \multirow{2}{*}{\multicolumn{2}{|c|}{ Before }} & \multirow{2}{*}{\multicolumn{2}{|c|}{ Same }} & \multirow{2}{*}{\multicolumn{2}{|c|}{ After }} & \multirow{3}{*}{$\begin{array}{l}\text { Total } \\
\%\end{array}$} \\
\hline & & & & & & & & & & \\
\hline & $\mathrm{N}$ & $\%$ & cum\% & $\mathrm{N}$ & $\%$ & $\mathrm{~N}$ & $\%$ & $\mathrm{~N}$ & $\%$ & \\
\hline o days & 6 & 5.7 & 5.7 & 6 & 100 & ० & $\circ$ & $\circ$ & $\circ$ & I0०.० \\
\hline I-7 days & 29 & 30.7 & 33.0 & 23 & $79 \cdot 3$ & 3 & I0.3 & 3 & I0.3 & I00.0 \\
\hline 8-30 days & 32 & 30.2 & 63.2 & II & 34.4 & 2 & 6.3 & I9 & $59 \cdot 4$ & IOO.0 \\
\hline 3I-6o days & 25 & 23.7 & 86.8 & 5 & 20.0 & o & o & 20 & 80.0 & I00.0 \\
\hline 6I-90 days & $\mathrm{I} 4$ & $\mathrm{I} 3.2$ & IO०.० & o & o & o & o & I4 & IOO & I00.0 \\
\hline Total & Io6 & I00.0 & & 45 & 42.5 & 5 & 4.7 & 56 & 52.8 & I00.0 \\
\hline
\end{tabular}

and 1939, puerperal fever and other diseases of pregnancy were responsible for between 5.4 and IO.I per cent of all deaths among women aged 20-49'. In the Netherlands maternal deaths accounted for II.I\% of deaths among women ages I5-49 in the register data I85I-I920 (Table $7 \mathrm{~B}$ ) and $6.4 \%$ of all deaths among women in the vital statistics data from I87I-I920 (Table 7D). In Taiwan, maternal deaths accounted for $8.9 \%$ of all deaths among women aged $15-49$ in the register data (see table $7 \mathrm{~A}$ in the appendix), and $10 \%$ of all deaths among women in 
the vital statistics data for I929-3I (see table $7 \mathrm{C}$ in the appendix). This is a substantial added risk that men did not bear. Van Poppel relates high rates of maternal mortality to high levels of fertility: 'Maternal mortality was directly related to the number of pregnancies experienced, and additional risks were associated with pregnancies occurring at the late stages of a woman's reproductive period, as well as with very high parities. Repeated pregnancies and confinements may also have had an indirect influence on female mortality risks.' (Van Poppel 2000: I2I). Taiwan too had high rates of fertility and similar rates of maternal mortality in the periods under discussion and an even higher proportion of female deaths I5-49 attributed to maternal causes; yet Taiwan did not have a pattern of excess female mortality ages I5-49 because male rates were higher still.

The relationships between maternal age, fertility levels, and maternal mortality are discussed in greater detail in the section on maternal risk factors, below.

\section{The timing of maternal and associated infant deaths}

How soon after delivery did maternal deaths ensue? Aggregated data in published vital statistics reports are rarely organized to answer this kind of question. The household registers however, because they have information on individual life courses, are uniquely capable of linking events of birth and death. Table IIA shows that in Taiwan a quarter of the women who suffered complications during delivery died on the day that they gave birth; over half died within a week and almost $80 \%$ within a month of the delivery. It is likely that women suffering from toxemias of pregnancy and hemorrhage died shortly after birth, while a large proportion of maternal deaths occurring several days to weeks later can be attributed to puerperal fever. Maternal deaths following a stillbirth or abortion are not included in the data. Tables IIB and D for the Netherlands data shows unusually small proportions of mothers and infants dying in the first day. This suggests that the Dutch data is missing such deaths, probably due to an underregistration of children who died before the registers were updated. In some regions (notably Friesland), this updating was much slower than elsewhere.

We also tracked the fate of infants whose mothers died of maternal causes (see tables IIC and D). We found that of infants whose mothers died in the first 90 days, $57 \%$ in Taiwan and $73 \%$ in the Netherlands survived the first 90 days of life (see below tables I5A and B). Of the infants who passed away in Taiwan, Io\% died on the same day that they were born; almost half died within a week and $8 \mathrm{I} \%$ within a month. Of the infants who passed away in the Netherlands, 6\% died on day of birth, $33 \%$ within a week and $63 \%$ within a month. The tables further show that more than half of the infants $(57 \%$ in Taiwan and $53 \%$ in the Netherlands) died after the death of their mothers, perhaps due to premature weaning. The death of a substantial proportion of the infants $(36 \%$ in Taiwan and $43 \%$ in the Netherlands) preceded their mothers' deaths. In some of these cases 


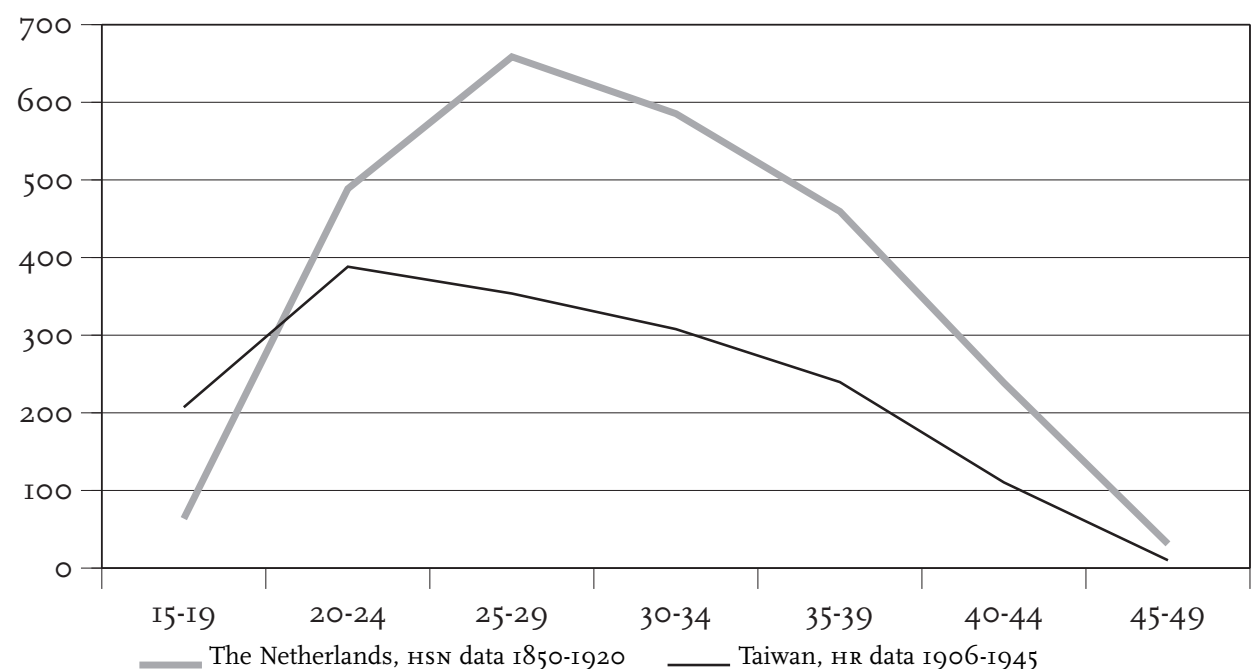

The sample excludes women who bore no children and live births for which mother's age is unknown. Source: Tables I2A and I2B, Appendix.

Graph 6. Maternal deaths per Ioo० births by age (Taiwan and The Netherlands, assorted years)

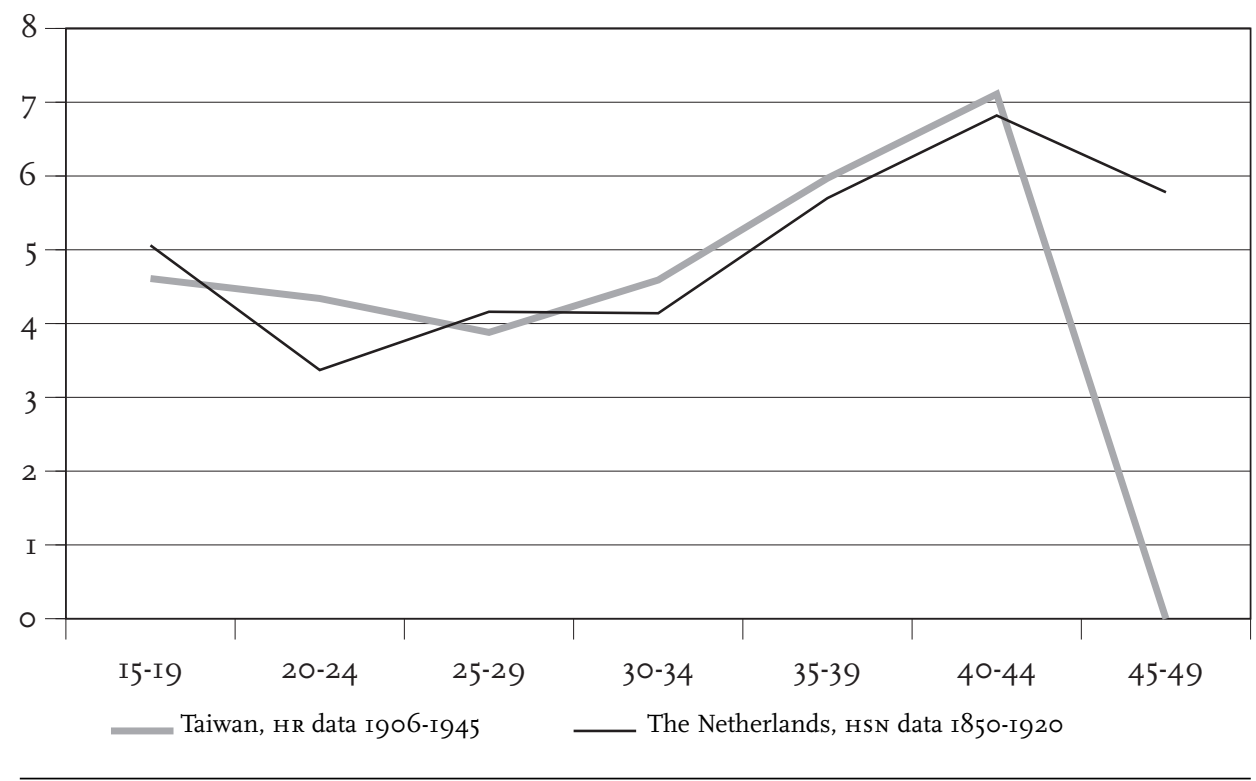

Source: Tables I2A and I2B, Appendix. 

data I906-1945 and the Netherlands, HSN data I851-1920)

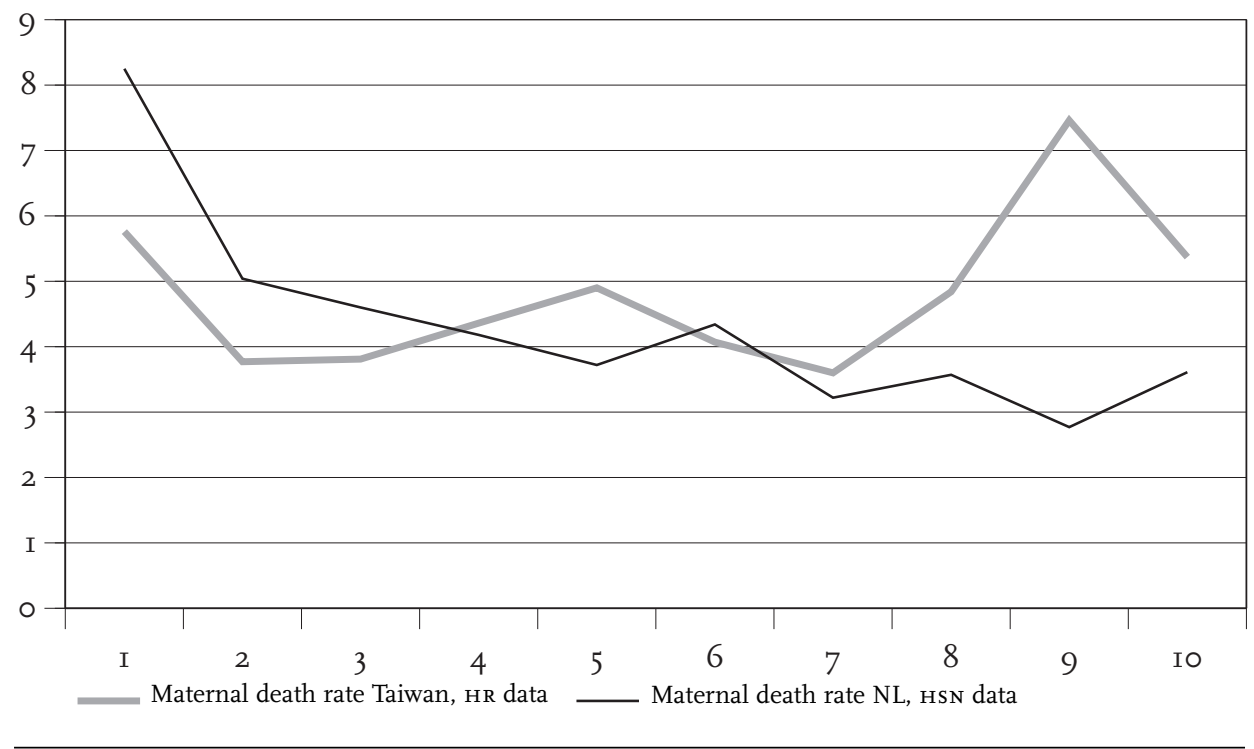

Source: Tables I3A and I3B, Appendix.

both deaths may be related to causes such as difficult labor or toxemias that affect both mother and newborn.

\section{Maternal mortality - risk factors}

In this section we discuss the importance of three risk factors for maternal mortality: age, parity, and birth interval. Numerous studies have documented the relationship between maternal age and parity and risk of maternal death (Woodbury I926: 34-36; Children's Bureau I934: 33-35; Loudon I992: 500-506). Maternal mortality has repeatedly been found to follow a "J" shape starting with high mortality in the first birth, descending to low levels with the second and third birth, and then rising steadily with each additional birth. A similar "J" shaped pattern emerges when maternal mortality is tracked by age, with the highest risk for the youngest and oldest mothers and the lowest risk typically for the age group 20-24. The higher mortality among the youngest mothers is related to the high proportion of first births occurring in that age group. Although higher parity can only be achieved as age increases, the risk associated with age is not simply a function of increasing parity. First births and parities four and above at higher ages are associated with significant increased risk (Loudon 1992: 500-506). The higher rate of maternal mortality in first order births is due to the higher incidence of puerperal toxaemia in first pregnancies, and a tendency for first labors to be more difficult. Higher 

HR data, 1906-1945)

\begin{tabular}{lllllll}
\hline Parity & I5-I9 & $20-24$ & $25-29$ & $30-34$ & $35-39$ & $40-44$ \\
\hline I & 5 I.5 & 63.0 & 50.7 & 5 I. 3 & 82.0 & 73.5 \\
2 & 2 I. 8 & 34.7 & 37.2 & 62.6 & 54.0 & 57.5 \\
$3-4$ & 43.9 & $29 . \mathrm{I}$ & 40.9 & 42.6 & 67.2 & 64.8 \\
$5-6$ & $*$ & $*$ & 29.6 & 44.5 & 65.5 & 104.4 \\
$7+$ & $*$ & $*$ & $*$ & 42.3 & 50.2 & 63.7 \\
\hline
\end{tabular}

* No rates are reported for cells having fewer than 2 maternal deaths.

Table I5B. Maternal mortality, age by parity, deaths per I0,000 births (the Netherlands, HSN data, I850-1920)*

\begin{tabular}{lllllll}
\hline Parity & I5-I9 & $20-24$ & $25-29$ & $30-34$ & $35-39$ & $40-44$ \\
\hline I & 49.0 & 37.2 & 78.7 & I33.0 & 252.0 & 417.0 \\
2 & 69.4 & 42.5 & 34.6 & 48.2 & 136.5 & 192.3 \\
$3-4$ & $*$ & 16.6 & 28.5 & 43.6 & 87.8 & 134.4 \\
$5-6$ & $*$ & $*$ & 45.0 & 32.0 & 42.6 & 60.9 \\
$7+$ & $*$ & $*$ & 29.0 & 19.8 & 33.7 & 43.8 \\
\hline
\end{tabular}

* Numbers for age group 45-49 are too small

maternal mortality of women at older ages and higher parities results from higher rates of all causes, especially puerperal hemorrhage. With older age comes a rising incidence of placenta praevia and especially postpartum hemorrhage, which occurs when the weakened uteri of older, multiparous women fail to contract strongly enough to shut off bleeding (Loudon I992: 506).

Less commonly studied is the relationship between length of the birth interval and the risk of maternal death. Household register-based data, which can track individual life courses, is one of the few historical data sources capable of addressing this issue.

\section{Age and Maternal Mortality}

Graph 5 (see tables I2A and B in the appendix) shows fertility rates of women who bore children for the different age groups. This measure of fertility is higher than marital fertility (which includes infertile women) and as expected is higher in The Netherlands than in Taiwan (see Chuang et al. 2006: II2, 215). 

I945 and the Netherlands, HSN data $1850-1920)$

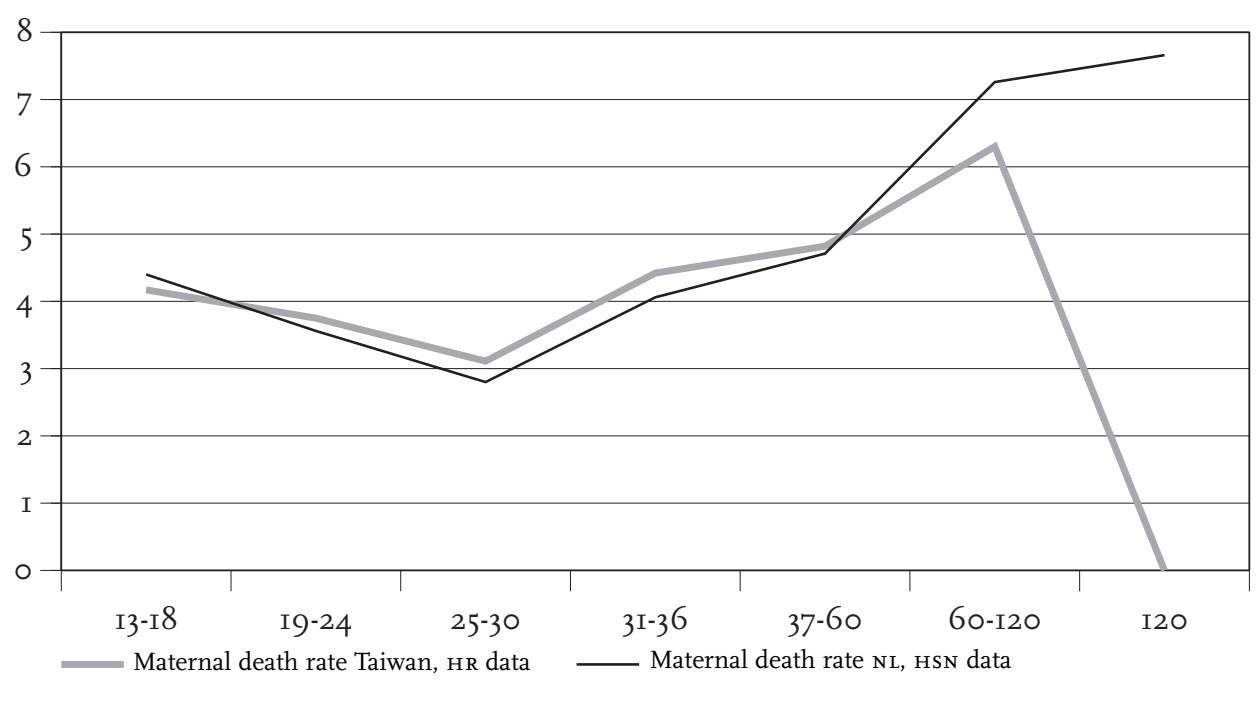

Source: Tables I4A and I4B, Appendix.

Graph 6 (see tables I2A and B in the appendix) shows maternal mortality for the different age groups. Though fertility rates were highest among women aged 20-34 in both populations, maternal mortality was lower among these groups than among other age groups. Maternal mortality in both populations was highest for the age groups 35-44 (and 45-49 for the Netherlands) despite declining fertility rates. Increasing rates of maternal mortality at these ages point to the risks of pregnancy at advanced age; these deaths are likely also associated with high parities, an issue we turn to next.

\section{Parity}

The effect of an increasing number of births on the survivorship of mothers is shown in graph 7 (see tables I3A and I3B in the appendix). A curvilinear relationship is often found between maternal deaths and birth parity and Taiwan is no exception. The elevated risk associated with the first birth drops to its lowest point at parity two after which maternal deaths increase with additional births. Maternal causes of death associated with increasing parity and age include hemorrhage resulting from the failure of the uterus to contract sufficiently, and an increasing susceptibility to puerperal infection (Loudon 1992: 99, 506). Interestingly in the Netherlands, we find the usual peak at the earliest ages, but a much less pronounced increase. 
In tables $\mathrm{I}_{5} \mathrm{~A}$ and $\mathrm{B}$ we examine patterns of maternal mortality by age and parity to assess the relative contribution of these factors to risk. In both of our populations the risk of mortality associated with a first birth is comparatively high at all ages, and increases significantly for women having a first birth above age 30. In both populations a second birth at the highest ages is also associated with elevated risk. In general our tables show a more consistent rise in risk with age than with parity. The major exception is in the youngest group of mothers, I5-I9, where high parity for age elevates risk in both populations. But in general rather than risk being associated with short birth intervals and high parity for age, the highest risks are associated with delayed childbearing and low parity for age, or extremely long birth intervals (see below). Koenig et al. in a report on maternal mortality from Matlab, Bangladesh, state that "after controlling for parity, we find little evidence that younger maternal age is associated with higher mortality risks. ... Higher parity-for-age and lower age-for-parity both imply ... shorter average intervals between births. If, as has been posited by some observers, birth spacing is an important determinant of maternal mortality, then at a given age mortality risks should increase with higher parity, and conversely, at a given parity level mortality risks should be expected to increase with lower age. Our results show little support for this hypothesis...." (Koenig et al.I988: 78). Except in the case of the youngest age group, the data from Taiwan and the Netherlands agree with Koenig et al.'s conclusion. Taking the evidence of maternal risk by age and parity as our guide, it appears that in neither population did birth spacing become so short as to significantly raise the risk of maternal mortality. We do not find significantly elevated levels of risk at the highest parities in age groups above 20; indeed women who reached the highest parities appear to have been a robust group. This does not rule out a finding that risk rises when birth intervals are unusually short. Our direct measure of the relationship between interval length and maternal mortality and the possible reasons for this pattern are discussed next.

\section{Birth Interval Length}

Graph 8 (see tables I4A and I4B in the appendix) shows the effect of the length of birth intervals on maternal mortality. For both Taiwan and the Netherlands we find a J-shaped curve, with a minor peak in death rates in the shortest interval, followed by low rates that begin to rise with increasing interval length above $3 \mathrm{I}$ months. In Taiwan the lowest maternal death rates are found for birth intervals between one-and-a-half and two-and-a-half years, and in the Netherlands for birth intervals from one and a half to three years. Interestingly in Taiwan the risk is greater for the many intervals above two and a half years than for the intervals below i 8 months. In both populations, very long intervals of greater than 5 years present the highest risk for mothers. These findings with respect to relationship 


\begin{tabular}{|c|c|c|c|}
\hline & Infants ০-9o days: & & \\
\hline & survive & die & total \\
\hline mother survives $0-90$ days & I08I22 (92\%) & $8973(8 \%)$ & II7095 (I00\%) \\
\hline mother dies 0-90 days & 3 IO $(57 \%)$ & $232(43 \%)$ & 542 (100\%) \\
\hline \multirow[t]{3}{*}{ total } & $108432(92 \%)$ & $9205(8 \%)$ & II7637 (I00\%) \\
\hline & Infants 91-365 days: & & \\
\hline & survive & die & total \\
\hline mother survives $0-90$ days & 102009 (94\%) & $6 \mathrm{II} 3(6 \%)$ & IO8I22 (IOO\%) \\
\hline mother dies ০-9० days & $242(78 \%)$ & $68(22 \%)$ & 310 (I००\%) \\
\hline \multirow[t]{3}{*}{ total } & I0225I (94\%) & $6183(6 \%)$ & I08432 (I00\%) \\
\hline & Infants 91-365 days: & & \\
\hline & survive & die & total \\
\hline mother survives 9I-365 days & IOI686 (94\%) & $6047(6 \%)$ & IO7733 (I0०\%) \\
\hline mother dies 9I-365 days & $330(83 \%)$ & 68 (I7\%) & 389 (100\%) \\
\hline total & 102009 (94\%) & $6113(6 \%)$ & I08I22 (I00\%) \\
\hline
\end{tabular}

\section{Table I6B. Infant survival related to maternal survival (The Netherlands, HSN} data $1850-1920)$

\begin{tabular}{|c|c|c|c|}
\hline & Infants o-9o days: & & \\
\hline & survive & die & total \\
\hline mother survives ০-9० days & 78626 (93\%) & $6032(7 \%)$ & 84658 (100\%) \\
\hline Mother dies ০-9० days & $293(73 \%)$ & I06 (27\%) & 399 (100\%) \\
\hline \multirow[t]{3}{*}{ total } & 78919 (93\%) & 6138 (7\%) & 85057 (100\%) \\
\hline & Infants 91-365 days: & & \\
\hline & survive & die & total \\
\hline mother survives $0-90$ days & 71696 (91\%) & $6930(9 \%)$ & 78626 (100\%) \\
\hline mother dies $0-90$ days & 2I8 (74\%) & $75(26 \%)$ & 293 (100\%) \\
\hline \multirow[t]{3}{*}{ total } & 7I9I4 (91\%) & 7005 (9\%) & 78919(100\%) \\
\hline & Infants 91-365 days: & & \\
\hline & survive & die & total \\
\hline mother survives 9I-365 days & $7 \mathrm{II} 24$ (9I\%) & $6804(9 \%)$ & 77928 (100\%) \\
\hline mother dies 9I-365 days & $210(74 \%)$ & $73(26 \%)$ & 283 (I00\%) \\
\hline total & 7I334 (91\%) & $6877(9 \%)$ & 782 II (100\%)* \\
\hline
\end{tabular}

* A number of mothers left observation between 90 and 365 days. 
of birth interval length to maternal mortality largely parallel the relationship of

birth interval length to infant mortality. In very short intervals it is thought that maternal depletion operates to raise the risk for both mother and infant. Perhaps rates of maternal mortality are not as high as anticipated for very short intervals as those who are most depleted are also more likely never to become pregnant or to suffer miscarriages if they do, leaving only the most hardy in our sample? In very long intervals the higher risks resemble those of nulliparous women, and may reflect the presence of a disproportionate number of women who have had difficulty getting pregnant or miscarried because their general and reproductive health is impaired.

\section{Survivorship of mother and child}

A strong relationship exists between the survivorship of the mother and that of the child she has given birth to, especially under conditions where breastfeeding is essential to infant survival. Previous research has indicated that parental mortality particularly that of the mother, reduced the survival chances of offspring (Penn and Smith 2007). How close was the relation between the death of mother and child in Taiwan and the Netherlands during our research period? Tables I6A and I6B show the survivorships of mother and infant in the year following the delivery. The period has been divided between the first 90 days after the delivery and the remaining 9 months. The data indicate that when mothers survived the first three months after having given birth, a very high proportion of the infants also survived those months: $92 \%$ in Taiwan and $93 \%$ in the Netherlands. If the mother died within the first three months, many fewer children survived the same period, $57 \%$ in Taiwan and $73 \%$ in the Netherlands. Of children whose mothers died in the first ninety days, an additional proportion died in the succeeding period, $22 \%$ in Taiwan and $26 \%$ in the Netherlands, compared to only $6 \%$ and $9 \%$ of children whose mothers survived days 0-90. Mothers who survived days 9I-365 following delivery lost only a few of their children in that period, $6 \%$ in Taiwan and $9 \%$ in the Netherlands. But infants who survived the first 90 days but whose mothers died 9I-365 days following delivery were still vulnerable to much higher risk of death: $17 \%$ in Taiwan and $26 \%$ in the Netherlands of such children died before the end of their first year of life. In both populations the loss of a mother during infancy significantly lowered an infant's chances of survival.

\section{Conclusions}

In both our subject populations, we find that maternal mortality declined significantly over the periods under observation, though from different levels and at different rates. The declines in maternal mortality were achieved in the context of two very different health environments and fertility trends, that nevertheless had points in common. 
Both our populations benefited from increasing numbers of midwives trained in modern biomedical techniques. Advances in germ theory and antisepsis in the late nineteenth century put in the hands of trained midwives knowledge of techniques that should have enabled them to limit the danger of bacterial infections like puerperal fever that endangered the lives of mothers. Other antiseptic practices like putting silver nitrate in the eyes and the sanitary cutting of the umbilical cord benefited newborns. Evidence of the impact of antisepsis in reducing maternal deaths is shown most clearly in the decline of maternal mortality in hospital births in late nineteenth century Netherlands. The decline in the proportion of maternal deaths attributed to puerperal hemorrhage in the Netherlands in the twentieth century also suggests that midwives may have learned skills that enabled them to manage these crises and save lives. But we have no direct indicators that tell us whether the ability of trained midwives to recognize problem births in advance, identify toxemias, and recommend treatments contributed significantly to the reduction of maternal mortality rates. Nor do we know if midwives exacerbated the risks in some births by their greater tendency to intervene or their advocacy of a prone position for birthing mothers. In general, we can only speculate that the knowledge of trained midwives must have made a positive contribution to the very real reductions in maternal mortality that we document.

The achievement of a reduction in maternal morality is perhaps most impressive in Taiwan, where the decrease was achieved despite an increase in fertility rates that presumably increased the number of high risk pregnancies. In the Netherlands a decline in general fertility paralleled the decline in maternal mortality from the end of the nineteenth century. This suggests that part of the decline in maternal mortality in the Netherlands is to be attributed to fewer high risk births connected to high parity, close spacing, and advanced age associated with high levels of fertility. Both of our populations show the expected J-shaped patterns of higher maternal mortality as age and parity increase. We also identified in both our populations a higher risk of maternal mortality associated with both very short and very long birth intervals.

In both populations a substantial overall decline in female mortality I5-49 took place in the periods under observation. Vital statistics data (tables $7 \mathrm{C}$ and $\mathrm{D}$ ) show that deaths per I0,000 woman years $15-49$ fell from as high as 190 to 70 in Taiwan and from IO3 to 45 in The Netherlands by the end of the period (I94I and I9I5, respectively). This paralleled the fall in maternal mortality per I0,000 live births from 75 to 33 in Taiwan and from 56 to 23 in The Netherlands. This suggests an overall improvement in the health of fertile age women (attributed to lower rates of disease and better nutrition) that contributed to their ability to survive the rigors of pregnancy and childbirth. The general improvement in female health in these populations must have contributed significantly to lower maternal 
mortality, quite apart from trends in fertility (the fertility increase in Taiwan may itself be the result of improved maternal health), and improvements in midwifery.

Surprisingly, the proportion of total female deaths 15-49 attributed to maternal causes increases in Taiwan over the period, and decreases in the Netherlands. The vital statistics data show that the proportion of deaths from maternal causes rose from $7 \%$ to $9.5-11 \%$ of total deaths to Taiwanese women, age $15-49$, but declined from $8 \%$ to $5 \%$ of total deaths to Dutch women. This suggests that in Taiwan greater progress was achieved in dealing with non-maternal causes, while in the Netherlands, maternal causes declined at a faster rate than non-maternal causes. The divergent trends in fertility, increasing in Taiwan and declining in the Netherlands, help explain this difference. The biggest divergence between our populations emerges when we examined sex differences in mortality. The common expectation of excess female mortality in the fertile ages due to the risks of maternal mortality and the added burdens of childrearing is borne out in the case of The Netherlands (ages 25-44), but not in the case of Taiwan, where male mortality I5-49 signifcantly exceeded female mortality during the period.

The contribution of maternal mortality to infant mortality is documented in our analysis of the register data for both populations. While the infrequency of maternal mortality means only a small proportion of infants were affected by the loss of a mother, the survival chances of infants who did lose their mothers were significantly reduced. In Taiwan $43 \%$ of infants who lost their mothers in the first 90 days of life were themselves likely to die in that period, compared to only $8 \%$ of infants whose mothers survived. In The Netherlands $27 \%$ of infants who lost their mothers in the first 90 days of life were themselves likely to die in that period, compared to only $7 \%$ of infants whose mothers survived. 
Table 6 . Maternal mortality rates by period, comparing vital statistics and register samples, deaths per Io,००० live births (Based on Tables 7A, B, C and D)

\begin{tabular}{|c|c|c|c|c|c|}
\hline Year & $\begin{array}{l}\text { MMR vit.stat. } \\
\text { Taiwan* }\end{array}$ & $\begin{array}{l}\text { MMR registers } \\
\text { Taiwan }\end{array}$ & Year & $\begin{array}{l}\text { MMR vit.stat. } \\
\text { Netherlands }{ }^{* *}\end{array}$ & $\begin{array}{l}\text { MMR registers } \\
\text { Netherlands }\end{array}$ \\
\hline I906-Io & 74.6 & 39.8 & I $85 \mathrm{I}-55$ & & I24.7 \\
\hline I9II-I5 & 65.2 & $45 \cdot 3$ & $1856-60$ & & 73.8 \\
\hline I9I6-20 & 66.2 & 55.2 & I86I-65 & & 7I.9 \\
\hline I92I-25 & $54 \cdot 4$ & 33.6 & I866-70 & & 73.8 \\
\hline I926-30 & $45 \cdot 4$ & 3 I. 6 & I87I-75 & 56.8 & 92.5 \\
\hline I93I-35 & 40.8 & 35.4 & I $876-80$ & $4 \mathrm{I} .5$ & 50.3 \\
\hline I936-40 & 36.8 & $37.6 *$ & I88I-85 & 4I. 8 & 68.4 \\
\hline \multirow[t]{7}{*}{ I94I-45 } & 30.3 & $34 \cdot \mathrm{I}^{*}$ & I886-90 & 36.8 & 59.0 \\
\hline & & & I89I-95 & 30.8 & $4 \mathrm{I} \cdot 4$ \\
\hline & & & I896-০o & $25 \cdot 5$ & $39 \cdot 9$ \\
\hline & & & I9OI-05 & 24.8 & 30.2 \\
\hline & & & I906-Io & 24.4 & $4 \mathrm{I} .6$ \\
\hline & & & I9II-I5 & 23.0 & 25.6 \\
\hline & & & I9I6-20 & 27.4 & 36.I \\
\hline
\end{tabular}

* Source: Shepherd 2002: 3I. Contrary to expectation, the Taiwan register sample gives a rate higher than the census data in the years $1936-45$. At this point we have no ready explanation for this discrepancy.

** Source: Geneeskundig Staatstoezicht I876-I90I; CBS I90I-I920. 


\begin{tabular}{|c|c|c|c|c|c|c|c|c|}
\hline Years & $\begin{array}{l}\text { Woman } \\
\text { years } \\
15-49\end{array}$ & $\begin{array}{l}\text { Live } \\
\text { Births }\end{array}$ & $\begin{array}{l}\text { Births } \\
\text { per } \\
1000 \\
\text { woman } \\
\text { years, } \\
15-49\end{array}$ & $\begin{array}{l}\text { Female } \\
\text { deaths, } \\
15-49\end{array}$ & $\begin{array}{l}\text { Maternal } \\
\text { deaths * }\end{array}$ & $\begin{array}{l}\text { Female } \\
\text { deaths } \\
\text { per 10,000 } \\
\text { woman- } \\
\text { years, } \\
15-49\end{array}$ & $\begin{array}{l}\text { Maternal } \\
\text { deaths } \\
\text { per 10,000 } \\
\text { woman- } \\
\text { years } \\
15-49\end{array}$ & $\begin{array}{l}\text { Maternal } \\
\text { deaths* } \\
\text { per } 10,000 \\
\text { live births }\end{array}$ \\
\hline I906-IO & 58I7I.I5 & I5575 & 267.74 & 809 & 62 & I39.07 & Io.66 & 39.8 \\
\hline I9II-I5 & 6I4IO.34 & I6557 & $269.6 \mathrm{I}$ & 712 & 75 & II5.94 & $\mathrm{I} 2.2 \mathrm{I}$ & $45 \cdot 3$ \\
\hline I9I6-20 & $65829.9 \mathrm{I}$ & I577I & 239.57 & $90 \mathrm{I}$ & 87 & I36.87 & I 3.22 & 55.2 \\
\hline I92I-25 & 70464.17 & I7578 & $249 \cdot 46$ & 632 & 59 & 89.69 & 8.37 & 33.6 \\
\hline I926-30 & 76002.32 & I7727 & 233.24 & 594 & 56 & 78.16 & $7 \cdot 37$ & 3 I. 6 \\
\hline I93I-35 & 80892.16 & I9I88 & 237.20 & 554 & 68 & 68.49 & $8.4 \mathrm{I}$ & 35.4 \\
\hline $1936-40$ & 87738.56 & I94I8 & $22 \mathrm{I} .32$ & $68 \mathrm{I}$ & 73 & 77.62 & 8.32 & 37.6 \\
\hline I94I-45 & 98843.05 & I8I95 & I84.08 & 750 & 62 & 75.88 & 6.27 & $34 . I$ \\
\hline Total & 599351.66 & 140009 & 233.60 & 5633 & $54^{2}$ & 93.98 & 9.04 & 38.7 \\
\hline
\end{tabular}

* Deaths within 90 days of delivery.

Table 7 B. Female Mortality, ages $15-49$ (The Netherlands, HSN data I850-1920)

\begin{tabular}{|c|c|c|c|c|c|c|c|c|}
\hline Years & $\begin{array}{l}\text { Woman } \\
\text { years } \\
15-49\end{array}$ & $\begin{array}{l}\text { Live } \\
\text { Births }\end{array}$ & $\begin{array}{l}\text { Births } \\
\text { per } \\
1000 \\
\text { woman } \\
\text { years, } \\
15-49\end{array}$ & $\begin{array}{l}\text { Female } \\
\text { deaths, } \\
15-49\end{array}$ & $\begin{array}{l}\text { Maternal } \\
\text { deaths * }\end{array}$ & $\begin{array}{l}\text { Female } \\
\text { deaths } \\
\text { per 10,000 } \\
\text { woman- } \\
\text { years, } \\
15-49\end{array}$ & $\begin{array}{l}\text { Maternal } \\
\text { deaths } \\
\text { per 10,000 } \\
\text { woman- } \\
\text { years } \\
15-49\end{array}$ & $\begin{array}{l}\text { Maternal } \\
\text { deaths* } \\
\text { per 10,000 } \\
\text { live births }\end{array}$ \\
\hline $185 \mathrm{I}-55$ & 6722.65 & 802 & II9.3 & 47 & IO & $69 \cdot 9$ & I4.9 & I2 4.7 \\
\hline I856-60 & 9326.92 & 1084 & II 6.2 & 76 & 8 & $8 \mathrm{I} .5$ & 8.6 & 73.8 \\
\hline I86I-65 & I6044.42 & 2920 & I 82.0 & II 5 & $2 \mathrm{I}$ & 7I.7 & I3.I & 71.9 \\
\hline I866-70 & 20188.53 & 3388 & I67.8 & I93 & 25 & $95 \cdot 6$ & I 2.4 & 73.8 \\
\hline I87I-75 & $2524 \mathrm{I} .5 \mathrm{I}$ & $335^{\mathrm{I}}$ & I32.8 & 222 & $3 \mathrm{I}$ & 87.2 & $\mathrm{I} 2.3$ & 92.5 \\
\hline I876-80 & 28719.97 & $358 \mathrm{I}$ & I 24.7 & I8I & I8 & 63.0 & 6.3 & 50.3 \\
\hline I88I-85 & 34230.37 & 5706 & 166.7 & 218 & 39 & 63.7 & II. 4 & 68.4 \\
\hline I886-90 & $35 \mathrm{II} 6.28$ & $7 \mathrm{II} 7$ & 202.7 & 249 & 42 & 70.9 & I2.0 & 59.0 \\
\hline I89I-95 & 50683.90 & 8856 & I74.7 & 303 & 38 & 59.8 & $7 \cdot 5$ & 42.9 \\
\hline I896-00 & 59430.03 & 9279 & I56.I & 324 & 37 & 54.5 & 6.2 & $39 \cdot 9$ \\
\hline I9OI-05 & 71829.60 & 10282 & I43.I & 332 & $3 \mathrm{I}$ & 46.2 & $4 \cdot 3$ & 30.2 \\
\hline I906-I0 & 82718.30 & 9626 & II 6.4 & $39 \mathrm{I}$ & 40 & $47 \cdot 3$ & 4.8 & 4I. 6 \\
\hline I9II-I5 & 92910.02 & 9775 & 105.2 & 398 & 25 & 42.8 & 2.7 & 25.6 \\
\hline I9I6-20 & 99620.22 & $9 \mathrm{I} 5 \mathrm{I}$ & 91.9 & 529 & 33 & 53.I & $3 \cdot 3$ & 36.1 \\
\hline Total & 632782.72 & $849^{18}$ & 134.2 & 3578 & 398 & 56.5 & 6.3 & 46.9 \\
\hline
\end{tabular}

* Deaths within 90 days of delivery. 


\begin{tabular}{|c|c|c|c|c|c|c|c|c|c|c|}
\hline Years & $\begin{array}{l}\text { Female } \\
\text { populaion } \\
15-49\end{array}$ & $\begin{array}{l}\text { Live } \\
\text { births* }\end{array}$ & $\begin{array}{l}\text { Births } \\
\text { per } 1000 \\
\text { woman } \\
\text { years } \\
15-49\end{array}$ & Stillbirths* & $\begin{array}{l}\text { Female } \\
\text { deaths, } \\
15-49\end{array}$ & $\begin{array}{l}\text { Maternal } \\
\text { deaths } * *\end{array}$ & $\begin{array}{l}\text { Female } \\
\text { deaths } \\
\text { per 10,000 } \\
\text { offem.pop. } \\
15-49\end{array}$ & $\begin{array}{l}\text { Maternal } \\
\text { deaths } \\
\text { per 10,000 } \\
\text { offem. pop. } \\
\text { 15-49 }\end{array}$ & $\begin{array}{l}\text { Maternal } \\
\text { deaths } \\
\text { per 10,000 } \\
\text { live births }\end{array}$ & $\begin{array}{l}\text { Maternal } \\
\text { deaths as } \\
a \% \text { of } \\
\text { total fem. } \\
\text { deaths } \\
15-49\end{array}$ \\
\hline I906-08 & 718889 & 126320 & I75.7 & 2962 & 13634 & 954 & I89.7 & 13.3 & 75.5 & $7.0 \%$ \\
\hline I9I4-I6 & 769010 & 137067 & $\mathrm{I} 78.2$ & 6201 & II5OI & $93 \mathrm{I}$ & I49.6 & I2.I & 67.9 & 8.I \\
\hline I9I9-2I & $80535^{8}$ & I44393 & I79.3 & 6374 & 12246 & 866 & I52.I & Io. 8 & 60.0 & $7 . I$ \\
\hline I924-26 & 875746 & 164638 & I88.0 & 6634 & $932 \mathrm{I}$ & 852 & 106.4 & 9.7 & 5 I. 8 & 9.I \\
\hline I929-3I & 993698 & I98785 & 200.0 & $7 \mathrm{II} 2$ & 8073 & 806 & $8 \mathrm{I} .2$ & 8.I & 40.6 & IO.० \\
\hline I934-36 & I08333I & 223043 & 205.9 & 7379 & 8445 & 943 & 78.0 & 8.7 & 42.3 & II. 2 \\
\hline I939-4I & I2I7055 & 24443 I & 200.8 & 8629 & 8460 & 797 & 69.5 & 6.6 & 32.6 & 9.4 \\
\hline
\end{tabular}

Figures represent a three-year average around census years, with the exception of I9०6-8.

*Live births have been corrected for unregistered nonsurvivors in the period I906-I9I5; no corrections are made to stillbirths, which are also underreported in this period.

$* *$ Maternal deaths identified in cause of death reports, corrected I920-29 as detailed in Shepherd 2002: 22.

\section{Table 7D. Female Mortality, ages I5-49 (The Netherlands, Vital statistics)}

\begin{tabular}{|c|c|c|c|c|c|c|c|c|c|c|}
\hline Years & $\begin{array}{l}\text { Female } \\
\text { populaion } \\
15-49\end{array}$ & $\begin{array}{l}\text { Live } \\
\text { births* }\end{array}$ & $\begin{array}{l}\text { Births } \\
\text { per } 1000 \\
\text { woman } \\
\text { years } \\
15-49\end{array}$ & Stillbirths* & $\begin{array}{l}\text { Female } \\
\text { deaths, } \\
15-49\end{array}$ & $\begin{array}{l}\text { Maternal } \\
\text { deaths } * *\end{array}$ & $\begin{array}{l}\text { Female } \\
\text { deaths } \\
\text { per 10,000 } \\
\text { of fem.pop. } \\
15-49\end{array}$ & $\begin{array}{l}\text { Maternal } \\
\text { deaths } \\
\text { per 10,000 } \\
\text { of fem. pop. } \\
15-49\end{array}$ & $\begin{array}{l}\text { Maternal } \\
\text { deaths } \\
\text { per 10,000 } \\
\text { live births }\end{array}$ & $\begin{array}{l}\text { Maternal } \\
\text { deaths as } \\
\text { a \% of } \\
\text { total fem. } \\
\text { deaths } \\
15-49\end{array}$ \\
\hline I87I-75 & 4564230 & 677239 & I 48.0 & 25316 & 47206 & $38 \mathrm{I} 8$ & IO3. 4 & 8.4 & 56.4 & $8.1 \%$ \\
\hline I876-80 & 4715116 & $73074 \mathrm{I}$ & I55.0 & 26134 & 4I9I3 & 3033 & 88.9 & 6.4 & $4 \mathrm{I} .5$ & 7.2 \\
\hline I88I-85 & 4983573 & 742269 & 148.9 & 26001 & 41052 & 3099 & 82.4 & 6.2 & 4I. 8 & $7 \cdot 5$ \\
\hline I886-90 & $525902 \mathrm{I}$ & 763166 & I45.I & 25938 & 39450 & 2809 & 75.0 & $5 \cdot 3$ & 36.8 & 7.I \\
\hline I89I-95 & 5612303 & 787164 & 140.3 & 25300 & 40016 & 2423 & 7I.3 & $4 \cdot 3$ & 30.8 & 6.I \\
\hline I896-00 & 6043895 & 817646 & $\mathrm{I} 35 \cdot 3$ & 24965 & 36692 & 2096 & 60.7 & 3.5 & $25 \cdot 5$ & $5 \cdot 7$ \\
\hline I9OI-05 & 6515940 & $84937 \mathrm{I}$ & I30.4 & 24577 & 35644 & $2 \mathrm{IO} 3$ & 54.7 & 3.2 & 24.8 & $5 \cdot 9$ \\
\hline I906-IO & 7038063 & 853979 & I2I. 3 & 23892 & 35338 & 2083 & 50.2 & 3.0 & 24.4 & $5 \cdot 9$ \\
\hline I9II-I5 & 7680178 & $85459 \mathrm{I}$ & III. 3 & 22792 & $3445^{I}$ & 1964 & 44.9 & 2.6 & 23.0 & $5 \cdot 7$ \\
\hline I9I6-20 & $834 \mathrm{I} 384$ & 876266 & I05.I & $229 I 7$ & 50434 & 2398 & 60.5 & 2.9 & 27.4 & 4.8 \\
\hline Totals & 60753703 & 7342434 & 120.9 & 247832 & 402196 & 25826 & 63.2 & 4.25 & 35.2 & 6.4 \\
\hline
\end{tabular}

* Source: Van Poppel and Beekink (2003). Variations in the trend of stillbirth rates might be caused by different definitions of stillbirths during the research period. (Ward 2003:385).

** Source: Geneeskundig Staatstoezicht I876-I90I; CBS I90I-I920. 


\begin{tabular}{|c|c|c|c|c|c|c|c|}
\hline Age Group & Man-years & $\begin{array}{l}\text { Male } \\
\text { deaths }\end{array}$ & $\begin{array}{l}\text { Male } \\
\text { mortality, } \\
\text { deaths } \\
\text { per 1,000 } \\
\text { man-years }\end{array}$ & $\begin{array}{l}\text { Woman- } \\
\text { years }\end{array}$ & $\begin{array}{l}\text { Female } \\
\text { deaths }\end{array}$ & $\begin{array}{l}\text { Female } \\
\text { mortality, } \\
\text { deaths } \\
\text { per 1,000 } \\
\text { woman-years }\end{array}$ & $\begin{array}{l}\text { Sex Ratio } \\
\text { of Mortality. } \\
\text { Male/Fem. }\end{array}$ \\
\hline I5-I9 & I35419.99 & 786 & 5.80 & I23II9.98 & 675 & 5.48 & 1.06 \\
\hline $20-24$ & II 8870.39 & II79 & 9.92 & I07I33.6I & 842 & 7.86 & 1.26 \\
\hline $25-29$ & 105283.59 & II59 & II.OI & 94073.29 & 909 & 9.66 & I.I4 \\
\hline $30-34$ & 92689.82 & I 216 & I3.I2 & 82955.17 & 890 & 10.73 & $\mathrm{I} .22$ \\
\hline $35-39$ & 79022.65 & I27I & I6.08 & 71291.03 & 936 & $\mathrm{I} 3.13$ & I. 23 \\
\hline $40-44$ & 65465.26 & 1326 & 20.26 & 6040I.II & 832 & I3.77 & I. 47 \\
\hline $45-49$ & 53355.II & $\mathrm{I} 420$ & $26.6 \mathrm{I}$ & 51606.13 & 868 & I 6.82 & I. 58 \\
\hline All Ages & 650106.8 & 8357 & $\mathrm{I} 2.85$ & 590580.3 & 5952 & I0.08 & I. 28 \\
\hline
\end{tabular}

Table ı०B. Age and sex specific mortality rates (The Netherlands, HSN data I850-1920)

\begin{tabular}{|c|c|c|c|c|c|c|c|}
\hline Age Group & Man-years & $\begin{array}{l}\text { Male } \\
\text { deaths }\end{array}$ & $\begin{array}{l}\text { Male } \\
\text { mortality, } \\
\text { deaths } \\
\text { per 1,o0o } \\
\text { man-years }\end{array}$ & $\begin{array}{l}\text { Woman- } \\
\text { Years }\end{array}$ & $\begin{array}{l}\text { Female } \\
\text { deaths }\end{array}$ & $\begin{array}{l}\text { Female } \\
\text { mortality, } \\
\text { deaths } \\
\text { per } 1,000 \\
\text { woman-years }\end{array}$ & $\begin{array}{l}\text { Sex Ratio } \\
\text { of Mortality. } \\
\text { Male/Fem. }\end{array}$ \\
\hline I5-I9 & 100826.31 & 567 & 5.62 & IOI22I.O & 548 & $5 \cdot 4 \mathrm{I}$ & 1.03 \\
\hline $20-24$ & 69164.89 & GIo & 8.82 & 66485.09 & 432 & 6.50 & 1.36 \\
\hline $35-39$ & 46295.26 & 367 & $7 \cdot 93$ & 50068.89 & 622 & $\mathrm{I} 2.42$ & 0.64 \\
\hline $40-44$ & 40459.57 & $47 \mathrm{I}$ & II. 64 & 41106.48 & 586 & $\mathrm{I} 4.26$ & 0.82 \\
\hline $45-49$ & 33683.83 & 482 & $\mathrm{I} 4 \cdot 3 \mathrm{I}$ & $32 \mathrm{I} 33 \cdot 5 \mathrm{I}$ & 447 & I3.9I & 1.03 \\
\hline All Ages & 4II793.5 & 3228 & 7.84 & 423643.2 & 3690 & $8.7 \mathrm{I}$ & 0.90 \\
\hline
\end{tabular}


Table ıоC. Age and sex specific mortality rates (Taiwan, Census and vital statistics data $\left.1929-31^{*}\right)$

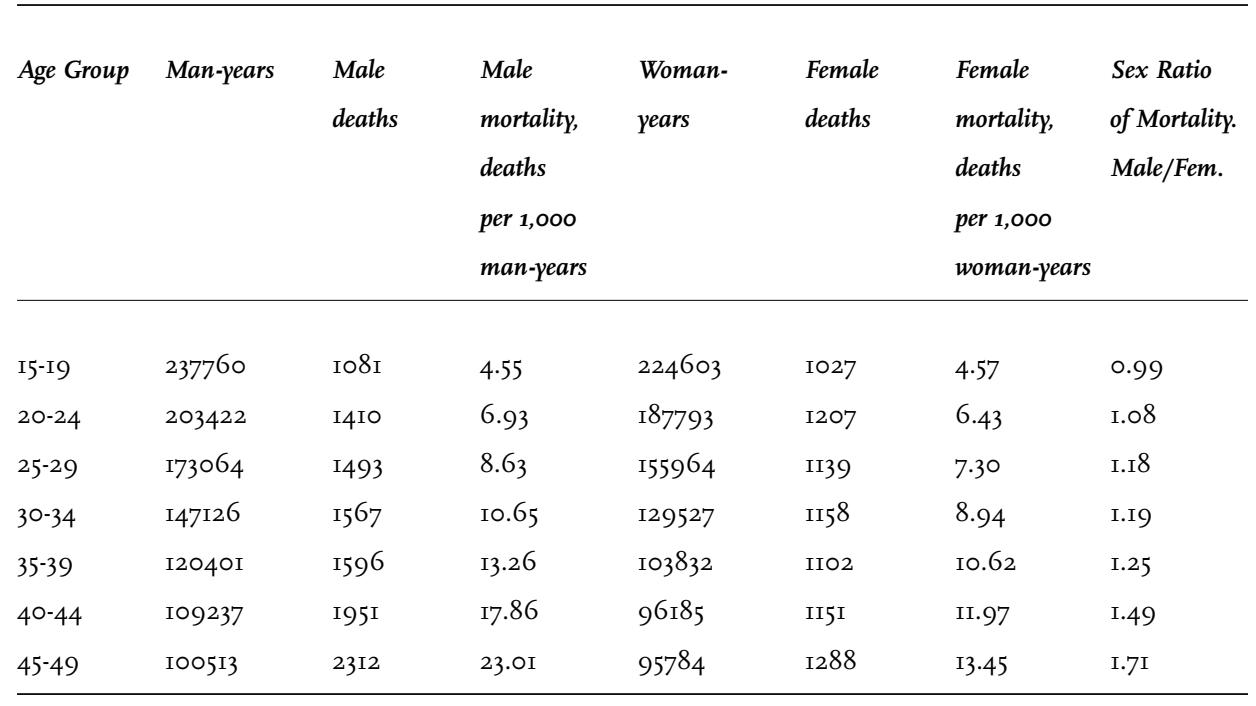

*In I929-3I the overall average death rate is close to the death rate found in the household registers

Table roD. Age and sex specific mortality rates (The Netherlands, Human Mortality Database 1850-1920)

\begin{tabular}{|c|c|c|c|c|c|c|c|}
\hline Age Group & Man-pears & $\begin{array}{l}\text { Male } \\
\text { deaths }\end{array}$ & $\begin{array}{l}\text { Male } \\
\text { mortality, } \\
\text { deaths } \\
\text { per 1,000 } \\
\text { man-years }\end{array}$ & $\begin{array}{l}\text { Woman- } \\
\text { years }\end{array}$ & $\begin{array}{l}\text { Female } \\
\text { deaths }\end{array}$ & $\begin{array}{l}\text { Female } \\
\text { mortality, } \\
\text { deaths } \\
\text { per } 1,000 \\
\text { woman-years }\end{array}$ & $\begin{array}{l}\text { Sex Ratio } \\
\text { of Mortality. } \\
\text { Male/Fem. }\end{array}$ \\
\hline I5-I9 & I 4985862 & 71366 & 4.76 & I49II373 & 71595 & 4.80 & 0.99 \\
\hline $20-24$ & I333382I & $9302 \mathrm{I}$ & 6.98 & I3579028 & 78709 & 5.80 & I. 20 \\
\hline $25-29$ & II 8882 I3 3 & 80739 & 6.79 & I2341045 & 85380 & 6.92 & 0.98 \\
\hline $30-34$ & I0707890 & 75472 & 7.05 & III27347 & 9I2I4 & 8.20 & 0.86 \\
\hline $35-39$ & 9661938 & 79687 & 8.25 & 9974852 & $9468 \mathrm{I}$ & 9.49 & 0.87 \\
\hline $40-44$ & 8666786 & 87059 & 10.05 & 8898699 & $9048 \mathrm{I}$ & I0.I7 & 0.99 \\
\hline $45-49$ & 7678787 & 98189 & I2.79 & 7920879 & 84795 & I0.7I & I.I9 \\
\hline
\end{tabular}




\begin{tabular}{llllll}
$\begin{array}{l}\text { Mother's age } \\
\text { group }\end{array}$ & Woman-years* & Maternal deaths & Live births** & $\begin{array}{l}\text { Births per } \\
\text { thousand } \\
\text { woman-years }\end{array}$ & $\begin{array}{l}\text { Maternal deaths } \\
\text { per thousand } \\
\text { births }\end{array}$ \\
\hline I5-19 & & & & \\
$20-24$ & 62832.34 & 60 & I3OI8 & 207.19 & 4.6 I \\
$25-29$ & 87293.44 & I47 & 33889 & 388.22 & 4.34 \\
$30-34$ & 82286.61 & II3 & 29103 & 353.68 & 3.88 \\
$35-39$ & 71548.14 & IOI & 22024 & 307.82 & 4.59 \\
$40-44$ & 58724.12 & 84 & I4069 & 239.58 & 5.97 \\
$45-49$ & 45854.04 & 36 & 5061 & IIO.37 & 7.11 \\
All ages & 34570.77 & 0 & 348 & I0.07 & 0.00 \\
\hline
\end{tabular}

* Sample excludes women who bore no children

** Excludes live births for whom mother's age is unknown.

Table I2B. Fertility and maternal mortality by age (The Netherlands, HSN data I850-1920)

\begin{tabular}{|c|c|c|c|c|c|}
\hline $\begin{array}{l}\text { Mother's age } \\
\text { group }\end{array}$ & Woman-years* & Maternal deaths & Live births*** & $\begin{array}{l}\text { Births per } \\
\text { thousand } \\
\text { woman-years }\end{array}$ & $\begin{array}{l}\text { Maternal deaths } \\
\text { per thousand } \\
\text { births }\end{array}$ \\
\hline I5-I9 & I5506.82 & 5 & 988 & $63.7 \mathrm{I}$ & 5.06 \\
\hline $20-24$ & 22485.06 & 37 & 10987 & 488.63 & $3 \cdot 37$ \\
\hline $25-29$ & 33199.38 & $9^{\mathrm{I}}$ & 21864 & 658.57 & 4.I 6 \\
\hline $30-34$ & 40043.74 & 97 & 23440 & 585.36 & 4.I4 \\
\hline $35-39$ & 40453.64 & 106 & I 8584 & $459 \cdot 40$ & $5 \cdot 70$ \\
\hline $40-44$ & $35002.5 \mathrm{I}$ & 57 & 8352 & $238.6 \mathrm{I}$ & 6.82 \\
\hline $45-49$ & 27733.43 & 5 & 865 & 3I.I9 & 5.78 \\
\hline All ages & 2I 4424.59 & 398 & 85080 & 396.78 & 4.68 \\
\hline
\end{tabular}

\footnotetext{
* Sample excludes women who bore no children

** Excludes live births for whom mother's age is unknown.
} 

data 1906-1945)

\begin{tabular}{llll}
\hline Parity & $\begin{array}{l}\text { Maternal } \\
\text { deaths }\end{array}$ & Live births* & $\begin{array}{l}\text { Maternal } \\
\text { death rate }\end{array}$ \\
\hline I & I73 & 30009 & 5.76 \\
2 & 87 & 23079 & 3.77 \\
3 & 69 & I8097 & $3.8 \mathrm{I}$ \\
4 & $6 \mathrm{I}$ & $\mathrm{1} 3984$ & 4.36 \\
5 & 52 & 10623 & 4.90 \\
6 & 32 & 7866 & 4.07 \\
7 & 20 & 5563 & 3.60 \\
8 & I8 & 3716 & 4.84 \\
9 & I7 & 2280 & 7.46 \\
IO+ & I3 & 2420 & 5.37 \\
All parities & 542 & II7637 & 4.61 \\
\hline
\end{tabular}

* Sample excludes births for which parity is unknown.

Table I3B. Maternal mortality by parity, deaths per Ioo० live births (The Netherlands, HSN data I850-1920)

\begin{tabular}{llll} 
Parity & $\begin{array}{l}\text { Maternal } \\
\text { deaths }\end{array}$ & Live births* & $\begin{array}{l}\text { Maternal } \\
\text { death rate }\end{array}$ \\
\hline I & IOO & I2II4 & 8.25 \\
2 & 60 & II898 & 5.04 \\
3 & 53 & II532 & 4.60 \\
4 & 45 & IO772 & 4.18 \\
5 & 35 & 9416 & 3.72 \\
6 & 35 & 8056 & 4.34 \\
7 & 2 I & 6517 & 3.22 \\
8 & I8 & 5044 & 3.57 \\
9 & IO & 36 II & 2.77 \\
IO+ & 22 & 6097 & 3.6 I \\
All parities & 399 & 85057 & 4.69 \\
\hline
\end{tabular}

* Sample excludes births for which parity is unknown. 


\begin{tabular}{llll}
$\begin{array}{l}\text { Birth interval } \\
\text { in months }\end{array}$ & $\begin{array}{l}\text { Maternal } \\
\text { deaths }\end{array}$ & Live birth $*$ & $\begin{array}{l}\text { Maternal } \\
\text { death rate }\end{array}$ \\
\hline I3-I8 & 32 & $767 \mathrm{I}$ & $4 . \mathrm{I} 7$ \\
$\mathrm{I} 9-24$ & 58 & $\mathrm{I} 546 \mathrm{I}$ & 3.75 \\
$25-30$ & 68 & $2 \mathrm{I} 878$ & $3 . \mathrm{II}$ \\
$3 \mathrm{I}-36$ & 76 & $\mathrm{I} 72 \mathrm{I} 4$ & 4.42 \\
$37-60$ & 90 & $\mathrm{I} 8674$ & 4.82 \\
$60-\mathrm{I} 20$ & 27 & 4287 & 6.30 \\
I2O+ & 0 & $4 \mathrm{I} 2$ & 0.00 \\
All intervals & $35 \mathrm{I}$ & 85597 & $4 . \mathrm{IO}$ \\
\hline
\end{tabular}

* Sample exludes first births and births for which interval length is unknown

Table I4B. Maternal mortality by birth interval (The Netherlands, HSN data I850-1920)

\begin{tabular}{llll}
$\begin{array}{l}\text { Birth interval } \\
\text { in months }\end{array}$ & $\begin{array}{l}\text { Maternal } \\
\text { deaths }\end{array}$ & Live births* & $\begin{array}{l}\text { Maternal } \\
\text { death rate }\end{array}$ \\
\hline I3-18 & 89 & 20243 & 4.40 \\
I9-24 & 57 & I6027 & 3.56 \\
$25-30$ & 32 & II416 & 2.80 \\
3 I-36 & 26 & 6405 & 4.06 \\
$37-60$ & 38 & 8066 & 4,71 \\
60-I20 & I9 & 2616 & 7.26 \\
I20+ & 2 & 261 & 7.66 \\
All intervals & $263^{* * *}$ & 65034 & 4.04 \\
\hline
\end{tabular}

\footnotetext{
* Sample exludes first births and births for which interval length is unknown

$* * \mathrm{~N}$ is here 263 and not 399 because first-borns were left out; intervals shorter than I3 months were left out and twins were left out (interval o).
} 



\section{Maternal depletion and infant mortality}

Theo Engelen

Radboud University

Nijmegen

Arthur P. Wolf

Stanford University 
Maternal depletion refers to the possibility of ongoing decline in physical health during the reproductive life of a woman. It is the result of the growing metabolic burden of successive gestations and periods of lactation in societies where birth intervals are short. Especially when food is in short supply mothers will not be able to recover from a previous pregnancy before the next starts. Thus, depletion is a threat for all women experiencing short intervals between births. It is an even more serious threat for women growing older, since their recuperation takes longer (Wood I994; Ellison 200I).This phenomenon has many implications for the women themselves and for their fecundity. In this paper we are interested in one specific implication: infants of depleted mothers run a higher risk of dying. Ellison specifically points out: "The shorter the interval separating births, the greater the risk of mortality of the offspring. Intervals of less than two years between births are particularly dangerous," (Ellison 200I: 95-97).

Ellison's observation is not new. One of the well-known predictors for infant mortality is the length of the preceding birth interval. Studies of populations in different parts of the world and in different time periods have come to the general conclusion that inter-pregnancy intervals shorter than I 8 months, in some cases shorter than 24 months, have a negative effect on the survival chances of children closing this interval (De Sweemer i984; Conde-Agudelo 2006).

The causal link with infant mortality is through birth weight. Children born less than two years after the previous birth have a lower birth weight, their general condition is more likely to be frail, and, thus, their chances of reaching their first birthday relatively low (De Sweemer i984: 50). All things being equal we expect this phenomenon to be visible in all societies. By definition, however, all things are not equal. Since we compare in this paper a Western European and a Chinese population we are dealing with societies that, for those who believe the observations by Thomas Malthus, regulated population growth via a preventive and a positive check, respectively. The preventive check used marriage restriction to limit the number of women marrying and to keep the age at marriage high. This check was greatly fostered by the custom of neo-locality. Only those couples who had the resources to start a new family were enabled to procreate. Therefore, as a rule, only physically mature and relatively prosperous women bore children in Europe. In the Chinese situation the new couple after marriage lived with the parents of the groom. As a result young marriages were possible even if the standard of living from a European perspective did not allow for new household members (Malthus I960; Hajnal i965; Engelen and Wolf 2005).

These marriage patterns are expected to show when comparing the fertility patterns of married women in the Dutch city of Nijmegen and the Taiwanese city of Lugang. If Malthus is right, depletion must be a phenomenon more active in Taiwan than in the Netherlands, since women in Taiwan married younger and therefore had a longer reproductive span. The impact of small birth intervals on 
infant mortality should therefore be more manifest in Taiwan too. Also, we expect depletion to show more when women are older and parity grows. In order to make the comparison feasible, we selected our individual level data in Nijmegen for women marrying between 1840 and 1890 . This is the period in which the demographic and socio-economic conditions resemble Lugang society during the colonial period (I895-1945) as much as possible (See Engelen and Hsieh 2007). For these years the Japanese colonial government carefully compiled population registers in Taiwan.

When we compare the possible influence of the length of birth intervals on infant mortality in Nijmegen and Lugang, the comparison obviously has to take into account that both variables may be different. We start with the dependent variable, infant mortality. Infants in Lugang had a smaller chance to survive until their first birthday. Of I,000 births, infant mortality claimed I7I victims in Lugang against 145 in Nijmegen. Even more interesting is the finding that the relative levels of neonatal and post-neonatal mortality differed markedly. Neonatal mortality in Lugang was almost three times as high as in Nijmegen (93 against 36). Surprisingly, with regard to post-neonatal mortality the opposite was true; of I, 000 survivors of the first month of life, death claimed II3 victims in Nijmegen and 86 in Lugang. The higher level of infant mortality in Lugang was thus completely driven by the mortality of neonates (Engelen and Hsieh 2007: I04).

This finding is unexpected. Generally, we assume that post neonatal mortality is influenced by the general living standard of a population, the medical and hygienic situation, and by social position. Neonatal mortality, on the other hand, is caused by variables like obstetrical trauma, congenital defects, or functional inadequacy. Since the last mentioned variables are often described as being alike in most societies, scholars tend to explain the differences in infant mortality by different social and economic settings. When we introduce depletion, however, we logically expect the effects to show most of all for the neonates. It is exactly this group that is most vulnerable and would have to pay the price for the depletion of their mothers. Thus, the influence of maternal depletion could explain the differences in neo-natal mortality between Lugang and Nijmegen.

We now turn to birth intervals, our independent variable. Figure I (based on Table I in the Appendix) shows the relative frequency of birth intervals in the two populations. Nijmegen couples had less time at their disposal for childbearing since they married later than Taiwanese couples. The average age at first marriage for Nijmegen brides was 27.4 years, whereas women in Lugang married for the first time at age I8.5 (Engelen and Hsieh 2007: 67 and 70). Nijmegen couples clearly made up for this by smaller birth intervals. Forty-four percent of births in Nijmegen followed an interval of two years or less compared to only thirty-two percent in Lugang. This results in an average birth interval of 24.8 for Nijmegen and 29.6 for Lugang. According to Knodel (1988) the Nijmegen figure 


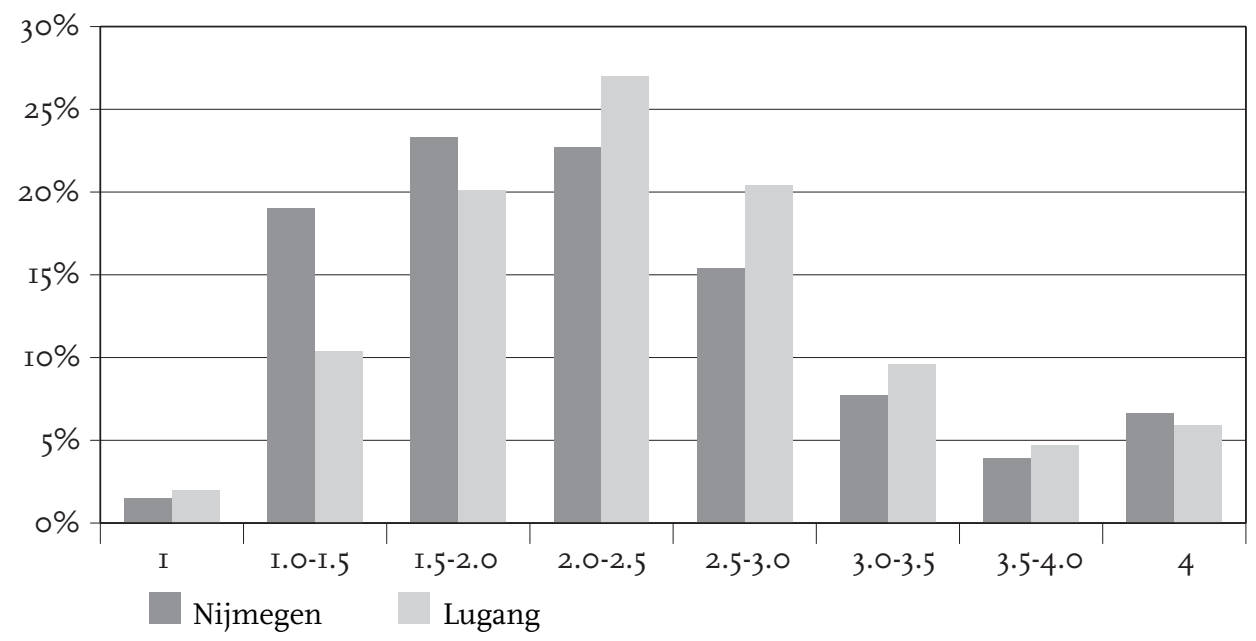

is representative for Western-European countries. Lugang is typically Taiwanese. The average birth interval for seventeen localities scattered over the island of Taiwan was 30.5 months, ranging from 28.3 to 35.2 months. Our first conclusion must be that, if all other circumstances were equal, the Dutch population is characterized by shorter birth intervals and thus meets the conditions for maternal depletion and higher infant mortality better than the Chinese population. Whether this is indeed the case, we will show later on.

As we see it, there are three possible explanations for the differential spacing of births in Nijmegen and Lugang. The first explanation is offered by authors who denounce the Malthusian explanation and claim that Chinese traditionally acted 'proactively' to limit the number of children born to a couple, long before this was customary in Western societies. That is, Chinese couples did not leave their fate in the hands of positive checks, but consciously planned their number of children (Lee and Wang 1999). One of the methods used was spacing and the logical result would be longer birth intervals. We will return to this assertion later. At any rate, these authors also consider infanticide as one of the proactive instruments used in Chinese society. This would result in higher infant mortality rates.

The second explanation hypothesizes that lower coital frequency in Taiwan resulted in longer birth intervals. This relates to Chinese marriage customs. Wolf and Huang neatly formulated the core of Chinese marriage by stating that "marriage and adoption are best viewed as the means by which families manipulated their composition to solve immediate problems and to achieve long-range goals." Therefore "decisions about marriage and adoption were instruments of family 
policy, the outcome of deliberate assessments of family needs, means, and aspirations" (Wolf and Huang I980: 57). Chinese marriages in other words were hardly arrangements of a romantic nature. The very choice of spouses and the form of marriage were not in the hands of the couple-to-be, but the exclusive right of the parents on both sides.

Basically, marriages in China consisted of a transfer of rights over the woman who was to be the bride. In many cases Chinese husbands and wives only met on the day of their wedding or very shortly before that date, and were essentially strangers. Dutch youngsters had the freedom to choose their partner themselves; they tried the relationship out in an engagement that lasted months or even years, and finally married when their choice proved to be right. We infer from this difference in courtship that the behaviour in the marital bed must have been different too. Since the strongest determinant of the probability of a conception is coital frequency, this could explain longer birth intervals in Taiwan.

The third explanation has already been mentioned: maternal depletion. This phenomenon not only dictates the survival chances of infants, it also lowers the chances of conception (Ellison 2001: 189; 192-193). If, following the Malthusian division of the world into a preventive and a positive part, Nijmegen women were better nourished and healthier than their Taiwanese counterparts, then birth intervals would logically be shorter. It is possible to use another test for this relationship. By definition, depletion is a process and will be more influential the older women become and the more children they have already born.

Our next step, therefore, is to ascertain the influence of women's age on spacing. In Figure 2 (based on Table 2 in the Appendix) we calculate the average length of birth intervals by the age of mother at the closing of the interval. Increasing age clearly results in longer birth intervals. This is the case both in Nijmegen and Lugang, and the linear development shows in both populations. Does this support the depletion hypothesis? Possibly, but we have to be aware of an alternative explanation. Since fecundity declines slowly when women's age progresses, even among well nourished women, this too may be responsible for longer intervals of women of higher ages.

Before assessing the influence of the length of birth intervals on infant mortality, we return to our first explanation for differences in the length of birth intervals between Nijmegen and Taiwan. This explanation claimed that proactive Chinese couples deliberately planned their offspring. Figure 2 provides a contra indication for this thesis. Henry's classical definition of 'natural fertility' assumes that in a controlled fertility population fertility is parity dependent and will be limited after the desired number of children is attained (Henry I96I). No such pattern of limitation shows up in the graphs. Taiwanese birth intervals are longer from the very beginning of marriage. The only possibility to maintain the proactive hypothesis would be that Chinese couples from the very start of the 


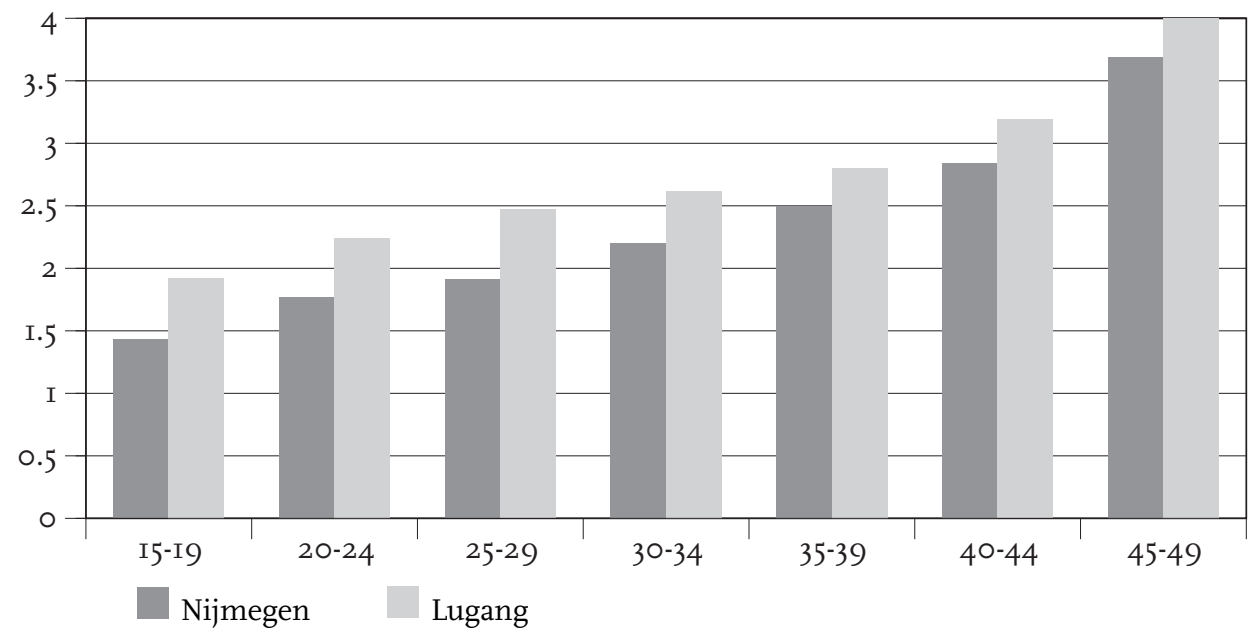

childbearing period introduced spacing. Given the emphasis on having as many sons as possible within a short period of time, this seems highly unlikely. We therefore eliminate this explanation for the longer birth intervals in Taiwan.

We now have two alternatives left to explain longer birth-intervals: lower coital frequency and/or maternal depletion. Since we are dealing with the relationship between birth intervals and infant mortality, only the last possibility remains. It is hard to see how coital frequency could influence the survival chances of infants. The depletion hypothesis on the other hand still stands. When mothers grow older their bodies pay the price for successive pregnancies and semi-continuous breastfeeding. What is more, infants born to them pay an even higher price.

In Figure 3 (based on Table 3) the relationship between birth intervals and infant mortality is plotted by calculating the infant deaths per birth by the length of the preceding birth interval. We have already mentioned the large structural difference in the absolute levels of infant mortality in Nijmegen and Lugang, I45 and I7I respectively. Here, we focus on the influence small birth intervals have on infant mortality. Therefore, we calculated for both cities indices using the 2.5 to 3 year interval as the standard (=IO०).

We find that short birth intervals have the expected negative effect on survival chances of infants, and for the intervals shorter than a year this effect is much stronger in Taiwan than in the Netherlands. Also, birth intervals longer than three years cause a moderate rise in infant mortality. As a general conclusion we find that, although the absolute level of infant mortality differed, a quick succession of births indeed caused infant mortality to rise in both societies. The 


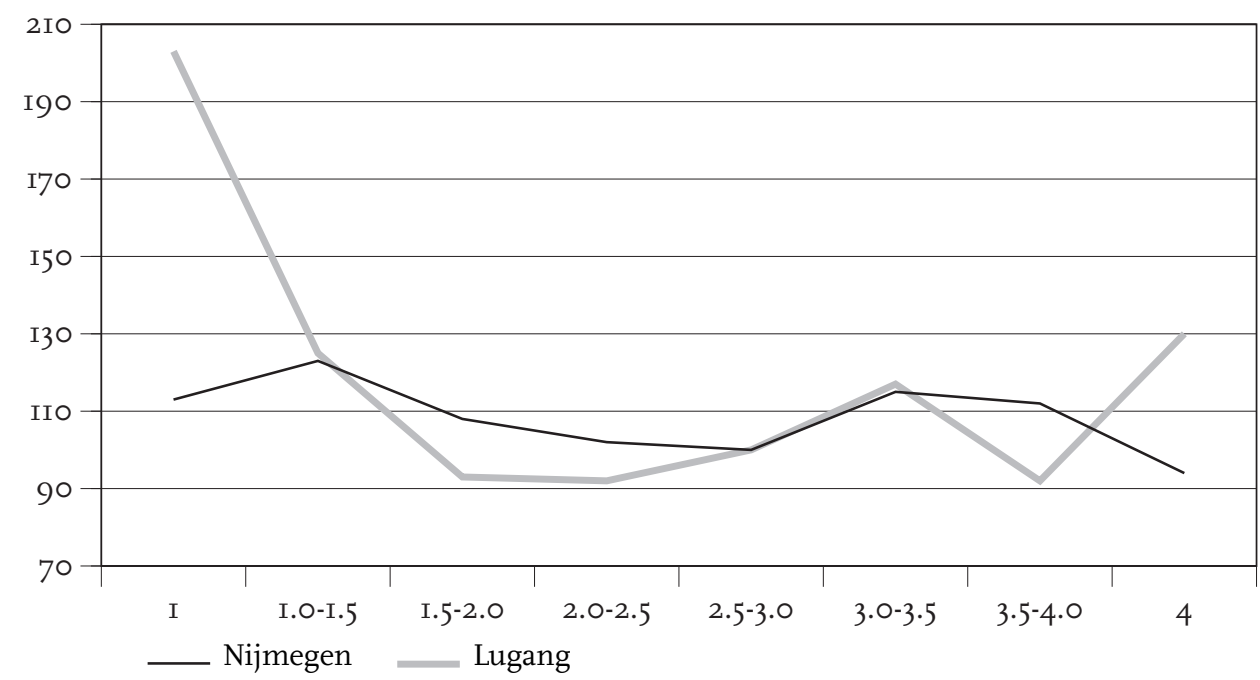

increase is especially remarkable for the birth interval smaller than one and a half years.

Our next step will be to look into the impact of rising age of the mother. As mentioned, depletion will be more manifest when mothers grow older. Do we find a corresponding increase in the probability of infant deaths? Figure 4 provides us with a positive answer to this question. The rise in infant mortality between children born to mothers aged 20-24 and those born to women aged 2529 is visible already for Nijmegen, but the more dramatic decline in survival chances of infants occurs when mothers are in their thirties and forties. If we take the level of infant mortality for mothers giving birth at age 20-24 as our starting point, the relative growth by age is higher in Lugang. The increase between the first and the last age categories is $46 \%$ in Lugang against 38\% in Nijmegen.

Our conclusion until this point must be that small birth intervals lead to high infant mortality and that survival chances of newly born children are negatively related to the age of the mother. In both cases we have reason to believe that maternal depletion is the causal factor. A direct link is difficult to prove, since infant mortality in influenced by both endogenous and exogenous variables. We may therefore refine our approximation by looking specifically at neonatal mortality, the death of infants within the first month of life. 


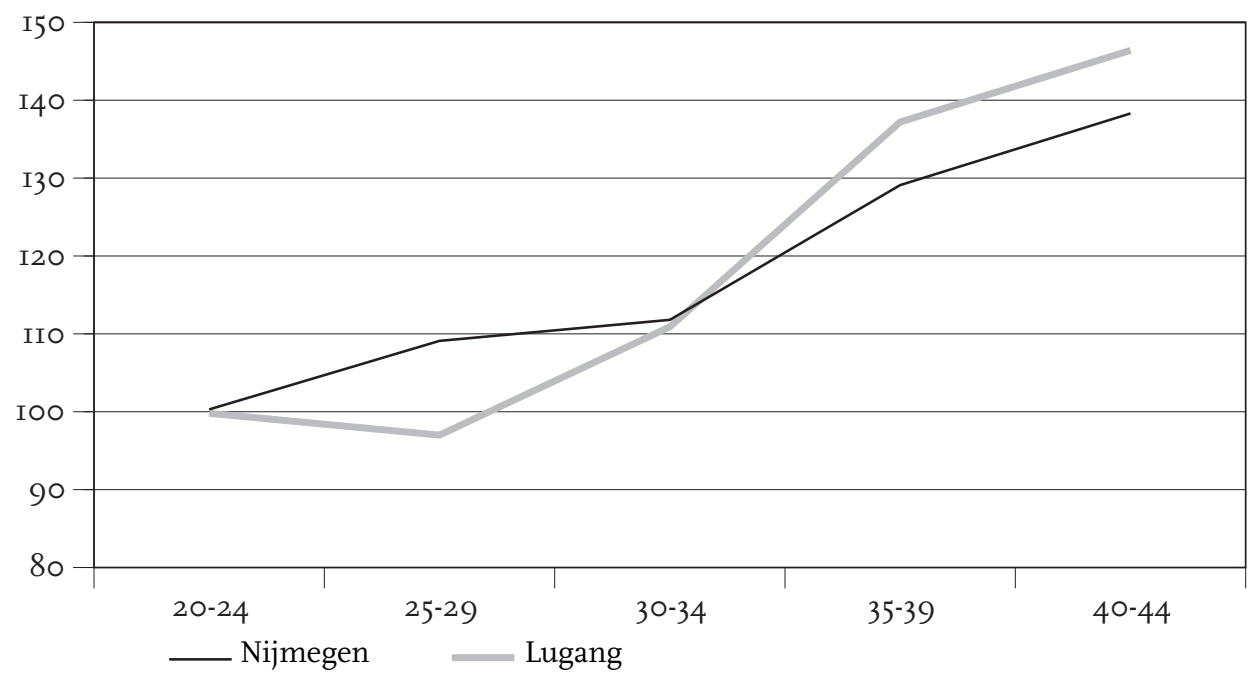

Differences between populations in this type of mortality are most likely the result of maternal depletion, whereas in post-neonatal mortality a host of other factors may be involved.

Figure 5 once again shows the validity of the generalizations about the relation between birth intervals and mortality risks, in this case neonatal mortality. In order to exclude the possible distortion of the results by adoption and out migration of Lugang neonates, our denominator in the calculation is the number of person months lived by neonates instead of births (see Table 5). In the case of neonatal mortality the safest interval between births is between 2.5 and 3 years in both populations. Clearly both shorter intervals (smaller than one and a half year) and longer intervals (more than three years) are dangerous for the infants closing that interval. If we leave the absolute differences in neonatal mortality between Nijmegen and Lugang aside, and concentrate on the relative differences with regard to birth intervals, there is a remarkable resemblance. Up through the interval 2.5-3 years it is hard to distinguish between the two curves. Consequently, the effect of increases in the length of the birth-interval on the probability of dying appears to be the same in the Netherlands and Taiwan.

Do we reach the same conclusion when we focus on the influence of mother's age on neonatal mortality? As the index curves in Figure 6 show, we do indeed. The indexes should not be misread to suggest Nijmegen neonatal mortality is higher; the opposite is the case (see Table 6). The graph only confirms that when a mother grows older, the mortality risk for her neonate rises substantially. 


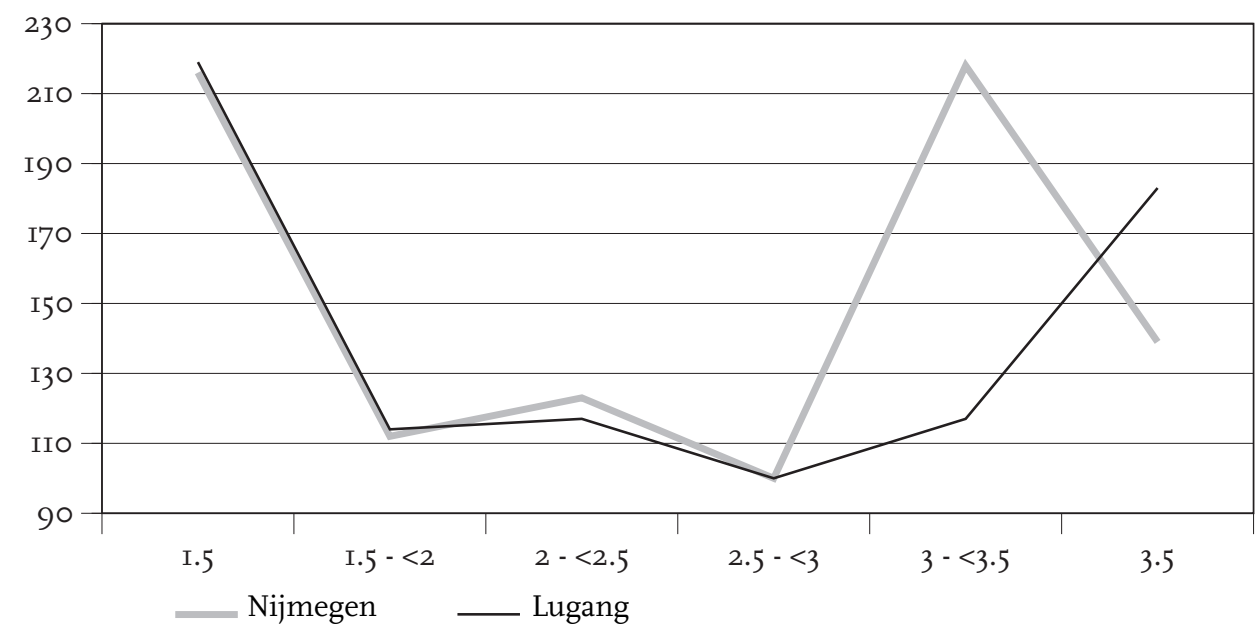

After age 35 this risk is about $40 \%$ higher than at age $20-24$. Although the mortality risk in Nijmegen between age 25 and 34 increases more rapidly than in Lugang, the absolute level still is much lower. Our general conclusion must be that the more precise measure of neonatal mortality also shows the effect of maternal age.

The evidence we presented in this paper is not without problems. Although elsewhere it was demonstrated that infant mortality and fertility in Nijmegen were representative for the Netherlands as a whole, even for Western Europe, and the demography of Lugang was very Chinese, our case would be more convincing if we had used a dataset for larger proportions of the Dutch and Taiwanese populations. Still, the results all point in the same direction. Small birth intervals indeed fostered high infant mortality, especially in Lugang, but also in Nijmegen. In Taiwan, another finding from the relevant literature is confirmed. Very long birth intervals are also negatively correlated with survival chances of infants.

The comparison of the two societies also reveals interesting differences. The average birth interval in the Netherlands was markedly smaller, as if Dutch couples tried to make up for the shorter period in marriage. Also, Nijmegen mothers were on average older than their Taiwanese counterparts (see Table 2). Although one would expect these factors to be associated with higher infant mortality, this is not the case. Survival chances of Nijmegen infants were better for children born at all birth interval lengths. 

I00)

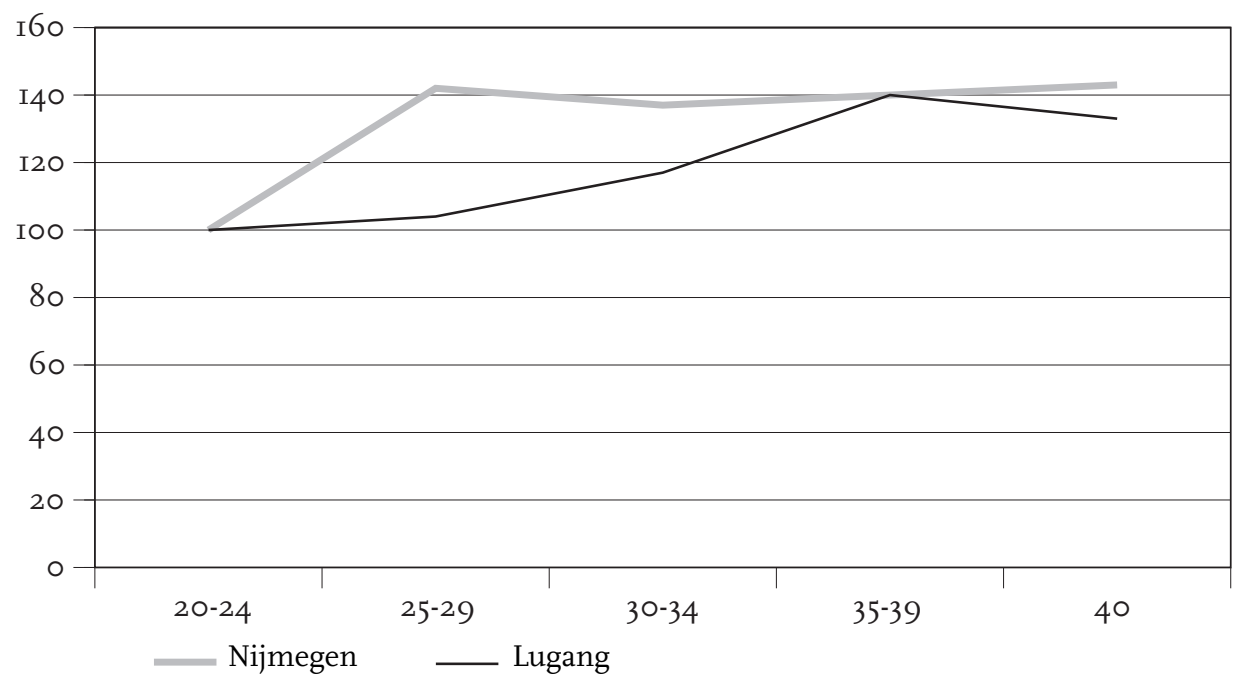

This, however, does not rule out the role of maternal depletion as the intermediate variable. Both in Nijmegen and Taiwan birth intervals smaller than one and a half years boosted the chances of infant death. Our results also show that maternal depletion was a more active phenomenon in Taiwan. Infants born within I8 months after the previous child had a 37 per cent higher chance of dying in Lugang than they had in Nijmegen (see Table 3). At the other end of the spectrum we find that babies born more than 48 months after the previous child have a much higher survival rate in Nijmegen. Since age of the mother is positively correlated with infant mortality, our case for depletion as an important factor is strong.

In the end, then, we can only conclude that depletion explains the relationship between short birth intervals and infant mortality. Most of all, however, we find that the burden of maternal depletion is heavier for Taiwanese than for Dutch women. Thomas Malthus would have nodded approvingly, had he been able to read this conclusion. For those who deride his ideas as mythology, the same conclusion should be a reason to rethink their views. 
Table I. Relative Frequency of Birth Intervals of Various Lengths

\begin{tabular}{lllll}
\hline \multicolumn{3}{c}{ Nijmegen } & \multicolumn{3}{c}{ Lugang } \\
Length & $N$ & $\%$ & $N$ & $\%$ \\
interval & & & & \\
\hline & & & & \\
$<\mathrm{I}$ & 68 & $\mathrm{I} .53$ & 59 & $\mathrm{I} .95$ \\
I.0-I.5 & 844 & $\mathrm{I} 8.97$ & $3 \mathrm{I} 3$ & 10.36 \\
I.5-2.0 & I035 & 23.27 & 606 & 20.05 \\
$2.0-2.5$ & IOO9 & 22.68 & $8 \mathrm{I} 5$ & 26.97 \\
$2.5-3.0$ & 683 & 15.36 & 616 & 20.38 \\
$3.0-3.5$ & 342 & 7.69 & 291 & 9.63 \\
$3.5-4.0$ & I72 & 3.87 & I43 & 4.73 \\
$>4$ & 295 & 6.63 & I79 & 5.92 \\
All & 4448 & 100.00 & 3022 & 100.00 \\
\hline
\end{tabular}

Table 2. Length of Birth Interval by Age of Mother

\begin{tabular}{lllll}
\hline Age of & $\begin{array}{c}\text { Nijmegen } \\
\text { Number of } \\
\text { mother }\end{array}$ & $\begin{array}{l}\text { Lverage length } \\
\text { intervals } \\
\text { of interval } \\
\text { (in years) }\end{array}$ & $\begin{array}{l}\text { Number of } \\
\text { intervals }\end{array}$ & $\begin{array}{l}\text { Average length } \\
\text { of interval } \\
\text { (in years) }\end{array}$ \\
\hline & & & & \\
I5-19 & 6 & I.43 & I2I & I.92 \\
$20-24$ & 245 & I.77 & 924 & 2.24 \\
$25-29$ & 932 & I.91 & 957 & 2.47 \\
$30-34$ & I327 & 2.2 & 597 & 2.62 \\
$35-39$ & I2I4 & 2.5 & 317 & 2.8 \\
$40-44$ & 625 & 2.84 & I02 & 3.19 \\
$45-49$ & 99 & 3.69 & 4 & 4 \\
All & 4448 & & 3022 & \\
\hline
\end{tabular}


Nijmegen

\begin{tabular}{|c|c|c|c|c|c|c|c|c|}
\hline $\begin{array}{l}\text { Length of } \\
\text { interval }\end{array}$ & Births & $\begin{array}{l}\text { Infant } \\
\text { deaths }\end{array}$ & $\operatorname{InfD} / B$ & Indices & Births & $\begin{array}{l}\text { Infant } \\
\text { deaths }\end{array}$ & $\operatorname{InfD} / B$ & Indices \\
\hline$<\mathrm{I}$ & 68 & IO & O.I47 & II3 & 59 & I9 & 0.322 & 203 \\
\hline I.O-I. 5 & 844 & I35 & 0.160 & I23 & $3 \mathrm{I} 3$ & 62 & o.I98 & I25 \\
\hline I. $5-2.0$ & 1035 & I45 & O.I40 & IO8 & 606 & 90 & 0.149 & 93 \\
\hline $2.0-2.5$ & 1009 & I34 & 0.133 & 102 & $8 \mathrm{I} 5$ & II9 & 0.146 & $9^{2}$ \\
\hline $2.5-3.0$ & 683 & 89 & 0.130 & 100 & $6 \mathrm{I} 6$ & 98 & 0.159 & 100 \\
\hline $3 \cdot 0-3 \cdot 5$ & 342 & $5^{I}$ & O.I49 & II 5 & $29 \mathrm{I}$ & 54 & 0.186 & II7 \\
\hline$>3.5$ & 233 & 3I & O.I34 & IO3 & I6I & 29 & O.I77 & III \\
\hline
\end{tabular}

Table 4. Infant Deaths per Birth by Age of Mother

\begin{tabular}{|c|c|c|c|c|c|c|}
\hline \multirow[b]{2}{*}{$\begin{array}{l}\text { Age of } \\
\text { mother }\end{array}$} & \multirow[b]{2}{*}{ Births } & \multicolumn{2}{|c|}{ Nijmegen } & \multicolumn{3}{|c|}{ Lugang } \\
\hline & & Infant & $\begin{array}{l}\text { InfD } / B \\
\text { deaths }\end{array}$ & Births & Infant & $\begin{array}{l}\text { InfD } / B \\
\text { deaths }\end{array}$ \\
\hline $20-24$ & 245 & 29 & O.II8 & 924 & $\mathrm{I} 42$ & 0.154 \\
\hline $25-29$ & 932 & $\mathrm{I} 20$ & 0.129 & 957 & I43 & 0.149 \\
\hline $30-34$ & I327 & I75 & 0.132 & 597 & IO2 & O.I7I \\
\hline $35-39$ & $\mathrm{I} 2 \mathrm{I} 4$ & 185 & 0.152 & 317 & 67 & $0.2 \mathrm{II}$ \\
\hline $40-44$ & 625 & IO2 & 0.163 & IO2 & 23 & 0.225 \\
\hline
\end{tabular}

Table 5. Neonatal Mortality per Person Month by Length of Birth Interval

Absolute

Indices

\begin{tabular}{lllll} 
Interval & Nijmegen & Lugang & Nijmegen & Lugang \\
\hline$<\mathrm{I} .5$ & 0.0432 & 0.158 & $2 \mathrm{I} 6$ & $2 \mathrm{I} 9$ \\
$>=\mathrm{I} .5-<2$ & 0.0223 & 0.082 & $\mathrm{II} 2$ & $\mathrm{II} 4$ \\
$>=2-<2.5$ & 0.0246 & 0.084 & $\mathrm{I} 23$ & $\mathrm{II} 7$ \\
$>=2.5-<3$ & 0.02 & 0.072 & $\mathrm{IOO}$ & $\mathrm{IOO}$ \\
$>=3-<3.5$ & 0.0435 & 0.084 & $2 \mathrm{I} 8$ & $\mathrm{II} 7$ \\
$>=3.5$ & 0.0353 & 0.097 & $\mathrm{I} 39$ & $\mathrm{I} 83$
\end{tabular}




\begin{tabular}{|c|c|c|c|c|c|c|c|c|}
\hline \multirow[b]{2}{*}{ Age } & \multicolumn{3}{|c|}{ Nijmegen } & \multicolumn{3}{|c|}{ Lugang } & Nijmegen & \multirow{2}{*}{$\begin{array}{l}\text { Lugang } \\
\text { es }\end{array}$} \\
\hline & pmonts & deaths & ratio & pmonts & deaths & ratio & indi & \\
\hline I5-19 & o & ० & o & IIо. 88 & I4 & 0.1263 & & \\
\hline $20-24$ & 242.65 & 6 & 0.0247 & $868.7 \mathrm{I}$ & 74 & 0.0852 & IOO & 100 \\
\hline $25-29$ & $9 \mathrm{I} 3.2 \mathrm{I}$ & 32 & 0.035 & 904.96 & 80 & 0.0884 & $\mathrm{I} 42$ & IO4 \\
\hline $30-34$ & I297.49 & 44 & 0.0339 & $559 \cdot 73$ & 56 & O.I & I37 & II7 \\
\hline $35-39$ & II85.32 & $4 \mathrm{I}$ & 0.0346 & 292.69 & 35 & 0.1196 & I4O & I4O \\
\hline$>=40$ & 708.04 & 25 & 0.0353 & 97.43 & II & 0.1129 & I43 & $\mathrm{I} 33$ \\
\hline
\end{tabular}





\section{II}

\section{The massacre of the innocents}

Infant mortality in Lugang (Taiwan) and Nijmegen (the Netherlands)

Theo Engelen

Radboud University

Nijmegen

Hsieh Ying-Hui

Academia Sinica,

Taiwan 


\section{Introduction}

Infant mortality is one of the most striking characteristics of pre-industrial demography. By modern standards the chances of survival for newly born children were astonishingly low. Almost one quarter of infants did not reach the first birthday, and mortality remained high in childhood. From an economic point of view one might conclude that pre-industrial fertility was very inefficient. It took many births to produce a smaller number of surviving children. From an emotional point of view some authors have referred to this phenomenon as "the massacre of the innocents." The high death rates of the very young deserve attention because they highlight the economic conditions of life in the societies involved, the social differentiation within these societies, and the 'deliberate' choices made by historical actors.

When comparing a Western European and a Chinese population, as we do here, one also confronts an important issue, the practice of infanticide in China. Thomas Malthus pointed to the effects of early and universal marriage among the Chinese which resulted, in his view, in a high growth rate of population which "must be repressed by occasional famines, and by the custom of exposing children, which, in times of distress, is probably more frequent than is ever acknowledged to Europeans," (Malthus I960). Malthus clearly distinguished European demography from Chinese demography by attributing preventive checks of late, non-universal marriage to the European system and positive checks to the Chinese system.

This view has been challenged by a new generation of scholars in the China field (Wang, Lee and Campbell I995; Lee and Campbell I997; Zhao I997). Their views were brought together in One Quarter of Humanity. Malthusian Mythology and Chinese Realities by James Lee and Wang Feng (1999). The authors challenged the traditional assumptions of demographers with regard to Chinese fertility. Malthus was wrong, the authors argued, when he claimed that positive checks controlled Chinese population growth. Chinese actors should not be seen as passive victims of circumstances. Four mechanisms actively influenced growth rates: (mostly female) infanticide, a gender-unbalanced marriage market, a low level of marital fertility and, lastly, adoption. In Lee's view, the gender differentiated character of infant mortality provides a strong example of 'proactive' behavior, and thus of the inadequacy of the Malthusian model. In our paper we will test one part of this hypothesis. Is there indeed a higher mortality among female infants than among male infants in our Chinese population? And - since this custom does not have to be restricted to Chinese parents only - do we find evidence of gender differences in infant mortality in our Dutch sample?

We take the towns of Nijmegen in the Netherlands and Lugang in Taiwan as examples of the two demographic regimes said to rule Europe and China. By zooming in on these two populations we can examine both the general charac- 
teristics of the countries they are situated in and their local peculiarities. Lugang is located on the west coast of central Taiwan. Until I850, it had been Taiwan's second largest city, a situation which is captured in the saying "Yi Fu, Er Lu, San Mengjia" (first Tainan, second Lugang, and third Taipei). This position was the result of being the main seaport connecting central Taiwan with southern Fukien, on the other side of the Chinese strait. Although Lugang had to struggle constantly against silting and blockage, for a long time there was no better way to transport goods from or to the Changhua plain. DeGlopper described the city in this boom period as follows: "Lugang had official yamens, granaries, warehouses, temples, and academies, and was the site of magnificent annual festivals and conspicuous displays of wealth. But it produced practically nothing for itself, and depended on the trade that exchanged the rice and agricultural products of central Taiwan for the cloth and manufactured articles of Southern Fukien" (DeGlopper I995: 78).

This one-sided orientation of the city backfired in the second half of the Igth century. The development of the northern part of the island was responsible for a declining relative position of Lugang, but the city also witnessed an absolute decline. More and more, rice was not exported to the mainland, but consumed by the growing population of Taiwan itself. Fukien province managed to buy rice in Indochina and transported it cheaply by way of large steamships. The final blow came when the Japanese finished the north-south railway, in I905 connecting Changhua and Kaohsiung, and in I908 Changhua and the north. The newly developed seaports of Keelung and Kaohsiung could host modern steam ships, and took over almost all transport. Lugang remained a port visited by small junks only. The following figures are indicative: in 1896 1051 ships arrived in port, in 1937 only 8.

At the other end of the Eurasian continent we find Nijmegen, a mediumsized provincial town located, north-south, in the middle of the Netherlands, close to the eastern border. The city was founded along the river Waal that connected the western part of the Netherlands with Germany. This geographic position had made the city a thriving river port for centuries. The Waal and the trade it generated between several parts of Europe formed the core of Nijmegen's economic activities from the Middle Ages on. Time and again, however, the vulnerability of the river trade showed when the succession of wars that characterized European history in the early modern era resulted in traffic and trade barriers. The occupation of the country by the French at the end of the i8th century dealt a final blow to Nijmegen's trade, because it closed the border with Germany. Also, when the French army approached the city in October 1794, many members of the Protestant elite fled the city and found refuge in Holland, leaving Nijmegen without its traditional ruling class.

This was only one reason for the decline. Nijmegen also became the vic- 
tim of the structural transformation of interregional transport routes. Larger cities, like Rotterdam in the Netherlands, and Köln and Düsseldorf in Germany, took over the position of the traditional towns along the rivers Waal, Maas and Rijn, leaving them only a small part of the total trade. The effect of the financial catastrophe following the French invasion was visible during a large part of the I9th century. Nijmegen entrepreneurs became very cautious and they made few investments in new products and production processes. The number of rentiers who chose to buy land and obligations rose. The city government too cut back on improvements (Engelen 2005; Klep 2005).

The comparison of the two towns is made difficult since they had different histories of development. What periods can we compare? The detailed individual level data available for Taiwan cover the years of the Japanese colonial period between I895 and I945. We therefore selected a period in Dutch history that was similar with regard to economic and demographic development. An analysis of relevant indicators showed that for Nijmegen the years between approximately I840 and I890 resembled Lugang in the period I895-I945 (Engelen and Hsieh 2006). To be sure, in these periods the cities resembled each other as much as two cities at the both ends of the Eurasian continent could. Both were medium sized provincial towns with a regional function, both were once flourishing ports and both were, in the period studied, suffering from an economic crisis.

\section{The level and development of infant mortality in Nijmegen and Lugang}

The European decline in mortality started during the I8th century when crisis mortality was mitigated through successful preventive measures against epidemic infectious diseases. After that, for most of the I 9 th century, mortality stabilized, until around I900 a new period of decline set in. This latter phase is characterized mainly by lower infant and childhood mortality as a result of the prevention and better treatment of diarrhea and tuberculosis (Schofield et al. I99I). The general mortality level of the igth century hides interesting developments for infant mortality. Whereas adult mortality stabilized or even slightly declined, the chances of survival for the very young declined in the third quarter of the century. In Germany (Knodel I988: 40), France (Vallin I99I: 5I) and Spain (Reher et al. I997) we find evidence of rising infant mortality between roughly i 840 and I870. This development and the reason behind it was recognized very early. L. Emmett Holt mentioned it in his I9I3 presidential address for the American Association for the Study and Prevention of Infant Mortality. He attributed the mid-Igth century increase of infant mortality to the process of urbanization and industrialization. Densely populated cities and, especially, mothers working in factories proved fatal for many babies.

The link between women's work and infant mortality is breastfeeding, 
because all authors agree on the fact that the extent and duration of breastfeeding is the best predictor of infant mortality. The most striking example of this relationship is provided by Knodel who found a marked difference in infant mortality between his Bavarian villages, where breastfeeding was rare, and the villages in East Frisia, where breastfeeding was common (Knodel I988: 45). The Netherlands were no exception to the development mentioned. Van Poppel and Mandemakers observed that for the country as a whole infant mortality increased markedly between I840 and I875 (Van Poppel and Mandemakers I997: 276).

We probably know more of the demography of early 20 th century Taiwan than of any other Asian country. The reason for this exceptional position is the amount and quality of data available. The censuses conducted by the Japanese colonial government (I895-I945) provide information on the aggregate level. On top of that, the accurately kept household registers contain detailed information on individuals and their households. Taiwan, however, was not representative of other countries in the region, because of the influence of its colonial ruler. The Japanese Government-General realized early on that more Japanese soldiers died of diseases than as a result of hostilities. In order to eliminate epidemics and indigenous diseases on the island the colonial government launched large-scale programs to control major epidemics, to improve public health conditions, and to increase medical resources. The effects of this effort show in a declining crude mortality rate of Taiwan from 30 per I000 inhabitants in 1906 to I6 per thousand in I942 (Barclay I954: I45).

Whether or not this general decline affected infant mortality has been recently assessed by Yang Wen-Shan and Hsieh Ying-Hui on the basis of data from I4 field sites across the island. They confirm Barclay's finding (Barclay I954: I6I) of a long-term decline of infant mortality between I905 and I945. Still, they also point to the temporal fluctuations in the development, and their graphs show that the secular decline only started after 1920. As far as the magnitude of the decline is concerned we disagree with these authors when they state that it was characterized by a relatively slow pace (Yang and Hsieh 2004: I8-I9). Since male infant mortality went from 223 in 1908 to 195 in 1925 to 130 in I945, and from 207 to 136 to 130 for females, we consider this an impressive decline. On the whole, the colonial period thus witnessed a general decline of infant mortality and a closing of the distance between male and female infant mortality.

The findings mentioned above guide our expectations for infant mortality in Lugang and Nijmegen. If the Dutch town lives up to the national average, the mortality among the very young will probably show a rise, whereas the probability of survival for infants in the Taiwanese town is expected to increase. In Nijmegen, we calculated infant mortality by using the information on births and infant deaths of I2OI non-sterile marriages. The Lugang infant mortality rates 


\begin{tabular}{|c|c|c|c|c|c|c|c|}
\hline \multirow[b]{2}{*}{ Period } & \multicolumn{3}{|c|}{ Nijmegen } & \multirow[b]{2}{*}{ Period } & \multicolumn{3}{|c|}{ Lugang } \\
\hline & live births & $\begin{array}{l}\text { infant } \\
\text { deaths }\end{array}$ & $I M R$ & & live births & $\begin{array}{l}\text { infant } \\
\text { deaths }\end{array}$ & $I M R$ \\
\hline I830-I849 & IOI9 & I32 & I29 & I922-I933 & 1670 & 344 & 206 \\
\hline I850-I869 & 2770 & 385 & I39 & I934-I945 & 2228 & $32 \mathrm{I}$ & I44 \\
\hline I870-1889 & $\mathrm{I} 42 \mathrm{I}$ & 237 & 167 & & & & \\
\hline Total & 5210 & 754 & 145 & Total & 3898 & $66_{5}$ & 171 \\
\hline
\end{tabular}

were derived from the household registers in the same way, starting in the I920s. We have reason to believe that, especially in the first years after the introduction of these registers, there was a slight under registration with regard to births as well as infant deaths. This was already established by Barclay who expected under registration only for the period before I9I5. The same author also refers to three exceptional years of epidemic diseases. In I9I5 the country suffered from an unusually high number of malaria deaths. The worldwide influenza outbreaks following World War I hit Taiwan in I9I8 and I920 (Barclay I954: I46 and I60). Since we are interested in the long term development, we only used information from I920 on, and divided the colonial period between I922-I933 and I934-I945.

Our first observation is that the average level of the infant mortality rate (IMR) we find for Nijmegen is I45. The national average of IMR is markedly higher since the provinces in the western part of the country witnessed the death of more than a quarter of all infants. The Nijmegen level, however, fits the description for the province of Gelderland as given by Hofstee. Infant mortality in

I. To be sure, more infants died in Nijmegen than I45 per Iо००. Since we reconstituted a sample of marriages from the Nijmegen registers we retrieved by definition only information on the sedentary population. When a city has a more or less closed population, this does not pose a problem. In Nijmegen, however, this is not the case. For the second half of the Igth century we have information on the migratory movements in the city. Between I85I and I900 every year on average I859 persons left and 2090 people migrated to Nijmegen. This implies there was a change of about 15 per cent of the population each year. Obviously, the mobile part of the population was not a representative sample of the total. It consisted for the major part of members of the garrison, people working in shipping, and casual laborers, many of them moving in and out of the city with their families. Given the nature of the occupations and the social strata involved we expect the IMR of these groups to be higher than for the sedentary population. This is indeed the case. The average infant mortality according to the civil registration is I75. For our sample of Nijmegen residents infant mortality declines to I45. In the comparison with the sedentary Lugang population we will therefore use the infant mortality of the resident inhabitants of Nijmegen only. 
Gelderland ranged from 126 in the 1840 's to $15 \mathrm{I}$ in 1875 -1879 to 145 in 1890 I894 (Hofstee I98I: I34-I35). Infant mortality in Nijmegen exhibits a marked development, which by and large follows the general direction we expected given findings in other research. The general rise of European IMR in the second half of the century, in other words, is visible for Nijmegen residents too, especially after I870. Contrarily, Lugang IMR declined dramatically from well above the Nijmegen level (206 versus 129) at the beginning of the periods compared here, to a level below the Nijmegen value (I44 versus I67).

This allows us to deal with the prediction made by Thomas Malthus. He expected positive checks to be more active in China than in Europe. Since we have only two observations for Lugang (206 in I922-1933 and I44 in 1934-I945), we have to be careful with our conclusions. Still, Malthusian penalties for unlimited female nuptiality seem to have been the fate of Lugang. The Japanese health measures started before I920, so the IMR must have been higher at the start of the century, leaving us with a marked difference when compared to Nijmegen. We have to put this observation in context, however. First, the sharp decline between the two periods shows that a Chinese population could very quickly move to an IMR markedly below the average European level. On the other hand, a European population could reach a 'Chinese' level of IMR at the same pace. The difference in other words, was not as structural or as marked as we expected.

\section{The components of infant mortality: neonatal and post-neonatal mortality}

We now move to the two components of infant mortality. Deaths in the first month of life are commonly referred to as neonatal mortality. Causes for neonatal mortality are mostly endogenous following obstetrical trauma, congenital defects, or functional inadequacy, but could also include some exogenous factors like malnutrition, infections, and unhygienic circumstances. Mortality from the first month to age I (post-neonatal mortality) is mostly attributed to exogenous causes only. At this age, infants die mostly of diseases of the digestive system, especially those weaned early, of respiratory diseases, and of epidemic diseases such as smallpox, measles and dysentery (Knodel I988: 46; Morel I99I: I97). Clearly, differences in the socio-economic situation of a population, and changes in this situation over time will have a stronger effect on post-neonatal than on neonatal mortality. Table 2 contains the information on the relative distribution of neonatal and post-neonatal mortality. Note that neonatal mortality is defined as the number of deaths in the first month of life divided by the number of live births, whereas the deaths between month I and month I2 (post-neonatal) are divided only by the number of children surviving the first month. As a result the sum of neonatal and post-neonatal mortality is not equal to the IMR.

Given the different causes for neonatal and post-neonatal mortality it is 


\begin{tabular}{lcclllll}
\hline & \multicolumn{3}{c}{ Nijmegen } & & & Lugang \\
Period & IMR & neonatal & $\begin{array}{l}\text { postneo- } \\
\text { natal }\end{array}$ & Period & IMR & neonatal & $\begin{array}{l}\text { postneo- } \\
\text { natal }\end{array}$ \\
\hline I830-I849 & I3I & $4 \mathrm{I}$ & 92 & I922-I933 & 206 & I22 & 95 \\
I850-I869 & I39 & 34 & I09 & I934-I945 & I44 & 70 & 79 \\
I870-I889 & I67 & 36 & I36 & & & & \\
Total & 145 & 36 & 113 & Total & 171 & 93 & 86 \\
\hline
\end{tabular}

generally accepted that neonatal mortality is less dependent on changes in socioeconomic circumstances, and, thus, more stable. This is what we find in Nijmegen. Changes in neonatal mortality are relatively modest and the general direction is downward. This is the same conclusion reached for Belgium and France. In those countries the decline in neonatal mortality is attributed to two causes. More and better trained midwives are said to reduce the mortality of newborns. Also, since mothers were better nourished, they had fewer premature births and they gave birth to children with a better natural resistance (Morel I991: 204). This may have also been the case in Nijmegen, but the latter explanation becomes doubtful when we look at the development of post-neonatal mortality. The rise of general IMR is completely driven by increasing post-neonatal mortality. Since this part of infant mortality is caused by exogenous factors only, the result points to impoverishment rather than a rising standard of living. Therefore, only the influence of better medical knowledge concerning childbirth, and the presence of trained midwives seems responsible for the modest decline of neonatal mortality in Nijmegen.

The relative significance of the components of infant mortality in Lugang was manifestly different from that in Nijmegen. First of all, the general direction of the IMR was downward instead of upward. This resulted in the surprising finding that chances of survival for infants were higher in Lugang than in Nijmegen by the end of the two periods compared here. When we look at the two parts constituting infant mortality, Lugang again deviates sharply from Nijmegen. The relative importance of neonatal mortality was much higher, in the first period even higher than post-neonatal mortality. So, although the general decline of the IMR was caused also by a decline of post-neonatal mortality, the greatest contribution was made by the decreasing neonatal mortality.

Barclay already noticed the high level of neonatal mortality in Taiwan, and the sharp decline during the colonial period. He was surprised to find this since 
"neonatal mortality is thought to be resistant to measures that bring infant mor-

tality under control and thus to most general health measures". His explanation, however, amounts to saying that neonatal mortality was influenced by almost every characteristic of society (Barclay I954: I62-I63). Anyway, we may well call the extent of the decline revolutionary, and again this probably was the result of the measures taken by the Japanese colonial government. Still, even at the low level of I933-I945, neonatal mortality in Lugang was double the level in Nijmegen in the comparable period. This is the more surprising since postneonatal mortality at the same time was much lower in Lugang than in Nijmegen.

A conclusion like this immediately raises doubt about the quality of the data used. Since the level and development of both neonatal and post-neonatal mortality in Nijmegen follow closely what we find elsewhere in Europe, this doubt is directed at the Lugang data especially. To check for irregularities in the household registers of Lugang we calculated infant, neonatal, and post-neonatal mortality for three other field sites too. Chu-shan, Tanei, and Ta-Tao-Cheng served as our control populations. The results only confirm the situation in Lugang. In all three populations we find a sharp decline in neonatal mortality between I922-1933 and I934-1945, whereas post-neonatal mortality was less important for the general decline of infant mortality. This finding is also corroborated by the multivariate analysis of infant mortality in Taiwan between I905 and $\mathrm{I} 945$ by Yang and Hsieh. When compared to the IMR in the second half of the first year of life, the chance of dying in the first week is four times as high, and in the next three weeks twice as high (Yang and Hsieh 2004: 2I-23).

There is only one conclusion possible. Obviously, the impact of medical innovations and health measures both in the Netherlands and Taiwan affected primarily chances of survival for babies immediately after birth. We must also conclude that the effect in Taiwan was more impressive. Whether this is the result of better measures as such, or of a lower starting point of the development, we do not know. The very low post-neonatal mortality in Lugang (and in the three additional populations) can be explained by the custom of Chinese mothers breastfeeding their infants for a long period of time. This is in sharp contrast to the declining number of European mothers who did so. The result is shown clearly in rising post-neonatal mortality on the European continent after approximately I850 (Vandenbroeke, C., F. van Poppel, and A.M. van der Woude i98r: 475).

\section{Gender differences in infant mortality}

We already concluded from Table I that positive checks in Lugang were initially greater than in Nijmegen, although the differences were not as sharp as expected. One way to confirm the existence of positive checks is to look for gender differences in infant mortality in our two towns, because both Malthus, in I798, 

Mortality in Lugang and Nijmegen

\begin{tabular}{|c|c|c|c|c|c|c|c|c|c|c|c|c|c|}
\hline \multirow{3}{*}{ Period } & \multicolumn{6}{|c|}{ Nijmegen } & \multirow{3}{*}{ Period } & \multicolumn{6}{|c|}{ Lugang } \\
\hline & \multicolumn{2}{|c|}{$i m r$} & \multicolumn{2}{|c|}{ neonatal } & \multicolumn{2}{|c|}{ post-neonatal } & & \multicolumn{2}{|c|}{$i m r$} & \multicolumn{2}{|c|}{ Neonatal } & \multicolumn{2}{|c|}{ post-neonatal } \\
\hline & $M$ & $F$ & $M$ & $F$ & $M$ & $F$ & & $M$ & $F$ & $M$ & $F$ & $M$ & $F$ \\
\hline I830-I849 & I25 & I35 & 39 & 44 & 89 & 96 & I922-I933 & 222 & I 88 & I37 & 105 & 99 & 92 \\
\hline I850-I869 & I45 & I33 & 38 & 29 & III & 107 & I934-I945 & I55 & I33 & 83 & 57 & 78 & 80 \\
\hline I870-I889 & I90 & $\mathrm{I} 42$ & 44 & 27 & I53 & II8 & & & & & & & \\
\hline Total & 153 & 136 & 40 & 31 & 118 & 108 & Total & 184 & 156 & 107 & 77 & 87 & 85 \\
\hline
\end{tabular}

and Lee and Wang, in 1999, referred to infanticide as one of the options Chinese parents used to control the number of their offspring. Given the importance of sons in the lineage system we expect that girls will be eliminated more often than boys. The topic is complicated however. First of all, biology favors the survival chances of girls. So, if mortality rates for boy and girl infants are the same, this would imply that sons get some preferential treatment. A higher female infant mortality rate points almost certainly at gender specific treatment of infants. The demographic measures alone do not tell exactly what happened. A society could use direct infanticide, preferential neglect, differences in age of weaning, or a combination of all these measures.

To be sure, the literature on the subject is biased in suggesting that direct or indirect infanticide is a Chinese or Asian prerogative. When comparing a European and a Chinese population, however, one has to be aware of son preference in European societies too. A study in Italy, for instance, showed that during the last two decades of the I9th century only infant mortality exhibited the gender difference predicted by biology. Male infant mortality had an excess of about Io per cent. At older ages, probability of death for girls was higher, 3 per cent between ages I and 4, 6 per cent between ages 5 and 9, and as much as I7 per cent between ages io and I4. Clearly, the infant mortality differences were driven by biological factors, whereas social factors dominated mortality for those from I to 15 years. We find evidence for this conclusion in the disappearance of excess female child mortality after I900 when the status of girls gradually improved (Pinelli and Mancini 1997: 78).

Isabelle Devos found that mortality of girls in Igth century Belgium was about I5 to $20 \%$ higher than mortality of boys. To be sure, her conclusions refer especially to childhood and adolescent mortality. Devos claimed that her findings were representative of most Western European countries (Devos 2000). There is evidence, however, that a higher probability of dying for girls is not a universal 
European phenomenon. Knodel, for instance, did not find evidence for preferential treatment of sons in his fourteen German villages (Knodel I988: 79).

What about Lugang and Nijmegen then? Do we find sex differences in infant mortality here too? In both cities average infant mortality among boys was higher than among girls. More precisely male infant mortality exceeded female infant mortality in Nijmegen by I3 per cent and in Lugang by I8 per cent. When we divide infant mortality between neonatal and post-neonatal mortality the conclusion remains the same. For the whole period studied here, both neonatal and post-neonatal mortality were higher for boys than for girls, in Lugang as well as in Nijmegen. Gender differentiation was highest in the first month of life. Excess male mortality was 39 per cent in Lugang and 29 per cent in Nijmegen.

The development during the period studied points in the same direction. In Nijmegen, male IM R rose markedly during the igth century, whereas female IMR declined first, and then increased only slightly above its original level. The neonatal mortality of males rose slightly in the last period of observation, while neonatal mortality of females declined, especially between the first two periods. The largest contribution to the rise of male IMR came from post-neonatal mortality. The increase in post-neonatal mortality for females in this age group was less marked. Contrary to our expectations, the gender differentiated probability of dying favored male infants in the first period (I830-I849), in both the neonatal and the post-neonatal periods. Only after I 850 did the biological advantage of females become manifest.

The Lugang data tell a different story. Assuming that neonatal mortality is caused mainly by endogenous factors, we find the expected result. Male neonatal mortality is higher and even rises between the two periods. In postneonatal mortality, on the other hand, we find evidence for preferential treatment of sons. Even in the first period the differences between male and female mortality is only marginal. More significant is the finding that between I933 and I945 female post-neonatal mortality was 5 per cent higher, which runs contrary to the biological advantage girls had on boys. The interpretation could be that this reflects son preference. Interestingly, though, there is no sign of son preference in the case of neonatal mortality in the two periods, or in the case of post-neonatal mortality in the first period. These calculations hardly provide evidence for a specific Chinese form of 'proactive' behavior, namely infanticide through neglect, especially given that we find higher female infant mortality in Nijmegen before I850.

\section{Causes of infant deaths and the seasonal distribution}

There is little doubt as to what caused the general decline of mortality in Lugang. The beneficial effects of the Japanese health measures showed here as elsewhere in Taiwan, and brought down neonatal mortality especially. In Nijmegen, neona- 


\begin{tabular}{lllll} 
Year & Sex & $\begin{array}{l}\text { Intestinal } \\
\text { Diseases }\end{array}$ & $\begin{array}{l}\text { Respiratory } \\
\text { Diseases }\end{array}$ & $\begin{array}{l}\text { Percentage } \\
\text { of Total }\end{array}$ \\
\hline \multirow{2}{*}{ 1938 } & M & 33.7 & 30.9 & 64.6 \\
& F & 33.5 & 31.7 & 65.2 \\
1942 & M & 33.8 & 24.0 & 57.8 \\
& F & 34.1 & 26.5 & 60.6 \\
\hline
\end{tabular}

tal mortality was already relatively low, but the general infant mortality was high and rising. Information on the causes of death could help us to understand better what was happening. Was there, for instance, a difference between the two towns in the causes of infant deaths? Unfortunately, there are no direct data available on the causes of death in Nijmegen and Lugang. We do have information, however, on the national level. A convenient source provides data on causes of death by age for 1938 and 1942 (Taiwansheng wushiyinianlai tongitiyao). This allows us to assess the contribution of the two main causes of infant deaths, intestinal and respiratory diseases. The first category comprises what the report calls Intestinal Infection and Diarrhea, the second category brings together Bronchitis and Pneumonia. The two categories together explain the major part of infant deaths. More importantly, however, they show that respiratory diseases, which are not directly related to breastfeeding, made an important contribution to the overall infant mortality.

There is general agreement on the main cause of death for Dutch infants. As early as I809, during the French occupation, King Louis Napoleon decreed that mothers should breastfeed their children and for longer periods to avoid exposing their infants to the risk of intestinal diseases from contaminated food. Several I9th and early 2oth century medical observers also pointed at the high infant mortality as a result of intestinal diseases, especially in the summer months (Hoogerhuis 2003: 4-I2). A more recent study of infant mortality in the city of Tilburg showed that intestinal diseases were the major cause of death in the igth and early 2oth century, especially in the warm summer months (Van der Heijden I995: I72 and I88-I89). A quantitative analysis of causes of death revealed that for the period 1903-1907 almost 33 per cent of all Dutch infant deaths were the result of intestinal diseases, against I4.9 per cent for diseases of the respiratory system (Methorst I909). Please note that the percentage for intestinal diseases closely matches the Taiwan data mentioned above, whereas the percentage for respiratory diseases was much lower in the Netherlands.

This situation was not specifically Dutch. In the late igth century there was 
a marked urban sanitary-diarrheal-effect especially in summer, in crowded urban centers in England and Wales (Woods, Watterson and Woodward I988 and I989). A convincing proof of the relationship between excess mortality of infants in summer and breastfeeding is reported by Pollet. She presented a graph of weekly deaths from diarrhea in Paris I898. When comparing children that were breastfed and those that were bottle-fed she finds, throughout the year, a higher number of infant deaths among the bottle-fed. In weeks 3I till 4I (mainly July and August) this difference reached a tremendous magnitude. The chance of dying for weaned children was up to 8 times higher than for breastfed children (Pollet I997: 224). The limited data we have points to different factors behind infant mortality in Lugang and Nijmegen. The seasonal distribution of infant deaths can shed more light on this issue.

The probability of dying is not evenly spread over the year. Most populations, including historical ones, are aware of seasonal fluctuations in mortality. Most often the seasonality of deaths is most visible among the most vulnerable groups in society, the very young and the very old. We therefore calculated for our two cities the number of infant deaths per month. ${ }^{2}$ The main reason for this calculation is that it provides us with information on the vulnerability of the infant populations, on the type of dangers, and possibly even on the causes of death. Breschi and Livi Bacci concluded that children born in the winter period were especially at risk of respiratory infections. They also found that these risks became small when adequate measures for protection were taken. When children were born in summer the risks of infections of the digestive tract prevailed. This, according to the authors, was related to breastfeeding. Since mother's milk provided the child with immunity and avoided contaminated watery substitutes, the danger was highest for infants that were not breastfed (Breschi and Livi Bacci I997: 159).

If our hypothesis is right and Nijmegen mothers indeed breastfed their infants less, especially in the second half of the Igth century, we expect a higher incidence of infant mortality in summer. In I903, Jonkers already established that Dutch infant mortality was especially high in summer. The cause, in his view, was clear. High temperatures contaminated the food infants were given. As a result the high infant mortality in summer consisted mainly of infants that were not breastfed (Jonkers I903: 38). More than 90 years later, Hoogerhuis came to the same conclusion for the province of Zeeland (Hoogerhuis 2003: I2II26). To be sure, Knodel also found higher levels of infant mortality in late-sum-

\footnotetext{
2. In order to avoid influences of the seasonality of births, the calculation takes the number of deaths below age I per month divided by the number of live births in the same month. This obviously creates a slight bias since not all children are born on the first day of the month and, thus, we find their deaths over a two month span. We consider this bias negligible
} 

(infant deaths/births per month; average $=100$ )

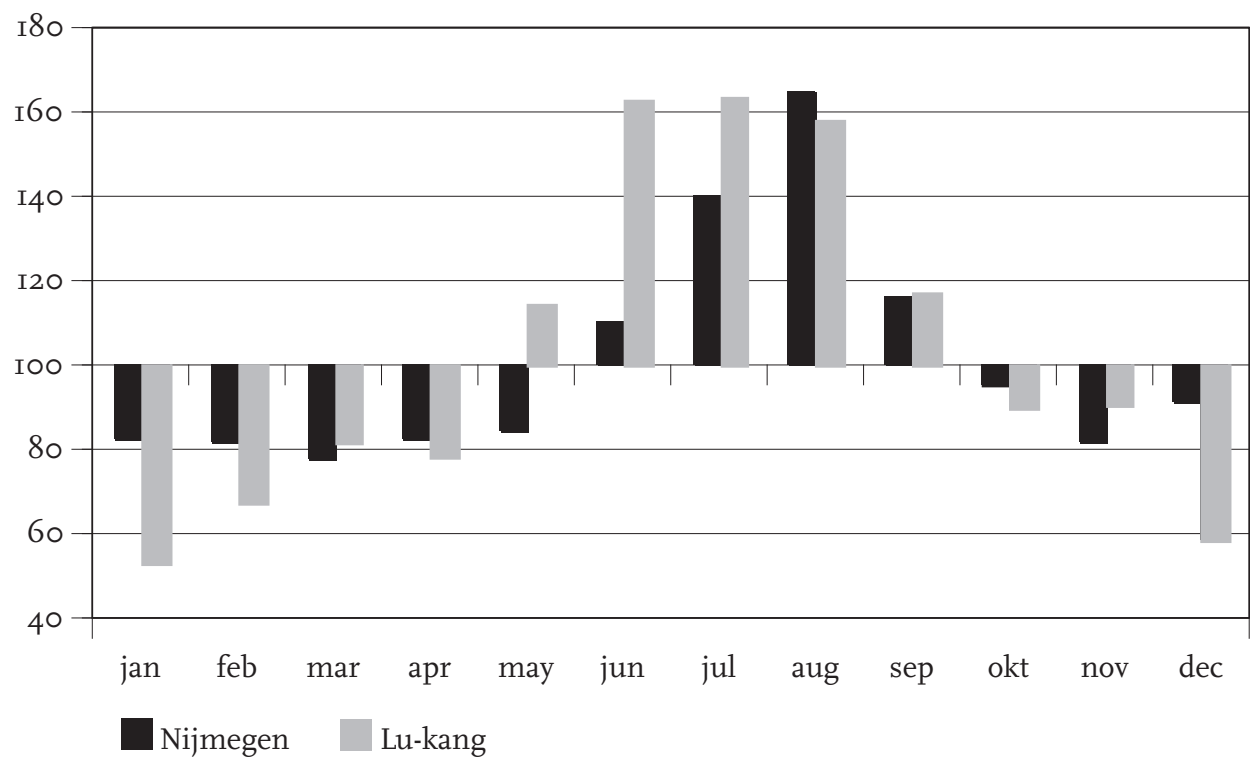

mer for his German villages. In his case, however, there was also a winter peak, since cold weather was dangerous for infants too (Knodel I988: 6I-62).

Graph I suggests that our hypothesis for Nijmegen is correct. July and August are especially dangerous for infants. These are the only two months with an average maximum temperature of over 2I degrees Celsius (Historical data of the Koninklijk Nederlands Meteorologisch Instituut in the Netherlands at www.knmi.nl). In this period the danger of contamination of supplementary food obviously was highest. Surprisingly, the seasonal fluctuation of infant mortality was about the same in Lugang. Since breastfeeding was nearly universal in Taiwan, the causes for the summer infant mortality peak cannot be the same as in Nijmegen, where breastfeeding was less universal and probably even declining in our period. When we look at the critical threshold above which ImR rises over the average level, we find in the Lugang case an average maximum temperature of 29 degrees Celsius in the months from May until October. Temperatures of 30 degrees and over in June, July and August prove to be especially fatal for many infants (Historical data of the Central Weather Bureau of Taiwan at www.cwb.gov.tw). The different threshold levels already indicate that in Taiwan possibly other variables may cause the summer mortality. As for winter, mortality among infants was higher in Nijmegen than in Lugang. Again, the climate best explains this. On average, the maximum temperature in the months November 

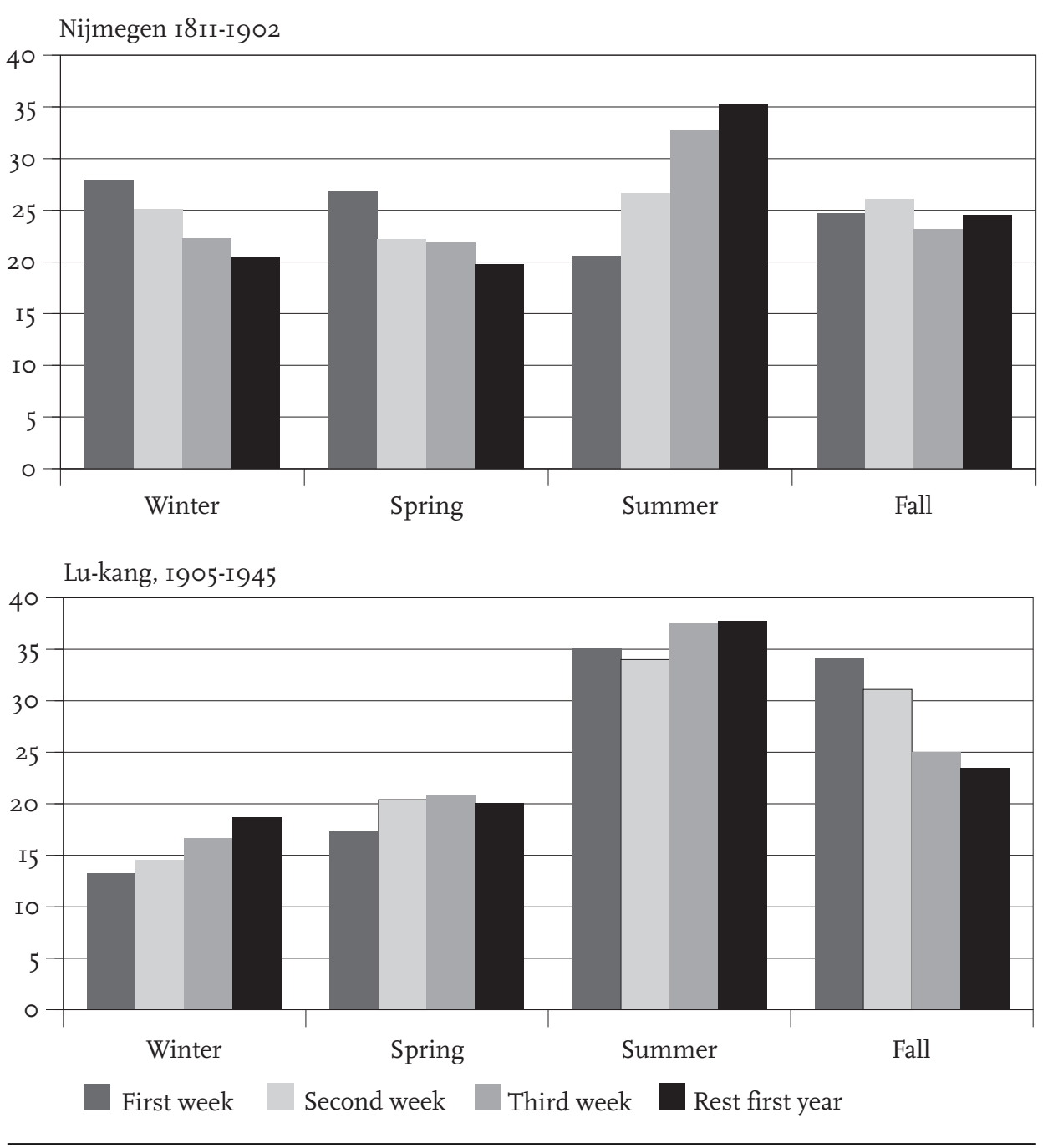

till February in Nijmegen was 6.I degrees. The same months averaged in Taiwan 2I.9 degrees. Thus, the mild winters in Taiwan appear to have been less dangerous than the relatively cold winters in Nijmegen.

For the time being there is another indication in favor of the breastfeeding hypothesis in Nijmegen. When we divide infant mortality in this city during the I9th century between two periods the impact of summer becomes more pronounced in the second period. Before I850, 3I.2 per cent of all infant deaths occurred during the months July, August and September, after that year the percentage was 36.0. This is in line with the predicted effect of more women working in occupations outside their own homes during the second half of the Igth 
century. Atkins reported on the effect of women working on breastfeeding in the English community of Blackburn in I9I5. His findings show that whereas about 75 per cent of all women breastfed their infants in the first month, this percentage declined sharply in the second month. In the fifth month half of the women not working still breastfed their child. The percentage for women working outside their home was less than 25. The impact of this differentiation on infant mortality was enormous. Artificially fed children had higher chances of dying for every cause of death. As far as diarrhea and enteritis were concerned the death rate of children breast-fed was 3.7, against 34.8 for children who were bottle-fed (Atkins 2003). Although we take into account that Atkin's study covers the first decades of the 2oth century and the English experience, we expect the Nijmegen situation to be comparable.

There is still another way to gain more insight into the causes of Nijmegen and Lugang infant mortality. According to the literature on the subject infants in the first month are protected by the immunity they received from their mother. Also, if breast feeding was given only for a short period of time, as was the case in Nijmegen, the number of breastfed babies would decline rapidly during and especially after the first month of life. The expected effect from possibly contaminated supplementary food would therefore only gradually show up in our data. In order to check this possibility we divided infant mortality in the weeks immediately after birth and the rest of the first year. Since Lugang mothers breastfed their children for a long period of time, up to 30 months, the pattern should be different.

Graph 2 indeed qualifies the findings from Graph I. In Nijmegen, the impact of cold weather in winter and part of spring on infants declines with age. The vulnerability of the newly born showed most clearly in the first week, but was less already in the second week, and declined further in the third week and the rest of the first year. There were no consistent variations in infant mortality by age in autumn. The effects of summer, however, again favor the breastfeeding hypothesis. The older the infant was, the more it suffered from high temperatures. If we assume that babies were only breastfed for a very short period immediately after birth, this is the effect one may expect. As long as the baby was living on mother's milk the risk of infections by contaminated food was small. The situation in Lugang was clearly different. Summer was a dangerous period of the year for infants of all ages, starting already in the first week of life. For this reason we may conclude that differences in breastfeeding by age of infant were not significant. This is in line with universal and prolonged breastfeeding by Chinese mothers. From Table 4 we learned that there was a striking resemblance between the causes of death for male and female infants in Taiwan, highlighting once more that preferential treatment of sons probably did not influence infant mortality. We, therefore, must look for reasons of high infant mortality that were active mainly in summer (37 per cent of all infant deaths) and that did not dif- 
ferentiate according to sex. Paul Katz described the danger of the hot and humid summer months for the inhabitants of Chekiang. In his view the high temperatures allowed insects and micro parasites to grow in food and water, and, thus, to infect human beings with contagious diseases like cholera, dysentery, smallpox and malaria. In its endemic forms these diseases frequently took the lives of the old, the young, and the infirm (Katz I995: I; for more on causes of death, see Shepherd, "Trends", this volume). If anything, the summers in Lugang were hotter and more humid than in Chekiang. We take it, then, that a large part of Nijmegen infant mortality was the result of a relatively low incidence of breastfeeding and the dangers resulting from contaminated supplementary food. We conclude for Lugang that infants there rather fell victim to general infectious diseases from which breastfeeding offered little protection.

\section{Socio-economic differences in infant mortality}

The level of infant mortality in historical western societies is often attributed to the socio-economic status of the parents, and, thus, to standard of living. Thomas McKeown is the best known advocate of this position (McKeown I976). The discussion on this topic is not settled, however. Samuel Preston, for instance, argued that indicators of standard of living were responsible for 25 per cent of the rise in life expectancy at most. In his view the effects of public-health technology had a greater impact (Preston I980). This discussion is highly confounded by the use of different populations in different periods of development. Still, if we only look at comparable pre-industrial populations the findings vary. Knodel found remarkably little difference in infant mortality between social classes and attributes this to general influences prevailing in the countryside that affected infants irrespective of social class (Knoedel I988: 74). Two studies in the Dutch province of Noord-Brabant reached the same conclusion (Boonstra I993: 295 and Van der Heijden I989: I4I)

If we look at other studies for historical Dutch society, however, the evidence also points to social class as an important covariate of infant mortality. Van Poppel and Mandemakers conclude their study of igth century Dutch infant and child mortality by stating that although the risk of dying was relatively high for infants and children in all social groups, there still was a considerable difference between these groups. Middle and upper class families used their resources to improve the chances of survival of their children. This was mediated by the acceptance of hygienic practices, by using pure water, and by a better disposal of waste and sewage (van Poppel and Mandemakers I997: 298-299). Hoogerhuis too found clear social differences in infant mortality in Goes. Infants born in the group of laborers had a relatively low chance of survival. This author, however, also points to high infant mortality among children of the lower middle class (Hoogerhuis 2003: I43-146). 


\begin{tabular}{llllllll}
\hline \multicolumn{3}{c}{$\begin{array}{c}\text { Nijmegen } \\
\end{array}$} & Live births & Deaths <1 & IMR & & \multicolumn{3}{c}{ Lugang } \\
Live births & Deaths <1 IMR \\
\hline proletarians & 558 & 97 & I73,8 & & & & \\
laborers & 3265 & 464 & I42,I & "lower" & 2465 & 458 & I85,8 \\
farmers & 445 & 65 & I46,I & & & & \\
higher & 728 & 90 & I23,6 & "higher" & 2532 & 437 & I72,6 \\
unknown & $2 \mathrm{I} 4$ & 38 & I77,6 & unknown & 622 & 92 & I47,9 \\
All & 5210 & 754 & 144,7 & All & 5619 & 987 & 175,7 \\
\hline
\end{tabular}

The discussion on the reasons behind the decline of infant mortality in Taiwan is dominated by the question of whether or not the measures taken by the Japanese colonial government worked. In I954, Barclay acknowledged that the Japanese "aside from probably raising levels of living ... developed a concerted program against an important group of dangers to health. ... In fifty years of administration the Japanese quickly eliminated epidemics." (Barclay I954: I70I7I). His analysis did not include differences in social position of the parents. This is also the case with later studies on differential infant mortality in Taiwan. They deal extensively with gender and ethnic differences, causes of death, demographic characteristics of the births and the families involved, but leave occupation out of the analysis (Yang and Hsieh 2004).

According to Table 5 the social and economic position of the parents did indeed influence infant mortality, especially in Nijmegen. In the Dutch city our findings show that the lower the standard of living, the higher the chance that an infant died before reaching its first birthday. Given the small number of cases in the group "upper middle class" we decided to create one group joining upper middle and lower middle; in this group I24 of Iooo live births died before reaching their first birthday. At the other extreme we find children of proletarians. Their chance of dying as an infant was about 175 per Iooo. The infant mortality of laborers with a fixed position and farmers hardly differed, and fell between the other two groups.

For Lugang we had to create two groups, one consisting of proletarians, laborers and farmers, the other formed, as in Nijmegen, by the two representatives of the middle class. Although here too we find higher infant mortality in the lower class, the differences are less extreme. Please note that the information on occupation comes mainly from the first two decades of the household registers, and that many of the households in the 'unknown' category were newly formed in later decades. Since there is a marked decline of infant mortality during the 


\begin{tabular}{llll} 
Religion & Live births & Deaths $<\mathbf{1}$ & IMR \\
\hline Catholic & & & \\
liberal protestants & 284 & I 85 & II2,7 \\
orthodox protestants & 42 & 42 & I47,9 \\
unknown & 3597 & 562 & II9,0 \\
All & 5210 & 754 & I56,2 \\
\hline
\end{tabular}

period of observation, it is no surprise to find the category "unknown" to have the lowest infant mortality. On the basis of the descriptive statistics we are inclined to conclude that infants in Lugang were subject to general environmental influences that were less dependent on social class. We have to wait for the multivariate analysis to assess whether the differences found are statistically significant.

Dutch demographic history is heavily influenced by religious differences, especially in the early stage of the modern fertility decline. For Roman Catholics and to a lesser degree Orthodox Protestants who started this process later, the decline was relatively slow. There is evidence of religious differentiation in infant mortality too. The latest contribution on the subject is by Van Poppel, Schellekens and Liefbroer who analyzed differentials in infant and child mortality in Holland between I855 and I9I2. They start with an overview of a well known discussion. Are religious differences in mortality caused by socio-economic characteristics or by lifestyle? The authors cite several studies in which the relative contribution of the two major causes are assessed. The conclusion is unambiguous. Even when the socio-economic differences are controlled for, direct causal links between religion and (infant) mortality remain (Van Poppel, Schellekens and Liefbroer 2002: 277).

Only in the Nijmegen case are we able to test the influence of religion on infant mortality. There are no significant religious differences in Lugang. The closest one can get in Taiwan to a cultural type of variable comparable to religion in the Netherlands is ethnicity. Ordinarily, one divides the population between two Han groups (Hokkien and Hakka), and a non-Han group consisting of Aborigines. The Lugang population, however, is totally Hokkien. For that reason, our 'cultural' explanation of infant morality only deals with Nijmegen. The large group with unknown religion makes it difficult to draw firm conclusions from Table 6 . Since they have the highest infant mortality, they are not a residual category divided representatively over the religions. As it is, the most 
obvious conclusion is surprising. If anything, the literature on the subject expects Roman Catholics to have a relatively high infant mortality (Van Poppel, Schellekens and Liefbroer 2002; Hoogerhuis 2003: 8I). This is not the case in Nijmegen. Catholics, closely followed by Orthodox Protestants, have the lowest level of IMR, whereas the chance of dying for infants of Liberal Protestants is 30 per cent higher. This may be the result of adhering to different socio-economic groups. The numbers are too low to subdivide the table further, so we will establish whether or not religion has an independent influence in the following multivariate analysis.

\section{Multivariate Analysis of Infant Mortality}

In the previous paragraphs we found several factors to be linked to the level of infant mortality and its two components. The problem with these relationships, however, is that they hide the interrelationships of the independent variables. When, in the Nijmegen case, both higher occupational position and Catholicism go together with relatively low infant mortality, this may be due to one of the two only, the second just being a covariate of the other. Statistically we can use a logistic regression to assess the independent influence of every variable (exept breastfeeding for which we have no individual level data) while simultaneously controlling for the other influences. In order to do so infant mortality for every case is dichotomized, having the value $o$ when the child survived at least until its first birthday, and the value I when the infant died. The procedure provides us with the possibility to establish the strength of the association of every variable with infant mortality via the so-called odds ratio, the chi-square and the level of significance. For every variable one value is treated as the standard providing us with the I.०० level against which the influence of the other possible values is assessed.

The model to explain infant mortality consists of variables measuring social and cultural differences between the couples, but the model also includes demographic and biological characteristics. First of all, we divided the period into two subperiods. In Lugang the effect of the Japanese health measures was noticeable from approximately I925 on. We therefore used this year as the dividing point. The rise of infant mortality in Nijmegen started about I860. For that reason we expect infant mortality to be higher in the period I860-I890 than in the years between I830 and I860. The sex of each child born is included in the model to find possible differential mortality as the result of gender preferences. Whenever female infant mortality does not show the expected biological advantage over male infant mortality, this points to preferential treatment. We also expect age of mother to have an influence on the chances of dying for an infant. Relatively young and relatively old mothers may, for biological reasons, give birth to more vulnerable children. Given the concept of maternal depletion (Wood I994: I6; Ellison 200I: 95-97), we also predict the infant to be especially vulner- 
able when the birth interval was small (shortening the time for the mother to recover from the previous pregnancy and delivery), or when the parity of the child is high (indicating that the mother may be weakened by a rapid succession of births). The introduction of the variable "twins" is guided by the idea that in pre-industrial societies the survival chances of twins were especially small. In order to control for this influence we included a dummy variable. The variables mentioned until this point have a biological background. The socio-cultural influences are measured by looking at occupational class and, in the Dutch case, at religious denomination. The definition of these variables is the same as in the previous paragraphs. Since the model also tries to assess the influence of birth intervals the regression is limited to second births and higher only.

Our first regression deals with infant mortality in general. Table 7 clearly rules in favor of biological determinants of infant mortality. Both in Lugang and Nijmegen the birth of a twin was a situation society could not handle. The chance of dying for twins in Lugang was more than twice as high as for single births. In Nijmegen, the chance was four times as high. Obviously, pre modern cities did not have the facilities to take care of premature and underweight babies. Maternal depletion appears to be more than a theoretical construct. When the interval with the previous birth was less than $\mathrm{I} 6$ months a mother was faced with a triple burden. Her body was still recovering from the previous pregnancy and delivery, was probably still nursing the previous child, and, on top of that, experienced the effects of the new pregnancy. As a result the child born after this second pregnancy had a 40 per cent (in Nijmegen) or 54 per cent (in Lugang) higher chance of dying within one year. Independent of the birth interval children born at parity seven or higher had significantly lower chances of survival than lower parity children.

The period variable has the expected effect. Since Nijmegen witnessed a rise in infant mortality, we find the odds ratio to be relatively high. Declining infant mortality rates in Lugang resulted in a 30 per cent lower chance of dying after I925. Please note that the Nijmegen odds ratio is not significant at the 5 per cent level. The most surprising finding, however, comes from the gender differences. If anything, we would expect female children to be worse off in Lugang. The actual situation shows better survival chances for females which is in line with the biological advantage female babies have. In Nijmegen too, male infants have a higher risk of dying, but again this finding is not statistically significant.

The death of infants in the first month of life is generally expected to be determined by factors other than those causing death in the rest of the first year. We therefore present a separate logistic regression for neonatal mortality in Table 8. As predicted, the demographic variables have an important influence. Small birth intervals and being a twin implied a dangerous situation for both Lugang and Nijmegen infants, and this effect was even more visible than for infant mor- 


\section{Nijmegen}

Lukang

Odds ratio $\mathrm{Chi}^{2} \quad$ P-value Odds ratio $\mathrm{Chi}^{2} \quad$ P-value

Period

$<$ I860 (I925 in Lukang) I.000

$>=$ I860 (I925 in Lukang) I.I22

I. 507

I.000

Sex

$\begin{array}{lllllll}\text { Male } & \text { I.I72 } & 3.294 & 0.070 & \text { I.230* } & 4.560 & 0.033 \\ \text { Female } & \text { I.000 } & & & \text { I.000 } & & \end{array}$

Mother's age at birth

$\begin{array}{lllllll}\mathrm{I} 5-24 & 0.84 \mathrm{I} & 0.662 & 0.4 \mathrm{I} 6 & 0.888 & 0.758 & 0.384 \\ 25-34 & \text { I.000 } & & & \text { I.000 } & & \\ 35-44 & \text { I.II8 } & \text { I.I29 } & 0.288 & \text { I. } 350 & 3.60 \mathrm{I} & 0.058 \\ >=45 & 0.943 & 0.036 & 0.849 & 0.00 \mathrm{I} & 0.00 \mathrm{I} & 0.97 \mathrm{I}\end{array}$

Birth interval (in months)

$\begin{array}{lllllll}<\mathrm{I} 6 & \text { I.40I* } & 6.4 \mathrm{I} 6 & 0.0 \mathrm{II} & \mathrm{I} .538 * & 6.065 & 0.0 \mathrm{I} 4 \\ \mathrm{I} 6-23 & \mathrm{I} .000 & & & \mathrm{I} .000 & & \\ >=24 & 0.9 \mathrm{I} 3 & 0.762 & 0.383 & 0.989 & 0.008 & 0.928\end{array}$

Parity

$\begin{array}{lllllll}\mathrm{I}-3 & 0.9 \mathrm{I} 4 & 0.7 \mathrm{I} 8 & 0.397 & \mathrm{I} . \mathrm{I} 68 & \mathrm{I} .347 & 0.246 \\ 4^{-6} & \mathrm{I} .000 & & & \mathrm{I} .000 & & \\ >=7 & \mathrm{I} .4^{2 \mathrm{I}^{* * *}} & 8.482 & 0.004 & \mathrm{I} .377^{*} & 4.509 & 0.034\end{array}$

Twin

$\begin{array}{lllllll}\text { Yes } & 3.906 * * * & 33.240 & 0.000 & 2.190 * * & 6.24 \mathrm{I} & 0.013 \\ \text { No } & 1.000 & & & 1.000 & & \end{array}$

Occupation

$\begin{array}{llll}\text { laborer } & \text { I.000 } & & \\ \text { proletarian } & \text { I.I74 } & \text { I.29I } & 0.256 \\ \text { agricultural } & 0.962 & 0.057 & 0.8 \mathrm{I} 2 \\ \text { higher occupation } & 0.932 & 0.274 & 0.60 \mathrm{I}\end{array}$

Occupation (social class)

$\begin{array}{llll}\text { Low } & - & - & - \\ \text { high } & - & - & - \\ \quad \text { unknown } & - & - & - \\ \text { Religion } & & & \\ \text { Liberal Protestants } & \text { I.000 } & & \\ \text { Roman Catholics } & 0.747 & 2.128 & \text { 0.I45 } \\ \text { Religion unknown } & \text { I.III } & 0.338 & 0.56 \mathrm{I}\end{array}$

$* \mathrm{p}<.05 ; * * \mathrm{p}<.01 ; * * * \mathrm{p}<.001$ 
tality in general. The differences from Table 7 are marked as well. The first three children a woman bore in Lugang, for instance, had a significantly higher chance of dying. Although this was also the case in Nijmegen, the result was not significant. We attribute this to the role of young, inexperienced mothers. This was clearly more the case in Lugang where many women married just after or even before menarche. Children of adolescent mothers faced even more risks than other children in our two cities. The risk of dying for very young boys was 32 per cent higher than for little girls. This clearly weighs in favor of biological explanations and, against the existence of large scale female infanticide in Lugang.

At first sight, the influence of socio-occupational position on neonatal mortality in Nijmegen is surprising. The literature on the subject agrees on the conclusion that neonatal mortality is less influenced by environmental variables. Still, when compared to the standard value for laborers, neonatal mortality was almost double the level for proletarians, and half the level for middle class families. General poverty is the best explanation for this finding, perhaps affecting both maternal and neonatal health. This conclusion can also be drawn from the Lugang data, although the finding here is not as strong and not significant. Poverty in Nijmegen probably influenced the risk of dying through the care given during and immediately after delivery. Traditionally, a woman giving birth was assisted by a midwife, and only when problems arose was a medical doctor called. Although since I8I8 midwives were officially trained, one finds regular complaints about unofficial midwives whose services were less expensive. The difference in neonatal mortality between the very poor and the well-to-do may result from difference in the quality of care they could afford during and after delivery (Hoogerhuis 2003: 59-67).

When we turn to the mortality of infants between one month and one year our model shows very few variables with a significant influence, see Table 9. The improvement of life chances for infants in Taiwan in the second half of the Japanese colonial period is still significant. The other significant variable is the age of the mother. When children survived their first month, their chance of dying was highest when the mother was over 35 . We must presume that older mothers were less capable of breastfeeding their children. Small birth intervals, both in Lugang and Nijmegen, did not predict post-neonatal mortality. Babies born within $\mathrm{I} 6$ months after the previous birth were at greater risk of dying within four weeks. If they survived until one month their chances of dying were not negatively influenced by the interval. High parity remained a risk factor in Nijmegen, also for infants over one month. Maternal depletion is a possible explanation, as is the standard of living that must have declined as children grew older and their needs increased.

In this paper we have paid special attention to the possible gender differences. Table 9 provides the same message as did the calculations for infant mor- 


\section{Nijmegen}

Lukang

Odds ratio $\mathrm{Chi}^{2} \quad P$-value Odds ratio $\mathrm{Chi}^{2} \quad P$-value

Period

$<$ I860 (I925 in Lukang) I.000

$>=1860$ (I925 in Lukang) 0.998

$0.000 \quad 0.989$

I. .000

Sex

$\begin{array}{lllllll}\text { Male } & \text { I.I48 } & 0.654 & 0.419 & \text { I. } 325^{*} & 4.888 & 0.027 \\ \text { Female } & \text { I.000 } & & & \text { I.000 } & & \end{array}$

Mother's age at birth

$\begin{array}{lllllll}\text { I5-24 } & 0.519 & \text { I.909 } & 0.167 & 0.729 & 3.194 & 0.074 \\ 25-34 & \text { I.000 } & & & \text { I.000 } & & \\ 35-44 & 0.927 & 0.133 & 0.715 & \text { I.I53 } & 0.477 & 0.490 \\ >=45 & \text { I.878 } & \text { I.78I } & 0.182 & <0.001 & 0.001 & 0.979\end{array}$

Birth interval (in months)

$\begin{array}{lllllll}<\text { I6 } & \text { I.90I* } & 6.120 & 0.013 & 2.082^{* * * *} & \text { II.736 } & 0.000 \\ \text { I6-23 } & \text { I.000 } & & & \text { I.000 } & & \\ >=24 & \text { I.I23 } & 0.284 & 0.594 & 0.997 & 0.000 & 0.985\end{array}$

Parity

$\begin{array}{lllllll}\text { I-3 } & \text { I.240 } & \text { I.08I } & 0.298 & \text { I. } 474^{*} & 4.982 & 0.026 \\ 4-6 & \text { I.000 } & & & \text { I.000 } & & \\ >=7 & \text { I.464 } & 2.503 & 0.1 I 4 & \text { I. } 497^{*} & 4.242 & 0.039\end{array}$

Twin

$\begin{array}{lllllll}\text { Yes } & 4.234^{* * * *} & 17.235 & 0.000 & 2.575^{* * *} & 7.277 & 0.007 \\ \text { No } & 1.000 & & & 1.000 & & \end{array}$

Occupation

$\begin{array}{llll}\text { Laborer } & \text { I.000 } & & \\ \text { proletarian } & \text { I. } 989 * * * & 8.389 & 0.004 \\ \text { agricultural } & \text { I.392 } & \text { I.373 } & 0.24 \mathrm{I} \\ \text { higher occupation } & 0.496 * & 4.2 \mathrm{I} 3 & 0.040\end{array}$

Occupation (social class)

\begin{tabular}{lllllll} 
Low & - & - & - & 1.000 & & \\
High & - & - & - & 0.796 & 3.075 & 0.080 \\
unknown & - & - & - & 0.870 & 0.259 & $0.6 \mathrm{II}$ \\
$\begin{array}{l}\text { Religion } \\
\text { Liberal Protestants }\end{array}$ & $\mathrm{I} .000$ & & & - & - & - \\
Roman Catholics & 0.542 & 2.689 & $0.10 \mathrm{I}$ & - & - & - \\
Religion unknown & 0.844 & 0.263 & 0.608 & - & - & - \\
\hline
\end{tabular}

$* \mathrm{p}<.05 ; * * \mathrm{p}<.01 ; * * * \mathrm{p}<.001$ 
Nijmegen

Lukang

Odds ratio $\mathrm{Chi}^{2} \quad P$-value Odds ratio $\mathrm{Chi}^{2} \quad P$-value

Period

$<$ I860 (I925 in Lukang) I.000

I.OOO

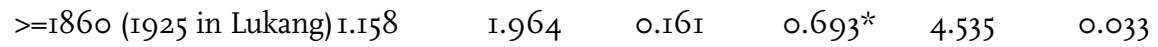

Sex

$\begin{array}{lllllll}\text { Male } & \text { I.I68 } & 2.532 & 0.112 & \text { I.I22 } & 0.735 & 0.39 \mathrm{I} \\ \text { Female } & \text { I.000 } & & & \text { I.000 } & & \end{array}$

Mother's age at birth

$\begin{array}{lllllll}\text { I5-24 } & 0.957 & 0.035 & 0.85 \mathrm{I} & \text { I.I24 } & 0.362 & 0.548 \\ 25-34 & \text { I.000 } & & & \text { I.000 } & & \\ 35-44 & \text { I.I67 } & \text { I. } 757 & 0.185 & \text { I. } 535^{*} & 3.89 \mathrm{I} & 0.049 \\ >=45 & 0.685 & 0.929 & 0.353 & <0.00 \mathrm{I} & 0.00 \mathrm{I} & 0.979\end{array}$

Birth interval (in months)

$\begin{array}{lllllll}<\mathrm{I} 6 & \mathrm{I} .273 & 2.627 & 0.105 & 0.978 & 0.007 & 0.935 \\ \mathrm{I} 6-23 & \mathrm{I} .000 & & & \mathrm{I} .000 & & \\ >=24 & 0.866 & \mathrm{I} .549 & 0.2 \mathrm{I} 3 & 0.988 & 0.005 & 0.942\end{array}$

Parity

$\begin{array}{lllllll}\mathrm{I}-3 & 0.839 & 2 . \mathrm{I} 4 \mathrm{I} & 0.143 & 0.889 & 0.383 & 0.536 \\ 4-6 & \mathrm{I} .000 & & & \mathrm{I} .000 & & \\ >=7 & \mathrm{I} .392^{*} & 6.200 & 0.013 & \mathrm{I} .235 & \mathrm{I} .008 & 0.315\end{array}$

Twin

$\begin{array}{lllllll}\text { Yes } & 3.324^{* * * *} & 19.948 & 0.000 & 1.494 & 0.631 & 0.427 \\ \text { No } & 1.000 & & & 1.000 & & \end{array}$

Occupation

$\begin{array}{llll}\text { Laborer } & \text { I.000 } & & \\ \text { proletarian } & 0.968 & 0.037 & 0.848 \\ \text { agricultural } & 0.849 & 0.767 & 0.38 \mathrm{I} \\ \text { higher occupation } & \mathrm{I} .057 & 0.149 & 0.699\end{array}$

Occupation (social class)

$\begin{array}{lllllll}\text { Low } & - & - & - & 1.000 & & \\ \text { High } & - & - & - & 0.887 & 0.742 & 0.389 \\ \quad \text { unknown } & - & - & - & 1.085 & 0.083 & 0.773 \\ \begin{array}{l}\text { Religion } \\ \text { Liberal Protestants }\end{array} & \text { I.000 } & & & - & - & - \\ \text { Roman Catholics } & 0.809 & 0.872 & 0.350 & - & - & - \\ \text { Religion unknown } & \text { I.173 } & 0.596 & 0.440 & - & - & -\end{array}$

$* \mathrm{p}<.05 ; * * \mathrm{p}<.0 \mathrm{O} ; * * * \mathrm{p}<.001$ 
tality in general and for neonatal mortality, although the results in Table 9 are not statistically significant. Being a boy was more dangerous than being a girl, irrespective of whether one lived in Nijmegen or Lugang.

\section{Conclusion}

Children born in I9th century Nijmegen had a I5 per cent chance of dying before their first birthday. The risk for their Lugang counterparts in the first decades of the 2oth century was I7 per cent. Although this confirms at first view Thomas Malthus' prediction on the prevalence of positive checks in Chinese society, it also shows that the difference between the two cities was not as marked as expected. Changes over time underline this conclusion since Nijmegen witnessed an increase in infant mortality of I2 per cent, while Lugang saw a decrease of 30 per cent. As a result, by the end of the periods we compare here, infants in Lugang were better off than infants in Nijmegen. A striking difference between the two cities is that while Nijmegen's infants suffered from much higher post-neonatal mortality, Lugang's neonatal mortality remained surprisingly high.

Although social class and religion seem to influence infant mortality when using simple descriptive statistics, this influence disappears when controlling for other variables. The only direct relation between social class and infant mortality that remains is found in Nijmegen neonatal mortality. We attribute this to differences in mothers' ability to hire adequate assistance for delivery. In Lugang, the level of neonatal mortality was remarkably high, especially in the period until I920. This provides us with an indication that birth in Lugang was even more precarious than in Nijmegen, but after the first month, Lugang infants enjoyed the protection afforded by higher rates of breastfeeding. In the Taiwanese city, on the other hand, there was no link with the socio-occupational situation. The most surprising finding about the background of infant mortality in our two cities, then, is the dominance of biologically proximate factors over socio-cultural factors (other than breastfeeding which could not be included in the regressions). The chances of survival were dictated by birth-interval, parity and twinship rather than by occupation or, in Nijmegen, religion.

A key question in this paper dealt with the possibility of gender differences in infant mortality. From Thomas Malthus to James Lee scholars have insisted on the significance of female infanticide in China. Our Lugang data tell another story. The hypothesis that proactive behavior affected infant mortality is clearly falsified. We find no clear distinction between female and male infant mortality, and the differences we do find were present in Nijmegen as well as in Lugang. 


I2

Illegitimacy, adoption, and mortality among Girls in Penghu, I906-1945

Yu Guang-hong

Huang Yu-lin

Chuu Ling-in

Institute of Ethnology,

Academia Sinica,

Taiwan 
This paper adopts an anthropological approach to the analysis of an unexpected demographic pattern. Our statistical findings reveal an extraordinarily high illegitimate birth rate and high female infant mortality rate in Penghu in the years 1906-1945. To anyone who grew up in Penghu or has studied the history of Penghu, the large proportion of illegitimate children in Japanese-ruled Penghu comes as a shock. Since the Qing dynasty, Penghu had been renowned for its strict and conservative norms governing male - female relationships. The historical records of Penghu stand out for their long lists of chaste women: a gazetteer compiled in 1832 lists II7 chaste Penghu women, and another completed in 1893 lists I95 chaste women (Jiang I832: 3I-5I; Lin I893: 256-300). These women, primarily virtuous widows who singlehandedly reared their children to adulthood, are surprisingly numerous, given Penghu's small population of 60-70 thousand people. How could a place renowned for its many chaste women be found to have a high rate of illegitimate births one or two decades later? The first part of this paper aims to solve this puzzle. The detailed data of the Japanese household registers give us an opportunity to cross-check our local informants' explanation for the pattern. After our first hypothesis proves wrong, we finally conclude that the most likely cause of the high illegitimate birth rate of Penghu is a form of "marriage" adopted by daughters of poor families, tacitly consented to by society, but not officially recognized. As for the high female infant mortality rate, most Penghu natives and scholars in the field of Penghu's history do not find it surprising because Penghu was notorious for its practice of female infanticide in the Qing Dynasty. However, our registration data do not support the hypothesis that female infanticide led to the high female infant mortality rate in Penghu. Inspired by Arthur Wolf's finding that adoption raised the risk of death for young girls elaborated in his 1995 work, we examine our household registration data, which testifies that the high adoption rate of female infants in Penghu could be one of the reasons for its high female infant mortality rate. Another possible reason for the high female infant mortality rate in Penghu could be the selective neglect of female infants.*

\section{The illegitimate children of Penghu}

The demographic statistics of Penghu during Japanese rule reveals a surprising phenomenon (Figure I and Table I). Of the I8 Taiwan research sites, the proportion of births registered as illegitimate in the three districts of Penghu that we have analyzed (Makung, Baisha and Huxi) is second only to Taipei city's two districts, Ta-tao-cheng and Meng-chia, which top the list. In the period I906-I945,

\footnotetext{
* We would like thank Professor Arthur Wolf for reading the first draft of this paper and Professor John Shepherd for editing the following drafts. Both of them gave us many invaluable suggestions.
} 
the illegitimate birth rate in Penghu averaged 6.2\%, and the rate in Huxi of I0.5\% approaches Taipei's average of I4.5\%. Taipei was Taiwan's major urban business center in the first half of the 2 oth century. The tea industry in Ta-taocheng and the sex and handicraft businesses in Meng-chia absorbed a great number of female laborers. Women in Taipei had more opportunities to make money to support independent lives and were bound by fewer constraints from traditional kinship and social connections (cf. Wolf and Gates 2004). It is thus not surprising to find a high illegitimacy rate in Taipei. By contrast, Penghu's society during the same period is generally considered conservative. Its high proportion of out-of-wedlock children amazes not only the co-authors of this paper but also the elderly of Penghu. One of the co-authors is a native of Penghu. The high illegitimacy rate of Penghu disclosed by the Japanese household registers contradicts his memory of the strict regulation of male and female relationships in Penghu in the I950's. A woman's merely having an informal chat with a man would incur harsh public criticism. Only engaged couples would dare to hold hands in public. If a couple married after the girl became pregnant, they would try very hard to conceal it; otherwise, they would face a lifetime of ridicule. No Penghu native women dared to work in local brothels, bars or tearooms, and only a tiny few would work in poolrooms as scorekeepers or in cafes as waitresses. Strict sexual segregation of unmarried youths remained strong at least to the I970's in Penghu. The situation described above is the collective experience of every Penghu native (male or female) more than 50 years old. Our informants were incredulous when informed of the high illegitimacy rate of Penghu in the early 2 oth century.

However, the facts revealed by the Japanese household registers cannot be denied. Although most of the elderly of Penghu we interviewed cannot provide a satisfactory explanation for this unexpected finding, nearly all the informants who are willing to contemplate this problem point out a possible association between sim-pua and the high illegitimacy rate. A sim-pua was a girl adopted in childhood to marry the son of her foster parents when she reached adulthood; the son she was to marry was called her thau-tui-a. ${ }^{\mathrm{I}}$ Marriages of sim-pua and thau-tui-a are called little-daughter-in-law marriages, or 'minor' marriages, in contrast to the culturally ideal virilocal marriages which brought adult brides into the husband's home, referred to as 'major' marriages. Briefly speaking, a child recorded as "illegitimate" in the Japanese household registers could be considered "legitimate" by social custom but would not acquire legitimate status if his or her parents failed to register their marriage. Marriages were more likely to

I. In Penghu, the foster brother intended to be paired with the adopted sim-pua in a minor marriage was called tui-thau-e 對頭仔. The term of thau-tui- $a$ adopted in this paper is generally used in Taiwan and widely known in anthropological circles. 


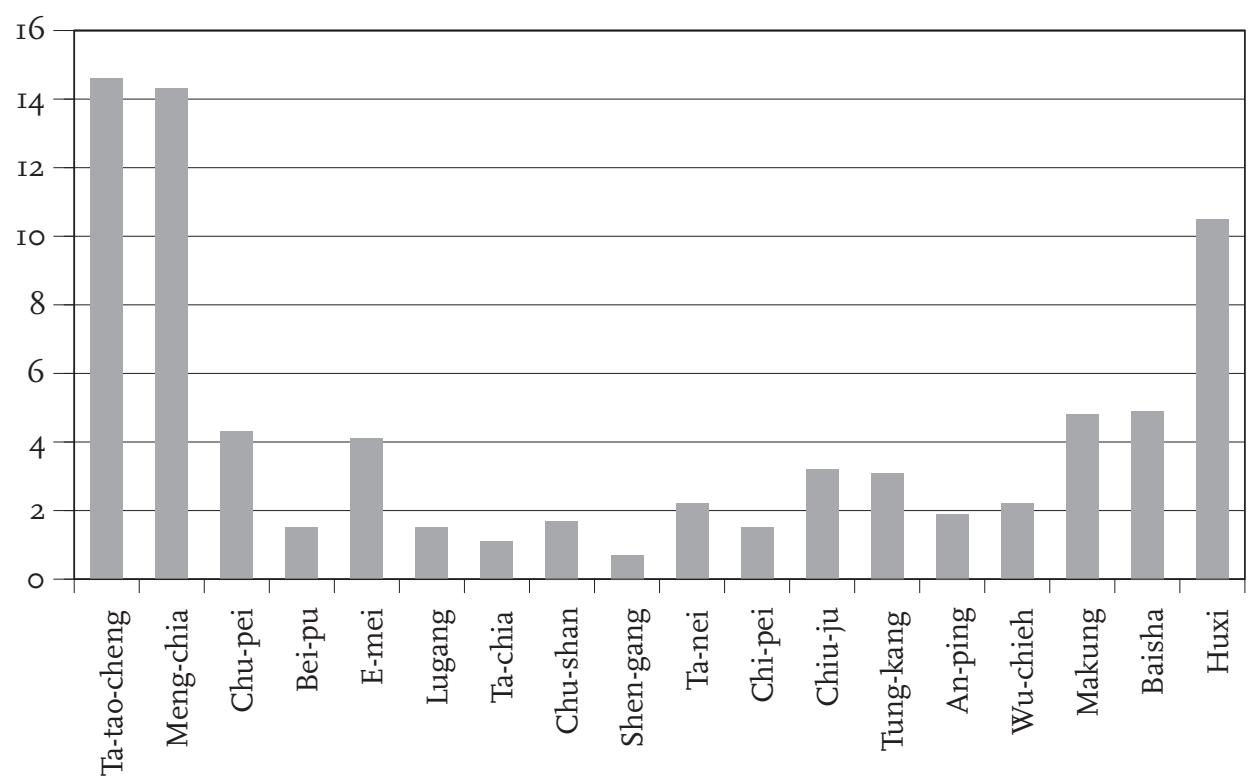

go unregistered when husbands worked away from home or the marriage was a minor marriage. A minor marriage involving a girl reared in the same household was usually held in a low-key style and did not require the girl to move to another family, a change of residence which would have to be reported to the registration office. So it was possible for a sim-pua's foster family to neglect to register her marriage unwittingly or intentionally, despite the strict implementation of household registration by the Japanese police. Children born to such unregistered marriages would be recorded as "illegitimate." This presumption accords with what Arthur Wolf discovered in North Taiwan. According to Wolf, in order to be sure a minor marriage would be fruitful, many families deliberately delayed registering minor marriages until they were certain that the sim-pua they pushed together with their son was pregnant (I995: 135-I49). This suggests that the registration of minor marriages could be circumvented despite the close surveillance of the Japanese police. In the following section, we will examine the hypothesis that failure to register minor marriages can account for high illegitimacy rates in Penghu.

\section{Sim-pua and illegitimate children}

The relative frequencies of minor marriages shown in Table 2 seem to support the assumption of a connection between sim-pua and high illegitimacy rates. In 
Children born in the research site Illegitimate children born

Site in the research site Proportion (\%)

\begin{tabular}{|c|c|c|c|c|c|c|c|}
\hline & Male & Female & All & Male & Female & All & \\
\hline North total & 16538 & I530I & 31839 & I30I & 1234 & 2535 & 8.0 \\
\hline Tai-pei & 6375 & $575 \mathrm{I}$ & I 2126 & 908 & 848 & 1756 & $\mathrm{I} 4.5$ \\
\hline Ta-tao-cheng & 3627 & 3192 & 68I9 & 523 & 475 & 998 & I4. 6 \\
\hline Meng-chia & 2748 & 2559 & 5307 & 385 & 373 & 758 & $\mathrm{I} 4.3$ \\
\hline Chu-pei & 5352 & 4906 & 10258 & $2 \mathrm{I} 7$ & 224 & $44 \mathrm{I}$ & $4 \cdot 3$ \\
\hline Bei-pu & IOI6 & 947 & 1963 & I7 & $\mathrm{I} 2$ & 29 & I. 5 \\
\hline E-mei & 3795 & 3697 & 7492 & 159 & 150 & 309 & $4 . \mathrm{I}$ \\
\hline Central total: & II59I & 10650 & 2224I & 140 & 140 & 280 & I.3 \\
\hline Lugang & 2907 & 2709 & 5616 & $4 \mathrm{I}$ & 43 & 84 & I. 5 \\
\hline Ta-chia & 965 & 849 & I8I4 & IO & IO & 20 & I.I \\
\hline Chu-shan & 3918 & 3676 & 7594 & 67 & 60 & I27 & $\mathrm{I} .7$ \\
\hline Shen-gang & 3801 & $34 \mathrm{I} 6$ & $72 \mathrm{I} 7$ & 22 & 27 & 49 & 0.7 \\
\hline South total: & 16136 & I5197 & 31333 & 366 & 327 & 693 & 2.2 \\
\hline Ta-nei & 6678 & 6356 & I3034 & 146 & I4I & 287 & 2.2 \\
\hline Chi-pei & 1040 & 954 & I994 & II & I8 & 29 & I. 5 \\
\hline Chiu-ju & $\mathrm{I} 338$ & II89 & 2527 & 40 & $4 \mathrm{I}$ & 8I & 3.2 \\
\hline Tung-kang & 1639 & I532 & 3I7I & 55 & 43 & 98 & $3 . I$ \\
\hline An-ping & $544 \mathrm{I}$ & $5 \mathrm{I} 66$ & 10607 & II4 & 84 & I98 & I.9 \\
\hline \multicolumn{8}{|l|}{ East } \\
\hline Wu-chieh & 4152 & 3908 & 8060 & 9I & 85 & I76 & 2.2 \\
\hline Peng-hu total: & 9455 & 8932 & 18387 & 576 & $5^{62}$ & 1138 & 6.2 \\
\hline Makung & $473 \mathrm{I}$ & 4647 & 9378 & 227 & 226 & 453 & 4.8 \\
\hline Baisha & 2472 & 2187 & 4659 & II 8 & IIO & 228 & $4 \cdot 9$ \\
\hline Huxi & 2252 & 2098 & 4350 & $23 \mathrm{I}$ & 226 & 457 & I0.5 \\
\hline
\end{tabular}

I. The illegitimate children calculated in this table are children identified in the Japanese household registers as illegitimate at birth, although their legitimacy status changed if they were later recognized by their fathers. A recognized child's status might shift to that of shu-zi 庶子, a legitimate status bearing two definitions: an illegitimate child recognized by its father or a recognized child of a concubine. A recognized child might also become legitimate if its father married its mother. [Although the column "siborder" in the Person Static Table (PersonStat) provides a code for illegitimate children, we do not select our sample of illegitimate children from this table because this table records only the last legitimacy status of a person, which differs from the status at birth in the case of recognized and legitimated children.] 
I. Only first marriages are counted, so those who married within or from the research sites on or after I886 are included. Those who married into the research sites from outside are excluded because we do not know if they were previously married.

2. Source: Program for Historical Demography, Research Center for Humanities and Social Sciences, Academia Sinica, Taipei, Taiwan. 
Mother's marital status

\begin{tabular}{|c|c|c|c|c|c|c|c|c|c|c|}
\hline \multirow[b]{2}{*}{ Site } & \multicolumn{2}{|c|}{ Never-married } & \multicolumn{2}{|c|}{ Widowed } & \multicolumn{2}{|c|}{ Divorced } & \multicolumn{2}{|c|}{ Married } & \multicolumn{2}{|c|}{ Unclear } \\
\hline & $N$ & $\%$ & $N$ & $\%$ & $N$ & $\%$ & $N$ & $\%$ & $N$ & $\%$ \\
\hline North total & 2006 & 79.13 & $36 I$ & I4.24 & IIO & 4.34 & 58 & 2.29 & $\circ$ & 0.00 \\
\hline Tai-pei & I524 & 86.79 & $16_{4}$ & 9.34 & 55 & 3.13 & I3 & 0.74 & $\circ$ & 0.00 \\
\hline Ta-tao-cheng & 878 & 87.98 & $8 \mathrm{I}$ & 8.12 & 28 & $2.8 \mathrm{I}$ & II & I.IO & $\circ$ & 0.00 \\
\hline Meng-chia & 646 & 85.22 & 83 & I0.95 & 27 & 3.56 & 2 & 0.26 & $\circ$ & 0.00 \\
\hline Chu-pei & $27 \mathrm{I}$ & 61.45 & $\mathrm{I} 20$ & $27.2 \mathrm{I}$ & 26 & $5 \cdot 90$ & 24 & 5.44 & $\circ$ & 0.00 \\
\hline Bei-pu & $\circ$ & 0.00 & I7 & 58.62 & IO & $34 \cdot 48$ & 2 & 6.90 & $\circ$ & 0.00 \\
\hline E-mei & $2 \mathrm{II}$ & 68.28 & 60 & 19.42 & I9 & 6.15 & I9 & 6.15 & $\circ$ & 0.00 \\
\hline Central total: & II9 & $4^{2.8} .8$ & 109 & 39.21 & 35 & 12.59 & 15 & 5.40 & $\circ$ & 0.00 \\
\hline Lugang & 65 & 79.27 & I2 & 14.63 & 4 & 4.88 & I & $\mathrm{I} .22$ & $\circ$ & 0.00 \\
\hline Ta-chia & $\circ$ & 0.00 & 7 & 35.00 & 4 & 20.00 & 9 & 45.00 & $\circ$ & 0.00 \\
\hline Chu-shan & 54 & 42.52 & 57 & 44.88 & I4 & II.O2 & 2 & I. 57 & $\circ$ & 0.00 \\
\hline Shen-gang & $\circ$ & 0.00 & 33 & 67.35 & I3 & 26.53 & 3 & 6.12 & $\circ$ & 0.00 \\
\hline South total: & 302 & $43 \cdot 5^{8}$ & 300 & 43.29 & 68 & $9.8 \mathrm{I}$ & 23 & $3 \cdot 32$ & 0 & 0.00 \\
\hline Ta-nei & 92 & 32.06 & I54 & 53.66 & 32 & II.I5 & 9 & 3.14 & $\circ$ & 0.00 \\
\hline Chi-pei & I2 & $4 \mathrm{I} .38$ & 9 & 31.03 & 5 & $\mathrm{I} 7.24$ & 3 & I0.34 & ० & 0.00 \\
\hline Chiu-ju & 25 & 30.86 & 49 & 60.49 & 3 & $3 \cdot 70$ & 4 & 4.94 & ○ & 0.00 \\
\hline Tung-kang & 68 & 69.39 & 24 & 24.49 & 5 & 5.10 & I & 1.02 & ० & 0.00 \\
\hline An-ping & 105 & 53.03 & 64 & 32.32 & 23 & II. 62 & 6 & 3.03 & $\circ$ & 0.00 \\
\hline \multicolumn{11}{|l|}{ East } \\
\hline Wu-chieh & ० & 0.00 & $\mathrm{I} 22$ & 66.30 & 50 & 27.I7 & I2 & 6.52 & $\circ$ & 0.00 \\
\hline Peng-hu total: & 746 & 65.55 & 239 & 21.00 & 113 & $9 \cdot 93$ & 39 & $3 \cdot 43$ & I & 0.00 \\
\hline Ma-kung & 280 & 6I.8I & 77 & I7.00 & 74 & I6.34 & $2 \mathrm{I}$ & 4.64 & I & 0.00 \\
\hline Bai-sha & I45 & 63.60 & $5^{2}$ & $22.8 \mathrm{I}$ & I7 & $7 \cdot 46$ & I4 & 6.I4 & $\circ$ & 0.00 \\
\hline Hu-xi & $32 \mathrm{I}$ & 70.24 & IIO & 24.07 & 22 & $4.8 \mathrm{I}$ & 4 & 0.88 & $\circ$ & 0.00 \\
\hline
\end{tabular}

I. Illegitimate children born to unmarried women: the birth date of a child is earlier than the date of the first marriage of his/her mother.

2. Illegitimate children born to widows or divorced women: the birth date of a child is 280 days later than the date his mother is widowed or divorced.

3. Illegitimate children born to married women: a child is born within a marriage or 280 days after a marriage ends, and his or her registered father is not the husband of his/her mother.

4. Illegitimate children born to women with unclear marital status: the household registers do not record the dates of the beginning or the end of marriages of the women who bore illegitimate children. 

women who were sim-pua

\begin{tabular}{|c|c|c|c|c|c|}
\hline Site & $\begin{array}{l}\text { Number of } \\
\text { illegitimate } \\
\text { children born } \\
\text { to never-married } \\
\text { women }\end{array}$ & $\begin{array}{l}\text { Number born } \\
\text { to sim-pua }\end{array}$ & $\begin{array}{l}\text { Percent born } \\
\text { to sim-pua (\%) }\end{array}$ & $\begin{array}{l}\text { Number born } \\
\text { to sim-pua } \\
\text { having } \\
\text { thau-tui-a }\end{array}$ & $\begin{array}{l}\text { Percent born } \\
\text { to sim-pua } \\
\text { having } \\
\text { thau-tui-a (\%) }\end{array}$ \\
\hline Penghu & 746 & 395 & 52.95 & 145 & 19.44 \\
\hline Makung & 280 & I3I & 46.79 & 55 & 19.64 \\
\hline Baisha & I45 & 69 & 47.59 & 34 & 23.45 \\
\hline Huxi & 321 & I95 & 60.75 & 56 & I7.45 \\
\hline
\end{tabular}

Table 5. Number and percent of never-married women who bore illegitimate children who were sim-pua

\begin{tabular}{|c|c|c|c|c|c|}
\hline Site & $\begin{array}{l}\text { Number of } \\
\text { never-married } \\
\text { women who } \\
\text { bore illegitimate } \\
\text { children }\end{array}$ & $\begin{array}{l}\text { Number who } \\
\text { were sim-pua }\end{array}$ & $\begin{array}{l}\text { Percent who } \\
\text { were sim-pua (\%) }\end{array}$ & $\begin{array}{l}\text { Number who } \\
\text { were sim-pua } \\
\text { having thau-tui-a }\end{array}$ & $\begin{array}{l}\text { Percent who } \\
\text { were sim-pua } \\
\text { having } \\
\text { thau-tui-a (\%) }\end{array}$ \\
\hline Penghu & 316 & 166 & 52.53 & 57 & 18.04 \\
\hline Makung & I28 & 64 & 50.00 & 25 & I9. 53 \\
\hline Baisha & 68 & 33 & 48.53 & I3 & I9.I2 \\
\hline Huxi & I 20 & 69 & 57.50 & I9 & 15.83 \\
\hline
\end{tabular}

general, minor marriages were most common in northern areas of Taiwan, including Ta-tao-cheng and Meng-chia of Taipei, the three Hakka communities of Bei-pu, E-mei and Chu-pei, the three sites of Penghu, and Wu-chieh in I-lan. Of these 9 research sites, 7 have an illegitimate birth rate higher than $4 \%$ (Table I). Only Wu-chieh and Bei-pu, two sites with high rates of minor marriage, do not have high illegitimacy rates. In Penghu, Huxi is the site of the highest illegitimacy rate and it has the highest rate of minor marriage; by contrast, Ma-kung's illegitimacy rate is comparatively low, and its rate of minor marriages is also low in comparison with other sites. The same situation also occurs in Bei-pu. Among the three Hakka communities, Bei-pu has a lower rate of illegitimate births, and its rate of minor marriage is relatively low. 
The correlation of minor marriage and illegitimacy is not, however, direct

evidence that failure to register minor marriages accounts for high proportions illegitimate. Were the mothers of illegitimate children simpua who had never registered a marriage? Table 3 shows the different marital states of women who bore illegitimate children. The situation in Taipei, a metropolis, was quite different from that in Penghu and the two Hakka communities of northern Taiwan. In Taipei, nearly $90 \%$ of the mothers of illegitimate children were never married. Only a few of the mothers were widowed or divorced, and married women bearing illegitimate children were extremely rare. By contrast, in Penghu, E-mei, and Chu-pei, where minor marriage was also common, only about $60 \%$ of the mothers of illegitimate children were never married, close to $20 \%$ were widowed, and around Io\% were divorced. Therefore, the causes of the high illegitimacy rates of Penghu and the Hakka communities in northern Taiwan must differ from that of Taipei, as at least $30 \%$ of the illegitimate children in these areas could not be the result of unregistered minor marriages.

To establish a connection between the high proportion of sim-pua and the high illegitimacy rate of Penghu, we need to determine what proportion of nevermarried Penghu women who bore illegitimate children were sim-pua and whether or not they were matched with foster brothers for a minor marriage. Tables 4 and 5 show that in the period I906-1945, around half of Penghu's illegitimate children of never-married mothers were born to sim-pua, and also about half of the never-married mothers bearing illegitimate children in Penghu were sim-pua. Of the three Penghu sites Huxi had the highest proportion of illegitimate children born to sim-pua ( 60.75\%) and the highest proportion of sim-pua bearing illegitimate children ( $57.50 \%$ ).

The left-most panels of Tables 4 and 5 imply a close association between illegitimacy and sim-pua whose marriages went unregistered. However, the right-most panels showing the proportions of sim-pua who had a thau-tui-a match and the illegitimate children born to them contradict our assumption. Only a small proportion of the women who bore illegitimate children were simpua with a match whose marriages might go unregistered. Most of the sim-pua who bore illegitimate children had no match. In other words, in most cases the fathers of illegitimate children were not the expected husbands-to-be of nevermarried mothers. Therefore, we can reject the hypothesis that the unregistered marriages of sim-pua account for the high rates of illegitimacy in Penghu.

\section{Probe into possible causes of illegitimacy in Penghu}

Although we have shown that the failure to register the minor marriages of simpua cannot account for the high percentage of illegitimate children in Penghu, we cannot ignore the connection between sim-pua and the high percentage of illegitimate children. Half of the illegitimate children born to never-married 
women were born to sim-pua and half of the never-married women who bore illegitimate children were sim-pua. The reasons for such a pattern are hard to find in the household registration data. In the following passages, we probe into the history and social cultural background of Penghu in order to find the connection between them.

Penghu consists of several near-desolate coral islands off the west coast of Taiwan. None of the islands have fertile soil or natural springs. Strong northeast seasonal winds blow across the islands from late fall to early spring every year. Economic development is extremely limited. Farmers can only grow drought-resistant crops, such as sweet potatoes, sorghum, and peanuts etc. The crops are often destroyed by acts of nature, such as drought, typhoons, etc. Even in good years the harvest is enough to feed the population for only three to four months. Although Penghu is surrounded by ocean and abundant marine resources, fishing was seriously limited before motorized boats became common. Thus, Penghu has been considered poor and backward since the Qing Dynasty. In his "Penghu Song," Hu Jian-wei, the local prefect of Penghu (澎湖通判) in the middle of the Qian-long reign (I736-I795), complained that "Penghu is unmatched when it comes to the infertility of its soil and the poverty of its people," (Hu i771:276). In the Gazetteer of Penghu Subprefecture completed at the end of the igth century, there is a similar portrayal of Penghu: "...among the infertile and poor areas in the world, there is no area more barren than Penghu” (Lin I893:349).

Under these difficult circumstances, the sexual division of labor in Penghu was one in which men fished and women farmed. When the weather was good, men would set sail to go fishing for a catch they could sell for cash. Before the I96os sailing on small fishing boats was a dangerous way of making a living. Many fishermen were lost when their boats overturned. Women in Penghu provided the daily meals by farming and gathering at the tidal zone. Women also had to take care of all the housework. There were two kinds of farmland. Sorghum, sweet potatoes, and peanuts were grown in dry fields. Vegetables, melons, fruits and beans were planted in walled gardens (ts'ai-chai 菜宅). Men in Penghu did almost no farming work. Even the heavy work, such as plowing, was normally done by women. In addition to the routine work of cooking and laundry, women had to take care of the elderly. Much of the daily work of the women in Penghu did not differ from the daily work of women in the farming and fishing villages of Taiwan. However, the lack of natural resources made Penghu women's tasks more strenuous. For example, because wood is scarce in Penghu, finding sufficient cooking fuel was a daily chore. In addition to gathering and drying cow dung, women collected low-grade fuels such as wild grass, leaves and twigs. Because wells were the only water source in Penghu, women were constantly busy lading water for cooking, washing, and watering. There is an old saying in Penghu: "Women in Penghu are like cattle in Taiwan." 
Despite their hard work, women in Penghu were not valued by families or society. The status of women in the old days of patriarchy was not high. Women were considered private property which parents could manage and dispose of at will. Most of the women in Penghu were resigned to lives devoted to their families, but there was little they could do to increase family incomes. Despite the small population, resources were inadequate. That Penghu was divided by the sea from the labor market of Taiwan further limited women's options, both economically, and in terms of marriage chances. High rates of adult male emigration made it more difficult for Penghu women to find husbands, and it made families less willing to part with female labor. When Penghu women did their best to farm and collect food at the tidal zone and still failed to support their families, they had few alternatives. Those who were able to cultivate stable relationships with men (whether encouraged or acquiesced in by their families) could obtain material aid and a helping hand that would help relieve the poverty of their families.

Men who had these relationships with women in Penghu can be divided into two groups. The first group of men was those who were married but liked to have extra-marital relations with other women. These men were generally from affluent families. They obtained sexual services by providing women money and financial aid. The other group was those who were unable to afford the expense of a wedding or were unable to marry for some other reasons (for example, disability). These single men who were unable to get married would provide women with labor services or fish catch in order to have relationships similar to those of married couples. The women who established such relationships with men were normally from poor families. Their families also usually lacked male labor. But that does not necessarily mean that there were no men in their families. It was common in Penghu for men to leave the islands for work in Taiwan. In times when transportation was not convenient and communications not well developed, men who left their hometowns for work were like kites with broken strings. Those left behind had to depend on themselves.

Women who had sexual relationships with men that they were not married to were not necessarily sim-pua. However, sim-pua were more likely to get involved in such relationships. Many sim-pua remained unmarried in their foster parents' home, either because no match survived, or because sexual aversion caused their minor marriage to fail (whether before or after a trial period) (Wolf I995: 223). If their foster families were unwilling to arrange and pay for a marriage, such sim-pua were left open to informal relationships. Although adopting girls for minor marriages was common in Penghu, the girls who were adopted as sim-pua were often abused. If we agree that women in Penghu worked as hard as cattle in Taiwan, we can also say that sim-pua in Penghu were the most unfortunate among them. They were normally considered slaves by their foster par- 


\begin{tabular}{|c|c|c|c|c|c|c|c|c|}
\hline & & Daughters & & & Sim-pua & & Chi-square & $P$-value \\
\hline & $\begin{array}{l}\text { Total } \\
\text { number }\end{array}$ & $\begin{array}{l}\text { Number } \\
\text { bearing } \\
\text { illegitimate } \\
\text { children }\end{array}$ & $\begin{array}{l}\text { Percent } \\
\text { bearing } \\
\text { illegitimate } \\
\text { children }\end{array}$ & $\begin{array}{l}\text { Total } \\
\text { number }\end{array}$ & $\begin{array}{l}\text { Number } \\
\text { bearing } \\
\text { illegitimate } \\
\text { children }\end{array}$ & $\begin{array}{l}\text { Percent } \\
\text { bearing } \\
\text { illegitimate } \\
\text { children }\end{array}$ & value & \\
\hline Makung & 3185 & I०8 & $3.39 \%$ & ${ }_{11} G_{3}$ & I03 & $8.86 \%$ & 55.1153 & 0.0002 \\
\hline Baisha & I537 & 57 & $3.71 \%$ & 716 & 50 & $6.98 \%$ & II. 5793 & 0.0007 \\
\hline Huxi & IO8I & 79 & $7.31 \%$ & 857 & 105 & I $2.25 \%$ & I3.5978 & $<0.0001$ \\
\hline
\end{tabular}

ents. Many sim-pua had to endure not only hard work, coarse clothes and coarse food but also constant scolding and abuse. Therefore, in the vocabulary used by the people in Penghu, almost any word related to sim-pua has a negative meaning. ${ }^{2}$ For example, "the fate of being a sim-pua"(sim7 pu5 a3 miã7, 媳婦仔命) means the worst fate a woman can have. If a woman is told by a fortune-teller that she has "the fate of being a sim-pua", she does not need to ask for details about her fate. A person who is bullied or pushed aside everywhere is said to "[be born under a] sim-pua star" (sim7 pu5 aI tshir, 媳婦仔星). A demeanor showing fear and backwardness is often called "the manner of a sim-pua" (sim7 pu5 aI heng5, 媳婦仔形). Given how families exploited, bullied and oppressed sim-pua, it is not surprising that sim-pua, whether willingly or not, were more likely to have non-marital relationships with men who had something to offer. For many, such relationships were their only opportunity to build a family of their own.

Table 6 compares the proportions of daughters and of sim-pua who gave birth to illegitimate children in our three Penghu districts. The table shows that sim-pua were nearly twice as likely to have illegitimate children as daughters. We also run a Chi-square test to examine the relation between adoption and illegitimate birth. The null hypothesis that there is no difference in the probability that sim-pua and daughters will bear illegitimate children is strongly rejected.

From Table 7, we learn more about the women having illegitimate births in Penghu from I906 to I945. Among the 502 women who ever bore out-of-wedlock children, more than half of them (254 women) had more than one illegitimate child. More than ten percent of them ( 55 women) had 5 or more illegitimate children. Villages in Penghu during the Qing Dynasty had village ordinances. These ordinances commonly provided that persons who committed adultery be

\footnotetext{
2, The only exception is “sim-pua empress,” (sim7 pu5 as ong5 媳婦仔王) which refers to a sim-pua spoiled by her adoptive parents.
} 


\begin{tabular}{|c|c|c|c|c|c|c|c|c|}
\hline \multirow[b]{2}{*}{$\begin{array}{l}\text { Number of } \\
\text { illegitimate } \\
\text { children }\end{array}$} & \multicolumn{2}{|c|}{ Penghu } & \multicolumn{2}{|c|}{ Makung } & \multicolumn{2}{|c|}{ Baisha } & \multicolumn{2}{|c|}{ Huxi } \\
\hline & $\begin{array}{c}\text { Number } \\
\text { of } \\
\text { Mothers }\end{array}$ & $\begin{array}{c}\text { Sim-pual } \\
\text { Non- } \\
\text { sim-pua }\end{array}$ & $\begin{array}{c}\text { Number of } \\
\text { Mothers }\end{array}$ & $\begin{array}{l}\text { Sim-pua/ } \\
\text { Non- } \\
\text { sim-pua }\end{array}$ & $\begin{array}{c}\text { Number of } \\
\text { Mothers }\end{array}$ & $\begin{array}{l}\text { Sim-pua/ } \\
\text { Non- } \\
\text { sim-pua }\end{array}$ & $\begin{array}{c}\text { Number of } \\
\text { Mothers }\end{array}$ & $\begin{array}{c}\text { Sim-pua/ } \\
\text { Non- } \\
\text { sim-pua }\end{array}$ \\
\hline I & 248 & II5 / I33 & I2I & 50 / 7I & $5 \mathrm{I}$ & 24 / 27 & 76 & 4I / 35 \\
\hline 2 & 95 & $5 \mathrm{I} / 44$ & 25 & $\mathrm{I} 3 / \mathrm{I} 2$ & 26 & I3 / I3 & 44 & 25 / I9 \\
\hline 3 & 70 & $32 / 3^{8}$ & 29 & I5 / I4 & $\mathrm{I} 2$ & $3 / 9$ & 29 & I4 / I5 \\
\hline 4 & 34 & $23 /$ II & I5 & $\mathrm{I} 2 / 3$ & 9 & $6 / 3$ & IO & $5 / 5$ \\
\hline 5 & 19 & $7 / \mathbf{1 2}$ & 8 & $3 / 5$ & 4 & $2 / 2$ & 7 & $2 / 5$ \\
\hline 6 & 16 & $7 / 9$ & 6 & $2 / 4$ & 3 & $0 / 3$ & 7 & $5 / 2$ \\
\hline 7 & IO & $8 / 2$ & 3 & $2 / I$ & I & I / O & 6 & $5 / \mathrm{I}$ \\
\hline 8 & 3 & $2 / I$ & I & I / O & I & $\circ / I$ & I & I / O \\
\hline 9 & 3 & $2 / I$ & I & $0 / I$ & $\circ$ & $0 / 0$ & 2 & $2 / 0$ \\
\hline IO & 2 & $\mathbf{I} / \mathbf{I}$ & I & $0 / I$ & $\circ$ & $0 / 0$ & I & I / O \\
\hline II & 2 & $2 / 0$ & I & I / O & $\circ$ & $0 / 0$ & I & I / O \\
\hline Total & 502 & $250 / 252$ & $2 \mathrm{II}$ & 99 / II2 & 107 & $49 / 58$ & I84 & IO2 / 82 \\
\hline
\end{tabular}

expelled from the village (Li I960: 20I). Thus the women who had multiple illegitimate births must have been in relationships condoned by their families and even their communities. As we learned from Tables 4 and 5 , more than $80 \%$ of sim-pua who gave birth to illegitimate children had no "thau-tui-a" in their adoptive families. We conclude that their illicit relationships were likely encouraged by foster parents who had no sons or other male labor in their families. Table 7 also shows that just as many non-sim-pua as sim-pua bore illegitimate children, and that non-sim-pua were also likely to have multiple illegitimate births. Many women (daughters, widows, divorcees) must have found themselves in situations comparable to those faced by sim-pua in which non-marital relationships provided an important alternative source of support and even a means of building a family.

Table 8 shows the professions of the heads of the households in which women who had illegitimate children lived. We classify as low-income tenantfarmers, fishermen, laborers, laundry men/women, and servants. Businessmen, teachers, and artisans are classified as high and middle income. The table clearly shows that most of the heads of the households in which the women who had illegitimate children lived had low-income professions. In the agricultural and fishing villages in Baisha and Huxi more than 80 percent had low-income professions. If we exclude the cases with unknown incomes, almost 70 percent 

ing illegitimate children

\begin{tabular}{|c|c|c|c|c|}
\hline \multicolumn{5}{|c|}{ Number of households } \\
\hline & $\begin{array}{c}\text { High and middle } \\
\text { income level }\end{array}$ & $\begin{array}{l}\text { Low income level } \\
\text { (number / percent) }\end{array}$ & $\begin{array}{c}\text { Unclear } \\
\text { (number / percent) }\end{array}$ & $\begin{array}{c}\text { Total } \\
\text { (number / percent) }\end{array}$ \\
\hline Makung & $57 / 27.01 \%$ & I27 / 60.19\% & 27 / I2.80\% & $2 \mathrm{II}$ \\
\hline Baisha & $7 / 6.48 \%$ & $90 / 83.33 \%$ & II / IO.I9\% & 108 \\
\hline Huxi & $7 / 3.80 \%$ & $160 / 86.96 \%$ & I7 / $9.24 \%$ & I84 \\
\hline
\end{tabular}

(69.02\%) of the heads of households in which the women who had illegitimate children lived had low-income professions in Makung, and more than 90 percent in Baisha and Huxi. The data shows that the women who had illegitimate children were mostly from families in poor financial condition. It is also likely that they had no male family members or that their male family members left the hometown for work. To have a sexual relationship with a man without marrying him might be a desperate measure, but it could be necessary for a woman of a poor family struggling to make ends meet.

\section{High mortality among illegitimate infant}

Table 9 compares infant mortality rates by legitimacy status and sex. Table 9 shows higher rates of mortality among illegitimate compared to legitimate infants of both sexes in all the regions. Clearly illegitimate status is unfavorable to infant survival. Poverty and stigma associated with illegitimacy probably added significantly to the risk of death.

We have seen from Table 3 that more illegitimate infants were born to never-married women than to widowed and divorced women. Were the illegitimate infants of never-married women at greater risk than the illegitimate infants of widows and divorcees? Or was the welcome and care they received of comparable quality? Perhaps widows, presumably older and many living among their deceased husband's kin, enjoyed greater security that benefited their illegitimate infants. Were widows pursuing deliberate family building strategies when bearing children out of wedlock, in contrast to never-married women for whom the bearing of an illegitimate child may have been more of an unfortunate accident? Or were unmarried women (whether daughters or sim-pua) also following deliberate family building strategies, perhaps encouraged by parents who lacked sons to continue the family, and to remain as contributing members of their natal families (cf. Gates, et al. 2006: 95-96)? How did the infants of divorcees fare? Lower infant mortality rates among illegitimates of one category 


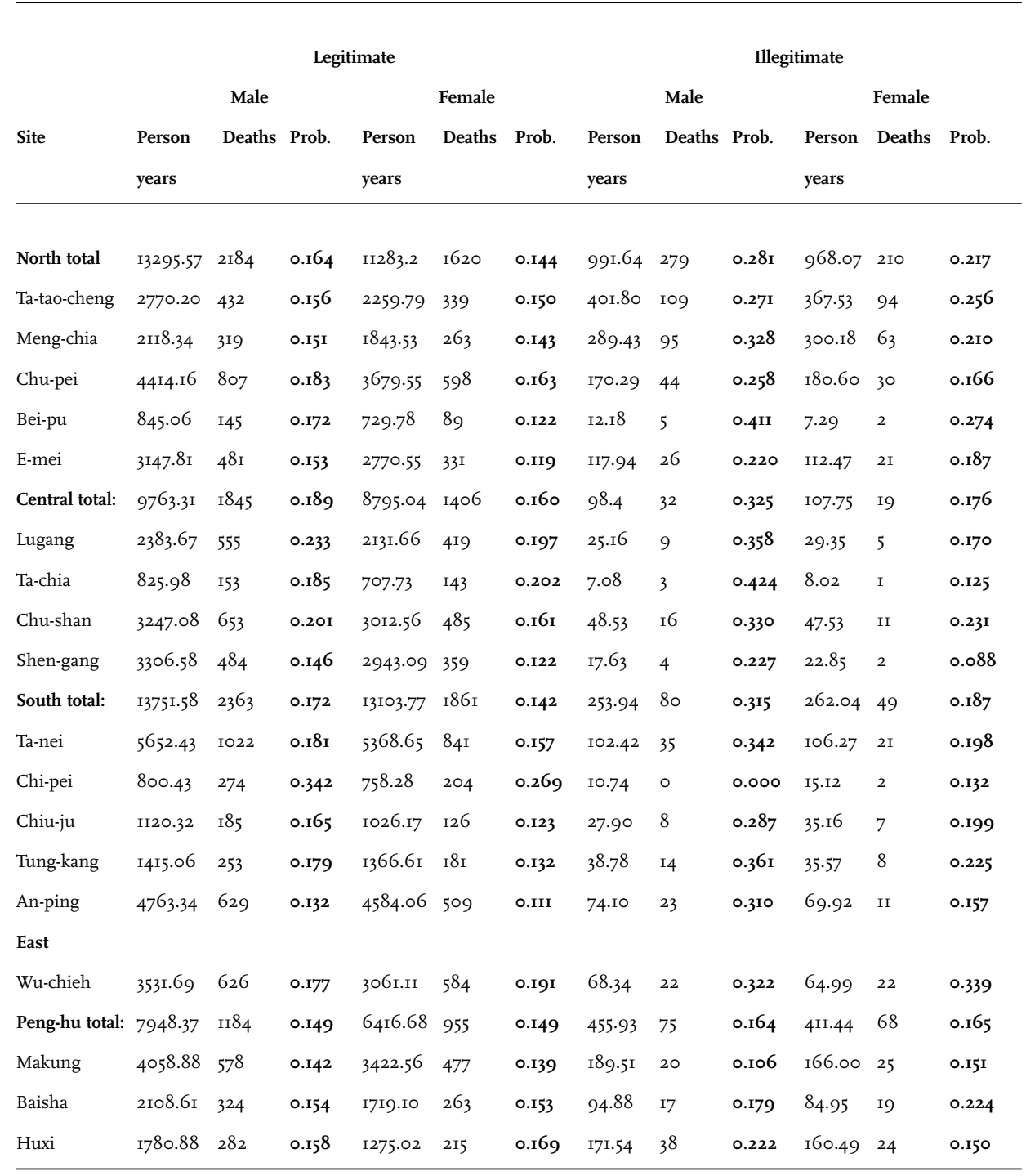

I. The samples of legitimate and illegitimate infants include the child years and deaths occurring to infants under observation according to their legitimacy status at birth. Infants remain in the legitimate and illegitimate categories only so long as their natal status is unchanged; infants who die or who are adopted are removed from the sample on the date of their death or adoption. Illegitimate children are identified in the registers as illegitimate; a few ambiguous cases are excluded from both categories. Infants born illegitimate are included in the illegitimate category only until they are recognized. They are not shifted to the legitimate category after they are recognized. Infants who moved out of the research site are removed from the sample on the date they left. Infants born outside the research site but moving into the research site before age I are included in the sample from the date they moved in. 

ers (Deaths per person years)

\begin{tabular}{|c|c|c|c|c|c|c|c|c|c|}
\hline \multirow[b]{2}{*}{ Site } & \multicolumn{3}{|c|}{ Never-married } & \multicolumn{3}{|c|}{ Divorced } & \multicolumn{3}{|c|}{ Widowed } \\
\hline & $\begin{array}{l}\text { Person } \\
\text { years }\end{array}$ & Deaths & Prob. & $\begin{array}{l}\text { Person } \\
\text { years }\end{array}$ & Deaths & Prob. & $\begin{array}{l}\text { Person } \\
\text { years }\end{array}$ & Deaths & Prob. \\
\hline North total & I349.223 & 406 & 0.301 & 73.98 & I7 & 0.230 & 519.78 & 57 & O.IIO \\
\hline Ta-tao-cheng & 577.198 & 189 & 0.327 & 20.689 & 4 & 0.193 & $5 \mathrm{I} .554$ & 9 & 0.175 \\
\hline Meng-chia & 424.953 & I33 & 0.313 & 20.014 & 5 & 0.250 & 34I.8I5 & I8 & 0.053 \\
\hline Chu-pei & 202.898 & 50 & 0.246 & 20.046 & I & 0.050 & $8 \mathrm{I} .485$ & I9 & 0.233 \\
\hline Bei-pu & $\circ$ & $\circ$ & & 3.106 & 4 & $\mathrm{I} .288$ & II. 699 & 3 & 0.256 \\
\hline E-mei & I44.I74 & 34 & 0.236 & IO.I25 & 3 & 0.296 & 33.227 & 8 & $0.24 \mathrm{I}$ \\
\hline Central total & 73.242 & 22 & 0.300 & 20.929 & 6 & 0.287 & $74.07 \mathrm{I}$ & 20 & 0.270 \\
\hline Lugang & $35 \cdot 727$ & IO & 0.280 & 2.016 & I & 0.496 & 4.II4 & 3 & 0.729 \\
\hline Ta-chia & $\circ$ & ० & & I. 422 & 2 & 1.406 & 6.016 & $\circ$ & 0.000 \\
\hline Chu-shan & 37.515 & I2 & 0.320 & I2.006 & 3 & 0.250 & 38.598 & II & 0.285 \\
\hline Shen-gang & ० & $\circ$ & & 5.485 & ० & 0.000 & $25 \cdot 343$ & 6 & 0.237 \\
\hline South total & I70.784 & 59 & 0.345 & 44.03 & 9 & 0.204 & I84.95 & 55 & 0.297 \\
\hline Ta-nei & 51.089 & I6 & 0.313 & 20.379 & 4 & 0.196 & 97.003 & 32 & 0.330 \\
\hline Chi-pei & $6.74 \mathrm{I}$ & I & 0.148 & 3.134 & I & 0.319 & 6.55 & ० & 0.000 \\
\hline Chiu-ju & I8.47 & 3 & 0.162 & 0.778 & 2 & $2.57 \mathrm{I}$ & 35.063 & 9 & 0.257 \\
\hline Tung-kang & 40.599 & I7 & 0.419 & I.I83 & I & 0.845 & 17.669 & 4 & 0.226 \\
\hline An-ping & 53.885 & 22 & 0.408 & 18.556 & I & 0.054 & 28.665 & IO & 0.349 \\
\hline \multicolumn{10}{|l|}{ East } \\
\hline Wu-chieh & ○ & $\circ$ & & 28.I49 & I2 & 0.426 & 85.769 & 27 & 0.315 \\
\hline Peng-hu total: & 431.459 & 99 & 0.229 & 59.488 & 7 & O.II8 & I24.089 & 29 & 0.234 \\
\hline Makung & I44.I 83 & 29 & 0.201 & $47 \cdot 42 \mathrm{I}$ & 6 & 0.127 & 47.155 & 6 & 0.127 \\
\hline Baisha & 86.263 & 22 & 0.255 & $7 \cdot 994$ & I & 0.125 & $27 \cdot 404$ & IO & 0.365 \\
\hline Huxi & 201.0I3 & 48 & 0.239 & 4.073 & $\circ$ & 0.000 & 49.53 & I3 & 0.262 \\
\hline
\end{tabular}

I. The illegitimate infants are classified by the marital status of their mothers at birth. The infants are included until they were recognized by their fathers, moved out of the research site or died. Illegitimate infants born outside the research site but moving into the research site before age I are included in the sample from the date they moved in.

of mothers may indicate the greater welcome and care with which they greeted their out of wedlock births.

Table io shows the probability of death among illegitimate infants by the marital status of their mothers. In the north, central and south regions of Taiwan, the probability of infant death is greater for the illegitimate children of 
never-married women than for the illegitimate children of divorced and widowed

women. In Penghu, the probability of death differs little for the illegitimate infants of never-married women and widows, both of which are much higher than for the illegitimate infants of divorced women. For Taiwan generally it seems that the illegitimate children of never-married women were at higher risk of death than the illegitimate children of widowed and divorced women. However, the table does not show a clear pattern telling us whether the illegitimate infants born to widows or born to divorcees suffered greater risk of death. Apparently marital status alone is not sufficient to distinguish those situations where illegitimate infants are more likely to be unwanted, or to enter unfavorable environments for survival, such as mothers needing to work outside the household.

\section{High mortality rate among female infants in Penghu}

Another distinctive demographic phenomenon of Penghu revealed by the Japanese household registers concerns the mortality of female infants. In most populations the mortality rate of male infants is higher than that of female infants. However, table II shows that the mortality of female infants is higher than male infants more frequently in Penghu than in any other site. Table 9 compares infant mortality rates by legitimacy status and sex. While legitimate male infants had a higher mortality rate than legitimate female infants in most of the Taiwan research sites, this was not true in Penghu, Ta-chia, and Wu-chieh. All three research sites within Penghu are distinctive for how high the infant mortality rates of legitimate females are compared to those of legitimate males; female mortality rates in Huxi are II points higher and in Baisha and Makung only I-3 points lower than those of males. The mortality rates of illegitimate infants of both sexes are generally much higher than those of their legitimate counterparts, but even among illegitimates, males have higher death rates than females in all the sites except Wu-chieh and Penghu's Makung and Baisha.

This phenomenon of higher female infant mortality (both illegitimate and legitimate) in Penghu should not surprise Penghu natives or scholars specializing in the history and culture of Penghu. During the Qing dynasty Taiwan and Fujian were notorious for practicing female infanticide, and to counter this, Penghu officials supported the establishment and maintenance of orphanages (Lin I893: 77). The government encouraged local people to send female infants to orphanages instead of killing them. However, limited funds meant the promotion of orphanages did not save many female infants. One of the co-authors of this paper still remembers stories about infanticide told by the elderly during his childhood in Penghu. According to the stories, female infants were the usual victims of infanticide but deformed male infants could also be killed. Illegitimate female infants were the most vulnerable to this practice. The means of infanti- 


\section{Birth cohort}

Site

$\begin{array}{cccccc}\text { 1906-1910 } & 1911-1915 & 1916-1920 & 1921-1925 & 1926-1930 & 1931-1935 \\ \text { Male Female } & \text { Male Female } & \text { Male Female } & \text { Male Female } & \text { Male Female } & \text { Male Female }\end{array}$

North

$\begin{array}{lllllllllllll}\text { Ta-tao-cheng } & 0.157 & 0.150 & 0.170 & 0.14 \mathrm{I} & 0.165 & 0.244 & 0.258 & 0.168 & 0.224 & 0.166 & 0.175 & 0.167 \\ \text { Meng-chia } & 0.239 & 0.203 & 0.159 & 0.193 & 0.24 \mathrm{I} & 0.17 \mathrm{I} & 0.169 & 0.170 & 0.200 & 0.134 & 0.162 & 0.129 \\ \text { Chu-pei } & 0.175 & 0.146 & 0.16 \mathrm{I} & 0.140 & 0.184 & 0.155 & 0.183 & 0.133 & 0.183 & 0.140 & 0.205 & 0.158 \\ \text { Bei-pu } & 0.122 & 0.143 & 0.132 & 0.126 & 0.219 & 0.157 & 0.237 & 0.113 & 0.237 & 0.130 & 0.215 & 0.06 \mathrm{I} \\ \text { E-mei } & 0.133 & 0.086 & 0.130 & 0.105 & 0.157 & 0.139 & 0.150 & 0.097 & 0.150 & 0.120 & 0.166 & 0.145\end{array}$

Central

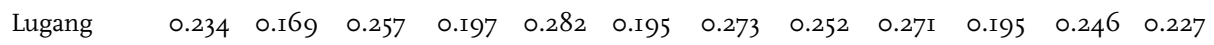

$\begin{array}{lllllllllllll}\text { Ta-chia } & 0.297 & 0.260 & 0.340 & 0.304 & 0.228 & 0.175 & 0.144 & 0.269 & 0.147 & 0.180 & 0.131 & 0.177\end{array}$

$\begin{array}{lllllllllllll}\text { Chu-shan } & 0.202 & 0.199 & 0.170 & 0.139 & 0.202 & 0.165 & 0.236 & 0.144 & 0.236 & 0.138 & 0.244 & 0.177\end{array}$

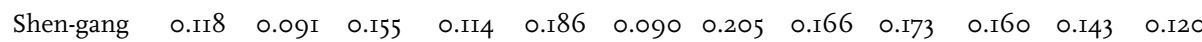

South

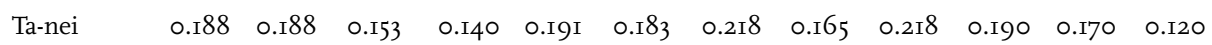

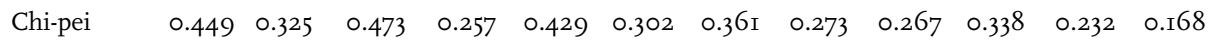

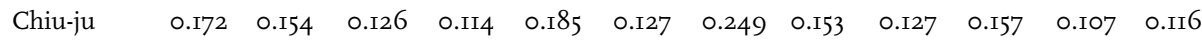

$\begin{array}{lllllllllllll}\text { Tung-kang } & 0.147 & 0.070 & 0.189 & 0.096 & 0.267 & 0.152 & 0.246 & 0.156 & 0.2 \mathrm{II} & 0.169 & 0.202 & 0.116\end{array}$

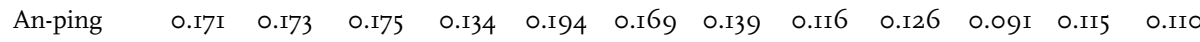

East

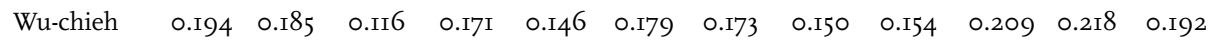

Penghu

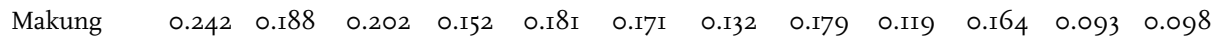

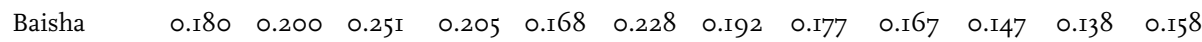

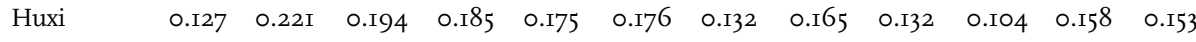

I. The sample of this table includes infants born in the research site during I906-I945.

Source: Program for Historical Demography, Research Center for Humanities and Social Sciences, Academia Sinica, Taipei, Taiwan.

cide included drowning (in a tub used for delivery or in shallow coastal waters), suffocating by using clothes or a quilt, and exposure by leaving a newborn to die of cold or starvation.

By I906, the Japanese had effective police control over Taiwan. The police, in conjunction with the baojia mutual security system, were able to keep a complete and accurate record of every household and to monitor unusual changes in 


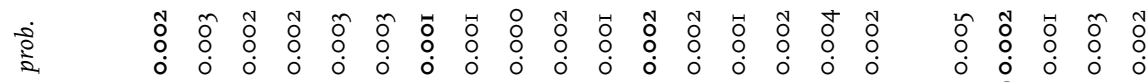

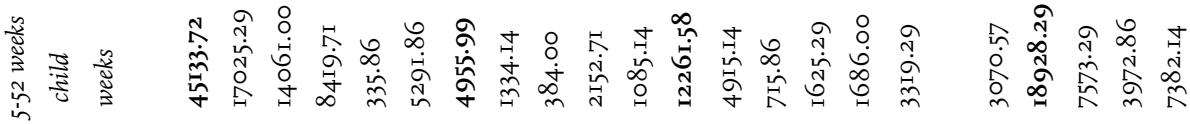

घ

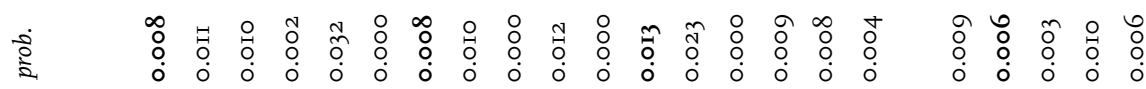

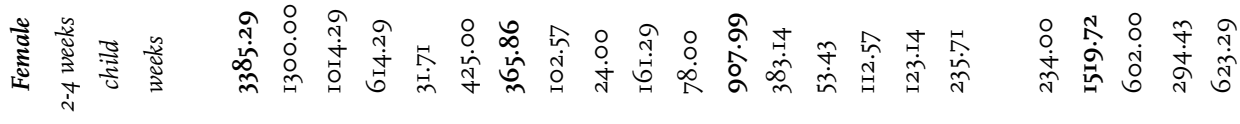

تय

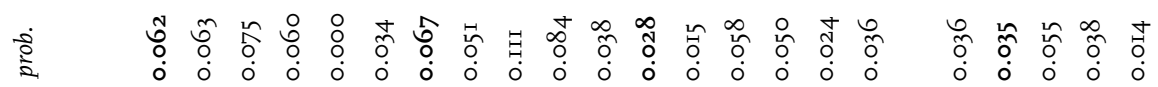

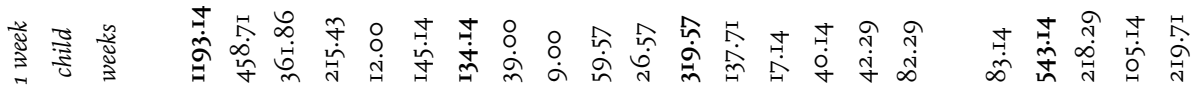
马 $\quad$ t

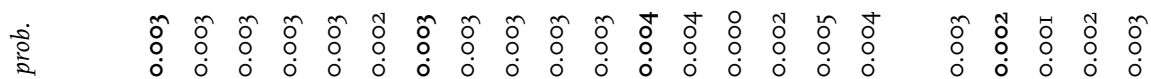

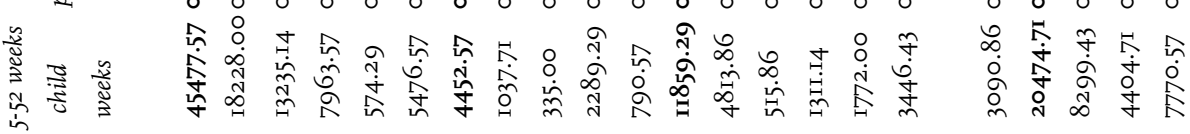

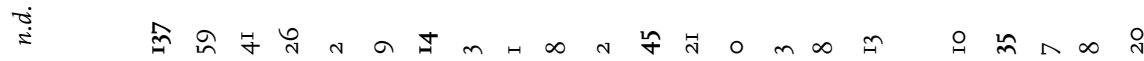

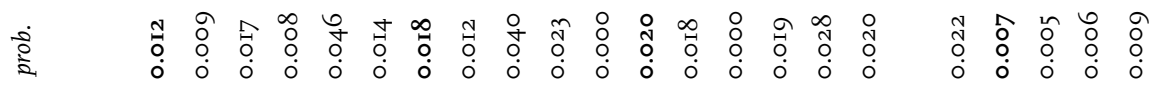

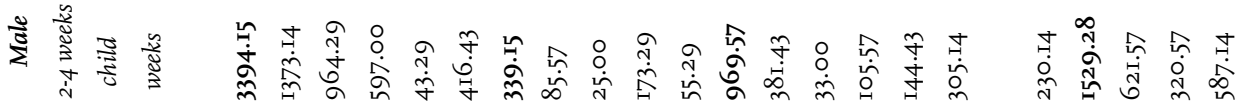

घं द

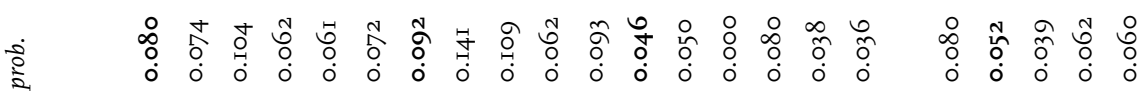

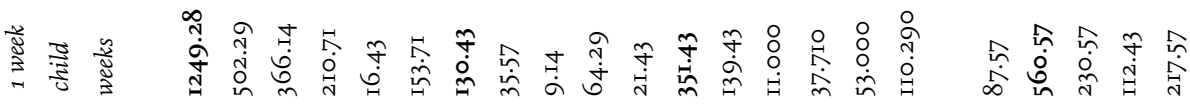

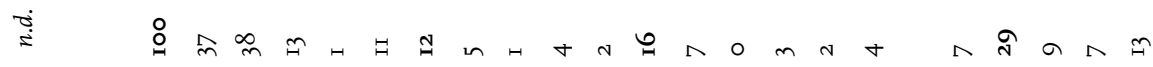

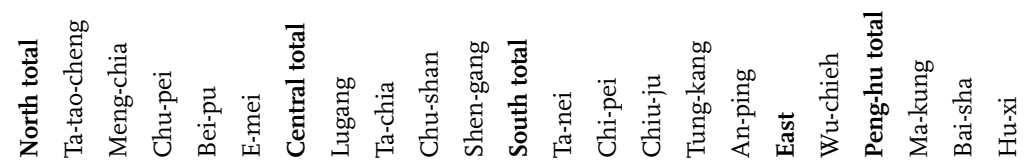

Sample as described in Table 9. 


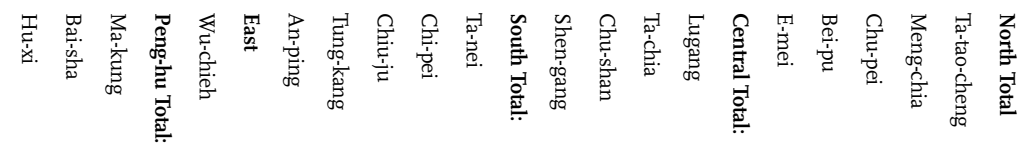

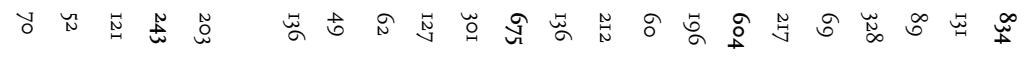

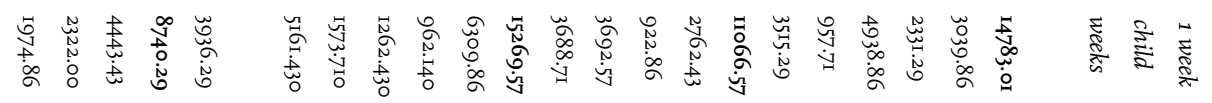

总总总递总

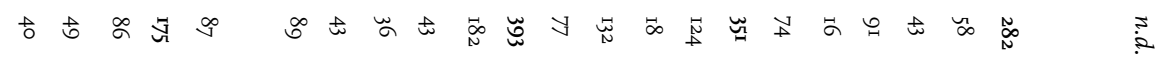

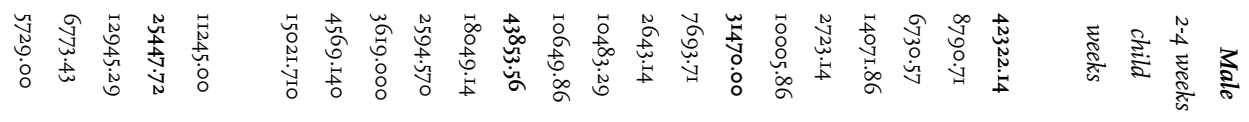

客 $\begin{aligned} & \circ \\ & \dot{0}\end{aligned}$

प

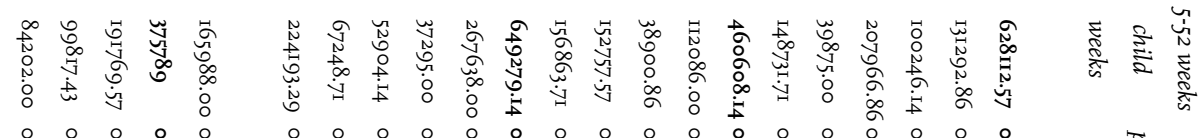

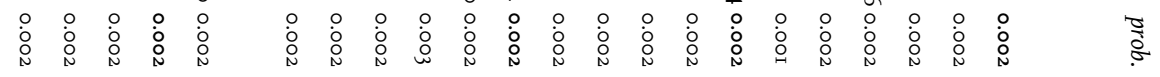

ऍ

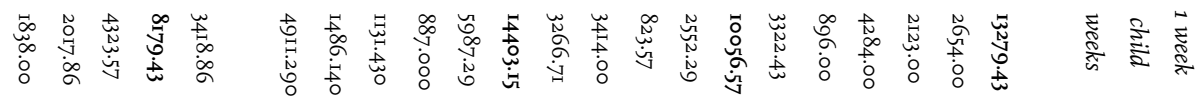

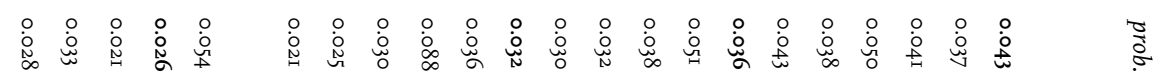

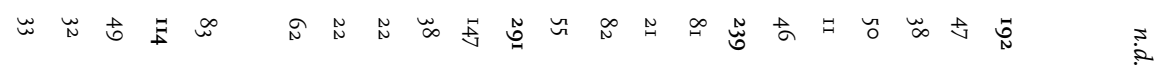

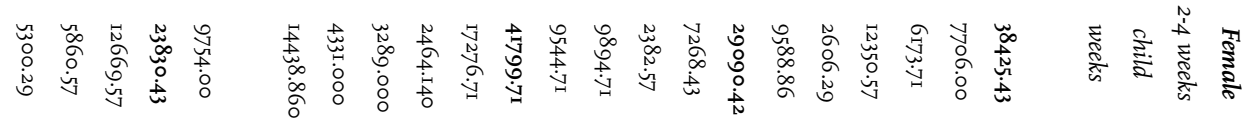

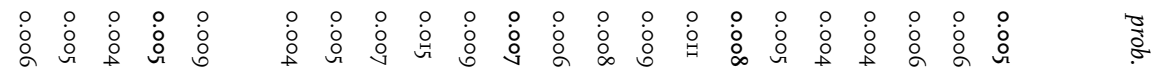

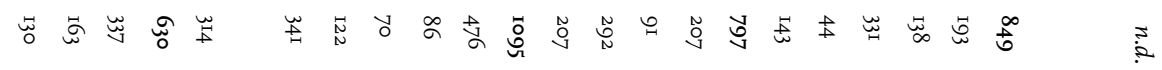

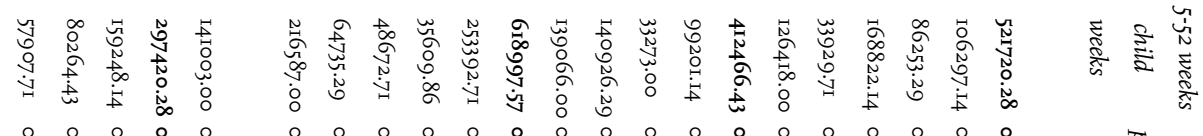

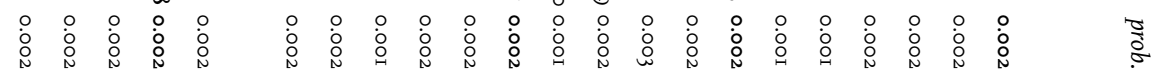


household membership. In addition, the doctors accredited to Penghu by the government since the I9I0's and the increasing number of midwives licensed since the 1920's were also an effective curb on infanticide (Xie 2005: IO-I3). Therefore, the opportune time to kill an infant was right after she or he was born. In some cases reporting the child as stillborn might conceal the crime. Delay increased the risk that infanticide would be discovered.

If the hypothesis that the higher mortality rate of Penghu's female infants was caused by deliberate female infanticide is correct, Penghu should have more female infants who died within a week after birth than most of the other research sites, and female infants should have a higher mortality rate than male infants within a week after birth.

In tables I2 and I3 we calculate the risk of mortality in three intervals, the first week, second to fourth week, and fifth to fifty-second weeks; the mortality rates of illegitimates are in table $\mathrm{I} 2$ and legitimates in table I3. Compared either to the other research sites or to male infants, the mortality rate of Penghu's female infants who were born between 1906 and 1945 does not appear to be unusually high in the first week or in the first month after birth. If we compare Penghu's female infants to Penghu's male infants, we see that the mortality rates of legitimate and illegitimate female infants are not higher than those of male infants either within the first week or the first month after birth, excepting illegitimate female infants in Makung and legitimate female infants in Baisha. In fact, the probability of death of male infants in the period from the second week to the fourth week after birth is generally higher than that of female infants in Penghu.

We also compare the sex ratio of legitimate and illegitimate children at birth in all of the research sites in table I4. If stillbirths were being used to conceal female infanticide, the sex ratio (males per too females) of reported live births in Penghu should be higher than in the other sites. However, the sex ratio of illegitimate births in Penghu averages I02.49, lower than the normal range for human births of I05-106. The highest sex ratio of illegitimate births among the three sites of Penghu is 107.27 in Baisha, still close to the expected range of I05Io6 and lower than the ratios of Ta-tao-cheng, Bei-pu, Chu-shan, Tung-kang, and An-ping. These results contradict the hypothesis that stillbirths or other unregistered births were being used to disguise events of female infanticide in illegitimate births. The sex ratio of legitimate births in Penghu averages Io6.08, close to the normal sex ratio at birth, while Baisha, again, has a higher sex ratio than the other two sites in Penghu. The sex ratio of legitimate births in Baisha is II3.34, lower only than Ta-tao-cheng's II4.I8 and Ta-chia's II3.83. If our assumptions are correct, this implies that female infanticide was practiced primarily in Baisha, and that it was practiced more among legitimate births than illegitimate births.

Our evidence has cast doubt on the importance of female infanticide to these high death rates, and points to the role of selective neglect of female 
Legitimate births

Illegitimate births

\begin{tabular}{|c|c|c|c|c|c|c|}
\hline & Male & Female & Sex ratio & Male & Female & Sex ratio \\
\hline North total & I5234 & 14065 & IO8.3I & 1305 & $\mathbf{1 2 3 5}$ & 105.67 \\
\hline Ta-tao-cheng & 3IOI & 2716 & II4.I8 & 527 & 476 & IIO.7I \\
\hline Meng-chia & 2363 & 2186 & IO8.IO & 385 & 373 & 103.22 \\
\hline Chu-pei & 5135 & 4682 & $\log .68$ & 217 & 224 & 96.88 \\
\hline Bei-pu & 999 & 934 & 106.96 & I7 & $\mathrm{I} 2$ & I4I. 67 \\
\hline E-mei & 3636 & 3547 & $102.5 \mathrm{I}$ & 159 & 150 & 106.00 \\
\hline Central total: & $1145^{\circ}$ & 10509 & 108.95 & 138 & 140 & 98.57 \\
\hline Lugang & 2867 & 2666 & IO7.54 & 39 & 43 & 90.70 \\
\hline Ta-chia & 955 & 839 & II 3.83 & IO & IO & 100.00 \\
\hline Chu-shan & $385 \mathrm{I}$ & 3616 & I06.50 & 67 & 60 & ІІг.67 \\
\hline Shen-gang & 3777 & 3388 & III. 48 & 22 & 27 & $8 \mathrm{I} .48$ \\
\hline South total: & 15764 & 14862 & 106.07 & 367 & 327 & $\mathrm{II} 2.23$ \\
\hline Ta-nei & 6530 & 62II & I05.I4 & I47 & I4I & 104.26 \\
\hline Chi-pei & 1029 & 936 & I09.94 & II & I8 & GI.II \\
\hline Chiu-ju & I298 & II 48 & II3.07 & 40 & $4 \mathrm{I}$ & 97.56 \\
\hline Tung-kang & 1580 & $\mathrm{I} 485$ & 106.40 & 55 & 43 & I27.9I \\
\hline An-ping & 5327 & 5082 & IO 4.82 & II4 & 84 & $\mathrm{I} 35 \cdot 7 \mathrm{I}$ \\
\hline \multicolumn{7}{|l|}{ East } \\
\hline Wu-chieh & 4060 & 3822 & 106.23 & 9I & 85 & 107.06 \\
\hline Penghu total: & 8879 & 8370 & 106.08 & 576 & 562 & I02.49 \\
\hline Makung & 4504 & $442 \mathrm{I}$ & IоI. 88 & 227 & 226 & 100.44 \\
\hline Baisha & 2354 & 2077 & II 3.34 & II 8 & IIO & I07.27 \\
\hline Huxi & $202 \mathrm{I}$ & I872 & 107.96 & $23 \mathrm{I}$ & 226 & IO2.2I \\
\hline
\end{tabular}

infants. Although the Japanese colonial government prohibited female infanticide, the traditional discrimination against girls could still kill female infants through passive neglect. For example, while a male infant was constantly looked after, a female infant might be left home alone and fall victim to a fatal accident. In the first half of the 2oth century, the financial situation of every family, medical services and sanitary conditions were all generally poor. When a baby boy was seriously ill, his family might trudge over a long distance to look for a doctor and pawn the valuables of the family or borrow money to pay for medication. But if the sick baby was a female, her family tended to ignore the illness, which might lead to her death. And the situation of illegitimate female infants could be worse than legitimate female infants. 
It is difficult to find direct evidence of the selective neglect of female

infants resulting in death, more than sixty years after the events being discussed. We attempted to collect data that would document discrimination against girls in terms of the frequency of receiving medical service in the hospital and in school attendance. Unfortunately, we have not found any statistics related to medical care. As for school attendance, the number of boys attending elementary school was always several times the number of girls throughout the Japanese period. In I935, 58\% of school age boys attended elementary school in Penghu, but only I3\% of school age girls (Taiwan Sōtokufu tōkeisho, I935). This was the lowest proportion of girls attending school of all Taiwan's eight prefectures, confirming the low priority Penghu society gave to investment in girls.

\section{The impact of adoption.}

Since tables I2, I3 and I4 do not support the presumption of female infanticide in Penghu, we have to look for other reasons behind Penghu's high female infant mortality rate. Arthur Wolf's research on north Taiwan (I995) provides us with some clues. Based on the data of Hai-shan, Arthur Wolf reached the conclusion that "adoption killed people". Wolf found that the mortality rate of sim-pua from age I to 5 was double that of daughters during the Japanese period, and the highest mortality rate of sim-pua occurred in the $5^{\text {th }}$ to $7^{\text {th }}$ months after birth (ibid: 305-6). Since minor marriages were common in Penghu and there were many sim-pua, the high mortality rate of female infants (both legitimate and illegitimate) in Penghu could be related to the custom of adoption. Our next tables examine whether adopted daughters had a higher risk of death than daughters in Penghu.

We compare the probability of death of daughters and adopted daughters in the first I2 months of life in the three research sites of Penghu (Tables I5, I6, I7). We select girls who entered (born, adopted or moved in by other means) the research sites in the period of 1906-I945 for observation. In Makung, the cumulative probability of death of daughters at age I2 months was 0.133 , lower than the cumulative probability of death of adopted daughters at age I2 months (0.150). In Baisha, the cumulative probability of death of daughters at age I2 months was 0.149 and of adopted daughters was 0.176. The results of these two places echo Arthur Wolf's claim that "adoption killed people". However, Huxi seems to be an exception. In Huxi, at age I2 months, the cumulative probability of death of daughters was 0.I5I, higher than that of adopted daughters (O.II2). If we look at the adoption age of girls (Table I8), we can find that in the three sites of Penghu, girls adopted in the first month of life comprise less than Io\% of all girls adopted before age $\mathrm{I}$, but the cumulative percentage of girls adopted by the age of 2 months suddenly rises to more than $35 \%$. Infant mortality is usually very high in the first month of life and many of these children died before they could 

adopted daughters in first 12 months - Makung (Deaths per person months)

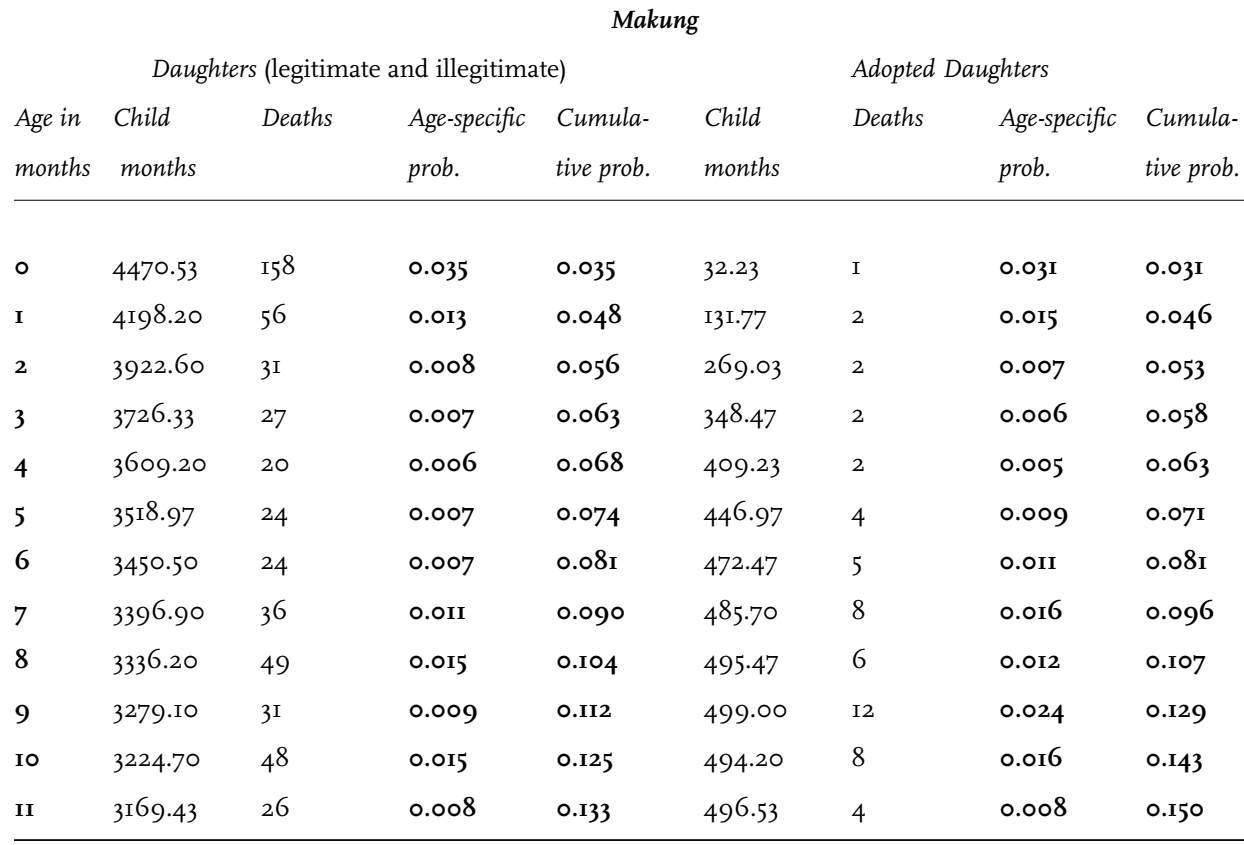

I. The sample of "daughters" includes both legitimate and illegitimate girls who have never been adopted, and that of "adopted daughters" includes all girls who have been adopted (from the date of the first adoption), regardless of their former status as legitimate or illegitimate.

2. Infants who moved out of the research site are removed from the sample on the date they left. Infants born outside the research site but moving into the research site before age I are included in the sample from the date they moved in.

be at risk of adoption. A better measure of the negative impact of adoption on survival would compare the mortality rates of daughters and adopted daughters beginning in the second month of life, when girls begin to bear the risks associated with adoption. The result of excluding the deaths in the first months is in Table I9. The cumulative probabilities of death of adopted daughters are all higher than those of daughters in the three sites. The average cumulative probability of death of adopted daughters was 0.I3I and of daughters was 0.I03, in line with Arthur Wolf's research on female adoption.

From table 9, we learned that illegitimate children had a higher infant mortality rate than legitimate children, and among illegitimates, females had a higher infant mortality rate than males in Penghu. From tables I5-I9, we also learned that adoption is another factor elevating female infant mortality. We next determine whether illegitimate or adopted children have the higher mortality 

adopted daughters in first 12 months - Baisha (Deaths per person months)

Baisha

Daughters (legitimate and illegitimate)

\begin{tabular}{|c|c|c|c|c|c|c|c|c|}
\hline $\begin{array}{l}\text { Age in } \\
\text { months }\end{array}$ & $\begin{array}{l}\text { Child } \\
\text { months }\end{array}$ & Deaths & $\begin{array}{l}\text { Age-specific } \\
\text { prob. }\end{array}$ & $\begin{array}{l}\text { Cumula- } \\
\text { tive prob. }\end{array}$ & $\begin{array}{l}\text { Child } \\
\text { months }\end{array}$ & Deaths & $\begin{array}{l}\text { Age-specific } \\
\text { prob. }\end{array}$ & $\begin{array}{l}\text { Cumula- } \\
\text { tive prob. }\end{array}$ \\
\hline ० & 2089.00 & I08 & 0.052 & 0.052 & 10.67 & $\circ$ & 0.000 & 0.000 \\
\hline I & I992.50 & I7 & 0.009 & 0.060 & I03.37 & 0 & 0.000 & 0.000 \\
\hline 2 & I9I3.20 & I3 & 0.007 & 0.066 & $2 \mathrm{I} 2 . \mathrm{I} 7$ & 3 & 0.014 & 0.014 \\
\hline 3 & 1862.50 & I6 & 0.009 & 0.074 & 267.67 & 3 & 0.011 & 0.025 \\
\hline 4 & I 822.40 & 16 & 0.009 & 0.082 & 302.70 & 7 & 0.023 & 0.048 \\
\hline 5 & I792.93 & I3 & 0.007 & 0.089 & 320.93 & 5 & 0.016 & 0.063 \\
\hline 6 & 1769.27 & I7 & 0.010 & 0.098 & 332.83 & 2 & 0.006 & 0.068 \\
\hline 7 & I745.90 & 16 & 0.009 & 0.106 & 340.67 & 8 & 0.023 & 0.090 \\
\hline 8 & I723.IO & $2 \mathrm{I}$ & 0.012 & 0.117 & 336.60 & I3 & 0.039 & 0.125 \\
\hline 9 & 1698.50 & 27 & 0.016 & 0.131 & 334.53 & 7 & 0.021 & 0.144 \\
\hline I0 & I676.77 & I4 & 0.008 & 0.138 & 337.93 & 9 & 0.027 & 0.166 \\
\hline II & 1655.67 & 20 & 0.012 & 0.149 & 335.00 & 4 & 0.012 & 0.176 \\
\hline
\end{tabular}

Table I7. Probability of death of daughters (legitimate and illegitimate) and adopted daughters in first I2 months - Huxi (Deaths per person months)

\section{Huxi}

Daughters (legitimate and illegitimate)

\begin{tabular}{|c|c|c|c|c|c|c|c|c|}
\hline $\begin{array}{l}\text { Age in } \\
\text { months }\end{array}$ & $\begin{array}{l}\text { Child } \\
\text { months }\end{array}$ & Deaths & $\begin{array}{l}\text { Age-specific } \\
\text { prob. }\end{array}$ & $\begin{array}{l}\text { Cumula- } \\
\text { tive prob. }\end{array}$ & $\begin{array}{l}\text { Child } \\
\text { months }\end{array}$ & Deaths & $\begin{array}{l}\text { Age-specific } \\
\text { prob. }\end{array}$ & $\begin{array}{l}\text { Cumula- } \\
\text { tive prob. }\end{array}$ \\
\hline ० & 2017.53 & 95 & 0.047 & 0.047 & 21.60 & o & 0.000 & 0.000 \\
\hline I & I8I0.37 & 25 & 0.014 & 0.060 & I7I.93 & I & 0.006 & 0.006 \\
\hline 2 & I606.57 & I6 & 0.010 & 0.070 & 366.77 & 3 & 0.008 & 0.014 \\
\hline 3 & I 488.77 & 8 & 0.005 & 0.075 & 470.13 & 3 & 0.006 & 0.020 \\
\hline 4 & $\mathrm{I} 4 \mathrm{I} 5.20$ & I4 & 0.010 & 0.084 & 522.37 & 8 & 0.015 & 0.035 \\
\hline 5 & I357.I7 & I2 & 0.009 & 0.092 & 553.93 & 3 & 0.005 & 0.040 \\
\hline 6 & I326.50 & II & 0.008 & 0.099 & ${ }_{5}^{6} 67.87$ & IO & 0.018 & 0.057 \\
\hline 7 & I294.70 & I9 & 0.015 & 0.113 & 572.30 & 7 & 0.012 & 0.069 \\
\hline 8 & I265.87 & I7 & 0.013 & 0.125 & 575.30 & 7 & 0.012 & 0.080 \\
\hline 9 & I 240.50 & I7 & 0.014 & 0.137 & 580.20 & 6 & 0.010 & 0.090 \\
\hline IO & $\mathrm{I} 2 \mathrm{I} 6.20$ & I3 & 0.011 & 0.146 & $58 \mathrm{I} .27$ & 7 & 0.012 & O.IOI \\
\hline II & II98.93 & 7 & 0.006 & $0.15 \mathrm{I}$ & 579.13 & 7 & 0.012 & 0.112 \\
\hline
\end{tabular}




\begin{tabular}{|c|c|c|c|c|c|c|}
\hline \multirow{2}{*}{$\begin{array}{l}\text { Adoption age } \\
\text { in months }\end{array}$} & \multicolumn{2}{|c|}{ Makung } & \multicolumn{2}{|c|}{ Baisha } & \multicolumn{2}{|c|}{ Huxi } \\
\hline & Number & Cum. \% & Number & Cum. \% & Number & Cum. \% \\
\hline ० & 47 & $7 \cdot 74$ & 33 & $7 \cdot 9 \mathrm{I}$ & 62 & $9 \cdot 39$ \\
\hline I & I7I & $35 \cdot 9 \mathrm{I}$ & I47 & 43.17 & 244 & 46.36 \\
\hline 2 & I35 & 58.15 & 92 & 65.23 & I42 & 67.88 \\
\hline 3 & 76 & 70.68 & 45 & 76.02 & 79 & 79.85 \\
\hline 4 & 50 & 78.9I & 32 & 83.69 & 50 & 87.42 \\
\hline 5 & 36 & 84.84 & I7 & 87.77 & 25 & $9 \mathrm{I} .2 \mathrm{I}$ \\
\hline 6 & 30 & 89.79 & I7 & 91.85 & I6 & 93.64 \\
\hline 7 & $2 \mathrm{I}$ & 93.25 & 9 & 94.00 & II & $95 \cdot 30$ \\
\hline 8 & I7 & 96.05 & 3 & 94.72 & I4 & $97 \cdot 4^{2}$ \\
\hline 9 & 5 & 96.87 & II & 97.36 & 6 & 98.33 \\
\hline IO & IO & 98.52 & 6 & 98.80 & 6 & 99.24 \\
\hline II & 9 & 100.00 & 5 & 100.00 & 5 & 100.00 \\
\hline Total & \multicolumn{2}{|c|}{607} & \multicolumn{2}{|c|}{$4 \mathrm{I} 7$} & \multicolumn{2}{|c|}{660} \\
\hline
\end{tabular}

I. First adoptions occurring in years I906-I945.

Table I9. Cumulative probability of death in first 12 months excluding deaths in first month (Deaths per person months)

Daughters $\quad$ Adopted daughters

\begin{tabular}{lll} 
Makung & 0.102 & 0.122 \\
Baisha & 0.102 & 0.176 \\
Huxi & 0.109 & 0.112 \\
Average & 0.103 & $0.13 \mathrm{I}$ \\
\hline
\end{tabular}

rates in Penghu. We classify infants born in the three sites of Penghu during I906-I945 into six groups according to sex, legitimacy status, and adoption, and present the neonatal and postneonatal death rates for each group in table 20 . In the first month, few infants (male and female) were adopted, so the neonatal death rate for adopted boys is 0 , and that of adopted girls is 0.0155 , much lower than the rates of the other four groups. In this month, illegitimates had a higher death rate than legitimates for both girls and boys, and boys generally had higher mortality rates than girls. In the following II months, the number of adopted children rapidly increased. The child months of adopted boys increased 

cy status, Penghu (Deaths per person months)

\begin{tabular}{|c|c|c|c|c|c|c|}
\hline & $\begin{array}{l}\text { Neonatal } \\
\text { months }\end{array}$ & $\begin{array}{l}\text { Neonatal } \\
\text { deaths }\end{array}$ & $\begin{array}{l}\text { Neonatal } \\
\text { death rate }\end{array}$ & $\begin{array}{l}\text { Post-neonatal } \\
\text { months }\end{array}$ & $\begin{array}{l}\text { Post-neonatal } \\
\text { deaths }\end{array}$ & $\begin{array}{l}\text { Cumulative } \\
\text { Post-neonatal } \\
\text { death rate }\end{array}$ \\
\hline Legitimate Boys & $8587.4 \mathrm{I}$ & 428 & 0.0498 & 86383.60 & 744 & 0.0905 \\
\hline Illegitimate Boys & $537 \cdot 43$ & 39 & 0.0726 & 4691.90 & 35 & 0.0766 \\
\hline Adopted Boys & 30.10 & $\circ$ & $\circ$ & $2454 \cdot 17$ & 40 & 0.1960 \\
\hline Legitimate Girls & 8062.24 & 330 & 0.0409 & 68688.57 & 6I6 & 0.0938 \\
\hline Illegitimate Girls & 519.37 & 29 & 0.0558 & 4339.05 & $4 \mathrm{I}$ & 0.0996 \\
\hline Adopted Girls & 64.50 & I & 0.0155 & I33I 4.44 & I78 & O.I3II \\
\hline
\end{tabular}

I. Neonatal mortality is mortality in the first month, and post-neonatal mortality is mortality in the remaining II months.

2. Adopted boys or girls include, from the day of adoption, those illegitimate children recognized by father first and then adopted out.

\section{Table 2I. Proportions adopted by legitimacy status, Penghu}

\begin{tabular}{llllll}
\hline & Not Adopted & Adopted & $\begin{array}{l}\text { Recognized } \\
\text { by father }\end{array}$ & $\begin{array}{l}\text { Recognized } \\
\text { and adopted }\end{array}$ & Total \\
\hline Legitimate Boys & $8549(96.28 \%)$ & $330(3.72 \%)$ & & & 8879 \\
Illegitimate Boys & $348(60.42 \%)$ & 5 I (8.85\%) & I74 (30.21\%) & $3(0.52 \%)$ & 576 \\
Legitimate Girls & $6420(76.70 \%)$ & I950 (23.30\%) & & 8370 \\
Illegitimate Girls & $326(58.01 \%)$ & II4 (20.28\%) & IIO (I9.57\%) & I2 (2.I4\%) & 562 \\
\hline
\end{tabular}

Table 22. Infant mortality by sex, Penghu (Deaths per person years)

\begin{tabular}{llll}
\hline & Person years & Deaths & Infant mortality rate \\
\hline Boys & 8557.05 & I286 & 0.1502854 \\
Girls & 7915.68 & II95 & 0.1509660 \\
\hline
\end{tabular}

from 30.IO in the first month to 2454.17 in the succeeding months, and the child months of adopted girls increased from 64.50 in the first month to 133I4.44. As shown in table 2I, the number of adopted boys is far less than that of adopted 
girls. Only $3.72 \%$ of legitimate boys and $9.37 \%$ of illegitimate boys in Penghu were adopted, far less than the proportion of girls adopted. While the small sample of adopted boys could account for their high post-neonatal death rate, which is higher than that of adopted girls and highest among the three groups of boys, it is possible that male infants were that much more vulnerable to the traumas surrounding adoption. In the postneonatal period, table 20 shows that the morality rates of both legitimate and illegitimate girls were higher than boys in the same categories.

In conclusion, in the neonatal period, the death rates of boys were higher than those of their female counterparts, and illegitimacy significantly increased the risk of death, even more so for boys $(46 \%)$ than for girls $(36 \%)$. In the postneonatal months, the death rates of girls are higher than their male counterparts for legitimates and illegitimates, and it is adoption that accounts for the highest risk of death for both boys and girls. Thereafter, the illegitimate child's survival chances were equivalent to those of legitimate children of the same sex. For girls especially, there was the added risk of adoption, but as we learn from Table 2I, illegitimate girls were not subjected to the risks of adoption in greater proportions than legitimate girls. Illegitimate boys, however, were given out in adoption more frequently than legitimate boys, but illegitimate boys were also more likely to be recognized than were illegitimate girls. Overall, the high proportion of girls adopted, and the heightened mortality risks associated with adoption, were the most significant contributor to high rates of female infant mortality in Penghu. They raised the mortality rate of female infants to as high as that of male infants, causing an exception to the expected pattern of male infants dying at higher rates than female infants (Table 22).

\section{Conclusion}

The arguments of this paper remain tentative. Although the Program for Historical Demography has collected all the Japanese household registers of Penghu, only a small portion has been computerized to date. The demographic patterns of Makung, Baisha and Huxi presented in this paper are based on the data of only 3 or 4 villages in each of these areas. Therefore, we cannot be sure they are representative of Penghu generally. Nor are we satisfied that we have obtained sufficient direct evidence to support our explanation of Penghu's high illegitimate birth rate, higher female infant mortality, and higher mortality of illegitimate infants. Nevertheless, this paper is a result of a continuous dialogue between quantitative and qualitative research that has important methodological implications.

This research has been a cooperative enterprise in which Huang and Chuu dealt with the quantitative data, and Yu did the qualitative research. Huang and Chuu first discovered the unusual phenomena of the high illegitimate birth rate 
and the high female infant mortality rate in Penghu of I906-I945 through analyzing the computerized Japanese household data. Yu then tried to account for these phenomena using historical documents and doing fieldwork interviews, Huang and Chuu again used the register data to test the hypotheses proposed by Yu. Our first hypothesis accounting for the large proportion of the illegitimate children in Penghu during Japanese rule was that failure to register minor marriages caused a 'legitimate' child to be recorded as 'illegitimate' in the household registers. Our first run through the data appeared to support this idea. Most of the research sites with high rates of minor marriages also have a high rate of illegitimate births. For instance, of the three sites of Penghu, Huxi had the most minor marriages and the highest rate of illegitimate births. Our data also showed that nearly $50 \%$ of sim-pua bore illegitimate children, and about half of the illegitimate children were born to sim-pua. These data appeared to support our presumption. We then made a further check to see whether the families of sim-pua bearing illegitimate children had an unmarried son in the same age range as the sim-pua who could have fathered the sim-pua's illegitimate children. The results of this check contradicted our hypothesis. Only $20 \%$ of the sim-pua who bore illegitimate children had a foster brother who could be her thau-tui-a. Thus we concluded that failures to register minor marriage could not explain the high illegitimate birth rate among sim-pua.

After our first hypothesis accounting for the large proportion of illegitimate children in Penghu was disconfirmed, we interviewed our informants again and developed our second hypothesis. The Penghu islands are well known for their lack of natural resources and relative poverty. It was hard for women to make a living independently in Penghu, so some Penghu women might try to win a helping hand and financial support from men by providing them with sexual services. Such women might be never-married daughters and sim-pua with little prospect of marriage, or widows and divorcees. Because these extramarital relationships with men often lasted several years, it is likely that their families and local society condoned them although the authorities did not recognize them as legitimate marriages. Women from poor families might consider their relationships to be no different from officially recognized marriages, or the same as a concubine marriage if the man was married and rich. Our data also shows that women who bore illegitimate children were from families lacking male labor and whose heads of household were usually in low-income careers.

Our second initial finding was that the female infant mortality rate in Penghu was relatively high between I906 and I945. Because Penghu was well known for practicing female infanticide in the Qing period, we assumed that high female infant mortality reflected the continuation of this custom under Japanese rule. We hypothesized that higher rates of female than male infant mortality in the first week of life would provide evidence of female infanticide. 
However, our evidence failed to bear this out; we found that the death rates of female infants in the first and second to fourth weeks were not consistently greater in Penghu, or consistently greater than male death rates. Having failed to find evidence of female infanticide, we hypothesized that the higher rate of female infant mortality in Penghu was the result of the comparative neglect and inferior care provided to female infants. One aspect of this neglect is manifested in the consequences of adoption: female infants were adopted out at high rates in Penghu, where minor marriage was very common, and we confirmed that the mortality rates of adopted daughters were significantly higher than those of daughters.

Our third finding was the higher infant mortality suffered by illegitimate infants of both sexes compared to legitimate infants. Clearly many illegitimate infants were born into circumstances unfavorable to survival; we found that generally illegitimate infants born to never-married mothers were at greater risk than those born to widows and divorced women. We also found that the mortality rates of illegitimate infants were higher than those of legitimate infants in the first month of life but thereafter illegitimate infants fared as well as legitimate infants. It appears that illegitimate infants that survived the first month of life were as wanted as legitimate infants. Three of our findings confirm the greater vulnerability of male infants even in Penghu: when subjected to the unfavorable conditions associated with illegitimacy and adoption, male infants died at higher rates than female infant counterparts in the neonatal and postneonatal periods, respectively. Legitimate male infants also died at higher rates than females in the neonatal period. That female infants overall died at the same rate as male infants in Penghu is due to the much higher proportion of females who were subjected to the risks of adoption in the postneonatal period.

Among the practitioners of ethnography and qualitative social research, it is often assumed that in-depth interviews with knowledgeable members of society are the best way to understand local social practices. What we have learned from the process of doing this research has undermined this assumption. When our informants were told that Penghu had high illegitimate birth rates and high female infant mortality rates, their reactions and explanations were similar. If we did not have the household registration data to test the validity of their explanations, this paper would end in midcourse. We would be unable to see whether there was a thau-tui-a in the foster family of a sim-pua who gave birth to illegitimate children and would have to accept our informants' suggestion that failure to register minor marriages was the reason for the high illegitimate birth rate. Without the registers we would also have no way of checking the timing of female infant deaths and would have to accept that female infanticide was the reason for the high female infant mortality rate. After analyzing the Japanese household registers, we found that the unanimous 
opinions of local informants were not always the best answers to our questions. The precise information contained in the household registers gives us an unusual opportunity to test accepted notions and to achieve new insights into the working of society in an historical era. 

I3

\section{How reliable is Taiwan's}

colonial period demographic data?

An empirical study using

demographic indirect estimation techniques

Li Chun-hao Department of Social and Policy Sciences, Yuan Ze University, Taiwan

Yang Wen-shan Institute of Sociology, Academia Sinica, Taiwan

Chuang Ying-chang College of Hakka Studies, National Chiao Tung University,

Taiwan 
When the Japanese first occupied Taiwan in 1895 after the Sino-Japanese war, the aim of the Japanese colonial government was to transform Taiwan into an agricultural base to supply foodstuffs and other raw materials for Japan. To better manage the people and resources of the colony, the Japanese organized investigation and research teams to survey Taiwan's lands and natural resources, register its population, and research its customary law. In 1905 , the Japanese government conducted its first modern population census in colonial Taiwan. ${ }^{\mathrm{I}}$ Later, the colonial government organized six other population censuses in I915, I920, I925, I930, I935, and I940, respectively. Vital statistics reporting based on the household registration system put in place by the Japanese shows that mortality in Taiwan started to drop not long after the Japanese occupation, and declined most significantly after the I920s. The crude death rate for the Taiwanese population, reported as 34.4 per thousand in I906, had dropped to 20.4 per thousand in 1937 (Chen I979: 40-4I).

The censuses conducted by the Japanese colonial government have long served as the mainstay of studies of the Taiwanese population in the colonial period. Moreover, Taiwan's colonial period censuses are among the oldest censuses in Asia and have long been highly regarded by professional demographers and social scientists both within and beyond Taiwan (Barclay 1954, Chen 1979). However, many demographers question the accuracy of population censuses and registration records in the developing and/or less developed countries (see Preston et al. I980; Preston and Hill I980; United Nations I983). Taiwan too was an underdeveloped agrarian society during the Japanese occupation. Should we therefore suspect the quality of data generated from Taiwan's population censuses and household registration-based vital statistics?

The quality and completeness of the Japanese census and household registration reporting system in Taiwan very favorably impressed the demographer George Barclay more than five decades ago (Barclay 1954). Yet it is rather hard to believe that all deaths were reported or registered during the colonial period, especially in the early stages of the Japanese occupation and before the household registration system could become fully operational. If deaths were under-reported in any period or for any age group, then we risk underestimating the true death rate. As shown in Manual X (United Nations I983:129), if deaths are underreported, the survival function $-l(x)$ - from the life table will fall too slowly as age increases. As a consequence, the estimates of life expectancy will be biased upward.

I. The late Chen Shao-xing (陳紹馨), a leading demographer of colonial Taiwan, received his training in Japan and was sociology professor in National Taiwan University. According to Chen (1979:35), the Japanese government had planned to conduct its first modern population census in Japan proper. But because the war with Russia broke out in I904, the plan was postponed, and the census was then first implemented in October I905 in Taiwan only. 
In this paper, we use indirect demographic estimation techniques to

examine the completeness and accuracy of the death reports from colonial Taiwan. These techniques exploit the data provided by a continuous series of population censuses as is available from Japanese period Taiwan to test the consistency and completeness of death registration. Consequently, the paper begins with an introduction to the history of the population census and household registration system in colonial Taiwan. The section describes how the first population census in colonial Taiwan was prepared and implemented, and how administering the first population census affected the development and maintenance of the household registration system. In turn, we introduce both direct and indirect demographic techniques to estimate the completeness of death registration and judge the quality and consistency of the censuses.

\section{Background - the implementation of the first population census in Taiwan}

Demographers and social scientists often compliment the population census data and the household registration system in colonial Taiwan for completeness and accuracy. Thus, it is important to verify whether the birth records and death registrations are reliable. Since deaths are registered in the household registration system, accurate death reporting relies upon a strong and reliable household registration system. The household registration system of Taiwan was first established by the Japanese government to better control and manage the movements of population on the island. At the end of the igth century, Japanese government officers, influenced by the example of western countries, encouraged the government to conduct surveys to enumerate the population (Lin 2006b). Most of the advanced countries in Europe and the United States had been conducting population censuses for decades, in some cases for more than a century. In order to prove to the other western industrialized nations that Japan, too, was an advanced nation, Japanese legislators and government officers advocated implementing population censuses. It was believed that the quantity and quality of population, as demonstrated in a census, represented the strength of a nation (Lin 2006a). Knowing the demographic characteristics of the population was beneficial to national policy making as well. In December of I902, the government of Japan adopted regulations that provided for administration of decennial censuses starting in I905 in Taiwan as well as in Japan.

In order to successfully carry out the mission in Taiwan, the government of colonial Taiwan recruited Shichisaburo Mizushina (水科七三郎) in I903 as a specialist to organize and implement the first census in Taiwan (Lin 2006b). Mizushina trained government and police officers who were responsible for government data collection to ensure that demographic methods and population enumeration techniques were understood. Mizushina designed the census tak- 
ers' curriculum which included I50 in-class lecture hours plus io practicum hours, and a final examination. Those who passed the test were issued a certificate and became census takers. In addition, census organizers gave lectures on census taking methods at the local level (Lin 2006b).

The first decennial census was not merely a door-to-door census count. The census system was designed to be conducted in conjunction with the household registration system (Lin 2006b). Local government officers, policemen, school teachers and employees who were trained to implement the decennial census were expected to carry the household registration records with them as they censused residents in their districts. The household registers were prepared by local police departments, and were supposed to be continuously updated. However, in I904, one year before the first population census was carried out, Mizushina found that the existing household registration system was problematic and unreliable. Some areas had better records than other areas. The registers were often found to be incomplete or missing, and record-keeping was discovered to be inaccurate and inconsistent. Mizushina believed that the problematic household registration records would cause unavoidable mistakes in the implementation of the first census. The registers and registration procedures needed to be reformed and standardized (Lin 2006b).

Mizushina suggested correcting the mistakes of the household registration records during the census taking period. He encouraged residents to report mistakes voluntarily to the local police departments or through the bao-jia local security system (保甲). The success of the first census can be attributed to the careful preparation and training of the census taking effort, along with the reforms of the household registration system. In carrying out the population census, the household registration system was strengthened and records became more accurate and complete. Death registrations, therefore, have been assumed to be accurate and complete.

\section{Demographic techniques for testing the completeness of death registration}

Barclay (I954) used a direct method to estimate the completeness of death registration in colonial Taiwan. He suggested that if the data is correct, then for any given cohort of births, the number of people counted in one census who were registered as dying before the next one should equal the number of survivors counted in the earlier minus the number counted in the later census (Barclay I954:I42). The completeness of death registration can be measured as a ratio of registered deaths $(\mathrm{Da})$ to the difference in the number of survivors in successive censuses $\left(\hat{D}_{a}\right) .{ }^{2}$ Assuming the census enumeration of survivors is correct and the population is closed to migration, then if the completeness of death registration ratio equals one, death registration can be assumed to be complete and accurate. Applying this approach to 
test for adequacy of death registration of Taiwanese in the colonial period, Barclay

(I954:I42-3) found that even though a few deaths went unregistered in certain years in the early colonial period, death registrations were nearly complete.

Since measuring the completeness of death registrations simultaneously relies on the census enumeration and vital registration records, it is difficult to determine whether discrepancies arise from unreported deaths or inaccuracy in the census counts. The completeness estimate of death registrations for age $\circ$ is especially vulnerable because mortality in the first year of life is usually measured on the basis of the reported number of live-born babies. Therefore, Barclay (1954:I42-I45) also tested the adequacy of birth registration by comparing the number of registered births for a cohort to the number of survivors in a subsequent census plus the number of intervening deaths to the cohort. This direct method, however, cannot guarantee the completeness estimate of the birth registrations, since it must assume that death registrations and census enumerations are both complete. In the case of both births and deaths, Barclay's direct methods for estimating the completeness of vital registration requires that at least census counts must be assumed to be complete and accurate. Given these assumptions, the results of Barclay's methods demonstrate a very high degree of consistency among the censuses, birth and death reports in colonial Taiwan, but not their independent completeness.

\section{An indirect technique estimating the completeness of death registration}

Where demographic data is neither reliable nor complete, direct estimation techniques are not very useful and demographers have to rely on indirect estimation techniques. Over the years, mathematical demographers have developed several methods to deal with the incompleteness of death records. In their paper, Bennett and Horiuchi (I98I) reviewed five techniques estimating the completeness of death registration in populations whose demographic records are not complete. The five techniques share three common assumptions. First, the population under study is closed; population growth is determined not by in- and out-migration ('social growth'), but by births and deaths ('natural growth'). Second, the completeness of death registration is constant across ages. Third, the ages of the living and the dead are accurately reported. In addition, some of these techniques assume stability of the population, and others do not. To implement those techniques which do not rely on the stability assumption, more information is required, such as data from two censuses, instead of just one.

2. The completeness of death registration for a given cohort of births $\left(C_{a}\right)$ can be expressed as: $C_{a}=\frac{D_{a}}{\hat{D}_{a}}$ 
Our estimate of the completeness of death registration in colonial Taiwan in this paper relies upon Bennett and Horiuchi's technique, which is derived from the method proposed by Preston, Coale et al. (I980). For this method, the age distribution of the population is estimated from the age distribution of reported deaths and age specific population growth rates (Bennett and Horiuchi I98I). The age-specific completeness of death registration can then be estimated by the ratio of estimated population to the reported population, expressed as:

$$
C_{x}=\frac{\hat{N}_{x}}{N_{x}}
$$

where, $\hat{\mathrm{N}}_{\mathrm{x}}$ and $\mathrm{N}_{\mathrm{x}}$ represent the estimated and the reported quantities of the population at age $x$, respectively. A ratio of $\hat{N}_{x}$ to $N_{x}$ that equals approximately I.oo indicates that death registrations are relatively complete.

The Preston-Coale method relies on the assumption of a stable population, in which the growth rate of births, the age-specific death rates and the age composition of the population are constant, and the population is closed to migration. In a stable population, there is a relationship between the number of current deaths and the number of persons in the population. The persons now aged $x$ are the survivors of births $x$ years ago. By the properties of a stable population with a growth rate $r$, the number of persons aged $x$ must be smaller than current births by a factor of $e^{-r * x}$. Therefore, the number of deaths that will occur among the current births when they are aged $x$ will be larger than the current number of deaths to persons aged $x$ by a factor of $e^{r^{* x}}$ (United Nations I983: 130).

Furthermore, in a closed population, the number of persons in a particular age group at a particular time $t$ will be equal to the total number of deaths to those persons from time $t$. Therefore, the number of deaths that will be experienced by persons currently at age $x$ can be estimated by the current number of deaths recorded at each age above $x$, "weighted by an exponential of the product of $r$ and the difference between the age at death and age $x$ " (Bennett and Horiuchi I981:209, Preston et al. I980: 183-85). In a stable population with a growth rate $r$, the number of persons aged $x\left(\mathrm{~N}_{\mathrm{x}}\right)$ can be estimated as:

$\hat{N}_{x}=\sum_{a=x}^{\mathrm{w}} D_{a} * e^{r(a-x)}$

In the equation, $D_{a}$ is the number of deaths at age $a, w$ is the highest age reached, and the sum cumulates all deaths at age $x$ and above that will be experienced by the cohort. If the population is stable, $r$ correctly represents the age-specific growth rate of the population, and if deaths and population are accurately reported, $\hat{N}_{x}$ will equal to $N_{x}$. However, if deaths are underreported by some fixed proportion, the ratio of $\hat{\mathrm{N}}_{\mathrm{x}}$ to $\mathrm{N}_{\mathrm{x}}$ will be less than I.oo, which can be used to represent the age-specific completeness of death registration (United Nations I983: 130). 
$\hat{N}_{x}$ is the number of persons at a given age $x$, estimated from the age distribution of deaths and the population growth rate. In the usual case in which the published statistics reports the population in five-year age groups, the reported number of persons between ages $x$ and $(x+5)$ is denoted as ${ }_{5} N_{x}$. The estimated number of the population at age $\mathrm{x}\left(\hat{N}_{x}\right)$ cannot be compared directly to ${ }_{5} N_{x}$ to estimate completeness. However, the reported number of persons at age $\mathrm{x}\left(N_{x}\right)$ can be obtained by Equation (3).

$N_{x}=\frac{{ }_{5} N_{x-5+5} N_{x}}{\text { IO }}$

Equation (3) follows an assumption of linearity that the population decreases by equal amounts from age to age over the range. In this case, age $\mathrm{x}$ is centered in an age range of ten years. The reported number of persons at age $\mathrm{x}\left(N_{x}\right)$ therefore can be calculated from the reported population sizes for the two adjacent five year age groups.

If the number of persons are estimated in single age years, the estimate of the population in the 5 year age group $x$ to $x+5,{ }_{5} \hat{N}_{x}$, can be approximated by multiplying the average of the estimated numbers at age $x$ and at age $x+5$ by ${ }_{5} \hat{N}_{x}=$ $2.5 *\left(\hat{N}_{x}+\hat{N}_{x}+5\right)$ (Bennett and Horiuchi I98I: 2I0). The completeness of death registration can therefore be estimated as:

$C_{x, x+5}=\frac{{ }_{5} \hat{N}_{x}}{{ }_{5}}$

$C_{x}$ and $C_{x, x+5}$ represent a series of the estimated completeness rates in a population. It is inadvisable to rely on a single ratio to estimate the completeness of death registration for the whole population as the number of persons reported at a particular age or in a specific age group may be subject to age-misreporting and produce an unreliable completeness ratio (United Nations I983:I30). Therefore, demographers suggest calculating the median of the series of completeness ratios to yield the best estimate of death registration completeness.

Age-specific completeness estimates for infants and young children, $C_{0}$ or $C_{0,5}$ are not calculated in this procedure as death reporting at these ages confronts special problems, and violates our assumption (number 2 in Bennett and Horiuchi's list cited above) that the completeness of death registration is constant across all age groups. Death rates at these ages are better estimated by other techniques (Preston et al. I980:I80). As stated in Manual X (I983:I3I), "estimates of $\hat{N}(0)$ and ${ }_{5} \hat{N}_{\circ}$ are based in part on the reported numbers of infant and child deaths, which usually constitute a large proportion of the total number of deaths and are often subject to a completeness of registration quite different from that of deaths at older ages." 3

3. In this paper, $\hat{N}_{0}$ is used to substitute for $\hat{N}(0)$. 
Another difficulty arises in estimating completeness at the upper end of the age range or "open interval," in which the number of deaths and the number of persons are tabulated in an undivided age category, such as $75^{+}, 80+, 85^{+}$, or $90+$, because "the distribution of deaths within the open interval is not available" (United Nations I983:I3I). Bennett and Horiuchi (I98I:2II, 2I7) suggest using the following equation to estimate $\hat{N} a$.

$\hat{N}_{a}=D_{a+} *\left(e^{\left.\left(r_{a+} * E_{a}\right)-\frac{\left(r_{a+} * E_{a}\right)}{6}\right)}\right.$

where, $r_{a+}$ is the growth rate in the open interval, and $E_{a}$ is the life expectancy at the beginning of the open interval. Once the $\hat{N}_{a}$ for the open interval is obtained, researchers can proceed to estimate all other $\hat{N}_{a}$, by iterating downwards the following equation.

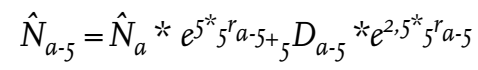

where ${ }_{5} r_{a-5}$ is the growth rate experienced by the persons in the age group of $a-5$ to $a$, and ${ }_{5} D_{a-5}$ is the number of deaths occurring in the same age cohort. Formula (6) was proposed by Bennett and Horiuchi to allow for different growth rates for different cohorts, which removes the need to assume a constant growth rate over the whole population, or stability (I98I:2I0). To implement formula (5), $r_{a+}$ can be obtained from the registered data. However, researchers have to obtain $E_{a}$ independently of the registered data; we use the estimates provided in MortPakLite (United Nations I988:37).4

In sum, since indirect estimation techniques are used when vital statistics are imperfect, these techniques must rely on some estimated components to

4. MortPak-Lite uses the following equations to estimate the life expectancies at several old ages.

$$
\begin{array}{lll}
E_{60}=9.345+12.403 * \frac{D_{60^{+}}}{D_{5^{+}}} & \text {(7) } & E_{65}=7.535+10.072 * \frac{D_{60^{+}}}{D_{5^{+}}} \\
E_{70}=6.049+7.918 * \frac{D_{60^{+}}}{D_{5^{+}}} & \text {(9) } & E_{75}=4.890+5.965 * \frac{D_{60^{+}}}{D_{5^{+}}} \\
E_{80}=4.060+4.162 * \frac{D_{60^{+}}}{D_{5^{+}}} & \text {(II) } & E_{85}=3.379+2.836 * \frac{D_{60^{+}}}{D_{5^{+}}}
\end{array}
$$

In equations (7)-(I2), $\mathrm{D}_{60} / \mathrm{D}_{5^{+}}$is the ratio of intercensal registered deaths for the age group 60 and over to those for the age group 5 and over. As mentioned in the MortPak-Lite user's manual, equations (7)-(I2) are the regression models that "were estimated from a set of data points simulated from stable populations generated from male and female model life tables from the United Nations General Pattern of life expectancy at birth varying from 35 years to 75 years, at one-year intervals, in conjunction with intrinsic growth rates varying from .015 to .035, at intervals of .005" (United Nations I988:37). 
obtain final estimates. In the case of the Bennett-Horiuchi technique life expectancies need to be estimated at the upper end of the age range.

\section{Data}

This study relies on the United Nations' software, MortPak-Lite, which enables researchers to apply age-specific growth rates to different age cohorts. Calculating age-specific growth rates requires data on age distribution from two successive censuses, in contrast to the use of a single census in techniques, assuming growth rates are constant across ages. Specifically, the following data items are required to use MortPak-Lite:

I. The population by single ages or age groups in the ist census.

2. The population by single ages or age groups in the 2nd census.

3. Registered deaths by single ages or age groups during the intercensal period.

In brief, the method "estimates completeness of death registration by using the growth-rate-transformed registered deaths to generate an independent estimate of the average intercensal population at an age above $x$; the ratio of this figure to that calculated from the two observed censuses provides an estimate of completeness of death registration above age $x$," (United Nations I988:36).

This study focuses on the period of 1905-1935 and draws the needed data from the digitized edition of the Statistical Summaries for the Past 51 Years of Taiwan Province including the age-specific populations at the census dates of I905, I9I5, I920, I925, I930, and I935 (Table 58), and age-specific deaths during the intercensal periods which are reported on a yearly basis (Table 89).5 Because the population censuses were conducted on October I-3 during each census year, we adjust the calendar year number of deaths to the intercensal periods. In the

5. Although deaths are reported by age at last birthday in our statistical source (Taiwan I946), the early censuses, I905-I925, reported age according to birth cohort. Barclay (I954:I4I) explains:

[i]n the earlier census enumerations, before I930, age was ascribed by calendar year of birth. Persons born after January I in the census year were placed into the first year of age, those born in the calendar year preceding the census into the second, and so on.

To bring the two data sources into better agreement, we shifted each cohort downward, thus age group I was recoded as age group o, age group 2 was recoded as age group I, and so on. Note that this adjustment does not recode the population into "correct" cohorts as defined by age at last birthday. The impact of the discrepancy in age reporting between deaths and age groups in the early censuses is greatest in infancy and early childhood when death rates change rapidly by age. In employing his direct method, Barclay used the original source in which deaths are reported by both age at last birthday and year of birth. 
census year that opens the interval, deaths between January I and September 30 are subtracted from the total annual deaths using a factor of 0.75 and, in the census year that closes the interval, deaths between October I and December 3I are subtracted from the total annual deaths using a factor of 0.25 . This adjustment assumes deaths occurred evenly throughout the year. The age-specific number of deaths are cumulated to yield the number of reported deaths at the given age groups during the intercensal period.

\section{The completeness of death registrations in colonial Taiwan}

In this study, we analyze death registration using data from five intercensal periods, I905-I9I5, I9I5-I920, I920-I925, I925-I930, and I930-I935. Separate completeness estimates are produced for the male and female populations. Figures I5 show the estimated completeness of death registration ratios by age group and sex for each successive period. The figures reveal two patterns common to all the periods. First, the completeness ratios for both the male and the female populations were generally close to I.००. Second, in each period the completeness ratios for the male and the female populations shared similar trends.

For the period I905-I9I5, the median estimates of death registration completeness for the male and female populations are $0.97 \mathrm{I}$ and 0.986 , respectively (see Tables I and 6 in the Appendix). ${ }^{6}$ The estimates show that during the period, deaths for both populations were recorded almost completely. Similarly high levels of median completeness were also found in the other four periods. In the period I9I5-1920, they are 0.959 and 0.970 (see Tables 2 and 7 in the Appendix). In the period I920-1925, they are 0.993 and I.003 (see Tables 3 and 8 in the Appendix). In the period I925-I930, the median estimated completeness ratios are 0.990 and 0.997 for the male and female populations, respectively (see Tables 4 and 9 in the Appendix). In the period I930-1935, they are 0.987 and 0.96I (see Tables 5 and Io in the Appendix). For all the periods, the median estimates of the completeness of death registrations are high in both male and female populations. In other words, during the five periods, at least 96 percent of deaths for both male and female populations were officially counted.

In addition, in each period, the completeness ratios of death registrations for both the male and the female populations share similar age patterns. Generally, the trend lines of the completeness ratios for the male and the female populations remain close to each other, except for the period of I905-I9I5 (as shown in Figures I-5). During the I905-I9I5 period, the male and the female populations share similar trend lines, which display an up-and-down pattern (as shown in Figure I); however, the distances between two trend lines are relatively larger than those displayed in other periods.

6. In the MortPak-Lite program, the estimates of death record completeness are calculated as ${ }_{\text {Io }} \hat{N}_{a-5} /{ }_{\text {Io }} \mathrm{N}_{\mathrm{a}-5}$. 
Although both male and female populations share similar patterns of death registration completeness, there are some discrepancies among different periods. As shown in Figures I-5, the trend lines of the completeness estimates for the periods I9I5-1920, I920-1925, and I930-1935 are much flatter than those for the periods of I905-I9I5 and I925-I930. Bennett and Horiuchi (I98I: 2I4) suggest that the up-and-down pattern of the trend line is caused by the fact that people at some age groups were undercounted in the censuses. For example, in the period of 1905-1915, the elevated values of the completeness estimates at age intervals of 25-30, 30-35, 35-40, 40-45, and 55-60 might be caused by undercounts in the censuses. In the period I925-1930 the trend line is likely distorted by the effect of the change between the two censuses in method of reckoning age (see note 5 above).

The higher completeness estimates for children at ages 5-Io (compared to other age groups) which are shown in Figures I-5 in all periods, have two likely causes. First, there may be under-reporting in the census enumeration for the age group of 5-Io in all of the five research periods. Second, the indirect estimation technique applied in this research assumes a uniform completeness of death reporting, which may not hold true for young children. Scholars point out that this indirect estimation technique is unable to present effectively mortality conditions during the first five or ten years (see Bennett and Horiuchi I984:231; Preston and Bennett 1983:I04; Preston et al. 1980). As Preston et al. (I980:I79) point out, "[c]ompleteness of death records (from registration systems or survey reports) for infants and young children is often different from the completeness of records for deaths at older age."

In sum, the completeness of death registration ratios produced by the Bennett-Horiuchi technique show that death registration in all five intercensal periods in colonial Taiwan was nearly complete. The flat trend lines of the completeness ratios in the periods of I915-1920, I920-I925, and I930-I935 suggest that death reporting may have been more reliable and complete in those periods than in the other periods. Population undercounts at certain age groups in the censuses of I905-I9I5 may cause variations by age in the degree of completeness in that period. The discrepancy in age reporting method in the censuses of 1925 and 1930 appears to affect the pattern of the completeness ratios in that period. Finally, the completeness estimates of death registrations for children at young ages are less reliable, but they have little effect on the median estimates of completeness, which remain high.

The advantage of the Bennett-Horiuchi technique of indirect estimation of death registration completeness over Barclay's direct method is that it does not estimate deaths from cohort survivorship in two successive censuses, which is vulnerable to age misreporting in the censuses (although Barclay's method is not troubled by the unusual method of age reporting in the early censuses). 
Figure I. Estimates of the Completeness of Death Registration for the Taiwanese Male and Female Populations in the Periods of 1905-1915.

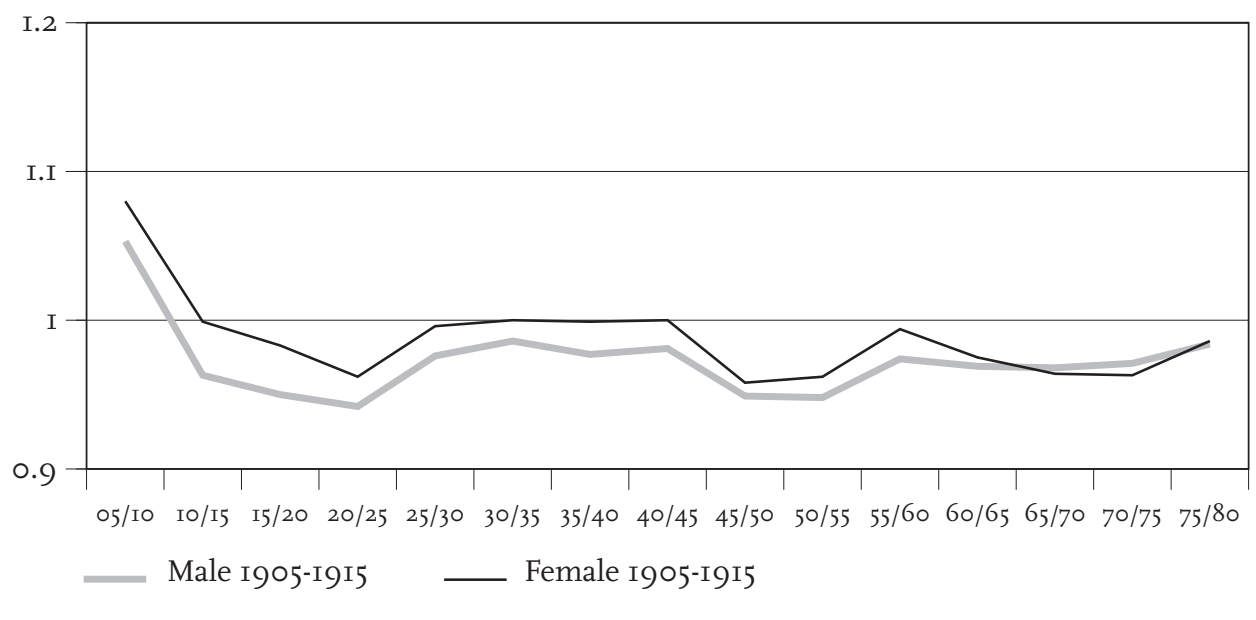

Figure 2. Estimates of the Completeness of Death Registration for the Taiwanese Male and Female Populations in the Periods of I915-1920.

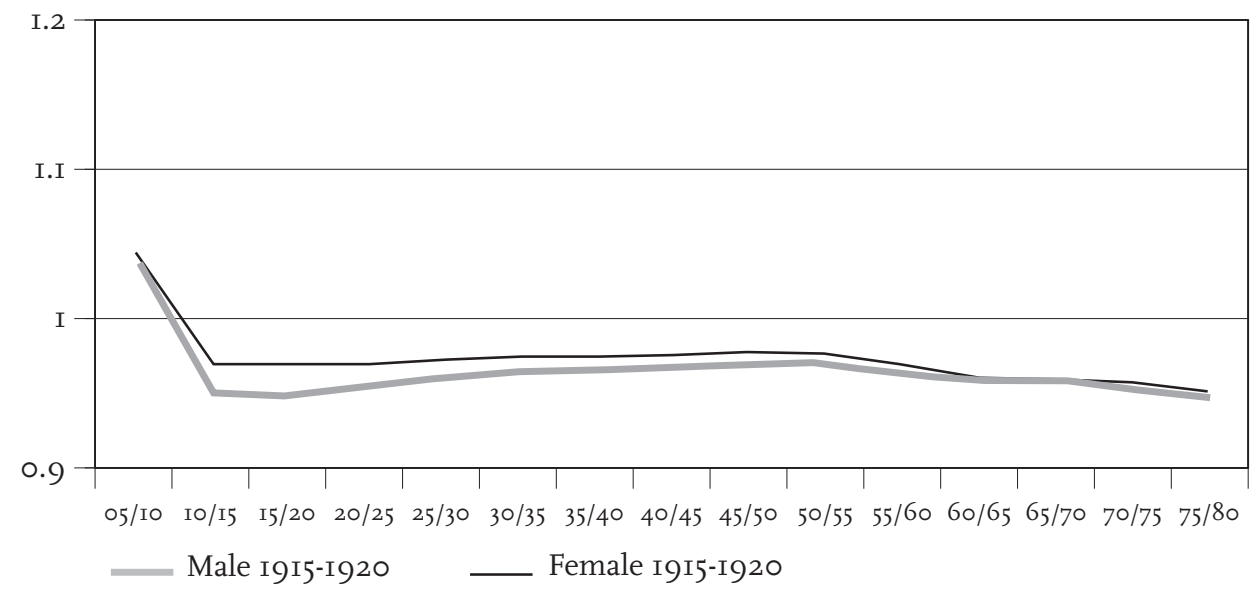


Figure 3. Estimates of the Completeness of Death Registration for the Taiwanese Male and Female Populations in the Periods of 1920-1925.

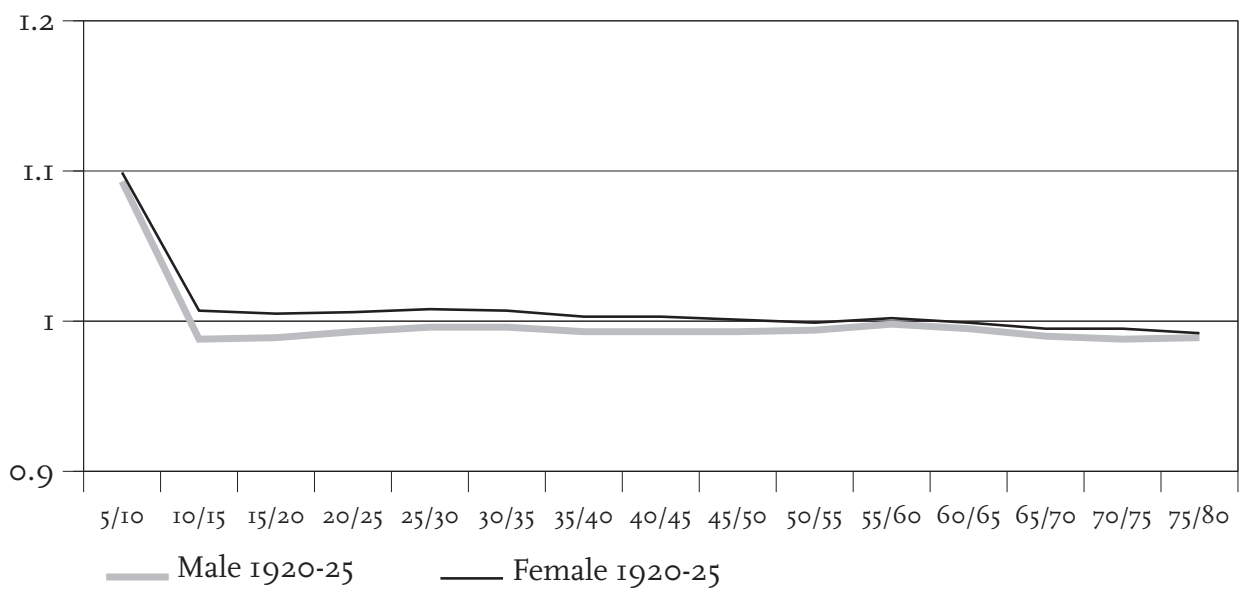

Figure 4. Estimates of the Completeness of Death Registration for the Taiwanese Male and Female Populations in the Periods of 1925-1930.

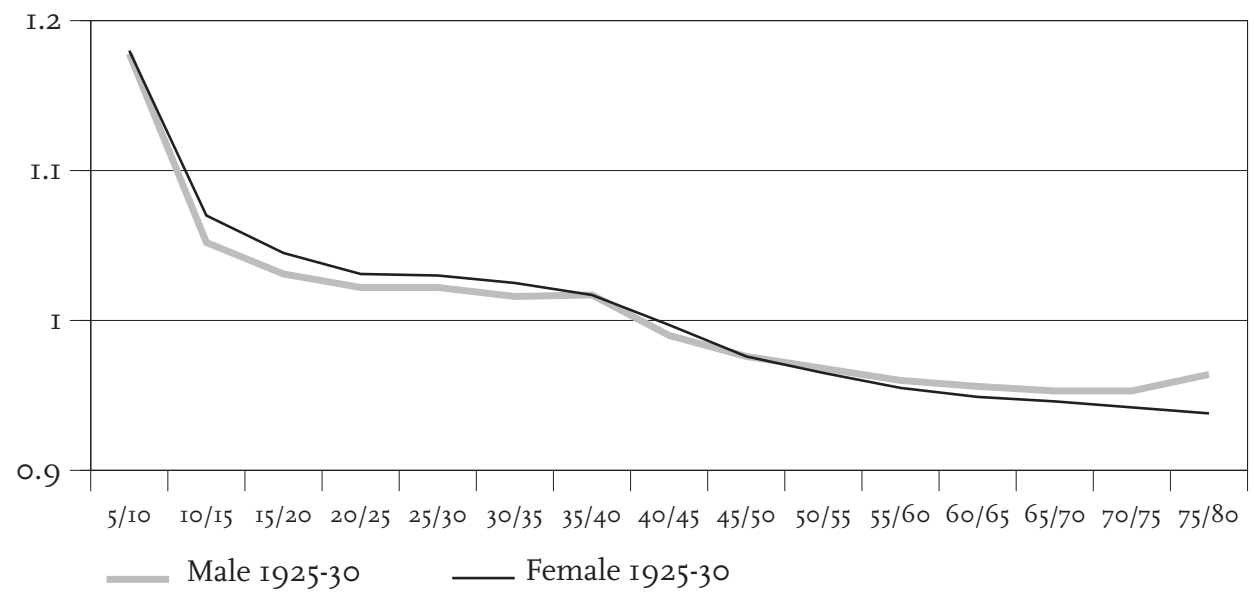




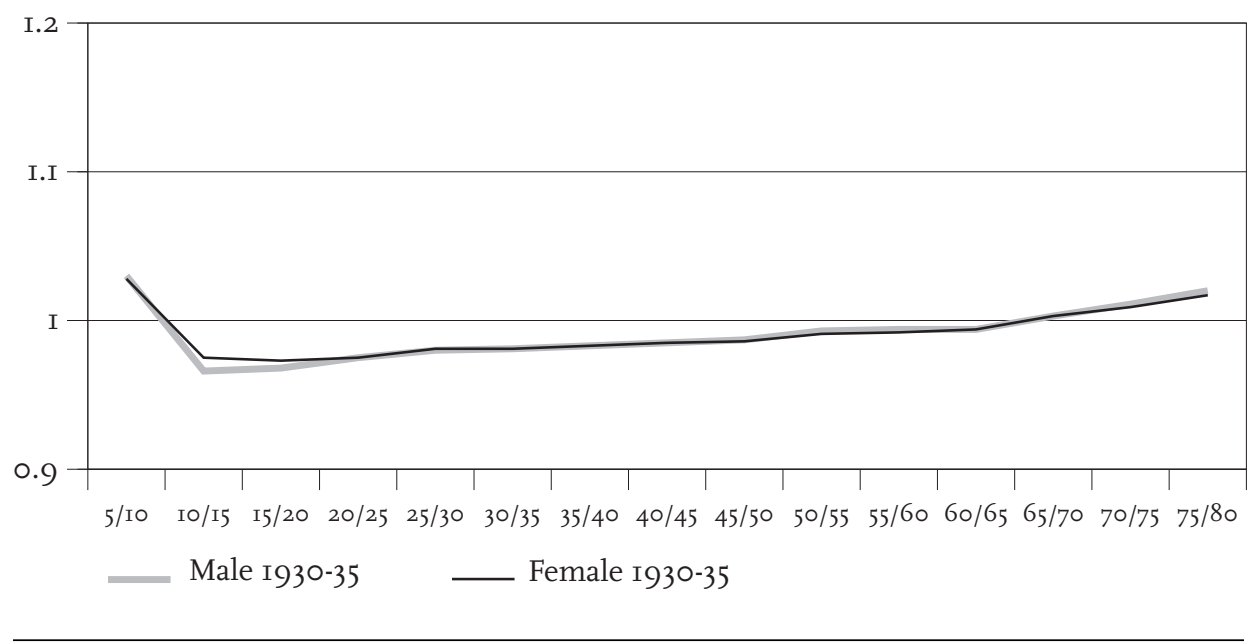

However, the indirect method is vulnerable to differential enumeration in two successive censuses, which would distort the growth rates used in estimating completeness (Bennett and Horiuchi I981:215). Thus while no technique for estimating death registration completeness can be completely independent of census counts, the indirect technique relies on only selected features of the censuses, and provides a useful check on Barclay's direct method.

\section{Conclusion}

Taiwan has a long history of conducting population censuses and operating a household registration system. In I905, the Japanese government conducted the first modern population census in colonial Taiwan. Another six censuses were conducted during the Japanese occupation. These population census data have been used for a variety of purposes to evaluate the success of Japanese colonial rule and the progress of living standards of Taiwanese people under Japanese rule. To check the validity of such use, in this paper we examine the quality of the demographic data in colonial Taiwan. Particularly, we estimate the completeness of death registration in five intercensal periods.

To achieve the research objective, we use the Bennett-Horiuchi indirect estimation technique, which has been applied to the virtually complete Swedish data to prove its credibility (see Bennett and Horiuchi, I98I). To apply this particular indirect technique, the population has to be closed to migration between censuses. The use of age-specific growth rates in the estimation procedure means stable populations need not be assumed. The Taiwanese population dur- 
ing the early 2oth century was, for the most part, closed to migration as little

movement was allowed between Taiwan and Mainland China by the colonial government. However, as death rates fell rapidly, especially after I920, the population was unstable. As a result, applying the Bennett-Horiuchi technique is appropriate to the Taiwanese population during the period of Japanese occupation.

By applying the MortPak-Lite program, which implements the BennettHoriuchi indirect technique, we are able to estimate the completeness of death registrations. The results shown in Figures I-5 and the tables in the Appendix show median estimates of death registration completeness which are consistently high. They are close to I.00 in all five periods, I905-1915, I915-1920, I920I925, I925-I930, and I930-I935. The estimated ratios of death registration completeness indicate that the deaths were almost completely reported.

Both the direct and the indirect estimation approaches provide similar results. Barclay (I954) employed a direct method to estimate the completeness of death registration. His direct method was applied to the analysis of census data and the vital statistics in the period of 1905-1920. In his analysis, Barclay (1954) focused on the cohorts born in the years between 1875 and I904 and found completeness rates ranging from 0.940 to 1.094 for each single year age cohort. This paper, using an indirect estimation technique, has arrived at the same conclusion: that death reporting was nearly complete. As shown in Tables I and 6, during the period of I905-I9I5, the completeness rates of death registration for the male and female populations range from 0.942 to I.053, and 0.958 to I.080, respectively. The results of both studies confirm that death registrations were well-maintained in colonial Taiwan, at least for the intercensal periods 1905I935. These studies provide convincing evidence that in carrying out the first population census in colonial Taiwan, Shichisaburo Mizushina was successful in reforming the household registration system to ensure complete and reliable death registration, and providing the basis for a series of highly accurate censuses. 
Figure 6. Estimates of the Completeness of Death Registration for the Taiwanese Male and Female Populations in the Periods of I905-1935.

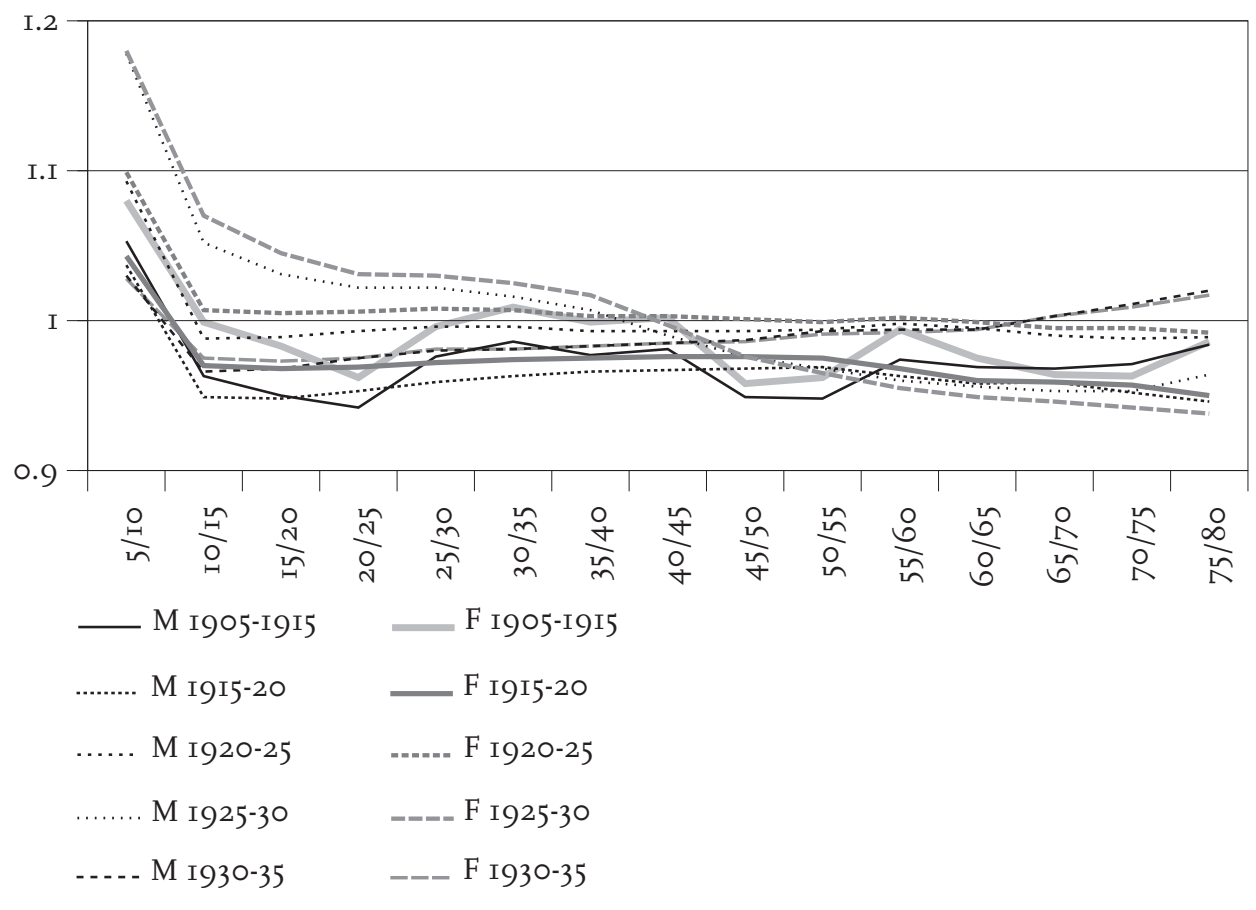


Figure 7. Estimates of the Completeness of Death Registration for the

Taiwanese Male Population in the Periods of I905-1935.

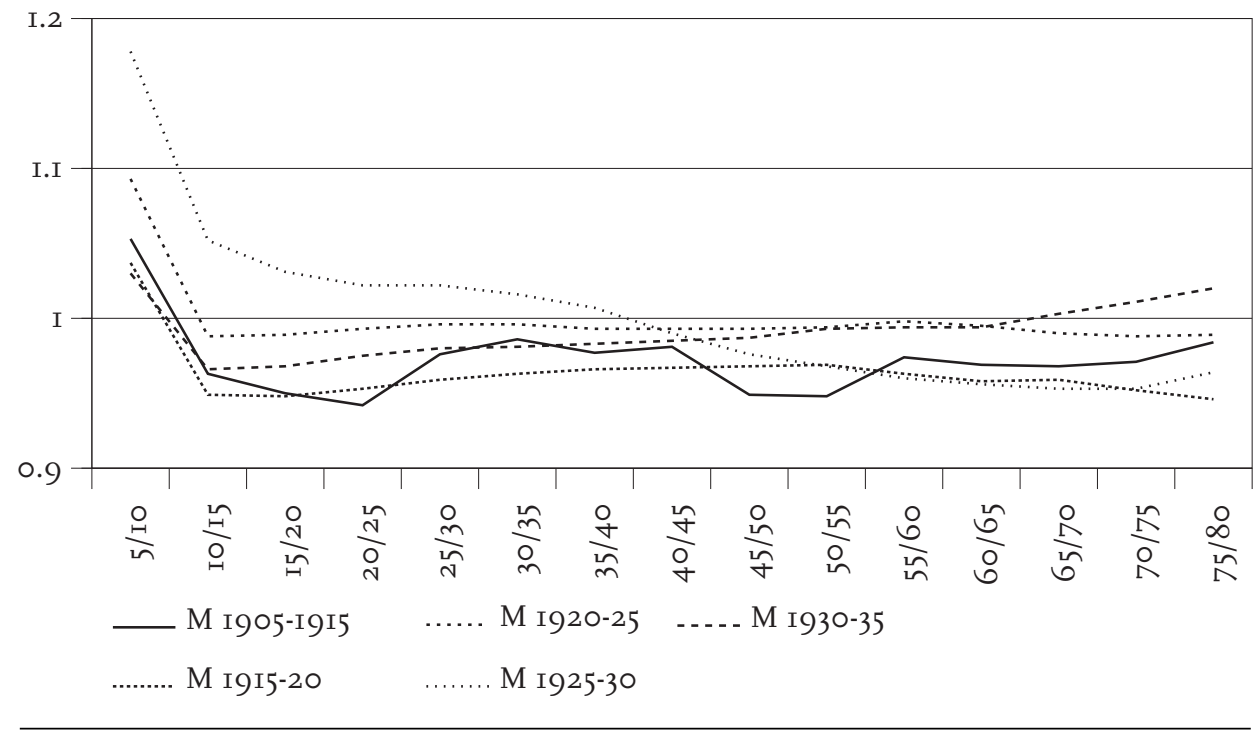

Figure 8. Estimates of the Completeness of Death Registration for the Taiwanese Female Population in the Periods of I905-1935.

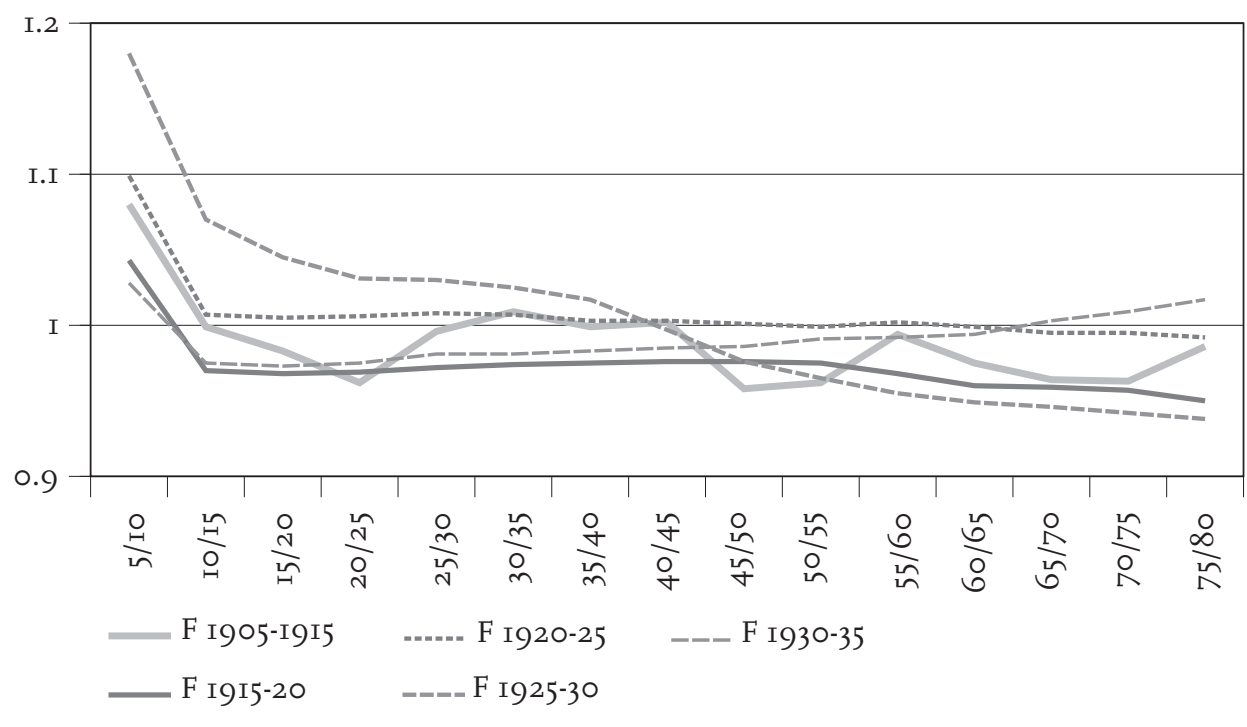



I9I5) ${ }^{\dagger *}$
(I)
(2)
(3)
(4)
(5)
(6)
(7)
(8)

\begin{tabular}{|c|c|c|c|c|c|c|c|c|}
\hline Age & $P_{1}$ & $P_{2}$ & & & & & & ${ }_{\text {10 }} \hat{N}_{a-5}$ \\
\hline group & Oct. I905 & Oct. I9I5 & ${ }_{5} r_{a}$ & ${ }_{5} D_{a}$ & ${ }_{5} N_{a}$ & $\hat{N}_{a}$ & ${ }_{5} \hat{N}_{a}$ & ${ }_{10} N_{a-5}$ \\
\hline $0-5$ & 221258 & 262315 & 0.0170 & I93205 & 2409135 & 664721 & 2725132 & - \\
\hline 5-10 & I89010 & 225540 & 0.0177 & 21884 & 2064687 & 425332 & I984402 & I.053 \\
\hline IO-I5 & $16704 \mathrm{I}$ & 195968 & 0.0160 & 10974 & 1809273 & 368428 & I7 45088 & 0.963 \\
\hline $15-20$ & I673I3 & I74599 & 0.0043 & I37I4 & I709172 & 329607 & 1596736 & 0.950 \\
\hline $20-25$ & 173546 & 151963 & -0.0133 & $2 \mathrm{I} 472$ & 1623963 & 309088 & I542999 & 0.942 \\
\hline $25-30$ & 150603 & I44993 & -0.0038 & 27805 & I47777I4 & $308 \mathrm{II} 2$ & I485I44 & 0.976 \\
\hline $30-35$ & I28799 & I 44087 & 0.0112 & 31279 & 1362287 & 285946 & 1314706 & 0.986 \\
\hline $35-40$ & 97928 & II 8603 & 0.0192 & 31612 & I077708 & 239937 & 1069564 & 0.977 \\
\hline $40-45$ & 74344 & 95745 & 0.0253 & $2907 \mathrm{I}$ & 843686 & I87889 & 8I54IO & $0.98 \mathrm{I}$ \\
\hline $45-50$ & 65404 & 68003 & 0.0039 & 27107 & 666908 & I38275 & 6I7594 & 0.949 \\
\hline $50-55$ & 49815 & 48665 & -0.0023 & 26027 & 492366 & 108763 & $48 \mathrm{I} 55^{8}$ & 0.948 \\
\hline $55-60$ & 35215 & 37947 & 0.0075 & 23317 & 365555 & $8386 \mathrm{I}$ & 354402 & 0.974 \\
\hline $60-65$ & 23048 & 25719 & 0.0110 & I89I6 & 243469 & 57900 & 235578 & 0.969 \\
\hline $65-70$ & $\mathrm{I} 359^{2}$ & 15485 & 0.0130 & I445I & I45077 & 36407 & I40374 & 0.968 \\
\hline $70-75$ & 6875 & 7936 & 0.0144 & $974^{2}$ & 73865 & $20 \mathrm{I} 2 \mathrm{I}$ & 72292 & $0.97 \mathrm{I}$ \\
\hline $75-80$ & 2627 & 3468 & 0.0278 & $5^{1} 84$ & 30183 & 9329 & $3009 \mathrm{I}$ & 0.984 \\
\hline $80+$ & II29 & I524 & 0.0300 & 2857 & I3II7 & 3283 & I5247 & - \\
\hline
\end{tabular}

$\uparrow$ For calculation purposes, $\mathrm{E}(80)$ is assumed equal to 4.735

$\ddagger$ Based on median completeness of .97I

* Eight columns are listed in Tables I to io in the Appendix. Their meanings are as follows:

(I) $P_{1}$ the population at time I, retrieved from the census.

(2) $P_{2}$ the population at time 2 , retrieved from the census.

(3) ${ }_{5} r_{a}$, the growth rate experienced by those in the age group a to $a+5$. It is calculated as ${ }_{5} r_{a}=\frac{\ln \left(P_{1} / P_{2}\right)}{\mathrm{t}}$, where $\mathrm{t}$ is the length between time I and time 2.

(4) ${ }_{5} D_{a}$, the number of deaths occurring within the age group a to $a+5$, retrieved from reports of registered deaths.

(5) ${ }_{5} N_{a}$, the observed number of population in the age group a to $a+5$. It is calculated as ${ }_{5} N a=t * \sqrt{P_{1} * P_{2}}$.

(6) $\hat{N}_{a}$, the estimated number of people at age a. It is calculated as $\hat{N}_{a-5}=\hat{N}_{a} *^{5^{*}{ }_{5}{ }^{r} a-5+}{ }_{5} D_{a-5}{ }^{* 2.5^{*}}{ }_{5} r_{a-5}$

(7) ${ }_{5} \hat{N}_{a}$, the estimated number of population in the cohort of a to $a+5$. It is calculated as ${ }_{5} \hat{N}_{a}=2 \cdot 5 *\left(\hat{N}_{a}+\hat{N}_{a+5}\right)$

(8) ${ }_{\text {Io }} \hat{N}_{a-5 / 10} N_{a-5}$, the estimated completeness of death registration for the age group a to $a+5$ 

1920) फे

\begin{tabular}{|c|c|c|c|c|c|c|c|c|}
\hline \multirow{3}{*}{$\begin{array}{l}\text { Age } \\
\text { group }\end{array}$} & \multirow{3}{*}{$\begin{array}{l}\text { (I) } \\
\text { P1 } \\
\text { Oct. I9I5 }\end{array}$} & \multirow{3}{*}{$\begin{array}{l}(2) \\
P_{2} \\
\text { Oct. I920 }\end{array}$} & \multirow{3}{*}{$\begin{array}{l}\text { (3) } \\
{ }_{5} r_{a}\end{array}$} & \multirow{3}{*}{$\begin{array}{l}\text { (4) } \\
{ }_{5} D_{a}\end{array}$} & \multirow{3}{*}{$\begin{array}{l}\text { (5) } \\
{ }_{5} N_{a}\end{array}$} & \multirow{3}{*}{$\begin{array}{l}\text { (6) } \\
\hat{N}_{a}\end{array}$} & \multirow{3}{*}{$\begin{array}{l}\text { (7) } \\
{ }_{5} \hat{N}_{a}\end{array}$} & \multirow{3}{*}{$\begin{array}{l}\text { (8) } \\
\frac{{ }_{10} \hat{N}_{a-5}}{{ }_{10} N_{a-5}}\end{array}$} \\
\hline & & & & & & & & \\
\hline & & & & & & & & \\
\hline $0-5$ & 262315 & 252577 & -0.0076 & IIO623 & I287000 & 336905 & I435160 & - \\
\hline 5-10 & 225540 & $24337 \mathrm{I}$ & 0.0152 & 11653 & II7I430 & 237159 & III43IO & I. 037 \\
\hline IO-I5 & 195968 & 217376 & 0.0207 & 5775 & 1031973 & 208565 & 977766 & 0.949 \\
\hline $15-20$ & I74599 & 188264 & $0.015 \mathrm{I}$ & 7777 & 906514 & 182542 & 860860 & 0.948 \\
\hline $20-25$ & 151963 & $16_{33} 88$ & 0.0145 & IIO33 & 787860 & 161802 & $754 \mathrm{I} 26$ & 0.953 \\
\hline $25-30$ & I44993 & 138305 & -0.0094 & I 4048 & 708048 & I39848 & 680188 & 0.959 \\
\hline $30-35$ & I 44087 & I2 $84 \mathrm{I} 3$ & -0.0230 & I7134 & 680122 & I32227 & 656iio & 0.963 \\
\hline $35-40$ & II 8603 & 125189 & 0.0108 & I8०87 & 609258 & I302I7 & 589947 & 0.966 \\
\hline $40-45$ & 95745 & 100392 & 0.0095 & I7540 & 490205 & 105762 & 473746 & 0.967 \\
\hline $45-50$ & 68003 & 78717 & 0.0293 & I534I & 365821 & 83737 & 354544 & 0.968 \\
\hline $50-55$ & 47665 & 53553 & 0.0233 & 12653 & 252616 & $5808 \mathrm{I}$ & 244596 & 0.969 \\
\hline $55-60$ & 37947 & 35643 & -0.0125 & II4I4 & I 83885 & 39758 & I7577I & 0.963 \\
\hline $60-65$ & 25719 & 26544 & 0.0063 & IOI64 & I3064I & $3055^{\mathrm{I}}$ & 125462 & 0.958 \\
\hline $65-70$ & 15485 & 16183 & 0.0088 & 8069 & 79151 & 19596 & 75699 & 0.959 \\
\hline 70-75 & 7936 & 8560 & $0.015 \mathrm{I}$ & 5276 & 41210 & I0858 & 38858 & 0.952 \\
\hline $75-80$ & 3468 & 3547 & 0.0045 & $299 \mathrm{I}$ & 17536 & 4986 & 16702 & 0.946 \\
\hline $80+$ & I524 & IGI4 & 0.0115 & I8I7 & 7842 & I9I8 & 9320 & - \\
\hline
\end{tabular}

$\dagger$ For calculation purposes, $\mathrm{E}(80)$ is assumed equal to 4.750

$¥$ Based on median completeness of .959 

$1925)^{\uparrow}$
(I)
(2)
(3)
(4)
(5)
(6)
(7)
(8)

\begin{tabular}{|c|c|c|c|c|c|c|c|c|}
\hline Age & $P_{1}$ & $\mathrm{P}_{2}$ & & & & & & ${ }_{\text {Io }} \hat{N}_{a-5}$ \\
\hline group & Oct. I920 & Oct. I925 & ${ }_{5} r_{a}$ & ${ }_{5} D_{a}$ & ${ }_{5} N_{a}$ & $\hat{N}_{a}$ & ${ }_{5} \hat{N}_{a}$ & ${ }_{10} N_{a-5}$ \\
\hline $0-5$ & 252577 & 28874I & 0.0268 & IIO863 & $\mathrm{I} 350272$ & 396827 & 1600660 & - \\
\hline 5-10 & 24337I & 24I44I & -0.0016 & 9100 & $\mathrm{I} 2 \mathrm{I} 2 \mathrm{O} 2 \mathrm{O}$ & 243437 & II992IO & I.०93 \\
\hline IO-I5 & 217376 & 237135 & 0.0174 & 4927 & II 35203 & 236247 & II 20228 & 0.988 \\
\hline I5-20 & 188264 & 210770 & 0.0226 & 6623 & 995997 & $2 \mathrm{II} 845$ & 987022 & 0.989 \\
\hline $20-25$ & I63388 & I80000 & 0.0194 & $84 \mathrm{I} 8$ & 857465 & I82964 & $85255^{8}$ & 0.993 \\
\hline $25-30$ & 138305 & I54IO3 & 0.0216 & 9257 & $72995^{2}$ & I58059 & 727860 & 0.996 \\
\hline $30-35$ & $\mathrm{I} 284 \mathrm{I} 3$ & I2 8548 & 0.0002 & I0395 & 642402 & 133085 & 639104 & 0.996 \\
\hline $35-40$ & 125189 & II73I9 & -0.0130 & I2508 & $60595^{I}$ & 122556 & 601032 & 0.993 \\
\hline $40-45$ & 100392 & III8I4 & 0.0216 & I348I & 529746 & $\mathrm{II} 7857$ & $52725 \mathrm{I}$ & 0.993 \\
\hline $45-50$ & $787 \mathrm{I} 7$ & 875 II & 0.0212 & I2940 & 4I4988 & 93044 & $4 \mathrm{III} 6 \mathrm{I}$ & 0.993 \\
\hline $50-55$ & 53553 & 66287 & 0.0427 & II29I & 297904 & $7 \mathrm{I} 42 \mathrm{I}$ & 297433 & 0.994 \\
\hline $55-60$ & 35643 & $43 \mathrm{I} 33$ & $0.038 \mathrm{I}$ & 9483 & 196048 & $4755^{2}$ & 195566 & 0.998 \\
\hline $60-65$ & 26544 & 26619 & 0.0006 & 8774 & I32907 & 30674 & I3I 803 & 0.995 \\
\hline $65-70$ & 16183 & I8229 & 0.0238 & 7456 & 85878 & 21826 & $8479^{2}$ & 0.990 \\
\hline $70-75$ & 8560 & 9728 & 0.0256 & 5187 & 45627 & $\mathrm{I} 235^{\mathrm{I}}$ & $45^{109}$ & 0.988 \\
\hline $75-80$ & 3547 & 4360 & $0.04 \mathrm{I} 3$ & 3020 & 19663 & 6003 & I9468 & 0.989 \\
\hline $80+$ & I6I4 & I797 & 0.0215 & I948 & 8515 & 2159 & 10238 & 一 \\
\hline
\end{tabular}

$\uparrow$ For calculation purposes, E(80) is assumed equal to 4.875

† Based on median completeness of .993 

(I)
(2)
(3)
(4)
(5)
(6)
(7)
(8)

\begin{tabular}{|c|c|c|c|c|c|c|c|c|}
\hline Age & $P_{1}$ & $P_{2}$ & & & & & & ${ }_{\text {Iо }} \hat{N}_{a-5}$ \\
\hline group & Oct. I925 & Oct. I930 & ${ }_{5} r_{a}$ & ${ }_{5} D_{a}$ & ${ }_{5} N_{a}$ & $\hat{N}_{a}$ & ${ }_{5} \hat{N}_{a}$ & $\overline{{ }_{10} N_{a-5}}$ \\
\hline $0-5$ & 28874I & 375296 & 0.0524 & I2I2O4 & 1645929 & 533223 & 2092890 & - \\
\hline 5-10 & 24I44I & 284199 & 0.0326 & 6888 & I309745 & 303933 & I389475 & I.I78 \\
\hline IO-I5 & 237135 & 239915 & 0.0023 & 3873 & II92605 & 251857 & 1242363 & 1.052 \\
\hline $15-20$ & 210770 & 237760 & $0.024 \mathrm{I}$ & 5749 & III9293 & 245088 & II42354 & I.O3I \\
\hline $20-25$ & I80000 & 203422 & 0.0245 & 7736 & 956765 & 211853 & 980093 & I. 022 \\
\hline $25-30$ & I54IO3 & 173064 & 0.0232 & 8I86 & $8 \mathrm{I} 6543$ & I80I84 & 832254 & I. 022 \\
\hline $30-35$ & I2 8548 & I47I26 & 0.0270 & 8616 & 687618 & I527I 8 & 695246 & I.०I6 \\
\hline $35-40$ & II73I9 & I2O4OI & 0.0052 & 9637 & 594250 & I25380 & 595096 & 1.007 \\
\hline $40-45$ & III8I4 & $\log 237$ & -0.0047 & II537 & 552590 & II 2658 & 540753 & 0.990 \\
\hline $45-50$ & 875 II & 100513 & 0.0277 & I2239 & 468935 & 103643 & 456 I49 & 0.976 \\
\hline $50-55$ & 66287 & 76024 & 0.0274 & II930 & 354944 & $788 \mathrm{I} 6$ & 340996 & 0.968 \\
\hline $55-60$ & 43133 & 55294 & 0.0497 & IOI33 & 244182 & 57582 & 233875 & 0.960 \\
\hline $60-65$ & 26619 & 33200 & 0.0442 & 8466 & I48640 & 35968 & I4I68I & 0.956 \\
\hline $65-70$ & 18229 & I8572 & 0.0037 & 7209 & 91999 & $2 \mathrm{I} 258$ & 87580 & 0.953 \\
\hline $70-75$ & 9728 & II294 & 0.0299 & 5548 & 52409 & I3723 & 50082 & 0.953 \\
\hline $75-80$ & 4360 & 4848 & 0.0212 & 3510 & 22988 & 6671 & $226 I 4$ & 0.964 \\
\hline $80+$ & I797 & 2219 & 0.0422 & 2179 & 9984 & $267 I$ & I2O43 & 一 \\
\hline
\end{tabular}

$\uparrow$ For calculation purposes, $\mathrm{E}(80)$ is assumed equal to 4.967

$\ddagger$ Based on median completeness of .990 

$1935^{\dagger *}$
(I)
(2)
(3)
(4)
(5)
(6)
(7)
(8)

\begin{tabular}{|c|c|c|c|c|c|c|c|c|}
\hline Age & $P_{1}$ & $\mathrm{P}_{2}$ & & & & & & ${ }_{\text {I0 }} \hat{N}_{a-5}$ \\
\hline group & Oct. I930 & Oct. I935 & ${ }_{5} r_{a}$ & ${ }_{5} D_{a}$ & ${ }_{5} N_{a}$ & $\hat{N}_{a}$ & ${ }_{5} \hat{N}_{a}$ & ${ }_{10} N_{a-5}$ \\
\hline $0-5$ & 375296 & 437959 & 0.0309 & I37487 & 2027093 & 540079 & 2189028 & 一 \\
\hline 5-IO & 284199 & 345252 & 0.0389 & 7185 & 1566208 & 335533 & I5I303I & I. .030 \\
\hline IO-I5 & 239915 & 278366 & 0.0297 & $36_{51}$ & I292I32 & 269680 & 1246796 & 0.966 \\
\hline I5-20 & 237760 & $23332 \mathrm{I}$ & -0.0038 & 5073 & $\operatorname{II} 77650$ & 229039 & II43286 & 0.968 \\
\hline $20-25$ & 203422 & 229895 & 0.0245 & 7I93 & 1081269 & 228275 & 1058746 & 0.975 \\
\hline $25-30$ & I73064 & 1956 I8 & 0.0245 & 7702 & 919979 & I95223 & 901732 & 0.980 \\
\hline $30-35$ & I47I26 & I64788 & 0.0227 & $795^{1}$ & 778534 & I65470 & 764230 & $0.98 \mathrm{I}$ \\
\hline $35-40$ & I2O4OI & I384I7 & 0.0279 & 8236 & 645476 & $\mathrm{I} 40222$ & 636279 & 0.983 \\
\hline $40-45$ & 109237 & III279 & 0.0037 & $935^{8}$ & $55^{12} 66$ & II4290 & 543026 & 0.985 \\
\hline $45-50$ & 100513 & 98360 & -0.0043 & III75 & 497I53 & I0292I & 49I994 & 0.987 \\
\hline $50-55$ & 76024 & 88352 & 0.0301 & I2106 & 409783 & 93877 & 408563 & 0.993 \\
\hline $55-60$ & 55294 & 64569 & 0.0310 & II 585 & 298759 & 69548 & 295964 & 0.994 \\
\hline $60-65$ & 33200 & 43796 & 0.0554 & 9992 & I90659 & 48837 & I90453 & 0.994 \\
\hline $65-70$ & 18572 & 24072 & 0.0519 & 7620 & 105720 & 28322 & 106959 & I. .003 \\
\hline $70-75$ & II294 & II989 & 0.0119 & 5970 & 58182 & I5158 & 58762 & I.OII \\
\hline $75-80$ & 4848 & 6035 & 0.0438 & 3976 & 27045 & 8485 & $28 \mathrm{I} 66$ & 1.020 \\
\hline $80+$ & 2219 & 2729 & $0.04 \mathrm{I} 4$ & 2650 & I23O4 & 3252 & 14692 & - \\
\hline
\end{tabular}

$\uparrow$ For calculation purposes, $\mathrm{E}(80)$ is assumed equal to 5.095

$\mp$ Based on median completeness of .987 

I905-1915) ${ }^{\dagger+}$

\begin{tabular}{|c|c|c|c|c|c|c|c|c|}
\hline \multirow{3}{*}{$\begin{array}{l}\text { Age } \\
\text { group }\end{array}$} & \multirow{3}{*}{$\begin{array}{l}\text { (I) } \\
P_{1} \\
\text { Oct. I905 }\end{array}$} & \multirow{2}{*}{$\begin{array}{l}(2) \\
P_{2}\end{array}$} & \multirow[t]{2}{*}{ (3) } & \multirow[t]{2}{*}{ (4) } & \multirow[t]{2}{*}{ (5) } & \multirow[t]{2}{*}{ (6) } & \multirow[t]{2}{*}{ (7) } & \multirow{2}{*}{$\begin{array}{l}\text { (8) } \\
{ }_{\text {} 0} \hat{N}_{a-5}\end{array}$} \\
\hline & & & & & & & & \\
\hline & & Oct. I9I5 & ${ }_{5} r_{a}$ & ${ }_{5} D_{a}$ & ${ }_{5} N_{a}$ & $\hat{N}_{a}$ & ${ }_{5} \hat{N}_{a}$ & ${ }_{10} N_{a-5}$ \\
\hline $0-5$ & 203405 & 252848 & 0.0218 & I8668I & 2267830 & 642934 & 2606984 & - \\
\hline 5-10 & I63597 & 207739 & 0.0239 & 22635 & 1843515 & 399859 & I833449 & 1.080 \\
\hline IO-I5 & I37I37 & I73979 & 0.0238 & 9629 & 1544635 & 333520 & I551389 & 0.999 \\
\hline $15-20$ & 133205 & I5IIII & 0.0126 & I2392 & I41 8758 & 287036 & 136I304 & 0.983 \\
\hline $20-25$ & 140683 & $1256 \mathrm{I7}$ & -0.0113 & 16950 & 1329367 & 257486 & I28I347 & 0.962 \\
\hline $25-30$ & I23342 & $\operatorname{II7} 66_{3}$ & -0.0047 & I8794 & 1204690 & 255053 & I242929 & 0.996 \\
\hline $30-35$ & I08253 & I2I 230 & 0.0113 & I9749 & II 45579 & 242 II 9 & II 29285 & I.००9 \\
\hline $35-40$ & $84 \mathrm{I} 86$ & IO4I55 & 0.0213 & I 8838 & 936397 & 209595 & $95042 \mathrm{I}$ & 0.999 \\
\hline $40-45$ & 66гол & $89 \mathrm{II} 6$ & 0.0299 & I558I & 767506 & I70573 & 757546 & 1.002 \\
\hline $45-50$ & 65606 & 68242 & 0.0039 & I5I87 & 669i1o & I32445 & 6I8I74 & 0.958 \\
\hline $50-55$ & $5523 \mathrm{I}$ & 51764 & -0.0065 & 17189 & 534694 & II 4824 & 539903 & 0.962 \\
\hline $55-60$ & 44357 & $4^{8 I} 47$ & 0.0082 & I825I & 462132 & IOII37 & 450829 & 0.994 \\
\hline $60-65$ & 33384 & 37099 & 0.0106 & I 8028 & 351925 & 79194 & 342750 & 0.975 \\
\hline $65-70$ & 23869 & 26438 & 0.0102 & I7274 & 251207 & 57566 & 238726 & 0.964 \\
\hline $70-75$ & $\mathrm{I} 3950$ & 15806 & 0.0125 & I505I & I48490 & 37859 & I46I47 & 0.963 \\
\hline $75-80$ & 6097 & 8566 & 0.0340 & 9946 & 72268 & 20979 & $7 \mathrm{I}_{4} \mathrm{G}_{3}$ & 0.986 \\
\hline $80+$ & 3325 & 4674 & $0.034 \mathrm{I}$ & 7212 & 39422 & 8564 & 39375 & - \\
\hline
\end{tabular}

$\dagger$ For calculation purposes, $\mathrm{E}(80)$ is assumed equal to 5.172

$\ddagger$ Based on median completeness of .986 

I915-1920) $)^{\dagger+}$
(I)
(2)
(3)
(4)
(5)
(6)
(7)
(8)

\begin{tabular}{|c|c|c|c|c|c|c|c|c|}
\hline Age & $P_{1}$ & $P_{2}$ & & & & & & ${ }_{\text {Io }} \hat{N}_{a-5}$ \\
\hline group & Oct. I9I5 & Oct. I920 & ${ }_{5} r_{a}$ & ${ }_{5} D_{a}$ & ${ }_{5} N_{a}$ & $\hat{N}_{a}$ & ${ }_{5} \hat{N}_{a}$ & ${ }_{10} N_{a-5}$ \\
\hline $0-5$ & 252848 & 243840 & -0.0073 & 104582 & I24I5I6 & 321913 & 1373056 & 一 \\
\hline 5-10 & 207739 & 227803 & 0.0184 & I28I9 & 1087699 & 227309 & $1055^{891}$ & I. 043 \\
\hline IO-I5 & I73979 & 198728 & 0.0266 & $555^{\circ}$ & $9297 \mathrm{II}$ & 195047 & 901527 & 0.970 \\
\hline $15-20$ & I5IIII & 167905 & $0.021 \mathrm{II}$ & 7372 & 796434 & 165564 & 768935 & 0.968 \\
\hline $20-25$ & I256I7 & I4I6I5 & 0.0240 & $918 \mathrm{I}$ & 666882 & I420IO & 648327 & 0.969 \\
\hline $25-30$ & II7663 & II564I & -0.0035 & 9822 & 583238 & II732I & 566963 & 0.972 \\
\hline $30-35$ & I2I 230 & I0680I & -0.0253 & IIO93 & 568935 & 109465 & 554749 & 0.974 \\
\hline $35-40$ & IO4I55 & 109440 & 0.0099 & II 354 & 533824 & II2435 & 520909 & 0.975 \\
\hline $40-45$ & 89і16 & $9323 \mathrm{I}$ & 0.0090 & 10057 & $45575^{I}$ & 95929 & 444477 & 0.976 \\
\hline $45-50$ & 68242 & 79620 & 0.0308 & 8745 & 368559 & 81862 & 359824 & 0.976 \\
\hline $50-55$ & 51764 & 59834 & 0.0290 & $803 \mathrm{I}$ & 278265 & 62068 & 270736 & 0.975 \\
\hline $55-60$ & $48 \mathrm{I} 47$ & 43487 & -0.0204 & 8984 & 228789 & 46227 & 219884 & 0.968 \\
\hline $60-65$ & 37099 & 38625 & $0.008 \mathrm{I}$ & 9562 & 189272 & $4 \mathrm{I} 727$ & I81648 & 0.960 \\
\hline $65-70$ & 26438 & 27267 & 0.0062 & 9256 & I34247 & 30707 & I28680 & 0.959 \\
\hline $70-75$ & 15806 & 17436 & 0.0196 & 7779 & 83005 & 20659 & 79278 & 0.957 \\
\hline $75-80$ & 8566 & 8655 & $0.002 \mathrm{I}$ & 6094 & 43052 & II 322 & 40448 & 0.950 \\
\hline $80+$ & 4674 & 4943 & 0.0112 & 4856 & 24033 & $5 \mathrm{I} 43$ & 25007 & - \\
\hline
\end{tabular}

$\dagger$ For calculation purposes, E(80) is assumed equal to 5.I72

$\uparrow$ Based on median completeness of .970 

I920-1925)

\begin{tabular}{|c|c|c|c|c|c|c|c|c|}
\hline \multirow{3}{*}{$\begin{array}{l}\text { Age } \\
\text { group }\end{array}$} & \multirow{2}{*}{$\begin{array}{l}\text { (I) } \\
P_{1}\end{array}$} & \multirow{2}{*}{$\begin{array}{l}(2) \\
P_{2}\end{array}$} & \multirow[t]{2}{*}{ (3) } & \multirow[t]{2}{*}{ (4) } & \multirow[t]{2}{*}{ (5) } & \multirow[t]{2}{*}{ (6) } & \multirow[t]{2}{*}{ (7) } & \multirow{2}{*}{$\begin{array}{l}\text { (8) } \\
{ }_{\text {Io }} \hat{N}_{a-5}\end{array}$} \\
\hline & & & & & & & & \\
\hline & Oct. 1920 & Oct. I925 & ${ }_{5} r_{a}$ & ${ }_{5} D_{a}$ & ${ }_{5} N_{a}$ & $\hat{N}_{a}$ & ${ }_{5} \hat{N}_{a}$ & ${ }_{10} N_{a-5}$ \\
\hline $0-5$ & 243840 & $28228 \mathrm{I}$ & 0.0293 & IOI443 & I3II7 87 & 382455 & ${ }_{154} \sigma_{3} G_{3}$ & - \\
\hline 5-10 & 227803 & 229482 & 0.0015 & 9485 & II 43205 & 236090 & II 52504 & 1.099 \\
\hline IO-I5 & I98728 & $22 \mathrm{I} 748$ & 0.0219 & 4462 & 1049613 & 224912 & 1055629 & 1.007 \\
\hline $15-20$ & 167905 & I94I27 & 0.0290 & 5559 & 902703 & I97340 & 907133 & 1.005 \\
\hline $20-25$ & $14 \mathrm{I} 6 \mathrm{I} 5$ & 161183 & 0.0259 & 6971 & $7554 \mathrm{I} 3$ & 165514 & 760999 & 1.006 \\
\hline $25-30$ & II564I & I34750 & 0.0306 & 6504 & 624152 & I38886 & 630127 & I.००8 \\
\hline 30-35 & I0680I & Iо9ा6I & 0.0044 & $709 \mathrm{I}$ & 539873 & I13165 & $542 \mathrm{I} 74$ & I.०07 \\
\hline $35-40$ & I09440 & 99646 & -0.0188 & 7924 & $522 \mathrm{I} 4 \mathrm{I}$ & 103705 & 523244 & I.०03 \\
\hline $40-45$ & 93231 & IOI433 & 0.0169 & 7679 & 486228 & 105593 & 488215 & 1.003 \\
\hline $45-50$ & 79620 & 86385 & $0.016_{3}$ & 7365 & $4 \mathrm{I} 4668$ & 89693 & $4 \mathrm{I} 3227$ & I.OOI \\
\hline $50-55$ & 59834 & 72243 & 0.0377 & 7227 & 328732 & $7559^{8}$ & 329084 & 0.999 \\
\hline $55-60$ & 43487 & 52702 & 0.0384 & 6827 & 239366 & 56036 & 240180 & I.०O2 \\
\hline $60-65$ & 38625 & 36657 & -0.0105 & $78 \mathrm{I} 4$ & I88I4I & 40036 & I8669I & 0.999 \\
\hline $65-70$ & 27267 & 30200 & 0.0204 & $8 \mathrm{I} 30$ & I 43480 & $34{ }^{1} 6_{5}$ & I43122 & 0.995 \\
\hline 70-75 & $\mathrm{I} 7436$ & 19380 & 0.0211 & 7634 & 91912 & $2312 \mathrm{I}$ & 91205 & 0.995 \\
\hline $75-80$ & 8655 & 10602 & 0.0406 & 5633 & 47896 & I356I & 47534 & 0.992 \\
\hline $80+$ & 4943 & 5773 & 0.0310 & 5087 & 26710 & $598 \mathrm{I}$ & 27703 & - \\
\hline
\end{tabular}

$\dagger$ For calculation purposes, $\mathrm{E}(80)$ is assumed equal to 5.34I

$\uparrow$ Based on median completeness of 1.003 

1925-1930) †े
(I)
(2)
(3)
(4)
(5)
(6)
(7)
(8)

\begin{tabular}{|c|c|c|c|c|c|c|c|c|}
\hline Age & $P_{1}$ & $\mathrm{P}_{2}$ & & & & & & ${ }_{\text {Io }} \hat{N}_{a-5}$ \\
\hline group & Oct. I925 & Oct. I930 & ${ }_{5} r_{a}$ & ${ }_{5} D_{a}$ & ${ }_{5} N_{a}$ & $\hat{N}_{a}$ & ${ }_{5} \hat{N}_{a}$ & ${ }_{10} N_{a-5}$ \\
\hline $0-5$ & $28228 \mathrm{I}$ & 364965 & 0.0514 & 109305 & 1604857 & 509916 & 2020448 & - \\
\hline 5-10 & 229482 & 274307 & 0.0357 & 6673 & I254477 & 298264 & I354209 & I.I8O \\
\hline IO-I5 & 221748 & 228248 & 0.0058 & 3382 & II 24873 & 243420 & II9I437 & I. 070 \\
\hline $15-20$ & I94I27 & 224603 & 0.0292 & 5200 & 1044049 & 233155 & I074597 & I.O45 \\
\hline $20-25$ & I6II83 & I87793 & 0.0306 & 6497 & 869900 & I96684 & 898698 & I.O3I \\
\hline $25-30$ & I 34750 & I55964 & 0.0292 & $6+69$ & 724847 & I62795 & $744^{282}$ & I. .030 \\
\hline $30-35$ & IogI6I & I29527 & 0.0342 & 6108 & 594544 & I349I8 & 607537 & I.O25 \\
\hline $35-40$ & 99646 & 103832 & 0.0082 & 6146 & 508587 & I08097 & 514537 & I.OI7 \\
\hline $40-45$ & IOI433 & 96185 & -0.0106 & 6636 & 493871 & 97718 & 484883 & 0.997 \\
\hline $45-50$ & 86385 & 95784 & 0.0207 & 6880 & $4548 \mathrm{I} 6$ & 96235 & $44 \mathrm{I} 233$ & 0.976 \\
\hline $50-55$ & 72243 & 80004 & 0.0204 & 7396 & 380123 & $8025^{8}$ & 364256 & 0.965 \\
\hline $55-60$ & 52702 & 65370 & $0.043 \mathrm{I}$ & 7419 & 293476 & 65444 & 278862 & 0.955 \\
\hline $60-65$ & 36657 & 44858 & 0.0404 & 7235 & 202754 & 46100 & 192183 & 0.949 \\
\hline $65-70$ & 30200 & 29100 & -0.0074 & 7690 & I48224 & $3 \mathrm{II} 32$ & I399I4 & 0.946 \\
\hline $70-75$ & I9380 & 21938 & 0.0248 & 7595 & I03097 & 24475 & 96828 & 0.942 \\
\hline $75-80$ & 10602 & II983 & 0.0245 & 6226 & 56357 & I 4483 & 52661 & 0.938 \\
\hline $80+$ & 5773 & 6836 & 0.0338 & $58 \mathrm{I} 3$ & 3I4IO & 6957 & 32008 & - \\
\hline
\end{tabular}

$\uparrow$ For calculation purposes, E(80) is assumed equal to 5.456

† Based on median completeness of .997 
Table io. Estimated Completeness of Death Registration (Taiwanese Females, 1930-1935) के

\begin{tabular}{|c|c|c|c|c|c|c|c|c|}
\hline \multirow{3}{*}{$\begin{array}{l}\text { Age } \\
\text { group }\end{array}$} & \multirow{2}{*}{$\begin{array}{l}\text { (I) } \\
P_{1}\end{array}$} & (2) & \multirow[t]{2}{*}{ (3) } & \multirow[t]{2}{*}{ (4) } & \multirow[t]{2}{*}{ (5) } & \multirow[t]{2}{*}{ (6) } & \multirow[t]{2}{*}{ (7) } & \multirow{2}{*}{$\begin{array}{l}\text { (8) } \\
{ }_{10} \hat{N}_{a-5}\end{array}$} \\
\hline & & $P_{2}$ & & & & & & \\
\hline & Oct. I930 & Oct. I935 & ${ }_{5} r_{a}$ & ${ }_{5} D_{a}$ & ${ }_{5} N_{a}$ & $\hat{N}_{a}$ & ${ }_{5} \hat{N}_{a}$ & $\overline{{ }_{10} N_{a-5}}$ \\
\hline $0-5$ & 364965 & 425469 & 0.0307 & I23 885 & I970287 & 514707 & 2103701 & 一 \\
\hline 5-10 & 274307 & 332517 & 0.0385 & 7050 & 1510064 & 326774 & I 474849 & I.O28 \\
\hline IO-I5 & 228248 & 269428 & 0.0332 & 3285 & I239923 & 263166 & I2077I3 & 0.975 \\
\hline $15-20$ & 224603 & 223935 & -0.0006 & 4910 & II2I344 & 219919 & I088944 & 0.973 \\
\hline $20-25$ & I87793 & 217446 & 0.0293 & 6265 & IOIO382 & 215658 & 990212 & 0.975 \\
\hline $25-30$ & 155964 & I8I394 & 0.0302 & 5949 & 840995 & I80427 & 825107 & $0.98 \mathrm{I}$ \\
\hline $30-35$ & I29527 & I49755 & 0.0290 & 6045 & 696371 & 149616 & 683503 & $0.98 \mathrm{I}$ \\
\hline $35-40$ & I03832 & I23III & $0.034 \mathrm{I}$ & 5852 & 565316 & I23785 & 557019 & 0.983 \\
\hline $40-45$ & 96185 & 97763 & 0.0033 & 5619 & 484854 & 99023 & 477184 & 0.985 \\
\hline $45-50$ & 95784 & 89923 & -0.0126 & 6I2I & 464036 & $9185 \mathrm{I}$ & 458428 & 0.986 \\
\hline $50-55$ & 80004 & $8849^{8}$ & 0.0202 & 7402 & 420719 & 91520 & 418047 & 0.991 \\
\hline $55-60$ & 65370 & 72392 & 0.0204 & 8269 & 343957 & 75698 & $34049 \mathrm{I}$ & 0.992 \\
\hline $60-65$ & 44858 & $5^{6} 574$ & 0.0464 & 8136 & 251883 & 60498 & $25156 \mathrm{I}$ & 0.994 \\
\hline $65-70$ & 29100 & 36506 & 0.0453 & 7727 & 162967 & 40725 & $\mathrm{I} 64455$ & I.003 \\
\hline $70-75$ & 21938 & 21487 & -0.0042 & 8040 & 108557 & 25564 & I09393 & I.०09 \\
\hline $75-80$ & IIg83 & I3754 & 0.0276 & 7196 & 64190 & I7977 & 66247 & I.OI7 \\
\hline $80+$ & 6836 & 8192 & 0.0362 & $735^{\circ}$ & 37417 & 8945 & 40917 & - \\
\hline
\end{tabular}

$\dagger$ For calculation purposes, E(80) is assumed equal to $5.58 \mathrm{I}$

$†$ Based on median completeness of .986 



\section{References}


Aaby, P. I991. "Lessons for the past: Third World evidence and the reinterpretation of developed world mortality decline". Paper presented at the Annual Conference of the British Society for Population Studies on Historical Epidemiology and the Health Transition, University of Southampton, Southampton, IIth-I3th September.

Abraham-Van der Mark, E. (ed.) I993. Successful home birth and midwifery: the Dutch model. Westport: Bergin\&Garvey

Anderson, M. I988. Population Change in North-Western Europe, 17501850. London: MacMillan.

Appendix, Taiwan jinkō dōtai tōkei 臺灣人口動態統計, I906, Appendix: Classification of causes of death indexed to disease names (Siwang yuanyin leibie bingming suoyin 死亡原因類別病名索引).

Arriaga, E.E. I984. "Measuring and explaining the change in life expectancies”. Demography. 2I (I): 83-96.

Atkins, P.J. 2003. "Mother's Milk and Infant Death in Britain, circa I900-I940". Anthropology of Food 2 (September).

Baelz, Erwin (Dokutoru Berutsu). I886. "Nippon jinsho kairyōron (On the improvement of Japanese race)." Dainipon shiritsu eiseikai zasshi (Journal of the Japanese Private Society of Hygiene) no.43: 3-26.

Ballot, A.M. I87I. "Overzicht van de epidemieën van pokken, roodvonk en mazelen van I778-I8II en van I8I5-I870”. Nederlandsch Tijdschrift voor Geneeskunde. I, I87I: 309-3I4.

Barclay, George. W. I954. Colonial Development and Population in Taiwan. Princeton, New Jersey: Princeton University Press.

Barclay, George W. I958. Techniques of Population Analysis. New York: John Wiley \& Sons, Inc.

Benedict, Carol. 1996. Bubonic Plague in Nineteenth Century China. Stanford: Stanford University Press.

Benenson, Abram S. I982. "Smallpox", in: Evans, A.S. (ed.), Viral Infections of Humans. Epidemiology and Control, second edition, pp. 54I-568. New York-London: Plenum.

Bennett, Neil G., and Shiro Horiuchi. I98I. "Estimating the Completeness of Death Registration in a Closed Population." Population Index, 47(2): 207-221.

Bennett, Neil G., and Shiro Horiuchi. I984. "Mortality Estimation from Registered Deaths in Less Developed Countries." Demography, 2I(2):2I7-233.

Bieleman, Jan. I992. Geschiedenis van de landbouw in Nederland 15001950. Meppel: Boom.

Binneveld, Hans and Rudolf Dekker eds. I993. Curing and insuring. Essays on illness in past times: The Netherlands, Belgium, England and Italy, 16th2oth centuries. Hilversum: Verloren. 
Biraben, J.-N. I973. “Aspects médicaux et biologiques de la démographie historique," Démographie historique. Bulletin d'information 3: 25-33.

Boonstra, O.W.A. I993. De waardij van eene vroege opleiding. Een onderzoek naar de implicaties van het analfabetisme op het leven van inwoners van Eindhoven en omliggende gemeenten, 1800-1920. Wageningen: A.A.G. Bijdragen 34.

Borg, H.A. van der. I992. Vroedvrouwen: beeld en beroep. Ontwikkelingen in het vroedvrouwschap in Leiden, Arnhem, 's-Hertogenbosch en Leeuwarden, 16501865. Wageningen: Academic press.

Bouvier-Colle, M.H. et al. I991. "Reasons for the underreporting of maternal mortality in France, as indicated by a survey of all deaths among women of childbearing age." International Journal of Epidemiology 20.7: I7-21.

Bowers, John. I980. When the Twain Meet: The Rise of Western Medicine in Japan. Baltimore, MD: Johns Hopkins University Press.

Boyce, Rubert W. I909. Mosqutio or man? The Conquest of the Tropical World. London: John Murray.

Breschi, Marco and Massimo Livi Bacci. I997. "Month of Birth as a Factor in Children's Survival.” In: Alain Bideau, Bertrand Desjardins, and Héctor PérezBrignoli (eds.), Infant and child mortality in the past. Oxford [England]: Clarendon Press; New York: Oxford University Press. Pp. I57-I73.

Campbell, Cameron. I995. "Chinese Mortality Transitions: the Case of Beijing, I700-I990.” Ph.D. Diss. University of Pennsylvania.

Cappers, Wim. I993. "Money and medals for saving the drowned. The financial factor in Dutch discourse on apparent death during the second half of the eighteenth century." In: Binneveld, Hans and Rudolf Dekker (eds.). Curing and insuring. Essays on illness in past times: The Netherlands, Belgium, England and Italy, 16th-2oth centuries. Hilversum: Verloren. Pp. 82-94.

Caselli, G. I991. "Health transition and cause-specific mortality." In The decline of mortality in Europe, R. Schofield, D. Reher and A. Bideau eds., pp. 6896. Oxford: Clarendon Press.

CBS I9OI-I920. Statistiek van de sterfte naar den leeftijd en naar de oorzaken van den dood over het jaar... Den Haag: Belinfante.

Census of I905, kekka hyo. Rinji Taiwan kokō chōsa, kekka hyō, Meiji 38nen 臨時台灣戶口調查, 結果表, 明治38年 (Results of provisional household census, I905). Rinji Taiwan kokō chōsa-bu.

Census of I9I5, kekka hyo. Dai-niji rinji Taiwan kokō chōsa, kekka hyō, Taisho yo'nen 第二次臨時台灣戶口調查 結果表 大正4年 (Results of second provisional household census, I9I5). Taiwan sōtoku kambō rinji kokō chōsa-bu.

Census of I920, Dai-ikkai Taiwan kokusei chōsa, shukei gempyō, zentō no $b u$, Taisho ku'nen. 第一會台灣國勢調查, 集計原表, 全島/部, 大正九年 (first census of Taiwan, detailed tables, entire island, I920). Taiwan sōtoku kambō rinji kokō chōsa-bu. 
Census of I920, Dai-ikkai Taiwan kokusei chōsa, yōran hyō 第一會台灣國勢 調查, 要覽表, 大正九年 (First census of Taiwan, summary tables, I920). Taiwan sōtoku kambō, rinji kokusei chōsa-bu.

Chemouilli, Philip. 2004. "The cholera epidemic and the development of public health in Meiji Japan," Medical Science 20:I: Io9-II4.

Chen, C.H., Tao, J.C. et al. I96r. Epidemiology of Tuberculosis in Taiwan. Taipei: Provincial Taipei Tuberculosis Control Center.

Chen Cheng-siang. I995. Geo-Essays on Taiwan. Taipei: smc Publishing.

Chen, Lincoln C., Melita C. Gesche, Shamsa Ahmed, A. I. Chowdhury, W. H. Mosley. I974. "Maternal Mortality in Rural Bangladesh”. Studies in Family Planning. 5: II: 334-34I.

Chen Shao-hsing. I955a. "Population Growth and Social Change in Taiwan." (Part One). Bulletin of the Department of Archaeology and Anthropology, National Taiwan University, No. 5, May, I955: 76-103.

Chen Shao-hsing. I955b. "Population Change in Taiwan." Bulletin of the Department of Archaeology and Anthropology, National Taiwan University, No. 6, Nov., I955: 86-II9. (second part of "Population Growth and Social Change in Taiwan").

Chen, Shao-xing (陳紹馨). I979. Taiwan di renkou bianqian yu shehui bianqian (Taiwan's population change and social change, 臺灣的人口變遷與社會變遷). Taipei: Lianjing (Reprints I985, I997).

Chen Yungxin. I997. Taiwan iliao fazhanshi (The history of medical development in Taiwan). Taipei: Yuedan.

Chiao, C. M., Warren Thompson, D.T. Chen. 1938. An Experiment in the Registration of Vital Statistics. Oxford, Ohio: Scripps Foundation for Research in Population Problems.

Children's Bureau, U.S. Department of Labor. I934. Maternal Mortality in Fifteen States. Bureau Publication No. 223. Washington, D.C.: Government Printing Office.

Chuang Ying-chang. I994. Chia tsu yü Hun yin: T'ai-wan pei pu liang ke Min K'e ts'un lo chih yen chiu (Family and marriage: Hoklo and Hakka villages in North Taiwan). Taipei: Academia Sinica, Institute of Ethnology.

Chuang Ying-chang, Theo Engelen \& Arthur P. Wolf (eds.). 2006. Positive or Preventive? Reproduction in Taiwan and the Netherlands, 1850-1940. Amsterdam: Aksant.

Commissie voor de Statistiek. I828. Staat der overledenen volgens den ouderdom gedurende het jaar 1827 in het Koningrijk der Nederlanden. Etat des décès par âge, qui ont eu lieu dans le courant de 1827 dans le Royaume des Pays-Bas. s.l. s.a.

Commissie voor de Statistiek. I829. Lijsten der overledenen volgens ouderdom over het jaar 1828 Etats des décès par âge qui ont eu lieu dans le courant de 1828 , s.l. s.a.. 
Comstock, George W. I975. "Frost Revisited: The Modern Epidemiology of Tuberculosis." American Journal of Epidemiology гог: 363-382.

Conde-Agudelo, Augustin et al. 2006. "Birth Spacing and risk of adverse perinatal outcomes”. Journal of the American Medical Association 295: I809-1823.

The Conferees. "The Relationship of Nutrition, Disease, and Social Conditions: A Graphical Presentation.” I985. In Hunger and History, Robert Rotberg and T. R. Rabb, eds., pp. 305-308. Cambridge U.P.

Corsini, C.A. and P.P. Viazzo. I997. The decline of infant and child mortality. The Hague: Martinus Nijhoff Publishers.

Cortazzi, Hugh. 1985. Dr. Willis in Japan, 1862-1877: British Medical Pioneer. London: Athlone Press.

Craig, J. I998. “To be or not to be- what are the odds?” Population trends. 92 (Summer): 42-50.

Cronje, G. 1984. “Tuberculosis and Mortality Decline in England and Wales I85I-I9ıо." In Urban Disease and Mortality in Nineteenth Century England, R.I. Woods and J. Woodward, eds., pp. 79-Ior. London.

DeGlopper, Donald. I995. Lukang. Commerce and community in a Chinese city. Albany: State University of New York Press.

Del Panta, Lorenzo. I980. Le epidemie nella storia demografica italiana, Torino: Loescher.

Department of Health, ed. I991. Malaria Eradication in Taiwan. Taipei: Department of Health.

De Sweemer, Cecile. I984. “The influence of child spacing on child survival," Population Studies 38: 47-72.

Devos, Isabelle. 2000. “Te jong om te sterven. De levenskansen van meisjes in België omstreeks ı9oo." Tijdschrift voor Sociale Geschiedenis 26: 55-77.

Drogendijk, A.C. I936. "Het dagboek van vrouw Waltman. Vroedvrouw in de ige eeuw te Dordrecht." Bijdragen tot de Geschiedenis der Geneeskunde i6: 33-40.

Du Congming ed. I957. Takagi Tomoe sensei tsuiokushi (The collection to remember Takagi Tomoe). Tokyo: Takagi Tomoe kinenji iinkai.

Dupâquier, J. I979. La population rurale du Bassin Parisien à l'époque de Louis XIV. Paris-Lille I979; reprint Lille ı982.

Ellison, P.T. 200I. On Fertile Ground. A Natural History of Human Reproduction. Cambridge/London: Harvard University Press.

Emmett Holt, L. I9I3. "Infant Mortality, Ancient and Modern, An Historical Sketch.” Archives of Pediatrics 30: 885-915. See: http://www.neonatology.org/classics/holt.html.

Engelen, Theo. 2005. "Leven en dood onder controle. De bevolking in de negentiende en twintigste eeuw." In: Nijmegen. Geschiedenis van de oudste stad van Nederland, 3 Negentiende en twintigste eeuw. Nijmegen: Inmerc. Pp. 32-5I. 
Engelen, Theo. 2009. Van 2 naar 16 miljoen mensen. Demografie van Nederland, 1800-nu. Amsterdam: Boom.

Engelen, Theo and Arthur P. Wolf (eds.). 2005. Marriage and the Family in Eurasia. Perspectives on the Hajnal Hypothesis (Volume I of Life at the Extremes. The demography of Europe and Asia, edited by Chuang Ying-Chang, Theo Engelen and Arthur P. Wolf). Amsterdam: Aksant.

Engelen, Theo and Hsieh Ying-hui. 2007. Two Cities, One Life. Marriage and fertility in Lugang and Nijmegen (Life at the Extremes 3). Amsterdam: Aksant.

Fann Yann Chiou. 1994. Public Hygiene in colonial Taiwan (日據前期台湾 之公共衛生一以防疫為中心之研究), Taipei: Ph.D. dissertation of division of history, National Taiwan Normal University.

Fann Yann Chiou. 1996. "Medicine and Colonial Expansion: Taiwan's Malaria Research under Japanese Rule.” New History. 7-3:I33-I73.

Fan, Yenqiu. 2005. Yibing, Yixue yu Zhiming Xiandaixing (Epidemics, Medicine and Colonial Modernity). Taipei: Daoxiang.

Fenner, F. I989. Smallpox and its Eradication, Geneva: wно.

Flinn, Michael W. 198I. The European Demographic System, 1500-1820. Baltimore : John Hopkins University Press.

Fruhstuck, Sabine. 2003. Colonizing Sex: Sexology and Sex Control in Modern Japan. Berkeley: University of California Press.

$\mathrm{Fu}$, Dawei 傅大為. 2005. "Yaxiya de Xin Shenti: Xingbie, Yiliao yu Jindai Taiwan” 亞細亞的新身體 : 性別、醫療與近代台灣 (Assembling the New body: Gender/ Sexuality, Medicine, and Modern Taiwan). Taipei: Socio Publishing.

Fubo no nenreibetsu shussei oyobi shisan tokei. (Statistics of live births and stillbirths by age of parents). I94I, I942. Two volumes. Taiwan Sōtokufu Sōmukyoku. Taihoku.

Gales, B.P.A. et al. I995. Het Burgerlijk Armbestuur. Maastricht.

Garrett, E., Reid, A., Schurer, K. and Szreter, S. 2001. Changing family size in England and Wales. Place, class and demography, 1891-1911. Cambridge: Cambridge University Press.

Gates, Hill, Jan Kok and Siping Wang. 2006. "Burden or Opportunity? Illegitimate births in the Netherlands and Taiwan." In Positive or Preventive? Reproduction in Taiwan and the Netherlands, 1850-1940, Chuang Ying-chang, Theo Engelen, and Arthur P. Wolf, eds. Pp. 8I-I04. Amsterdam: Aksant Academic Publishers

Geneeskundig Staatstoezicht I876-1901. Verslag aan de Koning (KoninginWeduwe/Regentes/Koningin) van de Bevindingen en Handelingen van het Geneeskundig Staatstoezicht. Den Haag: Belinfante.

Gilles, H.M., J.B. Lawson, M. Sibelas, A. Voller, and N. Allan. I969. "Malaria, anemia, and pregnancy." Annals of Tropical Medicine and Parasitology 63.2: 245-263. 
Goldman, Noreen. I980. “Far Eastern Patterns of Mortality.” Population Studies 34.I: 5-I9.

Gould-Martin, K. I976. Women asking women: an ethnography of health care in rural Taiwan. Ph.D. dissertation, Rutgers University.

Government-General of Taiwan. I9ı2. Statistical Summary of Taiwan. Tokyo: The Japan Times Press.

Graham W., W. Brass, R.W. Snow. I989. "Indirect estimation of maternal mortality: the sisterhood method." Studies in Family Planning. 20: 125-35

Granger, Joey P. et al. 200ı. "Pathophysiology of hypertension during preeclampsia linking placental ischaemia with endothelial dysfunction." Hypertension 38: 718-722.

Guo, Wenhua and Ye Lin. I995. "Yixue yu jenwen lishi de jiaohui - fang Zhuang Yunmin tan Taiwan yixueshi (The interaction between medicine and humanity - interview with Zhuang Yunmin on Taiwan's medical history)." Yiwang (Hope) 8: 19-23.

Hajnal, John. I965. "European Marriage Patterns in Perspective”. In Population in History, eds. D.V. Glass and D.E.C. Eversley, pp. IOI-I43. London: Arnold.

Harrell, Stevan. I995. "Introduction: Microdemography and the Modeling of Population Process in Late Imperial China.” In Chinese Historical Microdemography, Stevan Harrell, ed., pp. I-2o. Berkeley: University of California Press.

Hatori Shigerō. I9ıI. “The consequence of anti-malaria measures in Beitou (北投におけるマラリア撲滅法實施の效果).” Journal of the Formosan Medical Association 100:204-221.

Heederik, G.J. I973. Van kasboekregister tot burgerlijke stand. Medischdemografische aspecten van de registratie van huwelijken, geboorte, sterfte. Meppel: Boom.

Heijden, C. van der. I989. "Gezin en huishouding in Oost-Brabant I850I900.” In: G.J.M. van den Brink, A.M.D. van der Veen, and A.M. van der Woude (eds.), Werk, kerk en bed in Brabant. Demografische ontwikkelingen in oostelijk Noord-Brabant 1700-1920. 's-Hertogenbosch: Stichting BRG. Pp. I3I-I43.

Heijden, C.G.W.P., van der. I995. Het heeft niet willen groeien. Zuigelingen- en kindersterfte in Tilburg, 1820-1930. Tilburg: Zuidelijk Historisch Contact.

Henry, Louis. I96r. “Some Data on Natural Fertility.” Eugenics Quarterly 8: 8I-9I.

Hieu, Do Trong, Robert Hanenberg, Trinh Huu Vach, Dao Quang Vinh, David Sokal. I999. "Maternal Mortality in Vietnam in I994-95." Studies in Family Planning 30 (4) (Dec.): 329-338.

Hino, Shuitsu. ı988. “Gotō Shinpei 'kokka eisei genri' shiriron no sen- 
384 gen (Gotō Shinpei's kokka eisei genri: a declaration of self-interest thought)." Nihon ishigakushi zasshi (Journal of the Japan Society of Medical History) 34:I: 79-8I.

Hirakawa, Sukehirō. I968. "Changing Japanese Attitudes toward Western Learning: Dr. Erwin Baelz and Mori Ogai.” Contemporary Japan 29: I38-I57.

Historical Sample of the Netherlands (HSN). Dataset Lifecourses, release 2007.01.

Hofstee, E.W. (1978). De demografische ontwikkeling van Nederland in de eerste helft van de negentiende eeuw. Een historisch-demografische en sociologische studie. Deventer: Van Loghum Slaterus.

Hofstee, E.W. I981. Korte demografische geschiedenis van Nederland van 1800 tot heden. Haarlem: Fibula/Van Dishoeck.

Hoogerhuis, Otto W. 2003. Baren op Beveland. Vruchtbaarheid en zuigelingensterfte in Goes en omliggende dorpen gedurende de 1gde eeuw. Wageningen: AAGBijdragen.

Hopkins, D.R. 1983. Princes and Peasants. Smallpox in History. ChicagoLondon: University of Chicago Press.

Horiuchi Tsugio. 1913. "Prevention and treatment of malaria (麻拉里亞豫 防撲滅法及治療法).” Ni’shin Igaku. 3:I:205.

Horiuchi Tsugio. I926. "Bankin Taiwan niokeru eisei jōtai gyakuten no genin oyobi sono kyūchisaku (輓近台湾に於ける衛生状態逆転の原因及其の救治策).” Taiwan Jiho, July.

Horiuchi Takao. I903. "Soeki sōkishin danhō." Taiwan igaku zasshi no.8:I9-2I.

Houwaart, E.S., I991. De hygiënisten. Artsen, staat en volksgezondheid in Nederland 1840-1890. Groningen: Historische Uitgeverij.

Houwaart, Eddy. I993. "Medical statistics and sanitary provisions. A new world of social relations and threats to health." Tractrix 5: 8I-II9.

Houwaart, E.S. I993. "Medische statistiek." In: H.W. Lintsen et al. (eds.). Geschiedenis van de techniek in Nederland. De wording van een moderne samenleving 1800-1890. vol. II: I9-45. Zutphen: Walburg Pers.

Hu Jian-wei. I776. Penghu ji lue (The brief history of Penghu).

Human Mortality Database. University of California, Berkeley (USA), and Max Planck Institute for Demographic Research (Germany). Available at www.mortality.org (data downloaded on December I2, 2006).

Hung, You-Chi and Li-Hsin Chen 洪有錫、陳麗新. 2002. Xianshengma, Chanpo yu Fuchanke Yishi 先生媽、產婆與婦產科醫師 (Xianshengma, midwives, and obstetrician-gynecologists). Taipei: Chien Wei.

Iijima, Wataru. 2003. "SARS and Chinese society," South China Research Resource Station Newsletter no. 32: I-I6. 
Iijima Wataru, Wakimura Kōhei. 200I. "Eisei to Teikoku- nichiei shokuminchi shugi no hikakushiteki kōsahe mukete(衛生と帝國一日英植民地主 義の比較史的考察へ向けて)." Journal of Japanese history. 462: 3-25.

Iijima Wataru, Wakimura Kōhei. 200I. "Kindai ajia niokeru teikoku shugi to iryo, kōshu eisei (近代アジアにおける帝国主義と医療・公衆衛生).” In Development, disease, and imperial medicine : the social history of medicine in the Asian context, ed. Miichi Masatosi, Saito Osamu, Wakimura Kōhei and Iijima Wataru, pp.75-94. Tokyo: Tokyo University Press.

Imhof, A.E. I983. "Man and body in the history of the modern age." Medical History 27: 394-406.

Imhof, A.E. I984. Die verlorenen Welten. Alltagsbewältigung durch unsere Vorfahren und weshalb wir uns heute so schwer damit tun. München: Beck.

Imhoff, A. 1990. Levenserwartungen in Deutschland vom 17. bis 19. Jahrhundert. Weinheim: Acta Humaniora.

Ino Kanori. I928 [I99I]. Taiwan wenhua zhi 台灣文化志 (The record of Taiwan's culture), Volume 2. Taichung: Taiwan Province Archives.

Ishigi Yoshifu ed. 1956. Horiuchi Takao boshi zhuidaozhi, Nanmin huazhi (special issue) no. II.

Ishii, Takeo. I957. "Maruyama Yoshito bokushi no jinyô de Taiwan no iryoshi hakase ate no shokan o note (Reading after Dr. Maruyama Yoshitō's recent achievement about Taiwan's medical and hygienic history)." Tokyo ishi shinji (Tokyo new medical magazine) 74:II: 44.

Itazawa Shyōgokō. I925. Tennentō ni kansuru kenkyu (Studies on Smallpox). Tokyo: Tobōdō.

Jannetta, Ann B. and Samuel H. Preston. I99I. "Two centuries of mortality change in central Japan: The evidence from a temple death register." Population Studies 45: 4I7-I36.

Japenga, Caren and Henk van der Velden. I993. "Access to curative health care: sickness funds versus medical relief in the Netherlands (I850I94I)." In: Binneveld, Hans and Rudolf Dekker eds. Curing and insuring. Essays on illness in past times: The Netherlands, Belgium, England and Italy, 16th-2oth centuries, pp. I69-188. Hilversum: Verloren.

Jiang Yong. I892. Penghu xupian (The continuous compilation of the history of Penghu).

Johnston, William. 1995. The modern epidemic: a history of tuberculosis in Japan. Cambridge, Mass.: Council on East Asian Studies, Harvard University.

Johansson, S.R. 2000. "Macro and micro perspectives on mortality history." Historical methods 33: 59-72.

Johansson S.R. and Alice B. Kasakoff. 2000. "Mortality history and the misleading mean." Historical methods 33: 56-58. 
Jonkers, E.J. 1903. Beschouwingen over de oorzaken der groote kindersterfte en de middelen, die tot verbetering daarvan kunnen leiden (meer speciaal in het eerste levensjaar). Groningen.

Katz, Paul. 1995. Demon Hordes and Burning Boats Albany. State University of New York Press.

Keene, Donald. 1969. The Japanese Discovery of Europe, 1720-1830. Stanford, California: Stanford University Press.

Kekkaku yobōhō 結核預防法 (Tuberculosis prevention law); Kekkaku yobōhō shikō kisoku 結核預防法施行規則 (Tuberculosis prevention regulations). 1938. Taiwan Igakkai Zasshi 臺灣醫學會雜誌 (Journal of the Formosan Medical Association) 37.396: pp. 629-32.

Klasen, S. I998. "Marriage, bargaining, and intrahousehold resource allocation: excess female mortality among adults during early German development, I740-1860." Journal of Economic History 58: 432-467.

Kleinman, Arthur. I980. Patients and Healers in the Context of Culture. Berkeley: University of California Press.

Klep, P.M.M. et al. (ed.). 1987. Wonen in het verleden: 17 e en 200 eeuw: economie, politiek, volkshuisvesting, cultuur en bibliografie. Amsterdam: Aksant.

Klep, Paul M.M. 2005. "De economische en sociale geschiedenis van de negentiende eeuw." In: Nijmegen. Geschiedenis van de oudste stad van Nederland, 3 Negentiende en twintigste eeuw. Pp. 52-I33. Nijmegen: Inmerc.

Kloek, Joost and Wijnand Mijnhardt. 200I. 1800: Blauwdrukken van een samenleving. Nederlandse cultuur in Europese context II. Den Haag: sDU Uitgevers.

Knodel, John E. I988. Demographic behavior in the past. A study of fourteen German village populations in the eighteenth and nineteenth centuries. Cambridge: Cambridge University Press.

Knotter, A. and A.C. Meijer (red.). I995. De gemeentelijke bevolkingsregisters 1850-1920. Den Haag: ING.

Koenig, Michael A., Vincent Fauveau, A.I. Chowdhury, J. Chakrborty, M.A. Khan. I988. "Maternal Mortality in Matlab, Bangladesh: I976-1985." Studies in Family Planning 19.2: 69-80.

Koizumi Tan. I920. "Taiwan niokeru kazoku no yobō igakutei kenkyū." Taipei: Kobunkan.

Koizumi Tan. 1928. “Taiwan niokeru mararia bōatsu sagyō ni kansuru shiken narabini teian (台湾二於ケルマラリア防遏作業二関スル私見並二提案一麻 刺利亞」ノ流行学及防遏二関スル研究竝私見第六).” Journal of the Formosan Medical Association 275:3.

Koizumi Tan. I929. "Mararia no ryūkogaku oyobi bōatsu sagyō (麻刺利亞ノ流行学及防遏作業).” Nishin Igaku 6:II5.

Kok, J. I991. Langs verboden wegen. De achtergronden van buitenechtelijke geboorten in Noord-Holland 1812-1914. Hilversum: Verloren. 
Kok, Jan. 2006. "Sources for the historical demography of the

Netherlands in the I9th and early 2oth centuries." Pp 4I-5I in: Y.-C. Chuang, T. Engelen and A.P. Wolf (eds), Positive or preventive? Reproduction in Taiwan and the Netherlands, 1850-1950. Amsterdam: Aksant.

Korst, J.K. van der. I988. Om lijf \& leden. Gezondheidszorg en geneeskunst in Nederland circa 1200-1960. Utrecht-Antwerpen: Bohn. Scheltema en Holkema.

Kramer, R. I916. Het vaccinatie-probleem, Kampen: Kok.

Ku Ya-wen. 2005. "A historical View of Malaria and its countermeasures in Taiwan." Ph. D. Diss. Yokohama University.

Ku Ya-wen. 2010. "Anti-malaria Policy in Colonial Taiwan" (this volume).

Landers, J. 1987. "Mortality and metropolis: the case of London I675I825." Population Studies 4I: 59-76.

Landers, J. 1990. "Age patterns of Mortality in London during the "Long Eighteenth Century: a test of the "High Potential" model of metropolitan mortality." Social History of Medicine 3: 27-60.

Lavely, William and R. Bin Wong. 1998. "Revising the Malthusian Narrative: The Comparative Study of Population Dynamics in Late Imperial China." Journal of Asian Studies 57.3: (August): 714-748.

Lee, Cheng-yi 李政益. 200I. Jibing, wenhua yu shehui bianqian, - you jiehebing liuxing guandian tanjiu erci shijie dazhan qianhou de Taiwan shehui 疾病,文化與社會變遷 一由結核病流行觀點探究二次世界大戰前後的台灣社會 (Disease, culture and social transition - delving into Taiwan society before and after world war II viewed from the epidemiology of tuberculosis). M.A. thesis, Taipei Medical University 台北醫學大學醫學研究 碩士 論文.

Lee, J., and Campbell, C. 1997. Fate and Fortune in Rural China: Social Organization and Population Behavior in Liaoning, 1774-1873. Cambridge: Cambridge University Press.

Lee, J. and Wang, F. I999. One Quarter of Humanity. Malthusian Mythology and Chinese Realities, 1700-2000. Cambridge: Harvard University Press.

Leeuwen, Marco van. 1992. Bijstand in Amsterdam ca. 1800-1850. Armenzorg als beheersings- en overlevingsstrategie. Zwolle: Waanders.

Li Denghui. I980. Taiwan nongye fazhan de jingji fenxi (The economic analysis of agricultural development in Taiwan). Taipei: Lianjin.

Lieburg, M.J. van, H. Marland. I989. "Midwife regulation, education, and practice in The Netherlands during the nineteenth century." Medical History 33 (3) (July): 296-3I7.

Li Shao-zhang. I960. Penghu xian zhi (The history of Penghu prefecture), Vol. I. Penghu: Penghu Government.

Li T’eng-yueh 李騰啍 (Ri Togaku). I938a. Taiwan hontōjin shibōritsu 
oyobi shibō genin no tōkeiteki kansatsu 台灣本島人死亡率及死亡原因 ノ統計的觀 察 (Statistical Observations on the Mortality Rates and the Causes of Death among the Formosans). 3 parts. Taiwan Igakkai Zasshi 台灣醫學會雜誌 (Journal of the Formosan Medical Association) Volume 37: First Report, pp. 580-6io. Second Report, pp. 6II-628. Second Report, continued, pp. 702-720.

Li T’eng-yueh 李騰嶽 (Ri Togaku). I938b. Taiwan zaiju naichijin no shibōritsu oyobi shibōgenin no tōkeiteki kansatsu 台灣在住內地人/死亡率及死 亡原因 /統計的觀察 (Statistical Observations on the Mortality Rates and the Causes of Death among the Japanese Population in Formosa). 3 parts. Taiwan Igakkai Zasshi 台灣醫學會雜誌 (Journal of the Formosan Medical Association). Volume 37: First Report, pp. I042-I06I. Second Report, pp. I062-I075. Second Report, continued, pp. II34-II53.

Li T’eng-yueh 李騰獄 (Ri Togaku). I938c. Taiwan ni okeru shōni shibōritsu oyobi ni, san shōni shibōgenin no tokeiteki kansatsu 台灣二於ケル小兒死亡 率及二三小兒死亡原因 /統計的觀察 (Statistical Observations on the Mortality Rates and some of the Causes of Death among the Children in Formosa). Taiwan Igakkai Zasshi (台灣醫學會雜誌) (Journal of the Formosan Medical Association) Volume 37: pp. I425-I450.

Li T'eng-yueh 李騰偝 (Ri Togaku). I938d. Taiwan ni okeru nyuyōji shibōritsu oyobi shibōgenin no tōkeiteki kansatsu, kotoni nyuji shibōgenin no nichirei getsurei betsu ni tsuite 台灣二於ケル乳幼兒 死亡率及死亡原因 /統計的 觀察, 殊二乳兒死亡原因/日齢月齢別二就テ (Statistical Observations on the Mortality Rates and the Causes of Death among Infants and Young Children in Formosa, especially on the Causes of Death among Infants According to Days and Months after Birth). 2 parts. Taiwan Igakkai Zasshi 台灣醫學會雜誌 (Journal of the Formosan Medical Association) Volume 37: I45I-I466, continued:I607I62I.

Lin Hao. I893. Penghu ting zhi (Gazetteer of Penghu Ting).

Lin Jichong ed. I997. Taida yiyuan bainianshi (I) Rizhishiqi (1897-1945) (The Hundred-Year History of the Medical School of National Taiwan University: The Japanese-Occupied Period, I897-45). Taipei: National Taiwan University Medical College.

Lin, Pei-xin (林佩欣). 2006a. Ping jie Sato Masahiro's 'Kokusei chosa to Nihon kindai' (Review of Masahiro Sato's 'National census and modern Japan', 評介佐藤正広 國勢調查と日本近代). Taiwan Shida lishi xuebao (臺灣師大歷史學報), 35: 279-294.

Lin, Pei-xin (林佩欣). 2006b. Mizushina Shichisaburo yu diyici linshi Taiwan hukou diaocha zhi shishi (Shichisaburo Mizushina and the implementation of the first provisional census of Taiwan, 水科七三郎與第一次臨時台灣戶口 調查之實施. Paper presented at the International Conference of “Riju shiqi Taiwan di wenhua yu shehui yundong, I92I-1936 (The culture of Japanese peri- 
od Taiwan and social movements, I92I-1936, 日據時期台灣的文化與社會運動, I92I-I936).” Taipei, Taiwan. (October 28-29).

Liu Ts'ui-jung and Liu Shi-yung. I998. "Disease and Mortality in the History of Taiwan," in Taiwanshi yenjiu (Taiwan Historical Research) 4:2: 90-132.

Liu, Ts'ui-jung, James Lee, David Sven Reher, Osamu Saito, and Wang Fang eds. 200I. Asian Population History. Oxford: Oxford University Press.

Liu Ts'ui-jung. 1985. "The Demography of Two Chinese Clans in Hsiaoshan, Chekiang, I650-I850." In Hanley, Susan and A.P. Wolf, eds., Family and Population in East Asian History, pp. I3-6r. Stanford: Stanford University Press.

Loudon, Irvine, 1992. Death in Childbirth, an international study of maternal care and maternal mortality, 1800-1950. Oxford: Clarendon Press.

Lunn, Peter. I99I. "Nutrition, Immunity, Infection." In The Decline of Mortality in Europe, Roger Schofield, David Reher, and A. Bideau, eds., pp. I3I45. Oxford.

Mackenbach, J.P. 1992. De veren van Icarus: over de achtergronden van twee eeuwen epidemiologische transities in Nederland. Utrecht: Wetenschappelijke Uitgeverij Bunge.

Mackenbach, J.P. I994. "Sociaal-economische gezondheidsverschillen". Nederlands Tijdschrift voor Geneeskunde. I994: I259-I26I.

Mackenbach, Johan . 2007. "Pragmatism works." British Medical Journal, 334: I7.

Malthus, Thomas R. 1798 (1960). An Essay on the Principle of Population. New York: Random House.

Marland, Hilary. 1993. “'A woman's touch'. Women doctors and the development of health services for women and children in the Netherlands I879-c. I925." In: Binneveld, Hans and Rudolf Dekker eds. Curing and insuring. Essays on illness in past times: The Netherlands, Belgium, England and Italy, 16th20th centuries. Pp. II3-I33. Hilversum: Verloren.

Marland, H. I995. "Questions of competence: the midwife debate in The Netherlands in the early twentieth century." Medical History 39 (3) (July): 317-337.

McFalls, J.A. and McFalls, M. Harvey. 1984. Disease and Fertility. Orlando: Academic Press.

McKeown, Th. I976. The modern rise of population. London: Edward Arnold.

Mercer, A.J. 1990. Disease, Mortality and Population in Transition. Epidemiological-Demographic Change in England since the Eighteenth Century as Part of a Global Phenomenon. Leicester: Leicester University Press.

Methorst, H.W. I909. "Eenige cijfers betreffende de sterfte van kinderen beneden het jaar in Nederland." Economist: 665-684.

J.-M. Meuvret, J.-M. 1946. "Les crises de subsistances et la démographie de la France d'Ancien Régime." Population 2-4 : 643-650. 
Miora, Seikō. I980. "Gotō Shinpei shoron - Nagoya ikanjidai kara eiseikyoku made no sokubakukento (A brief bibliography of Gotō Shinpei - From a medical officer in Nagoya to the Chief-deputy of Central Sanitation Bureau)." Ritsumeikanhōgaku (The law study of Ritsumeikan) 3: 723-75I.

Miura Morihari I986, "Taiwannetsu yobō kokoroe" Taiwan Sotokufu kōbun ruisan No. 30-I2, I896/05/II.

Morel, M. - F. I99I. "The Care of Children: The Influence of Medical Innovation and Medical Institutions on Infant Mortality I750-I9I4." In: R. Schofield, D. Reher and A. Bideau (eds.), The Decline of Mortality in Europe. Oxford: Clarendon Press. Pp. I96-219.

Morishita, Kaoru. 1976. Malaria: Epidemiology and Prevention-Reports and Researches in Taiwan during Japanese Rule (マラリアの疫学と予防 -台湾に於ける 日本統治時代の記録と研究-), Tokyo: Kikuya Syobō.

Nagaki Daiizō. I992. Kitasato Shibasaburu to sono ichimon (Kitasato Shibasaburu and his pupils), Tokyo: Keio.

Naimushō Eiseikyoku ed. 1925. Isei gojūnen shi (The fifty-year history of the medical system). Tokyo: Obunkai.

Nakamura, Humio. I992. Mori Ōgai to Meiji kokka (Mori Ōgai and the Meiji state). Tokyo: Sanichi shubō.

Ninomi, Fujiaki. 1987. "Meiji zenhanki oshui rugakusei ni tsuite (On the overseas students in the first-half Meiji period)." Nihon ishigaku zasshi 33:4: 54-60.

Ninoshima rinji rikugun kenekijo ed. I896. Ninoshima rinji rikugun kenekijo gyômu hōkoku kōhen (The business report of army quarantine institute at Ninoshima). Tokyo: Ninoshima rinji rikugun kenekijo.

Noordam, D.J. I986. Leven in Maasland. Een hoogontwikkelde plattelandssamenleving in de achttiende en het begin van de negentiende eeuw. Hilversum: Verloren.

Oda Toshirō. I977. "Takagi Tomoe hakase ate no shokan wo mite senjin wo shinobu (Reading letters of Takagi Tomoe and thinking of the pioneers)." Nippon ishi shinpō 2782.

Oda Toshirō. I995. Taiwan igaku gojūnen (The fifty-year history of Taiwanese medicine), trans. by Hong Youshi. Taipei: Qianwei.

Odaka, Takeshi. 1989. "Naimusho shokan densenbyô kenkyûsho (The institute of infectious disease under the Ministry of Home Affairs)." Nihon ishigaku zasshi 35:4: I-35.

Office of Inspector-General of Customs, ed. ı886. Customs Medical Report (1876-77). Shanghai: Inspector-General of Customs.

Omran, A.R. I97I. "The epidemiologic transition theory; a theory of the epidemiology of population change." Milbank Memorial Fund Quarterly, 49: 509-538.

Omran, A.R. I983. "The epidemiologic transition theory: a preliminary update." Journal of Tropical Pediatrics 29: 305-316. 
Oomens, C.A. I989. De loop der bevolking van Nederland in de negentiende eeuw. Den Haag: SDU-Uitgeverij.

Over, M., R. P. Ellis, J.H. Huber \& O. Solon. I992. “The consequences of adult ill-health." In Health of adults in the developing world. R. G. A. Feachem et al. eds. Pp. I6I-208. New York/ Oxford: Oxford University Press.

Pasternak, Burton. I972. Kinship a Community in two Chinese villages. Stanford: Stanford University Press.

Penn, D.J. and K.R. Smith. 2007. "Differential fitness costs of reproduction between the sexes." Proceedings of the National Academy of Sciences of the United States of America IO4 (2): 553-558.

Perrenoud, A. I999. “La mortalit”. In Histoire des Populations de l'Europe. Vol. III. Les temps incertains 1914-1998. J.P. Bardet \& J. Dupâquier, eds, pp. 2873I5. Paris: Fayard.

Perrenoud, A. and P. Bourdelais. I999. “Le recul de la mortalité.” In Histoire des Populations de l'Europe. Vol. III. Les temps incertains 1914-1998. J.P. Bardet \& J. Dupâquier, eds, pp. 57-IoI. Paris: Fayard.

Philips, J.F.R. I960. 50 jaar sociale gezondheidszorg in Limburg. De R.K. Vereniging "het Limburgse Groene Kruis" in het goud 1910-1960. Sittard.

Philips, J.F.R. I980. Gezondheidszorg in Limburg. Groei en acceptatie van de gezondheidsvoorzieningen 1850-1940. Assen: van Gorcum.

Pinelli, Antonella and Paola Mancini I997. "Gender Mortality Differences from Birth to Puberty in Italy, I887-I940.” In: Carlo A. Corsini and Pier Paolo Viazzo, The Decline of Infant and Child Mortality. The European Experience: 1750-1990. Pp. 73-93. The Hague: Martinus Nijhoff Publishers.

Pollet, Catherine. I997. "Childhood Mortality in High-Risk Groups: Some Methodological Reflections Based on French Experience”. In: Carlo A. Corsini and Pier Paolo Viazzo, The Decline of Infant and Child Mortality. The European Experience: 1750-1990. Pp. 213-225. The Hague: Martinus Nijhoff Publishers:

Poppel, F.W.A. van.I992. "Religion and Health: Catholicism and Regional Mortality Differences in Nineteenth-Century Netherlands." Social History of Medicine 5: 229-253.

Poppel, F. van, E. Tabeau and F. Willekens. I996. “Trends and sex-differentials in Dutch mortality since I850: insights from a cohort-and period perspective." Genus 52, 3-4, I07-134.

Poppel, F. van and Jitse P. van Dijk. I997. "The development of cause-ofdeath registration in the Netherlands." Continuity and Change I2, 2: 265-287.

Poppel, F. van, and K. Mandemakers. I997. "Differential Infant and Childhood Mortality in the Netherlands, I8I2-I9I2: First Results of the Historical Sample of the Population of the Netherlands." In Alain Bideau, Bertrand Desjardins, and Héctor Pérez-Brignoli (eds.), Infant and child mortality in the past. Pp. 276-300. Oxford/New York: Clarendon Press. 
Poppel, F. van. 2000. "Long-term trends in relative health differences between men and women." European Journal of Obstetrics and Gynecology and Reproductive Biology, 93: 2: II9-I22.

Poppel, F. van and J. P. Van Dijk. 2002. "The beginning of health statistics I750-I870." In Paul M.M. Klep and Ida H. Stamhuis (eds.) The statistical mind in a pre-statistical era: The Netherlands 1750-1850. Pp. 24I-277. Amsterdam: Aksant.

Poppel, F. van, K. Mandemakers. 2002. "Sociaal-economische verschillen in zuigelingen- en kindersterfte in Nederland, I8I2-I9I2." Bevolking en Gezin 3I (2): 5-39.

Poppel, Frans van, Jona Schellekens, and Aart C. Liefbroer. 2002. "Religious differentials in infant and child mortality in Holland, I855-ı9ı2." Population Studies 56: 277-289.

Poppel, F. van and E. Beekink. 2003. "De gezondheid van Nederland: sterftetrends en sterfteverschillen in de negentiende en twintigste eeuw". Pp 7I95 in: E. Beekink, O. Boonstra, T. Engelen and H. Knippenberg (eds), Nederland in verandering: maatschappelijke ontwikkelingen in kaart gebracht 1800-2000. Amsterdam: Aksant.

Poppel, F. van, M. Jonker and K. Mandemakers. 2005. "Differential infant and child mortality in three Dutch regions, I8I2-I909." Economic History Review LVIII: 272-309.

Porter, Dorothy and Roy Porter. I988. "What was social Medicine? An historiographical essay." Journal of Historical Sociology i:I: 90-Io6.

Preston, S.H. I975. "The changing relation between mortality and level of economic development." Population Studies 29: 23I-248.

Preston, Samuel H. 1980. "Causes and Consequences of Mortality Decline in Less Developed Countries during the Twentieth Century." In: R.E. Easterlin (ed.), Population and Economic Change in Developing Countries. Pp. 289-360. Chicago: University of Chicago Press.

Preston, Samuel, Ansley J. Coale, James Trussell, and Maxine Weinstein. I980. "Estimating the Completeness of Reporting of Adult Deaths in Populations That Are Approximately Stable." Population Index 46(2):I79-202.

Preston, Samuel, and Neil G. Bennett. I983. "A Census-based Method for Estimating Adult Mortality." Population Studies 37(I):9I-I04.

Preston, Samuel, and Kenneth Hill. I980. "Estimating the Completeness of Death Registration." Population Studies, 34(2):349-366.

Preston, S.H. and M.R. Haines. I991. Fatal years. Child mortality in late nineteenth-century America. Princeton: Princeton University Press.

Pyle, Kenneth B. 1974. "Advantages of Fellowship: German Economics and Japanese Bureaucrats I890-I925." Journal of Japanese Studies I:I: I27-I64.

Querido, A. 1965. Een eeuw staatstoezicht op de volksgezondheid. Den Haag: Staatsuitgeverij. 
Querido, A. 1968. The Development of Socio-Medical Care in the Netherlands. Library of Social Policy and Administration, Kathleen Jones ed. London-New York.

Qin, Xienyu(Chin Hsien-yu). I998. "Colonial medical police and postcolonial medical surveillance system in Taiwan, I895-I950s." Osiris I3: 326-338.

Razzell, P.E. 1977. The Conquest of Smallpox. The Impact of Inoculation on Smallpox Mortality in Eighteenth Century Britain. Firle: Caliban Books.

Reher, David S., Vincente Perez-Moreda and Joseph Bernabeu-Mestre. I997. "Assessing Change in Historical Contexts: Childhood Mortality Patterns in Spain during the Demographic Transition." In Carlo A. Corsini and Pier Paolo Viazzo, The Decline of Infant and Child Mortality. The European Experience: 1750-1990. Pp. 35-56. The Hague: Martinus Nijhoff Publishers.

Reher, D. S. 2004. "The demographic transition revisited as a global process." Population, Space Place, Iо: I9-4I.

Rich, Arnold R. I95I. The Pathogenesis of Tuberculosis. Second Edition. Springfield, Ill.: Charles C. Thomas.

Rigter, R.B.M. I992. Met raad en daad. De geschiedenis van de gezondheidsraad 1902-1985. Rotterdam: Erasmus Publishing.

Riley, James C. 200I. Rising life expectancy: a global history. Cambridge: Cambridge University Press.

Rombouts, K.H. I902. Beschouwingen over het geboorte- en kindersterftecijfer van Nederland gedurende het tijdvak 1875-1899. Harlingen: Drukkerij S.W. Houtsma.

Rosen, George. 1992. A History of Public Health. Baltimore: Johns Hopkins University Press.

Rosenberg, Charles and Janet Golden eds. 1992. Framing Disease. Studies in Cultural History. New Brunswick, NJ: Rutgers University.

Rutenberg N., J.M. Sullivan. I99I. Direct and indirect estimates of maternal mortality from the sisterhood method. Washington DC, IRD/Macro International Inc.

Rutten, Willibrord. I985. "Mortaliteit en medicalisering. Een regionaaldifferentiële analyse van de sterfte zonder geneeskundige behandeling in Nederland (ca. I870-I900) [Mortality and medicalization. A differential analysis of people dying without benefit of medical aid]". In: Holland en de historische demografie (Hollandse Studiën I6). Pp. I3I-I6o. Dordrecht.

Rutten, Willibrord. I986. "Ongelijke behandeling binnen het gezin. Een onderzoek naar de leeftijdsverschillen in de kans op geneeskundige hulp in Nederland (ca. I870-I900) (with summary: Unequal treatment within the family: an enquiry into age differentials in the chances of medical care in the Netherlands (about I870-I900)." In: Dertig jaar Afdeling Agrarische Geschiedenis. (A.A.G. Bijdragen 28). Pp. 245-265. Wageningen.

Rutten, Willibrord. 1993. "Smallpox, subfecundity, and sterility: a case study from a nineteenth-century Dutch municipality." Social History of Medicine 6: 85-99. 
Rutten, Willibrord. I997. “De vreselijkste aller harpijen.” Pokkenepidemieën en pokkenbestrijding in Nederland in de 18e en 1ge eeuw: een sociaal-historische en historisch-demografische studie. (A.A.G. Bijdragen 36). Wageningen.

Ryle, F. Alfred. I985. Changing Disciplines. London: Oxford University Press.

Schofield, R., D. Reher and A. Bideau (eds.). I991. The Decline of Mortality in Europe. Oxford: Clarendon Press.

Shepherd, John R. I998. "The I905 and I9I5 censuses and variation among Prefectures.” Unpub. Ms.

Shepherd, John R. I998b. "Japanese Rule and the Census of i905." Unpub. Ms.

Shepherd, John R. 200I. "Smallpox and the Pattern of Mortality in Late Nineteenth-Century Taiwan." Liu Ts'ui-jung et al. eds. Asian Population History, pp. 270-29I. New York: Oxford University Press.

Shepherd, John R. 2oora. "The Practice of Footbinding: Evidence from Taiwan." ms.

Shepherd, John R. 2002. "Maternal Mortality in Taiwan, I905-I942." Unpub. Ms.

Shepherd, John R. 2003. "Cause of Death Data from Taiwan, I9o6I942." Unpub. Ms.

Shepherd, John R., Pan Inghai, Jan Kok, Claudia Engel, Theo Engelen, Melissa Brown. 2006. "Group Identity and Fertility: An evaluation of the role of religion and ethnicity in the Netherlands and Taiwan." In Positive or Preventive? Reproduction in Taiwan and the Netherlands, 1850-1940, Chuang Ying-chang, Theo Engelen, and Arthur P. Wolf, eds., pp. I2I-I6I. Amsterdam: Aksant Academic Publishers.

Shepherd, John R. infra. "Trends in Mortality and Causes of Death in Japanese Colonial Period Taiwan.” (this volume).

Shepherd, John R. infra. "Regional and Ethnic Variation in Mortality in Japanese Colonial Period Taiwan.” (this volume).

Shimomura Hachigorō. I935. "Tainan shu ka niokeru mararia bōatsu sagyō no ji'sai to sono seiseki (台南州下におけるマラリア防遏作業の實際と其成績 )," Journal of the Formosan Medical Association 358:5I-76.

Shkolnikov, V., E. Andreev and A.Z. Begun. 2003. "Gini coefficient as a life table function: computation from discrete data, decomposition of differences and empirical examples.” Demographic Research 8 (II), 305-358.

Sköld, Peter. I996. The Two Faces of Smallpox. A Disease and its Prevention in Eighteenth- and Nineteenth-Century Sweden (Report from the Demographic Data Base Umeå; ı2), Umeå.

Smith, A.F.M. I996. "Mad cows and ecstasy: chance and choice in an evidence-based society." Journal of the Royal Statistical Society A I59 (3), 367-383.

Sonsbeek, J.L.A van. 2005. Van de schaduw des doods tot een licht ten leven: 
de historie van de methodiek van de doodsoorzakenstatistiek in Nederland, 18652005. Den Haag: cвs.

Stanton, Cynthia, Ken Hill, Carla AbouZahr, Tessa Wardlaw. ı996. “Modeling Maternal Mortality in the Developing World." Paper presented to Annual Meetings of the Population Association of America.

Stecklov G. I995. "Maternal mortality estimation: separating pregnancyrelated and non-pregnancy related risks." Studies in Family Planning 26: 33-38.

Suzuki Shintarō. I9I9. "Mararia kansenritsu nitsuite- ross si hansiki ron Taiwan niokeru kansenritsu ni oyobu (マラリア感染率二就テーロス氏範式論台湾 二於ケル感染率二及ブ),” Journal of the Formosan Medical Association 202:876890.

Suzuki, Tōen. I940. Taiwan no ho-kō seido (Taiwan's ho-kō system). Taihoku: Taiwan Sōtokufu.

Szreter, Simon. I988. “The importance of social intervention in Britain's mortality decline c. I850-I9I4: a reinterpretation of the role of public health." Social history of Medicine I(I): I-37.

Tabeau, E. I994. "Changing definitions in infant mortality: a case study of the Netherlands, I843-I991." Bevolking en gezin. I: 79-104.

Tabeau, E., F. Willekens. and F. van Poppel. I994. Mortality in the Netherlands: the data base. The Hague: Netherlands Interdisciplinary Demographic Institute.

Taeuber, Irene B. I958. The Population of Japan. Princeton: Princeton University Press.

Taihokushu keisatsu ka ed. I932-I940. Taihokushu keisatsu tokeisho (Statistical book of Taipei police force).

Taihoku igakkō, ed. I930. Sōritsu nijugo shūnen shukuga kiji. Taihoku: Taihoku igakkō.

Taiwan Jinkō Dōtai Tōkei 臺灣人口動態統計 (Vital Statistics of Taiwan, ı905-I942). Sōtoku kambo, tōkei-ka, Taihoku, ı906-ı943.

Taiwan Kōikai, ed. ıوı。. Taiwan no Eisei Jōtai (台湾の衛生状態), Taipei: Taiwan Kōikai.

Taiwan Sheng wenxianweiyuanhui ed. I953. Taiwansheng tongzhigao (The draft Taiwan gazetteer). Nantou: Taiwansheng wenxianweiyuanhui.

Taiwan Sheng Xingzheng Zhangguan Gongshu Tongji Shi (臺灣省行政長 官公署統計室). 1946. Statistical Summaries for the Past 51 Years of Taiwan Province (Taiwan sheng wushiyi nian lai tongji tiyao 臺灣省五十一年來統計提要). Taipei, Taiwan.

Taiwan Sheng Tongzhi. I970. Vol.r, Tudizhi, Jiangyupian, book I(台灣省通志. 卷一, 土地志, 疆域篇, 第一冊). Taipei: Taiwan sheng wenhsien wei yuan hui.

Taiwan shiryōhen saniinkai ed. I900. Taiwan shiryō kōhon (the collection of Taiwan's historical materials). Taihoku: Taiwan shiryōhen saniinkai. 
Taiwan Sōtokufu Chūōkenkyūjo Eiseibu, ed. I930. Taiwan Sōtokufu Chūōkenkyūjo Eiseibu Nenpō (台湾総督府中央研究所衛生部年報), No.I: 60-62.

Taiwan Sōtokufu Chūō kenkyūsho ed. I922 and 1942. Taiwan Sōtokufu Chūō kenkyūsho eiseibu gyōseiki. Taihoku: Taiwan Sōtokufu Chūō kenkyūsho eiseibu.

Taiwan Sōtokufu Keimukyoku Eiseika, ed. I921. Hoken Eisei chōsa yōkō (保健衛生調査要項). Taipei: Taiwan Sōtokufu Keimukyoku Eiseika.

Taiwan Sōtokufu Keimukyoku Eiseika, ed. I926. Eisei chōsasho-kihonchōsa no. 4: Taiwan mararia tōkei (衛生調査書一基本調查の四 : マラリア統計), Taipei: Taiwan Sōtokufu Keimukyoku Eiseika.

Taiwan Sōtokufu Keimukyoku Eiseika, ed. I932. Mararia bōatsu shi (マラ リア防遏誌), Taipei: Taiwan Sōtokufu Keimukyoku Eiseika.

Taiwan Sōtokufu Keimukyoku ed. I938. Taiwan Sōtokufu keisatsu enkakushi (The development history of Taiwan Sōtokufu police force). Taihoku: Morikomu shoji.

Taiwan Sōtokufu minseibu ed. I9I3. Taiwan eisei gaiiyō (The summary of Taiwan's hygiene). Taihoku: Taiwan Sōtokufu.

Taiwan Sōtokufu Tökeisho. 台灣總督府統計書 (Statistical yearbooks of the Taiwan government general). Taihoku, I899-1944.

Taiwan suidō kenkyūkai ed. I94I. Taiwan suidōji (Taiwan's water system). Taihoku: Taiwan suidō kenkyūkai.

Taiwan zongdufu gongwenleizuan di 6 men weisheng (The collection of Taiwan Sōtokufu documents, the sixth category, sanitation). Jan. 6,1906.

Taiwanshi Kenkyūbu, ed. 2003. Taiwan no kindai to Nippon (Taiwan's modern ages and Japan). Nagoya: Chōkyō daigaku.

Takagi Tomoe. 1905. “Mararia yobōhō nitsuite (マラリア予防法二就テ).” Journal of the Formosan Medical Association. 29:IOI-IO4.

Takagi Tomoe. I920. “Kanjō I8nenno kaiko (官場拾有八年の回顧上、中、下).” Taiwan Jihō, Jan., Feb., March.

Takekoshi Yosaburo. 1907. Japanese Rule in Formosa. London: Longmans, Green, and Co..

Takenaka, Masao. I958. The Development of Social, Educational and Medical Work in Japan since Meiji. Brussels: Uitgeverij Van Keulen.

Tomita Yoshirō. I955. "Research of towns and villages in Taiwan(台湾郷鎮 之研究).” Taiwan Yinhang Jikan. 7:3:90.

Tong, Huiwen. 2004. "Xingzheng jiankong yu yiliao guixun (Administrative structure and medical disciplines)." Master's thesis. Chiayi: Nanhua University.

Tsay Jiing-Tarng. 2002. "A study on the reality and falseness of "assimilation policy” during the period of Japanese rule (日本治台時期所謂「同化政策」的 實像與虛像初探).” Tamkang History I3:I8I-I92. 
Tsukiyama Kiichi. I905. “Mararia yobōhō (マラリア予防法).” Journal of the Formosan Medical Association 29:89-IOI.

Tsurumi, Tasukuho. 1985. Gotō Shinpei. Tokyo: Kubisōshoten.

United Nations. I983.Manual X: Indirect Techniques for Demographic Estimation. New York: United Nations Publication.

United Nations. 1988. MortPak-Lite: the United Nations Software Package for Mortality Measurement. New York: United Nations Publication.

Vallin, J. I99I. "Mortality in Europe from I720 to I9I4. Long-term trends and changes in patterns by age and sex." In R. Schofield, D. Reher and A. Bideau (eds.) The decline of mortality in Europe, 38-67. Oxford: Clarendon Press.

Valk, Loes van der. I99I. "Poor law and social security legislation in the Netherlands." Economic and Social History in the Netherlands. Vol. 3: 99-II8.

Vandenbroeke, Chr., F. van Poppel and A.M. van der Woude. 198I. "De zuigelingen- en kindersterfte in België en Nederland in seculair perspectief." Tijdschrift voor geschiedenis 94: 46I-49I.

Vaupel, J.W., Zhenglian W, Andreev, K.F., Yashin, A.I.. 1997. Population Data at a Glance: Shaded Contour Maps of Demographic Surfaces over Age and Time. Odense: Odense University Press.

Velden, Henk van der. I996. "The Dutch health services before compulsory health insurance, I900-I94I." Social History of Medicine 9: 49-68.

Verdoorn, J.A. I98I. Volksgezondheid en sociale ontwikkeling. Het gezondheidswezen te Amsterdam in de 19e eeuw. Utrecht-Antwerpen: Aula, tweede druk Nijmegen.

Wakimura Kōhei. 2002. "Shokuminchi tōchi to kōshu eisei: Indo to Taiwan (植民地統治と公衆衛生：インドと台湾).” In Kikin ekibyō shokuminchi tōchi (Famine, Disease and Colonial Rule), 216-244. Nagoya University Press.

Waldron, Ingrid. 1983. "Sex differences in human mortality: the role of genetic factors." Social Science and Medicine I7.6: 32I-33.

Wang, F., Lee, J. and Campbell, C. I995, "Marital fertility control among the Qing nobility: Implications for two types of preventive check." Population Studies 49: 383-400.

Ward, P. 2003. "Perinatal mortality in Utrecht, The Netherlands, I880I940." Economics and Human Biology I(3): 379-398.

Weinberg, Eugene D. I984. "Pregnancy-Associated Depression of CellMediated Immunity." Review of Infectious Diseases 6.6 (Nov.-Dec.): 8I4-83I.

Weishengshu ed. I995. Taiwan diqu gonggong weisheng fazhanshi (The development history of public health in Taiwan). Taipei: Weishengshu.

Wijnen-Sponselee, M. Th.I997. Het Wit-Gele Kruis in Noord-Brabant 1916-1974. Intermediair tussen medische verworvenheid en sociale acceptatie. Tilburg: Zuidelijk Historisch Contact. 
Wilson, Ch. and J. Oeppen. 2003. "On reification in demography." In J. Fleischhacker, H. de Gans and T. Burch (eds.). Populations, projections, politics: critical and historical essays on early twentieth century population forecasting, pp. II3-I29. Amsterdam: Rozenberg Publishers.

Wolf, Arthur P. I995. Sexual Attraction and Childhood Association: A Chinese Brief for Edward Westermarck. Stanford: Stanford University Press.

Wolf, A.P. and Chieh-shan Huang. 1980. Marriage and adoption in China, 1845-1945. Stanford: Stanford University Press.

Wolf, Arthur and Hill Gates. 2004. "Marriage in Taipei City: Reasons for rethinking Chinese demography." International Journal of Asian Studies 2 (I): III-I33.

Wolleswinkel-van den Bosch, J. 1998. The epidemiological transition in the Netherlands. Ph. D. Dissertation Erasmus University Rotterdam.

Wolleswinkel-van den Bosch, J. H., F. W..A. van Poppel and J. P. Mackenbach. 1996. "Reclassifying causes of death to study the epidemiological transition in the Netherlands, I875-1992." European Journal of Population I2, 4:327-36I.

Wolleswinkel-van den Bosch, J.H., F.W.A. van Poppel, C.W.N. Looman and J.P. Mackenbach. 2000. "Determinants of infant and early childhood mortality levels and their decline in The Netherlands in the late nineteenth century." International Journal of Epidemiology 29: IO3I-IO4O.

Wood, J.W. 1994. Dynamics of human reproduction. Biology, Biometry, Demography.New York: Aldine de Gruyter.

Woodbury, R.M. 1926. Maternal Mortality: the risk of death in childbirth and from all diseases caused by pregnancy and confinement. Children's Bureau, U.S. Department of Labor, Bureau Publication no. I58. Washington, D.C.: Government Printing Office.

Woods, R.I., P.A. Watterson, and J.H. Woodward. I988-I989. "The Causes of Rapid Infant Mortality Decline in England and Wales, I86I-I92г." Population Studies 42: 343-366 and 43: II3-I32.

Woude, A.M. van der. 1982. "Population developments in the Northern Netherlands (I500-I800) and the validity of the urban graveyard effect." Annales de Démographie Historique: 55-74.

Wu, Chia-ling 吳嘉苓. 2000. “Yiliao zhuanye, xingbie yu guojia: Taiwan zhuchanshi xingshuai de shehui fenxi 醫療專業, 性別 與 國家: 台灣助產士興衰的 社會分析 (Medical Professions, Gender and the State: A Sociological Analysis of the Rise and Decline of Midwives in Taiwan)." Taiwan shehuixue yanjiu (Taiwanese Sociology) 4: I9I-268.

Wu, Chia-ling 2004. "Infant Death and the Politics of Scientific Motherhood in Colonial Taiwan." Paper presented to the Hygiene Conference, Academia Sinica, Taipei, Nov.22-24. 
Wu Chia-ling. 20Io. "Have someone cut the umbilical cord: women's

birthing networks, knowledge and skills in colonial Taiwan." Forthcoming in Angela Leung and Charlotte Furth, eds., Health and Hygiene in Chinese East Asia: Policies and Publics in the Long Twentieth Century. Durham: Duke University Press.

Wu Wen Shing. 2002. "Transformation of Taiwanese Society Under Japanese Colonialism and its Historical Implication (日治時代的文教與社會一社 會變遷).” History of Taiwan, ed. Huang Hsiu Cheng, Wu Wen Shing, pp.223231. Taipei: Wunan.

Wu Yulin. I995. Memories of Wu Lienteh: The Plague Fighter. Singapore: World Scientific Publishing Company.

Xie Guo-xing. 2005. Xuxiu Penghu xian zhi (The continuous compilation of the history of Penghu prefecture). Vol. 9, Sanitation. Penghu: Penghu Government.

$\mathrm{Xu}$, Xiqing ed. \& trans. 2000. Taiwan zongdufu gongwen leizuan weisheng shiliao huibian. Nantou: Taiwansheng wenxian weiyunhui.

$\mathrm{Xu}$, Xueji, ed. 2004. Taiwan lishi cidian (Dictionary of Taiwan History). Taipei: Wenjinhuai.

Yang, Wen-shan and Hsieh, Ying-Hui. 2004. "Infant Mortality in Colonial Taiwan, I9OI-I945: Evidence of the Historical Household Registration Data of Taiwan." Paper presented at the International Conference on "The ideas, organization, and practice of hygiene in Han Society from traditional to the modern periods," Academia Sinica Taiwan, November 22-23.

Yip Ka Che. 2000. "Malaria eradication: the Taiwan experience." Parasssitologia 42:II7-I26.

Yip Ka Che. 200I. "Colonialism, post-colonialism and hegemony: perspectives on the history of malaria eradication in Taiwan." The Theses of the International Workshop on Colonial Medicine (2001/10/25-26), ed. Institute of Taiwan History of Academia Sinica: 6I-76.

Yoshino, Shigeru and Aida Toshiro. 1936. "Taiwan kaikyō e ken'etsu no kishi (Inspected seashore on the Taiwan Strait)." Koshu bōeki zasshi(Journal of public epidemic prevention) 23: 3-15.

Yu, Chien-Ming 游鑑明. I993. “Riju Shiqi Taiwan de Chanpo” 日據時期台 灣的產婆 (Taiwanese Midwives in Japanese Colonial Period). JinDai Zhongguo Funu Shi Yanjiu 近代中國婦女史研究 (Research on Women in Modern Chinese History) r: 49-88.

Yu Kuang-hong et al. infra. "Illegitimacy, Adoption and Mortality." (this volume).

Yuen K.Y. 2003. "The SARs attack on Hong Kong." Hong Kong Med Journal 9: 4: 302 .

Zhang Junhao. 200I. "Heiyunbiji (The Black Cloud covers the Sun)." Taiwan Fengwu 51:3: 13-70. 
Zhang Shuping. I986. "Taiwan zai rijushiqi jingcha faling yu fanzui kongzhi (The registration and crime prevention by the police in Japan-ruled Taiwan)." Master's thesis. Taipei: Fu-jen University.

Zhang Zhonghan. 1980. Guangfuqian Taiwan zhi gongyehua (The industrialization in Taiwan prior to wwII). Taipei: Lianjin.

Zhao, Z. I997. "Deliberate birth control under a high-fertility regime: Reproductive behavior in China before I970." Population and Development Review 23: 729-767.

Zhu, Zhimou. I998. "Guojia yu gerenguanxi de congzhu (Reconstructing the relationship between state and individual)." Master's thesis. Taipei: National Taiwan Normal University.

Zon, Henk van. 1986. Een zeer onfrisse geschiedenis. Studies over niet-industriële vervuiling in Nederland, 1850-1920 [A very dirty affair. Studies in non-industrial pollution in The Netherlands, I850-1920]. Groningen

Zon, Henk van. 1993. “Openbare hygiëne.” In: H. W. Lintsen et al. (eds.) Geschiedenis van de techniek in Nederland. De wording van een moderne samenleving 1800-189o, Vol. II: 47-80. Zutphen: Walburg Pers. 